\title{
A MULTI-OBJECTIVE OPTIMIZATION ANALYSIS OF PASSIVE ENERGY CONSERVATION MEASURES IN A TORONTO HOUSE
}

\author{
by \\ Matthew Steven Tokarik
}

B.Sc. in Civil Engineering, University of Alberta, 2011

\author{
A thesis \\ presented to Ryerson University \\ in partial fulfillment of the \\ requirements for the degree of \\ Master of Applied Science \\ in the Program of \\ Building Science
}

Toronto, Ontario, Canada, 2015

(C) Matthew Steven Tokarik, 2015 


\section{AUTHOR'S DECLARATION FOR ELECTRONIC SUBMISSION OF A THESIS}

I hereby declare that I am the sole author of this thesis. This is a true copy of the thesis, including any required final revisions, as accepted by my examiners.

I authorize Ryerson University to lend this thesis to other institutions or individuals for the purpose of scholarly research

I further authorize Ryerson University to reproduce this thesis by photocopying or by other means, in total or in part, at the request of other institutions or individuals for the purpose of scholarly research.

I understand that my thesis may be made electronically available to the public. 


\title{
A MULTI-OBJECTIVE OPTIMIZATION ANALYSIS OF PASSIVE ENERGY CONSERVATION MEASURES IN A TORONTO HOUSE
}

\author{
Master of Applied Science 2015, Matthew Steven Tokarik \\ Building Science Program, Department of Architectural Science, Ryerson University
}

\begin{abstract}
This study presents a multi-objective optimization environment in which passive energy conservations measures of a high performance house in Toronto are evaluated. The optimization environment was created using the jEPlus software suite where the case study house acted as the reference building. The study house simulation model was calibrated using a data-driven procedure, and acceptable CV(RSME) and NMBE tolerances were reached in accordance with ASHRAE calibration requirements. The optimization varied passive energy efficiency parameters in search of configurations yielding optimal building performance and life cycle cost. The optimization results showed that energy savings of 33\% relative to building code minimum were justified at the point of minimal life cycle cost via passive energy saving measures alone before considering active systems. These results suggest that improved thermal envelopes are economically advantageous with good building practice. However, they suggest that the current Passive House standard does not coincide with the economic minimum for the local economic and environmental climate.
\end{abstract}




\section{ACKNOWLEDGMENTS}

There are many people I would like to thank who helped me complete this work, both directly and indirectly. Without their support, this thesis may have never been finished.

I would like to thank my thesis supervisor, Dr. Russell Richman, for the guidance and mentorship throughout my research. Dr. Richman, as well as the other Ryerson Building Science faculty members, have created a rich learning environment which encourages exploration.

I would like to thank those who provided technical help during those times in which I could no longer find the answers in the manual. Specifically, I would like to acknowledge Hayes Zirnhelt and Dr. Yi Zhang for their guidance in EnergyPlus and jEPlus respectively.

I would like to express gratitude to my peers, Andrew, Maddie, Casandra, Denver, Pat, Matt, and Robin, who became friends during our period together at Ryerson. Spending time with these people, who were undertaking similar endeavors, helped balance the loneliness that can accompany research.

Finally, I would like to thank my girlfriend, Kirsten, who shared with me the journey of moving to a new city and helped ease my mind in times of stress, and my parents, Mark and Mary Anne, who have shown nothing but support for my decision to move across the country and continue my studies. 


\section{TABLE OF CONTENTS}

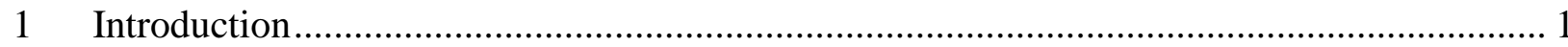

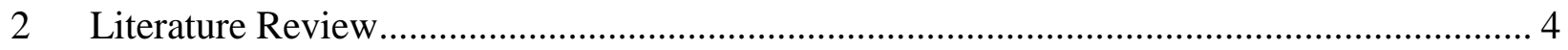

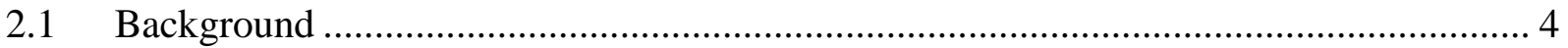

2.1.1 Economic Evaluation Metrics ........................................................................ 4

2.1.2 The Path to Carbon Neutrality under Economic Constraint .................................... 6

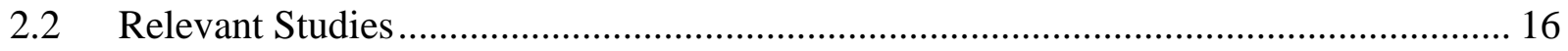

2.2.1 Parametric Optimization Techniques in Energy Efficient Building Design........... 16

2.2.2 Calibration Techniques for Whole Building Energy Models .................................. 23

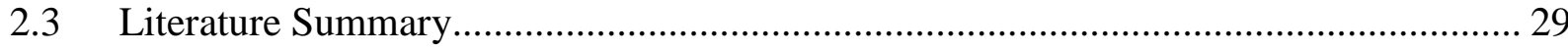

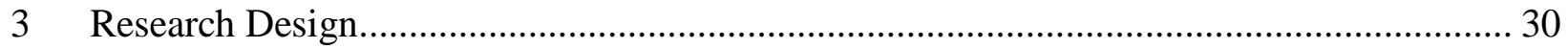

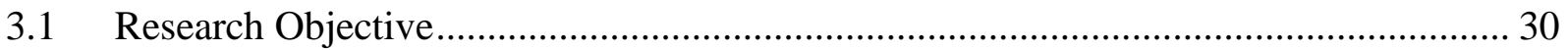

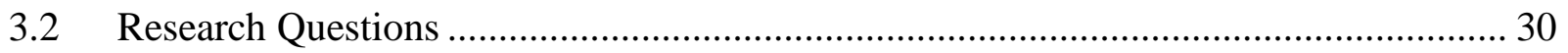

3.3 Methodology Overview.......................................................................................... 30

3.4 Scope of Work and Study Limitation............................................................................ 31

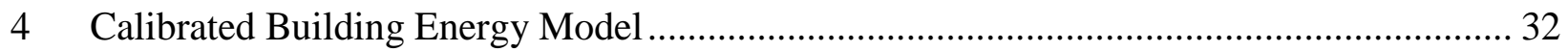

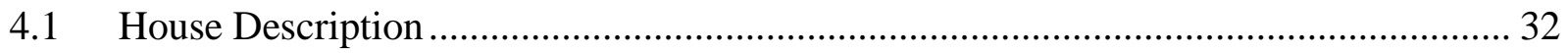

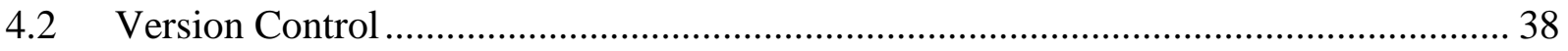

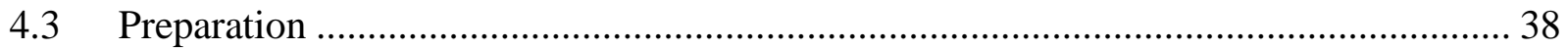

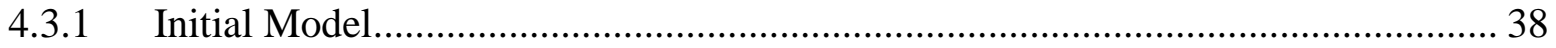

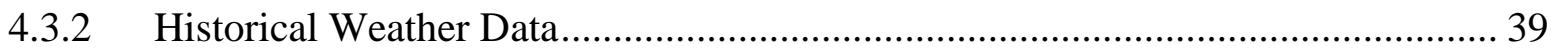

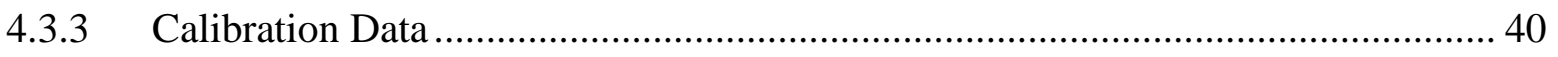

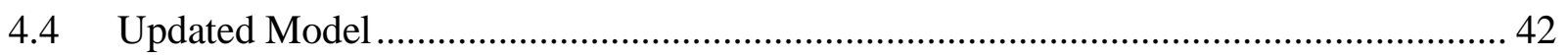

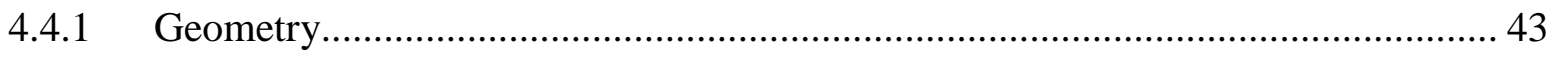




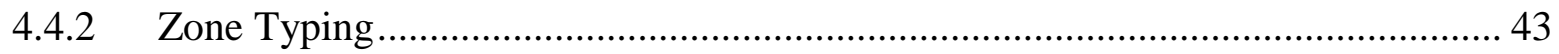

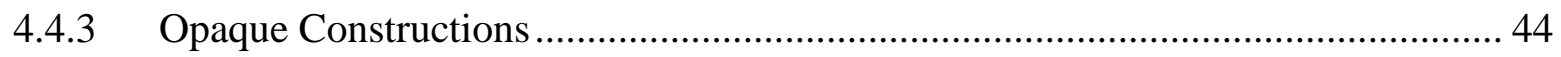

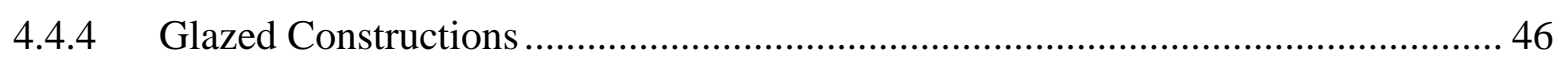

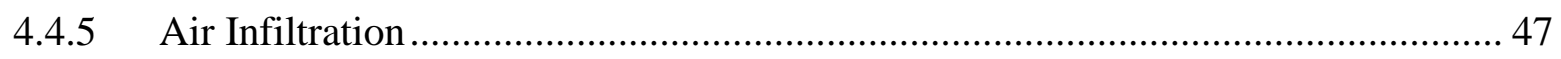

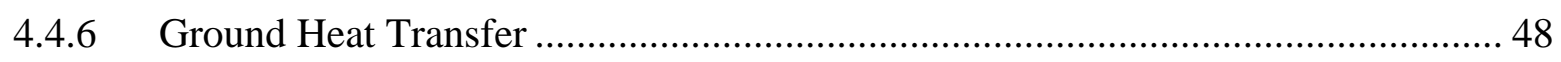

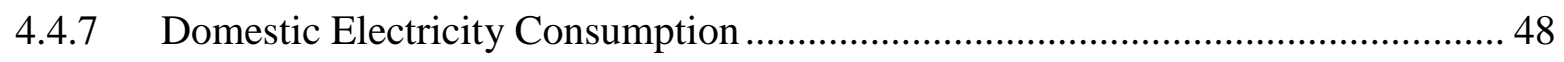

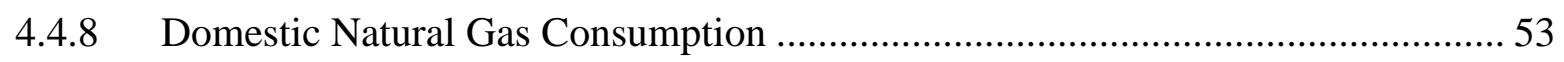

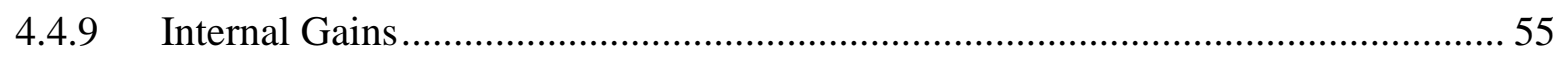

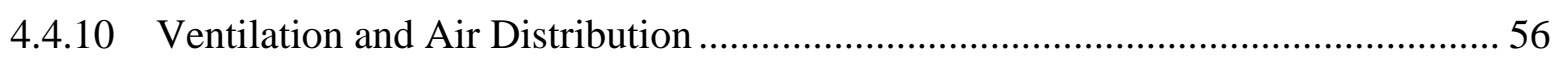

4.4.11 Air Source Heat Pump ………………………............................................... 57

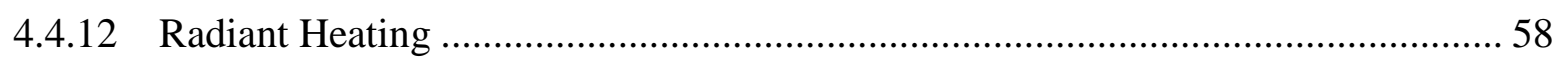

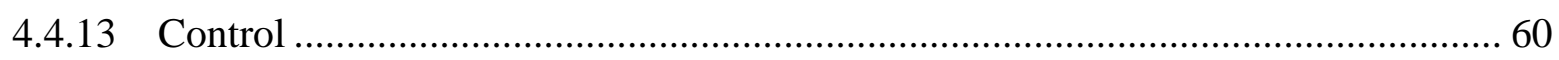

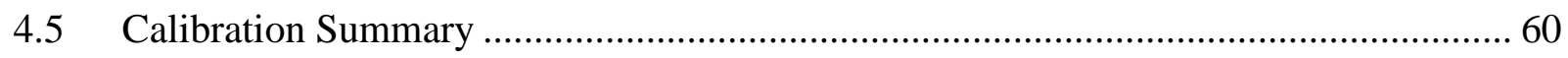

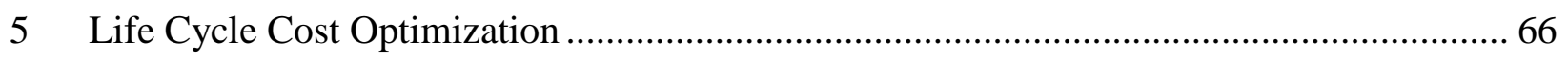

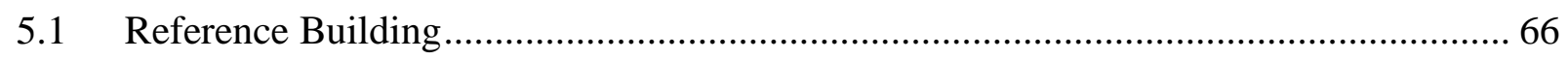

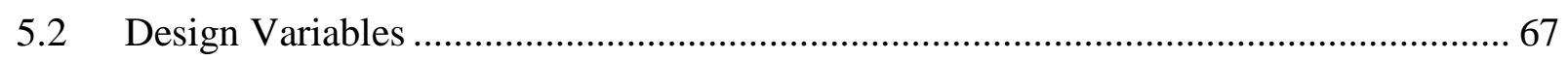

5.2.1 Closed Cell Spray Foam (CCSF) Cost ……………………………………....... 71

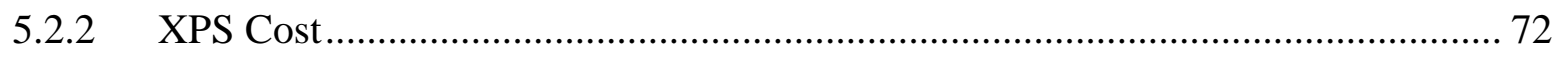

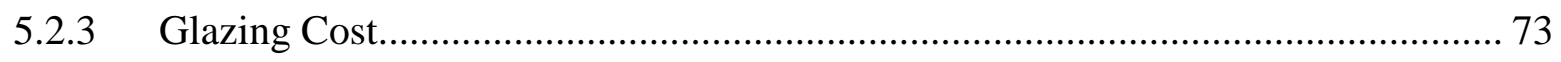

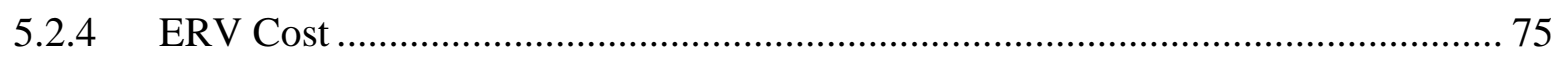

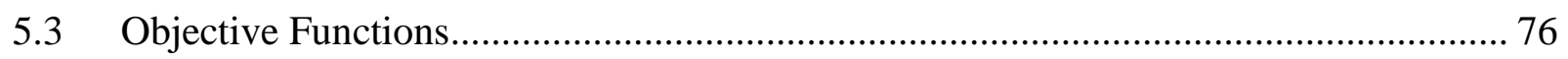

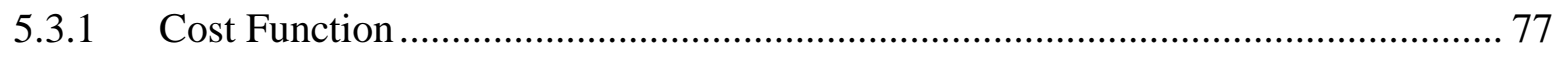

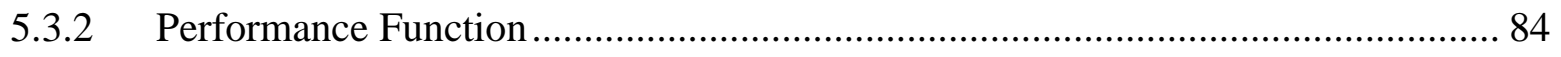

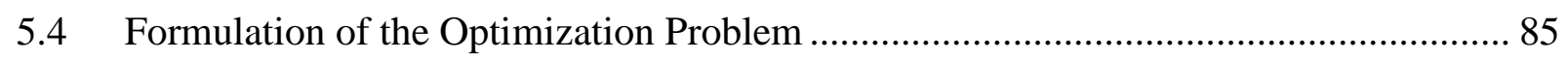

5.5 Optimization Results and Discussion..................................................................... 89 


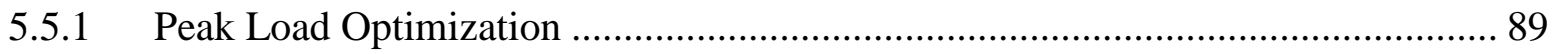

5.5.2 Annual Energy Savings Optimization ....................................................... 103

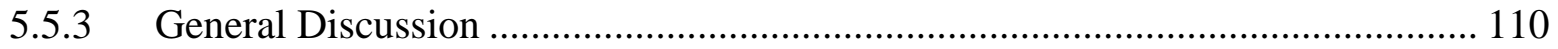

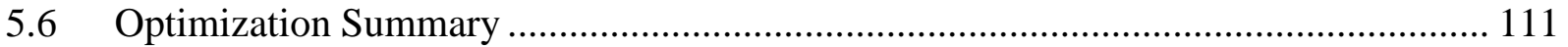

$6 \quad$ Future Work and Conclusions ......................................................................... 113

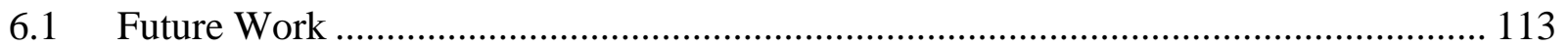

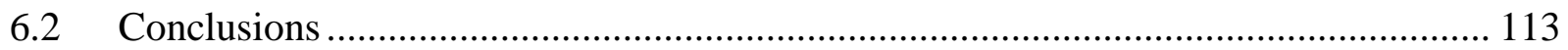

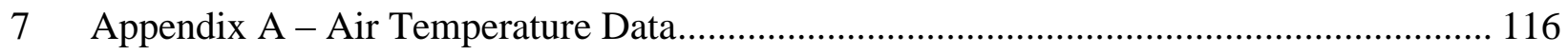

$8 \quad$ Appendix $\mathrm{B}$ - jEPlus and EnergyPlus Input ...................................................... 121

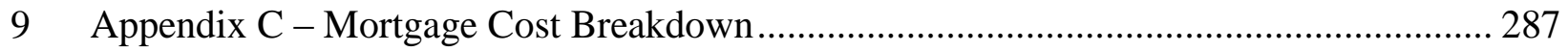

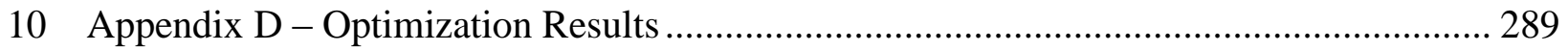

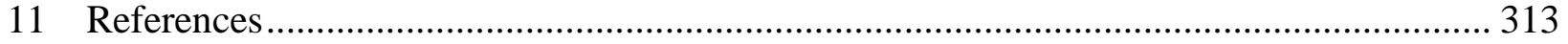




\section{LIST OF TABLES}

Table 1.1: EnerGuide for Houses rating system descriptions (Natural Resources Canada, 2015). 2

Table 2.1: Minimum energy efficiency requirements for Finnish buildings established by the EPBD protocol for cost-optimal energy efficiency packages ....................................... 9

Table 2.2: Optimal passive ECMs for EcoTerra house in Quebec (Bucking et al., 2014) .......... 14

Table 2.3: Error tolerance limits for building simulation calibration ....................................... 25

Table 2.4: Data source hierarchy of reliability for model calibration (Raftery, Keane, \& O'Donnell,

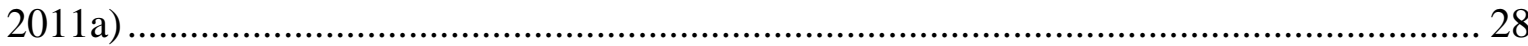

Table 4.1: Thermal properties of select materials .............................................................. 45

Table 4.2: Opaque assemblies for simulated case study house ........................................... 46

Table 4.3: Glazed construction summary for simulation model........................................... 46

Table 4.4: HOT2000 results and associated effective leakage area....................................... 48

Table 4.5: Monthly electricity adjustment factors ................................................................... 51

Table 4.6: Daily average appliance and lighting consumption breakdown ............................. 52

Table 4.7: Light schedules for building simulation model ................................................... 53

Table 4.8: Natural gas consumption input for cooktop........................................................ 54

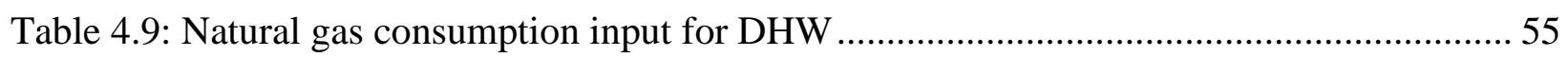

Table 4.10: Human internal gains for simulation model ....................................................... 56

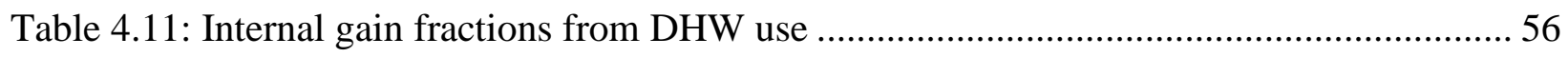

Table 4.12: Calibration summary for monthly utility consumption and hourly zone air temperature

61

Table 5.1: Parametric variables for glazed constructions (5 Options) .................................... 69

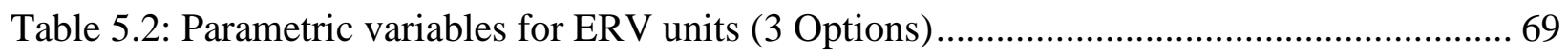

Table 5.3: Parametric variables for opaque constructions …............................................... 70

Table 5.4: UltimateAir parametric cost breakdown........................................................... 75

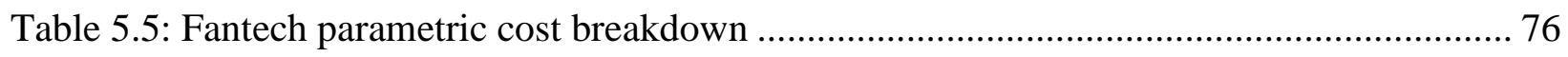

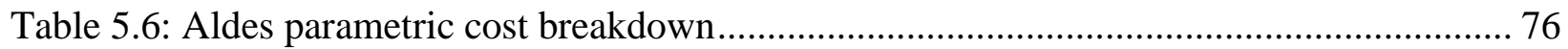

Table 5.7: Building optimization batch simulation parameters for predicted future financial rates

Table 5.8: data point information representative of real case study house 90 
Table 5.9: Case 1 - 4 optimal simulated design points for minimized dLCC .......................... 98

Table 5.10: Case 1 - 4 optimal simulated design points for minimized total peak design load ... 98

Table 5.11: Assemblies for maximum annual energy savings and minimal dLCC for Case $1-4$ 101

Table 5.12: Case 1 - 4 simulations and convergence points ............................................... 103

Table 5.13: Case 5 optimal simulated design points for minimized dLCC and annual energy

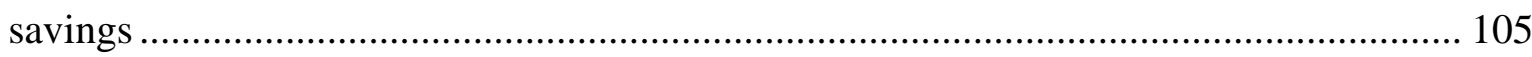

Table 5.14: Case 5 assembly configuration for minimized dLCC relative to reference............ 106

Table 5.15: PHIUS technical committee standard adjustment study results for Toronto (Wright,

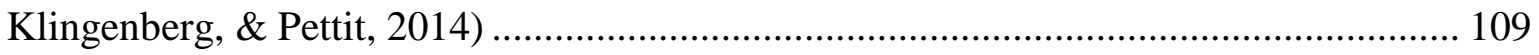




\section{LIST OF FIGURES}

Figure 2.1: Theoretical life cycle cost of a Passive House showing quantum drop off where conventional space conditioning systems can be minimized or negated (Feist \& Schnieders, 2009)

Figure 2.2: Iterative and integrated systems research approach (Andersen et al., 2006) ........... 15

Figure 2.3: Theoretical result from multi-objective optimization (Nguyen, 2014) .................... 19

Figure 2.4: Monthly natural gas consumption of a hypothetical measured building and two hypothetical simulation results to demonstrate the relationships of CV(RMSE) and NMBE 26

Figure 4.1: Overview of calibration methodology .............................................................. 32

Figure 4.2: Case study floor plans - basement and first floor ........................................... 34

Figure 4.3: Case study floor plans - second and third floor ............................................ 35

Figure 4.4: Ventilation and cooling air loops from case study house EnergyPlus output ........... 36

Figure 4.5: Radiant floor heating loops from case study house EnergyPlus output ................... 37

Figure 4.6: Outdoor air temperature of simulation weather file relative to measured data .......... 40

Figure 4.7: Typical residential electric equipment usage (Swinton et al., 2001)...................... 49

Figure 4.8: Daily average electricity profiles sorted by month recorded from Toronto Hydro hourly

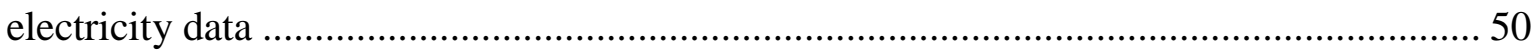

Figure 4.9: Average daily electricity profile recorded from Toronto Hydro hourly electricity data 50

Figure 4.10: Average daily electricity profile as in the calibrated model............................... 51

Figure 4.11: Natural gas spot measurement of volumetric meter reading ................................ 54

Figure 4.12: Total cooling electricity for the 2013 cooling season (Guadagnoli, 2014) ............. 59

Figure 4.13: Measured natural gas consumption relative to simulated consumption displayed with

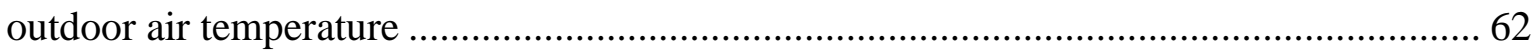

Figure 4.14: Measured natural gas consumption relative to simulated consumption displayed with days in natural gas billing period.

Figure 4.15: Measured electricity consumption relative to simulated consumption displayed with outdoor air temperature 
Figure 4.16: Model calibration signature showing measured and simulated total energy consumption and outdoor air temperature

Figure 4.17: Measured versus simulated hourly air temperature for sample zone (Living)........ 65

Figure 5.1: Overview of optimization methodology highlighting the coupling of optimization and building simulation engines..... 67

Figure 5.2: CCSF unit cost per thickness actually paid relative to RS Means estimated cost...... 72

Figure 5.3: XPS unit cost per thickness actually paid relative to RS Means estimated cost ........ 73

Figure 5.4: Glazing unit cost relative to overall $\mathrm{u}$-value ....................................................... 74

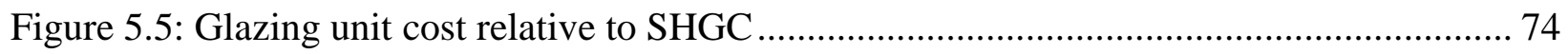

Figure 5.6: 2005-2015 Government of Canada Benchmark Bond interest rates for 30 year maturity

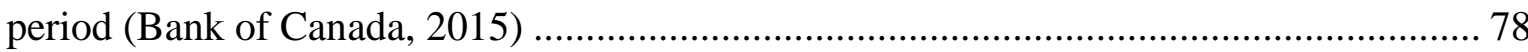

Figure 5.7: Predicted natural gas cost and escalation rate for Ontario until 2030 (National Energy

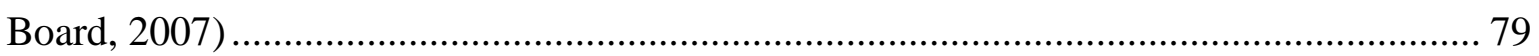

Figure 5.8: Natural gas price and escalation rate for Toronto from 1989 to 2011 (Statistics Canada, 2012) 80

Figure 5.9: Predicted electricity cost and escalation rate for Ontario until 2030 (National Energy Board, 2007) 81

Figure 5.10: Predicted electricity cost and escalation rate for Ontario until 2032 (Ontario Ministry of Energy, 2013). 81

Figure 5.11: Electricity price and escalation rate for Toronto from 2006 to 2014 (Ontario Energy Board, 2015) 82

Figure 5.12: jEPlus parametric search string example 86

Figure 5.13: Reference parameter (Case 1) multi-objective optimization for incremental LCC and total design load with as-built point highlighted 90

Figure 5.14: Example cash flow diagram over 30 year life cycle 93

Figure 5.15: Reference parameter (Case 1) multi-objective optimization for incremental LCC and total design load showing construction cost of ECMs versus dLCC 94

Figure 5.16: Reference parameter (Case 1) multi-objective optimization for incremental LCC and total design load showing simple payback versus dLCC 94

Figure 5.17: LCC and total peak load multi-objective optimization results for Case 1 (reference) 96 
Figure 5.18: LCC and total peak load multi-objective optimization results for Case 2 (low discount)

Figure 5.19: LCC and total peak load multi-objective optimization results for Case 3 (high escalation).

Figure 5.20: LCC and total peak load multi-objective optimization results for Case 4 (low mortgage)

Figure 5.21: Parametric results illustrating the relation between LCC and annual energy savings for optimization Case 1 (reference) highlighting maximum feasible energy savings 99

Figure 5.22: Parametric results illustrating the relation between LCC and annual energy savings for optimization Case 2 (low discount) highlighting maximum feasible energy savings . 100

Figure 5.23: Parametric results illustrating the relation between LCC and annual energy savings for optimization Case 3 (high escalation) highlighting maximum feasible energy savings 100

Figure 5.24: Parametric results illustrating the relation between LCC and annual energy savings for optimization Case 4 (low mortgage) highlighting maximum feasible energy savings 101

Figure 5.25: Passive House/BEopt comparison (Case 5) multi-objective optimization for incremental LCC and incremental annual energy savings highlighting point of minimal LCC 105

Figure 5.26: Parametric results illustrating the relation between LCC and annual heating demand 107

Figure 5.27: Parametric results illustrating the relation between LCC and annual cooling demand 107

Figure 5.28: Parametric results illustrating the relation between LCC and heating design load 108 Figure 5.29: Parametric results illustrating the relation between LCC and cooling design load 108 


\section{LIST OF ABBREVIATIONS}

\begin{tabular}{|c|c|}
\hline $\mathrm{AG}$ & Above grade \\
\hline ASHRAE & American Society of Heating, Refrigeration, and Air-Conditioning Engineers \\
\hline BEopt & Building Energy Optimizer \\
\hline BG & Below grade \\
\hline $\mathrm{BIPV} / \mathrm{T}$ & Building integrated photovoltaic/thermal \\
\hline $\mathrm{CCHT}$ & Canadian Centre for Housing Technology \\
\hline CCSF & Closed cell spray foam \\
\hline CEPHEUS & Cost Efficient Passive House European Standards \\
\hline c.i. & Continuous insulation \\
\hline $\mathrm{CMHC}$ & Canadian Mortgage and Housing Corporation \\
\hline CREEM & Canadian Residential End-use Energy Model \\
\hline CV(RMSE) & Coefficient of variation of the root mean square error \\
\hline DHW & Domestic hot water \\
\hline $\mathrm{dLCC}$ & Difference in life cycle cost \\
\hline DOE & [US] Department of Energy \\
\hline ECM & Energy conservation measure \\
\hline EIA & [US] Energy Information Administration \\
\hline ELA & Effective leakage area \\
\hline EGH & EnerGuide for Houses \\
\hline ERV & Energy recovery ventilator \\
\hline EPBD & Energy Performance of Buildings Directive \\
\hline ERS & EnerGuide Rating System \\
\hline EUI & Energy use intensity \\
\hline FEMP & [US] Federal Energy Management Program \\
\hline GHG & Greenhouse gas \\
\hline GSHP & Ground source heat pump \\
\hline HERS & Home Energy Rating System \\
\hline HVAC & Heating, ventilation, and air-conditioning \\
\hline iCFA & Internal conditioned floor area \\
\hline JESS & jEPlus Simulation Server \\
\hline
\end{tabular}




$\begin{array}{ll}\text { LCA } & \text { Life cycle analysis } \\ \text { LCC } & \text { Life cycle cost } \\ \text { MARR } & \text { Minimum acceptable rate of return } \\ \text { NMBE } & \text { Normalized mean bias error } \\ \text { NPV } & \text { Net present value } \\ \text { NRCan } & \text { Natural Resources Canada } \\ \text { NSERC } & \text { Natural Sciences and Engineering Research Council of Canada } \\ \text { NSGA-II } & \text { Non-dominated Sorting Genetic Algorithm II } \\ \text { NZE } & \text { Net zero energy } \\ \text { nZEB } & \text { Nearly zero energy buildings } \\ \text { OBC } & \text { Ontario Building Code } \\ \text { PHI } & \text { Passive House Institute [Europe] } \\ \text { PHIUS } & \text { Passive House Institute US } \\ \text { PHPP } & \text { Passive House Planning Package } \\ \text { PV } & \text { Photovoltaic } \\ \text { ROI } & \text { Return on investment } \\ \text { SNEBRN } & \text { Smart Net-Zero Energy Building Strategic Research Network } \\ \text { SQL } & \text { Structured Query Language } \\ \text { TFA } & \text { Treated floor area } \\ \text { XPS } & \text { Extruded polystyrene }\end{array}$




\section{INTRODUCTION}

Over the last two decades, the residential subsector has consumed approximately $17 \%$ of Canada's total secondary energy use and created 14\% of Canada's greenhouse gas (GHG) emissions on average (Natural Resources Canada's Office of Energy Efficiency, 2014). During this time period, energy efficiency improvements in thermal envelope, space and water conditioning systems, appliances, and lighting have decreased the energy use intensity (EUI) per building. However, housing number increase, due to population growth, resident per household decrease, household appliance concentration increase, and household cooling increase have led to a $13.5 \%$ increase in total secondary energy use of the residential subsector since 1990 (Natural Resources Canada's Office of Energy Efficiency, 2013). Therefore, further improvements are needed to combat Canada's population growth and reduce energy consumption and associated emissions in the residential subsector.

The ultimate goal adopted by the Canadian Government is to reach a net zero energy (NZE) point where houses require no purchased energy for operation and therefore produce no operational greenhouse gas (GHG) (Natural Resources Canada, 2014). A practical definition for a NZE building is one that produces as much energy on-site, often from photovoltaics (PV), as it consumes annually. This definition does not include material embodied energy. To provide quality assurance and quantify housing energy efficiency, Natural Resources Canada (NRCan) has adopted the EnerGuide for Houses (EGH) or EnerGuide Rating System (ERS) which ranks housing performance on a scale from 0 to 100 (Table 1.1), where 100 is a NZE home (Natural Resources Canada, 2005).

The approach to a NZE residential building sector is advancing, but still requires aggressive improvements in building energy conservation and onsite energy production technology for success. Typically, NZE houses require reduction of space conditioning load through building envelope improvements, direct solar exposure through good orientation, and energy demand reduction through selection of highly efficient appliances and space conditioning equipment before utilization of renewable energy sources can be considered viable. The passive measures create other added benefits such as improved thermal comfort through increased interior temperatures of exterior wall and fenestration surfaces, improved structural durability through moisture damage 
mitigation, and improved resilience against outages through reduced space conditioning demand and increased heat retention ability.

Table 1.1: EnerGuide for Houses rating system descriptions (Natural Resources Canada, 2015)

\begin{tabular}{cc}
\hline House description & Typical Rating \\
\hline Older house not upgraded & $0-50$ \\
Upgraded older house & $51-65$ \\
Energy-efficient upgraded older house & $66-74$ \\
New house built to building code standards without energy requirements & $70-76$ \\
New house built to building code standards containing energy requirements & $77-80$ \\
Energy efficient new house & $81-85$ \\
High-performance, energy efficient new house (Passive House) & $86-99$ \\
Net Zero Energy house & 100 \\
\hline
\end{tabular}

In Canada, NRCan (2014) has identified the R-2000 standard as the minimum envelope configuration with which to reach NZE in a select number of NZE pilot projects across the country. Comparatively, the US Department of Energy (DOE) has recognized the Passive House standard as a path toward NZE in America, and has entered into a partnership with the Passive House Institute US (PHIUS) (Wright, Klingenberg, \& Pettit, 2014).

The path to a carbon-neutral residential sector has been addressed by governments, yet cost continues to be a significant deterrent for majority market adoption of energy efficient building. In a survey of Canadian residential building contractors, the cost of high performance building materials and the cost of adoption, including training and certification, were the most significant barriers for energy efficient construction (Construction Sector Council, 2011). This common perception mainly considers initial cost and does not look at other measures of value or long term capital value. It is generally understood that the greater initial capital costs are required to achieve improved energy efficiency through the inclusion of energy conservation measures (ECM) but reduced energy bills can return this investment over the long-term while providing increased thermal comfort, greater structural durability, improved building resilience, and potentially higher property value. The actual financial relationship between initial capital cost and long-term savings for energy efficient homes is less known because of the variability in market construction rates, diminishing returns on ECM upgrades, mortgage rates, fuel price escalation, weather patterns, 
housing maintenance, and occupancy behavior. Therefore, while home builders, consumers, and policy makers are aware of the benefits of improved housing efficiency, they are unsure where the effort no longer becomes financially viable.

This study will present a virtual optimization environment, which couples a building simulation engine with batch handler and optimization algorithm, and use it to investigate the extent to which passive ECMs remain financially viable for housing in the cold climate of Toronto, Canada. The study uses multi-objective optimization to assess parameters for life-cycle cost and peak space conditioning load. A case study house is investigated and unascertainable values are tested under different circumstances to understand outcome variation. 


\section{LITERATURE REVIEW}

\subsection{Background}

The balance between residential energy efficiency demand and the associated cost barrier is delicate. Many home builders and consumers perceive the up-front costs to be too high to justify energy efficient upgrades. However, many researchers have investigated the long-term economic return associated with energy savings in response to this perception. This section will describe previous investigations into the economic considerations associated with energy efficient measures in retrofits, building codes for new construction, and high-performance houses (nearly net zero energy buildings or Passive Houses) with focus on the local situation. The intent of this section is to provide context and background theory from which to examine the next section (2.2 Relevant Studies).

\subsubsection{Economic Evaluation Metrics}

Numerous methods exist for evaluating the feasibility of energy efficiency improvements. No single method has been agreed upon as the established method of choice by builders, consumers, policy makers, and academics, and the evaluations range in complexity and uncertainty. Investment decisions become more difficult because improvements may seem attractive by one metric but less attractive by another.

An evaluation of construction cost is the simplest method for comparing the feasibility of energy conservation measures. Initial cost is the sum of the efficiency upgrades and is as accurate as the individual quotes provided for material and labor. Energy saving measures can be isolated and compared to decide on capital feasibility. Construction cost is the sum of first costs:

$$
\text { Construction Cost }=\sum I_{0}
$$

Where:

$$
\begin{aligned}
& \mathrm{I}_{0}=\quad \text { Initial capital investment with installation, tax, and profit for all } \\
& \text { components }
\end{aligned}
$$


Initial capital cost is only a small part of economic analysis and does not take into account long term savings from the reduced energy bills. Almost always, homeowners finance their housing purchase through a financial institution and pay for the house with mortgage payments over decades of time. As the monthly amount of purchased energy drops, because of reduced consumption demand, the homeowner is free to spend more money on the monthly mortgage payment. In other words, the home owner can spend money on home equity rather than on fuel and electricity. Therefore, capital project alternatives are better assessed over the long term.

Simple payback is a commonly used economic measure for long term capital investment (Fuller \& Petersen, 1996). It measures the time required to recover the initial capital investment, expressed in years. Discounted payback considers the discounted value of cash flow but is less popular than simple payback. Despite its popularity, the US Federal Energy Management Program (FEMP) (Fuller \& Petersen, 1996) stated that payback method is not acceptable for choosing between two mutually-exclusive project alternatives. Rather, it should be used as a screening method for identifying project inclusions that are so clearly positive they do not require full life cycle cost assessment. In practice, the commonly used formula for relative simple payback in years is (Fuller \& Petersen, 1996):

$$
\text { Simple Payback }=\frac{\Delta I_{0}}{\Delta E_{0}}
$$

Where:

$$
\begin{array}{ll}
\Delta \mathrm{I}_{0}= & \text { Difference in initial capital investment } \\
\Delta \mathrm{E}_{0}= & \text { Difference in initial annual energy cost }
\end{array}
$$

Life cycle cost (LCC) assessment is the most complete metric for evaluating all costs over the effective life cycle of a building and includes initial investment, regular utility payment, maintenance, and removal costs over a pre-determined length of time with provision for the time value of money (Fuller \& Petersen, 1996). It is very useful when comparing project alternatives that may have different initial capital costs and different levels of performance. Unlike the simple payback method which ends analysis once payback is reached, LCC accounts for the further costs and savings resulting after the point at which the payback is reached. The method is inherently uncertain because of the required future assumptions and should be calculated for various options 
of assumed values. However, the calculation is relative, and when considering two mutually exclusive options calculated under the same economic conditions the analysis should identify the favorable choice. The time value of money is represented by a discounted cash flow which analyzes the risk versus reward for investing money. Risking money in first costs is less favorable because spending flexibility is lost, additional investments (and therefore potentially further earnings) cannot be made, and a dollar loses spending power over time due to inflation (Flynn, 2010). In the LCC method, discount rates are applied to the project costs that occur at different times so their net present value can be combined directly. In general, life cycle cost is the cash flow sum of net present values for a given alternative, expressed by the formula (Fuller \& Petersen, 1996):

$$
\text { Life Cycle Cost }=\sum_{i=0}^{n} \frac{\left(I_{i}+E_{i}+O M \& R_{i}\right)}{(1+d)^{i}}
$$

Where:

$$
\begin{aligned}
& \mathrm{I}_{\mathrm{i}}=\quad \text { Asset costs incurred for year i (ex. mortgage payment) } \\
& E_{i}=\quad \text { Total energy costs for year } \mathrm{i} \text { (can include positive cash flows if power } \\
& \text { is generated and sold back to utility company) } \\
& O M \& R_{i}=\text { Operation, maintenance, replacement, and disposal for year } \mathrm{i} \\
& \mathrm{i}=\quad \text { Year in building's life cycle } \\
& \mathrm{d}=\quad \text { Discount rate to adjust cash flows to present value }
\end{aligned}
$$

\subsubsection{The Path to Carbon Neutrality under Economic Constraint}

Much of the existing housing stock, especially in well-established cities such as Toronto, was constructed before building codes mandated minimum required levels of energy efficiency. Furthermore, the housing density in such city cores leaves little to no room for new development. Therefore, restoration in the existing Canadian building stock provides a significant opportunity to reduce the energy consumption of this residential typology.

Previously, Guler et al. (2001) studied the energy savings of energy efficiency retrofits and the associated costs extrapolated to the entire Canadian housing stock, using the Canadian Residential End-use Energy Model (CREEM). The results showed modest efficiency 
improvements in the eligible housing stock, and that the long payback periods of greater than 20 years for most major upgrades made them unattractive unless a major renovation project was taking place concurrently or appliances were being replaced at the end of their useful life. However, given the choice, renovations utilize existing building components and reduce the need for excessive building material and the associated emissions for new production. Furthermore, the costs of a renovation is favorable compared to a complete rebuild despite the reduced energy savings that a new build could achieve (Dong, Kennedy, \& Pressnail, 2005). Recently, Jermyn (2014) addressed this issue and prioritized by cost retrofit strategies for archetypal housing types in Toronto.

The path to carbon neutrality in the residential sector is gradual and the journey is punctuated by mandated requirements. For example, the Supplementary Standard SB-12 Energy Efficiency for Housing, adopted in 2012, has amended the 2006 Ontario Building Code (OBC) and requires a minimum efficiency rating of 80 when assessed by EnerGuide for Houses (MMAH, 2009). The amendment has formulated a prescriptive path to achieve the target or offers alternative paths to compliance through whole building energy modelling. However, Policy updates must be justified economically and technically feasible for builders to gain market adoption without significant pushback.

Before SB-12 was implemented, Grin (2008) argued that a low-energy home could be built for less carrying cost than a comparable home built to the 2006 OBC minimum energy efficiency requirement. Consulting literature, 'green' standards were compared to the building code of the time and packages for parametric study were chosen to improve upon the building code. Using HOT2000, the packages were simulated for a single detached house in Toronto to determine monthly energy costs and added to monthly mortgage payments to result in total carrying cost. The results showed that the 2006 OBC minimum energy requirements could be improved by $30 \%$ without increasing the monthly carrying cost for homeowners financing their house (Grin, 2008).

More recently, Dembo (2011) proposed a series of "least cost upgrades" that could be implemented into new construction housing and future building standards in Canada. "Least cost upgrades" were determined using sensitivity analysis for energy saving measures being implemented by local homebuilders. These upgrades were applied individually to a reference house built to the R-2000 standard and modelled in HOT2000 to determine whole building energy 
consumption for cities across Ontario. Upgrades included building envelope systems and heating ventilation, and air-conditioning (HVAC) systems. A parametric assessment was performed for the upgrades and associated costs were determined for a 30 year building life cycle. It was determined that energy savings of $31 \%$ and total life cycle cost savings of $\$ 20,381$ could be achieved using the optimal combination of parameters while still meeting the requirements of SB12.

With the goal in mind of carbon neutrality in the residential sector, performance targets point beyond marginal improvements to net zero/nearly net zero energy or Passive buildings, which are of the greatest interest to this study. However, market adoption will only occur if the solutions are technically and economically feasible. The next portion of this section will present academic and regulation studies regarding the feasibility of high-performance housing.

In the European Union, the Energy Performance of Buildings Directive (EPBD) (The European Parliament and the Council of the European Union, 2010) created an obligation for all new buildings built after December 31, 2020 to be nearly zero energy buildings (nZEB). Each Member State was required to create their own national regulations that would allow buildings to meet the specified target by the end of 2020, but still account for traditional building practices, political processes, market conditions, and climate. Furthermore, the framework of the directive had Member States develop national regulations which ensure minimum energy performance requirements at "cost-optimal levels" calculated with a comparative methodology (European Council for an Energy Efficient Economy, 2011). The comparative methodology for calculating cost-optimal levels of building elements required Member States to:

i. Define reference buildings representative of their local practices for both residential and non-residential, and new and existing

ii. Define energy efficiency measures to be assessed for the reference buildings

iii. Calculate final and primary energy use for each reference building with applied energy efficiency measure

iv. Determine net present value costs of the energy efficient measures over the expected life cycle of the building including initial investment, maintenance and operating costs, and demolition and disposal costs 
Progress reports were required from each Member State in 2012, and the results showed that the feasible minimum energy requirements were generally much greater than those in North America of relative climates (Sutherland, Maldonado, Wouters, \& Papaglastra, 2013). The result is likely owing to the fact that energy costs are generally higher in Europe than in North America. For example, the minimum energy package as of 2013 in Finland is shown in Table 2.1.

Table 2.1: Minimum energy efficiency requirements for Finnish buildings established by the EPBD protocol for cost-optimal energy efficiency packages

\begin{tabular}{cc}
\hline Building Component & U-value $(\mathrm{W} / \mathrm{m} 2 \mathrm{~K}) / \mathrm{R}$-value $(\mathrm{m} 2 \mathrm{~K} / \mathrm{W})$ \\
\hline Exterior walls & $0.17 / 5.88$ \\
Roofs & $0.09 / 11.11$ \\
Exposed floor & $0.09 / 11.11$ \\
Slab on grade & $0.16 / 6.25$ \\
Floor above crawl space & $0.17 / 5.88$ \\
Windows & $1.0 / 5.68$ \\
Doors & $1.0 / 5.68$ \\
Annual efficiency for heat recovery systems & $45 \%$ \\
\hline
\end{tabular}

The efficiency code also has requirements for air leakage of the building envelope and maximum primary energy consumption values depending on building type. The Finnish regulations are the strictest in Europe, reaching super-efficient levels nearing that of the Passive House standard (Feist W. , Schnieders, Dorer, \& Haas, 2005), but are noteworthy because of the climate which is comparable to that of Canada. It is important to mention again that these regulations were determined using the EPBD framework that finds minimum energy requirements based on cost-optimal packages.

In North America, the move toward high-performance housing has been somewhat slower than in Europe. The 2030 Challenge, introduced in 2002 by architect Edward Marzia (2015), asked the global community to reach carbon neutrality in the building sector by 2030 . The initiative has gained popularity, especially in the North American architecture community, but is not mandated and has a less rigorous framework proposed to achieve the goal compared to the European directive. Nonetheless, the United States government and DOE have developed voluntary guidelines for homes to participate in the DOE Zero Energy Ready Home challenge. The challenge 
recognizes houses that are energy efficient enough that a renewable energy system could be installed to offset total annual energy consumption. The program builds on the ENERGY STAR for homes program and the Home Energy Rating System (HERS) index, similar to the EnerGuide for Homes score in Canada, in pursuit of eventually creating a stock of net zero energy houses (US Department of Energy, 2015).

Recently, the US DOE partnered with PHIUS and recognized the Passive House standard as a promising path to net zero energy for homes because the aggressive reductions in heating and cooling load through envelope improvements, solar utilization, and selection of highly efficient appliances aligns with the principles of the net zero ready initiative (US Department of Energy, 2015). The PHIUS+ certification will be used to encourage market transformation toward net zero ready homes while minimizing confusion for the housing industry (instead of creating another certification system).

The Passive House standard originated in the early 1990's in Germany with the belief that an economic optimum exists at a peak heat load of $10 \mathrm{~W} / \mathrm{m} 2$ or annual space conditioning demand of $15 \mathrm{kWh} / \mathrm{m} 2 \mathrm{a}$ (Feist W. , Schnieders, Dorer, \& Haas, 2005). This is the theoretical point at which space conditioning can be provided by only the ventilation system in conjunction with natural gains from solar exposure, human respiration, and waste heat from lights and appliances. Hence significant savings can be achieved because of the simplified heating system. This concept is sometimes described as "tunneling through the cost barrier" and is depicted in Figure 2.1. Envelope improvements require greater initial investment but reduce long term energy payments. If enough investment is put into the passive features to significantly reduce the space conditioning load, then the heating system can be effectively removed and initial costs are significantly reduced.

An economic demonstration of the Passive House in Europe was performed in a European Union funded project titled Cost Efficient Passive House European Standards (CEPHEUS). Data from 221 housing units in 14 buildings were studied in Germany, Sweden, Austria, Switzerland, and France were collected. On average, it was shown approximately $80 \%$ savings in space heating consumption and approximately $50 \%$ savings in primary energy consumption compared to a similar conventionally built home of the same vintage for an extra intial cost of approximately 10\% (Schnieders \& Hermelink, 2006). 


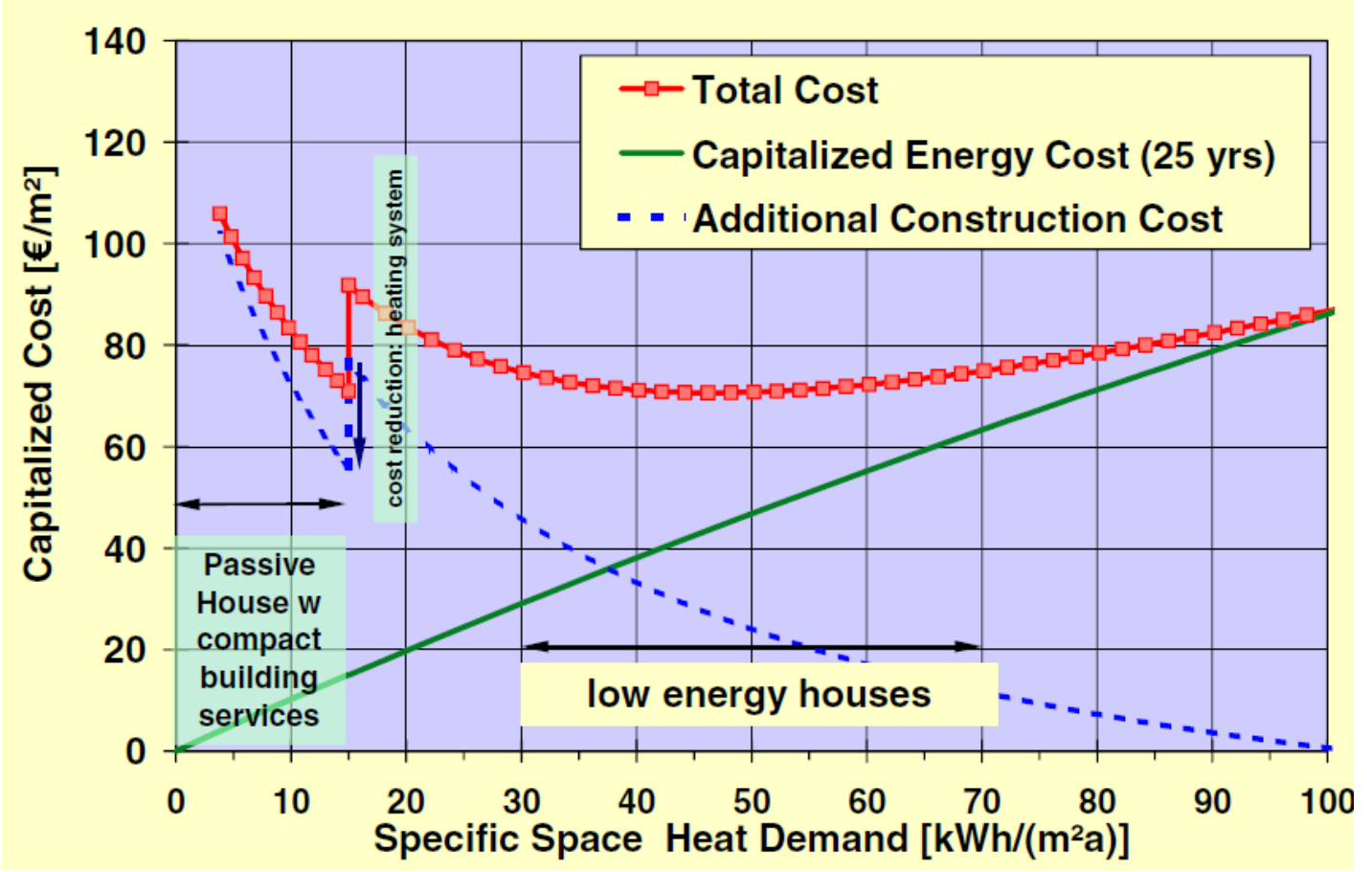

Figure 2.1: Theoretical life cycle cost of a Passive House showing quantum drop off where conventional space conditioning systems can be minimized or negated (Feist \& Schnieders, 2009)

Experience with Passive House in North America has shown that the effort required to obtain this level of thermal performance drives design past the economic optimum in many places because of the extreme cold or high latent load. Even when building designs are optimized using simulation to test every possible combination of passive parameters, the supply air heating criteria of the standard is impossible to meet in some North American climate zones (Abendroth, 2013). It was therefore recommended that an adapted Passive House standard be created that is customizable depending on climate region. A similar study modelled a house in all North American climate zones and determined that the effort and cost to meet the Passive House standard, as prescribed by the European Passive House Institute (PHI), varied greatly between climates and that it was not practical to do so in North America's extreme climates. The study concluded that the Passive House standard should be modified to be climate-dependent (Kruger, 2012).

Kruger (2012) used an optimization method to recommend a North American adaptation to the Passive House standard following the basic Passive House definition set by Dr. Feist of "the most energy efficient house design that is cost-competitive”. The Building Energy Optimizer tool (BEopt) (National Renewable Energy Laboratory, 2015) was first used to optimize envelope 
variables for cost in a typical German climate. Once the optimal house was established for the German climate, the house was modelled in climates across the United States to determine the equivalent heating and cooling demand. The results were used to recommend new heating demands for each climate. In some cases, where the climate is hot and dry, the recommended standard was stricter than the current standard, in that it would reduce allowable peak loads and annual space conditioning demand. Although BEopt uses the EnergyPlus platform, the objective cost function used by BEopt is non-customizable.

Since the completion of the first North American Passive House in 2003 (Stecher \& Klingenberg , 2008), PHIUS has followed the PHI's definition where peak heating and cooling load is $10 \mathrm{~W} / \mathrm{m} 2$ and heating is provided via supply air. The definition has since been challenged on the basis that the peak load requirements cannot be met at the economic optimum in all of North America's climate. Over the past three years, the PHIUS Technical Committee and Building Science Corporation have been working to update the PHIUS+ rating system with climate-specific considerations in hopes of promoting more wide-spread adoption (Wright, Klingenberg, \& Pettit, 2014). The method chosen by PHIUS to determine climate-specific adaptations for the standard is similar to the method proposed by Kruger (2012). The objective of the work was to determine cost optimal, or at least cost competitive, investment in passive measures. The new PHIUS+ 2015, released March 19, 2015, offers climate specific performance targets for 1000 North American climates (PHIUS, 2015). Detailed results will be discussed later in this document.

In the recent study (Wright, Klingenberg, \& Pettit, 2014), a representative detached house was optimized for life cycle cost in 111 North American climates. Simulations were run using BEopt, to optimize passive, equipment, and renewable energy parameters for minimized carrying cost over the building life cycle. The criteria for the updated PHIUS+ 2015 standard used results for maximum annual energy savings at a point near the minimum life cycle cost (some human judgment was involved). Recommendations for each climate were pushed past the cost-optimal point for the sake of the "more to life than money" argument and make a conservative buffer for future uncertainty.

As mentioned earlier, Canada continues its path toward super-efficient housing using the R2000 and EnerGuide for Homes rating systems. An R-2000 Net Zero Energy pilot project is currently underway which will provide technical support and promotion to builders across the 
country who are to build net zero energy homes that will be recognized by the government of Canada (Natural Resources Canada, 2014). The goal of the pilot project is to promote net zero, and net zero ready, homes and to enhance the next generation of R-2000 and EGH rating systems, rather than creating new rating systems. The project is nascent with little information published, and there is currently little discussion of cost optimization in the matter. The pilot will utilize the next generation of the R-2000 standard to first address the envelope and other passive means adequately before renewables are considered.

The Natural Sciences and Engineering Research Council of Canada (NSERC) has funded the Smart Net-Zero Energy Building Strategic Research Network (SNEBRN) which brings together a network of researchers from Canadian universities and industry partners. SNEBRN's goal is to facilitate research that will enable adoption of optimal net zero energy buildings suited to Canada's cold climate by 2030 (NSERC SNEBRN, 2012).

A recent study funded by this NSERC initiative used BEopt to complete an optimization study to identify pathways to a cost-optimal near net zero energy home in Canada (Bucking, Athienitis, \& Zmeureanu, 2014). The study was done using an existing detached net zero energy home located in Eastman, Quebec known as EcoTerra. The home utilizes Building Integrated Photovoltaics and Thermal (BIPV/T) solar panels with a ground source heat pump (GSHP) and was equipped with a number of temperature sensors to record data through the zones and assemblies. Modelling the case study house allowed the researchers to evaluate the current operation and test theoretical design improvements that could be implemented in future designs. The energy model was calibrated using the monitored data and then optimized for net energy consumption and incremental net present value life cycle cost. Component costs were taken from RS Means. The results showed that the original design of the house was fairly successful, but would require improved PV efficiency to reach net zero and initial costs were still quite high. It also showed that cost-optimal envelope investment was fairly significant for the Quebec climate. Some optimal results are shown in Table 2.2, although other factors were varied as test parameters, including building azimuth and aspect ratio, window to wall ratio for each face, shading, thermal mass, heating and cooling setpoints, and numerous PV factors. 
Table 2.2: Optimal passive ECMs for EcoTerra house in Quebec (Bucking et al., 2014)

\begin{tabular}{cc}
\hline Building Component & R-value (m2K/W) \\
\hline AG exterior walls & 8.56 \\
BG exterior walls & 5.08 \\
Roofs & 10.57 \\
Basement slab & 1.29 \\
Windows & vinyl \\
Air tightness & 0.45 ACH50 \\
\hline
\end{tabular}

The Canadian Mortgage and Housing (CMHC) has also contributed to Canada's advancement in high performance housing technology. The EQuilibrium ${ }^{\mathrm{TM}}$ Sustainable Housing Demonstration Initiative supports private designers and builders to build homes that demonstrate excellence in sustainable practices including energy efficiency and energy production (CMHC, 2015). The previously mentioned EcoTerra house was part of the EQuilibrium ${ }^{\mathrm{TM}}$ initiative. CMHC sponsored research on the Canadian Centre for Housing Technology $(\mathrm{CCHT})$ has also played a large role in advancing Canadian knowledge of high performance housing (Swinton, Entchev, Szadkowski, \& Marchand, 2003; Armstrong, Swinton, Ribberink, Beausoleil-Morrison, \& Millette, 2009).

Demonstration projects, and their review, play an important role in the movement toward carbon neutrality. The systems research process, proposed by Andersen et al. (2006), assesses whole building system performance and cost trade-offs. Systems interaction analysis must be performed to demonstrate viable innovations in high performance technology or building strategies. Test houses which use innovative techniques or technology must show cost-effective energy savings and total house quality before it can be applied on the production scale. To eventually integrate new systems into production building, test projects must be studied and conclusions must be shared to inform future projects in an iterative manner (Figure 2.2). 

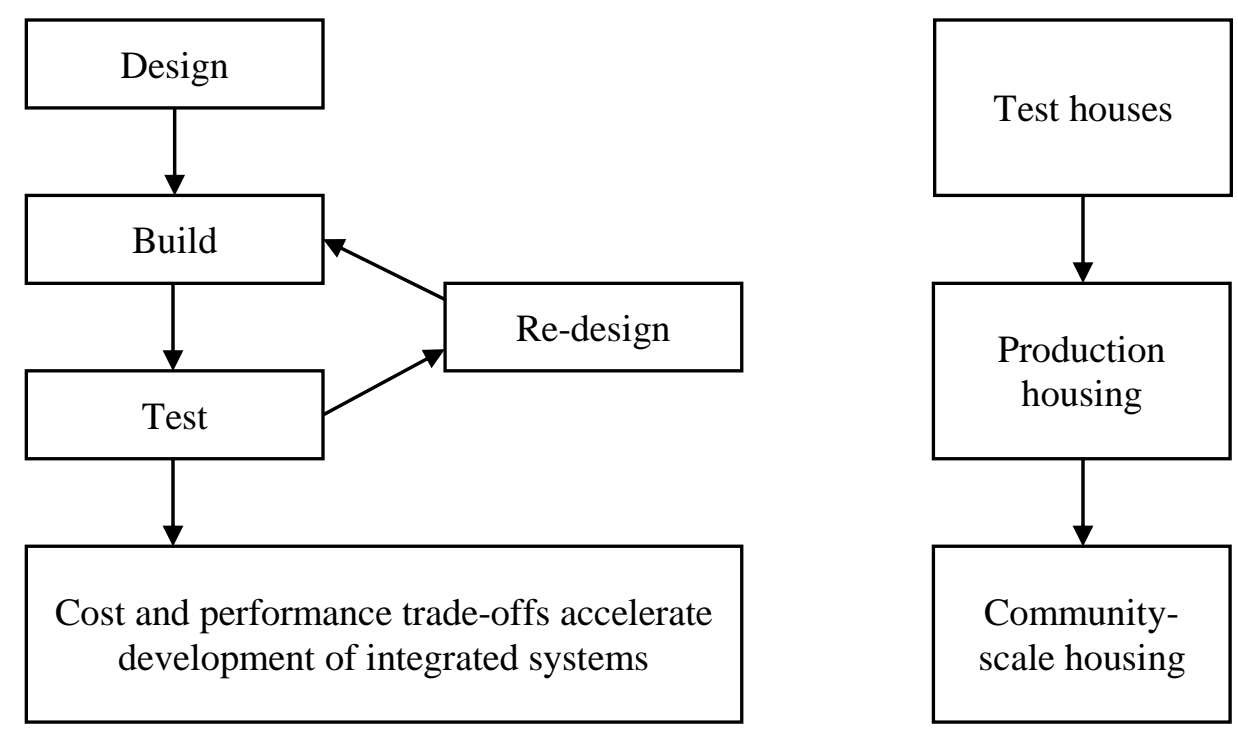

Figure 2.2: Iterative and integrated systems research approach (Andersen et al., 2006)

Recently, CMHC sponsored a research project carried out by RDH Building Engineering that assessed cost-effectiveness, energy savings, and durability of energy efficiency measures for retrofits of typical Canadian housing types (2011). The objective of the energy analysis was to determine the thermal performance required to reach net zero housing and the associated cost implications. Passive energy efficiency measures were applied to 4 simulated housing archetypes in 14 Canadian municipalities. The study used HOT2000 to determine building envelope packages that would achieve an EnerGuide rating of 83 while keeping mechanical equipment efficiency at mid-level (80\% efficient furnace, no cooling, and 80\% efficient heat recovery, 1.0 ACH50). Mechanical systems and renewable energy production were out of the scope of the study. Each energy efficiency package was compared to the base case, a code-built house, for simple payback, discounted payback, and return on investment (ROI). The costs included material, installation, and demolition and used RS Means, local suppliers such as Home Depot, and local installation contractors. The study determined that near-Net Zero Energy retrofits are technically possible, but are not feasible based on simple payback analysis especially for cities with low energy costs. They suggested it might be cheaper to instead invest in a combination of envelope retrofits and renewable energy such as photovoltaics, but did not perform the analysis. They also implied that an envelope level equivalent to EnerGuide 83 would not be sufficient in reaching net zero energy with PV applied, especially in cold climates, though it was more cost effective to upgrade the envelope first before installing PV. 


\subsection{Relevant Studies}

The previous sections described the context of the Canadian move toward a carbon neutral residential sector, with reference to the European Union and the United States, under consideration of economic feasibility. The following sections will describe relevant research efforts, from which the methods used for this study were derived.

\subsubsection{Parametric Optimization Techniques in Energy Efficient Building Design}

Increased concern for the environmental impact of buildings has led to a demand for energy efficiency. However, in reality design decisions are heavily influenced by construction cost. Designers are tasked with the challenge of maximizing energy efficiency while minimizing cost. With the advances of computer science, designers are well-equipped with building simulation programs to predict the effects of design variables. However, design most often involves iterative trial-and-error parametric runs to reach energy targets. The process relies on subjective experience, considers a relatively small solution space and, if only one parameter is varied while all others stay constant, is likely to miss interactive effects.

To mitigate such problems, simulation-based optimization has been considered as a way to effectively progress toward low-energy and low-cost buildings. Simulation-based optimization refers to the automated process of coupling a building simulation engine with mathematical optimization to iteratively determine the combination of chosen variables that minimize one or more functions. The process searches the solution space and objectively determines an optimal or near-optimal combination of variables in a relatively short time. The area of research has grown for almost the last three decades, with exponential progress beginning in the late 2000's (Nguyen, Reiter, \& Rigo, 2014).

\section{REFERENCE BUILDINGS}

As the name implies, simulation-based optimization requires a building simulation model on which to perform optimization. The model used should be simplified to reduce computing time but should not be over-simplified to the point where accuracy is lost (Nguyen, Reiter, \& Rigo, 2014). Wang et al. (2005) considered a single-story office building using default values from the Model National Energy Code of Canada for buildings and conventional local construction practices. Most often, typical residential buildings are created for reference using historic weather 
data, national building code standards, and national averages to determine building characteristics (Verbeeck \& Hens, 2007; Hamdy, Hasan, \& Siren, 2011; Fesanghary, Asadi, \& Geem, 2012; Ihm \& Krarti, 2012; Nguyen \& Reiter, 2012; Hamdy, Hasan, \& Siren, 2013). Other studies captured features of research houses made to represent typical dwellings, such as the Finnish RET project detached house (Hasan, Vuolle, \& Siren, 2008), the typical detached home used by the Building America Research Benchmark (Tuhus-Dubrow \& Krarti, 2010; Bichiou \& Krarti, 2011), or the Canadian Centre for Housing Technology Twin Research Houses (Dembo, 2011). Only one other study found used an actual, occupied reference building model calibrated to real-world data (Bucking, Athienitis, \& Zmeureanu, 2014).

\section{DESIGN VARIABLES}

Energy saving measures are the parameters or independent variables that are automatically varied during optimization. Energy use, and therefore energy cost, is reduced by adding energy saving measures to the reference case. However, by adding energy saving measures, initial construction cost increases. The goal of an optimization study is to determine which combination of variables yields the greatest energy and/or cost saving, depending on the goal of the study.

Design variables may be described mathematically as discrete or continuous. Discrete variables are those which exist in a finite number. For example, there are a finite number of insulation types that may be used in construction such as fiberglass, mineral wool, cellulose, polystyrene, etc. Continuous variables are those which exist in an infinite number, within constraints. For example, insulation thickness may assume any value between a given limit. However, insulation thickness may be better described in discrete increments of $25 \mathrm{~mm}$ to match the thicknesses provided by manufacturers. When designing optimization problems, variable type must be considered. Some numerical optimization methods that use differentials have a difficult time dealing with discrete variables.

To simplify the simulation model, many optimization studies consider only passive energy saving measures such as building orientation, building shape, building aspect ratio, thermal mass, window type, window-to-wall ratio, shading values, envelope type, envelope insulation value, and infiltration rates (Wang, Zmeureanu, \& Rivard, 2005; Tuhus-Dubrow \& Krarti, 2010; Fesanghary, Asadi, \& Geem, 2012; Nguyen \& Reiter, 2012). Other optimization studies consider not only passive energy saving measures, but also HVAC systems, HVAC efficiencies, heat recovery 
efficiencies, generation systems, lighting type, and control measures (Verbeeck \& Hens, 2007; Hasan, Vuolle, \& Siren, 2008; Bichiou \& Krarti, 2011; Hamdy, Hasan, \& Siren, 2011; Ihm \& Krarti, 2012; Dembo, 2011; Hamdy, Hasan, \& Siren, 2013).

\section{OBJECTIVE FUNCTIONS}

An objective function is the target value or dependent variable that is to be minimized in an optimization problem. Optimization may be done with respect to one objective or multiple objectives and usually include a combination of cost, energy, and carbon. Hasan et al. (2008), Tuhus-Dubrow and Krarti (2010), Bichiou and Krarti (2011), and Ihm and Krarti (2012) consider the life cycle cost of the energy saving measures, with respect to the reference case, as the single objective function. Dembo (2011) used the carrying cost, which includes initial cost, mortgage, and fuel costs, as the single objective function. To mirror reality more closely, multiple objectives should be considered, since there are generally multiple design goals for a building. Some studies attempt to minimize total life cycle impact by using life cycle cost and total energy (embodied and operational) energy (Wang, Zmeureanu, \& Rivard, 2005; Verbeeck \& Hens, 2007), or life cycle cost and cradle-to-grave $\mathrm{CO}_{2}$ emissions (Fesanghary, Asadi, \& Geem, 2012) as objective functions. Hamdy et al. (2011) set the objective functions as $\mathrm{CO}_{2}$-eq emissions and investment cost to achieve low-emission, cost effective solutions. Later, Hamdy et al. (2013) looked to

minimize primary energy consumption and life cycle cost searching for cost-optimal and nearly zero energy building solutions. Nguyen and Reiter (2012) consider life cycle cost and thermal comfort as their objective functions toward developing low-cost housing.

Multi-objective optimization produces a set of Pareto optimal points, which are those that cannot further improve one objective function without worsening the other objective function. Graphically, multi-objective optimization with two functions is represented with two axes where each axis depicts one of the objective functions (Figure 2.3); problems with three objective functions create a three-dimensional Pareto Front. Usually due to computational feasibility, researchers are limited to two objective functions. From the set of Pareto optimal points, the best solution for one objective function can be determined for a point deemed acceptable by the second objective function. For example, if a multi-objective problem were seeking minimize both construction cost and total operating energy, the minimal operating energy could be determined 
for the construction budget. On the same Pareto front, a lower point of operating energy could be found, but it could only be achieved with increased construction cost.

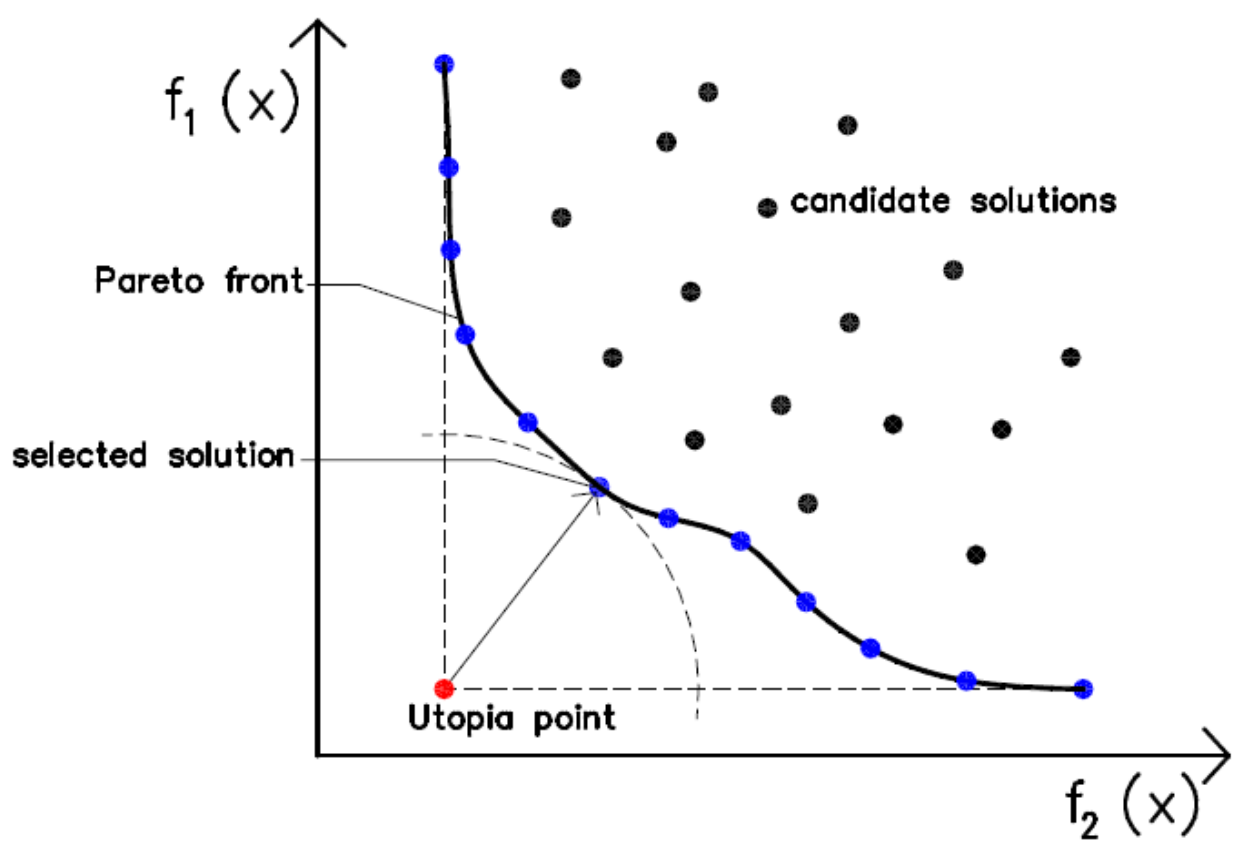

Figure 2.3: Theoretical result from multi-objective optimization (Nguyen, 2014)

\section{OPTIMIZATION METHODS}

Different methods of optimization exist which can find optimal results with varying levels of efficiency and accuracy. Brute-force, or full-factorial, parametric search is an exhaustive method of evaluating all variable combinations in a systematic manner. The method usually considers thousands of combinations but is computationally expensive. Brute-force searches may take many hours or days. Therefore, mathematic algorithms can be used to find optimal, or near optimal, results with much greater efficiency. Optimization algorithms, however, cannot always guarantee a global minimum in the way the brute-force method can, and may have difficulty handling discrete variables.

In a thorough literature review of building optimization studies, Nguyen et al. (2014) identified five main algorithm families commonly used in building optimization studies: the direct search family, integer programming family, gradient-based family, stochastic population-based family, and the trajectory search family. In the review of optimization methods, stochastic population-based algorithms were favored. Specifically, genetic algorithms were used 40 times, 
particle swarm algorithms 13 times, both from the population-based family of algorithms, hybrid algorithms 10 times, often including population-based algorithms, and all other optimization algorithms were used 5 or less times.

A genetic algorithm is a sub-classification of an evolutionary algorithm and is part of the stochastic population-based family, which takes from the biological principles of natural selection and random genetic mutation. A random combination of values for the given parameter search space creates the first generation. For each subsequent iteration, a new random individual in the population is added to the current generation and compared against the objective function. Elite mutations survive until convergence is reached. Many previous studies have utilized a genetic algorithm to perform multi-objective optimization for buildings (Wang, Zmeureanu, \& Rivard, 2005; Hamdy, Hasan, \& Siren, 2009; Hamdy, Hasan, \& Siren, 2011; Hamdy, Hasan, \& Siren, 2013; Tuhus-Dubrow \& Krarti, 2010; Verbeeck \& Hens, 2007; Bucking, Athienitis, \& Zmeureanu, 2014).

Meta-heuristic evolutionary algorithms, like genetic algorithms, which employ 'survival of the fittest' Darwinian principles have been shown to find good solutions for objective functions in fewer simulations than other optimization techniques, and have therefore become very popular methods for optimization problems (Evins, 2013; Nguyen, Reiter, \& Rigo, 2014). Bichiou and Krarti (2011) performed a study to compare the robustness of the genetic algorithm, particle swarm algorithm, and sequential search methods of optimization. It was determined that all three methods could produce the optimal design for the life cycle cost objective function, however it was shown that the sequential search technique had significantly greater computation efforts than the other two optimization algorithms. The genetic algorithm was the most efficient method for minimizing the objective function and could produce up to $70 \%$ savings in computations effort compared to the sequential search technique. Wetter and Wright (2004) compared optimization algorithms used to minimize cost functions with different smoothness. It was found that a hybrid particle swarm and Hooke-Jeeves algorithm obtained the largest cost reduction, but a simple genetic algorithm yielded only a slightly less accurate solution for far fewer iterations. Palonen et al. (2009) also concluded that the use of a hybrid algorithm provides more accurate results than a genetic algorithm alone. 
The sequential search technique searches the parameter space one parameter level at a time, and chooses the best parameter option at each step. Simulations are performed at each step to determine the best option for the given objective function. After optimization is complete, the intermediate steps taken can all be seen. The technique's advantage is that it shows the steps taken during the process to define a 'path' to the optimal solution set. This is the method used in BEopt software to perform optimization with the intent of illustrating the cost-optimal path to net zero energy (Christensen, Horowitz, Givler, Courtney, \& Barker, 2005). The sequential search technique has been used manually in previous research (Dembo, 2011; Jermyn, 2014; Anderson, Christensen, \& Horowitz, 2006; Ihm \& Krarti, 2012), and from within the BEopt simulation interface (Kruger, 2012; Wright, Klingenberg, \& Pettit, 2014; Bucking, Athienitis, \& Zmeureanu, 2014).

Optimization algorithms do not always reach the global minimum for the specified objective function. Instead, the optimization algorithm may get 'stuck' on local minimum points. However, near-optimal solutions may be acceptable if the computing demand is reduced with heuristics. Many studies have employed numerous optimization algorithms to compare their performance in accuracy and efficiency (Hamdy, Hasan, \& Siren, 2009; Tuhus-Dubrow \& Krarti, 2010; Bichiou \& Krarti, 2011; Nguyen \& Reiter, 2012). Ultimately, algorithm efficacy can be tested using brute force comparison. Hasan et al. (2008) included brute-force optimization to verify results obtained using a hybrid algorithm. More recent studies have used the same brute-force approach with limited solutions to verify algorithm results (Hamdy, Hasan, \& Siren, 2009; Palonen, Hasan, \& Siren, 2009; Hamdy, Hasan, \& Siren, 2011). Ihm and Krati (2012) also used the brute-force search approach to validate a sequential search optimization.

Brute force can be used alone, and guarantees a global maximum. Abendroth (2013) performed a full factorial experiment to assess the Passive House standard in the United States. The Passive House Planning Package (PHPP) was automated with use of macro-programming to find optimal combinations of building envelope to minimize the space conditioning and energy use criteria of the Passive House standard.

\section{OPTIMIZATION TOOLS}

Many optimization studies have developed custom optimization environments in MATLAB (Verbeeck \& Hens, 2007; Hamdy, Hasan, \& Siren, 2009; Tuhus-Dubrow \& Krarti, 2010; Hamdy, 
Hasan, \& Siren, 2011; Hamdy, Hasan, \& Siren, 2013) or other common programing platforms such as C\# (Fesanghary, Asadi, \& Geem, 2012), where the optimization program is coupled with simulation programs like EnergyPlus, TRYNSYS, DOE-2, or ESP-r which create text-based output which can be read by external code.

Other programs have been created from within the building simulation community that are specifically made to couple building simulation programs with optimization code. These programs can be used for optimization 'out of the box'. That is, they required little to no coding or light pseudo-code to set up and run an optimization problem, unlike MATLAB which requires the user to create the optimization engine nearly from scratch.

GenOpt is a free to use optimization engine that can be coupled with simulation programs to perform building optimization problems. It was developed in 2001 at the Lawrence Berkley National Laboratory (Wetter, 2001) and has since been used successfully in a number of optimization projects (Wetter \& Wright, 2004; Hasan, Vuolle, \& Siren, 2008; Palonen, Hasan, \& Siren, 2009; Nguyen \& Reiter, 2012; Ferraraa, Fabriziob, Virgone, \& Filippi, 2014; Karaguzel, Zhang, \& Lam, 2014). Its significant advantage is that it can run optimizations using a number of predefined optimization algorithms. The main shortfall of GenOpt is its inability to handle multiple objective functions. Users are limited to combine objective functions into a single function using weighted sums to balance the significance of certain objectives.

jEPlus is a similar tool that allows users to perform 'out of the box' parametric optimization problems with EnergyPlus or DOE-2 and light pseudo-code (Zhang, 2009; Zhang \& Korolija, 2010). jEPlus handles batch parametric simulations to explore a large parameter space in a fullfactorial manner (DeLarm-Neri, 2013). An additional tool, jEPlus+EA, has been developed to allow jEPlus projects undergo optimization using a genetic algorithm (Zhang, 2012). The program is relatively new in the research community, but it has shown that it can produce reliable multiobjective optimization results with a user-friendly interface for relatively low computational effort (Zhang, 2009; Zhang \& Korolija, 2010; Zhang, 2012; Dingwall, 2012; DeLarm-Neri, 2013; Naboni, Maccarini, Korolija, \& Zhang, 2013). A potential criticism of the jEPlus+EA program is that it only allows users to use one predetermined genetic algorithm. The decision was reportedly intentional to bolster simplicity and user-ease (JEPlus, 2015). However, as described above, 
genetic algorithms have been shown to offer good results for efficient computation demand, and are the most widely used algorithms in building optimization studies.

BEopt was created to identify least-cost paths to net zero or nearly net zero energy buildings (Christensen , Horowitz, Givler, Courtney, \& Barker, 2005; Anderson, Christensen, \& Horowitz, 2006). It can be used for life cycle cost optimization studies and uses EnergyPlus or DOE-2 simulation engines along with a predefined library of building parameters and their associated costs using a sequential search optimization algorithm. All optimization is run from within the BEopt interface with no coding required. It is the chosen simulation tool for the Building America efficiency improvement program in the US (Hendron \& Engebrecht, Building America House Simulation Protocols, 2010) and has been used in other optimization procedures (Kruger, 2012; Bucking, Athienitis, \& Zmeureanu, 2014; Wright, Klingenberg, \& Pettit, 2014). BEopt is a good tool for testing a large number of parameters for over numerous climates and economic jurisdictions, but lacks customizability. The building simulation interface is simplified and the objective functions cannot be manipulated.

\subsubsection{Calibration Techniques for Whole Building Energy Models}

Calibration, as it relates to building performance simulation, is the process whereby the simulation model is updated, changed, tuned, or refined in order to better reflect the monitored performance of the real building. Interest in building energy conservation triggered intervention in the existing building stock, and it was realized that favorable retrofit strategies could be determined using building simulation, which was a developing field at the time.

Reddy (2006) discussed the history and development of calibration techniques in detail in a thorough literature review. The two most common reasons for calibration are to more accurately determine energy savings from competing retrofit component options, and to monitor and verify the results of the implemented retrofit measures. Most of the previous work has demonstrated the use of calibrated energy models to compare potential energy conservation measures in commercial buildings (Pan, Huang, \& Wu, 2007; Iqbal \& Al-Homoud, 2007; Eskin \& Turkmen, 2008; Tian \& Love, 2009; Aynur, Hwang, \& Radermacher, 2009a; Aynur, Hwang, \& Radermacher, 2009b; Rahman, Rasul, \& Khan, 2010). Zirnhelt (2013) used a calibrated model of a Canadian house, the

$\mathrm{CCHT}$, to test glazing, massing, and orientation parameters for passive solar gain. Similarly, 
Bucking et al. (2014) used a calibrated model of a Canadian residential ZNE house, the EcoTerra house, to perform parametric optimization and evaluate the design.

In response to the growing calibration practice, the American Society of Heating, Refrigeration, and Air-Conditioning Engineers (ASHRAE) developed a reliable procedure for determining energy savings achieved in energy management projects, including retrofits (ASHRAE, 2002). One of the allowed methods for determining energy savings is to use the whole building calibrated simulation approach. By first establishing a baseline, or 'as-is', energy model then treating the baseline with simulated energy conservation measures, predicted energy savings can be determined by the difference. For the results to be deemed reliable, the model must simulate the energy consumption of the actual building to within an acceptable amount of error. Calibration error is described by two statistical indices that compare measured data from the real building to simulated results from the energy model. The error indices used are the Coefficient of Variation of the Root Mean Square Error (CV(RMSE)) and the Normalized Mean Bias Error (NMBE). The $\mathrm{CV}(\mathrm{RMSE})$ and NBME of the simulated results with respect to and monitored results can be calculated as follows (ASHRAE, 2002):

$$
\begin{gathered}
C V(R M S E)=100 \frac{\sqrt{\frac{\sum\left(y_{i}-\hat{y}_{i}\right)^{2}}{(n-p)}}}{\bar{y}} \\
N M B E=100 \frac{\sum\left(y_{i}-\hat{y}_{i}\right)}{(n-p) \times \bar{y}}
\end{gathered}
$$

Where:

$y_{i}=$ measured data point (ex. Monthly electricity, hourly air temperature, etc) $\hat{y}_{i}=$ simulated data point (ex. Monthly electricity, hourly air temperature, etc) $\bar{y}=$ mean of measured data points $n=$ number of data points per period (ex. 12 for monthly, 8760 for hourly) $p=$ number of parametric outputs (ex. 1 for electricity consumption) 
For a model to be considered calibrated in accordance with ASHRAE Guideline 14 (2002), it must be within the acceptable tolerance limits for error, which vary depending on the data timestep. The CV(RMSE) and NMBE tolerance limits are shown in Table 2.3:

Table 2.3: Error tolerance limits for building simulation calibration

\begin{tabular}{ccl}
\hline Data Time-Step & CV(RMSE) & NMBE \\
\hline Monthly & $<15 \%$ & $< \pm 5 \%$ \\
Hourly & $<30 \%$ & $< \pm 10 \%$ \\
\hline
\end{tabular}

The CV(RMSE) indicates the goodness of fit for the simulated results with respect to the monitored data. The NMBE indicates the error bias (positive or negative). Because positive bias can displace negative bias, NMBE can be a misleading metric for calibration alone, but helps to present the relative position of the simulated data with respect to the measured data. Figure 2.4 illustrates the point with a hypothetical set of monthly natural gas consumption data (Data Set 1) and two hypothetical sets of simulation results (Simulation Results $2 \& 3$ ). If the modeler were trying to calibrate their building simulation to the actual results, Simulation 2 would have relatively low CV(RMSE) and positive NMBE. In other words, the modeler would be nearing the calibration error limits, and would know to look for errors that are creating extra heating demand, such as over-estimated occupancy or infiltration, or under-estimated thermal resistance. The results from Simulation 3 would have a very large CV(RMSE) but very small or nearly zero NMBE. The results from Simulation 3 are exaggerated and unlikely for most simulation models, but are useful to illustrate the point that the error bias (NMBE) can be very minimal but have very poor fit (CV(RMSE)) relative to measured data due to the mathematical self-balancing that can occur.

Although Guideline 14 delimits criteria for acceptable calibration, it does not provide techniques or procedures for achieving calibration. Historically, calibration has been seen as an art form that involves past knowledge and experience, engineering judgment, and iterative trial and error (Reddy, 2006). Therefore methods have been developed to help systemize the calibration process. 


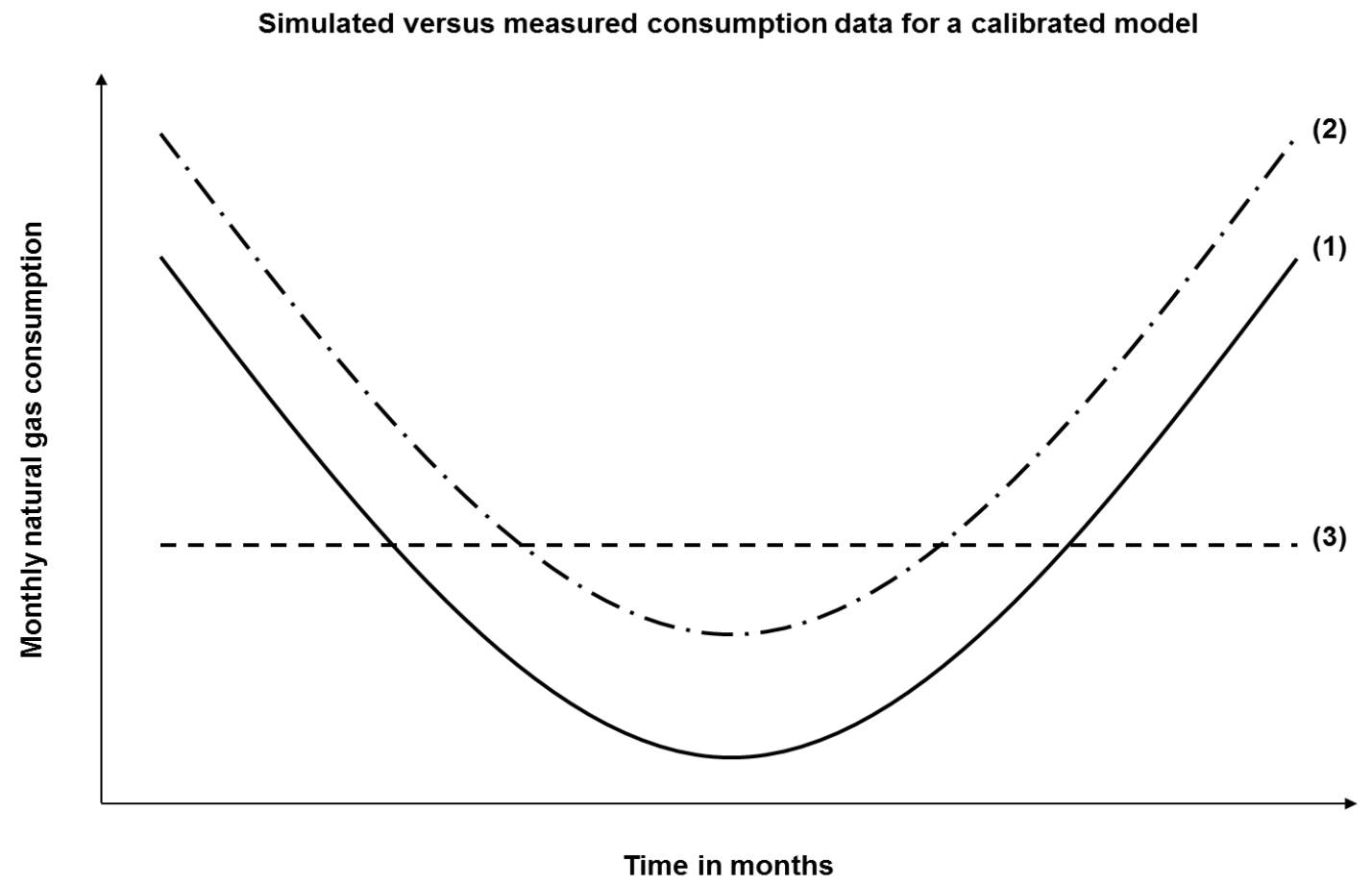

Figure 2.4: Monthly natural gas consumption of a hypothetical measured building and two hypothetical simulation results to demonstrate the relationships of CV(RMSE) and NMBE

Yoon et al. (2003) developed a "base load analysis approach" to aid in building energy audits and savings determination during building retrofits using sub-metered data in addition to monthly utility bills. Calibration uses the following steps:

i. Create the base case energy model.

ii. Analyze the consumption base load using utility bills and short-term sub-metered data. It is common for buildings in Korea, where the study was performed, to be equipped with electricity sub-meters. Base load is the minimum building energy consumption without heating or cooling and is weather independent. In other words, base load is the energy consumption of lighting, water heating, plug loads, appliances, etc. Base load can be determined by plotting utility consumption and outdoor temperature. At this point the internal gains can be validated.

iii. Calibrate the model for the shoulder seasons when the building is largely operating at base load (ie. without heating or cooling).

iv. Perform additional site visits and interviews to refine assumptions of occupancy, lighting density, equipment efficiency, etc. 
v. Calibrate the model for the heating and cooling seasons, focusing on the HVAC systems and controls.

vi. Validate the model against the acceptable calibration error tolerances (ASHRAE, 2002).

ASHRAE Research Project 1051 was undertaken to compile the best tools, techniques, approaches, and procedures to create a systematic method to calibrate a detailed energy model that is both robust yet computationally efficient (Reddy, Maor, \& Panjapornpon, 2007a; 2007b). The proposed methodology followed these steps:

i. Choose an adequate building simulation program capable of producing realistic results for the given building systems

ii. Define a set of significant building parameters and provide best-guesses for initial input and range of variation in a heuristic manner

iii. Subject the heuristic parameters to a course grid search for sensitivity using Monte Carlo simulation

iv. Further refine the sensitive parameters in a guided manner

v. Use a small set of calibrated solutions to guide project decisions with an acceptable amount of uncertainty

Raftery et al. (2011a; 2011b) felt that the previously discussed method (Reddy, Maor, \& Panjapornpon, 2007a; 2007b) was insufficient for obtaining accuracy beyond course refinement because it used subjective and 'ad hoc' methods rather than explicit evidence and well-documented procedure. The study presented a method for detailed whole-building energy model calibration using a systematic and evidence-based approach, often utilizing sub-utility measurement or direct investigation. Throughout the calibration procedure, it is recommended that all decision history and file versions be kept to organize the process and facilitate review. Changes to the model input should only be made if superseding information is more accurate according to the source hierarchy. The source hierarchy establishes an order of input reliability (Table 2.4). Specifically, a more accurate zone-typing strategy is described to better-simulate real buildings. The method produces a deterministic model that can produce reliable and accurate results, and provide an evidence trail for future analysis or review. 
Table 2.4: Data source hierarchy of reliability for model calibration (Raftery, Keane, \& O'Donnell, 2011a)

\begin{tabular}{cc}
\hline Hierarchy & Source Type \\
\hline 1 & Logged measured data \\
2 & Spot measured data \\
3 & Surveys and physical verification \\
4 & Interviews \\
5 & Material data-sheets \\
6 & Operation and maintenance manuals \\
7 & As-built documentation \\
8 & Benchmark of best practice models \\
9 & Standards and guidelines \\
10 & Initial model \\
\hline
\end{tabular}

Further calibration efforts have emphasized the use of measured data and parameter verification, rather than trial-and-error. Liu and Liu (2011) proposed a calibration method that used short-term field measured data. The advantage of the method is that it can be performed with as little as two weeks of measured data. The calibration procedure is carried out by iteratively computing the calibration signature until the error limits are achieved. The calibration signature is a graphical representation of the results that plots the difference between simulated and measured energy consumption and outdoor air temperature. A separate calibration signature is created for heating and cooling space conditioning consumption.

O'Neill et al. (2012) used a method of calibration which considered parametric uncertainty to automate the calibration process. First, the building parameters underwent sensitivity analysis to determine which had the most significant impact on the simulation results. This procedure reduced the number of parameters to focus on from 2036 to the 10 most influential. For each of the significant parameters, a range of possible values was defined. Then, a mathematical optimization problem was solved to find the minimal difference between the measured data and the simulated output for the subset of model parameters. A similar optimization-based calibration tool was created in MATLAB that allowed house parameters to be minimized for an objective function, which in this case was the difference between the measured and simulated energy consumption (Wassmer, 2013). 


\subsection{Literature Summary}

This chapter provided the foundation and context from which the current study was performed. Development of high performance housing under economic restraint was discussed with special focus on the local perspective. Canada, like the US and the European Union, has set targets of NZE in the residential sector, and has created a path to reach this goal. Each jurisdiction plans to meet the goal through house designs which simultaneously minimize building loads and life cycle cost before adding on-site power generation. Relevant studies have shown the use of optimization environments which couple building simulation and optimization techniques to perform the simultaneous minimization. These studies typically propose a representative reference building and vary parametric inputs with the intent of optimizing the building for metrics of performance and cost. However, few of the studies use calibrated simulation models. Building energy model calibration improves result reliability and has been become a more standardized process over the last decade. Recent studies have prioritized the use of reliable reference data for calibration over methods of trial and error. 


\section{RESEARCH DESIGN}

\subsection{Research Objective}

The objectives of this study are to (i) create an optimization environment which can evaluate passive energy conservation measure investment for life cycle cost and building performance, (ii) investigate the systems interaction of high performance technology and building practices employed in a test house to evaluate past decisions made and help inform future decisions, and (iii) study cost and performance trade-offs to determine recommended levels of energy performance in building standards.

\subsection{Research Questions}

The following research questions are to be answered in performing this work:

1. How could the building systems interaction have been improved, if at all, for both life cycle cost and total peak design load?

a. How are the results changed when predicted financial parameters, such as discount rate, fuel escalation rate, and mortgage rate, are varied?

2. What are the maximum annual energy savings recommended when building life cycle costs are minimized?

a. What combination of passive energy efficiency measures yield this recommended annual energy savings level?

b. What level of space conditioning performance would be recommended for the Passive House standard from an economic point of view?

\subsection{Methodology Overview}

The methodology presented in this thesis builds on that presented in the relevant literature where multi-objective optimization experiments are performed to minimize performance and cost objective functions. The reference building for the optimization experiment is a high performance house in Toronto where the building energy model is calibrated to measured data. The optimization experiment varies passive energy efficiency measures and employs a genetic algorithm to simultaneously optimize for total peak load and life cycle cost. 


\subsection{Scope of Work and Study Limitation}

This thesis will focus on high performance housing where the primary goal is to reduce space conditioning demand before considering active systems for the purposes of achieving Passive House certification or reaching net zero energy. This thesis is not intended to sell the merit of these building practices. It is assumed that the reader already understands the associated benefits in thermal comfort, durability, and reduced carbon emissions beyond the potential financial benefits. The intent is to investigate the economic feasibility of substantial envelope upgrade in pursuit of greater energy efficiency.

The scope of this thesis is limited to passive ECMs, which include insulation configurations, air-tightness, thermal bridging, window to wall ratio (WWR), glazing resistance and solar heat gain coefficient (SHGC), orientation, massing, and shading strategies. Active systems, including heating, cooling, ventilation, and renewable energy systems, are not included in the study.

Typically in optimization studies, assumptions and averages are used for building type, local construction practices and costs, and weather conditions. In these cases, accuracy is sacrificed in order to produce broad results. In this study, a calibrated model is used as a reference house in order to ascertain real-world study parameters. What this study gains in accuracy, it loses in broad applicability. However, it is important to review the performance of test houses and "close the loop' of the systems research methodology with the intent of eventually applying the learned knowledge on a broader scale. Furthermore, the particular case study house was chosen for research since it offered reliable datasets and records not typically found in most homes.

Although the case study house underwent extensive renovation to reach its current level of performance, the methodology of this study may be applied to either a new build or retrofit situation. When determining parametric unit costs, only material and installation of the energy saving technology were considered. Other assembly costs, nor demolition costs, were included so the results of the study are independent of building phase.

The life cycle cost analysis performed in this study should not be confused with Life Cycle Analysis (LCA). LCA typically assesses the total energy, including operational and embodied energy, of a building over its operational life, often with reference to total carbon emissions. This study is limited to operational energy at the site level and does not account for carbon emissions in any way. 


\section{CALIBRATED BUILDING ENERGY MODEL}

This chapter presents the methodology used to calibrate the building energy model. Calibration was used to prepare the reference model for the optimization experiment, and as such is only a sub-step of the procedure. However, significant effort was required to calibrate the model to within the acceptable error tolerances and requires a dedicated chapter to discuss adequately.

Calibration was achieved using a systematic, evidence-based procedure (Yoon, Lee, \& Claridge, 2003; Raftery, Keane, \& O'Donnell, 2011a; 2011b; Liu \& Liu, 2011). As discussed in the literature review, calibration procedures which emphasize repeatability and input reliability should be prioritized rather than trial and error procedures (Reddy, Maor, \& Panjapornpon, 2007a; 2007b). Further developments in automated calibration were beyond the scope of this work (O’Neill, Eisenhower, Fonoberov, \& Bailey, 2012; Wassmer, 2013). Figure 4.1 illustrates the calibration procedure which stresses the importance of data reliability.

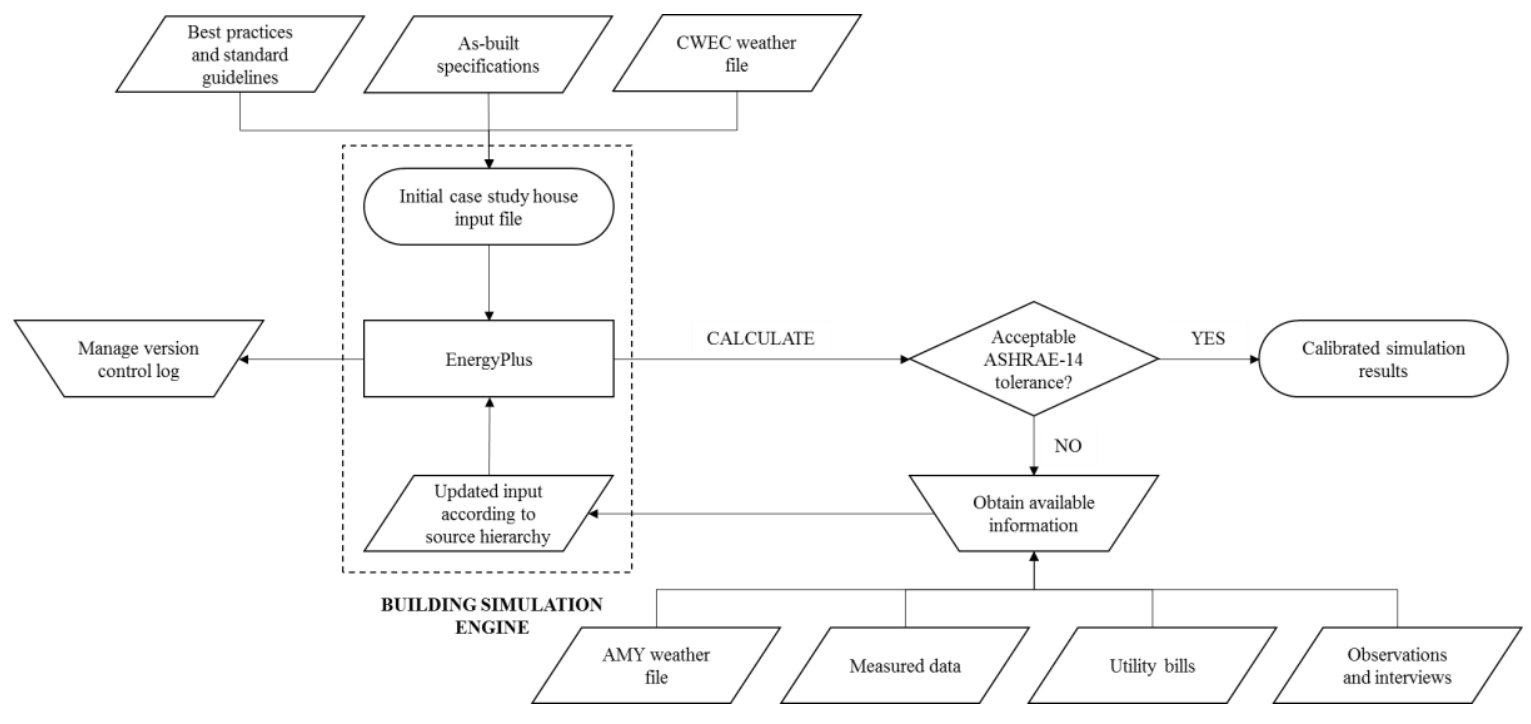

Figure 4.1: Overview of calibration methodology

\subsection{House Description}

The case study building is an existing 3-storey single family detached house in the Riverdale neighborhood of Toronto, Ontario (Figure 4.2 \& Figure 4.3). It is a century home (Blaszak, 2010) built in the early 1900's with double-wythe structural masonry, a rectangular footprint with the narrow dimension facing north and south, and flanking houses separated by approximately $1.5 \mathrm{~m}$. 
It underwent an extensive retrofit in 2010 with the objective of creating an exemplar for sustainable housing renovation. In general, the retrofit strategy followed the methodologies adopted in Passive House design (Passive House Institute US, 2010). Key envelope improvements included insulation with minimal thermal bridging, enhanced air-tightness, high-performance windows. The HVAC system for the case study house uses separate systems for heating, cooling, and ventilation functions. Figure 4.4 and Figure 4.5 illustrate the air loops (ventilation and cooling) and water loops (heating), as configured in the calibrated energy model.

Mechanical ventilation is the primary means of fresh air distribution for the house during the heating season, while natural ventilation is the primary fresh air supply during the cooling season. An energy recovery ventilator (ERV) drives the mechanical air-flow with its in-line fan and provides sensible and latent heat recovery between intake and exhaust streams of air. The system is balanced so that it intakes and exhausts at an approximately equal rate to minimize pressurization or depressurization within the house. The direct ducting strategy delivers fresh air to living spaces and bedrooms, and exhausts stale air from the kitchen, bathrooms, and mechanical room.

Cooling is provided primarily through natural ventilation, but one air-source heat pump terminal was mounted on the third floor wall to handle peak loads. A second air-source heat pump was installed recently on the main floor in 2014 because the owner was dissatisfied with the cooling distribution of the third floor unit (R. Richman, personal communication, June 27, 2014). However, for the calibration period, only the third floor terminal unit was accounted for.

Demand side heating is provided by in-floor radiant tubing. The heating plant for the hot water is a natural gas condensing boiler, which also supplies indirect heating for domestic hot water (DHW). This system is not typically used in Passive Houses because the super-efficient homes often require less heating capacity and can provide adequate heating with less capacity. However, the system does provide good efficiency for the given fuel and excellent thermal comfort.

During the renovation, the house was fitted with air-temperature sensors which have been collecting data on-the-minute since installation. Furthermore, the home owner was diligent in maintaining all financial transactions during the renovation, and was able to provide utility bill data for the study period. 

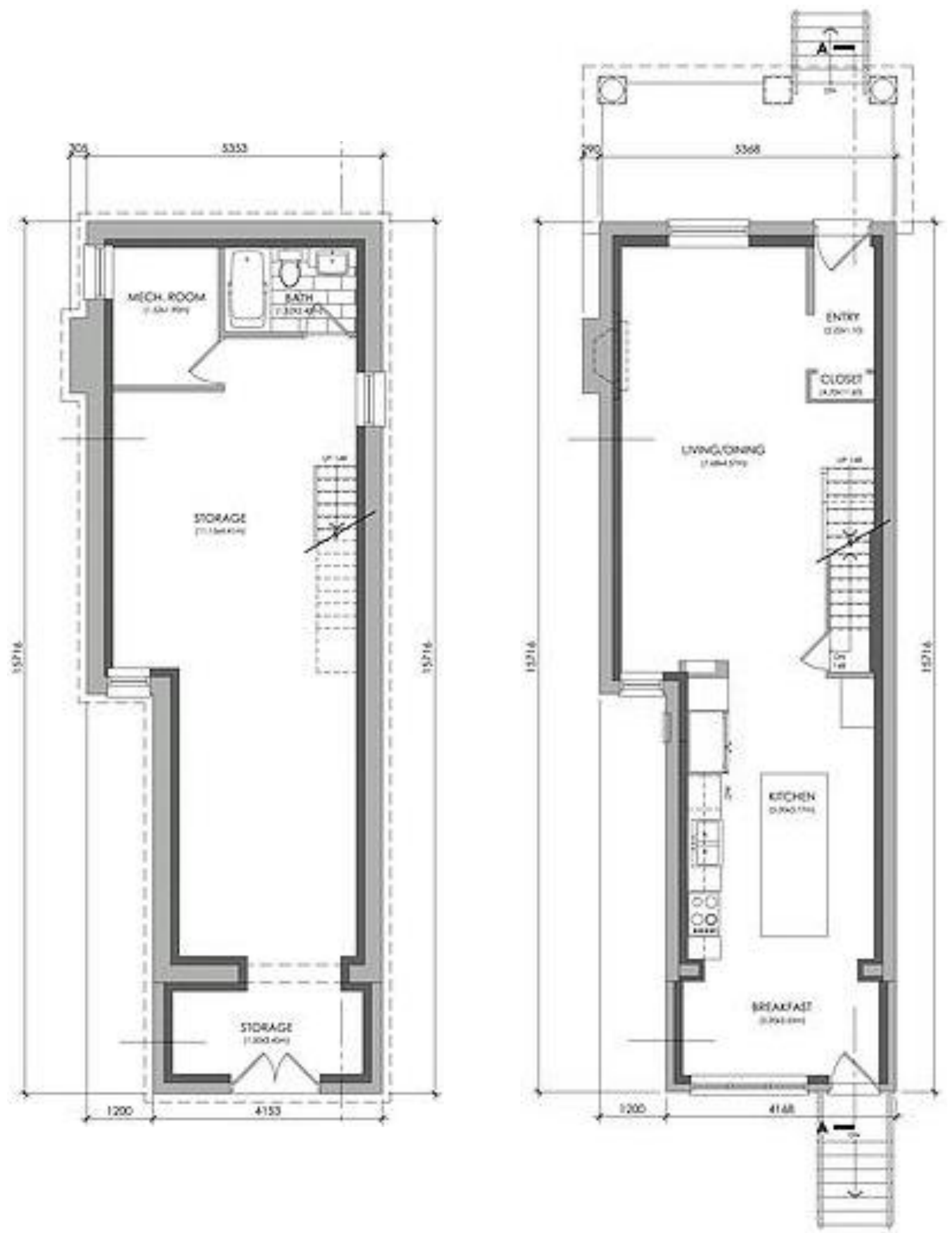

Figure 4.2: Case study floor plans - basement and first floor 

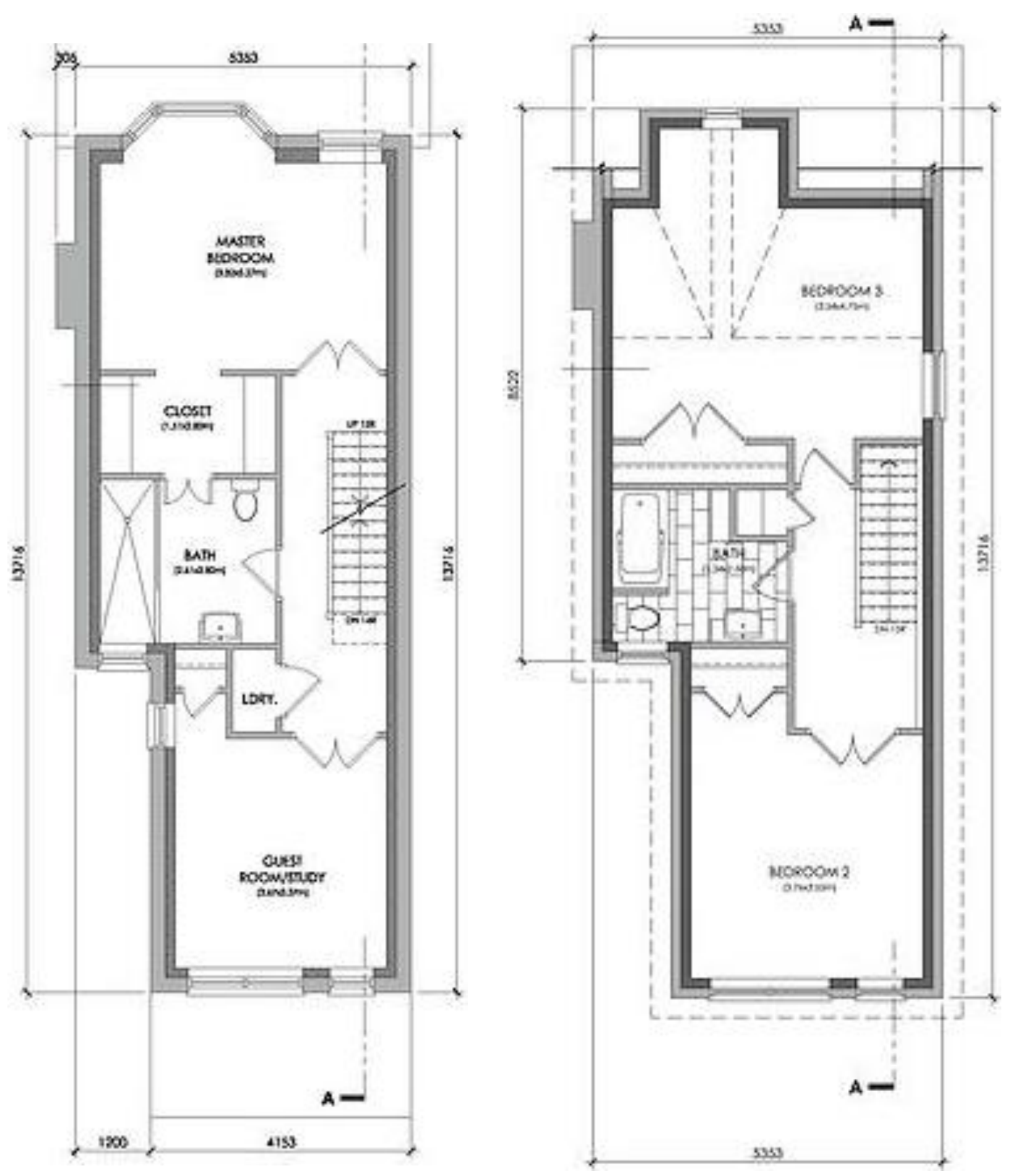

Figure 4.3: Case study floor plans - second and third floor 


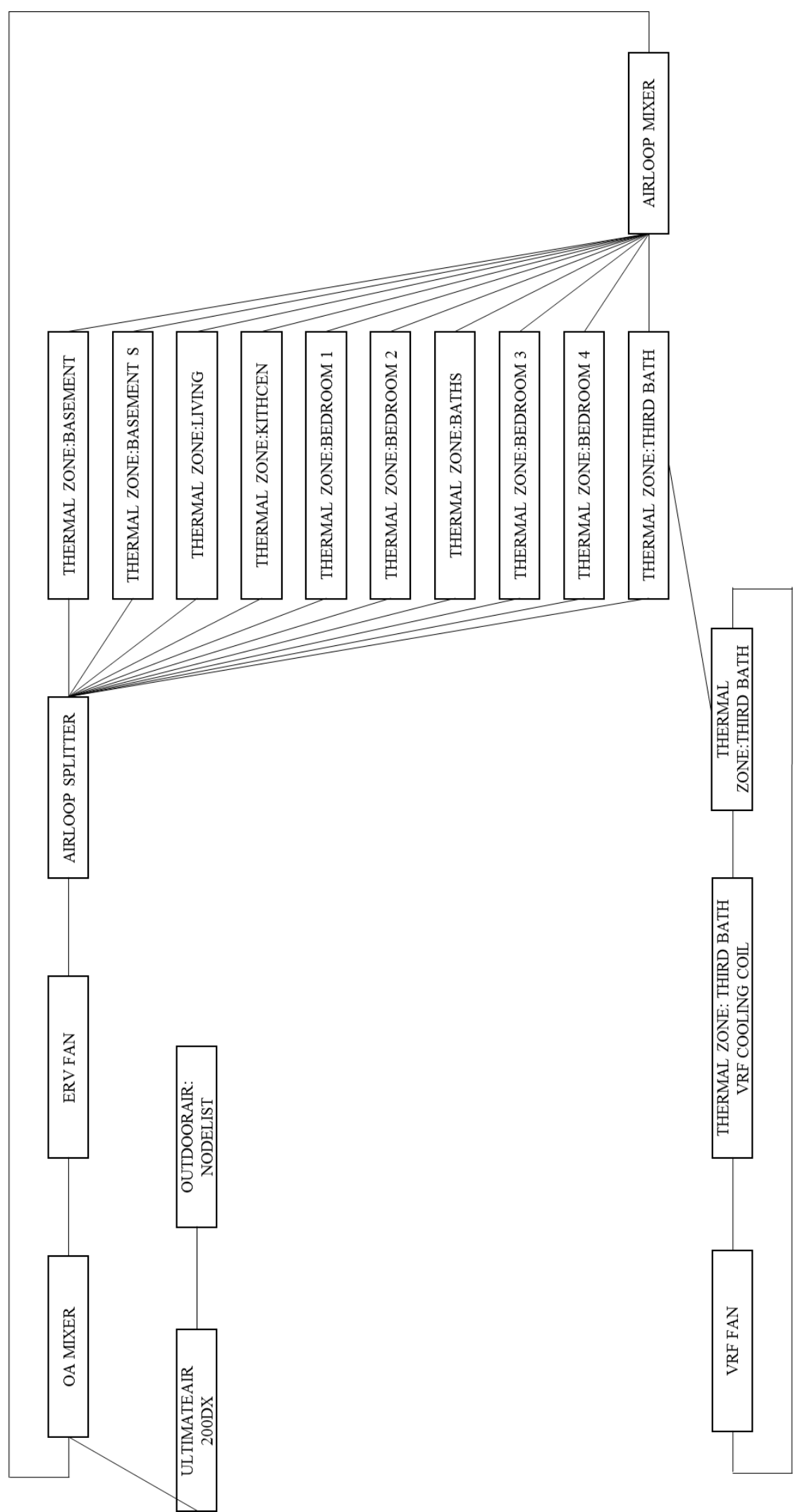

Figure 4.4: Ventilation and cooling air loops from case study house EnergyPlus output 


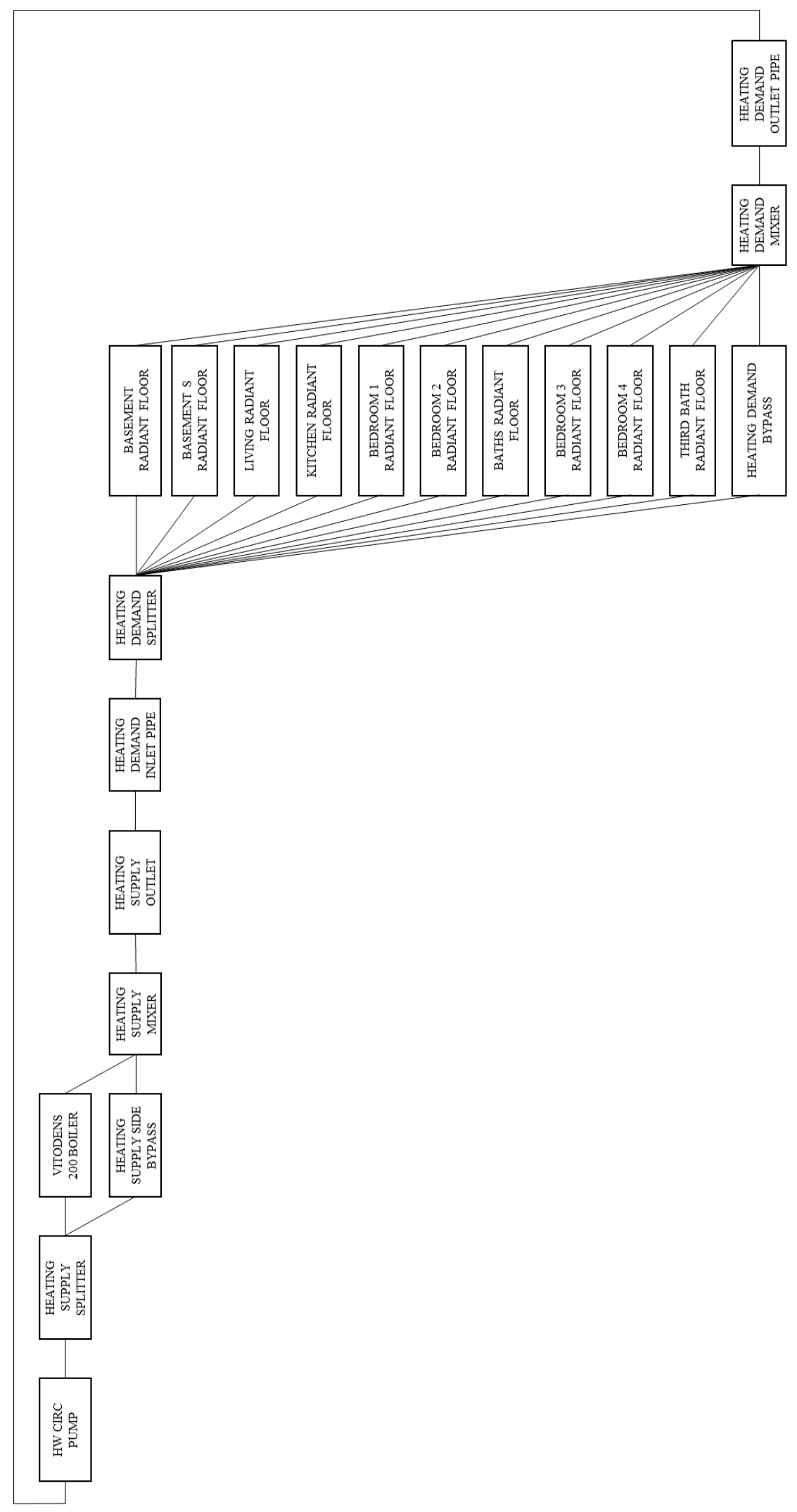

Figure 4.5: Radiant floor heating loops from case study house EnergyPlus output 


\subsection{Version Control}

Version control was handled manually, using a revision log to record changes, although version control software exists to track history automatically. The revision log includes file version, start date, revision details, and model result, and is included in Appendix B. Individual files were saved for each new version. New file versions and sub-versions were saved when significant sub-models were created or edited, success milestones were achieved, or fatal failures occurred.

\subsection{Preparation}

\subsubsection{Initial Model}

For the current Ontario Building Code, the supplementary energy standard SB-12 can be met with prescriptive treatments (MMAH, 2011). Therefore, building energy modelling for residential houses is uncommon unless there is interest in meeting a third-party standard or increased energy efficiency. However, because the case study is a field-research house, a building energy model was partially created in 2013 by Hayes Zirnhelt (H. Zirnhelt, personal communication, April 6, 2014).

The partial initial model was built in EnergyPlus v8.0 (US Department of Energy, 2015) and included the following:

- Geometry to match as-built drawings (Figure 4.2 \& Figure 4.3)

- Thermal zones

- Internal gains from humans, lights, and appliances

- Infiltration model

- Opaque and glazed constructions

- Radiant heating loop and boiler

The remainder of the initial model was completed by the author using updated EnergyPlus versions (v8.1 and 8.2) and included:

- Air source heat pump

- Ventilation air loop with ERV 
- Ground heat transfer model with Basement EnergyPlus sub-program

- DHW natural gas consumption

- Zone heat transfer surfaces

- Natural ventilation

- Economic parameters

A full description of the additions can be viewed in the revision history log located in Appendix B. Model version 3.7.1 is officially considered to be the 'initial model'. It represents a complete building energy simulation model including all geometry, constructions, internal gains, and systems. The model version contains 14 warnings and 0 severe errors in EnergyPlus and has the following error compared to the monthly natural gas consumption: $\mathrm{NMBE}_{\text {monthly }}=27.5 \%$, and $\mathrm{CV}$ (RMSE) monthly $=35.9 \%$. It is interesting to note that this model, though complete, does not acceptably reflect reality. This difference illustrates the need for model calibration for accurately conducting research. Each sub-model will be discussed in the upcoming sections.

\subsubsection{Historical Weather Data}

Full year simulation was performed using an Actual Meteorological Year (AMY) file for central Toronto. Unlike Typical Meteorological Year (TMY) weather files that average 15-30 years of data, AMY files use the actual hourly weather data for the simulated year. The file was provided in EnergyPlus format, EPW, with required weather variables in SI units. The data was purchased from Weather Analytics for central Toronto for 2012. Weather Analytics station 592803 represents a 35 x $35 \mathrm{~km}$ grid of data from nearby meteorological stations and National Oceanic and Atmospheric Administration, where the center point of the grid is located at Latitude/Longitude 43.551, -79.375 and elevation $105.0 \mathrm{~m}$ (Weather Analytics, 2014). This point represents the closest station for case study house which is located at latitude/longitude 43.67, 79.352 and elevation $104.55 \mathrm{~m}$. Weather Analytics provides weather for $35 \mathrm{~km} \mathrm{x} 35 \mathrm{~km}$ grids integrating data

Figure 4.6 compares the ambient dry-bulb air temperature of the AMY weather file and actual temperature, as measured by the front porch air temperature sensors. The simulation weather data has errors of $23.0 \% \mathrm{CV}$ (RMSE) and 13.2\% NMBE, which is considered to be outside of the acceptable limits of error for calibration. However, the discrepancy is likely due to the placement 
of the air temperature sensor. The sensor is protected somewhat from the wind, where the porch micro-climate is buffered. It is expected that this is the reason for the continually increased temperature detected by the sensor compared to the simulation data, and deemed acceptable for use in the remainder of the study.

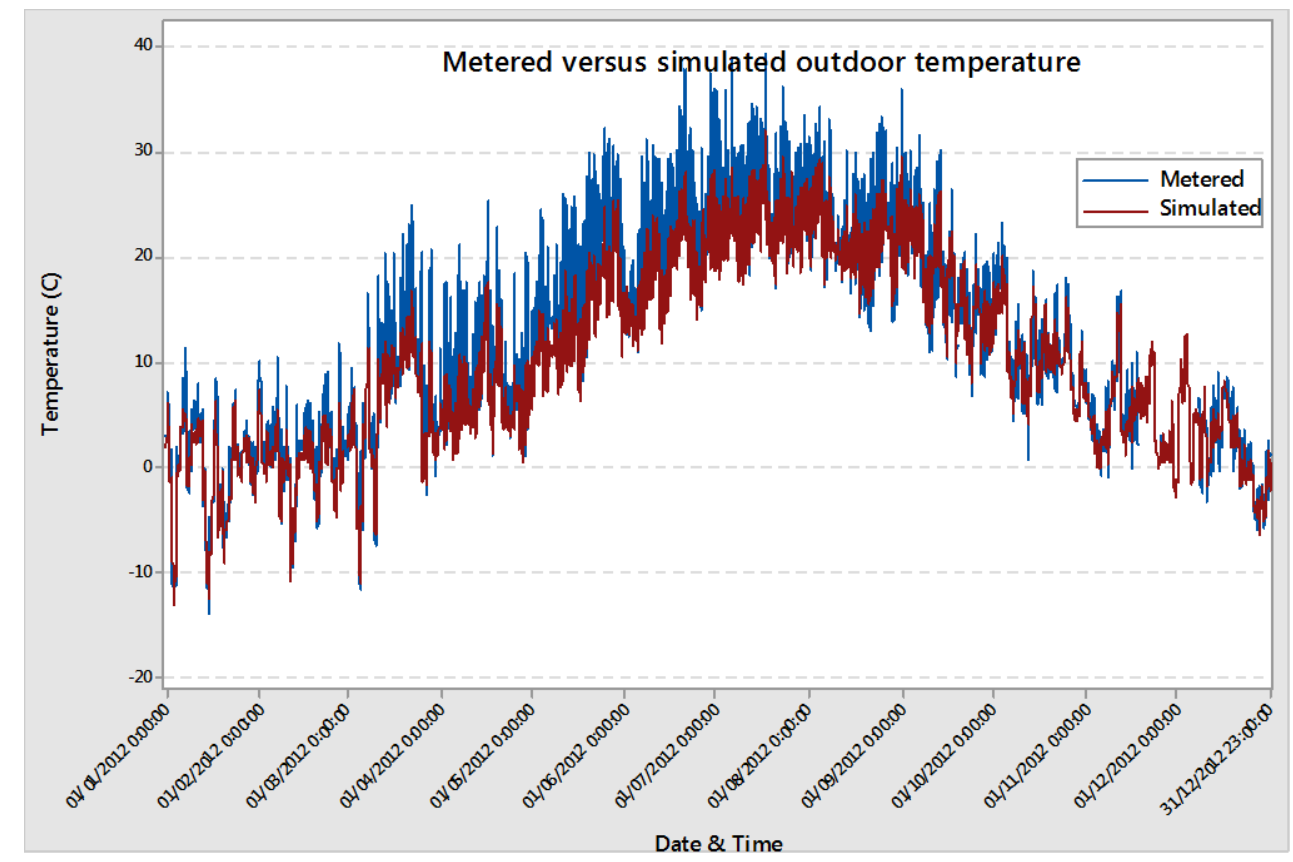

Figure 4.6: Outdoor air temperature of simulation weather file relative to measured data

Although full year hourly weather data is used to simulate total energy consumption, design day parameters are required for system sizing. ASHRAE equipment sizing design requires HVAC systems that can maintain thermal comfort during peak conditions in summer and winter. The design day objects used were provided by EnergyPlus, included in software download, and represent winter and summer peak conditions for Toronto.

\subsubsection{Calibration Data}

Model calibration was based on measured data provided by the homeowner. Monthly natural gas consumption and hourly electricity usage was available for 2012 and 2013. Since sensor installation at the end of 2011, air temperature data has been, and continues to be, available at minute-scale resolution. However, some air temperature sensors were removed in the middle of 2013 for use in other projects. Therefore, 2012 represents the most complete data set to use for 
calibration. Further isolated spot tests, such as seasonal cooling electricity and to-the-day gas consumption, have been conducted in other years to improve the accuracy of certain sub models.

Monthly gas consumption was obtained for 2012 and 2013 from the homeowner's utility bills. Consumption is measured volumetrically in $\mathrm{m} 3$. Some modification had to be completed to allow for direct comparison with simulation data. First, the volumetric measurement had to be represented by energy content. There is approximately $0.038 \mathrm{GJ}$ of energy content in $1 \mathrm{~m} 3$ (Natural Resources Canada, 2014).

Gas meter readings were collected by the homeowner for the period of April 12, 2014 to May 15, 2014. Volumetric readings were taken twice daily, ideally early in the morning before any occupant activity and late in the evening to capture the full day of activity. Recording time, volume observed, significant weather, and occupant behavior notes were noted for each data point. The data was used to determine average monthly cooking and domestic hot water natural gas usage. The recording period occurred during a shoulder season. Therefore, some natural gas consumption recorded was used for space heating energy. Energy was attributed to space heating when there was a difference in gas readings overnight when no domestic hot water use or cooking was assumed. Gas consumption attributed to space heating was subtracted from the total recorded volume to obtain the consumption for domestic hot water and cooking, 'baseline' natural gas. This data was used to calibrate the simulation model for monthly domestic natural gas in uses other than space heating. Again, this data contains some error. First, the data was collected in 2014 although the calibration period is 2012. Second, the measurement was taken only for a month, and did not capture seasonal weather changes or occupancy behavior changes, such as hour spent indoors or average shower temperature. However, since the recordings were taken during shoulder months, seasonal differences should balance near the shoulder average.

The 'My Toronto Hydro' online service (TorontoHydro, 2015) provided hourly historic electricity consumption for the case study house. The hourly data was sorted into time bins of days, weeks, and months to determine various trends and usage patterns. Again, the units has to be converted for model comparison. Usage was converted from kWh to GJ. Both kWh and GJ describe units of energy, but have different references to time. There are $0.0036 \mathrm{GJ}$ of energy in 1 $\mathrm{kWh}$. 
Sub-metered cooling electricity consumption was provided by the homeowner for a period of June 24, 2013 to September 13, 2013. Data was recorded on the minute and captured all cooling energy used for the entire 2013 cooling season (A. Guadagnoli, personal communication, May 27, 2014). There is a certain amount of inherent error using this data for two reasons. First, measurements were collected in 2013 which had different daily weather than the 2012 simulation period. Second, the air-conditioner is controlled manually unlike most cooling systems that are automatically controlled by thermostat. Therefore, cooling was used inconsistently and was not directly related to ambient zone air temperature. Instead, human comfort factors generally dictated operation. The total cooling season consumption data was used as reference for the air conditioner sub-model. But the model could not be calibrated to the data for the reasons mentioned above.

Air temperature data was obtained from sensors which were installed shortly after the house renovation was completed 2011. The sensors, from OmniSense (OmniSense, 2015), measure ambient air temperature and relative humidity and upload data on a minute time scale remotely to a web server. The homeowner installed 16 sensors throughout the house, as well as in inlet and exhaust points of the ERV, and the north exterior porch of the house, for research purposes. These points were compiled for each relative zone. For model comparison, the zone mean was used. Data points were logged on the web server and can be downloaded to local computers remotely. For unknown reasons, there are certain periods during the year where the sensors did not upload information leaving missing data points in the set. Although data can be retrieved at minute intervals, only hourly air temperature data was used. ASHRAE Guideline 14 (2002) only provides maximum error requirements for hourly comparison and no instruction for calibration to the minute. Further, calibrating to the minute is unrealistic because of simplifications required to model complex buildings and unattainable logging of events contributing to minutely variation (e.g. opening and closing of exterior doors).

\subsection{Updated Model}

This section describes the calibrated model in detail. Each sub-model is discussed with regards to assumptions used, information collected, and improvements made. The calibration process was conducted on the initial model, v3.7.1 as described previously, by systematically addressing each sub-model and updating information based on source hierarchy described in a previous chapter (Table 2.4). 


\subsubsection{Geometry}

Minor variances were used to simplify complex geometry and save time during the model's original build. It is common practice in building simulation to apply good engineering judgement and simplify geometry or assemblies without significant accuracy penalties (ASHRAE, 2011). The model was compared visually to the as-built drawings and did not require updating.

All geometric surfaces in EnergyPlus are represented as planar, with no thickness, and are attributed with conductivity and thermal mass by construction objects. For this reason, the geometry can accurately represent interior geometry, or exterior geometry, but not both, as real walls inherently have thickness. EnergyPlus developers (2013b) recommend adopting a consistent approach that uses outside dimensions for exterior surfaces, or centerline dimensions for very thick walls, and centerline dimensions for interior surfaces. This approach is convenient and creates fully connected geometry. When using exterior dimensions, however, interior floor area and zone volume are over-calculated. Zone volume can be manually overridden to account for the wall thickness discrepancy and interior furnishings, however, over-calculating the zone volume leads to conservative heating and cooling loads, and previous research shows the change makes little difference in model result (Zirnhelt, 2013). For the current research model, exterior dimensions were taken to the outside of the structural brick walls.

Shading surfaces were used to represent neighboring houses, porch projections, and roof overhangs, which play an important role in reducing solar exposure in heat gain simulation.

\subsubsection{Zone Typing}

According to the US DOE (2013a), zones are thermally uniform air volumes, not necessarily conforming to geometric boundaries. Including more thermal zones generally creates higher resolution and thus greater model accuracy, at the cost of increased model building time and simulation run time. As a basic rule, the minimum number of zones should be equal to the number of systems serving the building. Based on their research on thermal zoning for passive solar homes, O’Brien et al. (2011) recommend discretizing zones to include aspects such as exterior surface conditions, HVAC systems, control schemes, and unbalanced gains. This work emphasized the use of multiple zones to account for solar gains and overheating potential in passive solar houses. To standardize the classifications, Raftery et al. (2011a) refined the zone 
typing procedure to capture thermal differences in the model. The process involves distinguishing zones based on:

i. space use patterns and internal gains,

ii. solar and infiltration interaction with exterior,

iii. conditioning systems, controls, and setpoints, and

iv. available calibration data

While zone typing is a flexible procedure and still requires good judgement, it intends to minimize inaccuracies in the model zoning process. The following factors were considered when zone typing the research model:

- long rectangular house shape oriented north-south increased solar exposure on south face separates house into north and south

- basement wall ground contact isolates basement boundary conditions

- small and narrow building footprint with infiltration potential in each room leaves no fully-interior zones

- internal partitions of bedrooms prohibits solar penetration

- location of appliances dishwasher and range increase internal gains in kitchen

- approximately even distribution of lighting power density

- control of in-floor heating system controlled by two thermostats per above grade floor and one thermostat to control the basement

- point source delivery of cooling inhibits distribution

- 16 air-temperature sensors distributed throughout the house

The initial model contained 10 zones. This was unchanged in the final calibrated model. The upper two floors follow partition walls for zone boundaries, making three per floor. The house's basement and main floor are divided into north and south zones.

\subsubsection{Opaque Constructions}

Opaque wall, roof, and slab assemblies were created using as-built section details. Material properties including thermal conductivity, specific heat, and density were obtained from ASHRAE datasets (2005b), Passive House Institute datasets (2007), and manufacturer data (Table 4.1). 
Construction assemblies were built up in EnergyPlus using consecutive layers of defined materials with specified thicknesses.

To account for thermal bridging of structural members such as wood framing, composite layers were built using one-dimensional area-weighted thermal resistances. Typical framing accounts for approximately $25 \%$ of assembly area, however, using advanced framing techniques, framing can be reduced to approximately $15 \%$ of assembly area (Lstiburek, 2010). In a more precise analysis, Zirnhelt (2013) distinguishes between above grade walls with windows (23.2\% framing factor), above grade wills with no windows (15.1\% framing factor), below grade walls (11.1\% framing factor), and attic (6.3\% framing factor) by calculating areas from framing diagrams in as-built drawings. The initial model used $12 \%$ framing factor for the wall constructions where framing was present, based on geometry takeoffs from wall section diagrams.

Table 4.1: Thermal properties of select materials

\begin{tabular}{ccccc}
\hline Material & $\begin{array}{c}\text { PHPP Thermal } \\
\text { Conductivity } \\
(\mathrm{W} / \mathrm{mK})\end{array}$ & $\begin{array}{c}\text { ASHRAE } \\
\text { Thermal } \\
\text { Conductivity } \\
(\mathrm{W} / \mathrm{mK})\end{array}$ & Other (W/mK) & $\begin{array}{c}\text { Modelled } \\
\text { Thermal } \\
\text { Conductivity } \\
\text { (W/mK) }\end{array}$ \\
\hline Concrete & - & $0.9-2.9$ & - & 1.13 \\
Lightweight concrete & $0.15-0.3$ & $0.18-0.89$ & - & 0.53 \\
Hardwood flooring & 0.18 & $0.15-0.18$ & - & 0.167 \\
XPS & $0.03-0.04$ & $0.022-0.030$ & (Dow Chemical) & 0.02839 \\
Clay brick & $0.8-1.2$ & $0.36-1.47$ & - & 0.72 \\
Gypsum & 0.25 & 0.16 & - & 0.16 \\
Cement board & - & $0.06-0.25$ & $($ James Hardie) & 0.3 \\
OSB & 0.13 & $0.12-0.15$ & - & 0.091 \\
Asphalt shingles & - & 0.026 & - & 0.038 \\
Spray foam & $0.025-0.040$ & $0.026-0.042$ & $($ Lapolla) & 0.022 \\
Wood framing & & & & 0.11 \\
(softwood) & 0.13 & $0.09-0.16$ & - & 45.28 \\
Metal surface & $17-160$ & 45.3 & - & 0.0387 \\
Roxul & $0.035-0.045$ & 0.036 & (Roxul) & 0.2 \\
\hline Hollow wall cavity & - & $0.16-0.2$ & - & \\
(89mm) & - & & &
\end{tabular}


Material properties were updated with manufacturer material datasheets to replace generic values found in handbooks. Table 4.2 summarizes the thermal resistance of the opaque assemblies for the calibrated model.

Table 4.2: Opaque assemblies for simulated case study house

\begin{tabular}{ccc}
\hline Construction Assembly & EnergyPlus Reference & R-Value (m2K/W) \\
\hline Basement walls & Below Grade Wall & 6.76 \\
Original exterior wall, brick & Wall EW2 & 6.80 \\
Addition exterior wall, 2x6 stud & Wall EW3 & 6.71 \\
Sloped portion of roof & Sloped Roof & 7.75 \\
Flat portion of roof & Flat Roof & 9.62 \\
\hline
\end{tabular}

\subsubsection{Glazed Constructions}

Glazed constructions were created using WINDOW 6.3 open source software in the initial model (Lawrence Berkeley National Laboratory, 2013). The external software exports data into EnergyPlus syntax that can be used in the main model file. The program calculates whole unit thermal conductivity, solar hear gain coefficient, visible transmission, thermal transmission, and thermal absorption. It uses 2-D finite element analysis and considers the frame, divider, center of glass, and edge-of-glass for calculation (US DOE, 2013c). The export data creates objects to describe window glazing, gas mixture, frame and divider, and construction.

The building uses EcoInsulating SC75 quadruple pane gas filled insulated glazing units in Inline 325 fiberglass fixed and casement configurations. The following table summarizes the thermal resistance of the opaque assemblies:

Table 4.3: Glazed construction summary for simulation model

\begin{tabular}{|c|c|c|c|c|c|}
\hline Construction & EnergyPlus & Total & $\mathrm{COG}$ & Frame \& Divider & $\overline{\text { SHGC }}$ \\
\hline Assembly & Reference & $\begin{array}{l}\text { U-Value } \\
(\mathrm{W} / \mathrm{m} 2 \mathrm{~K})\end{array}$ & $\begin{array}{l}\text { U-Value } \\
(\mathrm{W} / \mathrm{m} 2 \mathrm{~K})\end{array}$ & $\begin{array}{l}\text { U-Value } \\
(\mathrm{W} / \mathrm{m} 2 \mathrm{~K})\end{array}$ & \\
\hline $\begin{array}{c}\text { Exterior fixed quad } \\
\text { pane IGU }\end{array}$ & $\begin{array}{c}\text { Sample fixed } \\
\text { eco quad }\end{array}$ & 0.681 & 0.397 & 0.709 & 0.23 \\
\hline $\begin{array}{c}\text { Exterior casement } \\
\text { quad pane IGU }\end{array}$ & $\begin{array}{c}\text { Sample csmt } \\
\text { eco quad }\end{array}$ & 0.625 & 0.397 & 1.476 & 0.23 \\
\hline
\end{tabular}




\subsubsection{Air Infiltration}

A primary heat loss and heat gain factor in residential buildings is air infiltration (ASHRAE, 2005a). Past studies have shown that air infiltration rates have significant effects on modelled energy usage (Zirnhelt, 2013). Significant effort was put into air-sealing the case study house during the retrofit. Numerous blower-door tests were performed to track the air-sealing process. The most recent blower-door test, performed by researchers, resulted in a total effective leakage area (ELA) of $342 \mathrm{~cm} 2$ at $4 \mathrm{~Pa}$ of pressure, which is considered to be the natural pressure difference across an envelope due to stack effect, wind pressure, and mechanical systems. ELA provides a good model for air leakage in smaller, residential-type buildings (US DOE, 2013c). For comparison, the ELA represents an air-leakage rate of $1.46 \mathrm{ACH}$ at $50 \mathrm{~Pa}$ pressure.

The ELA determined by the blower-door test represents the sum of all air leakage throughout the building, but the total ELA must be distributed among the zones to create accurate heat loss and gain for each zone. The initial model distributed the infiltration rate by zone floor area and zone window perimeter. It was assumed in the initial model that window perimeter accounted for $70 \%$ of zone infiltration. Studies using infrared cameras show that that this value is accurate for apartments, however in single family detached houses, window and door perimeters account for $30-32 \%$ of leakage area while junctions of exterior walls with base floors, intermediate floors, attic roofs, and adjacent walls accounted for 60-70\% of leakage area (Kalamees, Korpi, Eskola, Kurnitski, \& Vinha, 2008; Jokisalo, Kurnitski, Korpi, Kalamees, \& Vinha, 2009). In the same studies, penetrations through the air barrier accounted for up to $8 \%$ of the total air leakage.

The model was updated to reflect this change in infiltration weighting. Table 4.4 summarizes the area-weighting of the total infiltration for individual zone distribution. A weighting factor of $30 \%$ was used on external glazing perimeter to account for air leakage around external windows and doors and a factor of $70 \%$ was used on zone gross external wall area to account for air leakage through junctions of walls, roofs, and floors. No consideration was given to penetrations through the air barrier because it is likely insignificant at the zone level and difficult to quantify. 
Table 4.4: HOT2000 results and associated effective leakage area

\begin{tabular}{cccccc}
\hline Model Thermal Zone & $\begin{array}{c}\text { Area } \\
(\mathrm{m} 2)\end{array}$ & $\begin{array}{c}\text { Volume } \\
(\mathrm{m} 3)\end{array}$ & $\begin{array}{c}\text { Gross Wall } \\
\text { Area }(\mathrm{m} 2)\end{array}$ & $\begin{array}{c}\text { Window Glass } \\
\text { Area }(\mathrm{m} 2)\end{array}$ & $\begin{array}{c}\text { Effective Leakage } \\
\text { Area }(\mathrm{cm} 2)\end{array}$ \\
\hline Basement & 55.31 & 158.91 & 29.84 & 0.00 & 24.9 \\
Basement S & 26.12 & 39.62 & 18.26 & 1.49 & 11.6 \\
Living & 55.31 & 165.77 & 77.1 & 3.56 & 63.1 \\
Kitchen & 26.12 & 78.28 & 47.19 & 3.91 & 45.5 \\
Bedroom 1 & 29.86 & 85.91 & 45.97 & 4.25 & 46.1 \\
Bedroom 2 & 18.04 & 51.9 & 35.51 & 4.83 & 41.8 \\
Baths & 25.45 & 73.22 & 28.04 & 1.13 & 22.3 \\
Bedroom 3 & 40.41 & 99.18 & 38.03 & 1.55 & 30.3 \\
Bedroom 4 & 18.04 & 55.96 & 38.29 & 3.93 & 39.9 \\
Third Bath & 14.91 & 46.24 & 19.26 & 1.13 & 16.7 \\
\hline
\end{tabular}

\subsubsection{Ground Heat Transfer}

To model ground heat transfer, the EnergyPlus auxiliary-program, Basement, was used. Initially it was run as a sub-routine using assumptions from previous Canadian research (Zirnhelt, 2013) that calibrated a basement model in similar climate. Once the sub-routine was executed, the results were copied into the main IDF file. Subsequent simulations include the results of the Basement sub-program as part of the whole.

\subsubsection{Domestic Electricity Consumption}

A detailed list of lighting types and schedules were provided by the homeowner, as well as appliance types and schedules. Where values were not provided, the original model took ideal values from the CCHT reference house where the daily electricity consumption target was $20 \mathrm{kWh}$, which represents a typical household's electricity consumption (Swinton, Moussa, \& Marchand, 2001). The same study illustrated typical energy consumption occupancy patterns, normalized as a fraction of daily total (Figure 4.7). 


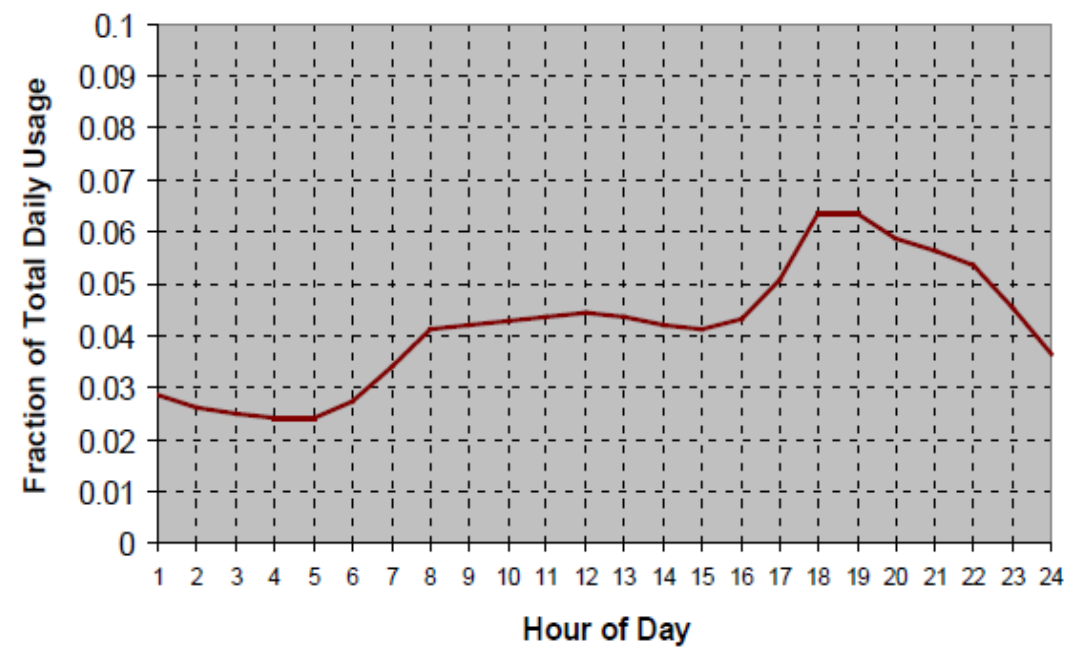

Figure 4.7: Typical residential electric equipment usage (Swinton et al., 2001)

For comparison, the Toronto Hydro data (2015) for the case study building was compiled and each hour of day was averaged for the 2012 calibration year and binned into months (Figure 4.8). Although this chart is somewhat indiscernible, there is valuable information in it which contributed to model calibration. Between the hours 02:00 and 06:00, all occupants are typically asleep and therefore not manually using any appliances or lights. Any electric consumption occurring during these hours can be considered phantom plug loads, refrigerator use, or the ERV. Further, the plot shows a noticeable difference between night time electricity consumption during the cooling months and the heating months. This difference can be attributed to ERV electricity consumption. Looking first at the shoulder seasons on the chart below, and then closer at the hourly consumption data from Toronto Hydro, the ERV operation days were determined. It was found that the ERV was turned off May 10 and turned back on September 10. This knowledge was also useful in determining the heating season which follows the annual ERV schedule to some extent. More specifically, during the shoulder seasons, the ERV is left on if the windows cannot be left open continually, even when heating is not being supplied.

It would be extremely difficult to create use profiles for each appliance and light fixture, for each month, to match each monthly profile. Therefore the monthly profiles were averaged to create a typical daily profile which was used all year long. It can be seen in Figure 4.9 that the average measured profile mirrors the theoretical daily profile fairly close (Figure 4.7). If the actual daily profile were normalized against the average daily total $(17.8 \mathrm{kWh})$, the peak which occurs at 18:00 would be 0.076 . The low which occurs in the middle of the night would be 0.020 . 


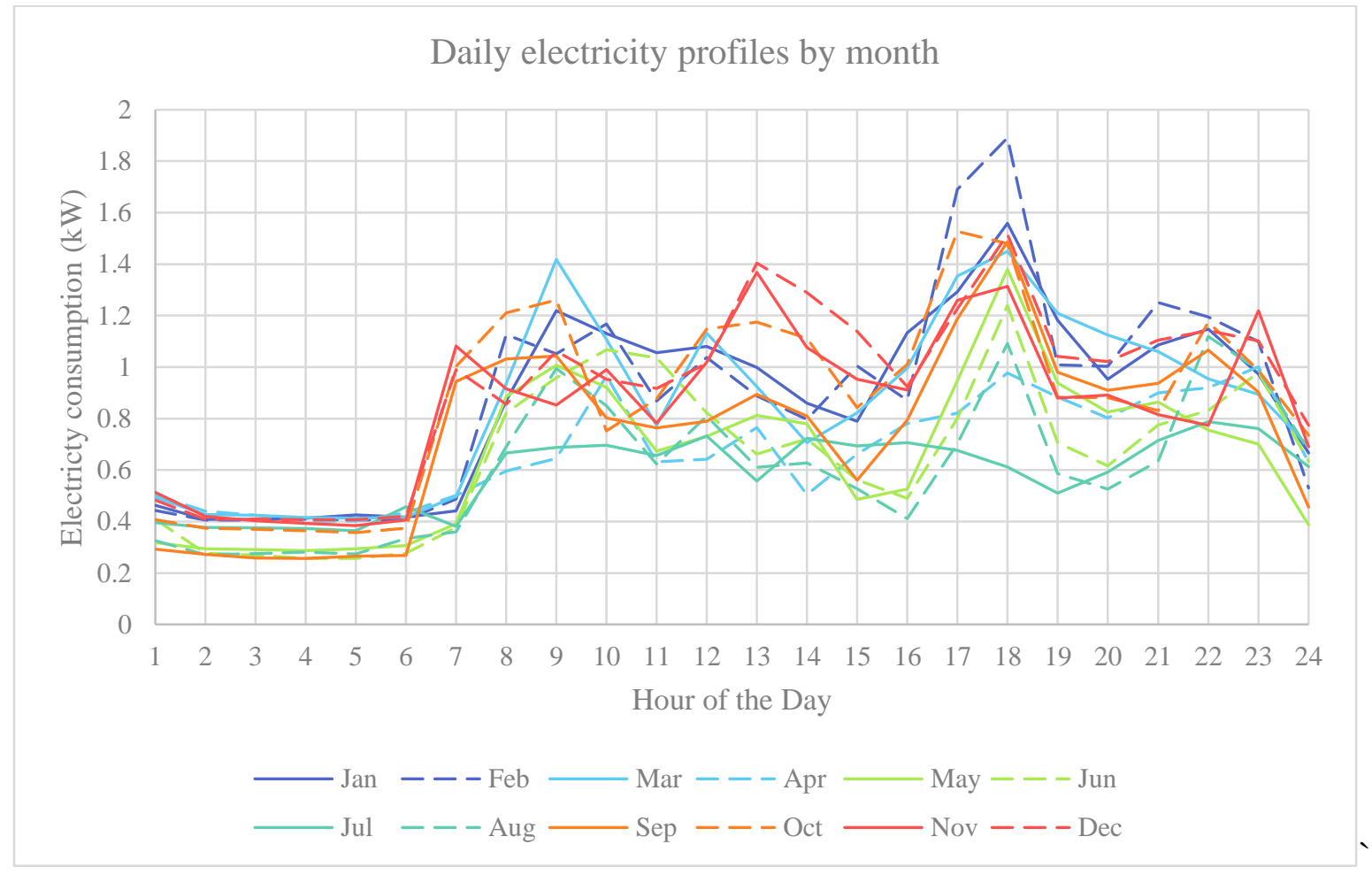

Figure 4.8: Daily average electricity profiles sorted by month recorded from Toronto Hydro hourly electricity data

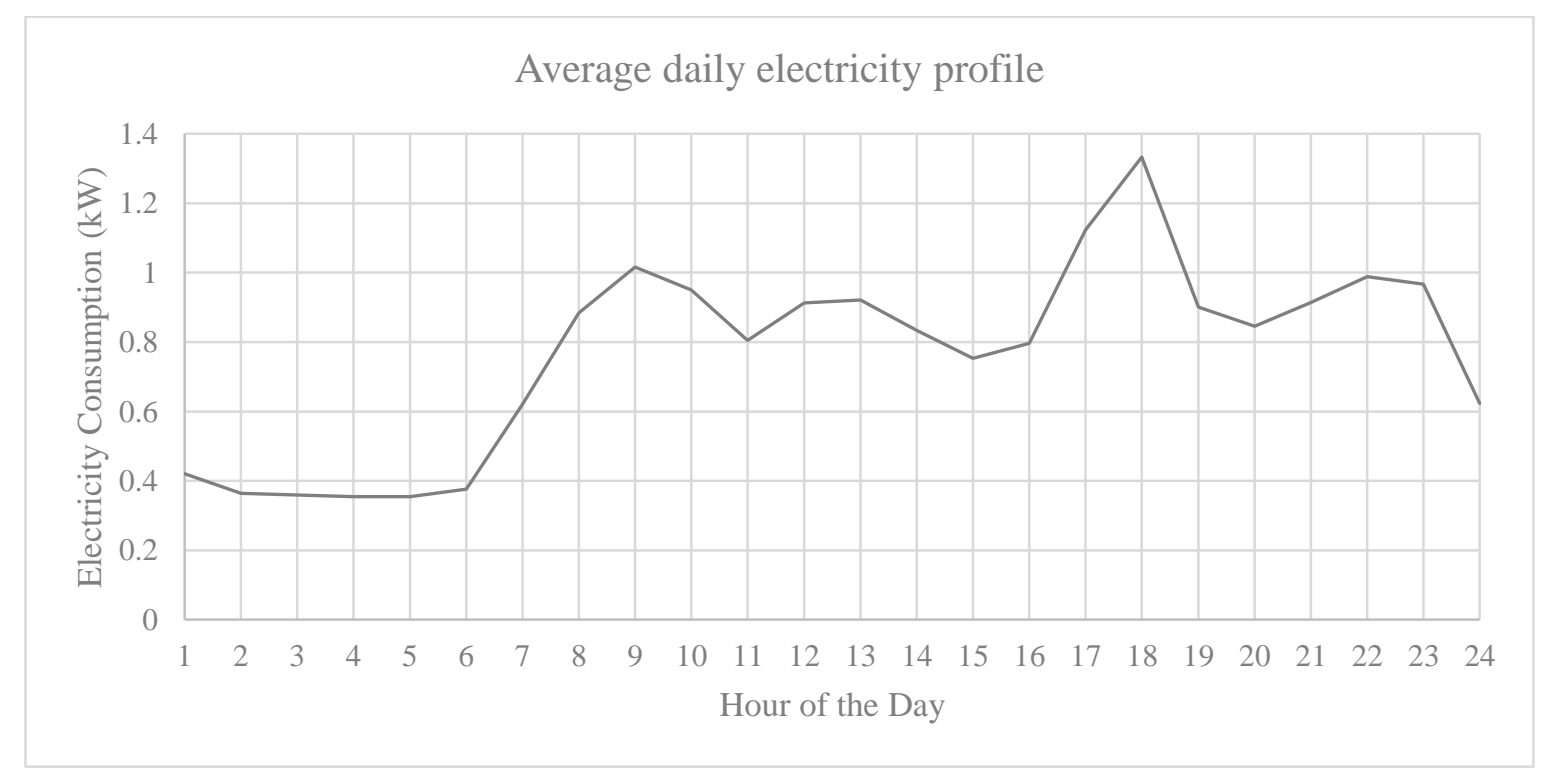

Figure 4.9: Average daily electricity profile recorded from Toronto Hydro hourly electricity data 
For the practicality of schedule definition in EnergyPlus, the actual profile used in the final model is presented in Figure 4.10. The average daily electricity consumption of the calibrated model is $17.55 \mathrm{kWh}$.

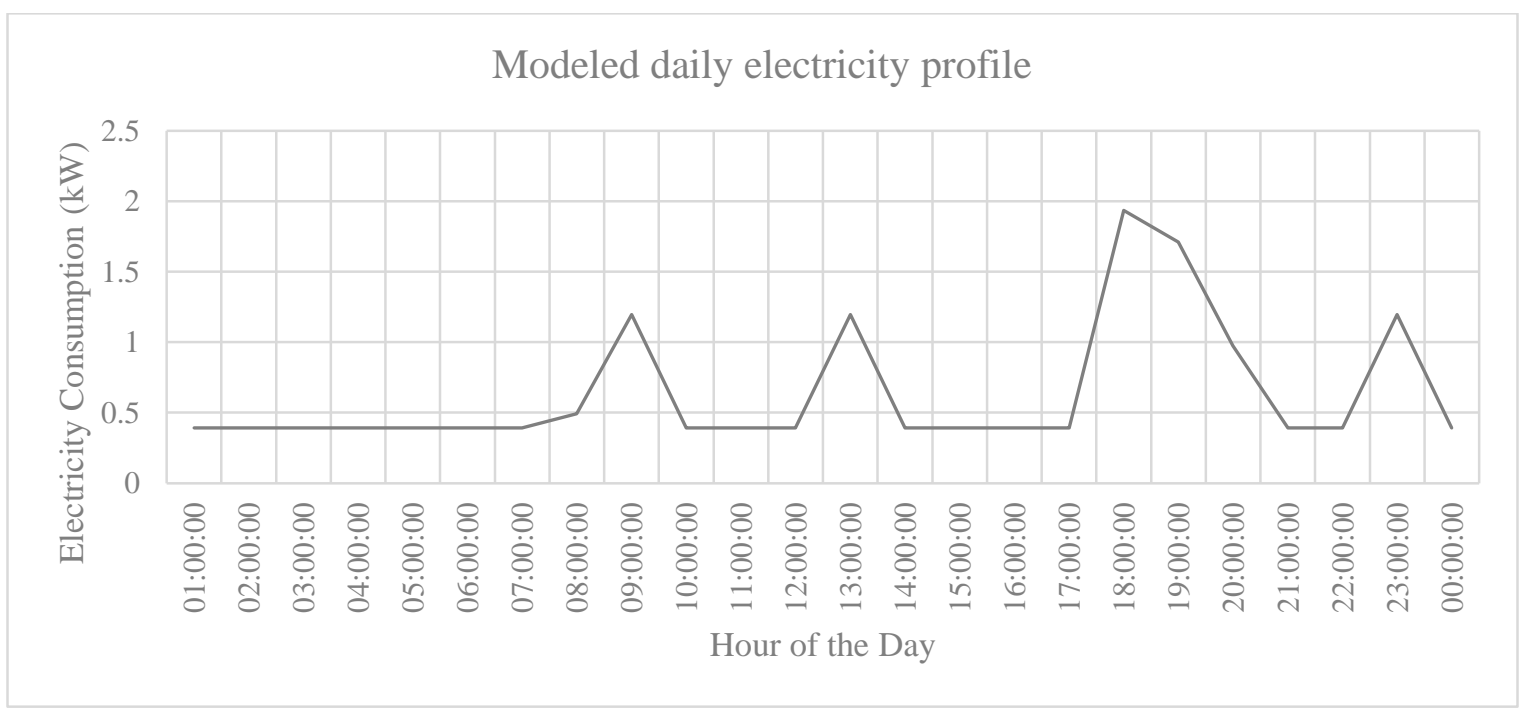

Figure 4.10: Average daily electricity profile as in the calibrated model

Electricity levels varied throughout the year because of daylight hours and time spent indoors. Once the appliance use was established, it remained constant for the year. The baseline ERV consumption, which was determined from the difference in baseline consumption for heating and cooling season, was used as required by ventilation demand, as was the cooling electricity. Once these values were defined, it was assumed that the remaining electricity consumption could be attributed to lights and miscellaneous plug use, which varied throughout the year. However, exact time of use values would be impossible to determine. To rectify the difference between monthly electricity consumption, monthly weighting factors were determined from the 2012 utility bills. Each weighting factor represents the fractional consumption normalized to the month of greatest electricity consumption (December). The monthly weighting factors are shown below (Table 4.5). These weighting factors were applied to the monthly light and plug schedules in the model to account for seasonal variation. The values may be representative of typical household electricity consumption patterns, but should not be used outside of this model.

Table 4.5: Monthly electricity adjustment factors

\begin{tabular}{lllllllllllll}
\hline & Jan & Feb & Mar & Apr & May & Jun & Jul & Aug & Sep & Oct & Nov & Dec \\
\hline Factor & 0.953 & 0.911 & 0.937 & 0.714 & 0.718 & 0.697 & 0.641 & 0.663 & 0.790 & 0.960 & 0.893 & 1.000 \\
\hline
\end{tabular}


Appliance type and schedule was provided by the homeowner. Significant appliances included a refrigerator, dishwasher, oven with range, and clothes washer and dryer. The initial model used electric equipment to represent internal gains for the kitchen fan, stove, refrigerator, dishwasher, other kitchen appliances, dining room appliances, clothes washing machine, and dryer and initial values were taken as assumptions from the CCHT test house appliances. The final calibrated model simplified the appliances and updated the values with manufacturer data where possible, and changed to cooktop to natural gas. Table 0.6 summarizes the electric appliances and lights in the model. The average daily consumption for the model totaled $17.55 \mathrm{kWh}$ as broken down in Table 4.6. For simplification, the daily light schedule remained the same all year (Table 4.7). For reference, the appliance and lighting tables also include the internal gain fractions which will be discussed further in the next section.

Table 4.6: Daily average appliance and lighting consumption breakdown

\begin{tabular}{|c|c|c|c|c|c|c|c|}
\hline Appliance & $\begin{array}{c}\text { Peak } \\
\text { Draw } \\
(\mathrm{W})\end{array}$ & $\begin{array}{c}\text { Fraction } \\
\text { Latent }\end{array}$ & $\begin{array}{l}\text { Fraction } \\
\text { Radiant }\end{array}$ & $\begin{array}{c}\text { Fraction } \\
\text { Convective }\end{array}$ & $\begin{array}{c}\text { Fraction } \\
\text { Lost }\end{array}$ & $\begin{array}{c}\text { Time of } \\
\text { Use }\end{array}$ & $\begin{array}{c}\text { Avg Daily } \\
\text { Consumption } \\
(\mathrm{kWh})\end{array}$ \\
\hline Electric oven & 1525 & 0.3 & 0.0 & 0.4 & 0.3 & $\begin{array}{c}17: 00- \\
17: 35\end{array}$ & 0.89 \\
\hline Dryer & 2500 & 0.05 & 0.15 & 0.0 & 0.8 & $\begin{array}{c}19: 00- \\
19: 50\end{array}$ & 2.08 \\
\hline Washing machine & 505 & 0.0 & 0.0 & 0.8 & 0.2 & $\begin{array}{c}18: 10- \\
19: 00\end{array}$ & 0.42 \\
\hline Dishwasher & 1020 & 0.7 & 0.0 & 0.3 & 0.0 & $\begin{array}{c}18: 00- \\
18: 50\end{array}$ & 0.85 \\
\hline Refrigerator & 48 & 0.0 & 0.25 & 0.75 & 0.0 & $\begin{array}{c}00: 00- \\
24: 00\end{array}$ & 1.15 \\
\hline Plug loads * & 360 & 0.0 & 0.5 & 0.5 & 0.0 & $\begin{array}{c}\text { 00: } 00- \\
\text { 24:00 }\end{array}$ & 8.64 \\
\hline Lights * & 844 & Varies & Varies & Varies & Varies & $\begin{array}{c}\text { See } \\
\text { below }\end{array}$ & 3.52 \\
\hline
\end{tabular}

\footnotetext{
* Plug loads and light peak draw varies depending on time of year
} 
Table 4.7: Light schedules for building simulation model

\begin{tabular}{cccccc}
\hline Thermal Zone & $\begin{array}{c}\text { Total Gain } \\
(\mathrm{W})\end{array}$ & $\begin{array}{c}\text { Radiant } \\
\text { Fraction }\end{array}$ & $\begin{array}{c}\text { Visible } \\
\text { Fraction }\end{array}$ & $\begin{array}{c}\text { Convective } \\
\text { Fraction }\end{array}$ & $\begin{array}{c}\text { Daily } \\
\text { Schedule }\end{array}$ \\
\hline Basement & 120 & 0 & 0.175 & 0.825 & \\
Basement S & 40 & 0 & 0.175 & 0.825 & \\
Living & 348 & 0.8 & 0.1 & 0.9 & $07: 00-08: 00 ;$ \\
Kitchen & 96 & 0 & 0.175 & 0.825 & $12: 00-13: 00 ;$ \\
Bedroom 1 & 64 & 0 & 0.175 & 0.825 & $17: 00-18: 10 ;$ \\
Bedroom 2 & 40 & 0.8 & 0.1 & 0.9 & $23: 00-24: 00$ \\
Baths & 24 & 0 & 0.175 & 0.825 & $\downarrow$ \\
Bedroom 3 & 40 & 0.8 & 0.1 & 0.9 & $\downarrow$ \\
Bedroom 4 & 40 & 0.8 & 0.1 & 0.9 & \\
Third Bath & 32 & 0 & 0.175 & 0.825 & \\
\hline
\end{tabular}

\subsubsection{Domestic Natural Gas Consumption}

Domestic natural gas was considered that which was not used for space heating. For the case study house, domestic natural gas consumption is attributed to domestic hot water generation and stove-top cooking. The case study house does not have a microwave, so the natural gas cooktop schedule was called more frequently than what may be typical in other homes.

As mentioned previously, a natural gas spot measurement was performed over a month during a 2014 shoulder season. The volumetric natural gas meter was read twice daily (Figure 4.11). The chart reports the difference between consecutive gas meter readings. Any value of zero signifies no appreciable amount of gas usage between readings. Any difference over $2 \mathrm{~m} 3$ was attributed to heating. With the heating natural gas accounted for, the remaining natural gas consumption was attributed to water heating and cooking. The monthly baseline domestic natural gas consumption was found to be $37.5 \mathrm{~m} 3$. 


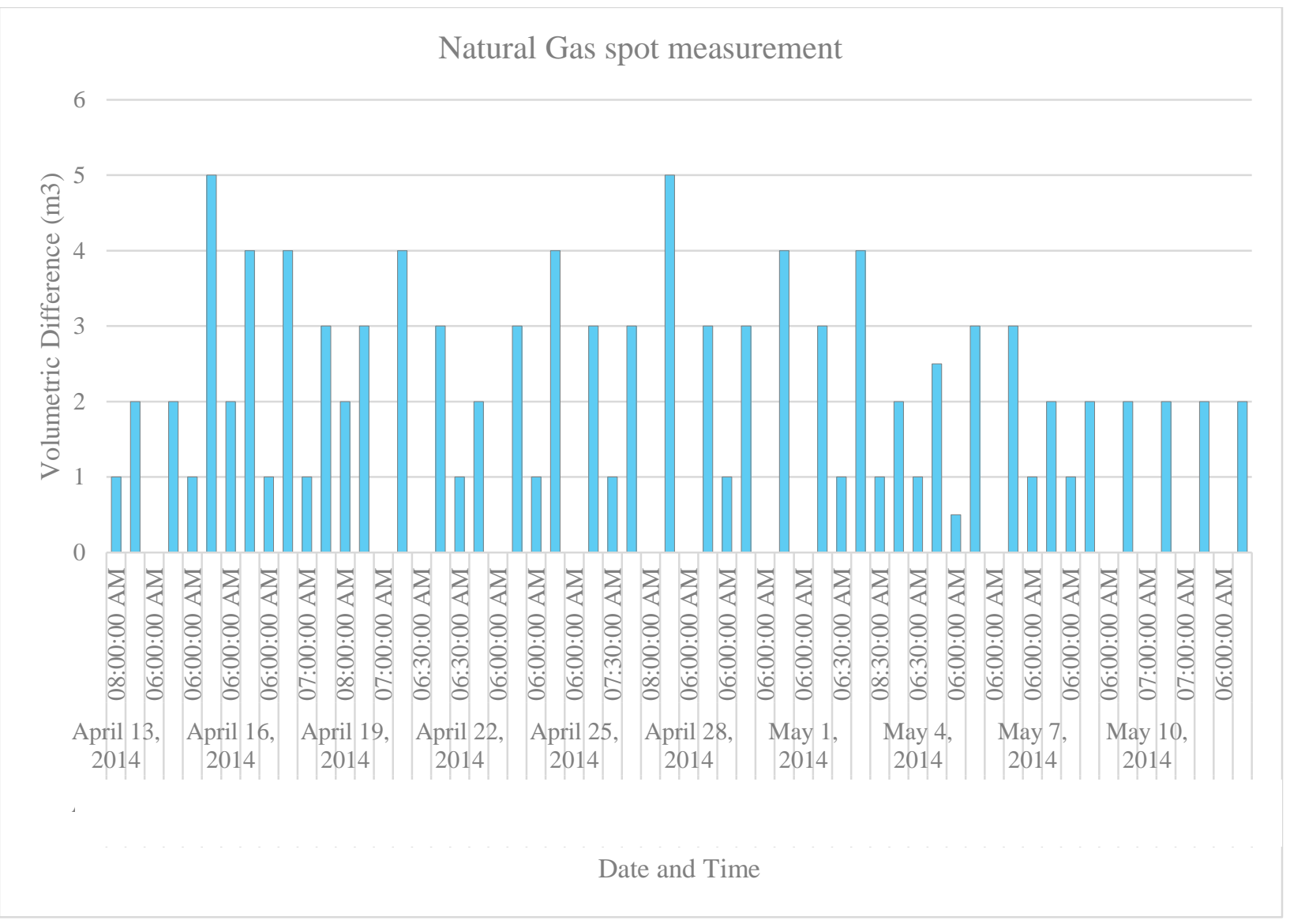

Figure 4.11: Natural gas spot measurement of volumetric meter reading

The natural gas cooktop output was determined from manufacturer data and the schedule determined from occupant report. The remainder of the domestic natural gas was attributed to domestic hot water (DHW). In the case study house, the hot water tank is served by the same boiler as the heating system. However, for simplification, the hot water heater was separated and set to meet consumption determined by the natural gas spot test, for the size, flow, and efficiency given by the manufacturer. The details of the cooktop and DHW heater, modeled to use a combined total of $37.5 \mathrm{~m} 3$ natural gas every month, are presented in Table 4.8 and Table 4.9 respectively.

Table 4.8: Natural gas consumption input for cooktop

\begin{tabular}{ccccccc}
\hline Appliance & $\begin{array}{c}\text { Peak Output } \\
(\mathrm{W})\end{array}$ & $\begin{array}{c}\text { Fraction } \\
\text { Latent }\end{array}$ & $\begin{array}{c}\text { Fraction } \\
\text { Radiant }\end{array}$ & $\begin{array}{c}\text { Fraction } \\
\text { Convective }\end{array}$ & $\begin{array}{c}\text { Fraction } \\
\text { Lost }\end{array}$ & $\begin{array}{c}\text { Time of Use } \\
\text { [\& Use } \\
\text { Fraction] }\end{array}$ \\
\hline Cooktop & 411 & 0.3 & 0.2 & 0.0 & 0.5 & $07: 00-07: 30 ;$ \\
& & & & & & $17: 00-18: 00$ \\
\hline
\end{tabular}


Table 4.9: Natural gas consumption input for DHW

\begin{tabular}{cccccc}
\hline & $\begin{array}{c}\text { Tank } \\
\text { Volume }(\mathrm{m} 3)\end{array}$ & Efficiency & $\begin{array}{c}\text { Peak Flow Rate } \\
(\mathrm{m} 3 / \mathrm{s})\end{array}$ & $\begin{array}{c}\text { Fraction Loss to } \\
\text { Zone }\end{array}$ & $\begin{array}{c}\text { Time of Use \& Use } \\
\text { Fraction }\end{array}$ \\
\hline Water & 0.144 & 0.9 & 0.000505 & 0.4 & $07: 00-7: 30[0.05485] ;$ \\
Heater & & & & & $17: 00-20: 00[0.01724]$ \\
\hline
\end{tabular}

\subsubsection{Internal Gains}

Internal gains were accounted for in the initial model from human occupants, lights, and appliances. Each heat source is broken into latent and sensible heat. Latent heat delivered to the space must be managed by ventilation or air-conditioning systems. Sensible heat is further divided into convective and radiant heat. Convective gains heat the zone air immediately while the radiative gains are distributed across zone surfaces and added to the heat balance according to surface properties.

Heat gain from lights and appliances are primarily sensible (US DOE, 2013d). For example, typical incandescent light bulbs convert only $10 \%$ of electricity to visible radiation while the remainder is converted into heat. Of the total input energy, $80 \%$ is released as thermal radiation, and $10 \%$ to convective gain. The initial model assumed $8 \%$ visible light, $83 \%$ radiation and $9 \%$ convective gain. The case study house uses LED lights which convert little or no energy to radiative heat. The US Department of Energy (2007) reported that LED lights convert 15-25\% of the energy to visible light, and the remaining $75-85 \%$ to convective heat. The radiative fraction for the LED lights was updated in the final model. The initial model assumed $25 \%$ visible light, $25 \%$ radiant fraction, and 50\% convective gain. The appliance and lighting schedules were determined from the electricity consumption schedules discussed above. Internal gain from appliances and lighting are broken down in Table 4.6 and Table 4.7 respectively.

Human heat dissipated is a function of metabolic rate and environmental condition (US DOE, 2013d). Typical total gain values from occupants range from 100-150 W/person for sedentary activity, but can be as low as $70 \mathrm{~W}$ for a person sleeping and up to $900 \mathrm{~W}$ for a person engaged in vigorous physical activity (US DOE, 2013c). The total heat is split into sensible and latent fractions. Then, the sensible portion is divided into radiant and convective potions. In the 
initial model, human heat gain is $60 \%$ latent, $12 \%$ radiant, and $28 \%$ convective. It is rare to have accurately measured data for occupancy schedules (Raftery, Keane, \& O'Donnell, 2011a). In this case, the homeowner gave an approximate account of the typical occupancy schedule, but there is no way to verify this information. Table 4.10 describes the internal gains from humans in the final model, which were simplified from the initial model.

Table 4.10: Human internal gains for simulation model

\begin{tabular}{cccccccc}
\hline Occupants & $\begin{array}{c}\text { Gain } \\
(\mathrm{W})\end{array}$ & People & $\begin{array}{c}\text { Sensible } \\
\text { Fraction }\end{array}$ & $\begin{array}{c}\text { Latent } \\
\text { Fraction }\end{array}$ & $\begin{array}{c}\text { Radiant } \\
\text { Fraction }\end{array}$ & $\begin{array}{c}\text { Convective } \\
\text { Fraction }\end{array}$ & Time \\
\hline Bedroom 1 - sleep & 90 & 2 & 0.4 & 0.6 & 0.12 & 0.28 & $21: 30-07: 00$ \\
Bedroom 3 - sleep & 90 & 1 & 0.4 & 0.6 & 0.12 & 0.28 & $21: 30-07: 00$ \\
Bedroom 3 - sleep & 90 & 1 & 0.4 & 0.6 & 0.12 & 0.28 & $21: 30-07: 00$ \\
Bedroom 4 - sleep & 90 & 1 & 0.4 & 0.6 & 0.12 & 0.28 & $21: 30-07: 00$ \\
$\begin{array}{c}\text { Remaining zones - } \\
\text { daytime }\end{array}$ & 200 & 5 & 0.4 & 0.6 & 0.12 & 0.28 & 7:00-8:30; \\
\hline
\end{tabular}

Internal gains from showers and kitchen sink were included in the model as hot water equipment objects, which produce significant latent load. Use patterns were provided by the home owner and the natural gas spot measurement described above. Table 4.11 describes the internal gain breakdown from water use, where time of use and use fraction is described in the DHW use schedule in Table 4.9. Internal gains from the hot water storage tank are also described above.

Table 4.11: Internal gain fractions from DHW use

\begin{tabular}{cccccc}
\hline Thermal Zone & $\begin{array}{c}\text { Gain } \\
(\mathrm{W})\end{array}$ & $\begin{array}{c}\text { Convective } \\
\text { Fraction }\end{array}$ & $\begin{array}{c}\text { Latent } \\
\text { Fraction }\end{array}$ & $\begin{array}{c}\text { Radiant } \\
\text { Fraction }\end{array}$ & $\begin{array}{c}\text { Lost } \\
\text { Fraction }\end{array}$ \\
\hline Baths (shower) & 41 & 0.35 & 0.45 & 0.00 & 0.10 \\
Third Bath (shower) & 41 & 0.35 & 0.45 & 0.00 & 0.10 \\
Kitchen (sink) & 20 & 0.50 & 0.50 & 0.00 & 0.00 \\
\hline
\end{tabular}

\subsubsection{Ventilation and Air Distribution}

The mechanical ventilation system was modelled initially using an air loop object with terminal ducts in each zone, and autosized in the original model. The air loop had an in-line fan to represent the ERV fan and drive the loop, with no cooling or heating coil in line. The air loop supplies and exhausts to every zone directly using splitters and mixers respectively to route the 
main air loop to and from each zone. The ventilation configuration does not accurately match that of the case study house which supplies to 'living' rooms and exhausts from 'wet/stale' rooms. A ventilation model was created that supplied and exhausted to the respective zones of the case study house and used zone mixing objects to transfer air between zones. However, this configuration resulted in a fatal error. It was determined through personal communication that EnergyPlus is not currently capable of simulating this type of ventilation configuration (M. Witte, personal communication, July 7, 2014). Zone cross mixing objects were created for each adjacent zone to allow air flow between them.

The ERV was modelled using a heat exchanger object capable of transferring sensible and latent energy between exhaust and fresh outdoor air streams. The sensible and latent recovery effectiveness were input manually according to manufacturer specification in the initial model. The fan for the ERV in the initial model is a constant volume fan with autosized maximum flow rate. The specified ventilation air flow was $0.3 \mathrm{ACH}$ and the average electricity consumption of the ERV was $150 \mathrm{~W}$, as determined from the monthly electricity profiles.

In the calibrated model, natural ventilation had a significant effect on the model behavior during the cooling season. The final model used natural ventilation rates of $1.5 \mathrm{ACH}$ for periods during the cooling season, May 11 to September 11, where indoor temperature was above 20C and wind speeds were below $40 \mathrm{~m} / \mathrm{s}$.

\subsubsection{Air Source Heat Pump}

The ductless air source heat pump was initially created using HVAC template VRF objects. Template objects run a pre-processing algorithm and expand into the necessary objects. Once the simulation was run, the expanded objects were copied and hard coded into the main IDF file to create the basis for the system. The system model was given more detail and fit into a single room air loop to model the point source terminal.

The split air conditioner removes heat from only the Third Bath zone. Ambient air is taken from the zone and blown past the cooling coil then returned to the same zone air. The heat is transferred via refrigerant lines to the outdoor condensing unit.

A variable refrigerant flow terminal unit object was used to model the demand side terminal of the split air conditioner. The object comprises a fan and cooling coil in a blow-through 
configuration. The fan for the indoor terminal unit in the initial model was an on/off fan with autosized maximum flow rate. The cooling coil in the original model was direct expansion variable refrigerant flow. Total cooling capacity and air flow were autosized, but part load curves were taken from the EnergyPlus database. These curves were adopted by EnergyPlus from a study done to create accurate part load curves for residential air conditioners and heat pumps (Cutler, Winkler, Kruis, Christensen, \& Brandemuehl, 2013).

The outdoor condenser was modeled using a variable refrigerant flow air conditioning equipment object. In the initial model, the gross rated cooling capacity was autosized with a manually set coefficient of performance. Part loads were taken from the same EnergyPlus database as the terminal object.

Occupancy patterns created a challenge for calibration since the cooling system was run manually based on subjective thermal comfort rather than automated setpoints. Sub-metered data of the cooling electricity consumption was provided by the homeowner for the 2013 cooling season, which equaled $78.0 \mathrm{kWh}$ for a separate study, which focused on the cooling system of the case study house (Guadagnoli, 2014). However, since the simulation period is 2012, the usage pattern cannot simply be built manually. Therefore, the overall cooling energy measured is useful as a reference for the season, but the approximation had to be accepted for the remainder of the study for continuity. The small difference is not significant. It is important, however, that the cooling strategy be consistent when testing parameters. The final model used a cooling setpoint of $28 \mathrm{C}$ to represent the manual operation, after balancing the cooling setpoint and natural ventilation rate.

\subsubsection{Radiant Heating}

The heating was modelled using a natural gas boiler and in-floor radiant water loops. The hot water loop is driven by a main circulating pump and flows through a natural gas condensing boiler with demand bypass. The main hot water loop is then split to supply hot water for each zone, and for the indirect domestic hot water heater, then mixed again and returned to the main loop.

Demand side heat delivery was modeled using internal source construction objects. Like other construction objects, this one uses material layers to create a composite, but unlike regular construction objects, this one allows for a heat source delivered at a specified layer with specified 
tube spacing. The object creates a model that incorporates layout, insulation, tube diameter, and heat control throttling range. These construction objects were assigned to thermal zones to distribute radiant heat to the space. Variable flow low temperature radiant objects correspond to each zone construction and make up the demand side hot water delivery loop. In the original model, hot water flow was autosized according to heat demand from the thermostat.

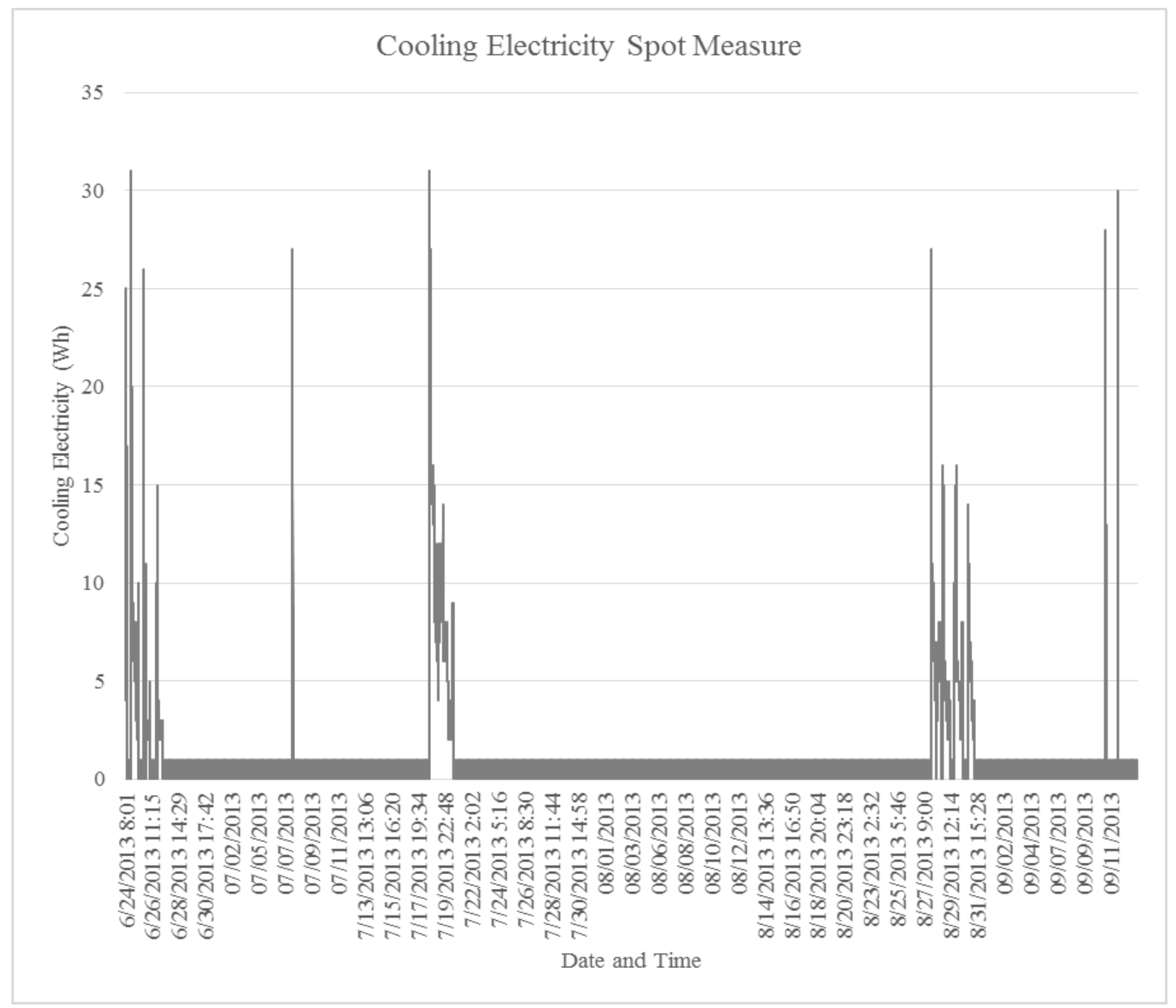

Figure 4.12: Total cooling electricity for the 2013 cooling season (Guadagnoli, 2014)

The heating plant model uses a natural hot water boiler with manually entered capacity, thermal efficiency, and flow rate. The water outlet temperature was set at 35C in the initial model, as it was observed at the case study house. The part load ratios were built manually in the initial model from manufacturer efficiency curves. 


\subsubsection{Control}

Thermostat objects were used for zone control. In the initial model, each zone had a separate thermostat object with heating setpoint of $20 \mathrm{C}$ and cooling setpoint of $25 \mathrm{C}$. In reality, the case study house has two thermostats per floor, except for the basement which has one, to control the heating system. Cooling control is performed manually by the homeowner on the basis of subjective thermal comfort and occupancy schedule. The owner estimated a cooling temperature of approximately 25C. However, the air-temperature data showed that higher temperatures were sustained for periods over the 2012 cooling season due to distribution problems. During the cooling period, the ERV was turned off to eliminate the electrical load of the fan, and fresh air as well as cooling were provided with natural ventilation through open windows. After calibration, the final heating and cooling setpoints were $20 \mathrm{C}$ and $28 \mathrm{C}$ respectively.

\subsection{Calibration Summary}

An evidence based technique was used to calibrate the energy model of the case study house where input priority was given to values higher of higher reliability, such as logged data. Hourly electricity data was used to set baseline levels of consumption, and determine occupant usage patterns and approximate heating and cooling periods. Daily measured natural gas consumption was used to set baseline levels of domestic consumption. Parameters were then adjusted iteratively, according to source reliability hierarchy, so that acceptable accuracy was established for monthly natural gas consumption, monthly electricity consumption, and hourly zone air temperature. Table 4.12 summarized the error tolerances achieved by the end of the calibration procedure. Outdoor air temperature did not meet the NMBE tolerance, although it was within acceptable range for $\mathrm{CV}(\mathrm{RMSE})$. As discussed before, this was likely caused by the sheltered location of the air temperature sensor which consistently recorded temperatures higher than the true outdoor air temperature. Bedroom 1 air temperature could not be verified for accuracy since no air temperature sensor was located in the zone for the study period. All other calibration values were within the tolerances outlined in ASHRAE Guideline 14. 
Table 4.12: Calibration summary for monthly utility consumption and hourly zone air temperature

\begin{tabular}{ccccc}
\hline Data set & \multicolumn{2}{c}{ Monthly } & \multicolumn{2}{c}{ Hourly } \\
\cline { 2 - 5 } Error & CV(RMSE) & NMBE & CV(RMSE) & NMBE \\
Tolerance & $+/-15 \%$ & $+/-5 \%$ & $+/-30 \%$ & $+/-10 \%$ \\
\hline Natural gas & $12.0 \%$ & $0.3 \%$ & - & - \\
Electricity & $4.6 \%$ & $-1.7 \%$ & - & - \\
Outdoor air & - & - & $23.0 \%$ & $13.2 \%$ \\
Basement & - & - & $3.2 \%$ & $0.6 \%$ \\
Basement S & - & - & $11.6 \%$ & $5.9 \%$ \\
Living & - & - & $5.4 \%$ & $0.1 \%$ \\
Kitchen & - & - & $6.3 \%$ & $2.9 \%$ \\
Bedroom 1 & - & - & - & - \\
Bedroom 2 & - & - & $7.0 \%$ & $1.9 \%$ \\
Baths & - & - & $6.2 \%$ & $0.7 \%$ \\
Bedroom 3 & - & - & $5.4 \%$ & $0.6 \%$ \\
Bedroom 4 & - & - & $6.5 \%$ & $-1.7 \%$ \\
Third Bath & - & $6.0 \%$ & $-1.9 \%$ \\
\hline
\end{tabular}

Near the point of calibration, the air temperature data for all zones mirrored the measured data within the allowed tolerances, but the natural gas data had errors of $\mathrm{CV}(\mathrm{RMSE})=23.1 \%$ and $\mathrm{NMBE}=0.7 \%$ and it became apparent that there was an error (Figure 4.13). It was determined that the error was due to read date discrepancy, so the simulated natural gas data had to be shifted to match the read dates of the utility bill.

Ideally, the gas meter would be read on the same day every month, but in reality, the utility company does not take readings on the same day every month. Therefore, billable amounts may actually represent more or less than an exact calendar month and introduce error into the data since simulation results are reported each exact calendar month. To account for this discrepancy, read dates from the natural gas bills were collected to determine actual number of days accredited to the nominal month. Simulated consumption per month was divided equally by days within the simulated month to obtain an average daily natural gas consumption for each month. Then the daily average was multiplied by the number of days in the billing period to obtain natural gas consumption for the adjusted month. Figure 4.14 shows the adjusted natural gas consumption, which is within the allowable error tolerances, and the number of days per billing period. 


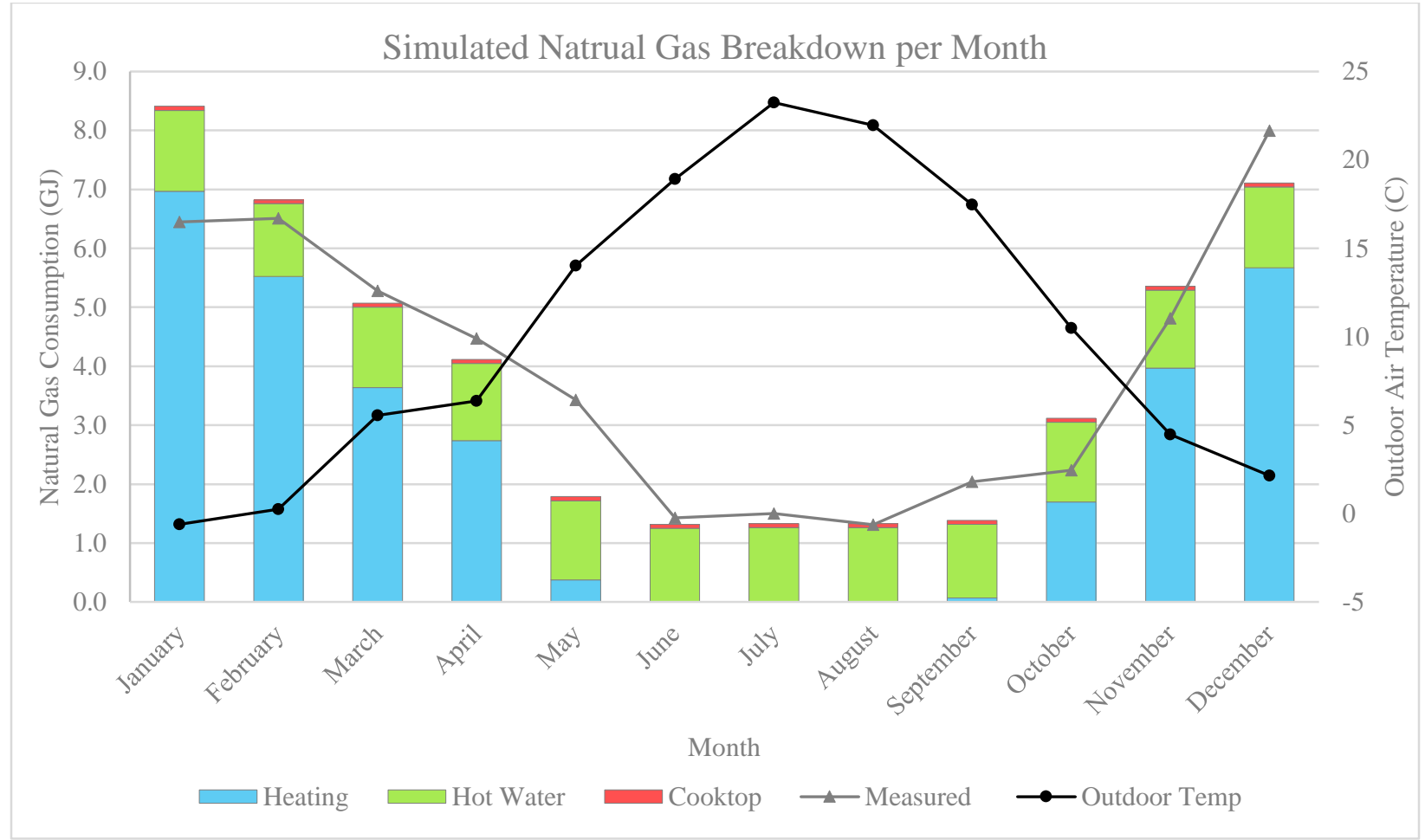

Figure 4.13: Measured natural gas consumption relative to simulated consumption displayed with outdoor air temperature

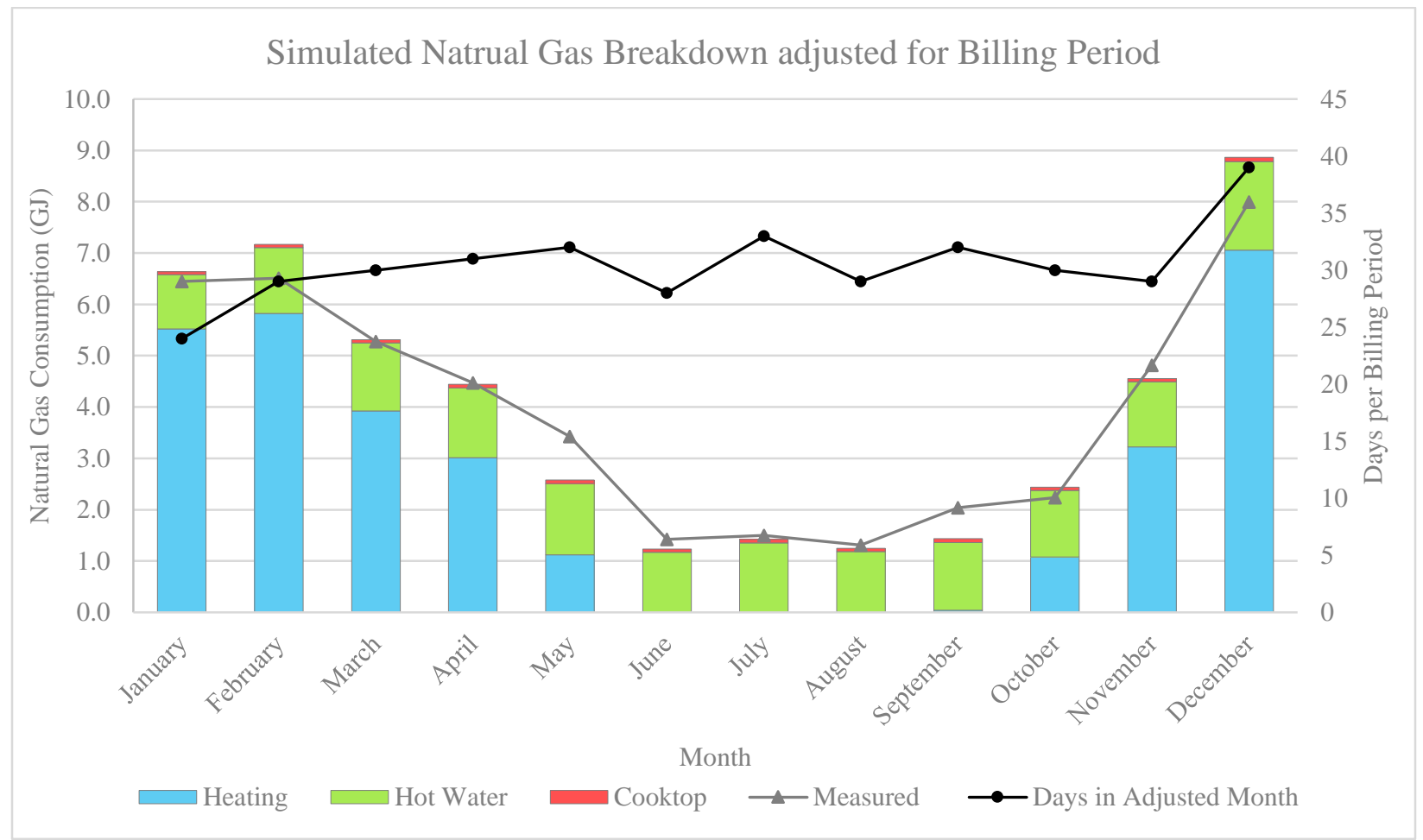

Figure 4.14: Measured natural gas consumption relative to simulated consumption displayed with days in natural gas billing period 
Monthly electricity consumption is showed in Figure 4.15. Electricity calibration read dates were not an issue because of the hourly data available from Toronto Hydro. However, monthly adjustments had to be made to account to seasonal usage patterns.

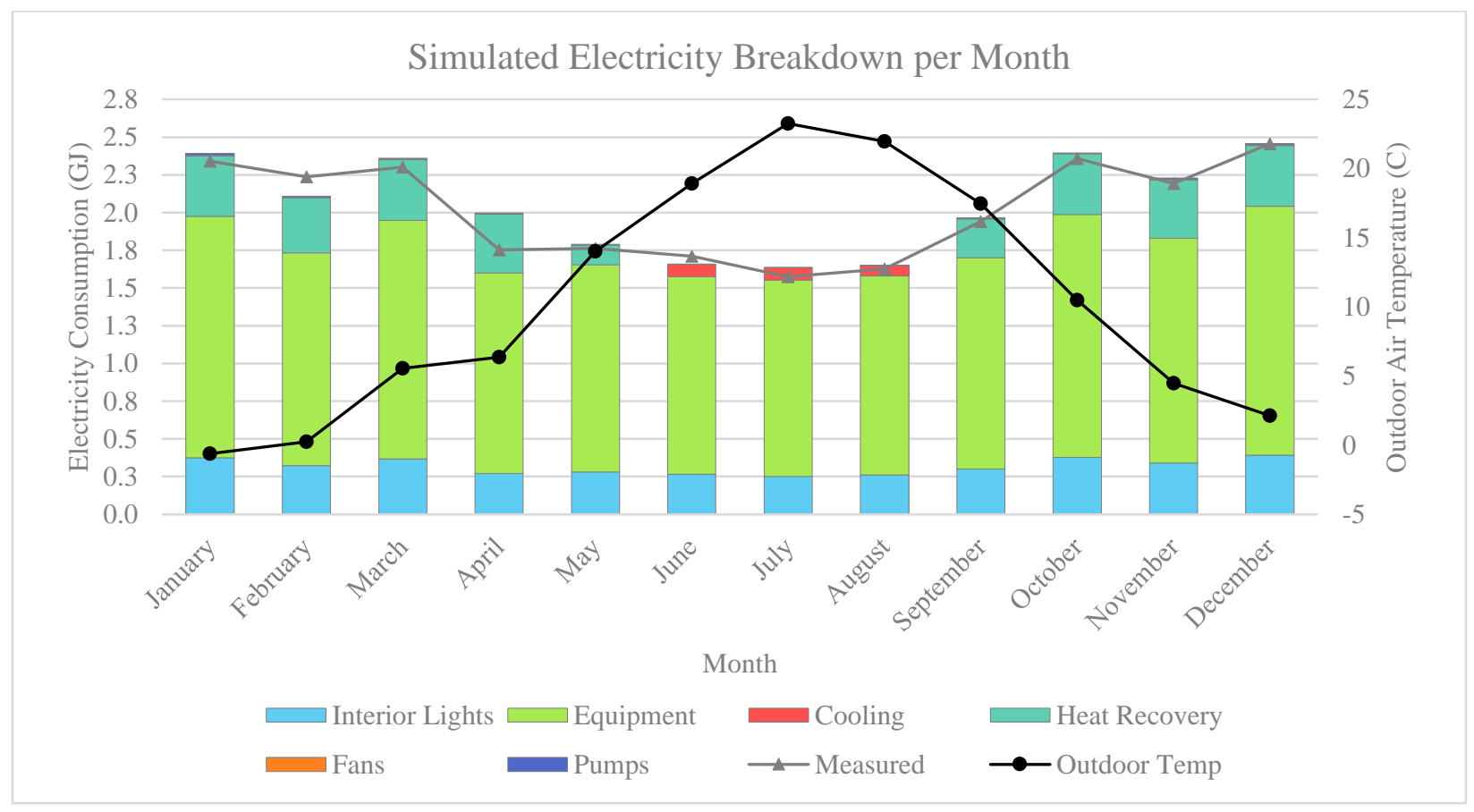

Figure 4.15: Measured electricity consumption relative to simulated consumption displayed with outdoor air temperature

Figure 4.16 shows the model calibration signature which compares total building energy and outdoor air temperature using the base load analysis approach (Yoon, Lee, \& Claridge, 2003; Liu \& Liu, 2011). Typically the plot would be V-shaped. The left side of the V-shape, values below $20 \mathrm{C}$ in this case, would represent heating related consumption, whereas the right side of the Vshape, above 20C, represent cooling related consumption. The consumption value at the bottom the V-shape is the base load for uses like lights, plug loads, and DHW which are temperature independent. The slope of each arm of the V-shape should be as close as possible. If only one side is dissimilar, then the modeler knows to address the factors in the model which affect the 'off' side. The calibration signature for this model is fairly accurate, but has only one arm of the Vshape. This is because the house is essentially operated without any cooling-related energy. The base load for the model is approximately $3 \mathrm{GJ}$. 


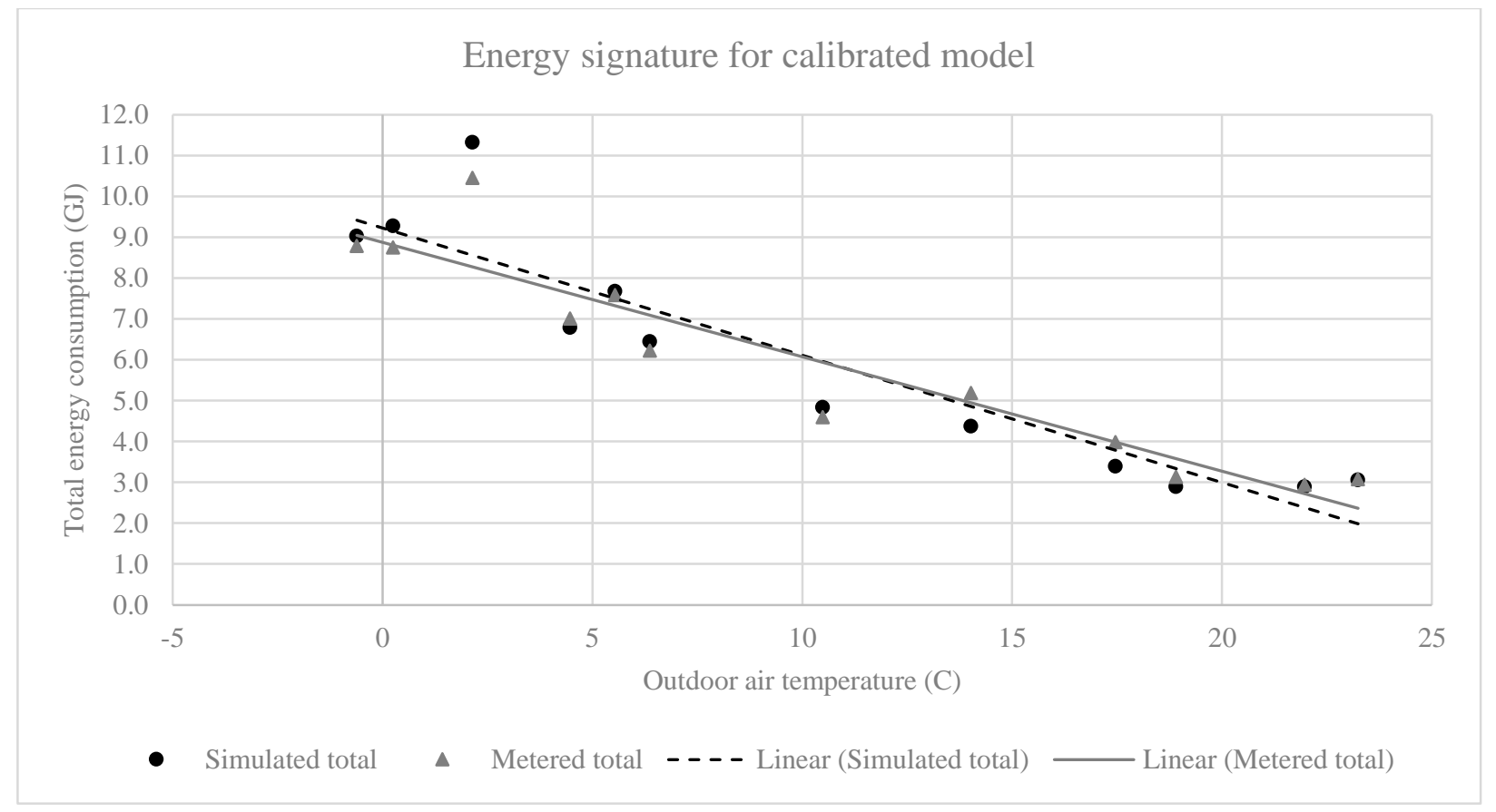

Figure 4.16: Model calibration signature showing measured and simulated total energy consumption and outdoor air temperature

Measured and simulated indoor air temperature is shown in Figure 4.17 for thermal zone 'Living' as an example. The remaining zone temperature comparisons can be seen in Appendix A. Successful air temperature calibration was highly dependent on several model features:

- Heating and cooling season date. Hourly electricity consumption data during the middle of the night was used to determine baseline use and highlighted the exact date the ERV was turned off for the cooling season.

- Natural Ventilation. Early versions of the model did not include natural ventilation and significant overheating was occurring in the model, especially during the shoulder seasons when the cooling system was not used. The addition of natural ventilation captured the indoor air temperature as it varied with diurnal swings in outdoor temperature.

- Cooling setpoint. The heating setpoint was known and easily modeled but the cooling setpoint that would imitate manual operation had to be determined. Trial and error was used, since there was no way to determine the manual usage, until the cooling setpoint made the model match cooling electricity consumption and air temperature data for all zones. 


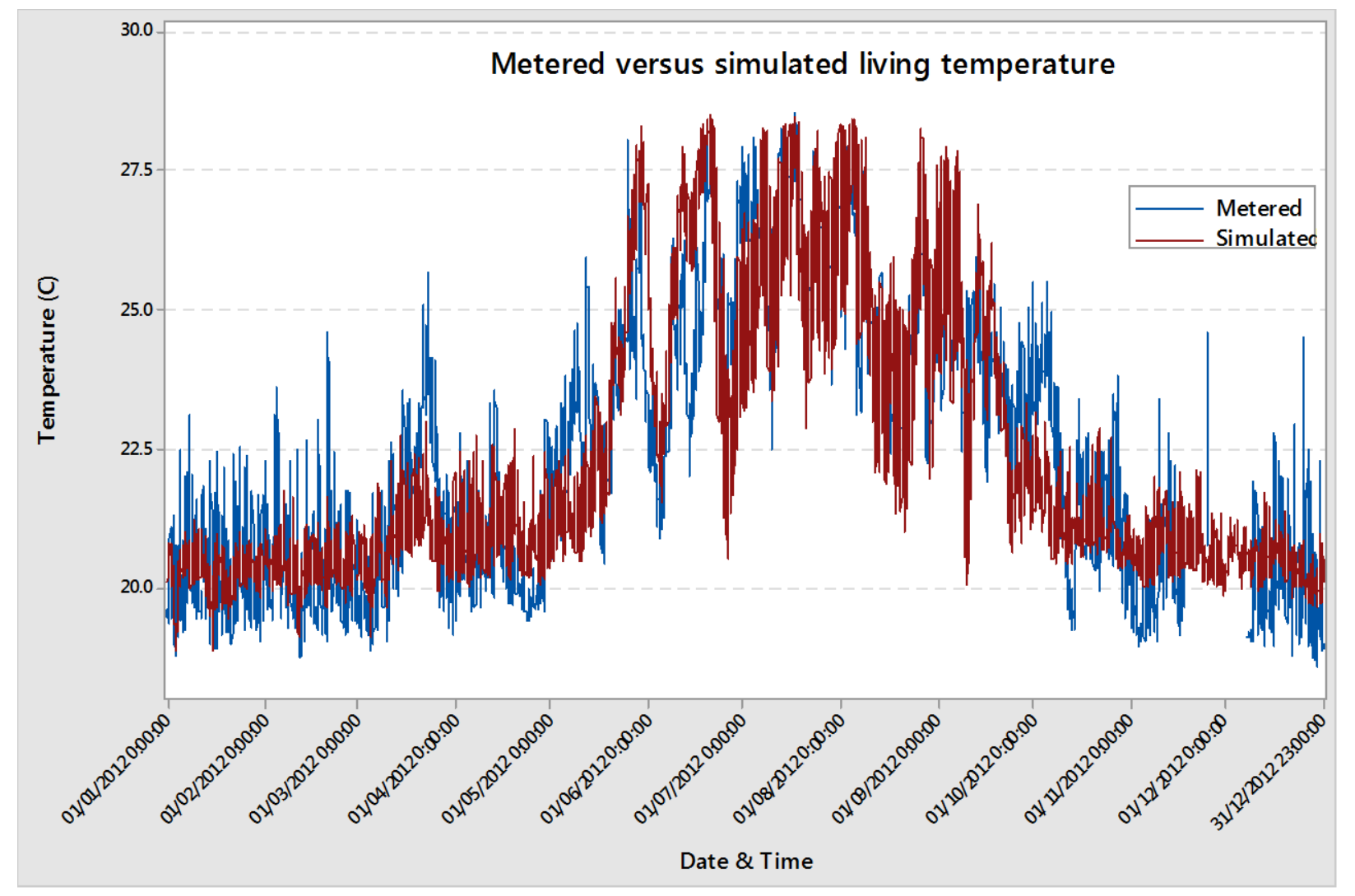

Figure 4.17: Measured versus simulated hourly air temperature for sample zone (Living) 


\section{LIFE CYCLE COST OPTIMIZATION}

Recent publications have shown excellent examples of coupling an optimization algorithm to a building simulation engine (Hasan, Vuolle, \& Siren, 2008; Bichiou \& Krarti, 2011; Hamdy, Hasan, \& Siren, 2011; Ihm \& Krarti, 2012; Bucking, Athienitis, \& Zmeureanu, 2014; Ferraraa, Fabriziob, Virgone, \& Filippi, 2014; Karaguzel, Zhang, \& Lam, 2014). Optimization for this study was performed taking best practices taken from these studies and applied relevance to objectives of this research.

Chapter 4 described the process used to calibrate the simulated energy consumption of the case study model to real-world data. The validated simulation model was then used as the reference building on which to perform the feasibility assessment of passive energy efficiency measures. In general, this involved coupling the building simulation engine with the jEPlus optimization suite, built specifically for the purpose of building optimization studies (Figure 5.1). The optimization engine utilizes the NSGA-II genetic algorithm with the purpose of minimizing the specified objective functions for the experiment. jEPlus software calls the building simulation file and is programmed to replace parametric inputs with other values allowable within the defined parametric study space. Output results are processed by jEPlus+EA using a genetic algorithm and are compared with the previous iteration's results for minimization of the objective functions. Iterations are repeating using different parametric input combinations until algorithm convergence is satisfied and a set of Pareto optimal solutions are produces for the batch of simulations. The following sections elaborate on the input parameters, procedural control, iterative algorithm, and solution sets for the building optimization problem.

\subsection{Reference Building}

As described in the literature review, building optimization problems require a reference building on which to perform optimization. For this study, the reference building was the case study house, chosen to represent a high performance house in Toronto. A full description of the house and its systems, as well as the calibration procedure can be found in the previous chapter. In Figure 5.1, the calibrated simulation model is represented by the input called 'Case study house input file'. 


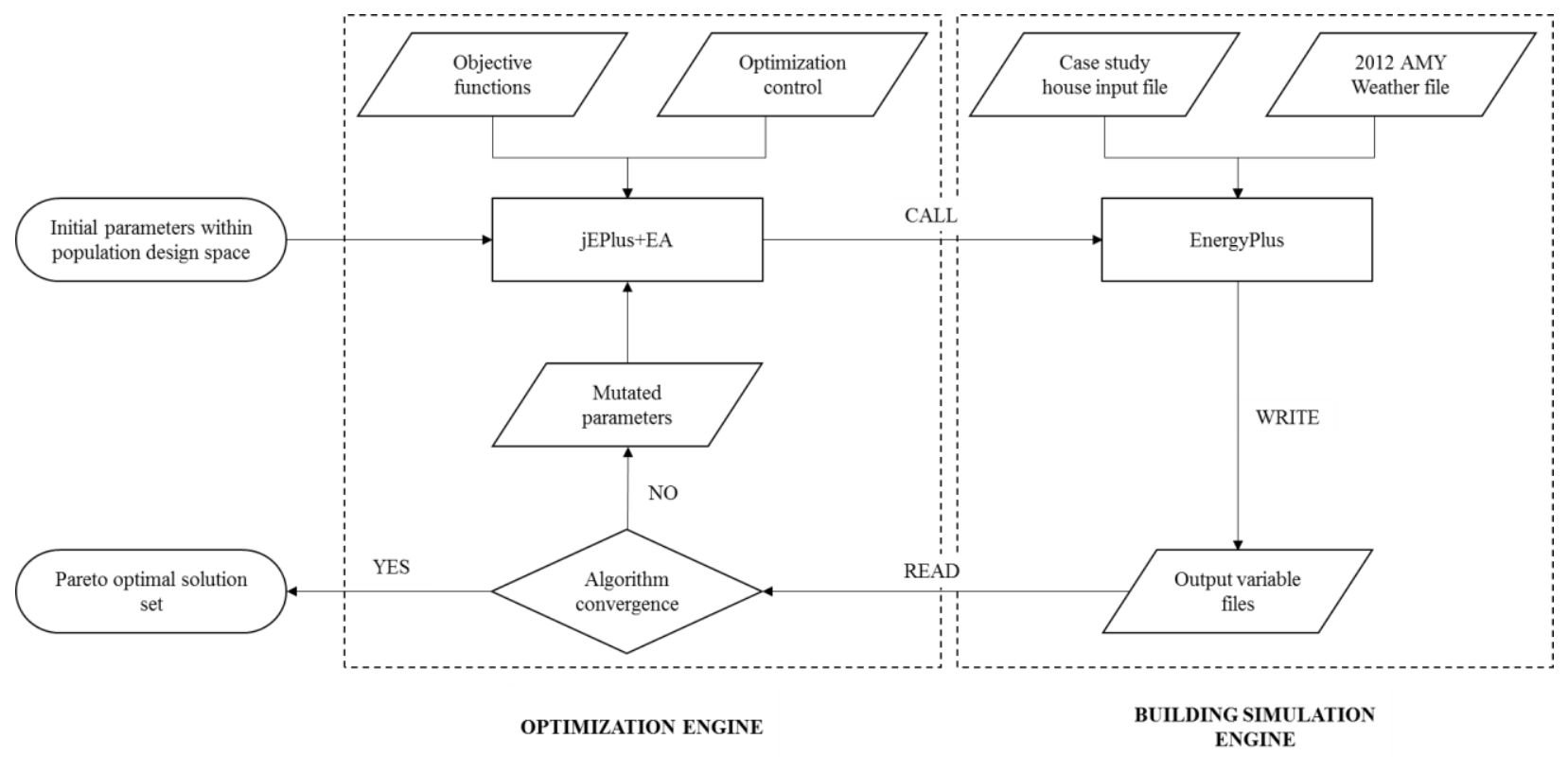

Figure 5.1: Overview of optimization methodology highlighting the coupling of optimization and building simulation engines

\subsection{Design Variables}

The goal of this study is determine the optimal configuration of passive energy efficiency measures as a path to super-efficient, net zero, or nearly net zero buildings. The intended design philosophy is to reduce the space conditioning loads as much as is feasible then consider system sizes and energy renewable energy production once significant reduction has been achieved. The maximum point of feasibility refers to the economic point where further investment cannot be returned in energy savings over the building life cycle. Again, passive measures are favored because of the added durability, comfort, resilience, and future assurance benefits.

In the optimization experiment, energy saving design parameters act as independent variables with the goal of determining the resulting space conditioning loads for the building. In this study, certain passive energy conservation measures will be treated as the independent variables. Parameters were chosen for the following reasons:

- Qualification as a passive feature: Passive features are defined as those which influence peak heating and cooling load and do not provide space conditioning through energy consumption. Examples include building aspect ratio, thermal mass, window to wall ratio, window solar heat gain, envelope thermal resistance, air-sealing, shading, and earth tube 
pre-conditioning. Mechanical ventilation is also considered a passive design feature as it is factored into the peak heating and cooling load calculations, even though electricity is required to power ventilator fans (Wright, Klingenberg, \& Pettit, 2014).

- Influence on peak heating and cooling load: Simulation parameters were chosen to reflect those which have the greatest effect on performance on real buildings. Residential loads are primarily imposed by conduction losses, especially through thermal bridges at structural members or glazing edges, infiltration and exfiltration through envelope leakage areas, and ventilation rates (ASHRAE, 2005a). Conversely, institutional and commercial building loads are largely impacted by internal gains from people, lighting, and equipment, which are far less significant in residential houses.

- Inclusion as a Passive House design strategy: Passive House design has been identified as a logical path to net zero or nearly net zero buildings through aggressive load reductions. These fundamental design features include: excellent continuous thermal insulation with exclusion/minimizing thermal bridging, low air leakage to minimize loads associated with uncontrolled infiltration, proper moisture management within the envelope, high-performance windows which allow for an advantageous energy balance depending on climate, and a constant fresh air supply through a balanced mechanical ventilation system (Passive House Institute US, 2010).

- Availability of cost information: In pursuit of the greatest accuracy possible, only parameters that could be accurately associated with an initial cost were included. Notably, air-tightness was excluded as an experiment parameter for this reason. The air-sealing strategy of the retrofit was attributed to the spray foam and was therefore binary. It may have been possible to attribute a cost of incremental air-sealing if a distinct air-barrier was created using tapes and sealants, for example. This approach was also taken by PHIUS in their recent study, where they left air tightness constant at 0.6 ACH50 (Wright, Klingenberg, \& Pettit, 2014). Similarly, other assembly types, such as cellulose filled Larsen trusses, exterior rigid foam, or SIPS, were not considered.

- Retention of calibrated behavior: The effort taken to calibrate the model of the case study house was done so to improve result reliability. Therefore, parameters were chosen that would not significantly change the interaction of the model with the simulated environment. For example, because the radiant heating system in the model was built 
using accurate node connections and specific EnergyPlus objects rather than predetermined system templates, it would be impossible to change the heating system to an air-source heat pump and electric baseboard heaters without fundamentally changing the behavior of the simulated building with respect to the measured data.

With these considerations in mind, the following parameters were chosen to be varied as independent variables for the optimization problem (Table 5.1, Table 5.2, and Table 5.3) leading to 119,070 unique configurations. In the following tables, the as-built systems are bolded. Cost estimating procedures are described below. All other inputs, including the remaining passive features, active systems, internal loads, and weather file were left constant for the duration of the experiment.

Table 5.1: Parametric variables for glazed constructions (5 Options)

\begin{tabular}{|c|c|c|c|c|c|}
\hline Description & $\begin{array}{l}\text { Assembly } \\
\text { U-Value } \\
(\mathrm{W} / \mathrm{m} 2 \mathrm{~K})\end{array}$ & $\begin{array}{c}\text { COG } \\
\text { U-Value } \\
(\mathrm{W} / \mathrm{m} 2 \mathrm{~K})\end{array}$ & $\begin{array}{c}\text { Frame } \\
\text { U-Value } \\
(\mathrm{W} / \mathrm{m} 2 \mathrm{~K})\end{array}$ & SHGC & $\begin{array}{l}\text { Cost } \\
(\$ / \mathrm{m} 2)\end{array}$ \\
\hline $\begin{array}{c}\text { Jeld-Wen V4500, double, low-e, } \\
\text { vinyl frame }\end{array}$ & 1.726 & 1.496 & 2.271 & 0.52 & 483.66 \\
\hline $\begin{array}{c}\text { Alpen } 7257 \mathrm{H} \text {, triple, low-e, } \\
\text { fiberglass frame }\end{array}$ & 1.087 & 0.875 & 1.703 & 0.41 & 810.50 \\
\hline $\begin{array}{c}\text { Alpen } 9259 \mathrm{H} \text {, triple, low-e, } \\
\text { fiberglass frame }\end{array}$ & 0.930 & 0.668 & 1.703 & 0.34 & 975.62 \\
\hline $\begin{array}{c}\text { Optiwin Alphawin, triple, low-e, } \\
\text { wood frame }\end{array}$ & 0.763 & 0.676 & 0.795 & 0.50 & $1,394.77$ \\
\hline $\begin{array}{l}\text { Eco-Insulating SC75, quadruple, } \\
\text { low-e, Inline } 325 \text { fiberglass frame }\end{array}$ & 0.652 & 0.385 & 1.476 & 0.23 & 862.83 \\
\hline \multicolumn{6}{|c|}{ Table 5.2: Parametric variables for ERV units (3 Options) } \\
\hline Description & $\begin{array}{r}\text { Sensib } \\
\text { Effective } \\
100 \%\end{array}$ & Effe & $\begin{array}{l}\text { atent } \\
\text { ctiveness } \\
100 \%\end{array}$ & $\begin{array}{c}\text { Average } \\
\text { Power }(\mathrm{W})\end{array}$ & Cost (\$/ea) \\
\hline Aldes Aeromatic E190-TRG & \multicolumn{2}{|c|}{0.73} & 0.55 & 91 & $3,567.00$ \\
\hline Fantech SER2004 & \multicolumn{2}{|l|}{0.84} & 0.71 & 128 & $4,305.00$ \\
\hline UltimateAir RecoupAerator 200DX & \multicolumn{2}{|l|}{0.93} & 0.55 & 155 & $7,669.00$ \\
\hline
\end{tabular}


Table 5.3: Parametric variables for opaque constructions

\begin{tabular}{|c|c|c|c|}
\hline Assembly & Description & $\begin{array}{c}\text { RSI }_{\text {eff }} \\
(\mathrm{m} 2 \mathrm{~K} / \mathrm{W})\end{array}$ & $\begin{array}{c}\text { Cost } \\
(\$ / \mathrm{m} 2)\end{array}$ \\
\hline \multirow{9}{*}{$\begin{array}{c}\text { Above Grade and Below } \\
\text { Grade Wall } \\
\text { (9 Options Each) }\end{array}$} & $64 \mathrm{~mm}$ cavity CCSF + $38 \mathrm{~mm}$ CCSF c.i. & 3.76 & 49.72 \\
\hline & $64 \mathrm{~mm}$ cavity CCSF $+51 \mathrm{~mm} \mathrm{CCSF}$ c.i. & 4.22 & 55.93 \\
\hline & $64 \mathrm{~mm}$ cavity CCSF + $76 \mathrm{~mm}$ CCSF c.i. & 5.46 & 68.36 \\
\hline & $64 \mathrm{~mm}$ cavity CCSF $+89 \mathrm{~mm} \mathrm{CCSF}$ c.i. & 6.03 & 74.58 \\
\hline & $64 \mathrm{~mm}$ cavity CCSF + $102 \mathrm{~mm}$ CCSF c.i. & 6.59 & 80.79 \\
\hline & $64 \mathrm{~mm}$ cavity CCSF + 127 mm CCSF c.i. & 7.71 & 93.22 \\
\hline & $64 \mathrm{~mm}$ cavity CCSF + $152 \mathrm{~mm} \mathrm{CCSF}$ c.i. & 8.82 & 105.65 \\
\hline & $64 \mathrm{~mm}$ cavity CCSF +178 mm CCSF c.i. & 9.94 & 118.08 \\
\hline & $64 \mathrm{~mm}$ cavity CCSF $+203 \mathrm{~mm}$ CCSF c.i. & 11.05 & 130.51 \\
\hline \multirow{7}{*}{$\begin{array}{c}\text { Basement Slab } \\
\text { (7 Options) }\end{array}$} & None & 0 & 0.00 \\
\hline & $25 \mathrm{~mm}$ XPS c.i. & 0.88 & 12.45 \\
\hline & $51 \mathrm{~mm}$ XPS c.i. & 1.76 & 24.90 \\
\hline & 76 mm XPS c.i. & 2.64 & 37.35 \\
\hline & 102 mm XPS c.i. & 3.52 & 49.80 \\
\hline & 127 mm XPS c.i. & 4.40 & 62.25 \\
\hline & 152 mm XPS c.i. & 5.28 & 74.70 \\
\hline \multirow{14}{*}{$\begin{array}{c}\text { Roof } \\
\text { (14 Options) }\end{array}$} & $127 \mathrm{~mm}$ cavity CCSF & 3.77 & 62.15 \\
\hline & $152 \mathrm{~mm}$ cavity CCSF & 4.53 & 74.58 \\
\hline & $178 \mathrm{~mm}$ cavity CCSF & 5.28 & 87.01 \\
\hline & $203 \mathrm{~mm}$ cavity CCSF & 6.04 & 99.44 \\
\hline & $229 \mathrm{~mm}$ cavity CCSF & 6.79 & 111.87 \\
\hline & $241 \mathrm{~mm}$ cavity CCSF & 7.17 & 118.08 \\
\hline & $241 \mathrm{~mm}$ cavity CCSF + $25 \mathrm{~mm}$ XPS c.i. & 8.31 & 130.53 \\
\hline & $241 \mathrm{~mm}$ cavity CCSF + $51 \mathrm{~mm}$ XPS c.i. & 9.35 & 142.98 \\
\hline & $241 \mathrm{~mm}$ cavity CCSF + $76 \mathrm{~mm}$ XPS c.i. & 10.35 & 155.43 \\
\hline & 241 mm cavity CCSF + 102 mm XPS c.i. & 11.32 & 167.88 \\
\hline & 241 mm cavity CCSF + 127 mm XPS c.i. & 12.26 & 180.33 \\
\hline & 241 mm cavity CCSF + 152 mm XPS c.i. & 13.19 & 192.78 \\
\hline & 241 mm cavity CCSF + 178 mm XPS c.i. & 14.12 & 205.23 \\
\hline & 241 mm cavity CCSF + 203 mm XPS c.i. & 15.03 & 217.68 \\
\hline
\end{tabular}


Performance values for glazed elements, opaque elements, and ERVs were taken from manufacturer specifications. Windows were modeled in WINDOW 6.3 using NFRC product directory data (NFRC, 2015), window sizes 600 x 1500 mm as per North American ratings, and environmental conditions according to NFRC testing methods (Lawrence Berkeley National Laboratory, 2013). The allowable parameter range was chosen to reflect performance levels ranging from OBC SB-12 minimum to those estimated to achieve Passive House certification. The Passive House level parameters were not tested for certification in PHPP or WUFI Passive. Manufacturers who had published performance and attainable cost data were selected.

Costs for the components were taken from case study house invoices and receipts, and supplier prices. The following sections outline the data collected and procedure taken to obtain capital investment costs for the passive parameters varied in the optimization experiment. All costs are for the construction year, 2010, and include 13\% Ontario HST and installation cost. Where costs were taken from other sources, location and year adjustment factors were applied to normalize the values. City index adjusts to local costs in Canadian dollar. All values were converted manually to 'per m2' costs from 'per sf'. Where possible, costs were compared to costs in the RS Means database to validate the costs used in the experiment (RS Means, 2012). The accuracy of the RSMeans has been deemed acceptable for academia and has been used in many previous North American cost-optimization studies (Wang, Zmeureanu, \& Rivard, 2005; Leckner, 2008; Tuhus-Dubrow \& Krarti, 2010; Bichiou \& Krarti, 2011; Fesanghary, Asadi, \& Geem, 2012; Dembo, 2011; Jermyn, 2014; Bucking, Athienitis, \& Zmeureanu, 2014). However, RS means more accurately describes commercial construction and does not provide estimates for high performance components.

\subsubsection{Closed Cell Spray Foam (CCSF) Cost}

An invoice to the home owner was provided by Avenue Insulation Inc. who supplied and installed the Lapolla foam-lok (orange) closed cell polyurethane foam. The invoice broke down costs according to application surface (wall or roof) and specified application thickness. Each subtotal was attributed to the associated wall area from the simulation model. Unit costs were binned according to insulation thickness. Invoice costs were compared to RS Means (2012) item 'Closed cell, spray polyurethane foam, 2 PCF' (Line: 0721 29.10 0300). The RS Means reference included material, installation, overhead and profit, location adjustment factor for Toronto (1.141), and time 
adjustment factor from 2012 to 2010 (0.963), up to 6" of insulation thickness. The remaining thicknesses were unavailable in the database. Unit cost per incremental thickness from invoice data compared to RS Means is shown in Figure 5.2. The costs in RS Means are typically for commercial application and reportedly lower than average residential costs (RS Means, 2012), as is illustrated in the chart.

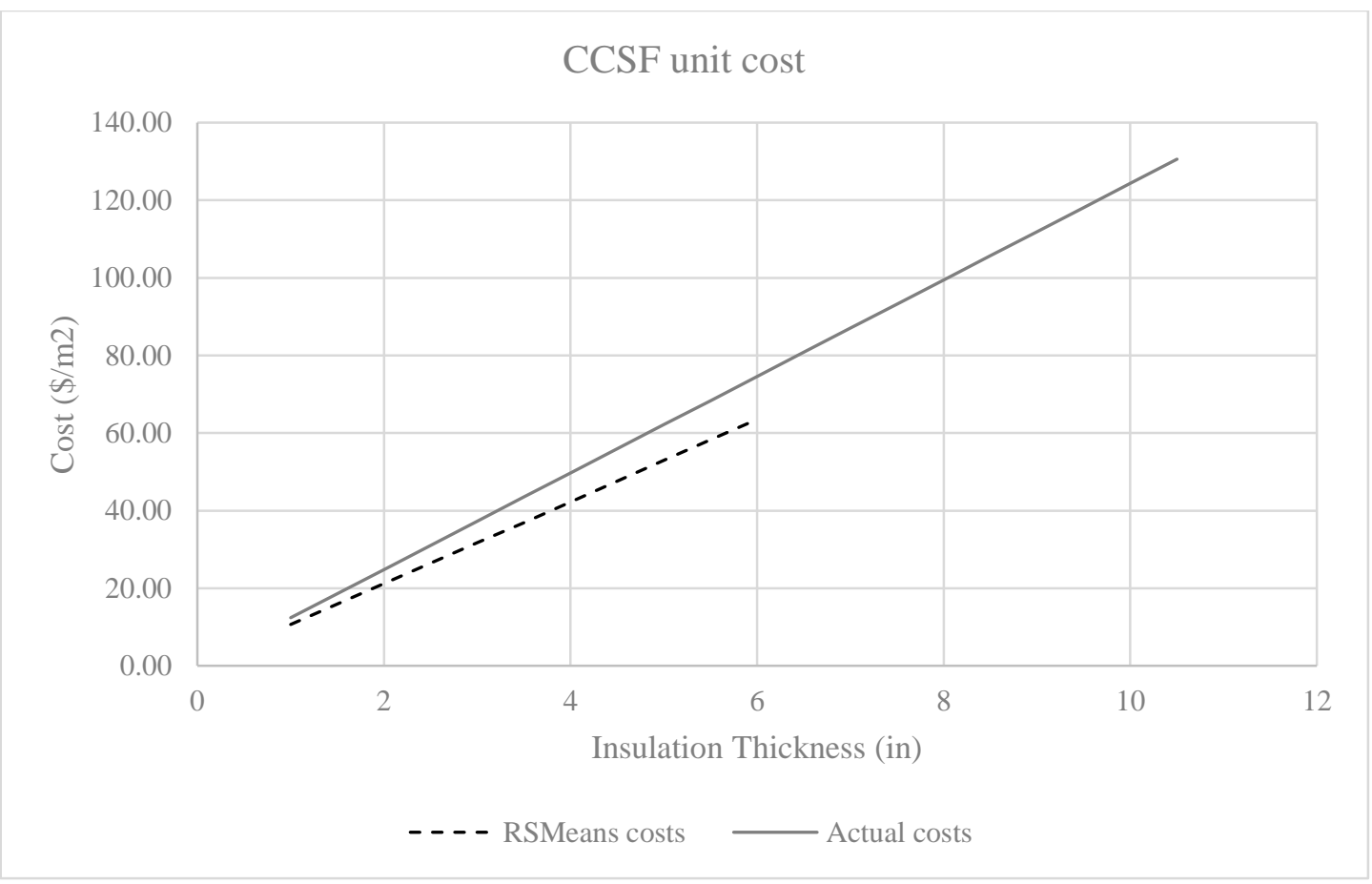

Figure 5.2: CCSF unit cost per thickness actually paid relative to RS Means estimated cost

\subsubsection{XPS Cost}

The material cost for XPS was determined from a project receipt from Rona Home \& Garden where the board insulation was purchased. The 2" thick XPS board cost was linearly interpolated to determine cost per thickness, including sales tax. Since the owner installed the insulation himself, RS Means (2012) installation and overhead costs, adjusted for year and location, were added to the unit cost, shown in Figure 5.3, which compares the RS Means cost for 'Extruded Polystyrene, 25 PSI' (Line: 072216.10 1940). The database only supplies values up to 4". 


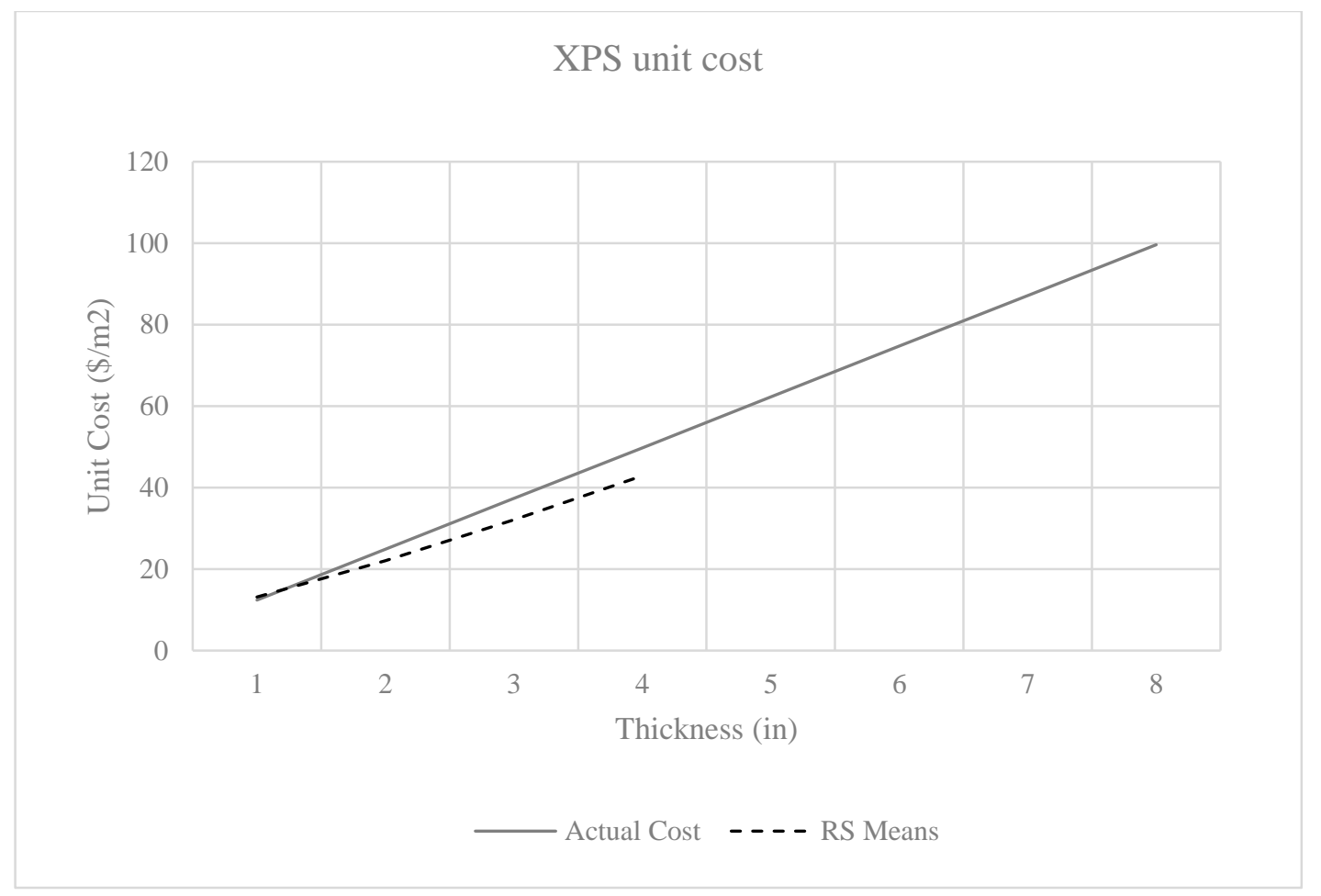

Figure 5.3: XPS unit cost per thickness actually paid relative to RS Means estimated cost

\subsubsection{Glazing Cost}

Costs for glazing units came from a number of sources. The cost for the case study windows were taken from invoices from ECO Insulating glass, who supplied the glazing, and Inline Fiberglass Ltd, who supplied the frames. Jeld-Wen window costs were retrieved from the Home Depot website (Home Depot, 2015). Supplier quotes were used to cost estimates for the Alpen Windows (Jermyn, 2014) and Optiwin (R. Tanner, personal communication, February 12, 2015). Installation costs, a historic adjustment for all but the case study windows (0.905 from 2015 to 2010), and sales tax were applied to all glazing units, since the costs only included material. Figure 5.4 and Figure 5.5 show the cost relationship with u-value and SHGC respectively. RS Means data was not available for any glazing assembly over double pane low-e and is therefore not useful for comparison. 


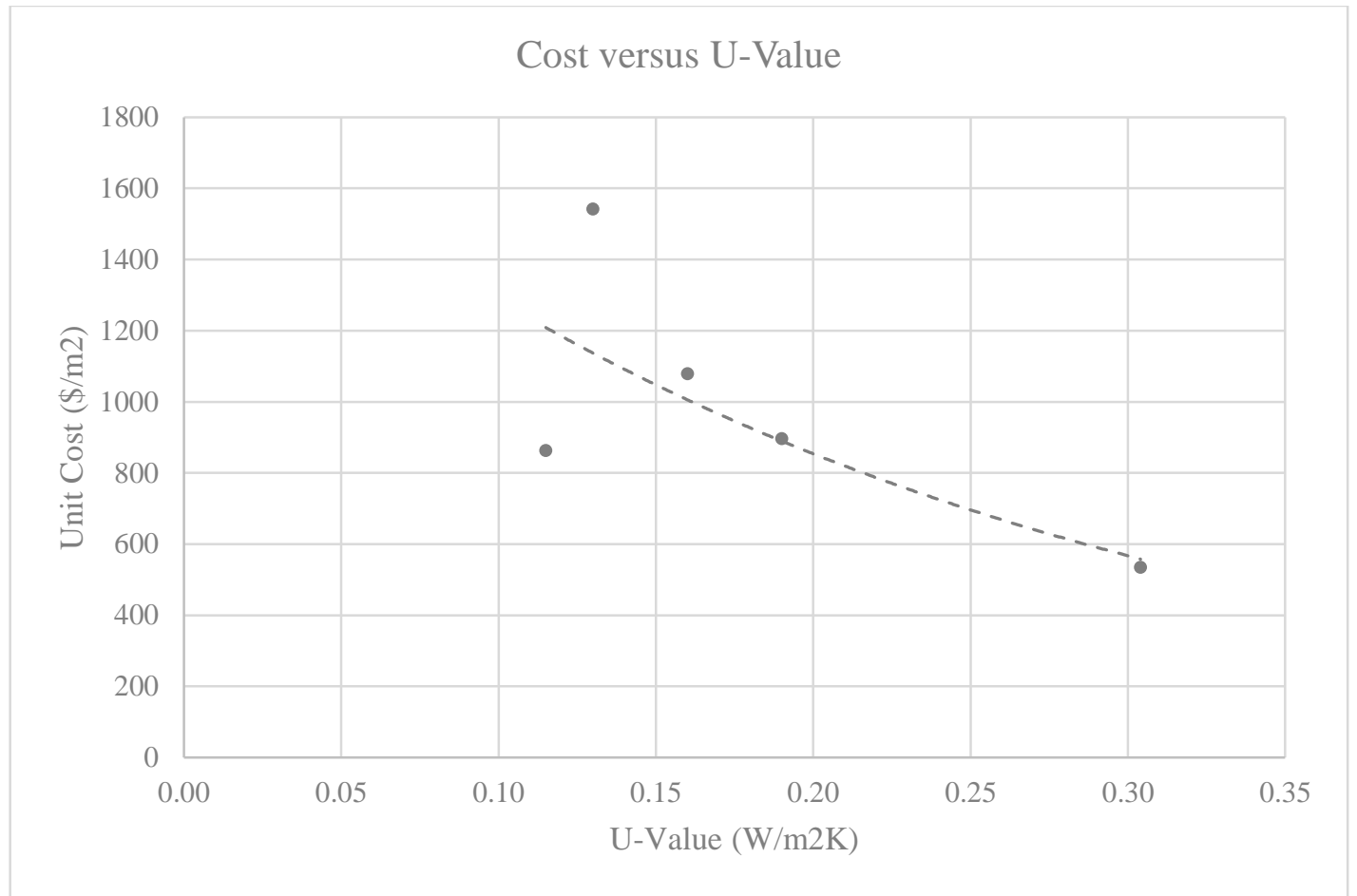

Figure 5.4: Glazing unit cost relative to overall u-value

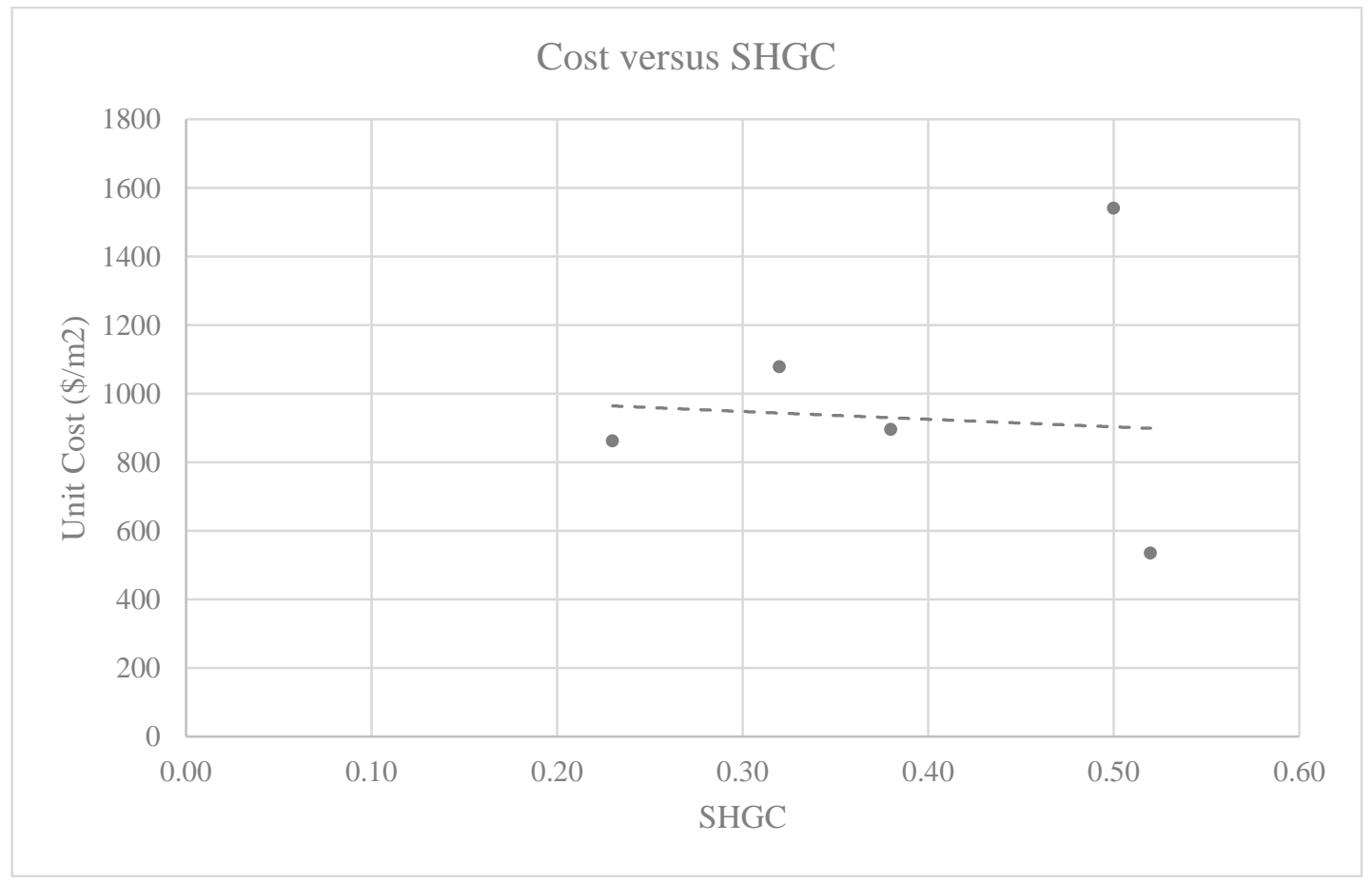

Figure 5.5: Glazing unit cost relative to SHGC 


\subsubsection{ERV Cost}

Although an invoice was available for the case study ERV from Total Home Comfort Heating and Air Conditioning, ERV parameter costs were taken from an online distributor (HVACQuick, 2015) so that estimates could be compared relative to each other. Each estimate included shipping costs from the US, average 2010 CAD to USD exchange rate at the time of calculation (1.03), sales tax, and historic conversion from 2015 to 2010 (0.905). All additional equipment installed in the case study house, or its equivalent, if available for the product, was also included in the cost. A normalizing factor, which was the difference between the estimated cost and invoiced cost, was used to account for installation and ductwork (\$1997) and was included in each ERV cost. For reference, BEopt's installation cost is \$618 (National Renewable Energy Laboratory, 2015). No residential heat recovery units were available for comparison in RS Means. UltimateAir, Fantech, and Aldes ERV cost breakdowns are detailed in Table 5.4, Table 5.5, and Table 5.6 respectively.

Table 5.4: UltimateAir parametric cost breakdown

\begin{tabular}{|c|c|c|c|c|}
\hline Item & Cost/ea & Number & Total Cost & \\
\hline $200 \mathrm{DX}$ & 2299 & 1 & 2299 & \\
\hline Prefilter & 49 & 1 & 49 & \\
\hline Filter & 89 & 1 & 89 & \\
\hline $\mathrm{CO} 2$ sensor & 389 & 1 & 389 & \\
\hline Pressure sensor & 579 & 1 & 579 & \\
\hline Timer & 98 & 5 & 490 & \\
\hline $1 \mathrm{kw}$ preheat & 559 & 1 & 559 & \\
\hline $6 "$ termination kit & 69 & 1 & 69 & \\
\hline Shipping & 761 & 1 & 761 & \\
\hline Installation \& ducts & 1997 & 1 & 1997 & \\
\hline \multirow[t]{4}{*}{ Total } & & 2015 & 7281 & USD \\
\hline & & 2010 & 7499 & CAD \\
\hline & & w HST & 8474 & CAD \\
\hline & & 2010 & 7669 & CAD \\
\hline
\end{tabular}


Table 5.5: Fantech parametric cost breakdown

\begin{tabular}{lllll}
\hline Item & Cost/ea & Number & Total Cost & \\
\hline SER 2004 & 1156 & 1 & 1156 \\
Touch display & 104 & 1 & 104 & \\
Timer & 32 & 5 & 160 \\
Shipping & 281 & 1 & 281 \\
Air quality sensor & 389 & 1 & 389 & \\
Installation \& ducts & 1997 & 1 & 1997 & \\
Total & & 2015 & 4087 & USD \\
& & 2010 & 4209 & CAD \\
& & w HST & 4757 & CAD \\
\hline
\end{tabular}

Table 5.6: Aldes parametric cost breakdown

\begin{tabular}{lllll}
\hline Item & Cost/ea & Number & Total Cost \\
\hline E190-TRG & 840 & 1 & 840 \\
Mode control & 36 & 1 & 36 \\
Speed control & 36 & 1 & 36 \\
Shipping & 202 & 1 & 202 \\
Control display & 98 & 1 & 98 \\
Timer & 36 & 5 & 179 & \\
Installation \& ducts & 1997 & 1 & 1997 & \\
Total & & 2015 & 3387 & USD \\
& & 2010 & 3488 & CAD \\
& & w HST & 3942 & CAD \\
& & 2010 & $\mathbf{3 5 6 7}$ & CAD \\
\hline
\end{tabular}

\subsection{Objective Functions}

In an optimization problem, the objective function is the dependent variable whose results differ in accordance with the combination of independent input variables. The objective function is the minimization target of the optimization algorithm and may be computed by the simulation 
software directly or computed in post-processing using simulation results. For this work, the objectives to be minimized were cost and performance, represented by life cycle cost (LCC) and total peak heating load.

\subsubsection{Cost Function}

Life cycle cost was chosen as the primary objective function for cost in the experiment because it is the most rigorous method for assessing financial investment in building measures, as discussed in the literature review. It includes all costs associated with construction, maintenance, repair, and demolition over the predicted life of the building. It also considers the time value of money and continuing return on investment beyond the simple payback period. In financial practice, internal rate of return (IRR), also called return on investment (ROI), which is the interest rate at which future positive cash flows offset the investment exactly, is the predominant method for screening investments. However, net present value (NPV), which is the additional future value compared to a competing investment at a defined interest rate, is the better comparison tool for investments that do not produce revenue (Flynn, 2010). In other words, NPV can be used to pick the least expensive alternative.

More specifically, the objective function represents the difference in LCC for the proposed package of energy conservation measures with respect to a base line. In other words, LCC $=0$ is the base line case, or the as-built design, LCC $<0$ is a cost savings option, and LCC $>0$ is net loss over the predicted life cycle of the building. EnergyPlus computes NPV using the set of life cycle cost objects. The life cycle cost analysis used is that created by the US Department of Energy to assess energy conservation and renewable energy production in new or existing federally owned buildings (Kneifel, 1996). End of year discounting was used over a 30 year building life cycle.

LCC is affected by financial parameters such as discount rate, inflation of fuel costs, and mortgage rates. These parameters vary according to macro-economic trends and can only be predicted within an envelope of possibility.

\section{DISCOUNT RATE}

NPV is determined using discounted cash flows. The discount rate represents the time value of money and is equivalent to the interest rate required to make the current cash flows and future cash flows equivalent. The discount rate used in the NPV calculation was a minimum hurdle rate 
of return, or minimum acceptable rate of return (MARR), determined for the homeowner. MARR considers the implicit risk of investing in passive energy efficiency measures, relative to a lowrisk investment that would guarantee a small return. In other words, it is the interest rate at which the homeowner would earn, should they choose not to invest in their home performance.

In Canada, the greatest guaranteed long term investment alternative for a typical homeowner would be a government bond. For the 2010 construction year, a bond with a 30 maturity period would average $3.73 \%$, with a low of $3.33 \%$ and a high of $4.07 \%$ (Bank of Canada, 2015). However, bond returns have showed steady decline in Canada over the past decade (Figure 5.6). For comparison, US FEMP life cycle cost assessments for Federal projects in 2014 used a discount factor of $3.0 \%$. The discount rate was calculated based on 12 month average market interest rates of long term Treasury Notes and Bonds (Rushing, Kneifel, \& Lavappa, 2014). In a recent study which assessed long term costs of house upgrades in Ontario, a discount factor of $2.0 \%$ was used (Dembo, 2011).

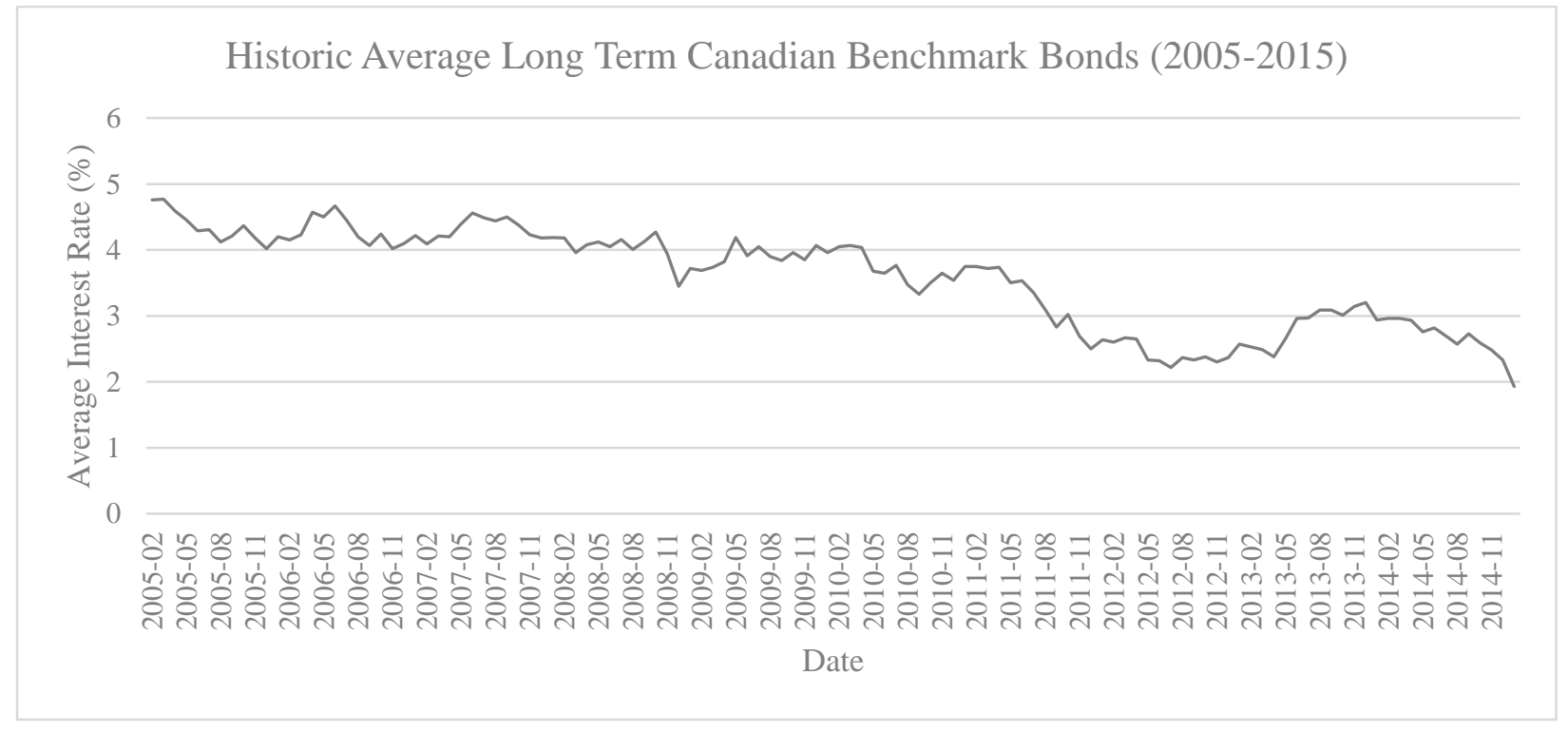

Figure 5.6: 2005-2015 Government of Canada Benchmark Bond interest rates for 30 year maturity period (Bank of Canada, 2015)

\section{FUEL COST ESCALATION}

Fuel costs from the case study house were obtained for the calibration year and included in the energy model to calculate annual utility costs. Effective natural gas costs for 2012, including supply to the utility, delivery to the site, and volume consumed, averaged $\$ 0.241$ per m3, plus \$20 
customer charge per billing period. Effective electricity costs for 2012, including usage, delivery, regulatory fees, and the Ontario Clean Energy rebate, averaged $\$ 0.168$ per $\mathrm{kWh}$. The simulation did not account for time-of-use activity (ie. off-peak, mid-peak, on-peak).

Fuel costs were adjusted to account for future price escalation. Inflation rates, generation capacity, local demand, import and export availability, and a number of other economic indicators are used by government agencies, banks, and utility suppliers to predict future fuel costs in the long term. Criticism of these economic predictions are out of the scope of this thesis. Escalation trends were also developed by interpolating historic local fuel costs. Average natural gas escalation varied from $0.1 \%$ to $4.2 \%$, and average electricity escalation varied from $1.2 \%$ to $2.6 \%$, as described below.

The National Energy Board (2007) predicted long term natural gas trends up to 2030 using continuing price trends and an array of other economic indicators. End use natural gas costs to residential customers per GJ in Ontario was predicted to escalate a year to year average of $0.1 \%$, with a low of $-6.7 \%$ and a high of $6.0 \%$ (Figure 5.7 ).

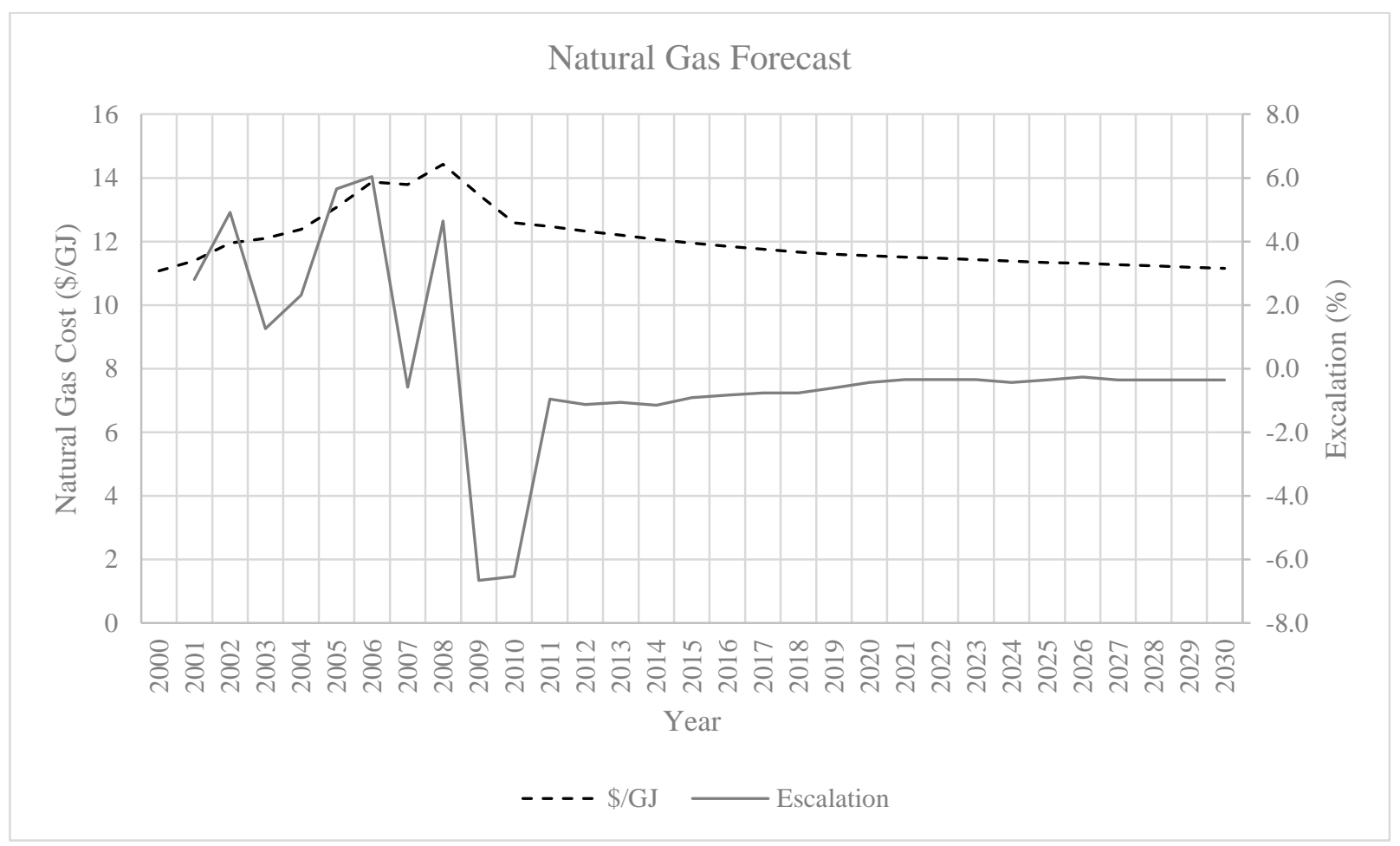

Figure 5.7: Predicted natural gas cost and escalation rate for Ontario until 2030 (National Energy Board, 2007) 
Historic residential natural gas prices were reported for Toronto by Statistics Canada (2012). For the period between 1989 and 2011, the natural gas unit price, excluding tax has seen an average year to year escalation of $4.2 \%$, with a low of $-17.4 \%$ and a high of $46.7 \%$ (Figure 5.8 ).

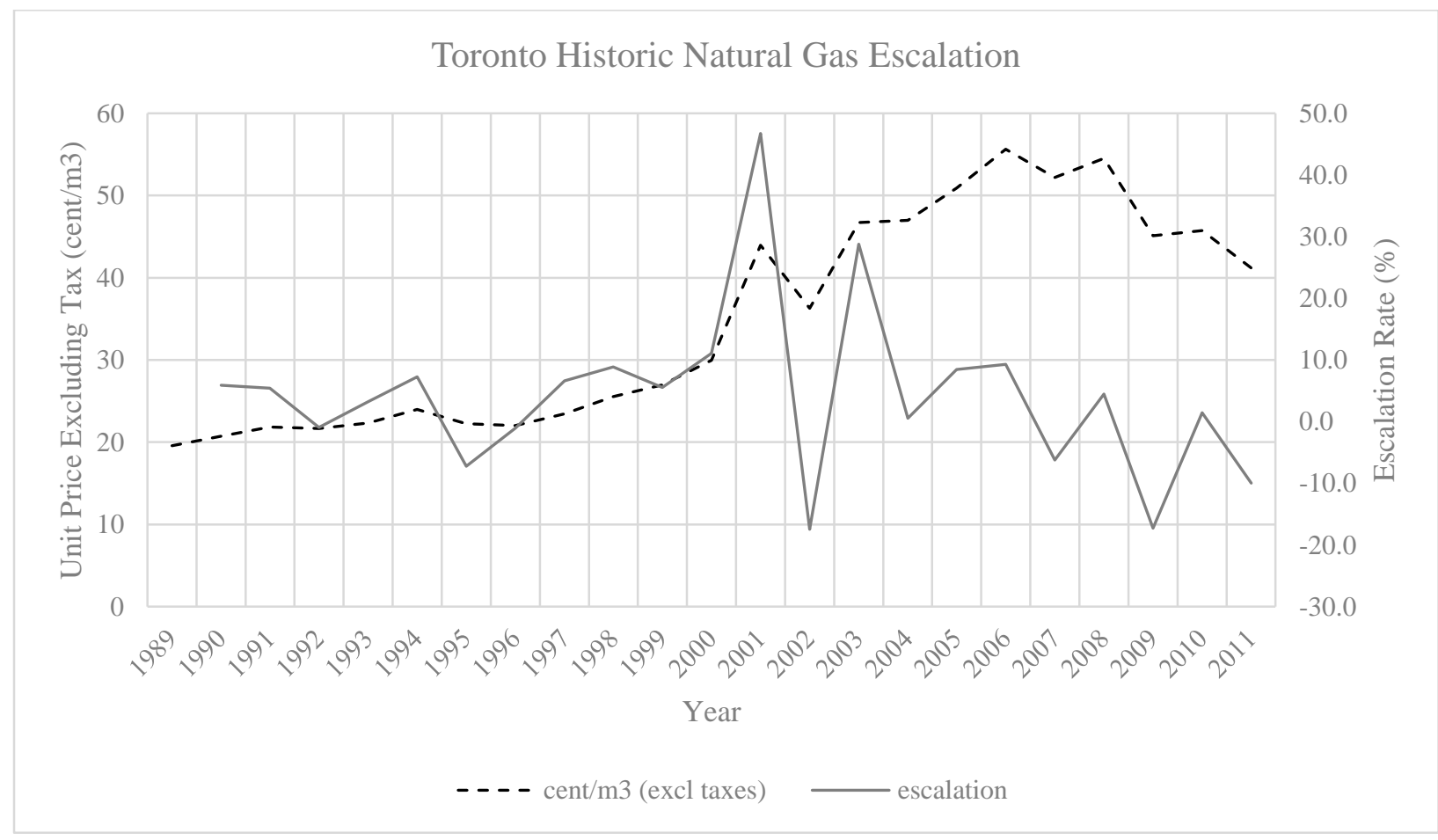

Figure 5.8: Natural gas price and escalation rate for Toronto from 1989 to 2011 (Statistics Canada, 2012)

For comparison, US federal building projects which undergo life cycle cost analysis must use the fuel escalation predictions provided by the Energy Information Administration (EIA) (Rushing, Kneifel, \& Lavappa, 2014). The natural gas escalation rates for northeast states, including Connecticut, Maine, New Jersey, New York, Pennsylvania, Rhode Island, and Vermont, have a year to year average of $1.3 \%$, with a low of $1.0 \%$ and a high of $1.6 \%$.

Electricity trends up to 2030 (National Energy Board, 2007), show that end use costs to residential customers per GJ in Ontario is predicted to escalate a year to year average of $1.2 \%$, with a low of $1.0 \%$ and a high of $-1.8 \%$ (Figure 5.9).

The Ontario Long Term Energy Plan reported a 20 year electricity bill forecast for typical residential houses using an average of $800 \mathrm{kWh}$ per month (Ontario Ministry of Energy, 2013). The projected year to year electricity escalation rate averaged $2.3 \%$, with a low of $-2.6 \%$ and a high of $10.1 \%$ (Figure 5.10). 


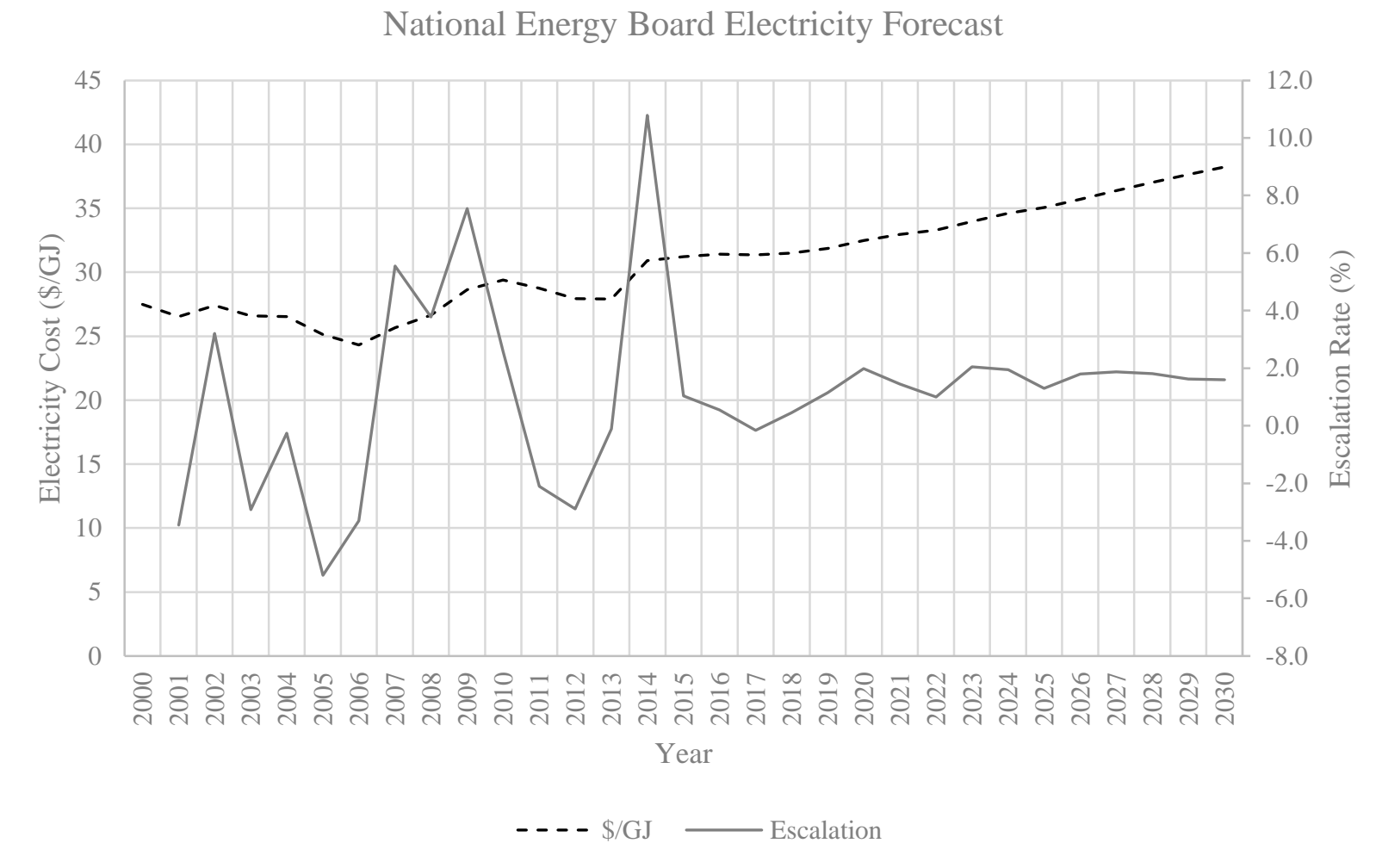

Figure 5.9: Predicted electricity cost and escalation rate for Ontario until 2030 (National Energy Board, 2007)

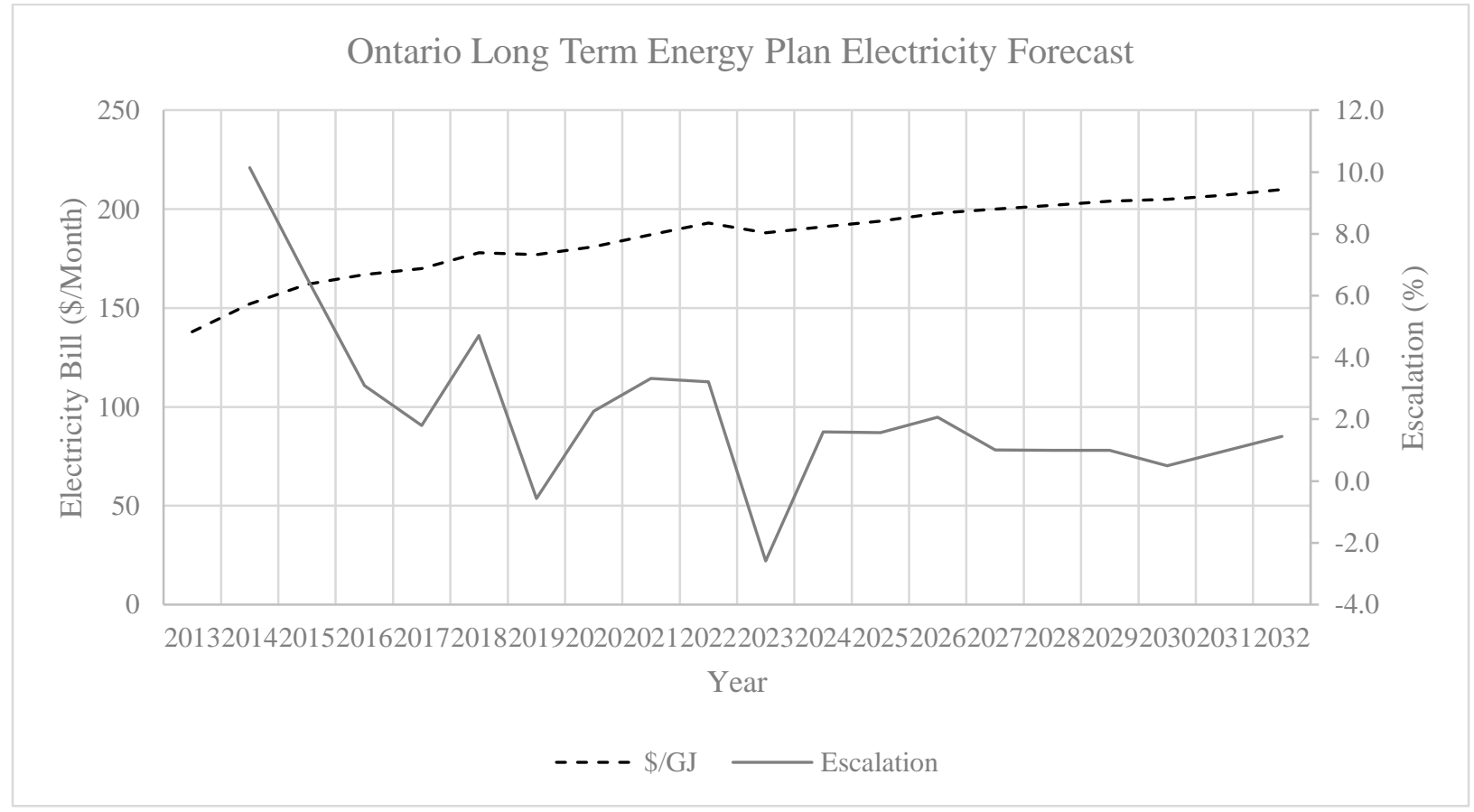

Figure 5.10: Predicted electricity cost and escalation rate for Ontario until 2032 (Ontario Ministry of Energy, 2013) 
Historic residential electricity prices were reported for Toronto by the Ontario Energy Board (2015). For the period between 2006 and 2014, the electricity base unit price, excluding tax and has seen an average year to year escalation of $2.6 \%$, with a low of $-5.3 \%$ and a high of $9.9 \%$ (Figure 5.11).

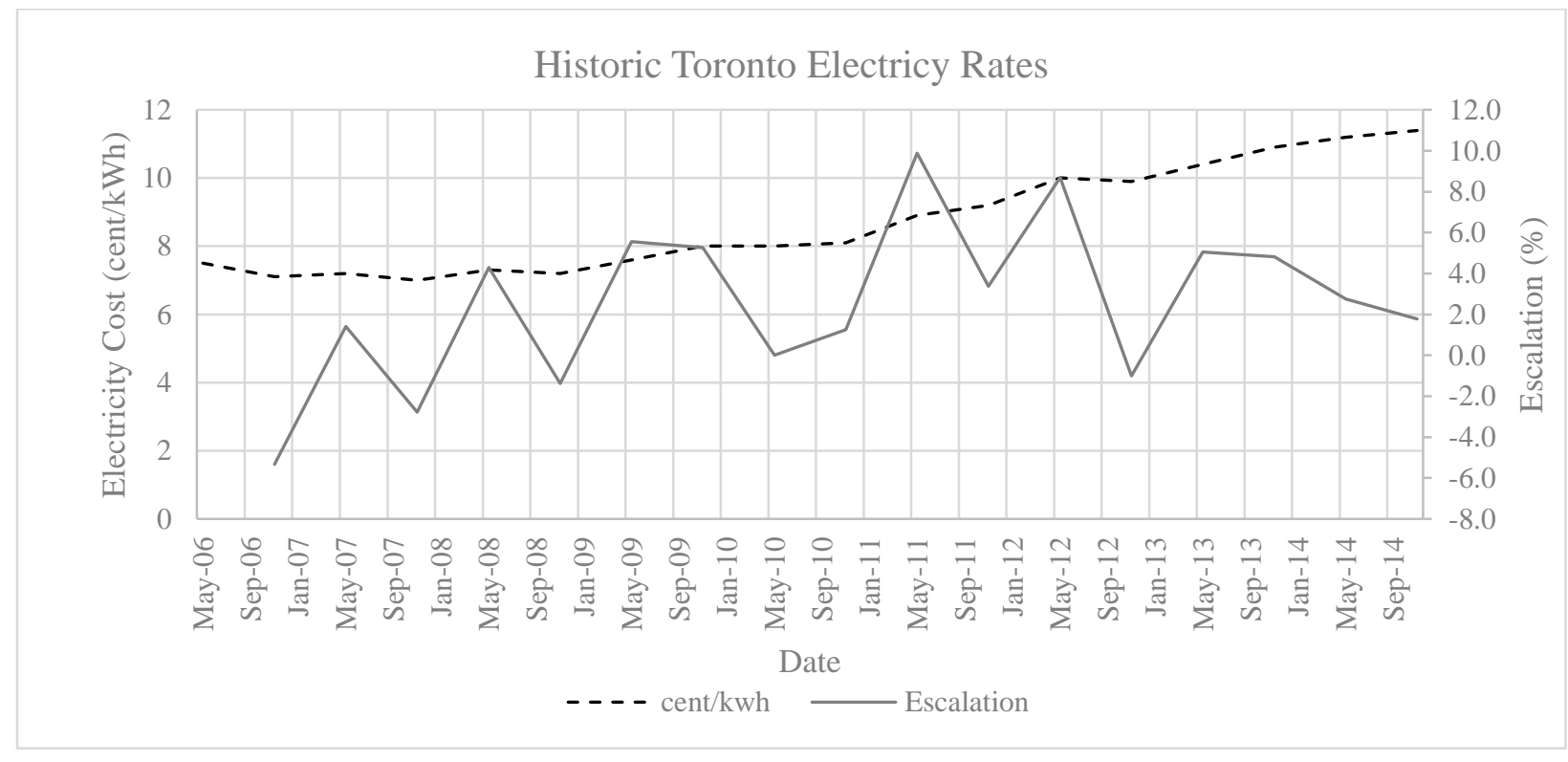

Figure 5.11: Electricity price and escalation rate for Toronto from 2006 to 2014 (Ontario Energy Board, 2015)

For comparison, the electricity escalation rates for northeast states, including Connecticut, Maine, New Jersey, New York, Pennsylvania, Rhode Island, and Vermont, have a year to year average of $1.1 \%$, with a low of $1.0 \%$ and a high of $1.2 \%$.

\section{MORTGAGE RATES}

The life cycle financial model used annual recurring costs to represent amortized payments over the mortgage length of the home (the EnergyPlus recurring cost objects could not be any shorter than a year). This allowed the incurred costs to be discounted for the appropriate year in the NPV calculation, rather than lumping all costs up front, creating a more accurate cash flow scenario that accounted for concurrent mortgage and utility payments. 2010 Average residential mortgage rates for 5 year fixed terms was $4.81 \%$ (CMHC, 2015). At the time of writing, private mortgage lenders offered 1 year term fixed mortgages at 2.24\% (TD Canada Trust, 2015). A down payment of $10 \%$ was assumed. Mortgage payments are were calculated using the following formula (Flynn, 2010): 


$$
\text { Monthly Payment }=P \frac{i(1+i)^{n}}{(1+i)^{n}-1}
$$

Where:

$$
\begin{array}{ll}
\mathrm{P}= & \text { Principal amount on loan after down payment } \\
\mathrm{i}= & \text { Monthly interest rate }(\text { ie. } 0.0481 / 12=0.004) \\
\mathrm{n}= & \text { Total number of payments }(\text { ie. } 12 \text { x } 30=360)
\end{array}
$$

Mortgage payments were calculated for each energy conservation upgrade. Monthly mortgage payments were summed to reflect annual mortgage payments were used as annual recurring costs by EnergyPlus. Quantity take offs and associated annuities are shown in Appendix C - Mortgage Cost Breakdown.

\section{$\underline{A S S U M P T I O N S}$}

For the life cycle cost calculations, it was assumed that all opaque envelope elements, including wall, roof, and slab insulation, and glazed envelope elements would last the 30 year test period without need for replacement, but that the ERV would need replacing after 20 years of service (National Association of Home Builders, 2007). To account for this, a non-recurring cost was built into the model equal to established construction cost, plus inflation, which was applied to the cash flows at 20 years.

It was assumed that no maintenance would be required to maintain service function of the envelope elements. Because the life cycle cost experiment was performed in relative costs, with respect to the baseline, it was assumed that any maintenance cost associated with ERV service would be required for all options and therefore neglected in the calculation. It was confirmed with the home owner that only filter cleaning is required periodically, which can be done without need for a service professional (R. Richman, personal communication, March 19, 2015).

\section{SIMPLE PAYBACK}

Simple payback was also monitored as an output in the optimization experiment. Simple payback was determined by dividing the incremental construction cost for the energy efficient 
measures by the incremental associated energy savings. For the calculation, the minimum performance package allowed by the $\mathrm{OBC}$ was used as a reference point from which to determine incremental cost and energy savings.

\subsubsection{Performance Function}

The second objective function in the optimization represents the energy performance of the building. The performance objective, or second dependent variable of the research, is the sum of the peak heating and cooling load of the case study house. Peak load was chosen as the primary indicator of performance because it is directly influenced by passive building features, which are the focus of this study. Peak load cannot be reduced by improving mechanical system efficiency or adding renewable energy production. Furthermore, peak load is one of the primary criteria targeted for Passive House certification.

A building load, in watts, is an instantaneous representation of a building's energy balance. All energy gains and losses, including solar, human, equipment, conduction, ventilation, and infiltration are arithmetically summed. The net balance is the load which must be met by the HVAC systems to maintain thermal comfort at the desired heating and cooling setpoints with acceptable levels of ventilation. Heating and cooling peak loads are calculated on one winter and one summer day which represents the climate's coldest and hottest expected temperatures, not considering statistical outliers. EnergyPlus calculates peak loads using the 'heat balance method' (US DOE, 2013d) as per ASHRAE guidelines (ASHRAE, 2005a).

Although Toronto is a heating dominated climate, the sum of the peak heating and cooling load was selected rather than peak heating alone. This was important because the neglect of cooling load can have negative repercussions on the comfort of the home. For example, abundant southern

glazing with high solar gain and low u-value can significantly reduce the heating load of a house but can lead to overheating problems even in the winter.

Throughout the progression of the optimization batches, energy use intensity (EUI) was recorded as a simulation outcome. Energy use intensity is a measure of the total site energy consumed in a year divided by the total area of the house. It includes all energy used for space heating and cooling, water heating, mechanical system operation, appliances, and plug loads. It is 
important to determine total energy consumption when considering on-site power generation requirements, and when normalized, EUI is commonly used for comparison between buildings.

Similarly, annual heating and cooling demand were calculated for each simulation run. These values only account for energy required for space heating or cooling. Like EUI, annual heating and cooling demand are effected not only by the passive energy saving features of a building but also by the active systems. For example, annual heating demand would be less for a design with a more efficient boiler. Annual heating and cooling demand were considered because they are primary criteria for Passive House certification and serve to directly calculate LCC through operating costs.

\subsection{Formulation of the Optimization Problem}

Optimization was performed using jEPlus, a batch simulation batch manager, and jEPlus+EA, an optimization processor built specifically to handle building optimization problems. jEPlus was developed in 2009 at De Montfort University, Leicester, UK, as an open source program on the Java platform to allow parametric batch simulations in EnergyPlus. More recent advancements, namely the addition of jEPlus+EA, allow building optimization using evolutionary algorithms (JEPlus, 2015). Specifically, the software uses the Non-dominated Sorting Genetic Algorithm II, a sub-classification of an evolutionary algorithm.

The jEPlus suite was chosen as the optimization engine for this study largely because it could be used 'out of the box' with minimal coding required while still offering all necessary functionality. The jEPlus suit offers a graphical user interface (GUI) and can perform parametric batch simulations or evolutionary optimizations through minimal wizard input and coding in the JavaScript Object Notation (JSON) programming language (European Computer Manufacturers Association, 2013).

The jEPlus parametric simulation handler requires a parameter tree, which is input into the GUI, weather file (.epw), a working EnergyPlus simulation file (.idf or .imf), and a control extension file (.rvi and/or .rvx). For this experiment, the simulation file was that which was calibrated against metered data using the Actual Meteorological Year weather data for 2012. The parameter tree defines the input parameters that are to be changed during simulation batches. Each parameter item includes a search tag and possible values that are to be executed over multiple 
simulation runs. The simulation input text file was modified so that the parameter inputs to be tested were replaced by a search tag. In this way, when simulations were executed, the search tag defined in jEPlus would find the matching search tag in the EnergyPlus file and replace the value with the specified input value. The extension control files define the simulation results to be extracted from EnergyPlus 'meter', 'variable', and 'SQL' (Structured Query Language) output files. The extension file allows output to be collected and reported in a common tabular (.csv) format. Output data from these sources can also be combined, sorted, and manipulated using logic statements, functions, or mathematical operators to define custom variables. The example figure below (Figure 5.12) illustrates the procedure.

For a modified EnergyPlus insulation object, defined by:

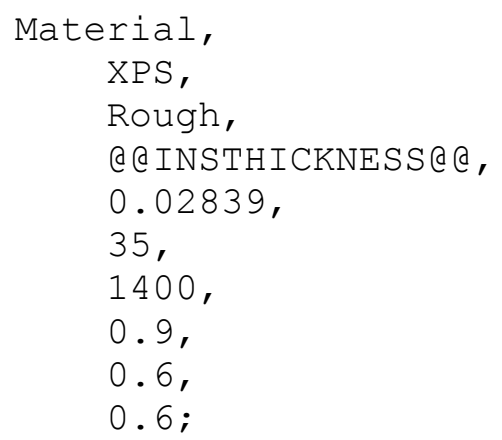

$$
\begin{aligned}
& \text { !- Name } \\
& \text { !- Roughness } \\
& \text { !- Thickness }\{\mathrm{m}\} \\
& \text { !- Conductivity }\{\mathrm{W} / \mathrm{m}-\mathrm{K}\} \\
& \text { !- Density }\{\mathrm{kg} / \mathrm{m} 3\} \\
& \text { !- Specific Heat }\{\mathrm{J} / \mathrm{kg}-\mathrm{K}\} \\
& \text { !- Thermal Absorptance } \\
& \text { !- Solar Absorptance } \\
& \text { !- Visible Absorptance }
\end{aligned}
$$

With a search tag and parametric values:

$$
\begin{aligned}
& \text { @ @INSTHICKNESS@ } \\
& \{0.000,0.025,0.051,0.076,0.102\}
\end{aligned}
$$

And an output extension file:

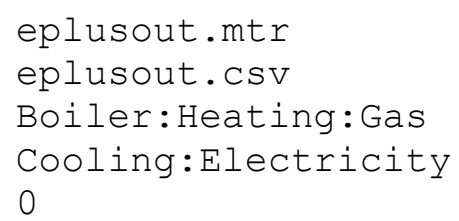

jEPlus would execute 5 distinct simulation runs where insulation thickness for XPS construction elements would correspond to the specified thickness values. Cooling electricity and heating gas consumption would be extracted and reported for each simulation run.

\section{Figure 5.12: jEPlus parametric search string example}


Parametric input may be defined for any EnergyPlus object and may be continuous or discrete. For this experiment, only discrete values were chosen because they represent commercially available products (e.g. rigid board insulation cannot be bought in increments less than $1 / 2$ ”). When multiple parameters and options are defined in a project, jEPlus can systematically perform simulations until all possible parameter combinations are tested. However, simulation runs can quickly add up with only a few parameter options. To perform a simulation for every parametric combination (ie. brute force method) within the design space, jEPlus would require approximately 3,969 hours on a local computer with $2.60 \mathrm{GHz}$ i5-3230M processor and $4.00 \mathrm{~GB}$ RAM. This was deemed unacceptable for this research.

As discussed in in the literature review, optimization algorithms allow objective function minimums to be determined within a given search space requiring far fewer simulation runs (Naboni, Maccarini, Korolija, \& Zhang, 2013). The jEPlus suite offers an optimization environment, called jEPlus+EA, which optimizes a jEPlus parametric batch simulation project using an evolutionary algorithm. It offers a GUI and handles multiple objective functions to determine a Pareto front of optimal solutions displayed as a visual scatter plot or exportable table of values. Objective functions are defined in the project extension files and are composed of EnergyPlus output values, as they were in jEPlus. Users can control the optimization parameters including population size, mutation rates, and crossover rates.

Preliminary simulation batch times were sped up by employment of the jEPlus Simulation Server (JESS) (Energy Simulation Solutions , 2015). JESS is a platform, installed on the 256-core De Montfort University cluster, built to run building simulations remotely. The server can run many jEPlus simulations simultaneously allowing significantly increased speed. For this research, the online server performed approximately 10 simulations per minute. The JESS online service costs $£ 0.25$ per CPU hour on the DMU cluster, which equals approximately $\$ 0.02$ CAD per simulation for the experiment's EnergyPlus file.

Final simulation batches were performed on a local 32-core machine at Ryerson University which was available for this research free-of-charge. For this simulation model, the local machine performed approximately 7 simulations per minute.

The majority of the experiment was performed using the calibrated model, where conditions approximated reality as closely as possible to maintain experiment accuracy. This included as- 
built air tightness and manual cooling control, modeled with a cooling setpoint of $28 \mathrm{C}$, and referenced the real conditioned space area. However, for the interest of the Passive House community, one batch cycle was run using inputs normally used for modelling in the Passive House certification process. These changes included Passive House level air-tightness at 0.6 $\mathrm{ACH} 50$, a cooling setpoint of $25 \mathrm{C}$, and reference to the treated floor area (TFA). All other inputs remained the same as the calibrated model.

TFA is a measurement of the area within the thermal envelope, from "plaster to plaster", calculated according to the German Floor Area Ordinance, and is the reference area used by the Passive House standard to determine peak heating/cooling load per area $(10 \mathrm{~W} / \mathrm{m} 2)$, annual heating/cooling demand per area $(15 \mathrm{kWh} / \mathrm{m} 2 \mathrm{a})$, and primary energy demand per area (120 $\mathrm{kWh} / \mathrm{m} 2 \mathrm{a}$ ) (Passive House Institute, 2007). Stairwells, landings, window niches, and other rooms with height less than $1 \mathrm{~m}$ are not counted as part of the TFA. Rooms with height between $1 \mathrm{~m}$ and $2 \mathrm{~m}$ are counted with $50 \%$ utilization factor, and secondary spaces within the envelope such as mechanical rooms are counted with $60 \%$ utilization factor. A detailed description can be found in the Passive House Planning Package (2007). Recently, the PHIUS technical committee amended the definition of the TFA in order to simplify the calculation procedure (Wright, Klingenberg, \& Pettit, 2014). The new internal conditioned floor area (iCFA) includes all conditioned floor area for all spaces over $7 \mathrm{ft}$ high, including stairwells and interior partitions, measured from the interior surface of the thermal envelope (typically interior drywall).

The calculated iCFA for the case study house was $220.3 \mathrm{~m} 2$, or about $79 \%$ of the total area measured to exterior dimensions. For comparison, the TFA calculated in accordance with PHI guidelines for the case study house was $189.5 \mathrm{~m} 2$, or about $68 \%$ of the gross area. The updated iCFA was used for this part of the experiment. Due to geometry simplifications in the energy model, the gross area is about $20 \mathrm{~m} 2$ larger than that calculated from as-built drawings. Therefore, the iCFA used for calculation was $79 \%$ of the energy model's total area, or $237.2 \mathrm{~m} 2$.

Table 5.7 summarizes the optimization batches performed for the experiment with various possible values for unknown future parameters. The following batches represent: (1) the reference case using the calibrated model and best possible predicted assumptions found in literature, (2) a low discount rate case using reduced rate of guaranteed investment return, (3) a high fuel cost escalation case using continued projections from historic trends, (4) a low mortgage case using 
possible 1-year term rates, (5) a Passive House case where the cooling setpoint is reduced to 25C, air leakage rate constrained to $0.6 \mathrm{ACH} 50$ (at no cost penalty), and reference area set to iCFA to align the model parameters to those required for Passive House certification. For Case 5, the performance objective function was changed from total peak load (W/m2) to annual energy savings (\%/yr) to better reflect the BEopt optimization output used in relevant North American Passive House studies (Kruger, 2012; Wright, Klingenberg, \& Pettit, 2014). No constraints were imposed on the optimization algorithm. Other variables, namely annual heating and cooling demand, peak heating and cooling load, EUI, construction cost, simple payback, and annual energy savings, were tracked during the optimization process.

Table 5.7: Building optimization batch simulation parameters for predicted future financial rates

\begin{tabular}{cccccccc}
\hline Case & $\begin{array}{c}\text { Discount } \\
\text { Rate }(\%)\end{array}$ & $\begin{array}{c}\text { Electricity } \\
\text { Escalation } \\
\text { Ave }(\%)\end{array}$ & $\begin{array}{c}\text { NG } \\
\text { Escalation } \\
\text { Ave }(\%)\end{array}$ & $\begin{array}{c}\text { Mortgage } \\
(25 \text { yr) }\end{array}$ & $\begin{array}{c}\text { Htg/Clg } \\
\text { Setpoints } \\
(\text { C) }\end{array}$ & $\begin{array}{c}\text { Infiltration } \\
\text { (ACH50) }\end{array}$ & $\begin{array}{c}\text { Reference } \\
\text { Area (m2) }\end{array}$ \\
\hline 1 & 0.0373 & 0.012 & 0.001 & 0.0481 & $20 / 28$ & 1.46 & 302.07 \\
2 & $\mathbf{0 . 0 2 0 0}$ & 0.012 & 0.001 & 0.0481 & $20 / 28$ & 1.46 & 302.07 \\
3 & 0.0373 & $\mathbf{0 . 0 2 6}$ & $\mathbf{0 . 0 4 0}$ & 0.0481 & $20 / 28$ & 1.46 & 302.07 \\
4 & 0.0373 & 0.012 & 0.001 & $\mathbf{0 . 0 2 2 4}$ & $20 / 28$ & 1.46 & 302.07 \\
$5^{*}$ & 0.0373 & 0.012 & 0.001 & 0.0481 & $\mathbf{2 0 / 2 5}$ & $\mathbf{0 . 6}$ & $\mathbf{2 3 7 . 1 6}$ \\
\hline
\end{tabular}

${ }^{*}$ Performance objective function for optimization changed from total peak load (W/m2) to annual site energy savings (\%/yr)

\subsection{Optimization Results and Discussion}

\subsubsection{Peak Load Optimization}

\section{REFERENCE CASE}

Figure 5.13 illustrate the simulation points for the reference financial parameters (Case 1). The red points represent the Pareto front of non-dominated solutions. The grey points represent the other dominated configurations within the design space. The figure highlights the data point representing the real case study house (blue point) (Table 5.8). It has an incremental LCC of $\$ 0$ and a total design load of $23.6 \mathrm{~W} / \mathrm{m} 2$, with reference to gross model area. Any of the design points within the delineated area, down and left of the as-built house point, would have lower total design load for equal or less LCC. In other words, this set of solutions represent 'better' designs than the as-built house. The remaining points outside of the delineated area would have worse performance for at least one objective function. 


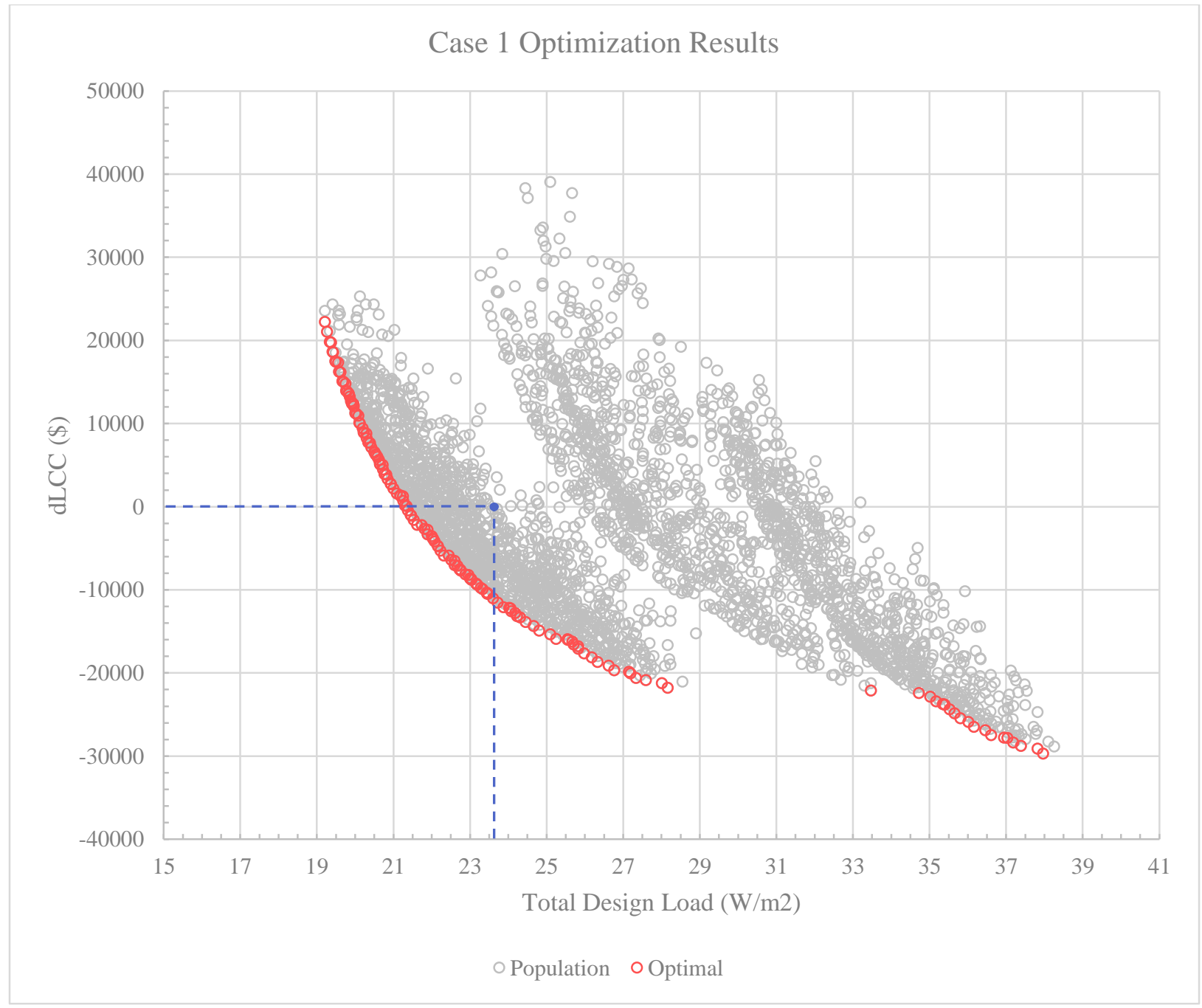

Figure 5.13: Reference parameter (Case 1) multi-objective optimization for incremental LCC and total design load with as-built point highlighted

Table 5.8: data point information representative of real case study house

\begin{tabular}{cc}
\hline & Calibrated Model \\
\hline dLCC $(\$)$ & 0 \\
Total LCC $(\$)$ & 125,563 \\
Total Load $(\mathrm{W} / \mathrm{m} 2)$ & 23.6 \\
Htg Load $(\mathrm{W} / \mathrm{m} 2)$ & 15.8 \\
Clg Load $(\mathrm{W} / \mathrm{m} 2)$ & 7.8 \\
Htg Demand $(\mathrm{kWh} / \mathrm{m} 2 \mathrm{a})$ & 27.9 \\
Clg Demand $(\mathrm{kWh} / \mathrm{m} 2 \mathrm{a})$ & 0.1 \\
EUI $(\mathrm{kWh} / \mathrm{m} 2 \mathrm{a})$ & 65.5 \\
\hline
\end{tabular}


Of the 351 design solutions found that performed better than the as-built house, 42 points in the subset created the Pareto front. These 42 points are denoted in red in Figure 5.13 within the delineated area down and left of the highlighted blue point.

The results of the optimization, with respect to total peak load, identified a number of redesign options which would theoretically perform better than the as-built house, for the given LCC scenario. Looking at frequency of efficiency measures for the 42 Pareto points of the subset of designs which improve upon the as-built design, the following trends were observed:

- Each optimal point had thicker above grade wall insulation thickness than the as-built house. This is likely because of the significant wall area of the three storey house, relative to its footprint, making conduction loss through the walls one of the major contributors to energy performance. For the homeowner, however, increased insulation thickness meant less livable floor area and more capital cost so a reasonable limit was put on the as-built house. No optimization or feasibility study was performed by the home owner before construction. However, the parameter combination still performed $90.3 \%$ as well as the optimal solution for the same life cycle cost.

- Optimal below grade wall insulation thickness and roof insulation thickness varied largely. Below grade wall thermal resistance ranged from 3.76 to $6.59 \mathrm{~m} 2 \mathrm{~K} / \mathrm{W}$ and roof thermal resistance ranged from 6.04 to $10.35 \mathrm{~m} 2 \mathrm{~K} / \mathrm{W}$. The performance of the design did not rely heavily on these thicknesses, as it did for above grade wall thickness. This is likely due to the reduced area for conduction loss, compared to that of the walls.

- Each design option had $25 \mathrm{~mm}$ of sub-slab XPS. This trend indicates that slab insulation is important to include in the design, but that efficacy quickly diminishes with increased thickness. According to the results, the as-built home over-insulated the basement slab.

- Each optimal design selected the as-built glazing package, namely EcoInsulating SC75 glazing custom fit into Inline 325 frames. This window package had exceptionally low uvalue, especially for the cost, but also had low SHGC. This trend may point to the importance of u-value in this building's performance, where-as it was originally posited that the low SHGC may reduce the selection of this window package within the optimization environment. However, it may also point to the fact that the bespoke windows were obtained by the homeowner for less cost than other windows of equal 
performance. For example, the OptiWin European window with a comparable u-value cost almost twice as much as the EcoInsulating/Inline combination.

- Each optimal design used the lowest performing ERV unit. This trend seems to indicate the diminished performance improvements relative to the steep incremental cost increase. The UltimateAir Recoupaerator seems to be especially costly, including a number of expensive add-ons which are typically included with other units. Including a parameter option with no ERV unit was considered, since it is allowed in some minimum packages in the OBC SB-12. However, exclusion of the ERV would have meant an entirely different ventilation system design for the house, rather than balanced-direct design, and would have deviated model behavior too far from the calibrated configuration to be considered reliable.

- Sub-fronts of dominated solutions were produced behind the Pareto front of nondominated solutions. These sub-fronts are made of parameter grouping which all share the same glazing type.

The Pareto front highlighted 42 parameter combinations that perform 'better' than the asbuilt house in design load and LCC. To differentiate between the points and choose the most favorable design among the points, a secondary evaluation of initial construction cost could be used.

While there is still room for improvement in the design, the renovation targets were met. The home owner set out to reach an annual EUI of less than $75 \mathrm{kWh} / \mathrm{m} 2$ and air tightness of less than 1.5 ACH50 (Richman, 2011). The relevant performance metrics were $65.5 \mathrm{kWh} / \mathrm{m} 2$ and 1.46 ACH50 respectively.

\section{COST RELATIONSHIPS}

A typical cash flow diagram is shown in Figure 5.14 that depicts the financial model used to calculate LCC. NPV adjustments are not shown in the diagram, though they were factored into the LCC calculation. Negative cash flows are shown for a 10\% down payment, 30 years of mortgage payments at $4.81 \%$, an ERV replacement cost after 20 years, and 30 years of utility payments which escalate over time. Although they do not generate revenue in reality, implied positive cash flows are shown for annual energy savings, relative to the OBC SB-12 minimum energy costs. 
The comparison highlights the fact that energy saved is small compared to additional investment cost due to low energy costs.

Throughout the experiment, a number of other output variables, other than the objective functions were tracked within the optimization environment. Two such building cost variables, construction cost and simple payback, were recorded during the procedure, although not used as an objective to minimize. Figure 5.15 shows the relationship between incremental LCC and initial construction cost. Initial construction cost is the total cost of material and installation for the selected energy conservation measures only. However, in the financial model, the entire construction cost was not paid up front. Instead, the model mirrors a typical mortgage where a down payment is given up front while the remainder is amortized over many years at a given rate of interest (Figure 5.14). Figure 5.16 shows the relationship between incremental LCC and simple payback. Simple payback is calculated by dividing the incremental construction cost for the energy conservation measures by the incremental utility cost savings. The incremental construction cost and utility costs are both with respect to the code built minimum package.

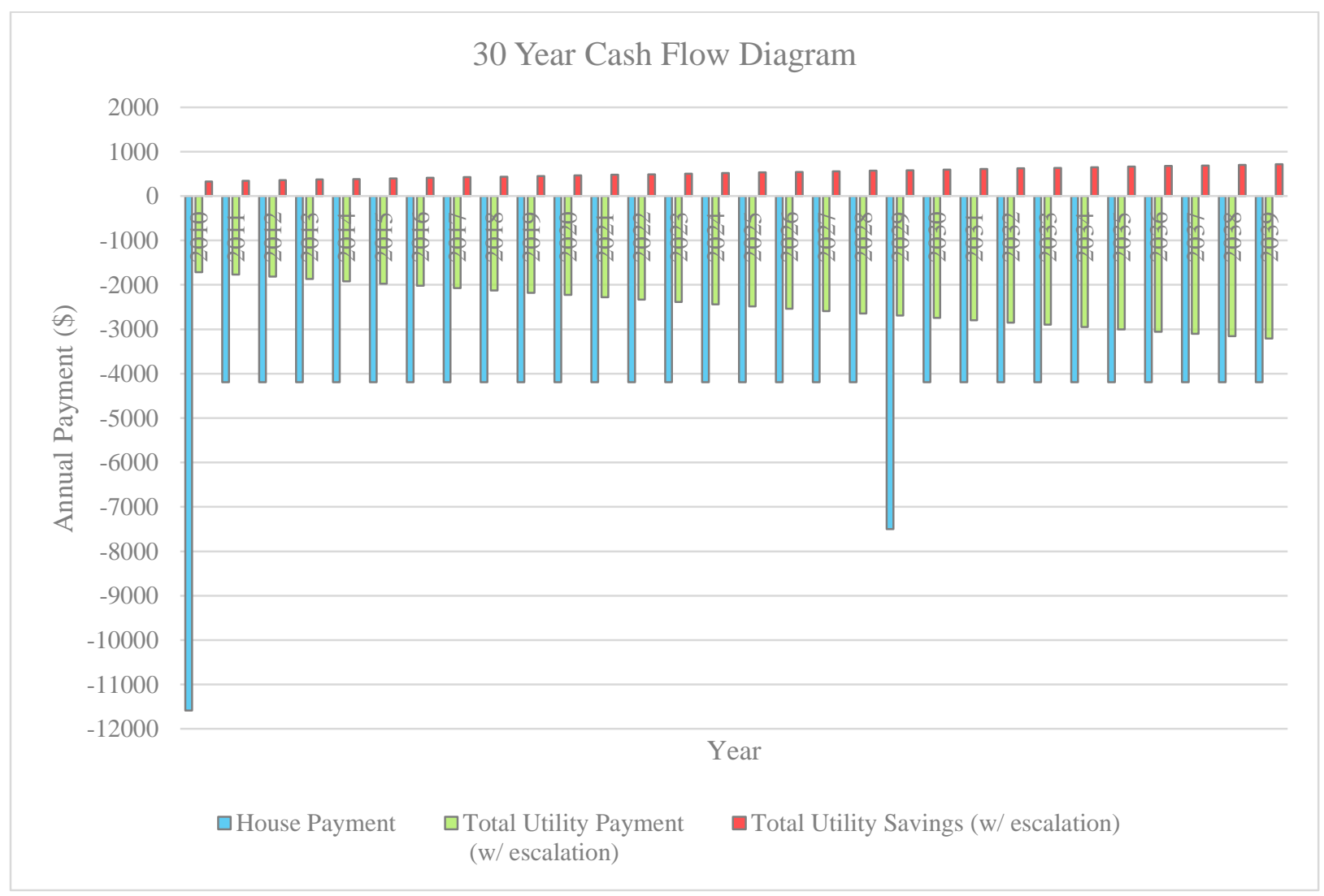

Figure 5.14: Example cash flow diagram over 30 year life cycle 


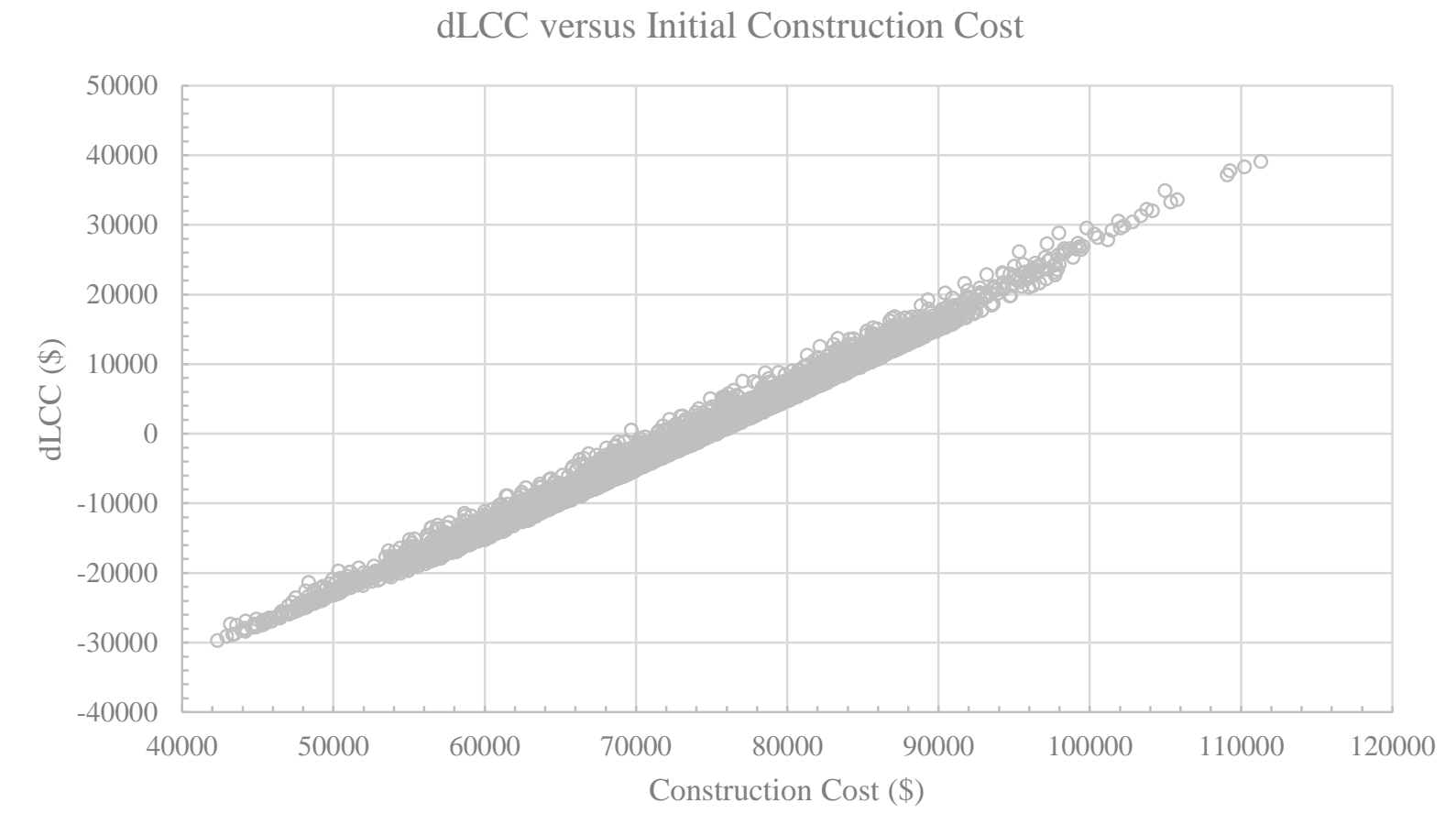

Figure 5.15: Reference parameter (Case 1) multi-objective optimization for incremental LCC and total design load showing construction cost of ECMs versus dLCC

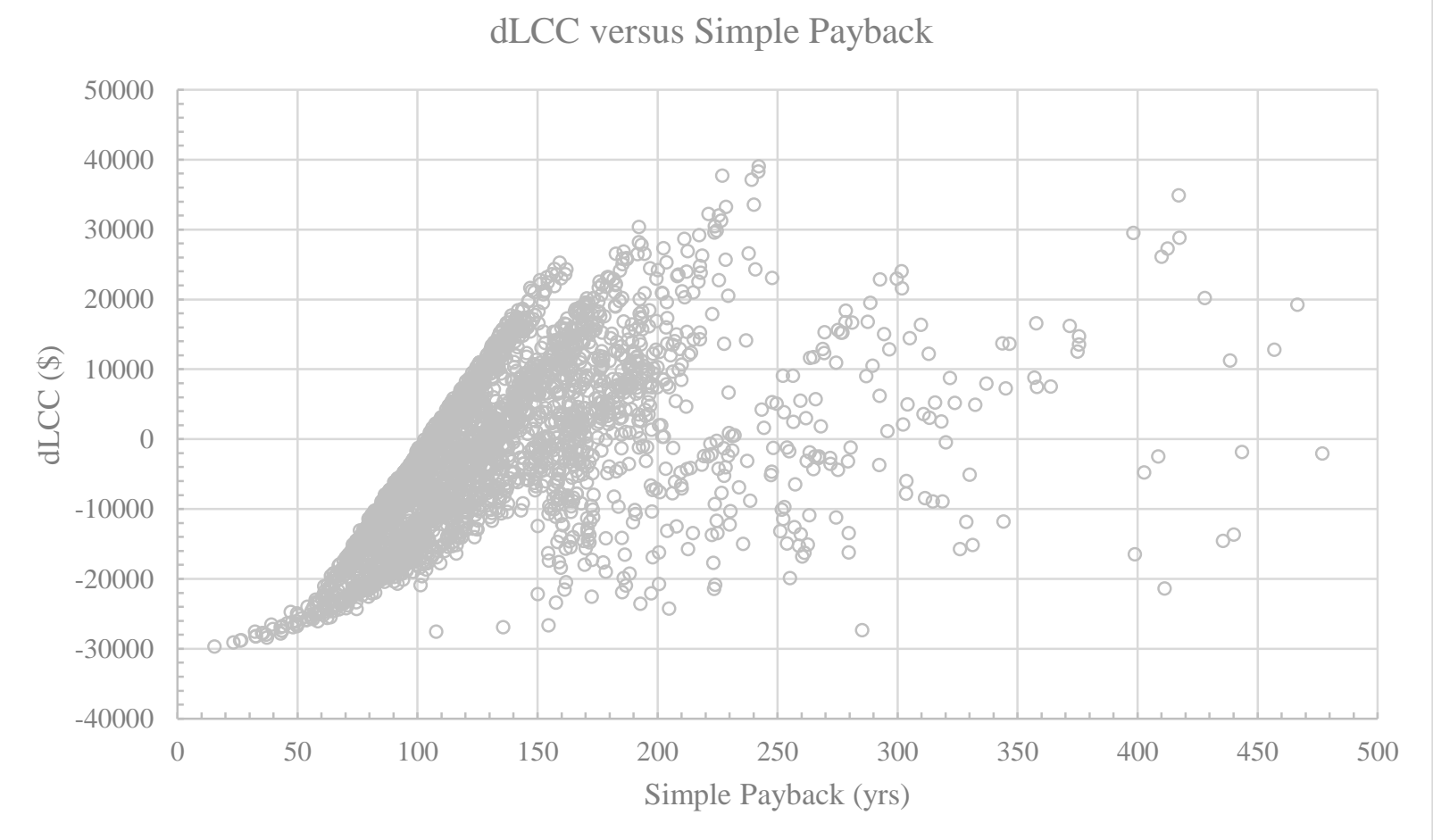

Figure 5.16: Reference parameter (Case 1) multi-objective optimization for incremental LCC and total design load showing simple payback versus dLCC 
The relationship between the LCC and the initial construction costs begins to quantify the known dependence of the LCC on material costs in this research context. Figure 5.15 shows strong correlation between LCC and total investment in energy conservation measures and that initial construction cost is a good indicator of total cost over the lifetime of a building, for the current economic conditions. This correlation shows that initial investment drives the LCC much more than the energy saving potential. This is likely because local utility costs are so cheap relative to the price of high performance building components. The predicted escalation trends for natural gas over the next 30 years is very modest, which does not support the argument for passive energy saving measures from an economic point of view. In short, the possible annual utility cost savings were on the order of $\$ 100$ 's while the corresponding investments were on the order of $\$ 1000$ 's.

Figure 5.16 shows a weak relationship between LCC and simple payback than that of initial construction cost. Simple payback was tracked as a variable within the optimization trend, but was deemed an unrepresentative indicator of long term LCC. The results from the simple payback analysis showed very long payback periods. Again, this is because the incremental energy savings were an order of magnitude lower than the incremental investment costs required. If only simple payback were considered for decision making, investment in passive energy saving measures would be deemed highly unattractive because there is no positive cash flow from passive measures, as there would be from a PV system for example.

\section{PREDICTED FINANCIAL PARAMETERS}

Figure 5.17, Figure 5.18, Figure 5.19, and Figure 5.20 illustrate the comparative simulation points for the reference case (Case 1), low discount rate (Case 2), high fuel escalation (Case 3), and low mortgage interest rate (Case 4) respectively. Various optimization batches were tested to determine the sensitivity of the driving parameters in the financial model. Different values were tested for these inputs because the parameters are likely to change in the future. The as-built house configuration is highlighted on each chart as a blue point. 


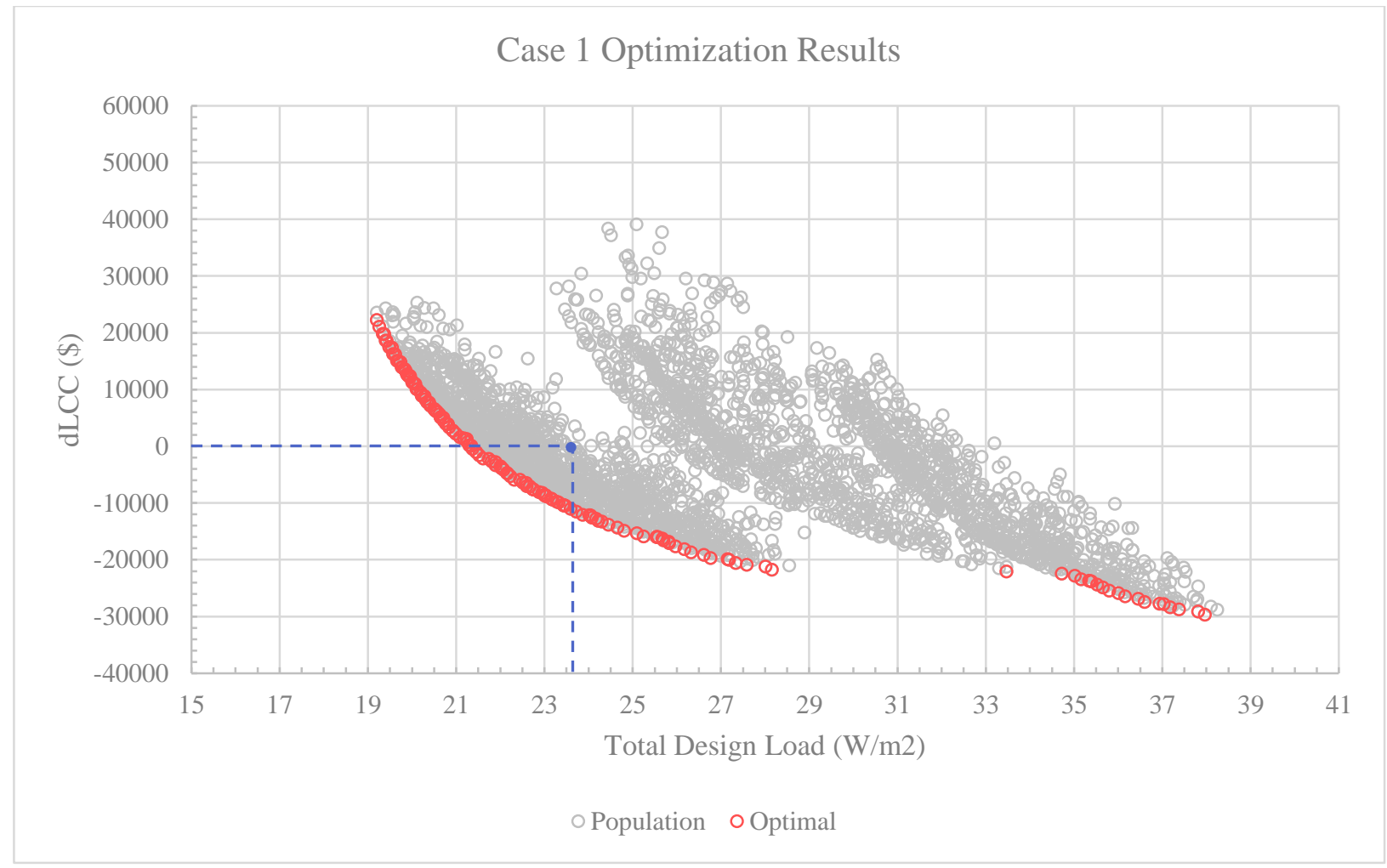

Figure 5.17: LCC and total peak load multi-objective optimization results for Case 1 (reference)

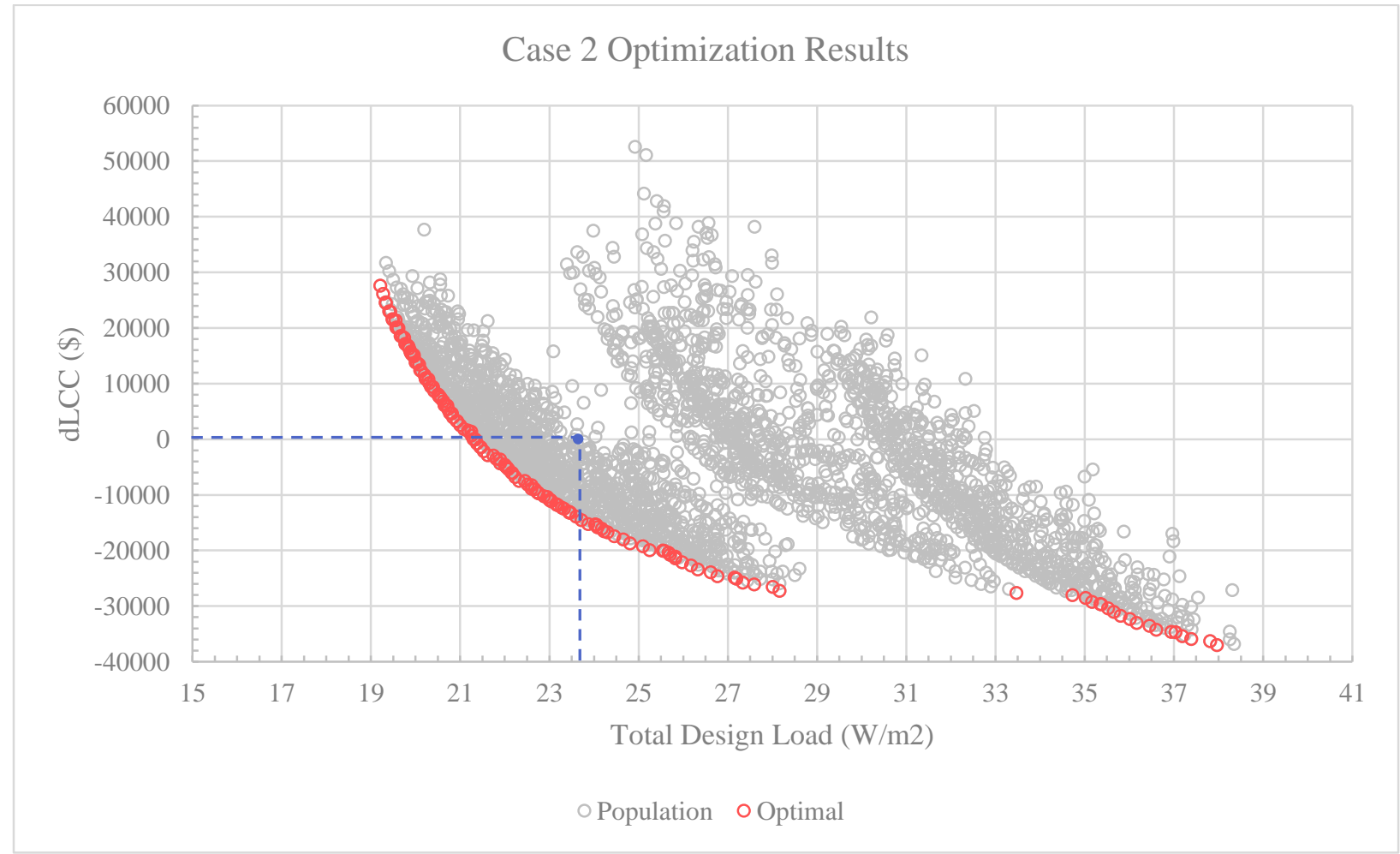

Figure 5.18: LCC and total peak load multi-objective optimization results for Case 2 (low discount) 
Case 3 Optimization Results

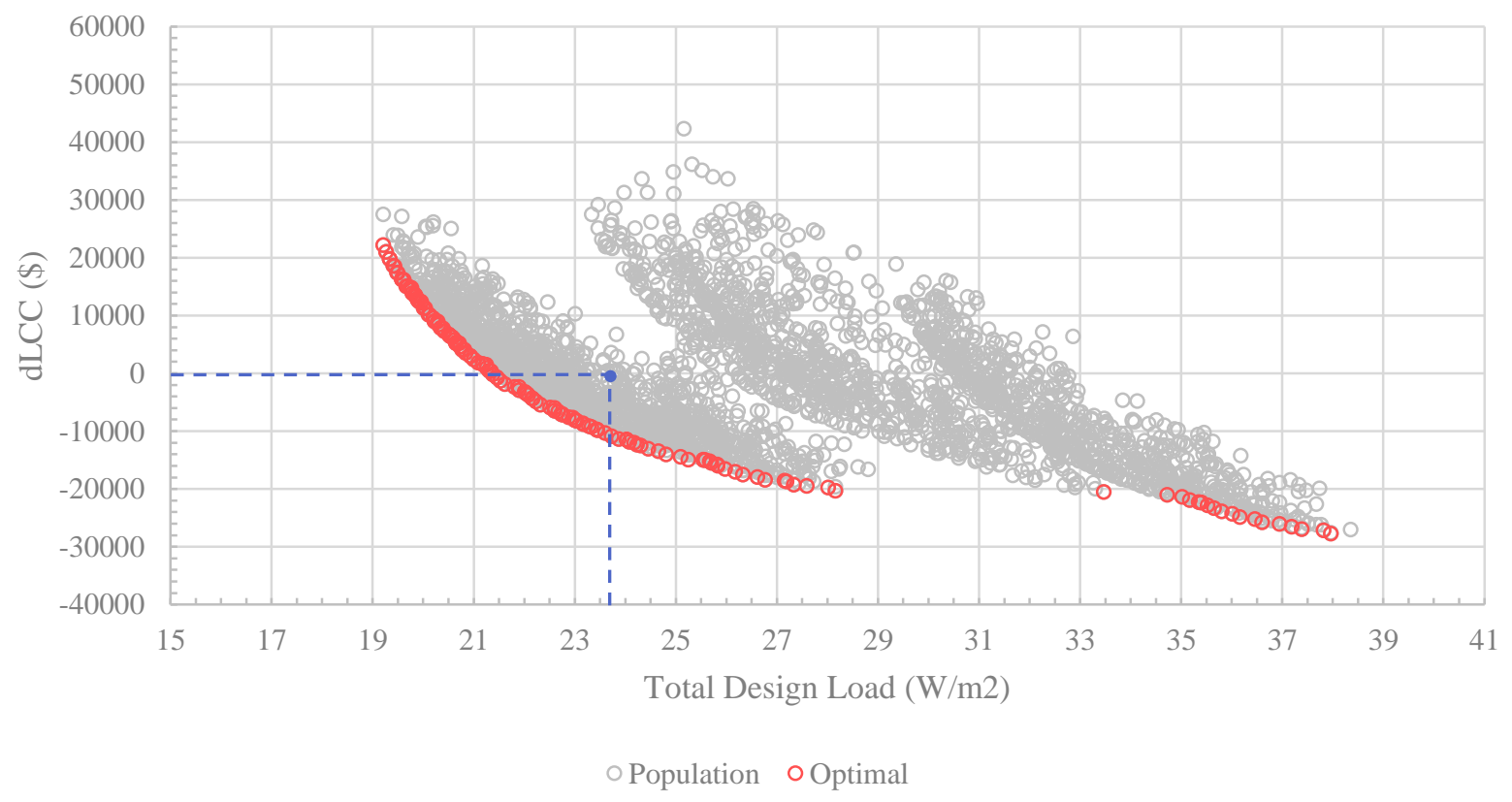

Figure 5.19: LCC and total peak load multi-objective optimization results for Case 3 (high escalation)

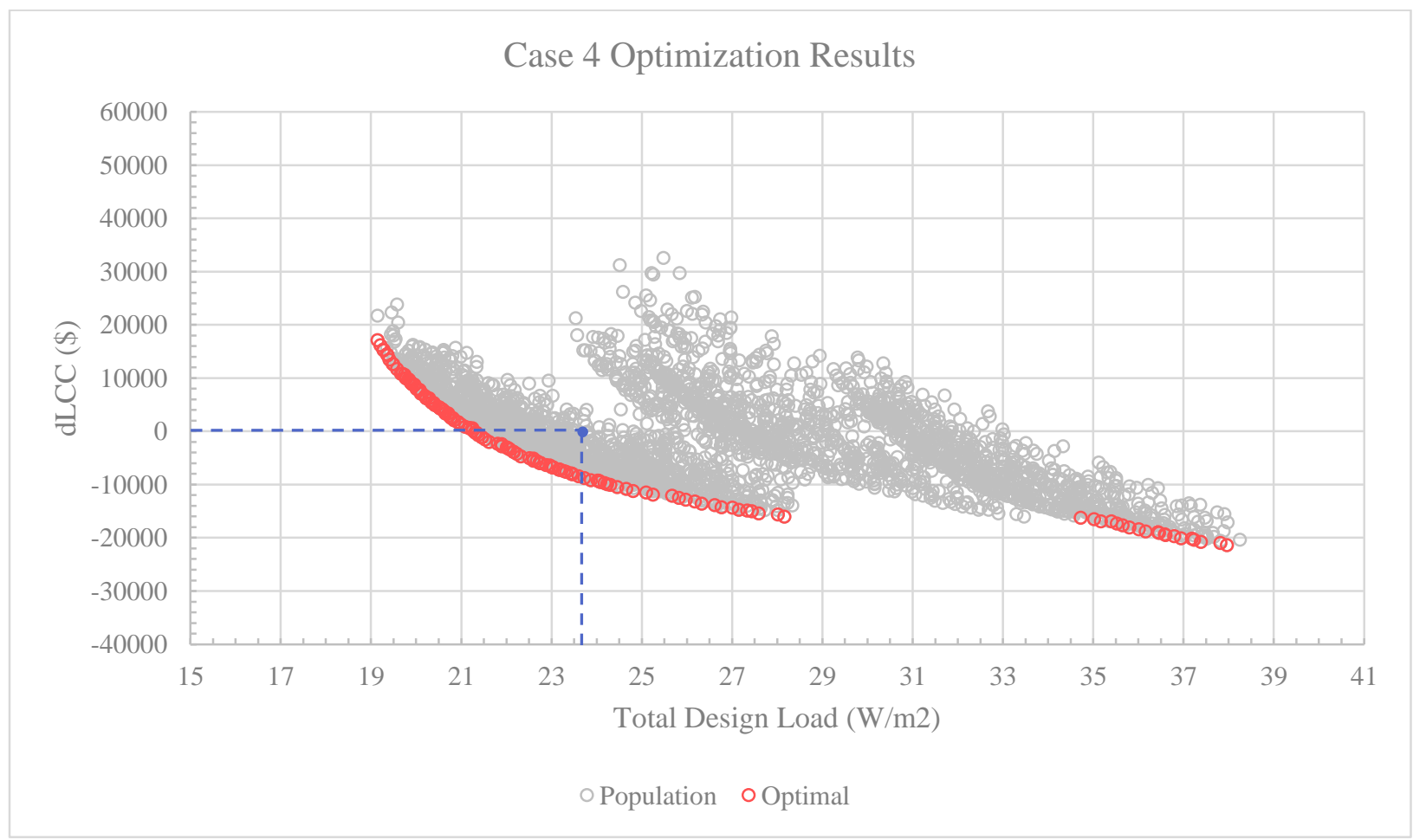

Figure 5.20: LCC and total peak load multi-objective optimization results for Case 4 (low mortgage) 
Table 5.9 summarizes the optimal points found by the genetic algorithm for the financial objective function (dLCC), while Table 5.10 summarizes optimal points found for the performance objective function (total design load). For Cases 1-4, the reference area for normalization is gross model floor area. For each case, the reference LCC was recalculated since it changed according to financial prediction parameters.

Table 5.9: Case 1 - 4 optimal simulated design points for minimized dLCC

\begin{tabular}{ccccc}
\hline & $\begin{array}{c}\text { Case 1 } \\
\text { (reference) }\end{array}$ & $\begin{array}{c}\text { Case 2 } \\
\text { (low discount) }\end{array}$ & $\begin{array}{c}\text { Case 3 } \\
\text { (high escalation) }\end{array}$ & $\begin{array}{c}\text { Case 4 } \\
\text { (low mortgage) }\end{array}$ \\
\hline dLCC (\$) & $-29,698$ & $-37,058$ & $-27,762$ & $-21,416$ \\
Total LCC (\$) & 85,674 & 107,621 & 93,366 & 74,578 \\
Total Load (W/m2) & 38.0 & 38.0 & 38.0 & 38.0 \\
Htg Load (W/m2) & 23.1 & 23.1 & 23.1 & 23.1 \\
Clg Load (W/m2) & 14.8 & 14.8 & 14.8 & 14.8 \\
Htg Demand (kWh/m2a) & 59.6 & 59.6 & 59.6 & 59.6 \\
Clg Demand (kWh/m2a) & 1.4 & 1.4 & 1.4 & 1.4 \\
EUI (kWh/m2a) & 97.5 & 97.5 & 97.5 & 97.5 \\
\hline
\end{tabular}

Table 5.10: Case 1 - 4 optimal simulated design points for minimized total peak design load

\begin{tabular}{ccccc}
\hline & $\begin{array}{c}\text { Case 1 } \\
\text { (reference) }\end{array}$ & $\begin{array}{c}\text { Case 2 } \\
\text { (low discount) }\end{array}$ & $\begin{array}{c}\text { Case 3 } \\
\text { (high escalation) }\end{array}$ & $\begin{array}{c}\text { Case 4 } \\
\text { (low mortgage) }\end{array}$ \\
\hline dLCC $(\$)$ & 22,221 & 27,543 & 22,129 & 17,073 \\
Total LCC $(\$)$ & 137,592 & 172,222 & 143,257 & 113,068 \\
Total Load (W/m2) & 19.2 & 19.2 & 19.2 & 19.2 \\
Htg Load (W/m2) & 12.5 & 12.5 & 12.5 & 12.4 \\
Clg Load $(\mathrm{W} / \mathrm{m} 2)$ & 6.7 & 6.7 & 6.7 & 6.7 \\
Htg Demand $(\mathrm{kWh} / \mathrm{m} 2 \mathrm{a})$ & 26.3 & 26.3 & 26.3 & 26.1 \\
Clg Demand $(\mathrm{kWh} / \mathrm{m} 2 \mathrm{a})$ & 0.1 & 0.1 & 0.1 & 0.1 \\
EUI $(\mathrm{kWh} / \mathrm{m} 2 \mathrm{a})$ & 62.8 & 62.8 & 62.8 & 62.6 \\
\hline
\end{tabular}

The sensitivity analysis of the varying predicted financial variables affected the 'steepness' of the Pareto optimal design points as expected. The lowest LCC was produced by the optimization environment when a low mortgage interest rate was assumed. This is because a low mortgage rate 
produced the cheapest annuity costs for high performance building components, which have the greatest impact on total LCC, as described above. The highest LCC was predicted when the discount rate was low. This is because discount rate is the primary driver of future cash flows in the NPV assessment. When the discount rate approaches zero, future cash flows equal present flows, which are more costly according to the time value of money theory. Whereas with a high discount rate, future cash flows are worth less than present cash flows. Therefore, when the discount rate is high, the sum of the cash flows over the 30 year test period yields a lower total compared to the sum of 30 year cash flows with low discount.

Figure 5.21, Figure 5.22, Figure 5.23, and Figure 5.24 graph the optimization batches plotting dLCC with respect to annual energy savings, rather than total peak load. The value referenced in each case $(8.9 \%)$ is the point where maximum energy savings, relative to code minimum, can be achieved before incremental LCC rises for additional energy savings.

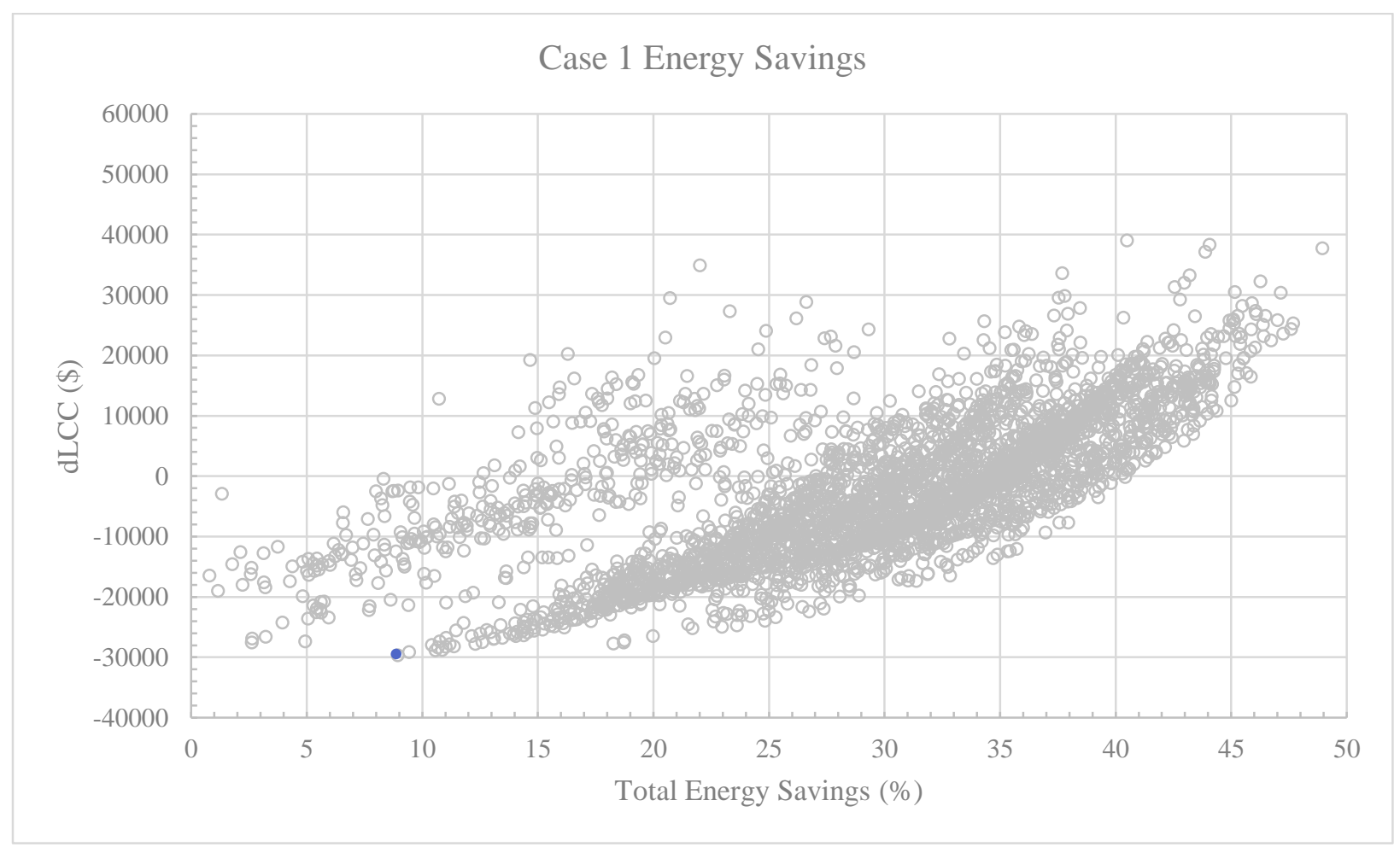

Figure 5.21: Parametric results illustrating the relation between LCC and annual energy savings for optimization Case 1 (reference) highlighting maximum feasible energy savings 
Case 2 Energy Savings

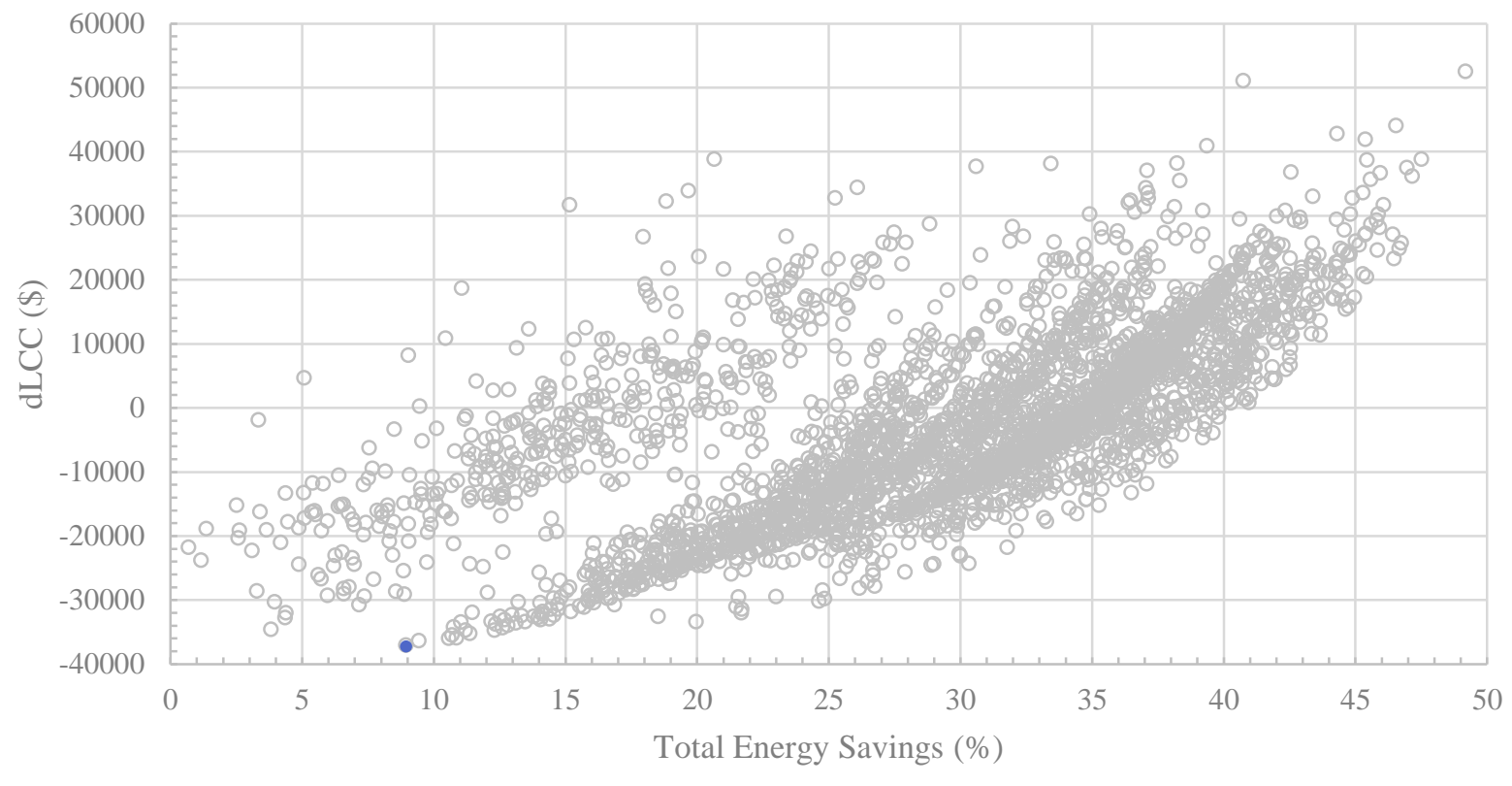

Figure 5.22: Parametric results illustrating the relation between LCC and annual energy savings for optimization Case 2 (low discount) highlighting maximum feasible energy savings

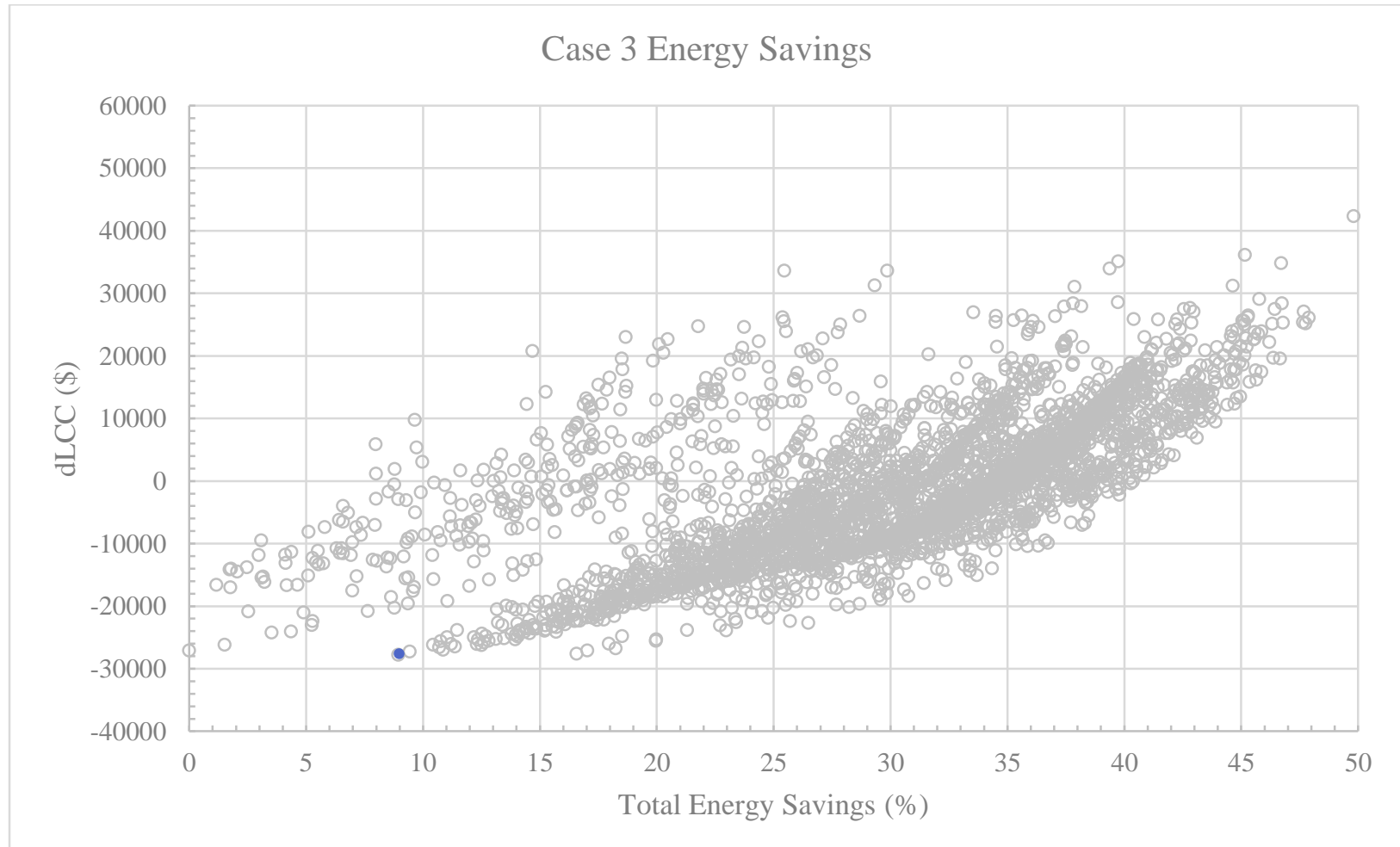

Figure 5.23: Parametric results illustrating the relation between LCC and annual energy savings for optimization Case 3 (high escalation) highlighting maximum feasible energy savings 


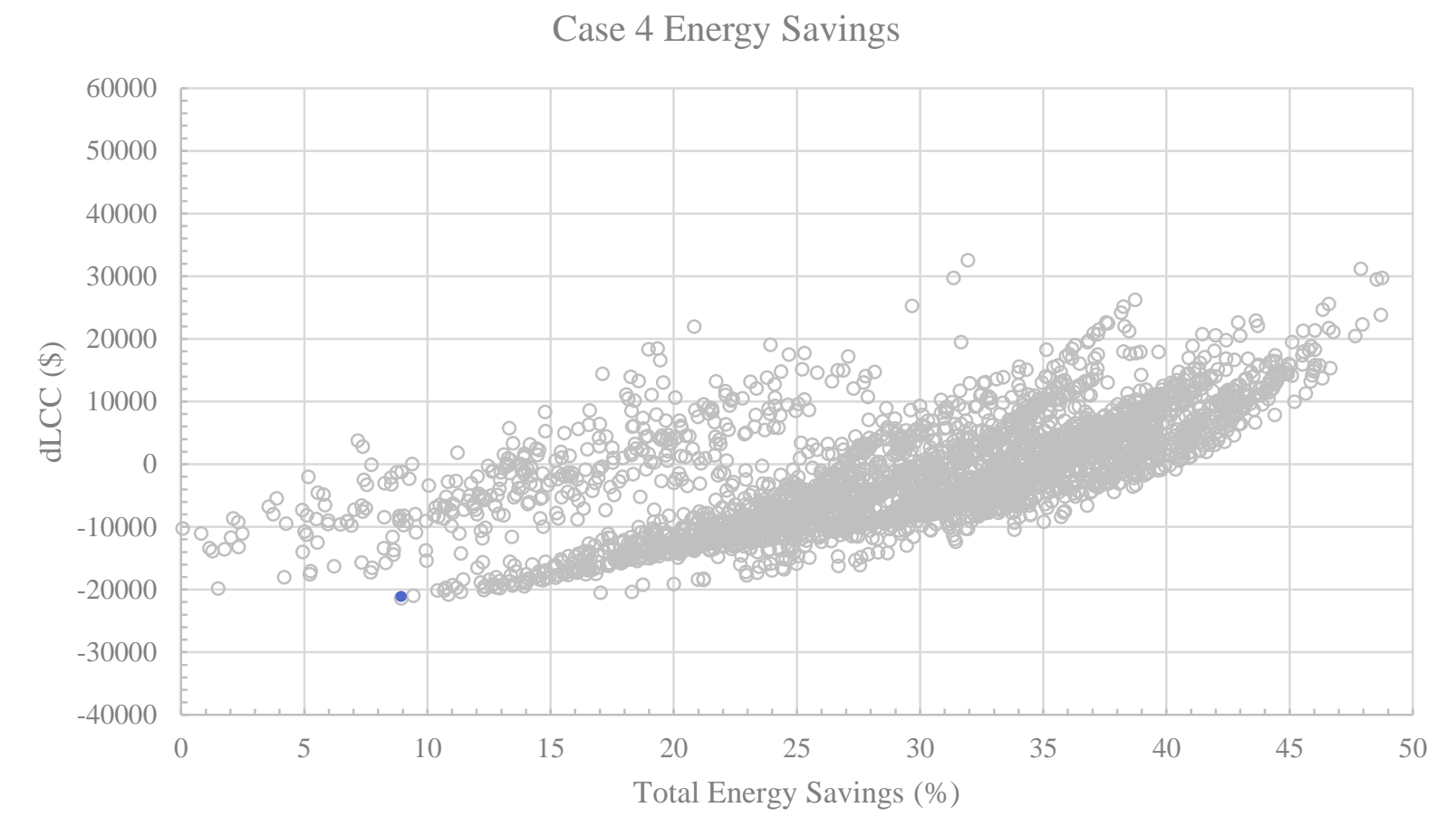

Figure 5.24: Parametric results illustrating the relation between LCC and annual energy savings for optimization Case 4 (low mortgage) highlighting maximum feasible energy savings

Table 5.11 describes the energy saving components which correspond to the points of maximum feasible energy savings highlighted above.

Table 5.11: Assemblies for maximum annual energy savings and minimal dLCC for Case $1-4$

\begin{tabular}{ccccccc}
\hline Case & $\begin{array}{c}\text { AG Wall } \\
\text { CCSF }\end{array}$ & $\begin{array}{c}\text { BG Wall } \\
\text { CCSF } \\
\text { thickness } \\
(\mathrm{mm})\end{array}$ & $\begin{array}{c}\text { Roof CCSF } \\
\text { thickness } \\
\text { thickness }(+\end{array}$ & $\begin{array}{c}\text { Slab XPS } \\
\text { XPS c.i. } \\
\text { thickness }) \\
(\mathrm{mm})\end{array}$ & $\begin{array}{c}\text { Window } \\
(\mathrm{mm})\end{array}$ & $\begin{array}{c}\text { PRV } \\
\text { Unit }\end{array}$ \\
\hline as-built & 140 & 140 & $241+51$ & 102 & EcoInsulating & UltimateAir \\
$1-4$ & 102 & 102 & 127 & 25 & JeldWen & Aldes Aeromatic \\
\hline
\end{tabular}

When the plotted variables were changed to show dLCC and annual energy savings (Figure 5.21, Figure 5.22, Figure 5.23, Figure 5.24), the results exposed the point at which annual energy savings, relative to OBC SB-12 minimum, can be justified financially over the lifetime of the building. It is important to note the shape of the plotted curve. Near the minimum dLCC, the curve 
is very shallow and there are a number of points which approximate the lowest possible lifetime cost. Therefore, some human judgment was introduced to determine the point at which the maximum energy savings could be realized for roughly the minimum dLCC, before the curve steepened.

Based on this assessment, it was determined that improvements of $8.9 \%$ could be justified economically based on the LCC assessment. These improvements included only passive features for the case study house. Therefore, results may differ using other housing typologies, construction assemblies, or occupancy patterns. It is expected that greater total energy savings could be justified if the mechanical system were included in the parametric options. Furthermore, the calibrated simulation model operated at a heating setpoint of 20C and a cooling setpoint of $28 \mathrm{C}$ to model the manual operation of the house's cooling system, leading to a negligible annual cooling demand. Therefore, it is expected that greater energy savings would be recommended if the simulation used a heating setpoint of $22 \mathrm{C}$ and a cooling setpoint of $24 \mathrm{C}$, as per local residential mechanical design recommendations (Heating, Refrigeration, and Air Conditioning Institute of Canada, 1996).

Of the four cases explored, the low mortgage case led to the cheapest total LCC. This is because cost of efficiency measures contributed to LCC so significantly. However, it is not entirely accurate to compare the different cases relative to one another since the parameter variations were not normalized. For example, the low discount rate experienced a change from $3.73 \%$ to $2.00 \%$ whereas the high escalation case experienced a natural gas escalation of $0.1 \%$ to $4.0 \%$ and an electricity escalation of $1.2 \%$ to $2.6 \%$. It would be unfeasible to run optimization batches for each incremental step in financial variable. Considering all financial variables, the ideal scenario for passive investment would be a future with high escalation, low mortgage rates, and poor personal investment opportunities, meaning low discount rate.

The optimization environment was used to optimize the simulation model simultaneously for life cycle cost and total peak load. Optimization experiments were performed, using these objectives, for Case 1 to Case 4. Table 5.12 shows the number of total simulations performed and the generation at which convergence was reached. The NSGA-II progressed with a population size of 30 , a crossover rate of 1.0 , and a mutation rate of 0.2 . High crossover rate, at or near 1.0, is recommended so many fit solutions merge, and low mutation rate is recommended, so the algorithm doesn't behave randomly in a trial and error manner. Population size should be high for 
more design variables (jEPlus, 2015). Although, the population size was set to 30 simulations per generation, some generations would populate as few as 9 simulations per generation for unknown reasons. jEPlus+EA does not stop automatically when convergence is detected, so for the optimization batches performed in this study, the algorithm was allowed to run for 200 generations. Convergence is reached when the algorithm is satisfied that it has found a solution set within the search space that has adequately minimized the objective functions. More practically, convergence is reached in when the number of optimal solutions stops increasing. Since this number is approached asymptotically, convergence was defined as the generation in which $90 \%$ of Pareto optimal solutions were found, although optimal trends appear much sooner than this.

Table 5.12: Case 1 - 4 simulations and convergence points

\begin{tabular}{ccc}
\hline Case & Total Simulations & Convergent Generation \\
\hline 1 & 3228 & 94 \\
2 & 3077 & 71 \\
3 & 3236 & 62 \\
4 & 3143 & 74 \\
\hline
\end{tabular}

As seen in the Figures produced by the optimization environment, the genetic algorithm was able to efficiently explore a large number of design possibilities within the search space and produce distinct Pareto fronts. To fully evaluate the optimizing efficacy of the genetic algorithm, a full factorial parametric optimization should have been performed for one of the optimization batches. Doing so would have explored the entire 119,070 combination design space. However, this exploration was unfeasible for this study as it would have taken approximately 13 days of simulation time on a local computer, or cost over $\$ 2,000$ to perform remotely on the JESS.

\subsubsection{Annual Energy Savings Optimization}

\section{PASSIVE HOUSE CASE ADJUSTMENTS}

The optimization environment was used to optimize an adjusted version of the calibrated model (Case 5) simultaneously for life cycle cost and annual site energy savings, whereas Cases 1-4 were optimized while the performance objective function was total peak load. For Case 5, a 
total of 4216 unique simulations were executed over 200 genetic algorithm generations. Algorithm convergence was reached in 153 generations.

For Case 5, the reference area for normalization is iCFA, the calibrated model of the case study house was adjusted so that air-tightness was increased to $0.6 \mathrm{ACH} 50$, and the cooling setpoint was reduced to $25 \mathrm{C}$, since these values significantly affect the performance of the model and would be used for Passive House certification modelling. The air-leakage rate would have to be field tested for certification. Although it is unlikely that the case study house would ever reach 0.6 ACH50 (the owner has made many efforts), it is important for this hypothetical Passive House scenario since air-tightness is central to the design philosophy. The predicted financial parameters for the LCC model were the same as for the original reference case (Case 1).

The objective of this procedural step was to create a reference for the procedure used by the PHIUS technical committee to establish climate-specific Passive House standards in North America (Wright, Klingenberg, \& Pettit, 2014). As discussed before, this procedure used BEopt to determine least cost energy efficiency packages. The study defined a typical American house, employing all electric systems, for reference and used a modified set of Passive House model inputs. The most significant change was the adjustment to the TFA calculation, to the new iCFA. Air tightness remained constant at $0.6 \mathrm{ACH} 50$ for the entirety of the optimization. BEopt performed sequential search optimization to minimize life cycle cost while maximizing site energy savings.

The optimization batch is plotted (Figure 5.25) and the optimal point for each objective function described below (Table 5.13). Figure 5.25 also highlights, in blue, the point of least LCC. For the adjusted parameters in Case 5, which attempted to match those outlined by the PHIUS technical committee, and the given case study house in the local climate and economic conditions, the point at which maximal energy savings could be economically justified is $33 \%$. Predicted financial parameters, such as discount rate, fuel escalation, or mortgage rates, were not varied. However, based on the previously observed trends, it is likely that greater energy savings would be recommended under conditions of low discount rate, high fuel escalation, and low mortgage rates. As discussed for the other cases, the curve near the minimal dLCC was shallow and there were many point roughly at the bottom. Therefore, the point of recommended energy savings is the point of greatest energy savings before the curve begins to rise steeply. 
Table 5.13: Case 5 optimal simulated design points for minimized dLCC and annual energy savings

\begin{tabular}{cccc}
\hline & $\begin{array}{c}\text { Adjusted as-built } \\
\text { house }\end{array}$ & Minimized dLCC & $\begin{array}{c}\text { Maximized annual } \\
\text { energy savings }\end{array}$ \\
\hline dLCC $(\$)$ & 0 & $-28,830$ & 46,842 \\
Total LCC $(\$)$ & 116,022 & 87,193 & 162,864 \\
Annual Energy Savings $(\%)$ & 45.9 & 33.4 & 56.1 \\
Htg Load (W/m2) & 14.5 & 23.2 & 10.7 \\
Clg Load (W/m2) & 14.0 & 22.5 & 18.7 \\
Htg Demand (kWh/m2a) & 25.4 & 42.4 & 9.1 \\
Clg Demand (kWh/m2a) & 1.8 & 3.6 & 4.5 \\
EUI (kWh/m2a) & 74.8 & 92.1 & 60.7 \\
\hline
\end{tabular}

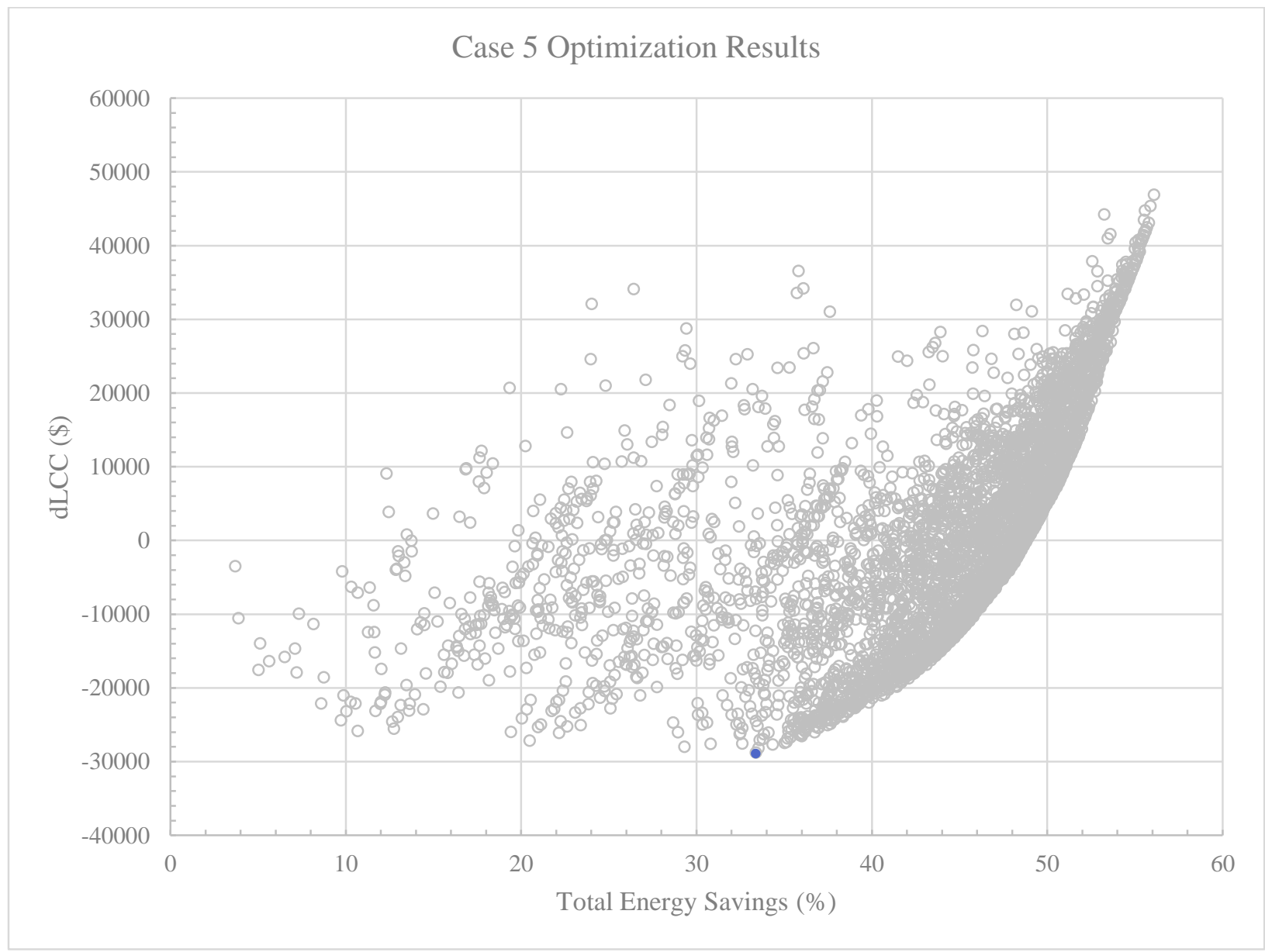

Figure 5.25: Passive House/BEopt comparison (Case 5) multi-objective optimization for incremental LCC and incremental annual energy savings highlighting point of minimal LCC 
The point of minimized dLCC is the point at which the PHIUS technical committee would theoretically set the climate-dependent performance standard. The assembly for the recommended standard is shown in Table 5.14.

Table 5.14: Case 5 assembly configuration for minimized dLCC relative to reference

\begin{tabular}{cccc}
\hline & As-built house & $\begin{array}{c}\text { Adjusted as- } \\
\text { built house }\end{array}$ & $\begin{array}{c}\text { Minimal } \\
\text { dLCC }\end{array}$ \\
\hline AG Wall CCSF thickness (mm) & & 140 & 102 \\
BG Wall CCSF thickness (mm) & 140 & 140 & 102 \\
Roof CCSF thickness (+ XPS c.i. thickness) (mm) & $241+51$ & $241+51$ & 152 \\
Slab XPS thickness (mm) & 102 & 102 & 76 \\
Window Package & EcoInsulating & EcoInsulating & JeldWen \\
ERV Unit & UltimateAir & UltimateAir & Aldes \\
Air Tightness (ACH50) & 1.46 & 0.6 & 0.6 \\
Heating and cooling setpoints (C) & $20 / 28$ & $20 / 25$ & $20 / 25$ \\
\hline
\end{tabular}

Figure 5.26, Figure 5.27, Figure 5.28, and Figure 5.29 illustrate the relationships between dLCC and metrics by which space conditioning is regulated for the Passive House standard. These Figures are all from the same optimization batch (Case 5), but have been plotted against different variables which were being collected within the optimization environment.

Of the points explored by the genetic algorithm, 272 combinations within the search space would meet the current international Passive House standard for annual heating and cooling demand (i.e. $15 \mathrm{kWh} / \mathrm{m} 2 \mathrm{a}$ ), according to this model. However, no points found by the genetic algorithm within the search space meet the current Passive House target for peak heating and cooling load (i.e. $10 \mathrm{~W} / \mathrm{m} 2$ ). Certification was not confirmed in PHPP of WUFI Passive.

For minimized LCC levels near 33\% energy savings, the assembly recommendations seem much more like small tweaks and improvements to the local building code, than like the superinsulated assemblies expected for Passive Houses. Again, this is likely because of the significant cost required to gain incremental utility bill savings. It is important to remember that Passive House does not explicitly prescribe envelope measures. Instead, it gives designers the freedom to achieve the standard using their own performance trade-offs. 


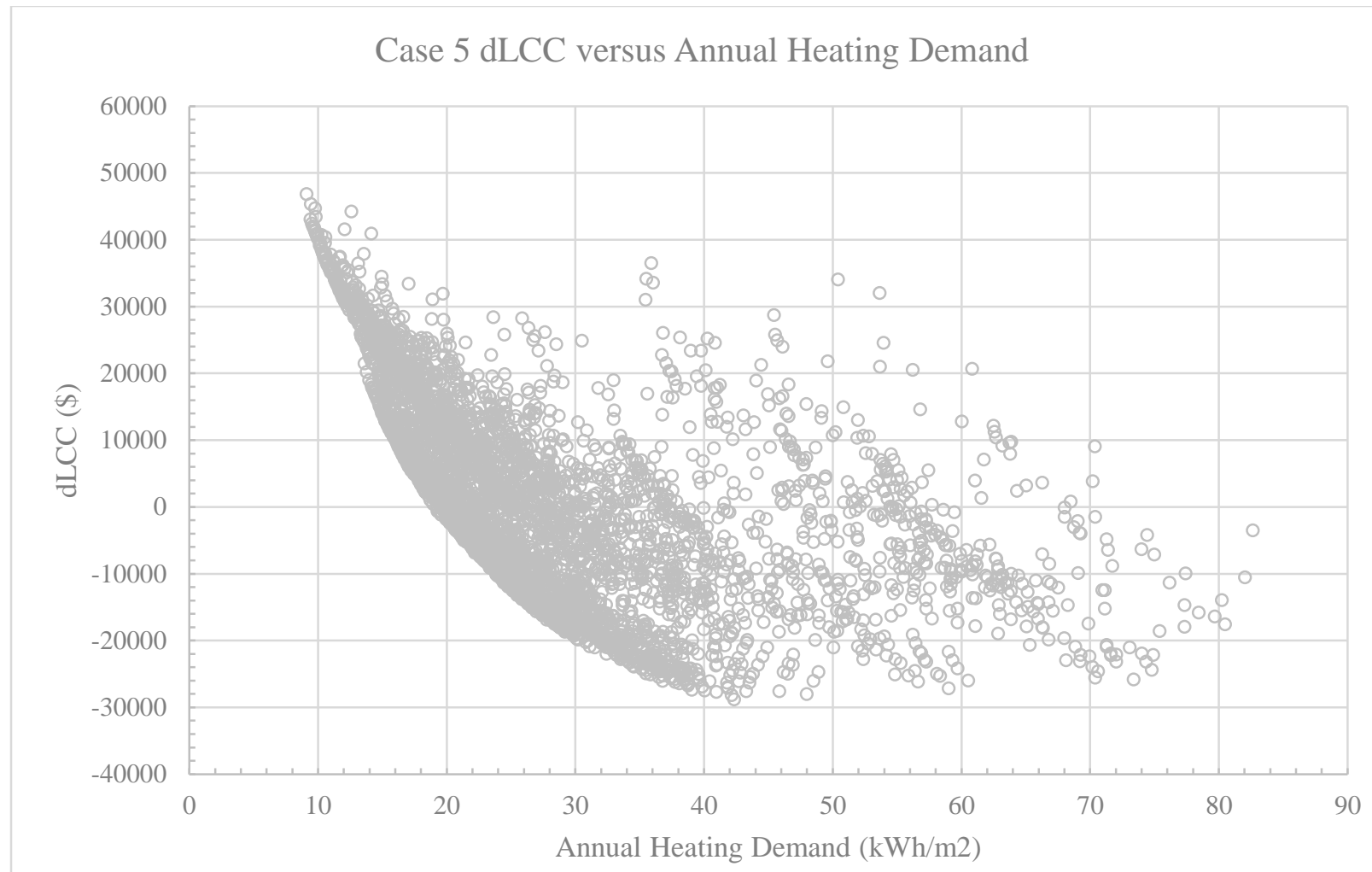

Figure 5.26: Parametric results illustrating the relation between LCC and annual heating demand

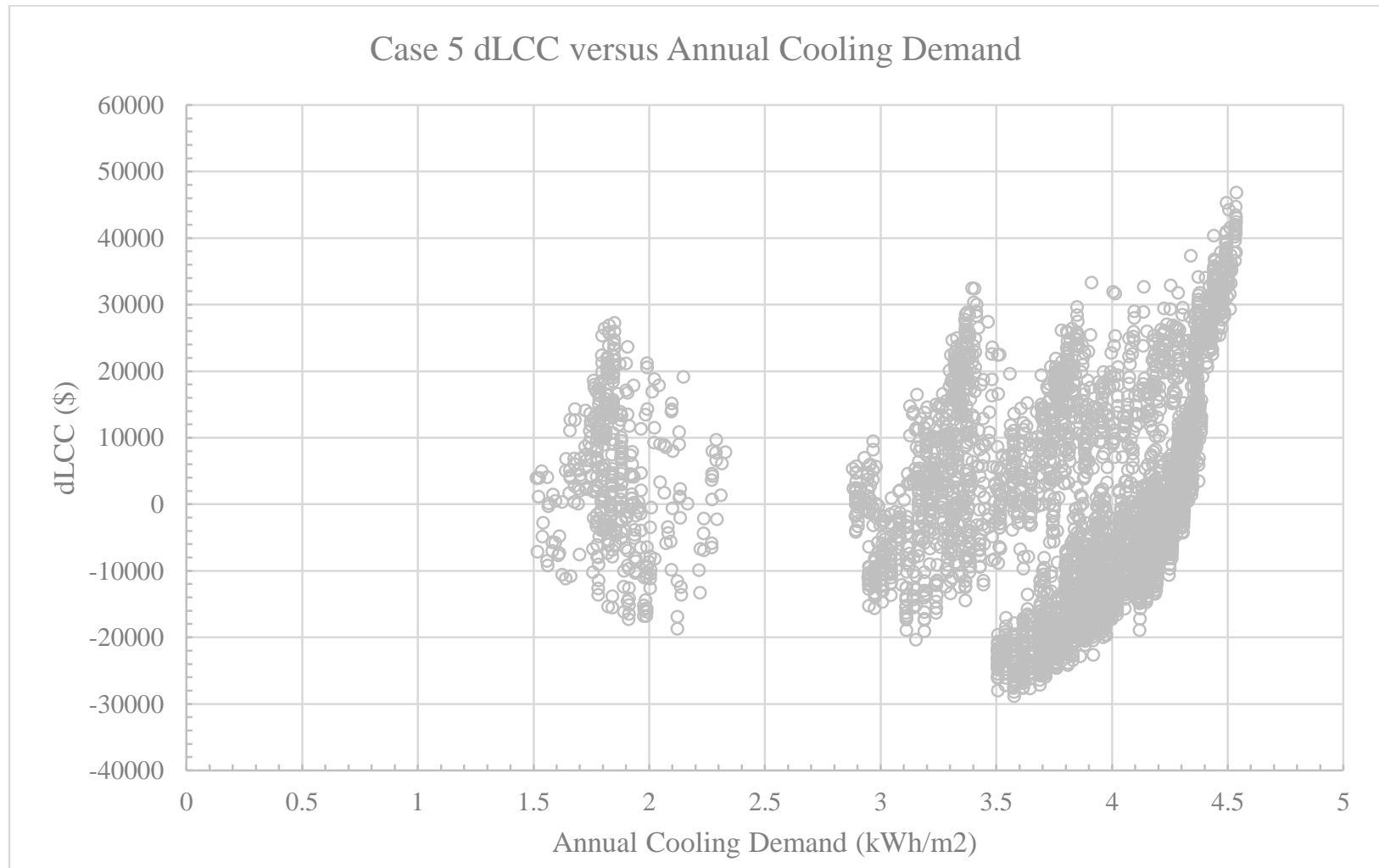

Figure 5.27: Parametric results illustrating the relation between LCC and annual cooling demand 


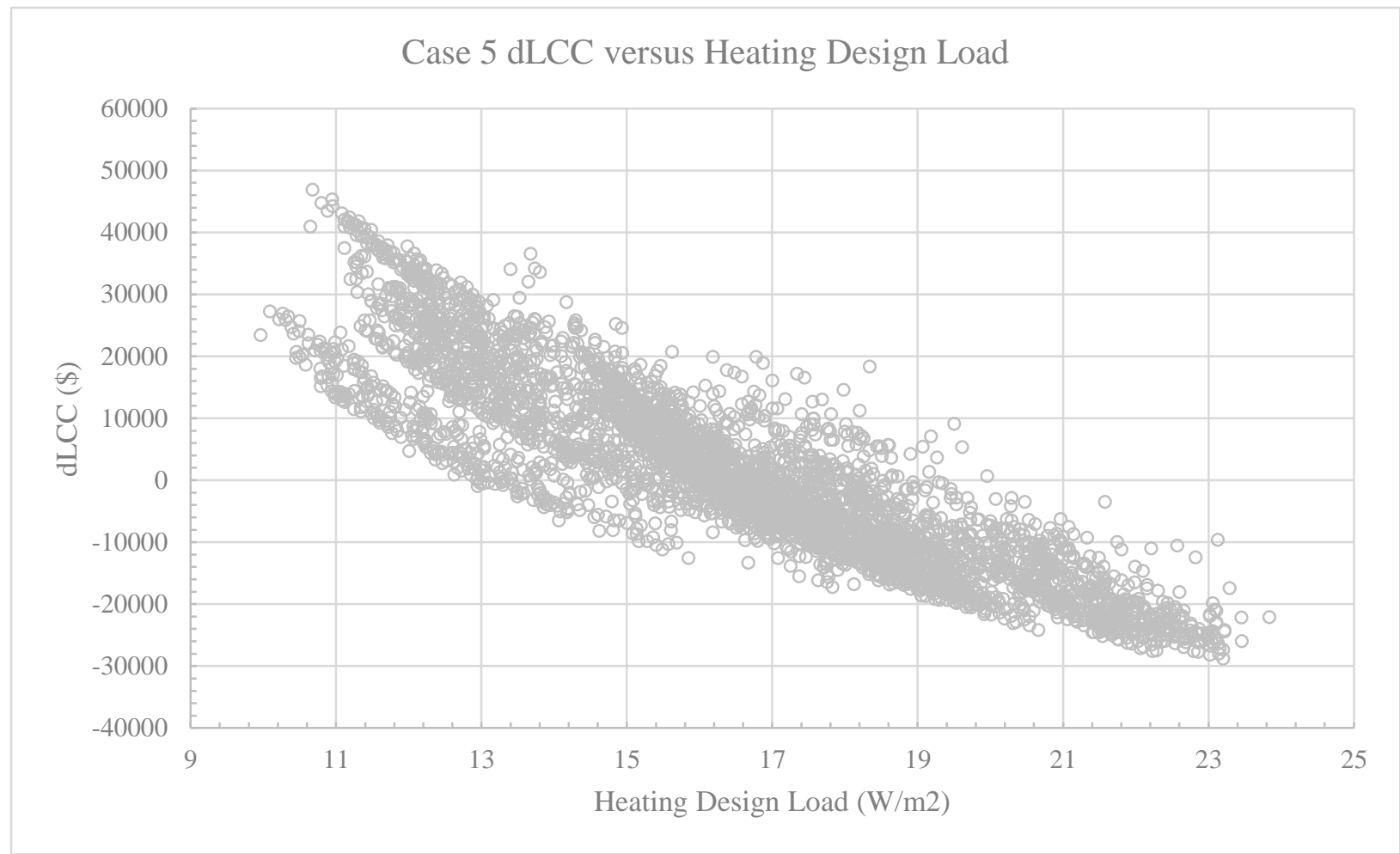

Figure 5.28: Parametric results illustrating the relation between LCC and heating design load

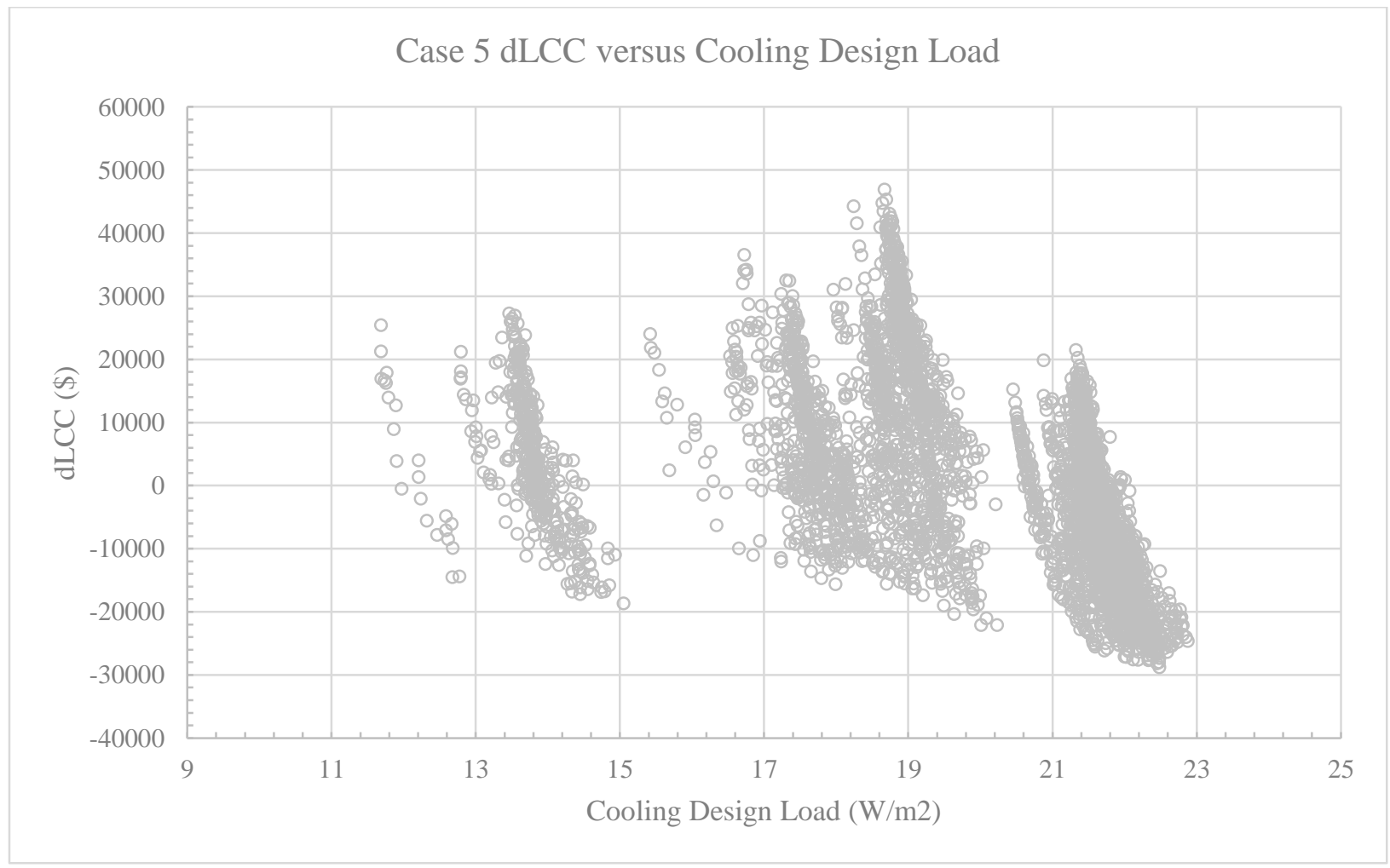

Figure 5.29: Parametric results illustrating the relation between LCC and cooling design load 
For comparison, the Toronto results of the PHIUS study are presented in Table 5.15. The new proposed North American Passive House standard mandates a limit for annual demand AND peak demand, for both heating and cooling, whereas the previous standard only required houses to meet annual demand OR peak demand. The PHIUS technical committee has still not reconciled the levels of various peak load calculation methods since nuance differences are present between BEopt/Manual J, PHPP, and WUFI Passive dynamic methods. Future work recommended by the technical committee includes the normalization of these calculation methods (Wright, Klingenberg, \& Pettit, 2014). The suggested maximum window u-value was determined by hand calculation which ensures thermal comfort. More specifically the calculation determines the uvalue required to allow no greater than $4 \mathrm{C}$ difference between the ambient room temperature and the inside surface of the glazing. This value is recommended for the climate, but is not a requirement of the standard.

Table 5.15: PHIUS technical committee standard adjustment study results for Toronto (Wright, Klingenberg, \& Pettit, 2014)

\begin{tabular}{cccccccc}
\hline Electricity & Annual & Annual & Manual J & Manual J & PHPP/ & PHPP/ & Suggested \\
price & heating & cooling & peak & peak & WP peak & WP peak & max window \\
$(\$ / \mathrm{kWh})$ & demand & demand & heating & cooling & heating & cooling & u-value \\
& $(\mathrm{kWh} /$ & $(\mathrm{kWh} /$ & load & load & $\begin{array}{c}\text { load } \\
(\mathrm{W} / \mathrm{m} 2)\end{array}$ & $\begin{array}{c}\text { load } \\
(\mathrm{W} / \mathrm{m} 2)\end{array}$ & $(\mathrm{W} / \mathrm{m} 2 \mathrm{~K})$ \\
& $\mathrm{m} 2 \mathrm{a})$ & $\mathrm{m} 2 \mathrm{a})$ & $(\mathrm{W} / \mathrm{m} 2)$ & $(\mathrm{W} / \mathrm{m} 2)$ & 12.6 & 12.6 & 0.908 \\
\hline 0.1380 & 20.2 & 6.6 & 20.8 & 18.0 & 12 &
\end{tabular}

It can been seen that the Manual $\mathrm{J}$ peak heating and cooling load results from the PHIUS study are reasonably close to the results found in this study, where recommended peak heating load and peak cooling load are $23.2 \mathrm{~W} / \mathrm{m} 2$ and $22.5 \mathrm{~W} / \mathrm{m} 2$ respectively. The PHPP results do not match the Manual $\mathrm{J}$ results, or the results found by calibrated EnergyPlus model in this study, because of the inaccuracies of the static program's calculation method (Kruger, 2012). Discrepancies in the Manual $\mathrm{J}$ results and the results of this study could be attributed to peak load calculation method, electricity price (this study found electricity costs averaged $0.168 \$ / \mathrm{kWh}$ after fees and taxes for the calibration year), or other assumed financial parameters such as discount rate or fuel escalation rate. 
There is a significant difference in the annual heating and cooling demand between the PHIUS study and this study, where recommended annual heating and cooling demand were 42.3 $\mathrm{kWh} / \mathrm{m} 2 \mathrm{a}$ and $3.6 \mathrm{kWh} / \mathrm{m} 2 \mathrm{a}$ respectively. This difference is most likely due to the fact that the PHIUS study included multiple active system parameter options, while this study left the active systems constant and varied only passive systems. Mechanical system parameters were considered for this study, but it was ultimately felt that the fundamental behavior of the calibrated model would be compromised if the mechanical system were entirely different.

This result reinforced the theoretical relationship between building loads and annual space conditioning energy consumption. Peak loads are dependent only on passive systems, environmental interaction, and human behavior, while energy consumption is based on these factors indirectly, since they determine system sizing, but it is also largely dependent on system efficiency.

Since there was no option for a smaller and cheaper system in the optimization environment, the Passive House concept of "tunneling through the cost barrier", where a quantum cost reduction is gained when the building loads are reduced significantly, could not be demonstrated. However, the concept assumes that active systems, other than ventilation, are omitted, which in reality is extremely unlikely in Canada's climate.

\subsubsection{General Discussion}

The optimization study provided an in-depth analysis of the case study house, demonstrating the capability of simulation as a design and review tool. By calibrating the simulation model and using actual construction costs, result reliability was increased, but at the same time, general applicability was reduced. Result application to other projects is limited because the envelope systems, active systems, orientation, footprint, and window-to-wall ratio were held constant, and costs were case-specific.

Ultimately, to make use of the calibration effort, the parameters available for modification were reduced significantly, to the disadvantage of the experiment. This conclusion highlights the benefit of the 'general' or 'archetypal' model, which is only representative of reality, but free to change in any way desired by the investigator. Results from such hypothetical models may be criticized by reviewers for their fictitious nature, but by applying real-world results, the more 
general studies can be evaluated. For example, the agreement of the present results with those of the PHIUS study (in peak load, as discussed) help to validate PHIUS' results for the Toronto climate, and in doing so, add confidence to the results of the other locations.

Costs were house-specific and may be unavailable to other home builders in future projects. Therefore, the results for the given costs and economic conditions may not apply to other cases. The most notable example was the glazing on the as-built house, which was custom ordered and achieved disproportionate performance for the cost. In general, glazing costs were the most inaccurate of the costs, since they came from different suppliers, and didn't follow a reliable trend of cost relative to performance. Other important costs, such as incremental air-tightness, had to be excluded all together because of unavailable data. It is expected that the results may have been different if this data was available because of the high cost-dependence of this experiment. The high costs point to the need for building subsidies and a reliable cost database of high-performance products to increase consumer awareness and improve cost estimating accuracy.

\subsection{Optimization Summary}

An optimization environment for the calibrated reference building was created in the jEPlus suite. Passive energy saving measures, ranging from OBC SB-12 minimum to super-efficient, were identified as independent variables and associated with unit costs. The passive parameters were varied to determine combinations of optimal performance and cost using genetic algorithm.

Multi-objective optimization was performed for total peak load and life cycle cost to evaluate the design of the as-built house and inform future design choices. The improved design solutions favored greater wall insulation, reduced slab insulation, and a less efficient (less expensive) ERV. Optimization batches were performed to test the effect of changing future economic values. Investment in passive energy saving features are favored when discount rate is low, fuel escalation is high, and mortgage rates are low. Although the case study house was retrofitted to achieve superefficiency, the costs used excluded demolition cost allowing result application for new or retrofit construction.

The performance objective was changed from total peak load to annual energy savings and another optimization batch was performed in an attempt to match the procedure performed by the PHIUS technical committee. The resulting recommendation for the local Passive House 
performance level agreed with the heating and cooling loads recommended by PHIUS, but were approximately twice as high for annual heating and cooling demand, likely because active systems were not included as variable parameters.

In general, modest investment in passive ECMs were recommended from the optimization results. However, with the current fuel costs being so low, super-efficient envelopes are difficult to justify with an economic argument alone, even over the long term.

While the results of the study were highly accurate for the case study house, they cannot be applied universally to all houses because of the housing type and project-specific costs. However, the results of this study help improve the reliability of other such studies which employ 'general' or 'archetypal' models. 


\section{FUTURE WORK AND CONCLUSIONS}

\subsection{Future Work}

This work showed the capabilities of building optimization through simulation. However, study limitations set boundaries on the results that could be obtained. Based on the limitations of this study, and the lack of existing information uncovered during the course of this work, the following items are recommended for future in-depth research:

- The optimization environment created should be used for further experiments. Future parameters should include a range of mechanical systems of varying performance levels, with accurate associated costs, and houses of different build style in different Canadian climates. An all-electric building case should be investigated with PV arrays of various size and orientation to explore how the economic investment in passive means changes when production options are available. The optimization environment could also be used to evaluate thermal comfort with respect to parameter variation.

- The parametric combinations which meet the international Passive House standard, as determined with the case study model, should be verified using PHPP software.

- Visible light transmission should be included as a variable, or imposed as a constraint, in future optimization studies since reduced visible light may result in increased artificial lighting demand and therefore affect energy consumption.

- A reliable cost database of high performance building elements should be compiled. The database should consider various manufacturers, locations, and installation practices, similar to the RSMeans database. Special attention would have to be given to high performance windows.

- Detailed investigations should be undertaken to correlate air-tightness levels with cost for typical air-sealing practices in North America. Air-sealing has a significant effect on the performance of houses has not been costed accurately at incremental levels.

\subsection{Conclusions}

Multi-objective optimization performed using the NSGA-II genetic algorithm in the jEPlus environment identified 42 solution sets which would improve the performance of the as-built 
house. The systems research process, where a test house is assessed for performance, demonstrated that improvements in above grade wall insulation, and reductions in slab insulation and ERV efficiency would have led to reduced life cycle cost for the case study house, under current economic conditions.

The optimized total peak load and LCC plot created a Pareto front where the objective functions trade off with an inverted relationship. The peak load comparison may be useful in future application of affordable housing design. To this end, a number of design options could be compared to determine the best performance possible for a given budget constraint.

For the same performance objective function (total peak load), investment in passive ECMs were favored for low discount rate, high fuel escalation rates, and low mortgage rates. The change in these financial parameters directly affected the steepness of the resultant Pareto front. However, only general trends were determined, as it was unfeasible to test sensitivity of incremental changes for each parameter.

Based on the optimization results for the case study house and its associated costs, target energy savings of $8.9 \%$, relative to $\mathrm{OBC}$ minimum requirements, from passive improvements would be recommended to achieve minimally incurred cost over the building's life cycle. This conclusion would justify further improvements to the minimum energy requirements of the local building code. However, the recommended combination of passive parameters would be less extensive than the combination of ECMs installed in the case study house.

Optimization executed using annual energy savings as the performance objective function, and altered model air-tightness, cooling setpoint, and reference floor area, produced a recommended Passive House standard of: $23.2 \mathrm{~W} / \mathrm{m} 2$ peak heating load, $22.5 \mathrm{~W} / \mathrm{m} 2$ peak cooling load, $42.3 \mathrm{kWh} / \mathrm{m} 2$ annual heating demand, and $3.6 \mathrm{kWh} / \mathrm{m} 2$ annual cooling demand, or $33 \%$ annual energy savings with respect to the minimum building code requirements. These results agreed relatively well with those produced by the PHIUS technical committee for peak heating and cooling load, but agreed poorly for annual heating and cooling demand. The discrepancy is likely due to the omission of active system variation in this study.

For all optimization batches performed, ECM capital costs were found to heavily influence life cycle costs because of their high investment demand, relative to the currently low natural gas 
costs. Even with moderate fuel escalation rates, incremental costs for energy efficiency features were an order of magnitude greater than the accompanying energy cost savings. This conclusion points to the need for energy efficiency subsidies to continue to improve the performance of buildings in the residential sector, until market adoption of high-performance products increases and competition drives market rates down. 


\section{APPENDIX A - AIR TEMPERATURE DATA}

Measured versus simulated hourly air temperature data for thermal zones

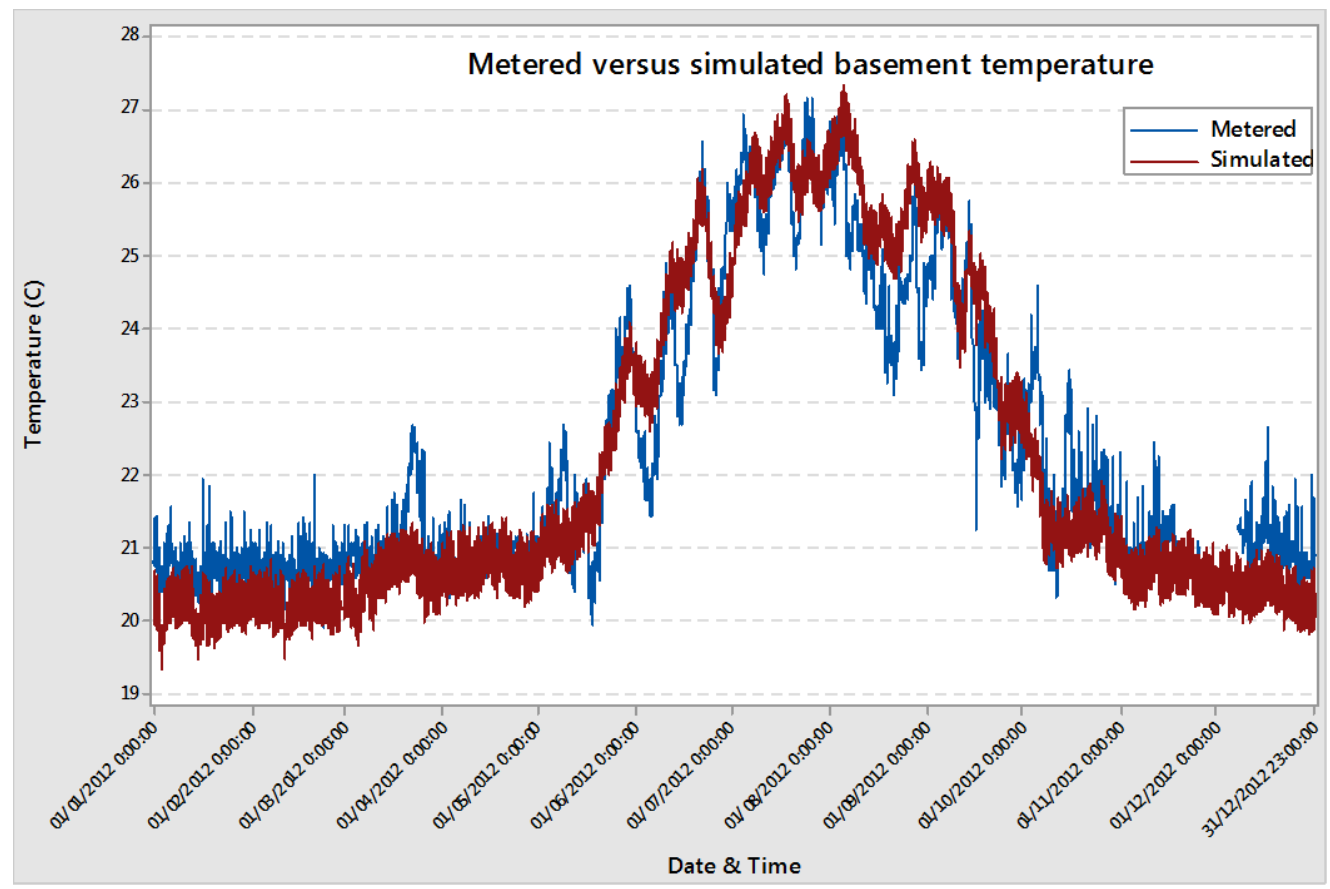

Figure 7.1: Thermal zone Basement air temperature comparison

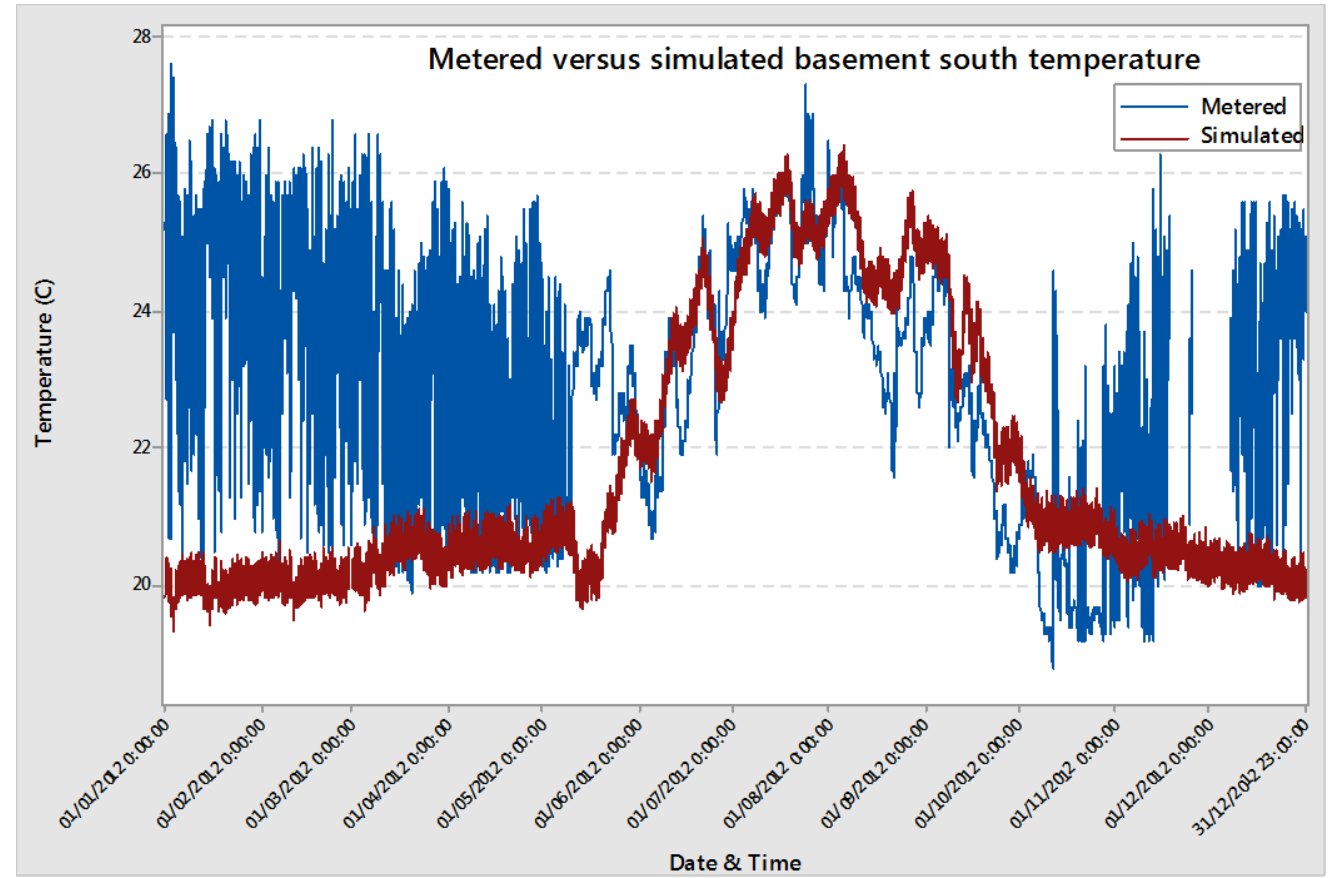

Figure 7.2: Thermal zone Basement $S$ air temperature comparison (noted Omnisense error) 


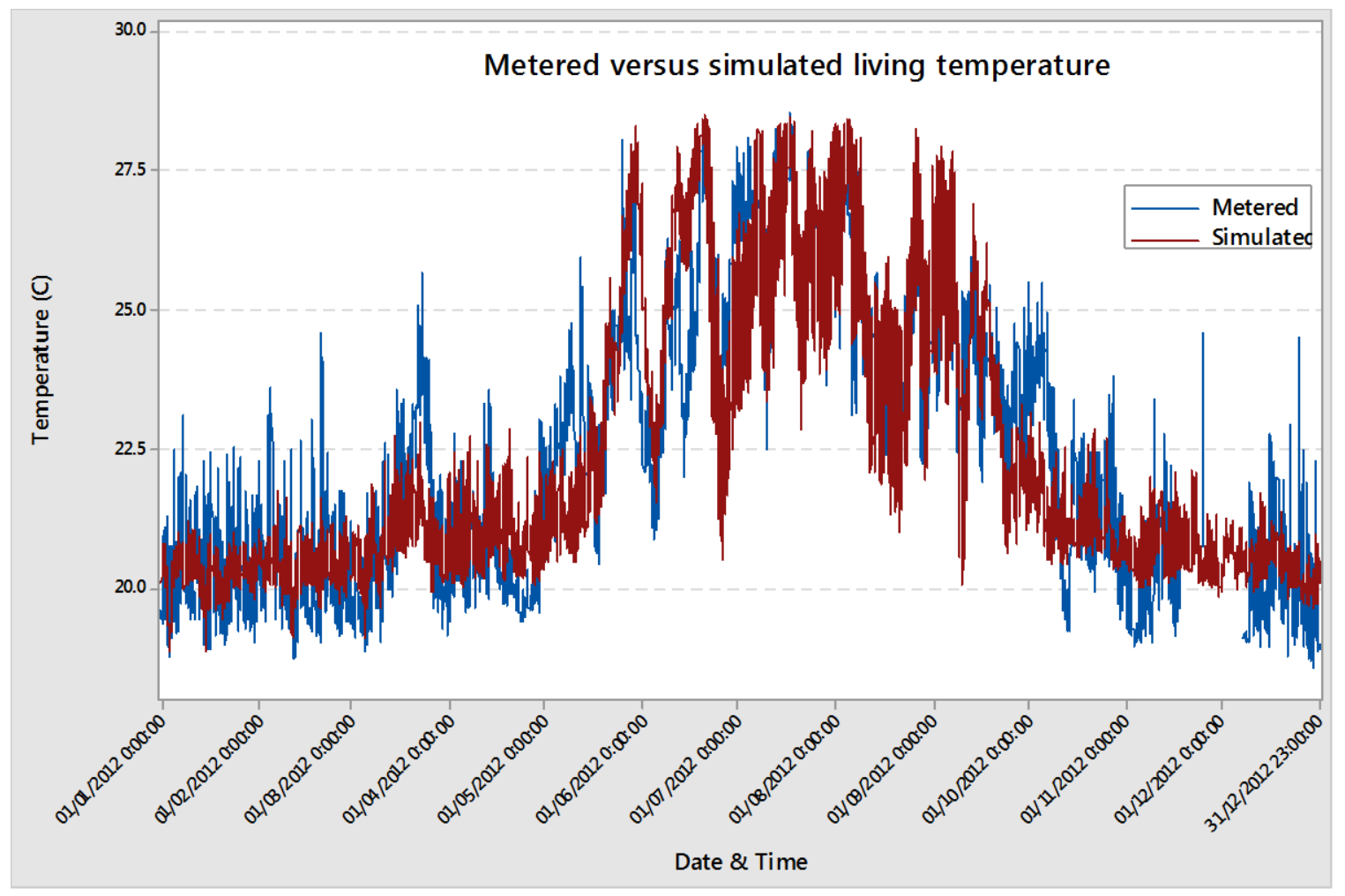

Figure 7.3: Thermal zone Living air temperature comparison

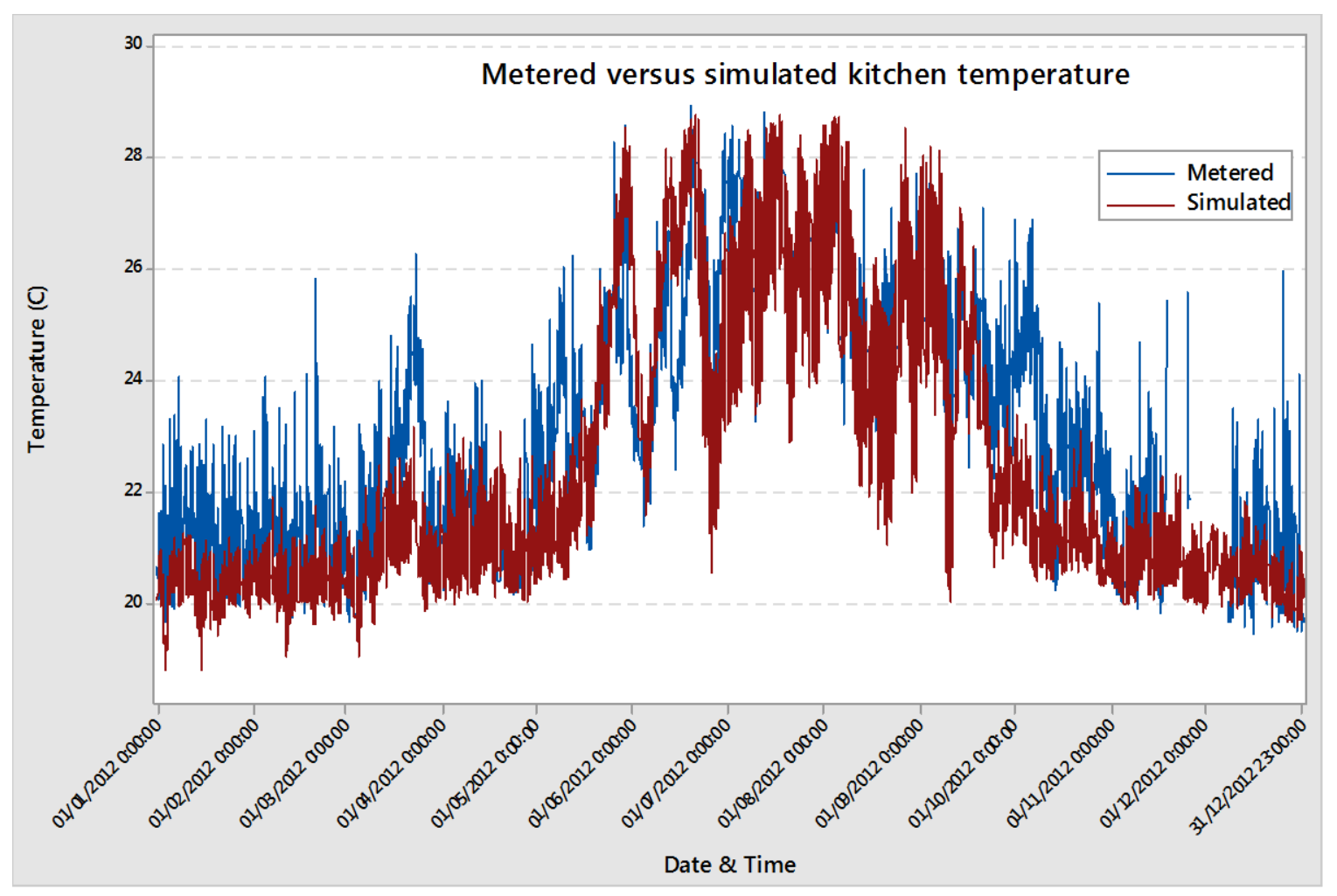

Figure 7.4: Thermal zone Kitchen air temperature comparison 


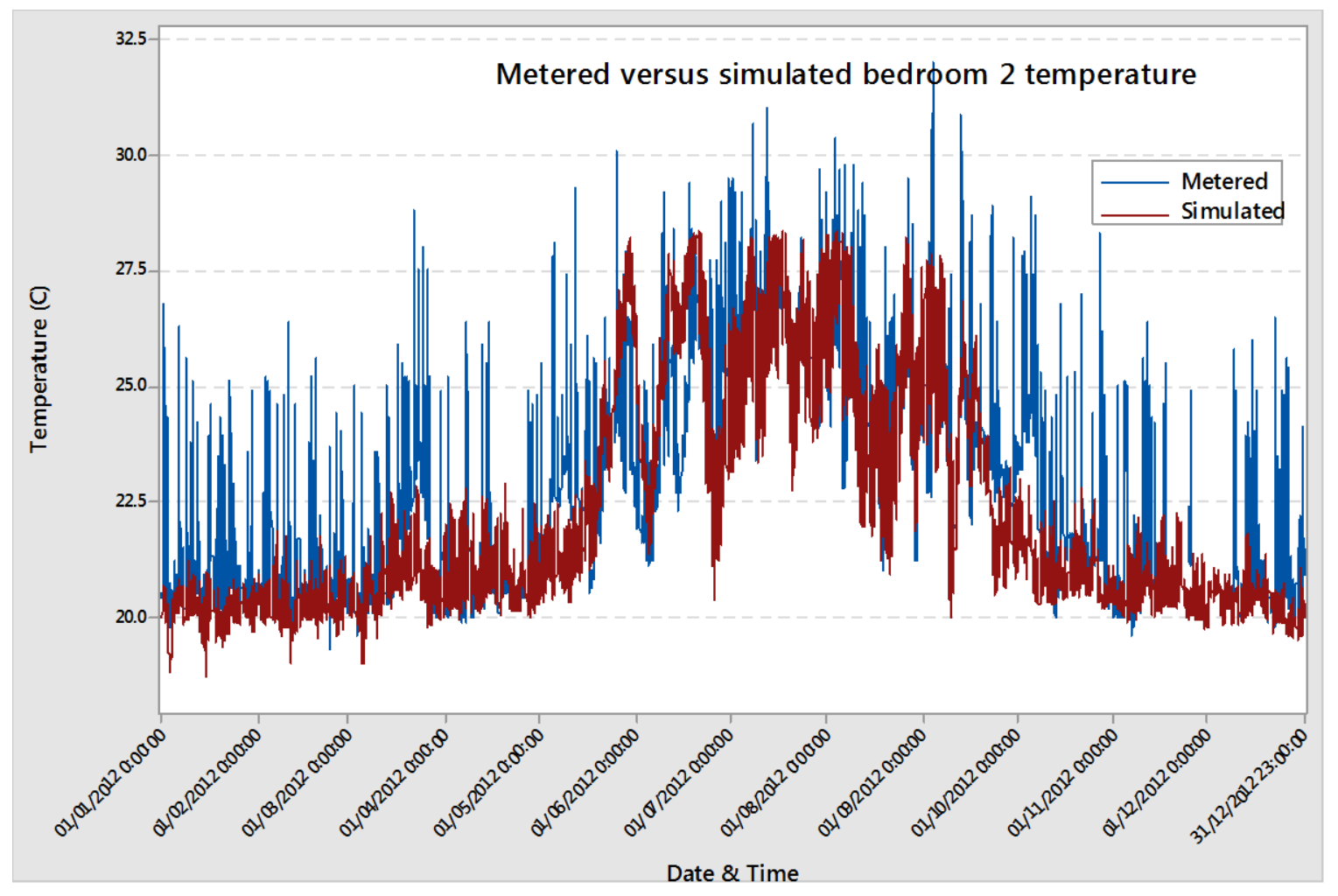

Figure 7.5: Thermal zone Bedroom 2 air temperature comparison

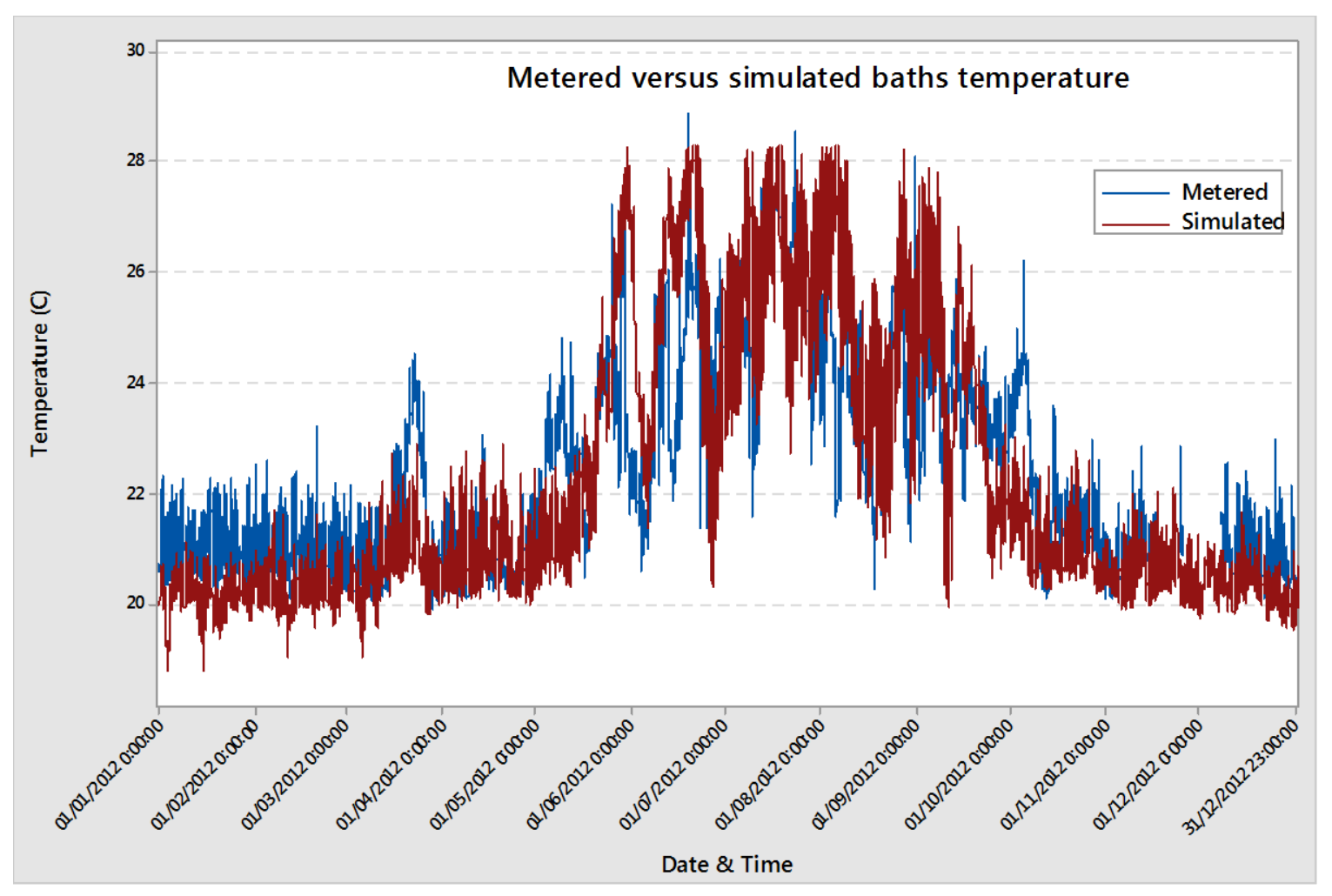

Figure 7.6: Thermal zone Baths air temperature comparison 


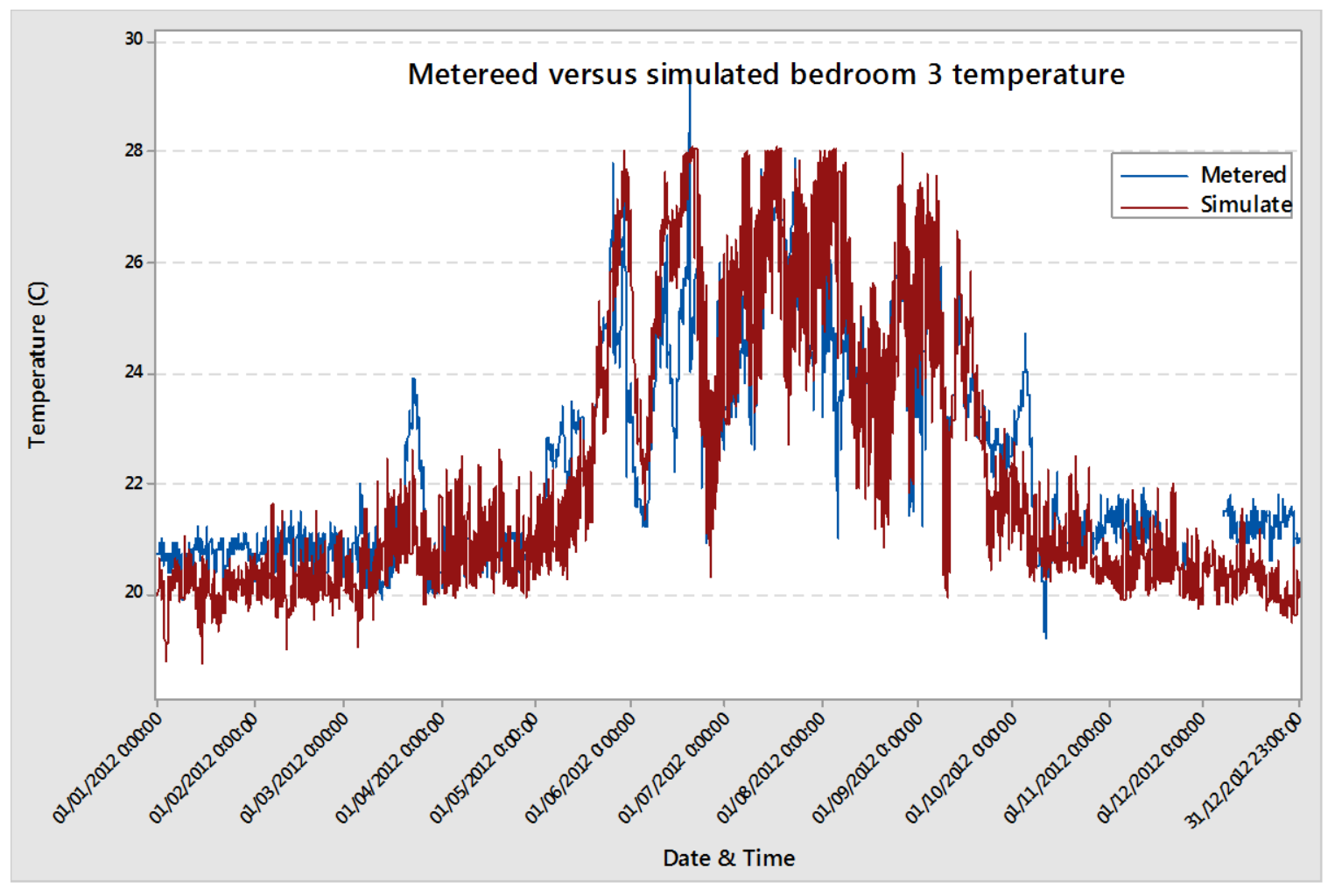

Figure 7.7: Thermal zone Bedroom 3 air temperature comparison

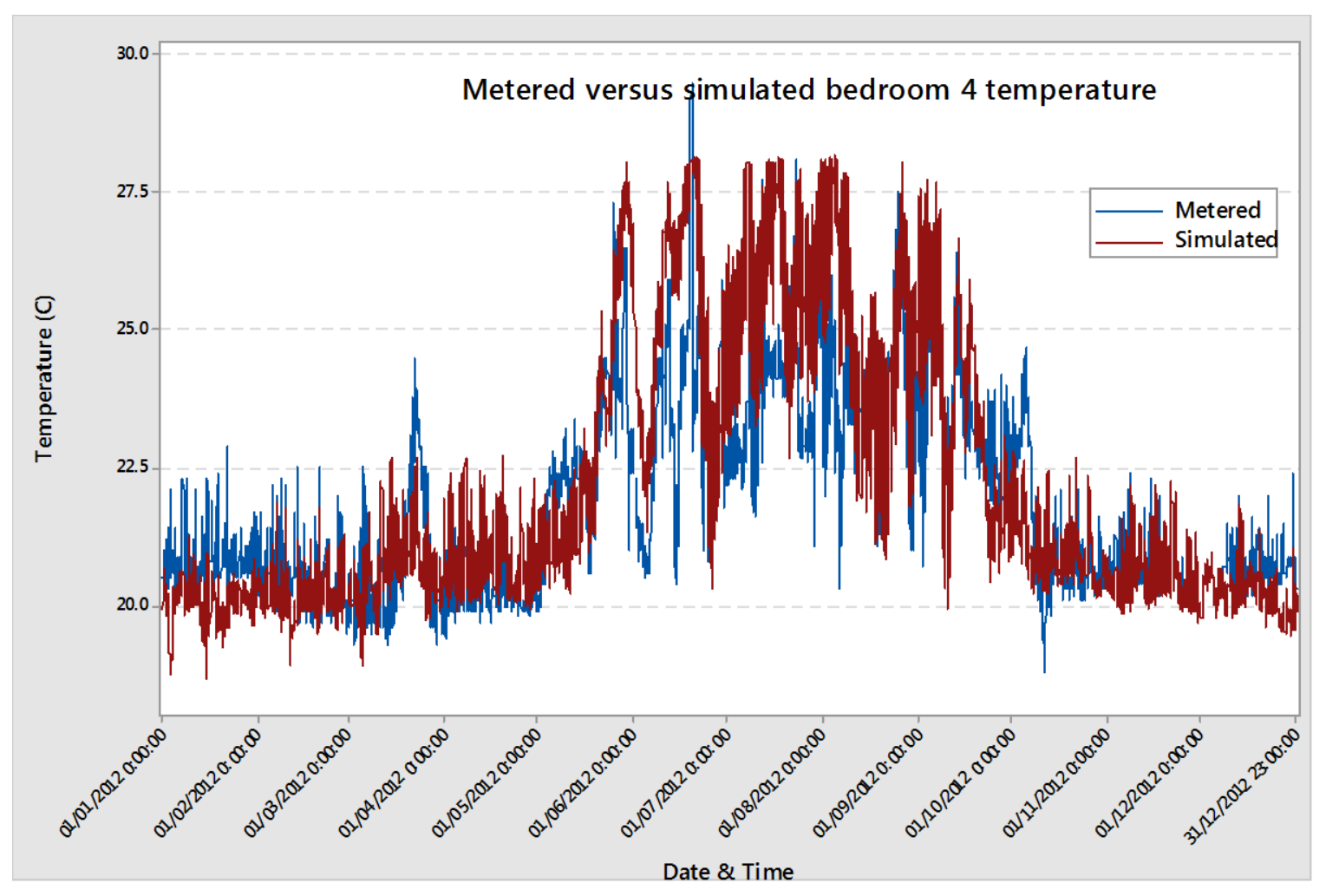

Figure 7.8: Thermal zone Bedroom 4 air temperature comparison 


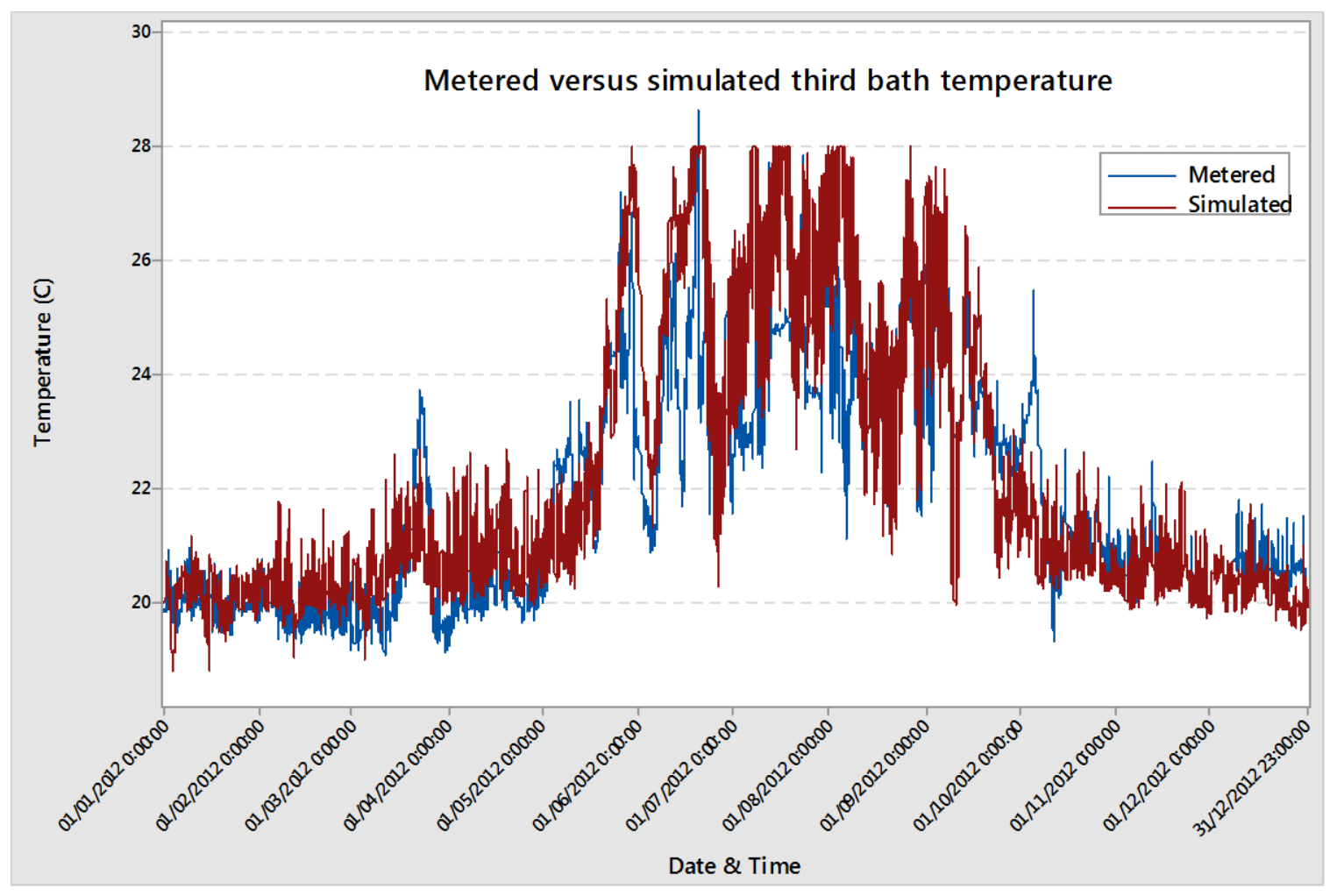

Figure 7.9: Thermal zone Third Bath air temperature comparison 


\section{APPENDIX B - JEPLUS AND ENERGYPLUS INPUT}

\section{jEPlus parameter tree descriptions and input}

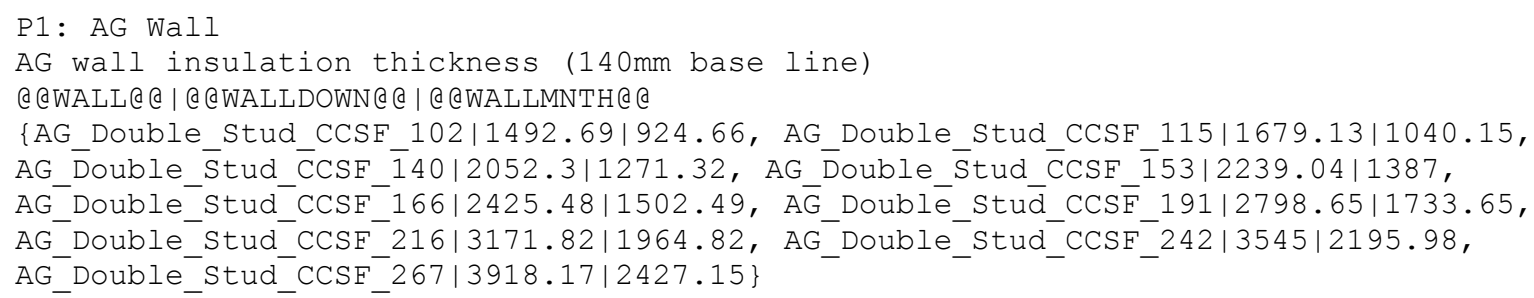


@ @BGWALL@@ | @ @BGWALLDOWN@ @ | @ @BGWALLMNTH@ @

\{BG Double Stud CCSF 102/484.82|300.33, BG Double Stud CCSF 115/545.37|337.84,

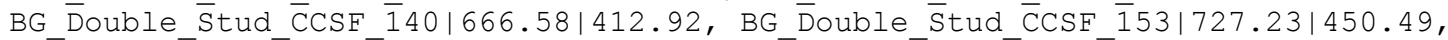

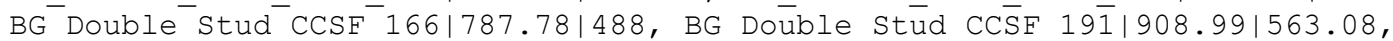

BG_Double_Stud_CCSF_216|1030.19|638.16, BG_Doüble_Stud_CCSF_242|1151.4|713.24, BG_Double_Stud_CCSF_267|1272.6|788.33\} 


\section{jEPlus extension (.rvi) file}

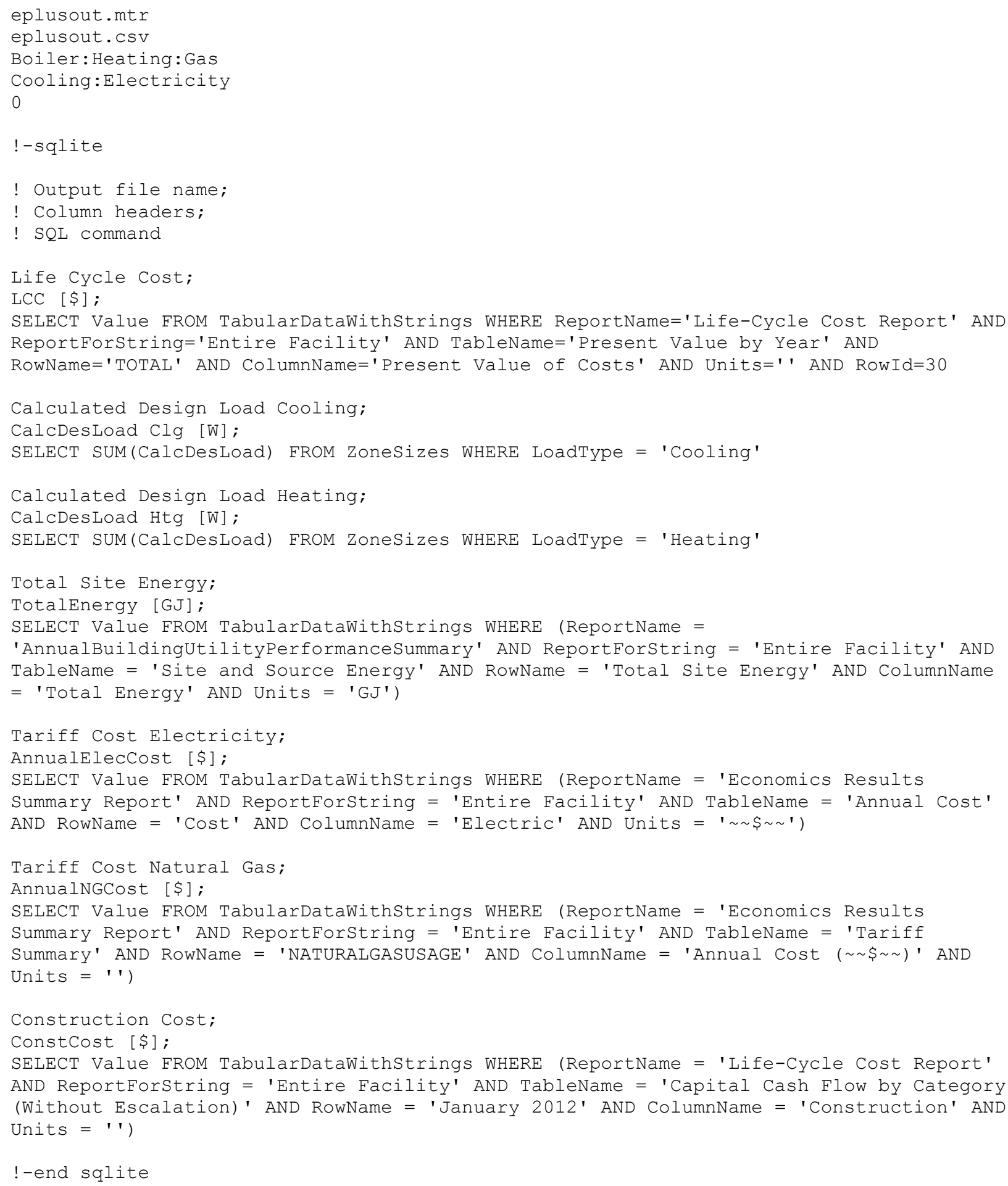




\section{jEPlus extension (.rvx) file}

"notes" : "RVX for MASc Thesis created by Matthew Tokarik January 21, 2015",

"rvis" : [

\{

"fileName" : "matt.rvi",

"tableName" : "SimResults"

\}

],

"sqls" :

\{

"tablename" : "Life Cycle Cost",

"columnHeaders" : "LCC [\$]",

"sqlcommand" : "select Value from TabularDataWithstrings WHERE

(ReportName='Life-Cycle Cost Report' AND ReportForString='Entire Facility'

AND Tablename='Present Value by Year' AND Rowname='TOTAL' AND

ColumnName='Present Value of Costs' AND Units='' AND RowId=30)"

\} ,

\{

"tableName" : "Calculated Design Load Cooling",

"columnHeaders" : "CalcDesLoad Clg [W]",

"sqlcommand" : "SELECT SUM(CalcDesLoad) FROM ZoneSizes WHERE LoadType =

'Cooling'"

\}，

\{

"tableName" : "Calculated Design Load Heating",

"columnHeaders" : "CalcDesLoad Htg [W]",

"sqlcommand" : "SELECT SUM(CalcDesLoad) FROM ZoneSizes WHERE LoadType =

'Heating'"

\} ,

\{

"tableName" : "Total site Energy",

"columnHeaders" : "TotalEnergy [GJ]",

"sqlcommand" : "SELECT Value FROM TabularDataWithStrings WHERE (ReportName

= 'AnnualBuildingUtilityPerformanceSummary' AND ReportForString = 'Entire

Facility' AND TableName = 'Site and Source Energy' AND Rowname = 'Total

Site Energy' AND ColumnName = 'Total Energy' AND Units = 'GJ')"

\} ,

\{

"tableName" : "Tariff Cost Electricity",

"columnHeaders" : "AnnualelecCost [\$]",

"sqlcommand" : "SELECT Value FROM TabularDataWithStrings WHERE (ReportName

= 'Economics Results Summary Report' AND ReportForString = 'Entire

Facility' AND TableName = 'Annual Cost' AND Rowname = 'Cost' AND

ColumnName = 'Electric' AND Units = ' \$ ')"

\} ，

\{

"tableName" : "Tariff Cost Natural Gas",

"columnHeaders" : "AnnualngCost [\$]",

"sqlcommand" : "SELECT Value FROM TabularDataWithStrings WHERE (ReportName

$=$ 'Economics Results Summary Report' AND ReportForString = 'Entire

Facility' AND TableName = 'Tariff Summary' AND RowName = 'NATURALGASUSAGE'

AND ColumnName = 'Annual Cost $(\sim \sim \sim \sim)$ ' AND Units $=$ ' ')"

\} ，

\{

"tableName" : "Construction Cost",

"columnHeaders" : "ConstCost [\$]", 


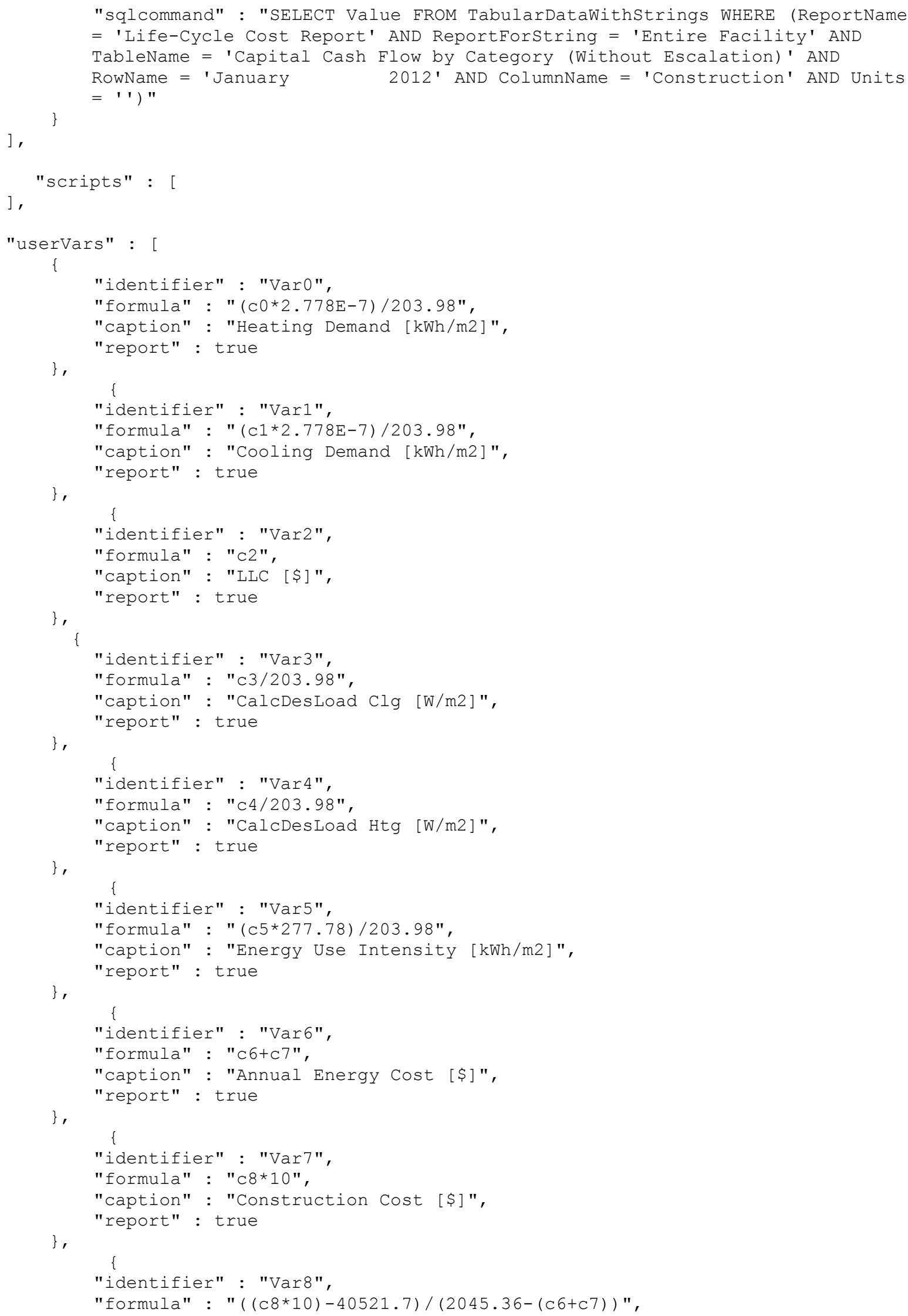




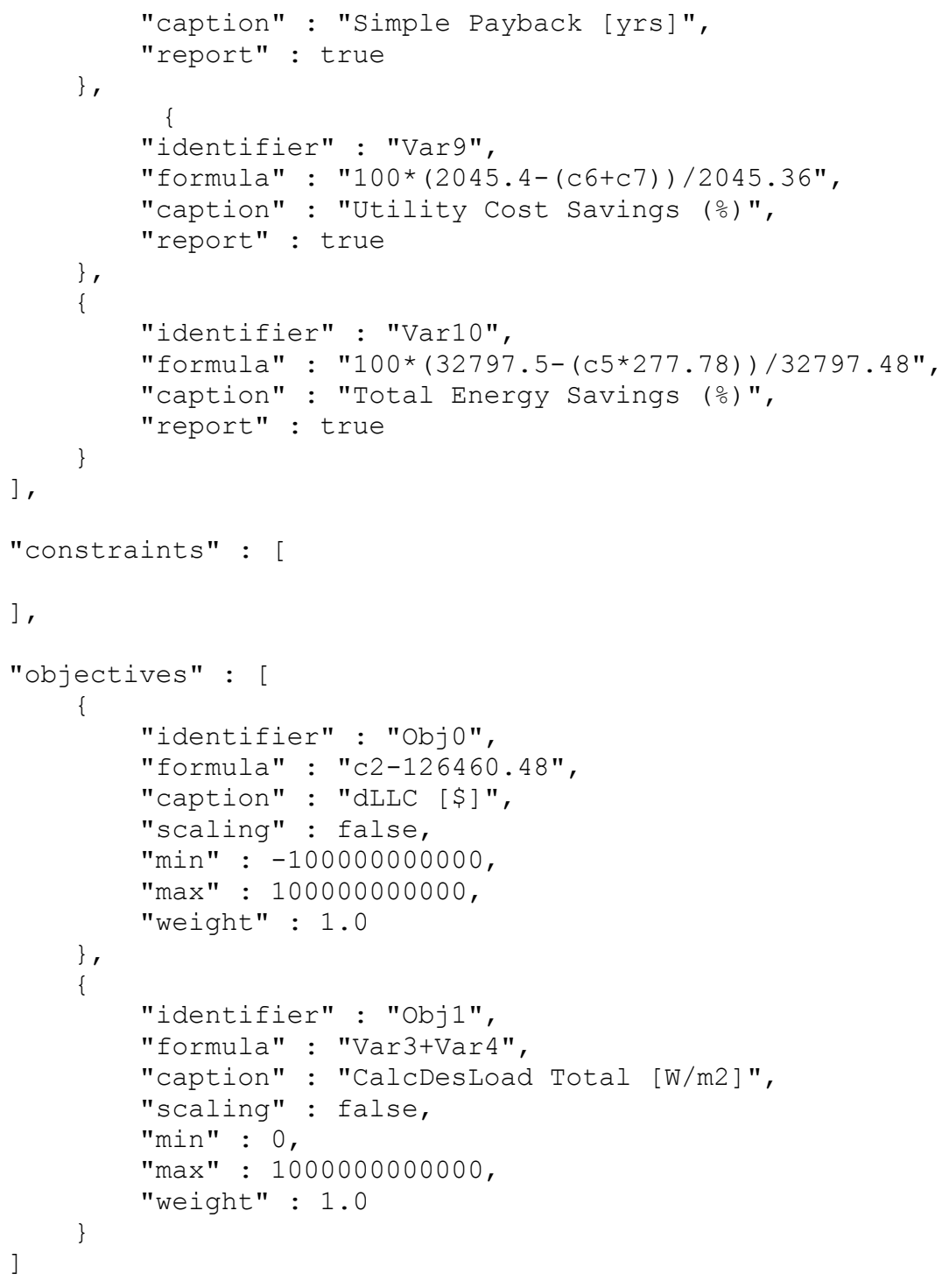




\section{EnergyPlus input (.idf) file with jEPlus input parameters noted as '@@example@@’}

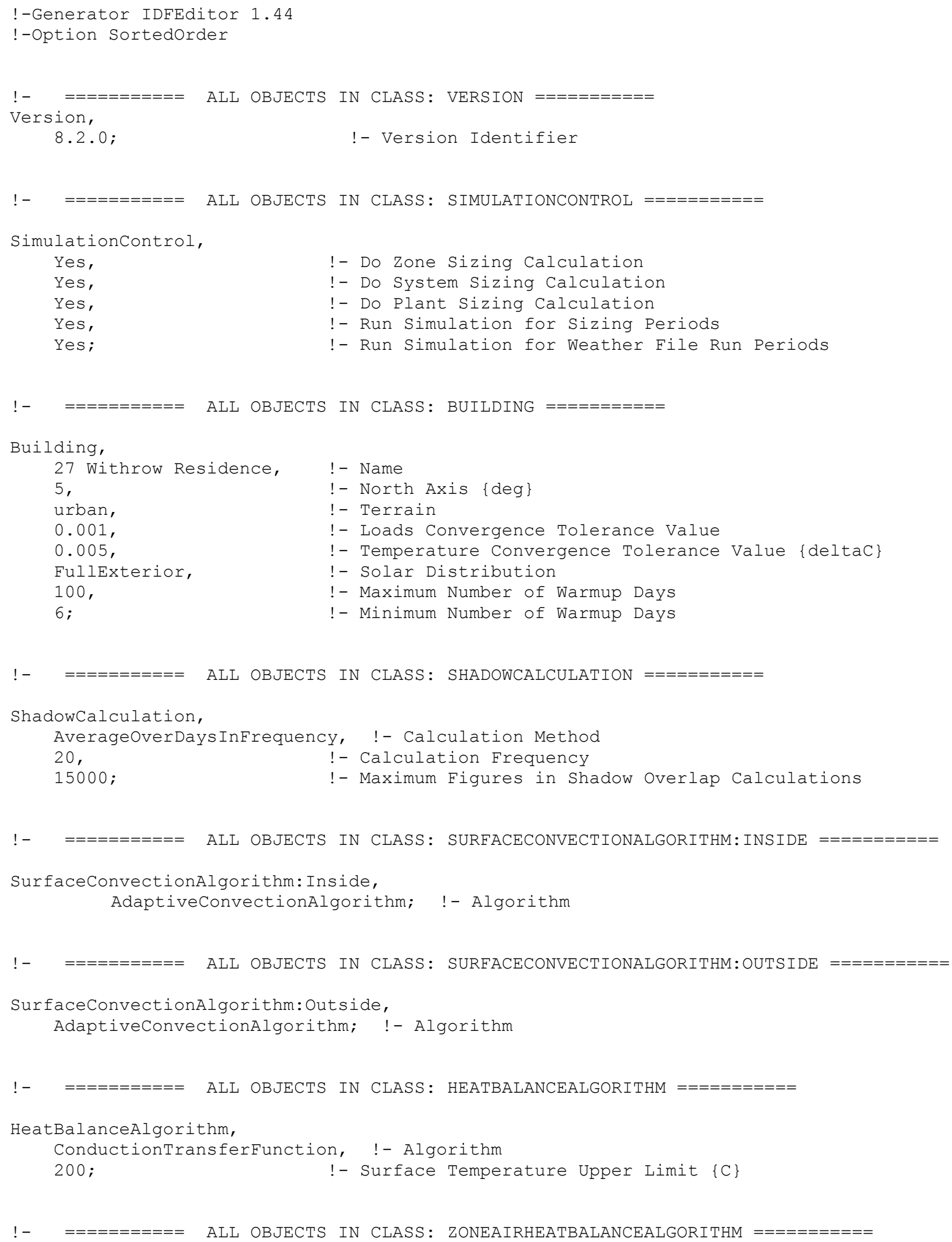




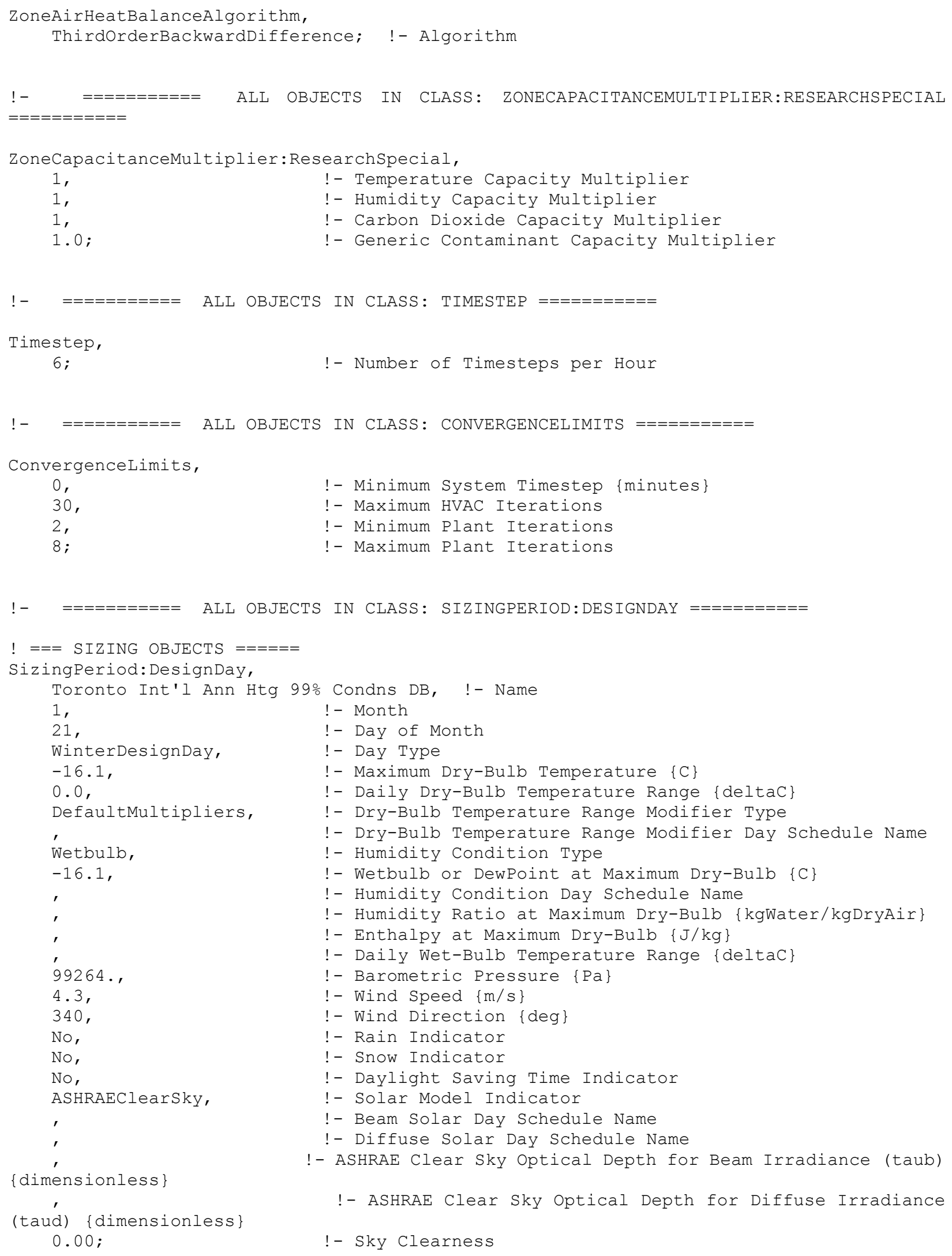




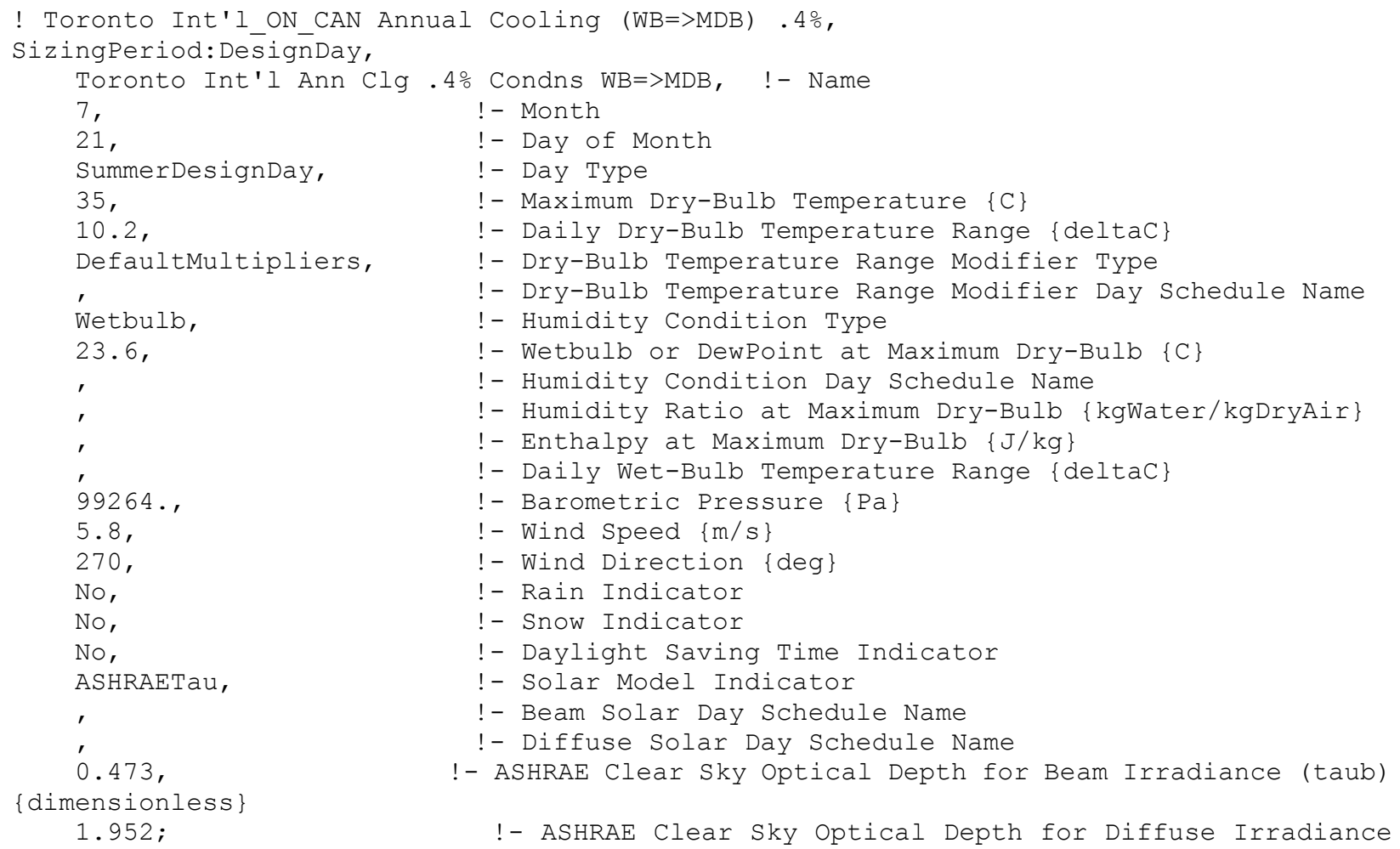

0.3 ,

0.3,

0.3 ,

0.3,

0.3 ,
!- January Ground Reflectance \{dimensionless\}

!- February Ground Reflectance \{dimensionless\}

!- March Ground Reflectance \{dimensionless\}

!- April Ground Reflectance \{dimensionless\}

!- May Ground Reflectance \{dimensionless\} 


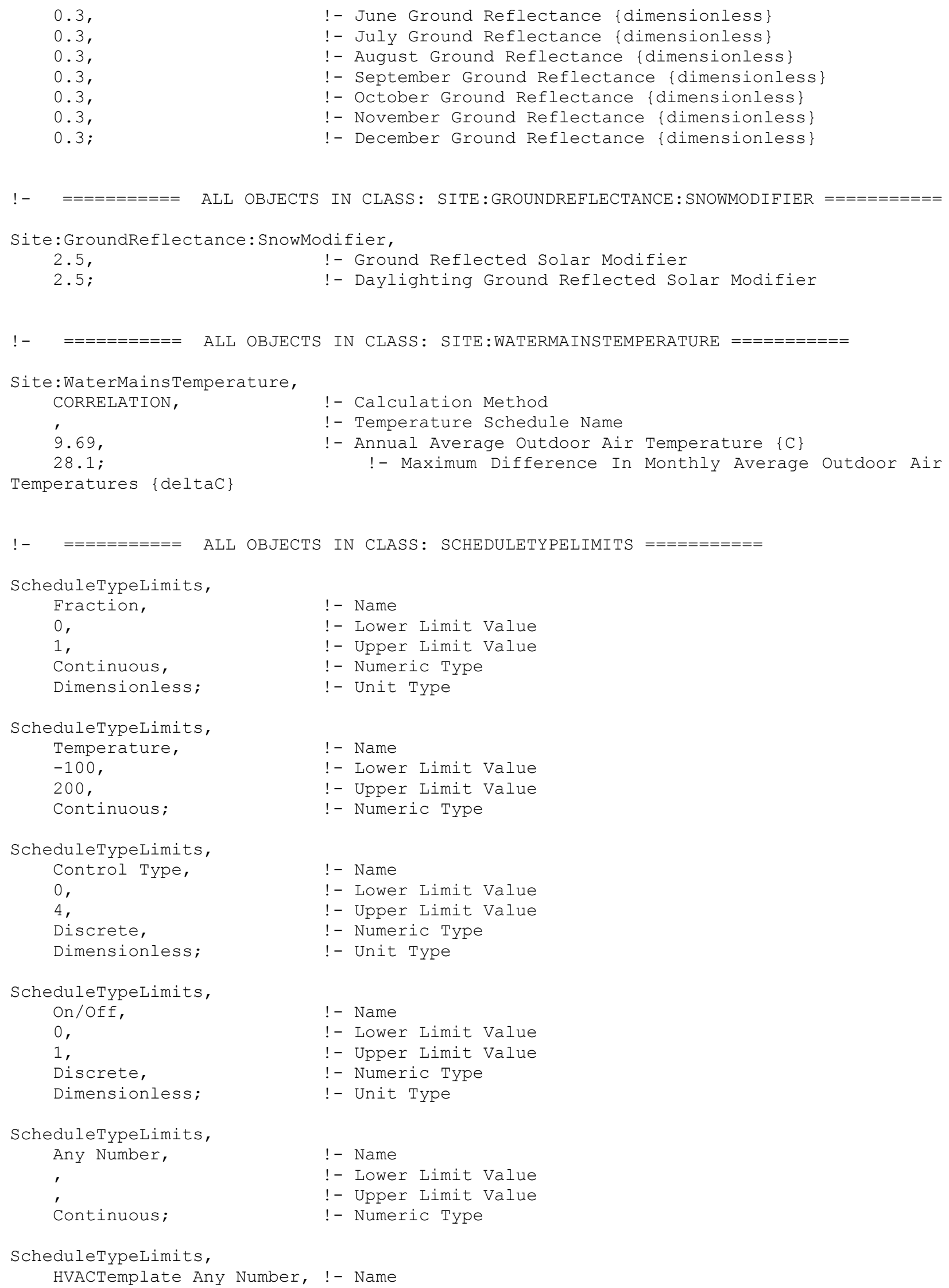




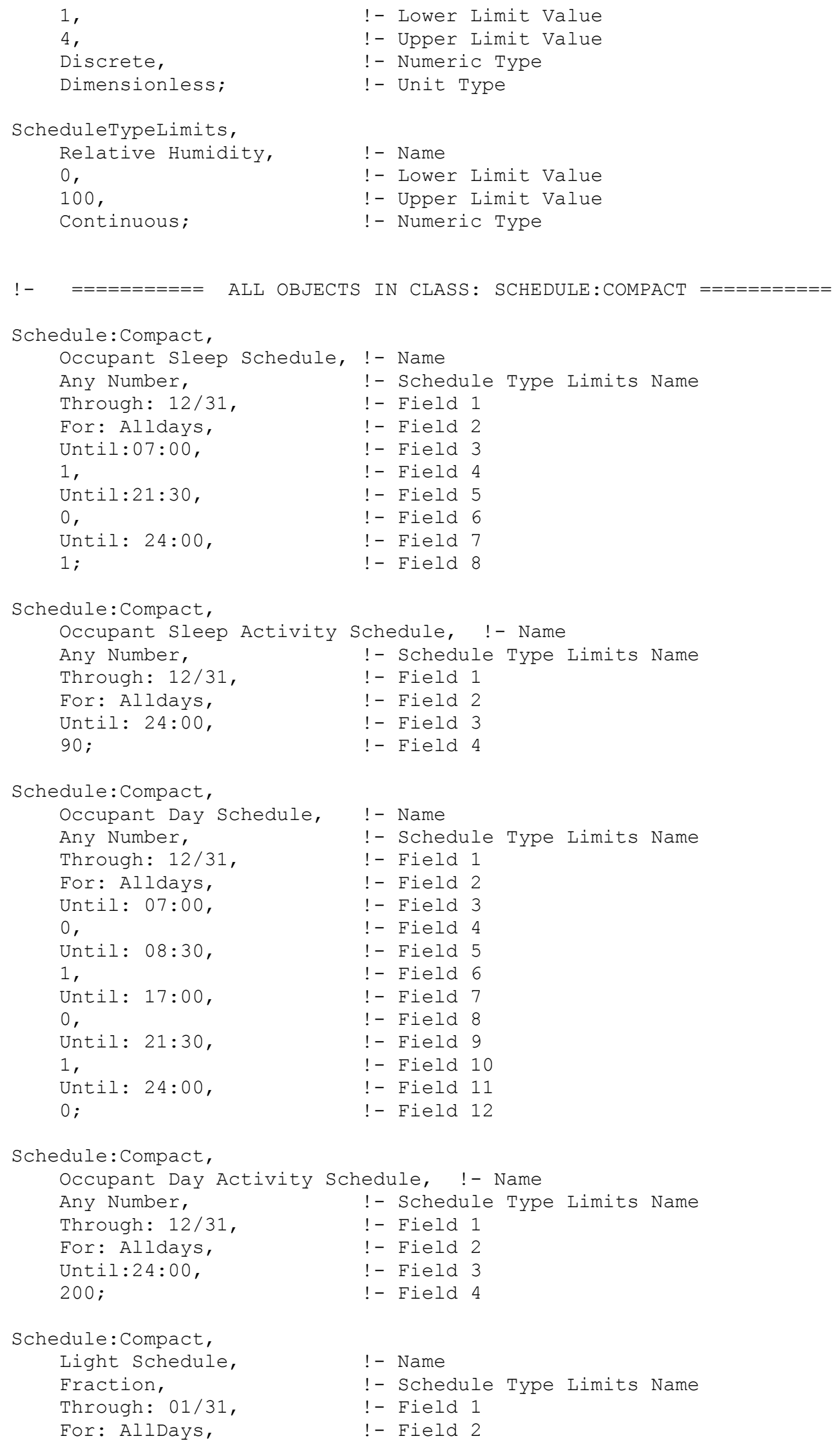

Schedule: Compact, Occupant Day Activity Schedule, !- Name Any Number, Through: $12 / 31$ For: Alldays, Until:24:00, 200 ;

Schedule: Compact, Light Schedule, Fraction, Through: 01/31, For: AllDays, 


\begin{tabular}{|c|c|}
\hline $\begin{array}{l}\text { Until: } 08: 00 \text {, } \\
0,\end{array}$ & $\begin{array}{l}\text { !- Field } 3 \\
\text { !- Field } 4\end{array}$ \\
\hline Until: 09:00, & !- Field 5 \\
\hline 0.9528 & !- Field 6 \\
\hline Until: 12:00, & !- Field 7 \\
\hline 0, & !- Field 8 \\
\hline Until: 13:00, & !- Field 9 \\
\hline 0.9528, & !- Field 10 \\
\hline Until: 17:00, & !- Field 11 \\
\hline 0 & !- Field 12 \\
\hline Until: 18:10, & !- Field 13 \\
\hline 0.9528 & !- Field 14 \\
\hline Until: 22:00, & !- Field 15 \\
\hline 0 & !- Field 16 \\
\hline Until: 23:00, & !- Field 17 \\
\hline 0.9528 & !- Field 18 \\
\hline Until: 24:00, & !- Field 19 \\
\hline 0 & !- Field 20 \\
\hline Through: $02 / 28$, & !- Field 21 \\
\hline For: AllDays, & !- Field 22 \\
\hline Until: 08:00, & !- Field 23 \\
\hline 0 & !- Field 24 \\
\hline Until: 09:00, & !- Field 25 \\
\hline 0.9112 & !- Field 26 \\
\hline Until: 12:00, & !- Field 27 \\
\hline 0 & !- Field 28 \\
\hline Until: 13:00, & !- Field 29 \\
\hline 0.9112 & !- Field 30 \\
\hline Until: 17:00, & !- Field 31 \\
\hline 0 & !- Field 32 \\
\hline Until: 18:10, & !- Field 33 \\
\hline 0.9112, & !- Field 34 \\
\hline Until: $22: 00$, & !- Field 35 \\
\hline 0 & !- Field 36 \\
\hline Until: 23:00, & !- Field 37 \\
\hline 0.9112, & !- Field 38 \\
\hline Until: $24: 00$, & !- Field 39 \\
\hline 0 & !- Field 40 \\
\hline Through: 03/31, & !- Field 41 \\
\hline For: AllDays, & !- Field 42 \\
\hline Until: 08:00, & !- Field 43 \\
\hline 0 & !- Field 44 \\
\hline Until: 09:00, & !- Field 45 \\
\hline 0.9371 & !- Field 46 \\
\hline Until: 12:00, & !- Field 47 \\
\hline 0 & !- Field 48 \\
\hline Until: 13:00, & !- Field 49 \\
\hline 0.9371 & !- Field 50 \\
\hline Until: 17:00, & !- Field 51 \\
\hline 0 & !- Field 52 \\
\hline Until: 18:10, & !- Field 53 \\
\hline 0.9371, & !- Field 54 \\
\hline Until: 22:00, & !- Field 55 \\
\hline 0 & !- Field 56 \\
\hline Until: 23:00, & !- Field 57 \\
\hline 0.9371 & !- Field 58 \\
\hline Until: 24:00, & !- Field 59 \\
\hline 0 & !- Field 60 \\
\hline Through: 04/30, & !- Field 61 \\
\hline For: AllDays, & !- Field 62 \\
\hline Until: 08:00, & !- Field 63 \\
\hline 0 & !- Field 64 \\
\hline Until: 09:00, & !- Field 65 \\
\hline
\end{tabular}




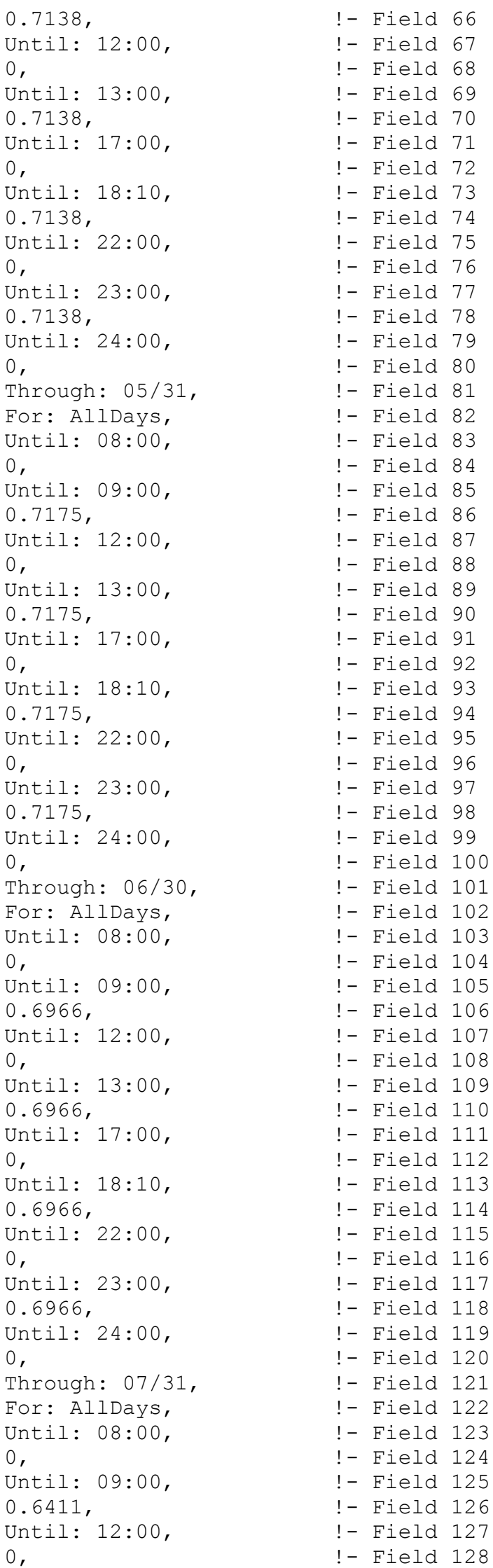




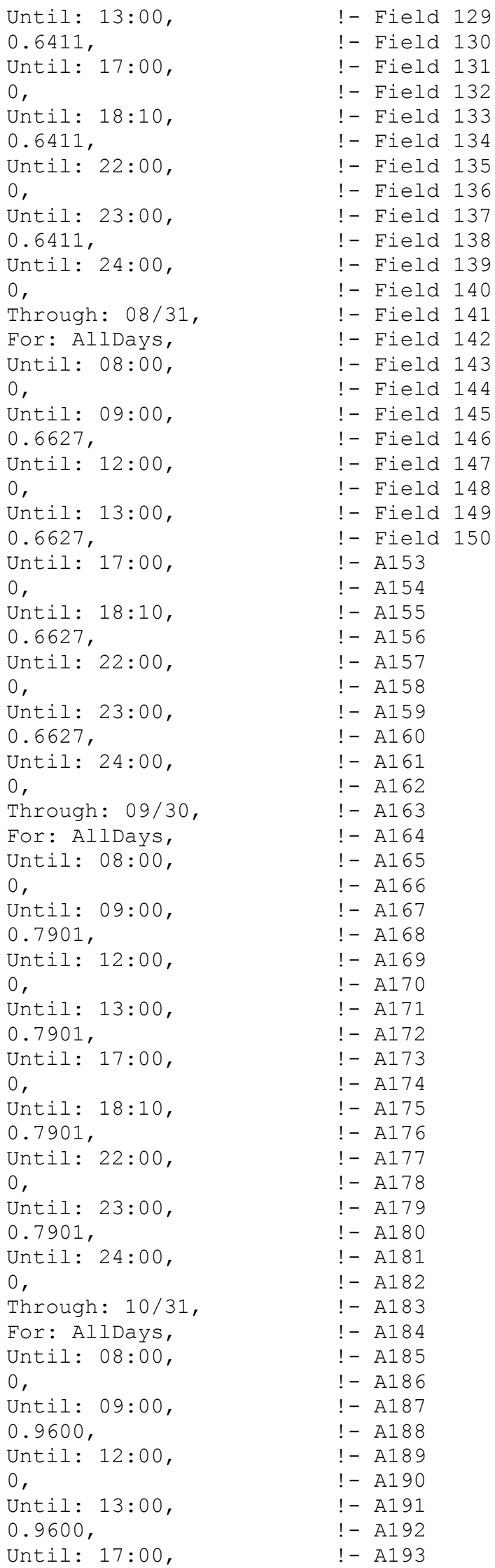




\begin{tabular}{|c|c|}
\hline 0 & ! - A194 \\
\hline Until: 18:10, & ! - A195 \\
\hline 0.9600 & ! - A196 \\
\hline Until: 22:00, & ! - A197 \\
\hline 0, & ! - A198 \\
\hline Until: 23:00, & ! - A199 \\
\hline 0.9600 & $!-\mathrm{A} 200$ \\
\hline Until: 24:00, & ! - A201 \\
\hline 0 & $!-\mathrm{A} 202$ \\
\hline Through: 11/30, & $!-\mathrm{A} 203$ \\
\hline For: AllDays, & $!-\mathrm{A} 204$ \\
\hline Until: 08:00, & ! - A205 \\
\hline 0, & $!-\mathrm{A} 206$ \\
\hline Until: 09:00, & ! - A207 \\
\hline 0.8929 & ! - A208 \\
\hline Until: 12:00, & $!-A 209$ \\
\hline 0 & $!-\mathrm{A} 210$ \\
\hline Until: 13:00, & $!-\mathrm{A} 211$ \\
\hline 0.8929 & ! - A212 \\
\hline Until: 17:00, & $!-\mathrm{A} 213$ \\
\hline 0 & $!-\mathrm{A} 214$ \\
\hline Until: 18:10, & ! - A215 \\
\hline 0.8929 & ! - A216 \\
\hline Until: 22:00, & ! - A217 \\
\hline 0 & $!-\mathrm{A} 218$ \\
\hline Until: 23:00, & $!-A 219$ \\
\hline 0.8929 & $!-\mathrm{A} 220$ \\
\hline Until: $24: 00$, & $!-\mathrm{A} 221$ \\
\hline 0 & $!-\mathrm{A} 222$ \\
\hline Through: 12/31, & $!-\mathrm{A} 223$ \\
\hline For: AllDays, & $!-\mathrm{A} 224$ \\
\hline Until: 08:00, & ! - A225 \\
\hline 0, & $!-A 226$ \\
\hline Until: 09:00, & $!-\mathrm{A} 227$ \\
\hline 1, & $!-\mathrm{A} 228$ \\
\hline Until: 12:00, & ! - A229 \\
\hline 0 & ! - A230 \\
\hline Until: 13:00, & $!-\mathrm{A} 231$ \\
\hline 1, & $!-\mathrm{A} 232$ \\
\hline Until: 17:00, & ! - A233 \\
\hline 0 & ! - A234 \\
\hline Until: 18:10, & ! - A235 \\
\hline 1, & $!-\mathrm{A} 236$ \\
\hline Until: 22:00, & ! - A237 \\
\hline 0, & $!-A 238$ \\
\hline Until: 23:00, & ! - A239 \\
\hline 1, & $!-\mathrm{A} 240$ \\
\hline Until: 24:00, & $!-\mathrm{A} 241$ \\
\hline $0 ;$ & ! - A242 \\
\hline
\end{tabular}

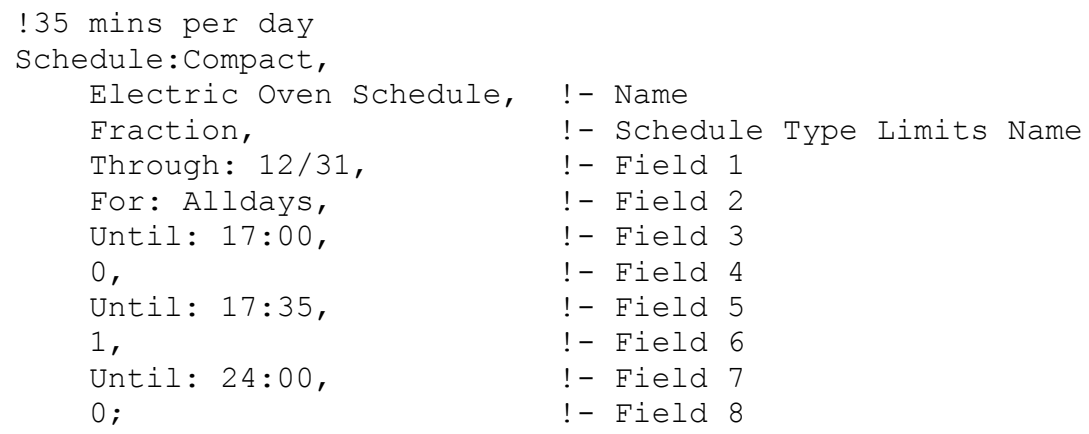




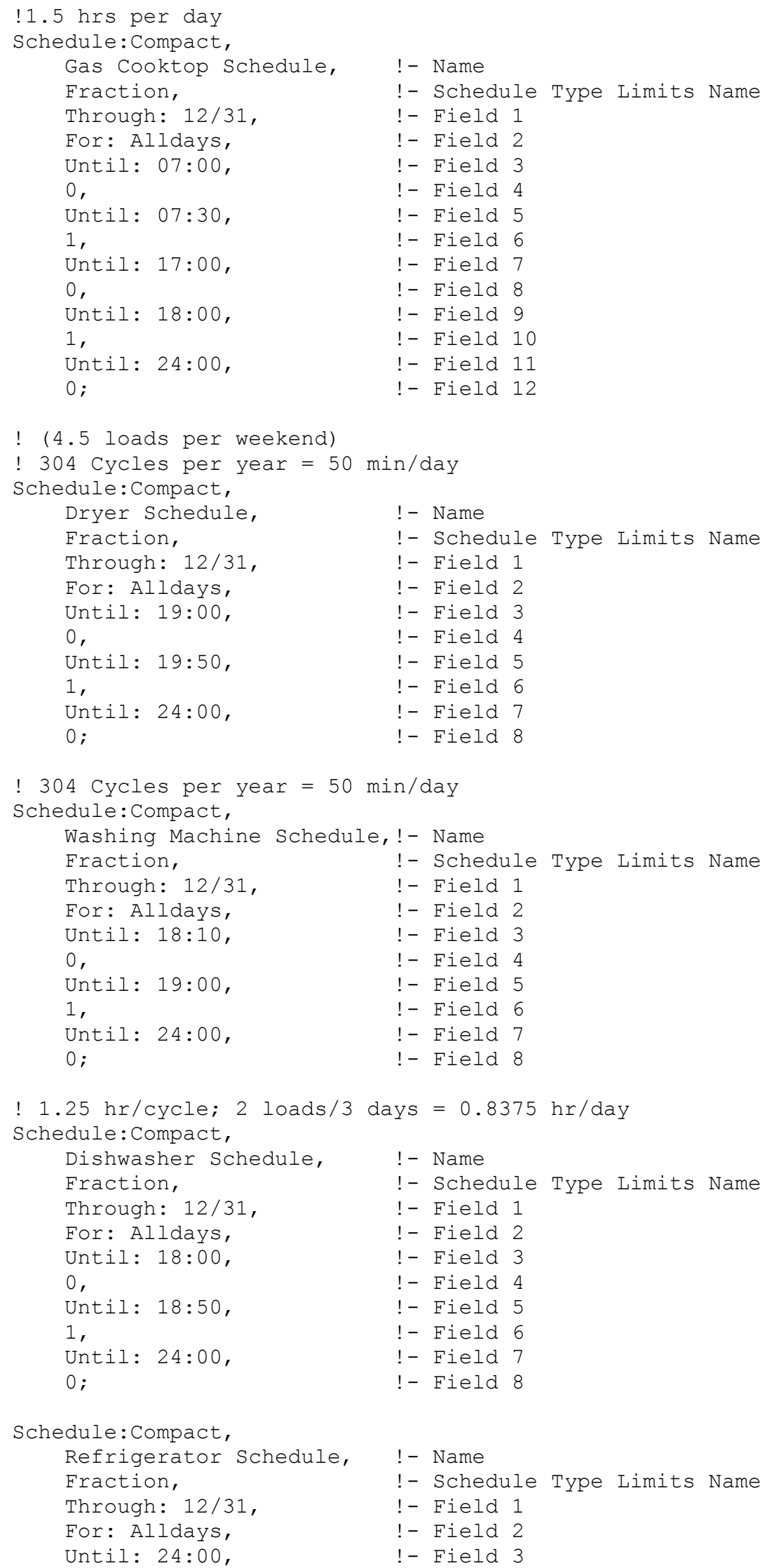


1 ;

Schedule: Compact, Plug Schedule, Fraction, Through: 01/31, For: AllDays, Until: 24:00, 0.9528 ,

Through: 02/28, For: AllDays, Until: 24:00, 0.9112 ,

Through: 03/31, For: AllDays, Until: 24:00, 0.9371 ,

Through: 04/30, For: AllDays, Until: 24:00, 0.7138 , Through: 05/31, For: AllDays, Until: 24:00, 0.7175 , Through: 06/30, For: AllDays, Until: 24:00, 0.6966 , Through: 07/31, For: AllDays, Until: 24:00, 0.6411 , Through: 08/31, For: AllDays, Until: 24:00, 0.6627 , Through: 09/30, For: AllDays, Until: 24:00, 0.7901 , Through: 10/31, For: AllDays, Until: 24:00, 0.9600 , Through: 11/30, For: AllDays, Until: 24:00, 0.8929 , Through: 12/31, For: AllDays, Until: 24:00, 1;

Schedule: Compact, $\mathrm{ON}$, Fraction, Through: 12/31, For: Alldays, Until: 24:00, 1 ;

Schedule: Compact,
!- Field 4

! - Name

!- Schedule Type Limits Name

! - Field 1

!- Field 2

! - Field 3

!- Field 4

! - Field 5

! - Field 6

!- Field 7

!- Field 8

!- Field 9

! - Field 10

!- Field 11

! - Field 12

! - Field 13

!- Field 14

!- Field 15

! - Field 16

!- Field 17

!- Field 18

!- Field 19

!- Field 20

!- Field 21

!- Field 22

!- Field 23

! - Field 24

! - Field 25

! - Field 26

! - Field 27

!- Field 28

! - Field 29

!- Field 30

!- Field 31

!- Field 32

!- Field 33

! - Field 34

!- Field 35

!- Field 36

!- Field 37

!- Field 38

!- Field 39

! - Field 40

!- Field 41

!- Field 42

!- Field 43

!- Field 44

!- Field 45

!- Field 46

!- Field 47

!- Field 48

! - Name

!- Schedule Type Limits Name

!- Field 1

!- Field 2

!- Field 3

!- Field 4 


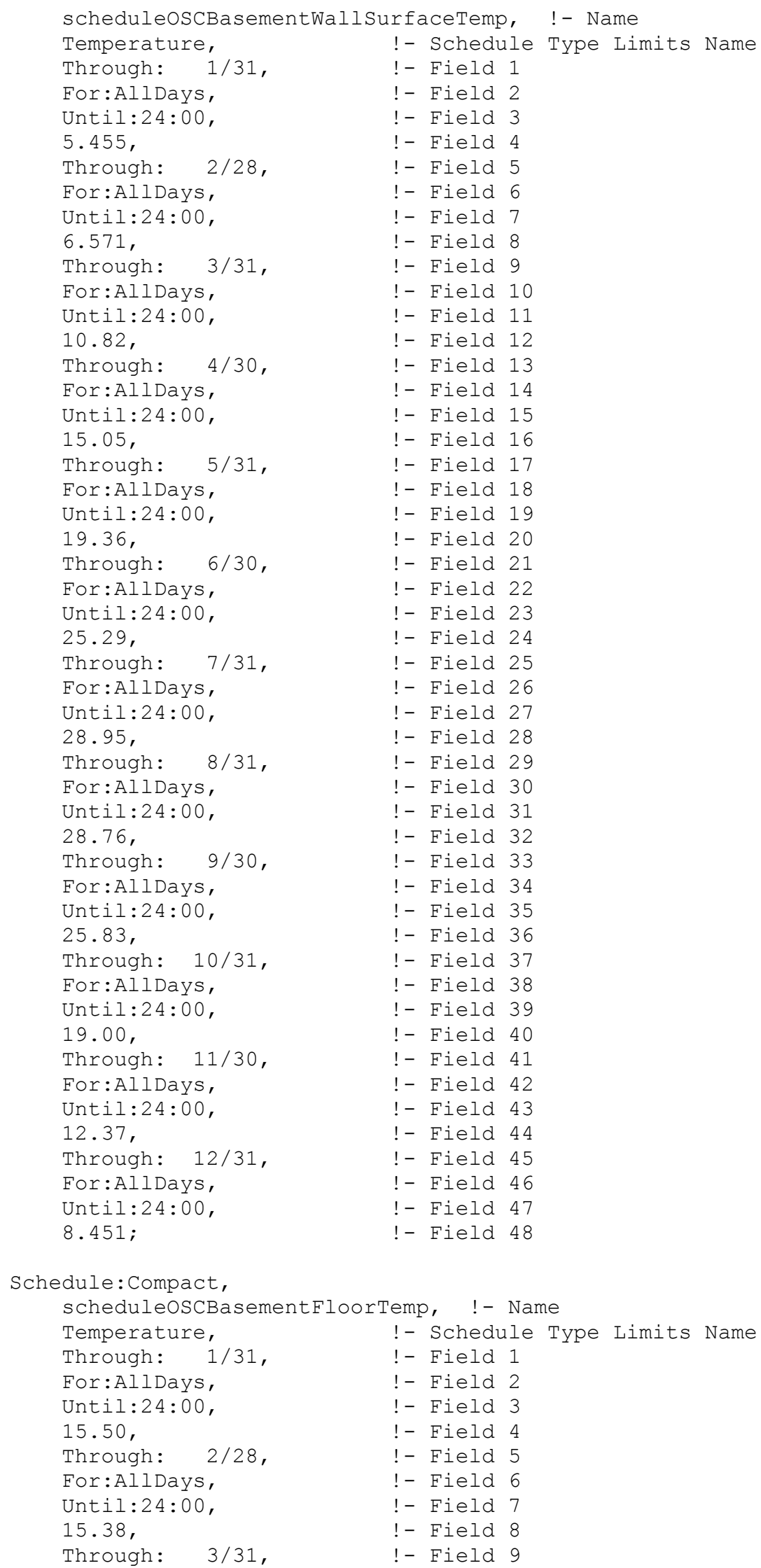




\begin{tabular}{|c|c|}
\hline & \\
\hline For:AllDays, & !- Field 10 \\
\hline Until:24:00, & !- Field 11 \\
\hline 16.19, & !- Field 12 \\
\hline Through: & !- Field \\
\hline For:AllDays, & !- Field \\
\hline Until:24:00, & !- Field \\
\hline 17.46 & !- Field \\
\hline Through: & !- Field \\
\hline For:AllDays, & !- Field \\
\hline Until:24:00, & !- Field \\
\hline 18.37, & !- Field \\
\hline Through: & !- Field \\
\hline For:AllDays, & !- Field \\
\hline Until:24:00, & !- Field \\
\hline 20.12 & !- Field \\
\hline Through: & !- Field \\
\hline For:AllDays, & ! - Field \\
\hline Until:24:00, & !- Field \\
\hline 21.38 & !- Field 28 \\
\hline Through: & !- Field 29 \\
\hline For:AllDays, & !- Field 3 \\
\hline Until:24:00, & !- Field \\
\hline 21.70 & !- Field 3 \\
\hline Through: & !- Field 3 \\
\hline For:AllDays, & !- Field 34 \\
\hline Until:24:00, & !- Field 3 \\
\hline 21.16 & !- Field 3 \\
\hline Through: 10/31, & !- Field 3 \\
\hline For:AllDays, & !- Field 3 \\
\hline Until:24:00, & !- Field 3 \\
\hline 19.57 & !- Field 4 \\
\hline Through: 11/30, & ! - Field 4 \\
\hline For:AllDays, & !- Field \\
\hline Until:24:00, & !- Field \\
\hline 17.69 & !- Field 4 \\
\hline Through: 12/31, & !- Field 4 \\
\hline For:AllDays, & !- Field \\
\hline Until:24:00, & !- Field \\
\hline $16.49 ;$ & !- Field \\
\hline
\end{tabular}

Schedule: Compact, scheduleoscBasementUpperWallTemp, !- Name Temperature, Through: 1/31, For:AllDays, Until:24:00, 4.869, Through: 2/28, For:AllDays, Until:24:00, 6.648, Through: 3/31, For:AllDays, Until:24:00, 11.90, Through: 4/30, For:AllDays, Until:24:00, 16.64, Through: 5/31, For:AllDays, Until:24:00, 21.91, !- Schedule Type Limits Name !- Field 1

! - Field 2

! - Field 3

!- Field 4

!- Field 5

! - Field 6

! - Field 7

! - Field 8

! - Field 9

!- Field 10

!- Field 11

!- Field 12

! - Field 13

! - Field 14

! - Field 15

! - Field 16

! - Field 17

!- Field 18

!- Field 19

!- Field 20 


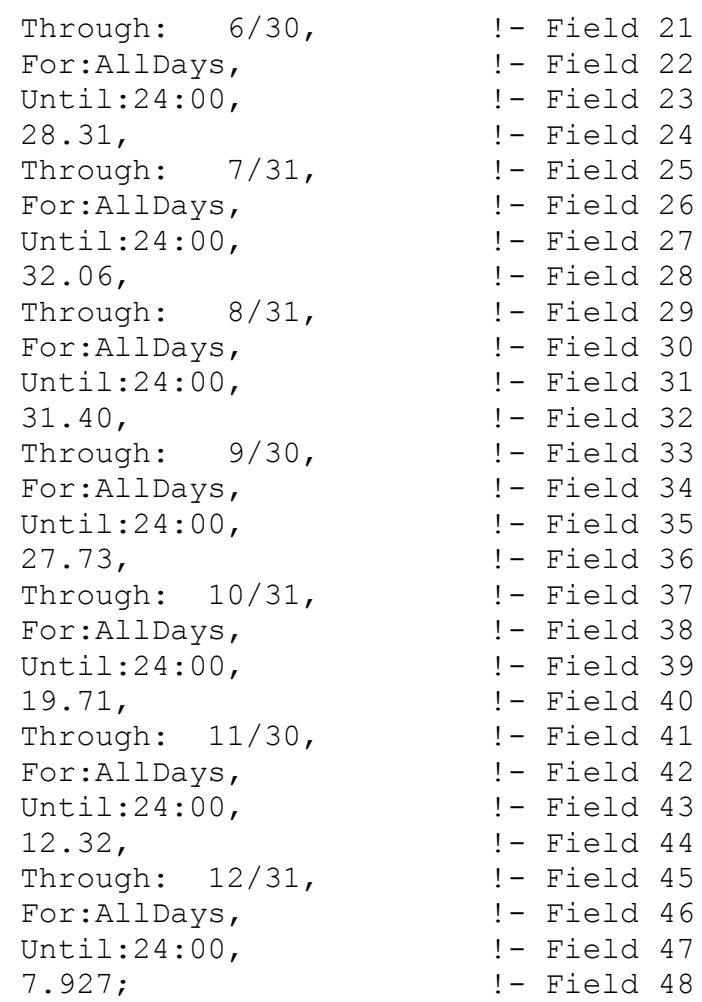

Schedule: Compact, scheduleoSCBasementLowerWallTemp, !- Name

Temperature,

Through: 1/31,

For:AllDays,

Until:24:00,

5.964,

Through: 2/28,

For:AllDays,

Until:24:00,

6.503 ,

Through: 3/31,

For:AllDays,

Until:24:00,

9.885 ,

Through: 4/30,

For:AllDays,

Until:24:00,

13.66 ,

Through: 5/31,

For:AllDays,

Until:24:00,

17.15,

Through: 6/30,

For:AllDays,

Until:24:00,

22.67 ,

Through: 7/31,

For:AllDays,

Until:24:00,

26.25,

Through: 8/31,

For:AllDays,

Until:24:00,
!- Schedule Type Limits Name

! - Field 1

!- Field 2

! - Field 3

! - Field 4

! - Field 5

! - Field 6

! - Field 7

!- Field 8

! - Field 9

! - Field 10

! - Field 11

!- Field 12

! - Field 13

! - Field 14

! - Field 15

!- Field 16

! - Field 17

! - Field 18

! - Field 19

! - Field 20

!- Field 21

! - Field 22

! - Field 23

! - Field 24

! - Field 25

! - Field 26

!- Field 27

! - Field 28

! - Field 29

!- Field 30

!- Field 31 


$\begin{array}{ll}\text { 26.46, } & \text { !- Field } 32 \\ \text { Through: 9/30, } & \text { !- Field } 33 \\ \text { For:AllDays, } & \text { !- Field } 34 \\ \text { Until:24:00, } & \text { !- Field } 35 \\ \text { 24.17, } & \text { !- Field } 36 \\ \text { Through: 10/31, } & \text { !- Field } 37 \\ \text { For:AllDays, } & \text { !- Field } 38 \\ \text { Until:24:00, } & \text { !- Field } 39 \\ \text { 18.39, } & \text { !- Field } 40 \\ \text { Through: 11/30, } & \text { !- Field } 41 \\ \text { For:AllDays, } & \text { !- Field } 42 \\ \text { Until:24:00, } & \text { !- Field } 43 \\ \text { 12.42, } & \text { !- Field } 44 \\ \text { Through: 12/31, } & \text { !- Field } 45 \\ \text { For:AllDays, } & \text { !- Field } 46 \\ \text { Until:24:00, } & \text { !- Field } 47 \\ \text { 8.907; } & \text { !- Field } 48\end{array}$

Schedule:Compact,

$\begin{array}{ll}\text { DHW Demand Schedule, } & !-\text { Name } \\ \text { Fraction, } & !-\text { Schedule Type Limits Name } \\ \text { THROUGH: 12/31, } & !-\text { Field } 1 \\ \text { FOR: AllDays, } & !-\text { Field } 2 \\ \text { UNTIL: 7:00, } & !-\text { Field } 3 \\ \text { 0, } & !-\text { Field } 4 \\ \text { UNTIL: 7:30, } & !-\text { Field } 5 \\ \text {.05485, } & !-\text { Field } 6 \\ \text { UNTIL: 17:00, } & !-\text { Field } 7 \\ \text { O, } & !-\text { Field } 8 \\ \text { UNTIL: 20:00, } & !-\text { Field } 9 \\ \text {.01724, } 10 \\ \text { UNTIL: 24:00, } \\ \text { 0; }\end{array}$

Schedule: Compact,

Hot Water Setpoint Temp Schedule, !- Name

Any Number, !- Schedule Type Limits Name

THROUGH: 12/31, !- Field 1

FOR: AllDays, ! - Field 2

UNTIL: 24:00, !- Field 3

$50 ; \quad !-$ Field 4

Schedule:Compact,

Constant Mains Temp Schedule, !- Name

Any Number, !- Schedule Type Limits Name

THROUGH: 12/31, !- Field 1

FOR: AllDays, !- Field 2

UNTIL: 24:00, !- Field 3

12; !- Field 4

Schedule:Compact, Inf schedule,

Fraction,

Through: $12 / 31$

For:Alldays,

Until: 24:00,

1 ;

!- Name
!- Schedul
!- Field 1
!- Field 2
!- Field 3
!- Field 4

! this schedule is for the boiler \& hw loop

Schedule:Compact, HW LOOP TEMP SCHEDULE, !- Name TEMPERATURE,

Through: 12/31,

!- Schedule Type Limits Name

!- Field 1 


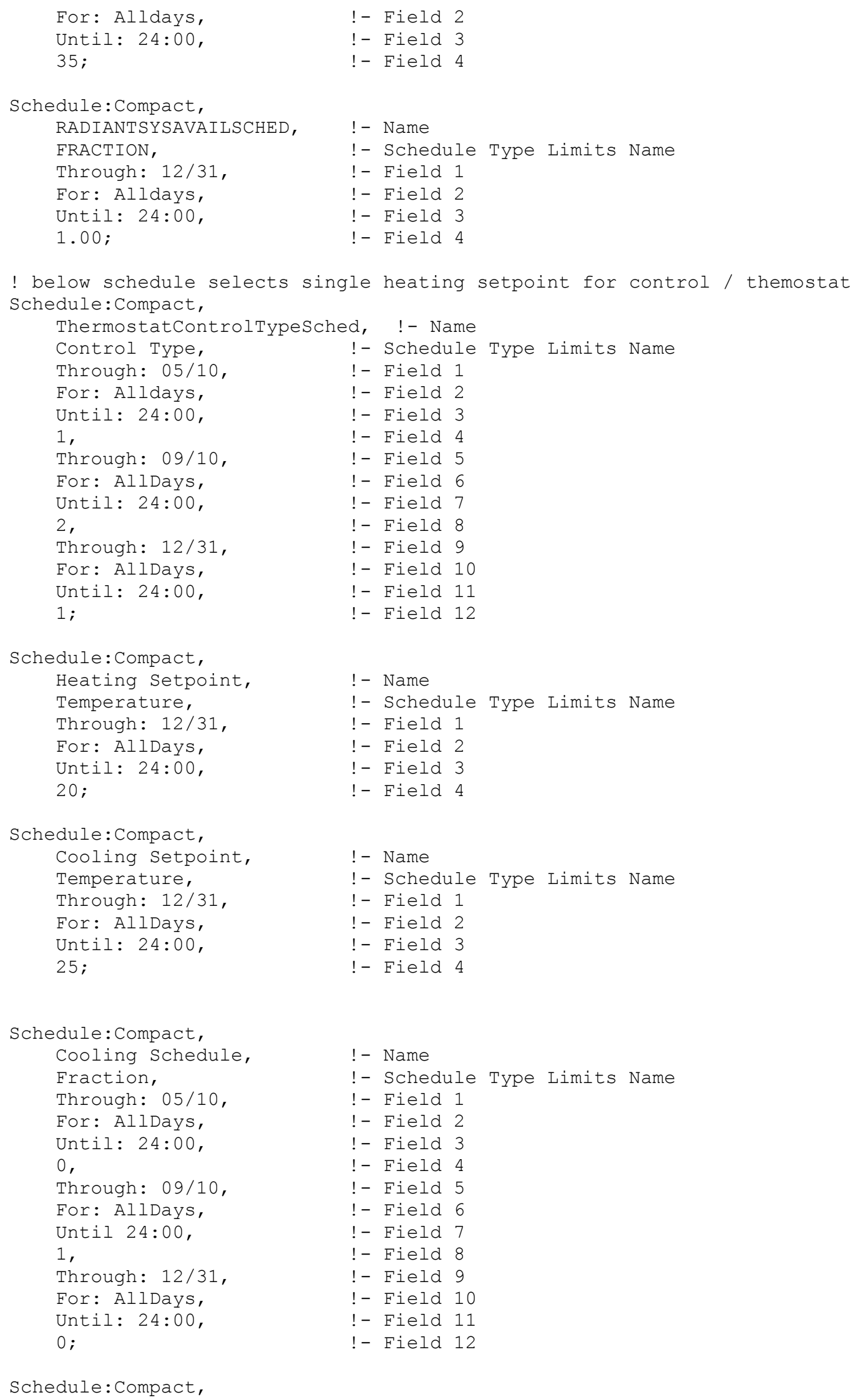

Schedule:Compact, 


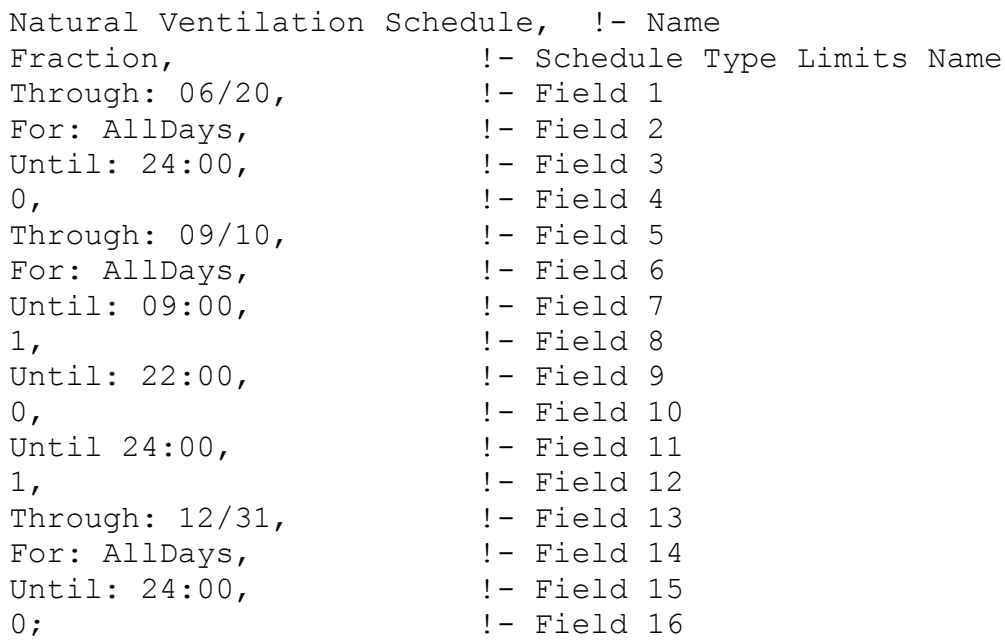




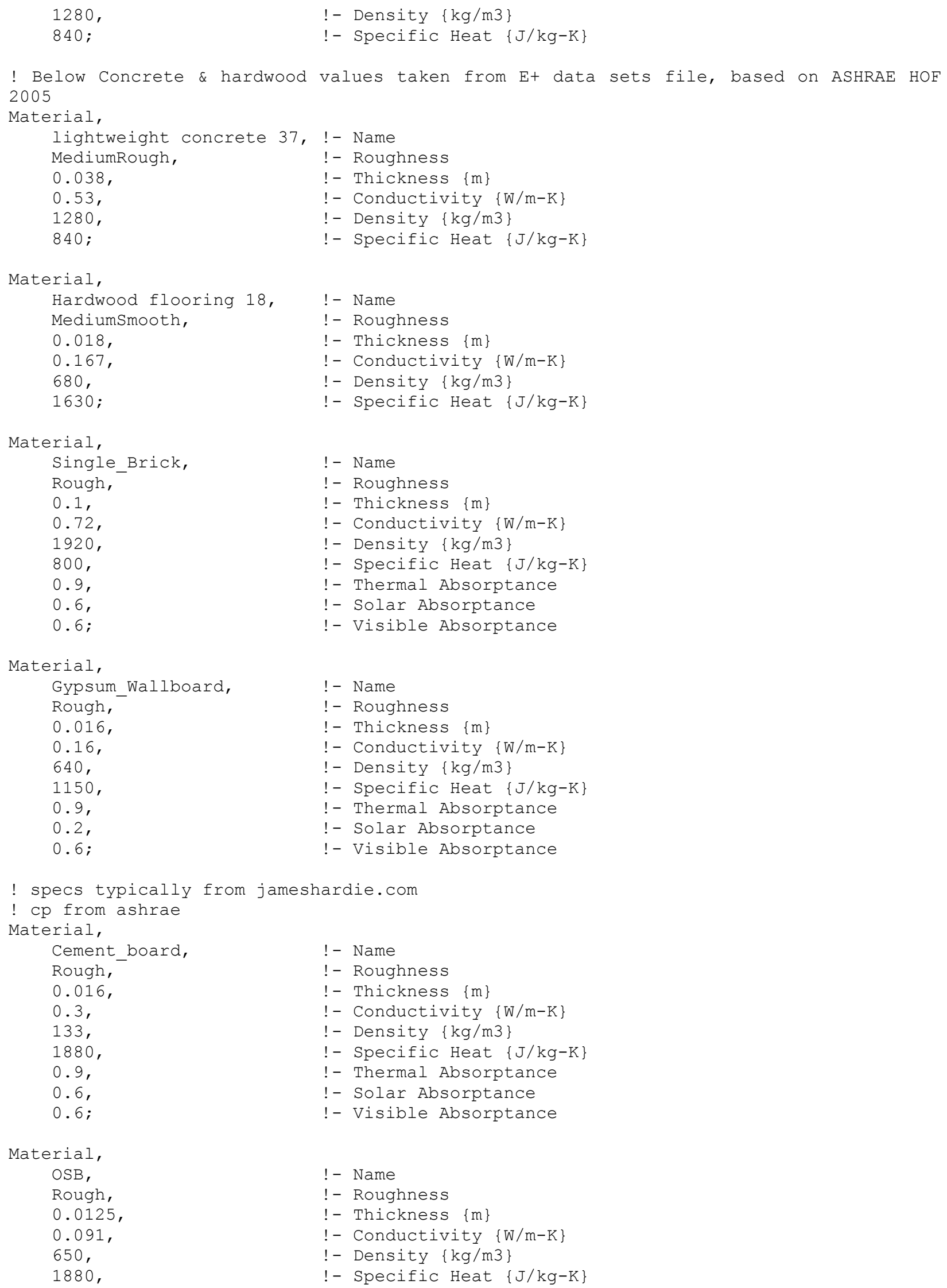



0.9,
!- Thermal Absorptance
0.4 ,
!- Solar Absorptance
0.6 ;
!- Visible Absorptance

Material,

Shingles Asphalt, !- Name

Rough,

0.003 ,

0.038,

!- Roughness

!- Thickness $\{\mathrm{m}\}$

920 ,

1510,

!- Conductivity $\{\mathrm{W} / \mathrm{m}-\mathrm{K}\}$

0.9 ,

!- Density $\{\mathrm{kg} / \mathrm{m} 3\}$

!- Specific Heat $\{\mathrm{J} / \mathrm{kg}-\mathrm{K}\}$

0.9 ,

!- Thermal Absorptance

0.9,

!- Solar Absorptance

!- Visible Absorptance

! below material taken from E+ data set ASHRAE F.25 2005

Material,

F08 Metal surface, !- Name

Smooth,

0.0008,

!- Roughness

!- Thickness $\{m\}$

45.28,

!- Conductivity $\{\mathrm{W} / \mathrm{m}-\mathrm{K}\}$

7824,

!- Density $\{\mathrm{kg} / \mathrm{m} 3\}$

500 ;

!- Specific Heat $\{\mathrm{J} / \mathrm{kg}-\mathrm{K}\}$

! area weighted properties based on 15\% wood framing \& air Material,

hollow_frame_wall_mat, !- Name

Rough, !- Roughness

0.14, !- Thickness $\{\mathrm{m}\}$

5, $\quad !-$ Conductivity $\{\mathrm{W} / \mathrm{m}-\mathrm{K}\}$

60,

1140,

0.9 ,

!- Density $\{\mathrm{kg} / \mathrm{m} 3\}$

0.4,

!- Specific Heat $\{\mathrm{J} / \mathrm{kg}-\mathrm{K}\}$

!- Thermal Absorptance

! - Solar Absorptance

0.6 ;

!- Visible Absorptance

Material,

6" Joists Insulated w Roxul, !- Name

Rough,

0.140 ,

0.0456 ,

101 ,

1081 ,

0.9,

0.7,

0.7 ;

! - Roughness

!- Thickness $\{m\}$

!- Conductivity $\{\mathrm{W} / \mathrm{m}-\mathrm{K}\}$

! - Density $\{\mathrm{kg} / \mathrm{m} 3\}$

!- Specific Heat $\{\mathrm{J} / \mathrm{kg}-\mathrm{K}\}$

!- Thermal Absorptance

!- Solar Absorptance

!- Visible Absorptance

Material,

XPS_0,

Rough,

! - Name

0.000001

0.02839,

35 ,

1400 ,

0.9 ,

0.6 ,

0.6 ;

! - Roughness

!- Thickness $\{\mathrm{m}\}$

!- Conductivity $\{\mathrm{W} / \mathrm{m}-\mathrm{K}\}$

!- Density $\{\mathrm{kg} / \mathrm{m} 3\}$

!- Specific Heat $\{\mathrm{J} / \mathrm{kg}-\mathrm{K}\}$

!- Thermal Absorptance

!- Solar Absorptance

!- Visible Absorptance

Material,

XPS_25,

Rough,

! - Name

0.025 ,

0.02839 ,

! - Roughness

!- Thickness $\{\mathrm{m}\}$

!- Conductivity $\{\mathrm{W} / \mathrm{m}-\mathrm{K}\}$ 


$$
\begin{aligned}
& 35, \\
& 1400, \\
& 0.9, \\
& 0.6 ; \\
& 0.6 ;
\end{aligned}
$$

Material, XPS_51, Rough,

0.051 , 0.02895 , 35 , 1400 ,

0.9 ,

0.6 ,

0.6 ;

Material, XPS_76, Rough,

0.076 ,

0.02876 ,

35 , 1400,

0.9 ,

0.6 ,

0.6 ;

Material, XPS_102, Rough, 0.102 , 0.02895 , 35 , 1400 ,

0.9 ,

0.6 ,

0.6 ;

Material, XPS_127, Rough, 0.127 , 0.02884 , 35 , 1400 ,

0.9 ,

0.6 ,

0.6 ;

Material, XPS 152, Rough, 0.152 , 0.02876 , 35 , 1400 ,

0.9 ,

0.6 ,

0.6 ;

Material, XPS_178,
!- Density $\{\mathrm{kg} / \mathrm{m} 3\}$

!- Specific Heat $\{\mathrm{J} / \mathrm{kg}-\mathrm{K}\}$

!- Thermal Absorptance

!- Solar Absorptance

!- Visible Absorptance

! - Name

! - Roughness

!- Thickness $\{\mathrm{m}\}$

!- Conductivity $\{\mathrm{W} / \mathrm{m}-\mathrm{K}\}$

!- Density $\{\mathrm{kg} / \mathrm{m} 3\}$

!- Specific Heat $\{\mathrm{J} / \mathrm{kg}-\mathrm{K}\}$

!- Thermal Absorptance

! - Solar Absorptance

!- Visible Absorptance

! - Name

! - Roughness

!- Thickness $\{\mathrm{m}\}$

! - Conductivity $\{\mathrm{W} / \mathrm{m}-\mathrm{K}\}$

!- Density $\{\mathrm{kg} / \mathrm{m} 3\}$

!- Specific Heat $\{\mathrm{J} / \mathrm{kg}-\mathrm{K}\}$

!- Thermal Absorptance

! - Solar Absorptance

!- Visible Absorptance

! - Name

!- Roughness

!- Thickness $\{\mathrm{m}\}$

!- Conductivity $\{\mathrm{W} / \mathrm{m}-\mathrm{K}\}$

!- Density $\{\mathrm{kg} / \mathrm{m} 3\}$

!- Specific Heat $\{\mathrm{J} / \mathrm{kg}-\mathrm{K}\}$

!- Thermal Absorptance

!- Solar Absorptance

!- Visible Absorptance

! - Name

!- Roughness

!- Thickness $\{\mathrm{m}\}$

! - Conductivity $\{\mathrm{W} / \mathrm{m}-\mathrm{K}\}$

!- Density $\{\mathrm{kg} / \mathrm{m} 3\}$

!- Specific Heat $\{\mathrm{J} / \mathrm{kg}-\mathrm{K}\}$

!- Thermal Absorptance

!- Solar Absorptance

!- Visible Absorptance

! - Name

! - Roughness

!- Thickness $\{\mathrm{m}\}$

!- Conductivity $\{\mathrm{W} / \mathrm{m}-\mathrm{K}\}$

!- Density $\{\mathrm{kg} / \mathrm{m} 3\}$

!- Specific Heat $\{\mathrm{J} / \mathrm{kg}-\mathrm{K}\}$

!- Thermal Absorptance

!- Solar Absorptance

!- Visible Absorptance

! - Name 


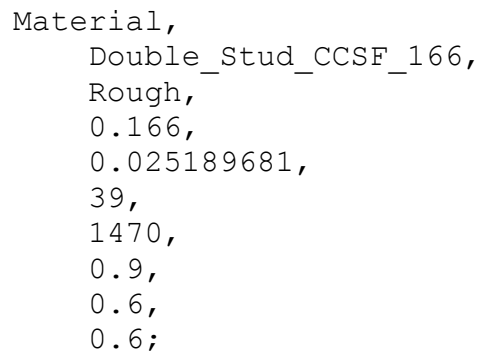

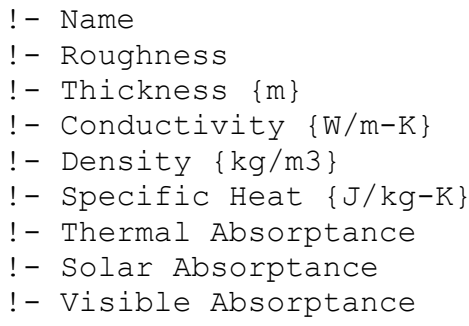



0.9,
!- Thermal Absorptance
0.6,
!- Solar Absorptance
0.6 ;
!- Visible Absorptance

Material,

Joist_CCSF_152, !- Name

Rough,

0.152 ,

!- Roughness

!- Thickness $\{\mathrm{m}\}$

0.033572623 ,

! - Conductivity $\{\mathrm{W} / \mathrm{m}-\mathrm{K}\}$

39 ,

1470,

0.9 ,

!- Density $\{\mathrm{kg} / \mathrm{m} 3\}$

!- Specific Heat $\{\mathrm{J} / \mathrm{kg}-\mathrm{K}\}$

0.6,

0.6 ;

!- Thermal Absorptance

! - Solar Absorptance

!- Visible Absorptance

Material,

Joist CCSF 178, ! ! Name

Rough,

0.178 ,

0.033698836 ,

! - Roughness

!- Thickness $\{\mathrm{m}\}$

!- Conductivity $\{\mathrm{W} / \mathrm{m}-\mathrm{K}\}$

39 ,

1470,

0.9 ,

!- Density $\{\mathrm{kg} / \mathrm{m} 3\}$

!- Specific Heat $\{\mathrm{J} / \mathrm{kg}-\mathrm{K}\}$

!- Thermal Absorptance

0.6 ,

0.6 ;

!- Solar Absorptance

!- Visible Absorptance

Material,

Joist CCSF 203, !- Name

Rough,

0.203 ,

0.033627841 ,

! - Roughness

!- Thickness $\{\mathrm{m}\}$

!- Conductivity $\{\mathrm{W} / \mathrm{m}-\mathrm{K}\}$

39 ,

1470 ,

0.9,

! - Density $\{\mathrm{kg} / \mathrm{m} 3\}$

!- Specific Heat $\{\mathrm{J} / \mathrm{kg}-\mathrm{K}\}$

!- Thermal Absorptance

! - Solar Absorptance

!- Visible Absorptance

Material,

Joist CCSF 229, !- Name

Rough,

0.229 ,

0.033719872,

! - Roughness

!- Thickness $\{\mathrm{m}\}$

! - Conductivity $\{\mathrm{W} / \mathrm{m}-\mathrm{K}\}$

39 ,

1470,

0.9,

0.6 ,

0.6 ;

!- Density $\{\mathrm{kg} / \mathrm{m} 3\}$

!- Specific Heat $\{\mathrm{J} / \mathrm{kg}-\mathrm{K}\}$

!- Thermal Absorptance

!- Solar Absorptance

!- Visible Absorptance

Material,

Joist CCSF 241, !- Name

Rough,

0.241 ,

0.033619123,

!- Roughness

!- Thickness $\{\mathrm{m}\}$

!- Conductivity $\{\mathrm{W} / \mathrm{m}-\mathrm{K}\}$

39 ,

1470,

0.9 ,

! - Density $\{\mathrm{kg} / \mathrm{m} 3\}$

!- Specific Heat $\{\mathrm{J} / \mathrm{kg}-\mathrm{K}\}$

0.6 ,

!- Thermal Absorptance

!- Solar Absorptance

0.6 ;

!- Visible Absorptance

! $-\quad========$ ALL OBJECTS IN CLASS: MATERIAL $:$ NOMASS $========$

Material: NoMass, 


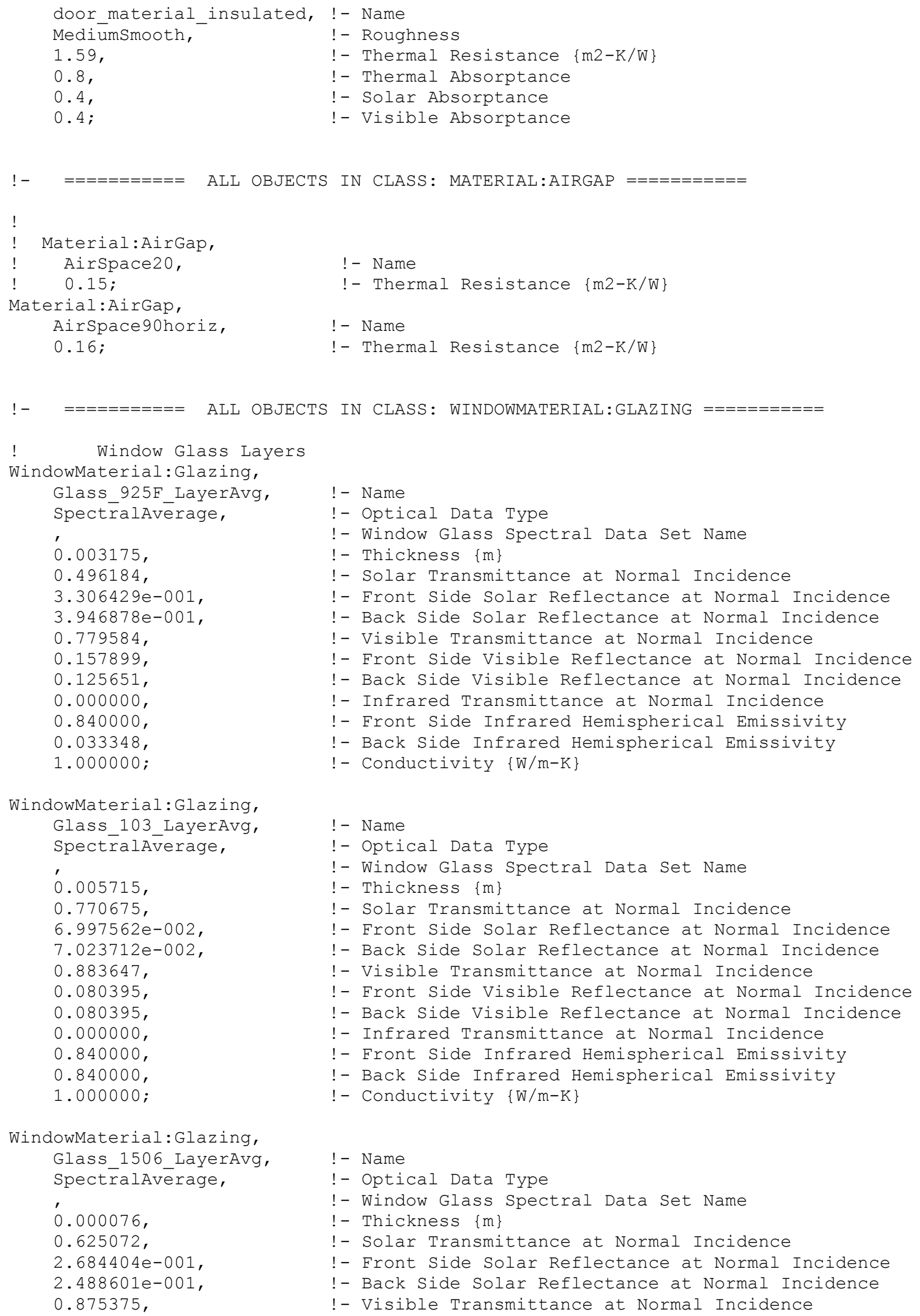


0.056914,

0.063447 ,

0.000000,

0.110000 ,

0.760000 ,

0.140187 ;

WindowMaterial:Glazing, Glass_2191F_LayerAvg, SpectralAverage,

0.003000 ,

0.689212 ,

$1.892671 e-001$

1.641387e-001,

0.870953 ,

0.077994,

0.091237 ,

0.000000 ,

0.068000 ,

0.840000 ,

1.000000 ;

WindowMaterial:Glazing, no glass, SpectralAverage,

'

0.001 ,

0.9 ,

0.1 ,

0.1 ,

0.9 ,

0.1 ,

0.1 ,

0.9 ,

0.1 ,

0.1 ,

100 ,

No ;

WindowMaterial:Glazing, Glass_2002_LayerAvg, SpectralAverage,

0.004060 ,

0.823491 ,

$7.377488 e-002$,

7.377488e-002,

0.900821 ,

0.081949 ,

0.081949 ,

0.000000 ,

0.840000 ,

0.840000 ,

1.000000 ;

WindowMaterial: Glazing, Glass_2192F_LayerAvg, SpectralAverage,

0.004060 ,

0.670741 ,
!- Front Side Visible Reflectance at Normal Incidence

!- Back Side Visible Reflectance at Normal Incidence

!- Infrared Transmittance at Normal Incidence

!- Front Side Infrared Hemispherical Emissivity

!- Back Side Infrared Hemispherical Emissivity

!- Conductivity $\{\mathrm{W} / \mathrm{m}-\mathrm{K}\}$

! - Name

!- Optical Data Type

!- Window Glass Spectral Data Set Name

!- Thickness $\{\mathrm{m}\}$

!- Solar Transmittance at Normal Incidence

!- Front Side Solar Reflectance at Normal Incidence

!- Back Side Solar Reflectance at Normal Incidence

!- Visible Transmittance at Normal Incidence

!- Front Side Visible Reflectance at Normal Incidence

!- Back Side Visible Reflectance at Normal Incidence

! - Infrared Transmittance at Normal Incidence

!- Front Side Infrared Hemispherical Emissivity

!- Back Side Infrared Hemispherical Emissivity

!- Conductivity $\{\mathrm{W} / \mathrm{m}-\mathrm{K}\}$

! - Name

!- Optical Data Type

!- Window Glass Spectral Data set Name

!- Thickness $\{m\}$

! - Solar Transmittance at Normal Incidence

!- Front Side Solar Reflectance at Normal Incidence

!- Back Side Solar Reflectance at Normal Incidence

!- Visible Transmittance at Normal Incidence

!- Front Side Visible Reflectance at Normal Incidence

! - Back Side Visible Reflectance at Normal Incidence

!- Infrared Transmittance at Normal Incidence

!- Front Side Infrared Hemispherical Emissivity

!- Back Side Infrared Hemispherical Emissivity

!- Conductivity $\{\mathrm{W} / \mathrm{m}-\mathrm{K}\}$

!- Dirt Correction Factor for Solar and Visible Transmittance !- Solar Diffusing

! - Name

!- Optical Data Type

!- Window Glass Spectral Data set Name

!- Thickness $\{\mathrm{m}\}$

! - Solar Transmittance at Normal Incidence

!- Front Side Solar Reflectance at Normal Incidence

!- Back Side Solar Reflectance at Normal Incidence

!- Visible Transmittance at Normal Incidence

!- Front Side Visible Reflectance at Normal Incidence

! - Back Side Visible Reflectance at Normal Incidence

! - Infrared Transmittance at Normal Incidence

!- Front Side Infrared Hemispherical Emissivity

!- Back Side Infrared Hemispherical Emissivity

!- Conductivity $\{\mathrm{W} / \mathrm{m}-\mathrm{K}\}$

! - Name

!- Optical Data Type

!- Window Glass Spectral Data Set Name

!- Thickness $\{\mathrm{m}\}$

!- Solar Transmittance at Normal Incidence 


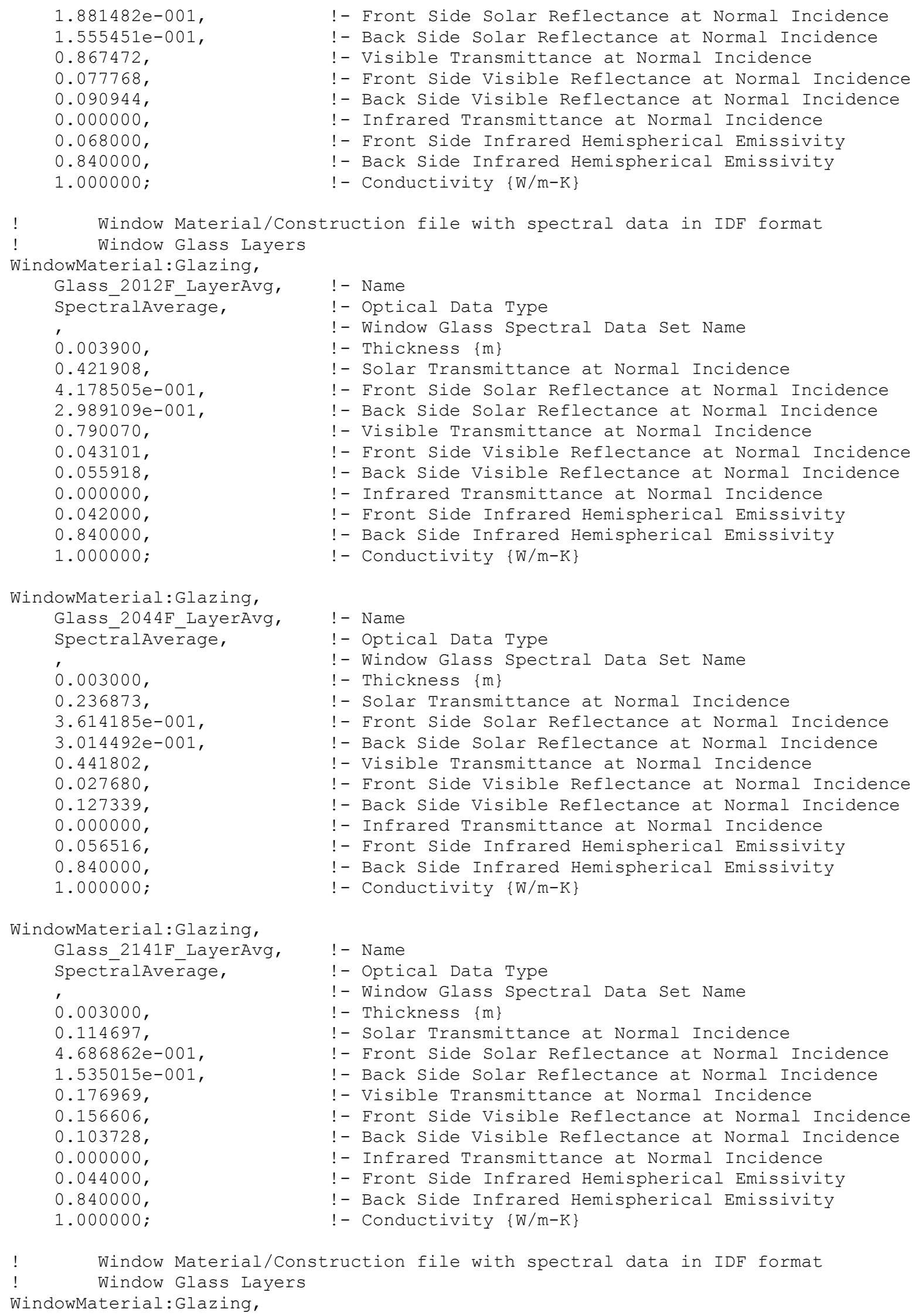

WindowMaterial:Glazing, Glass_2044F_LayerAvg, SpectralAverage,

WindowMaterial:Glazing, Glass_2141F_LayerAvg, SpectralAverage,

0.003000

0.114697 ,

$4.686862 e-001$,

$1.535015 e-001$,

0.176969 ,

0.156606,

0.103728,

0.000000,

0.044000

0.840000,

1.000000 ;

! - Name

! - Optical Data Type

!- Window Glass Spectral Data set Name

!- Thickness $\{\mathrm{m}\}$

! - Solar Transmittance at Normal Incidence

!- Front Side Solar Reflectance at Normal Incidence

!- Back Side Solar Reflectance at Normal Incidence

!- Visible Transmittance at Normal Incidence

!- Front Side Visible Reflectance at Normal Incidence

!- Back Side Visible Reflectance at Normal Incidence

!- Infrared Transmittance at Normal Incidence

!- Front Side Infrared Hemispherical Emissivity

!- Back Side Infrared Hemispherical Emissivity

!- Conductivity $\{\mathrm{W} / \mathrm{m}-\mathrm{K}\}$

! Window Material/Construction file with spectral data in IDF format ! Window Glass Layers

WindowMaterial:Glazing, 


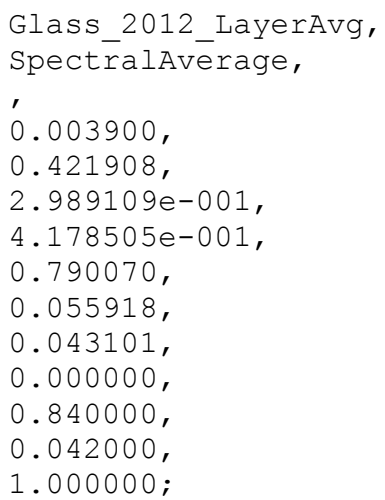

! Window Material/Construction file with spectral data in IDF format

WindowMaterial:Glazing, Glass_2001_LayerAvg, SpectralAverage,

! - Name

!- Optical Data Type

0.002970 ,

0.848127,

$7.557136 \mathrm{e}-002$,

$7.557136 e-002$,

0.904473 ,

0.082163,

0.082163,

0.000000

0.840000,

0.840000

1.000000

! - Window Glass Spectral Data set Name

!- Thickness $\{\mathrm{m}\}$

!- Solar Transmittance at Normal Incidence

!- Front Side Solar Reflectance at Normal Incidence

!- Back Side Solar Reflectance at Normal Incidence

!- Visible Transmittance at Normal Incidence

!- Front Side Visible Reflectance at Normal Incidence

!- Back Side Visible Reflectance at Normal Incidence

!- Infrared Transmittance at Normal Incidence

!- Front Side Infrared Hemispherical Emissivity

!- Back Side Infrared Hemispherical Emissivity

!- Conductivity $\{\mathrm{W} / \mathrm{m}-\mathrm{K}\}$

! Window Material/Construction file with spectral data in IDF format ! Window Glass Layers

WindowMaterial:Glazing, Glass 2192 LayerAvg, SpectralAvèrage,

,

0.004060

0.670741 ,

$1.555451 \mathrm{e}-001$

1.881482e-001,

0.867472 ,

0.090944,

0.077768,

0.000000,

! - Name

!- Optical Data Type

!- Window Glass Spectral Data set Name

!- Thickness $\{m\}$

!- Solar Transmittance at Normal Incidence

!- Front Side Solar Reflectance at Normal Incidence

!- Back Side Solar Reflectance at Normal Incidence

!- Visible Transmittance at Normal Incidence

!- Front Side Visible Reflectance at Normal Incidence

!- Back Side Visible Reflectance at Normal Incidence

!- Infrared Transmittance at Normal Incidence 


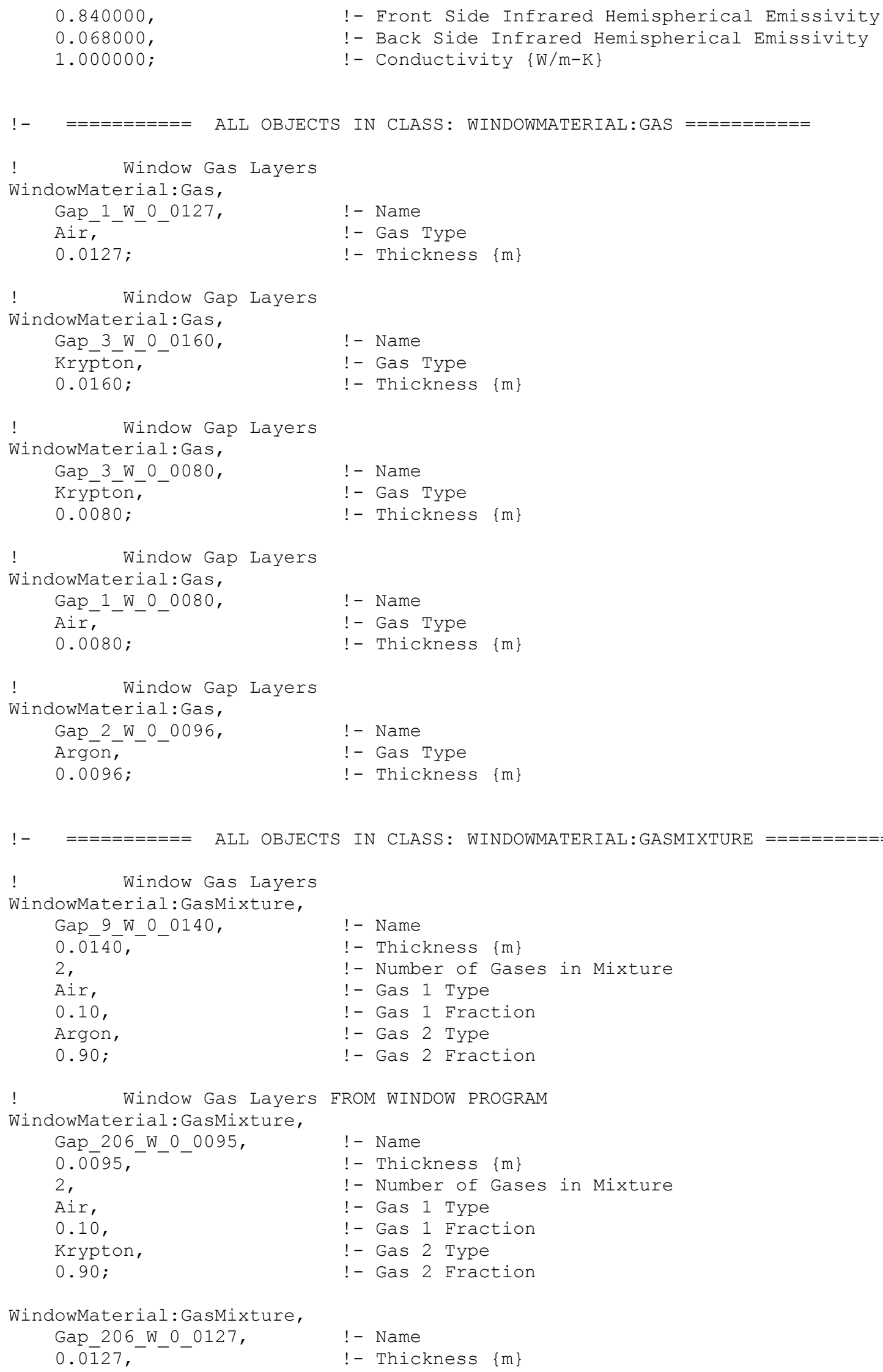



2,
!- Number of Gases in Mixture
Air,
0.10 ,
Krypton,
!- Gas 1 Type
!- Gas 1 Fraction
!- Gas 2 Type
0.90 ;
!- Gas 2 Fraction

! Window Mixed Gas Layers

WindowMaterial:GasMixture,
$0.007 \overline{9}$, W_- 0079 ,
! - Name
2,
Air,
0.05 ,
Krypton,
0.95 ;
!- Thickness $\{\mathrm{m}\}$
!- Number of Gases in Mixture
! - Gas 1 Type
!- Gas 1 Fraction
!- Gas 2 Type
!- Gas 2 Fraction

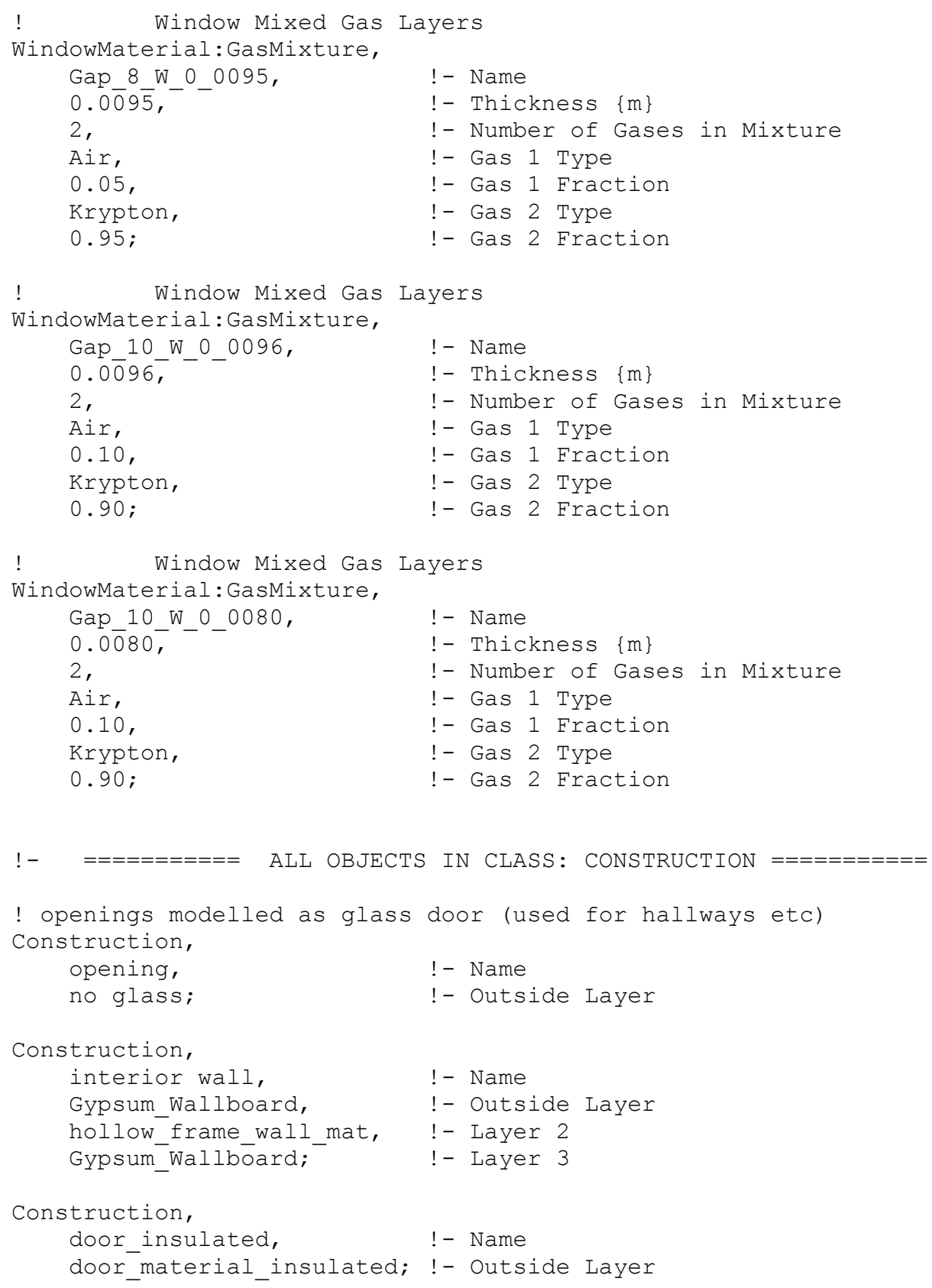




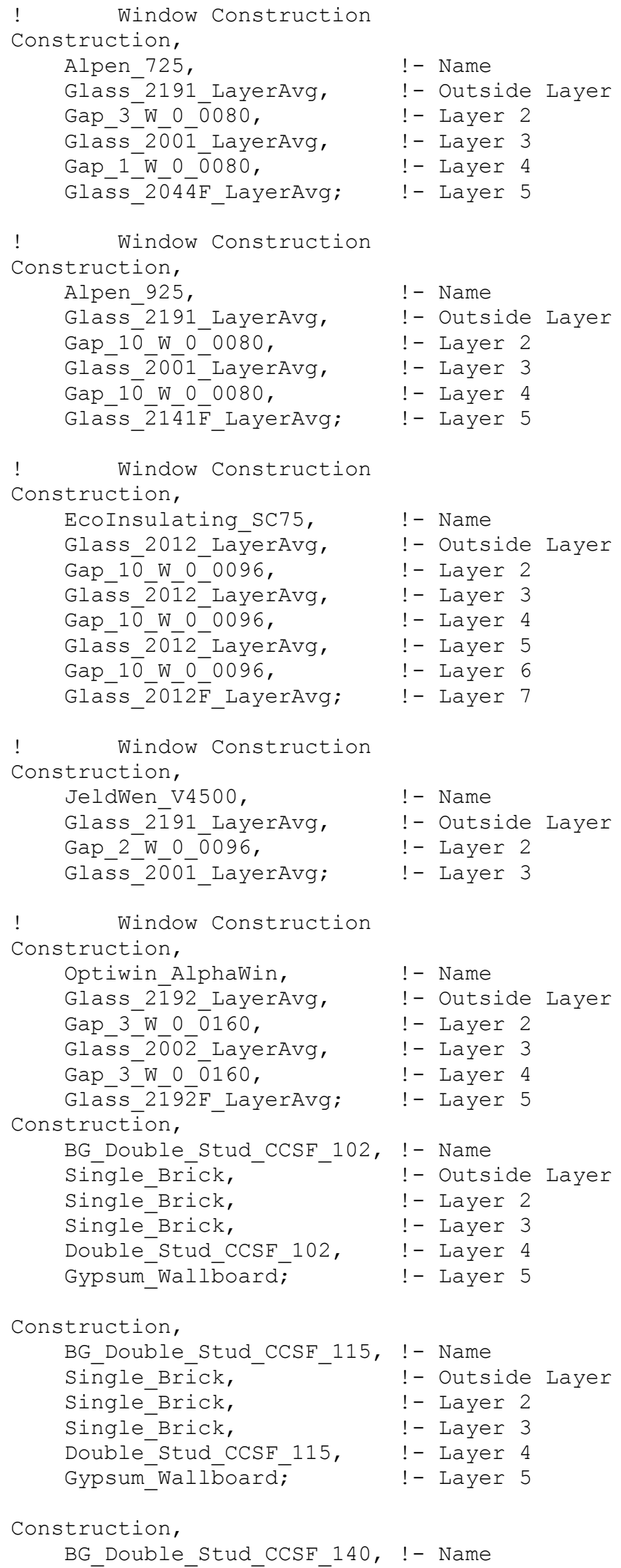




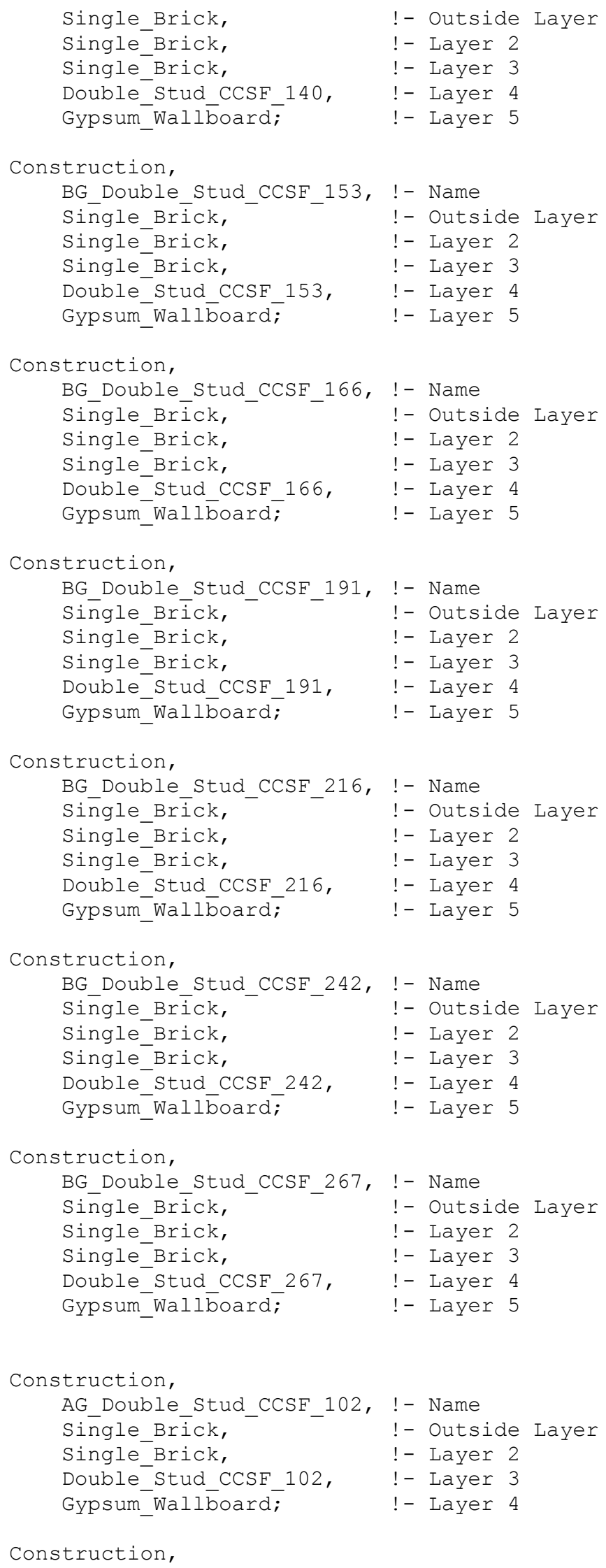




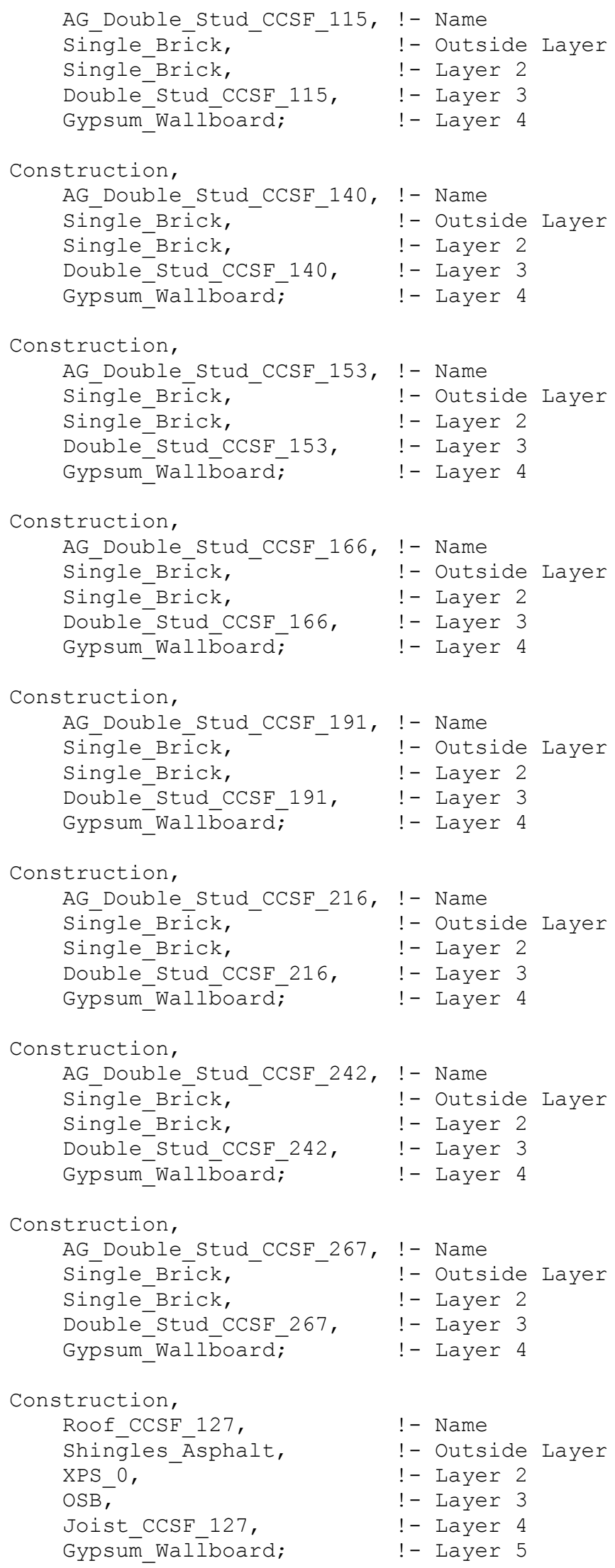




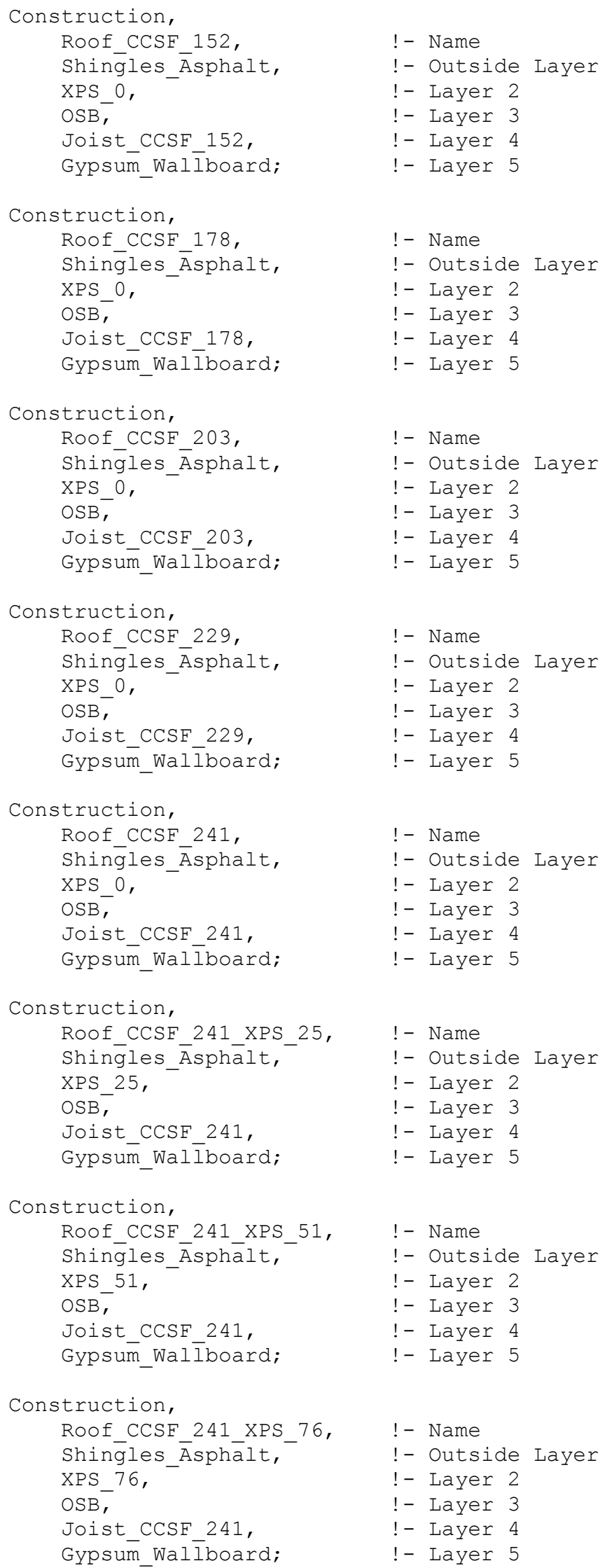




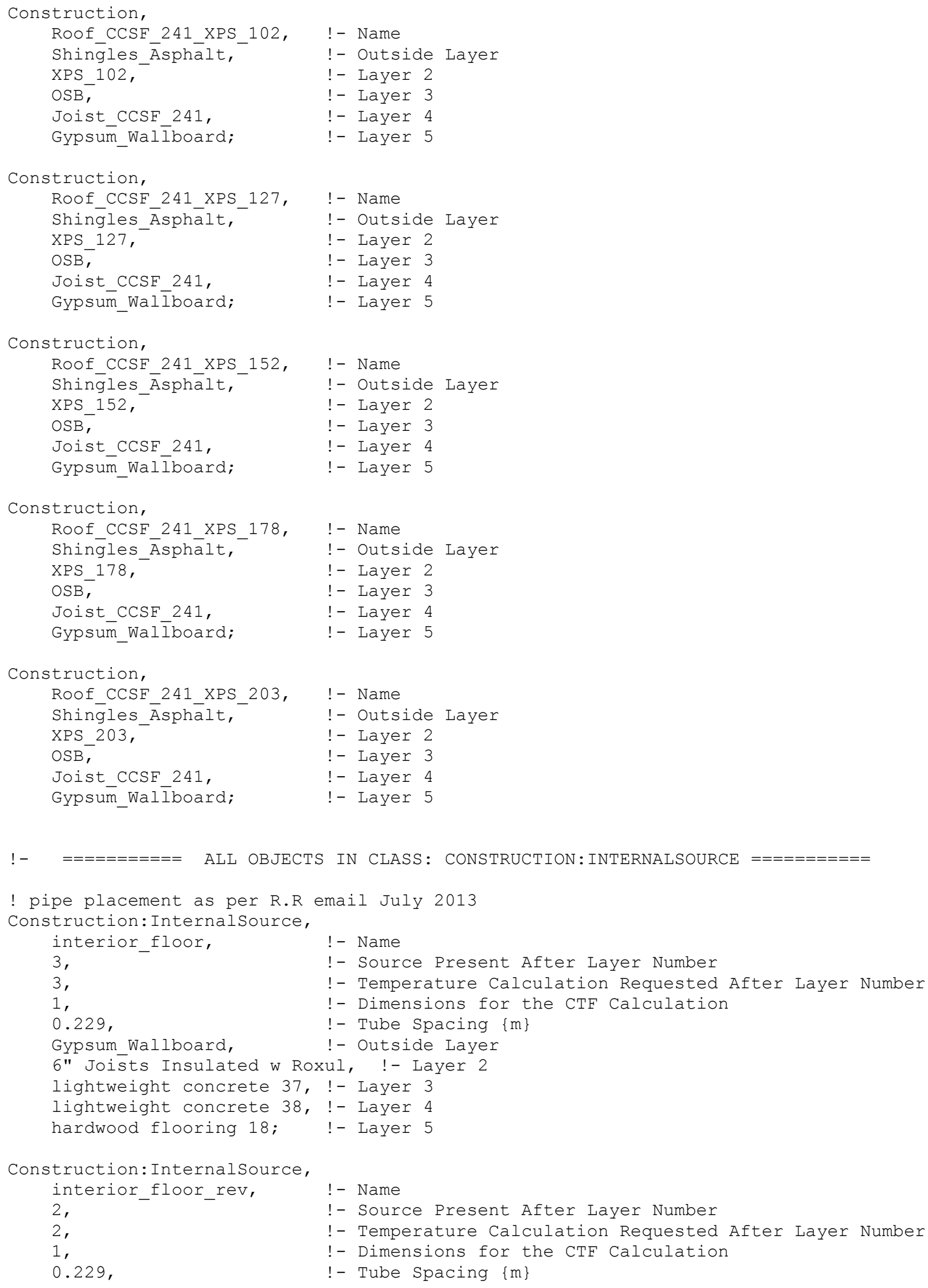




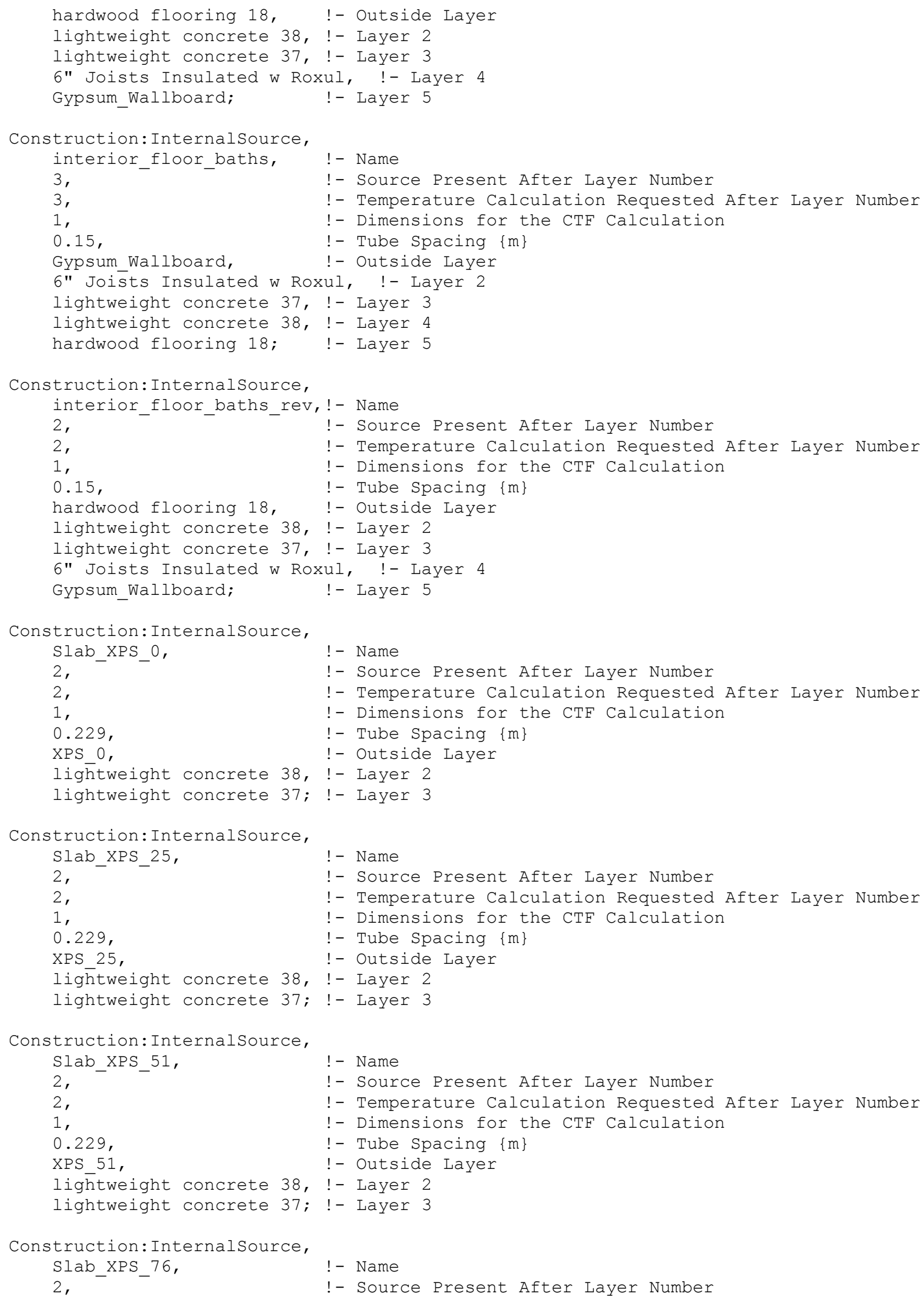




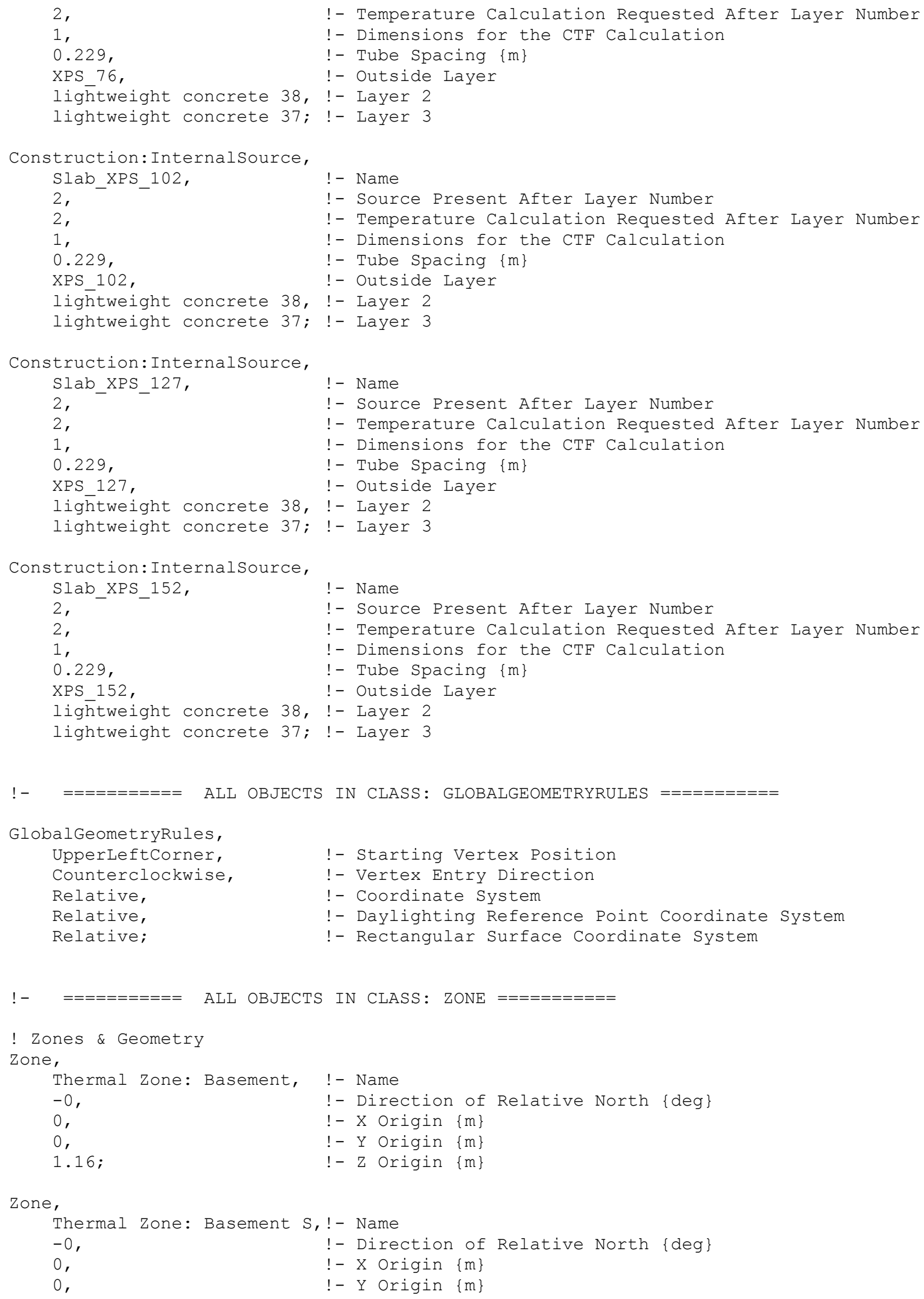



1.16
!- Z Origin $\{m\}$

Zone,

Thermal Zone: Bedroom 2, !- Name

-0 ,

0 ,

!- Direction of Relative North \{deg\}

0 ,

!- X Origin $\{\mathrm{m}\}$

Zone,

Thermal Zone: Bedroom 4, !- Name

-0 ,

0

0 ,

!- Direction of Relative North \{deg\}

1.16 ;

!- X Origin $\{\mathrm{m}\}$

!- Y Origin $\{\mathrm{m}\}$

!- Z Origin $\{m\}$

Zone,

Thermal Zone: Third Bath, !- Name

-0, !- Direction of Relative North $\quad$ deg\}

$0, \quad !-X$ Origin $\{\mathrm{m}\}$

$0, \quad !-$ Y Origin $\{m\}$

1.16; !- Z Origin $\{\mathrm{m}\}$

Zone,

Thermal Zone: Living, !- Name

-0 ,

4.753,

!- Direction of Relative North \{deg\}

14.7716

!- X Origin $\{\mathrm{m}\}$

!- Y Origin $\{m\}$

1.16

!- Z Origin $\{\mathrm{m}\}$

Zone,

Thermal Zone: Bedroom 1, !- Name

-0 ,

0 ,

!- Direction of Relative North \{deg\}

0 ,

!- X Origin $\{\mathrm{m}\}$

1.16; !- Z Origin $\{m\}$

Zone,

Thermal Zone: Baths, !- Name

-0, !- Direction of Relative North $\quad$ deg\}

$0, \quad !-X$ Origin $\{m\}$

$0, \quad !-Y$ Origin $\{m\}$

$1.16 ; \quad !-$ Z Origin $\{m\}$

Zone,

Thermal Zone: Kitchen, !- Name

-0 ,

!- Direction of Relative North \{deg\}

0 ,

!- X Origin $\{m\}$

$0, \quad \quad !-$ Y Origin $\{\mathrm{m}\}$

1.16; $\quad !-\mathrm{Z}$ Origin $\{\mathrm{m}\}$

Zone,

Thermal Zone: Bedroom 3, !- Name

-0 ,

0 ,

!- Direction of Relative North \{deg\}

0

1.16 ;

- X Origin $\{\mathrm{m}\}$

!- Y Origin $\{m\}$

!- Z Origin $\{m\}$

! $-\quad========$ ALL OBJECTS IN CLASS: ZONELIST $========$

ZoneList,

All Living Space Zones, !- Name 
Thermal Zone: Basement, !- Zone 1 Name Thermal Zone: Bedroom 1, !- Zone 2 Name Thermal Zone: Bedroom 2, !- Zone 3 Name Thermal Zone: Bedroom 3, !- Zone 4 Name Thermal Zone: Bedroom 4, !- Zone 5 Name Thermal Zone: Kitchen, !- Zone 6 Name Thermal Zone: Living, !- Zone 7 Name Thermal Zone: Baths, !- Zone 8 Name Thermal Zone: Third Bath, !- Zone 9 Name

Thermal Zone: Basement $S ;$ !- Zone 10 Name

ZoneList,

First Floor Zones, !- Name

Thermal Zone: Kitchen, !-Zone 1 Name

Thermal Zone: Living; !- Zone 2 Name

ZoneList,

Second Floor Zones, !- Name

Thermal Zone: Bedroom 1, !- Zone 1 Name

Thermal Zone: Bedroom 2, !- Zone 2 Name

Thermal Zone: Baths; !- Zone 3 Name

ZoneList,

Third Floor Zones, !- Name

Thermal Zone: Bedroom 3, !- Zone 1 Name

Thermal Zone: Bedroom 4, !- Zone 2 Name

Thermal Zone: Third Bath;!-Zone 3 Name

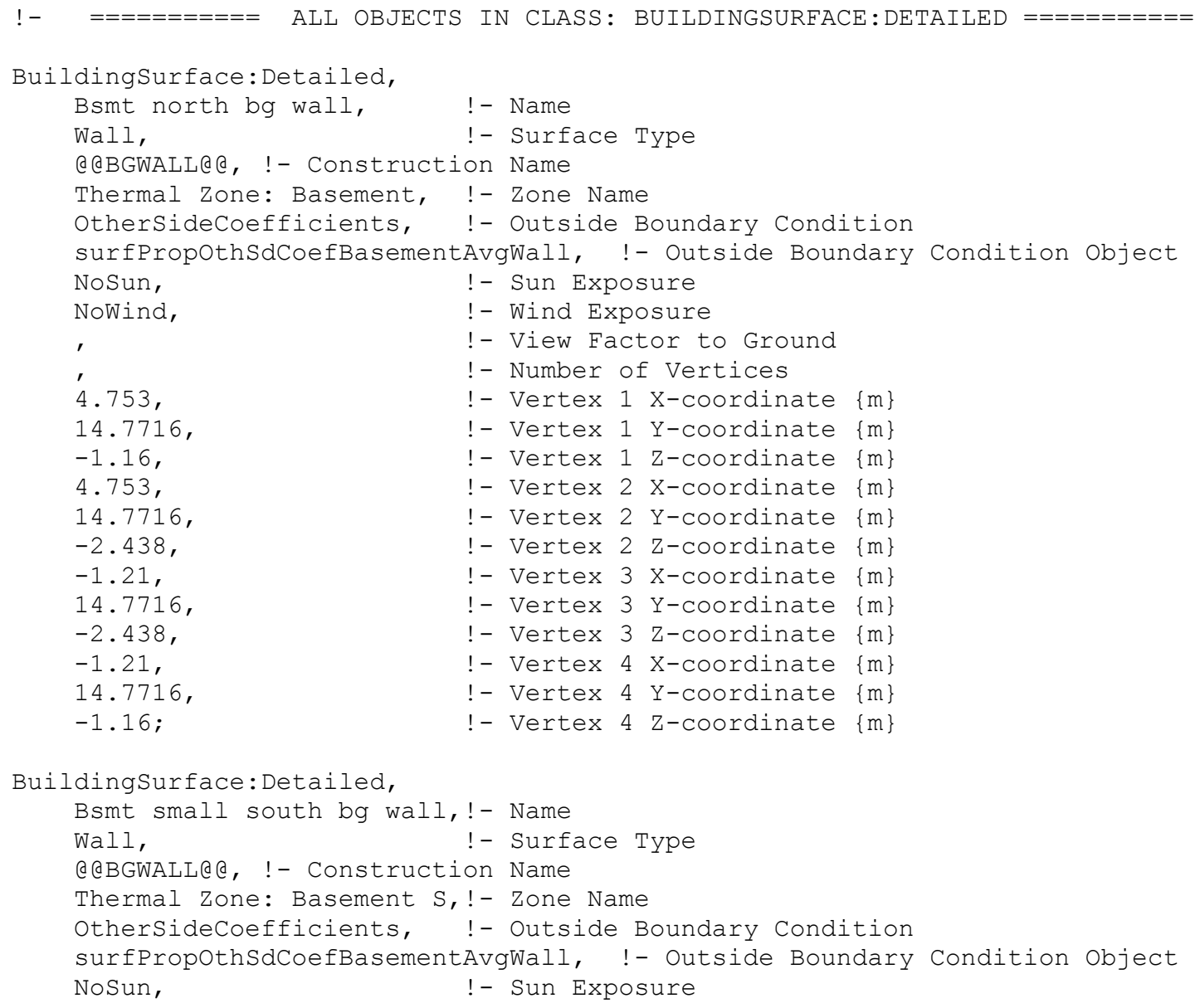




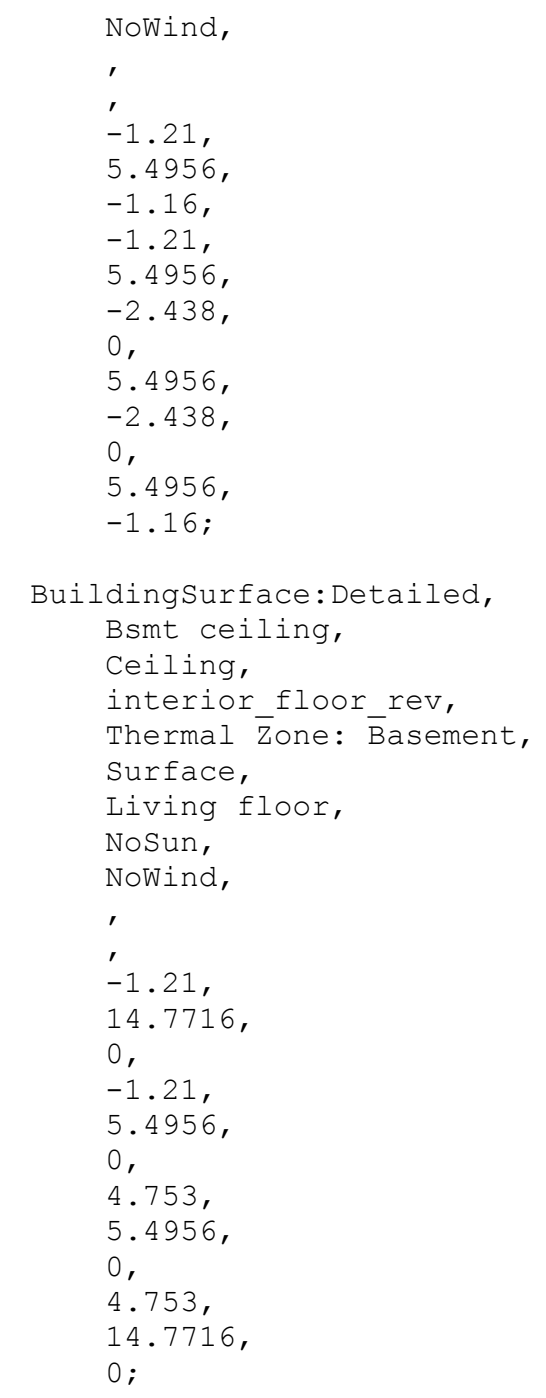

!- Wind Exposure

! - View Factor to Ground

!- Number of Vertices

!- Vertex $1 \mathrm{X}$-coordinate $\{\mathrm{m}\}$

!- Vertex 1 Y-coordinate $\{\mathrm{m}\}$

!- Vertex 1 Z-coordinate $\{\mathrm{m}\}$

!- Vertex $2 \mathrm{X}$-coordinate $\{\mathrm{m}\}$

!-Vertex 2 Y-coordinate $\{\mathrm{m}\}$

!- Vertex 2 Z-coordinate $\{\mathrm{m}\}$

!- Vertex $3 \mathrm{x}$-coordinate $\{\mathrm{m}\}$

!- Vertex 3 Y-coordinate $\{\mathrm{m}\}$

!- Vertex 3 Z-coordinate $\{m\}$

!- Vertex $4 \mathrm{X}$-coordinate $\{\mathrm{m}\}$

!- Vertex 4 Y-coordinate $\{\mathrm{m}\}$

!- Vertex 4 Z-coordinate $\{\mathrm{m}\}$

!- Name

!- Surface Type

!- Construction Name

!- Zone Name

!- Outside Boundary Condition

!- Outside Boundary Condition object

!- Sun Exposure

!- Wind Exposure

!- View Factor to Ground

!- Number of Vertices

!- Vertex $1 \mathrm{X}$-coordinate $\{\mathrm{m}\}$

!- Vertex 1 Y-coordinate $\{\mathrm{m}\}$

!- Vertex 1 Z-coordinate $\{\mathrm{m}\}$

!- Vertex $2 \mathrm{X}$-coordinate $\{\mathrm{m}\}$

!- Vertex 2 Y-coordinate $\{\mathrm{m}\}$

!- Vertex 2 Z-coordinate $\{\mathrm{m}\}$

!- Vertex $3 \mathrm{X}$-coordinate $\{\mathrm{m}\}$

!- Vertex 3 Y-coordinate $\{\mathrm{m}\}$

!- Vertex 3 Z-coordinate $\{\mathrm{m}\}$

!- Vertex $4 \mathrm{X}$-coordinate $\{\mathrm{m}\}$

!- Vertex 4 Y-coordinate $\{\mathrm{m}\}$

!- Vertex 4 Z-coordinate $\{m\}$

BuildingSurface: Detailed, Bsmt south ag wall S, Wall, deBGWALLAe, !- Construction Name

! - Name

Thermal Zone: Basement S,!- Zone Name

\section{Outdoors,}

,

SunExposed,

WindExposed,$$
\text { , }
$$$$
\text { , }
$$

0,

0 ,

0 ,

0 ,

$-1.16$

4.753,

0 ,

$-1.16$

4.753,

0 ,

0 ;
!- Outside Boundary Condition

!- Outside Boundary Condition Object

!- Sun Exposure

! - Wind Exposure

! - View Factor to Ground

!- Number of Vertices

!- Vertex $1 \mathrm{X}$-coordinate $\{\mathrm{m}\}$

!- Vertex 1 Y-coordinate $\{\mathrm{m}\}$

!- Vertex 1 Z-coordinate $\{\mathrm{m}\}$

!- Vertex $2 \mathrm{X}$-coordinate $\{\mathrm{m}\}$

!- Vertex 2 Y-coordinate $\{\mathrm{m}\}$

!- Vertex 2 Z-coordinate $\{\mathrm{m}\}$

!- Vertex $3 \mathrm{X}$-coordinate $\{\mathrm{m}\}$

!- Vertex 3 Y-coordinate $\{m\}$

!- Vertex 3 z-coordinate $\{\mathrm{m}\}$

!- Vertex $4 \mathrm{X}$-coordinate $\{\mathrm{m}\}$

!- Vertex 4 Y-coordinate $\{\mathrm{m}\}$

!- Vertex 4 Z-coordinate $\{\mathrm{m}\}$ 


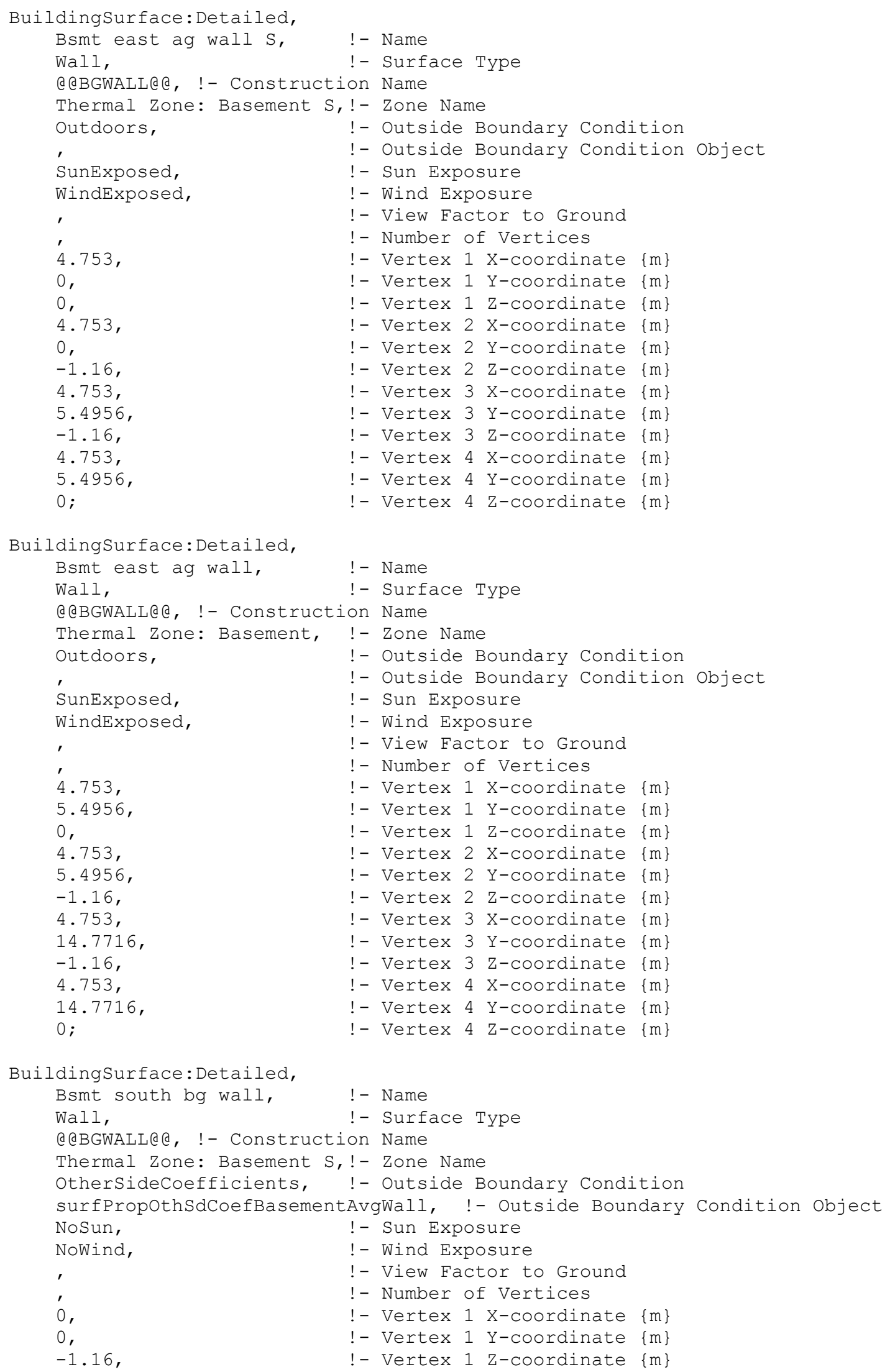




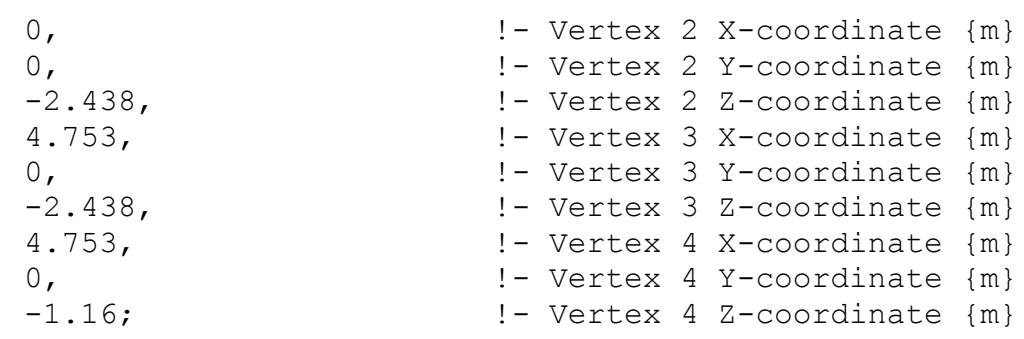

BuildingSurface: Detailed,

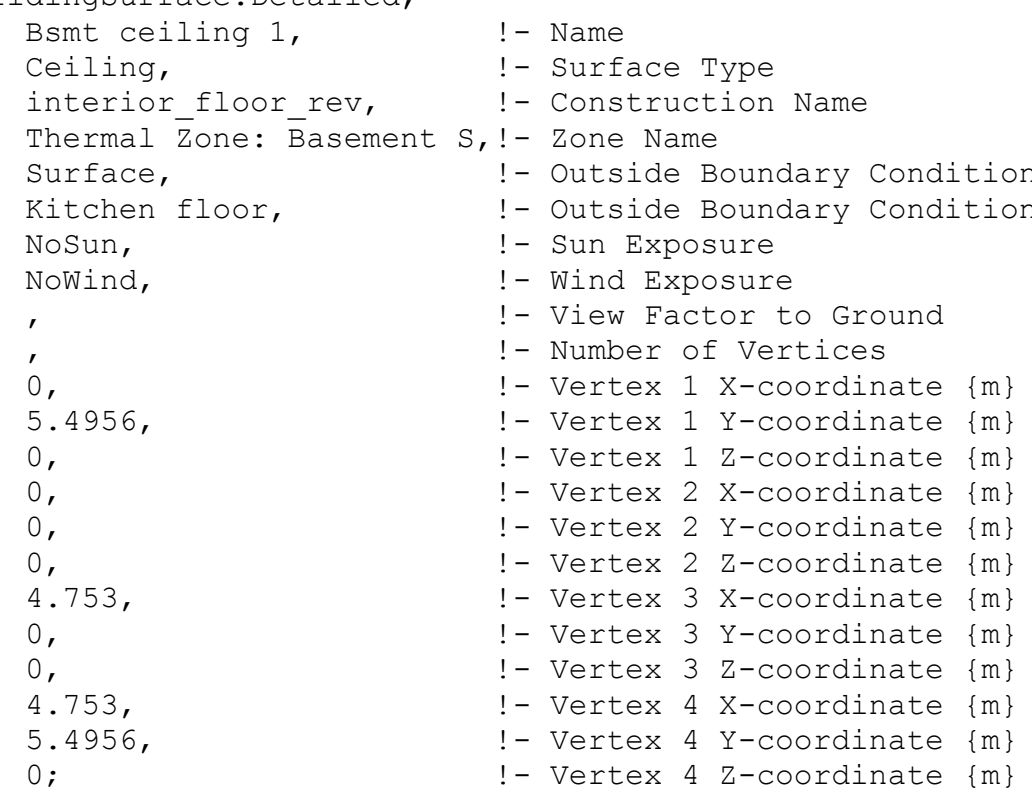

BuildingSurface: Detailed,

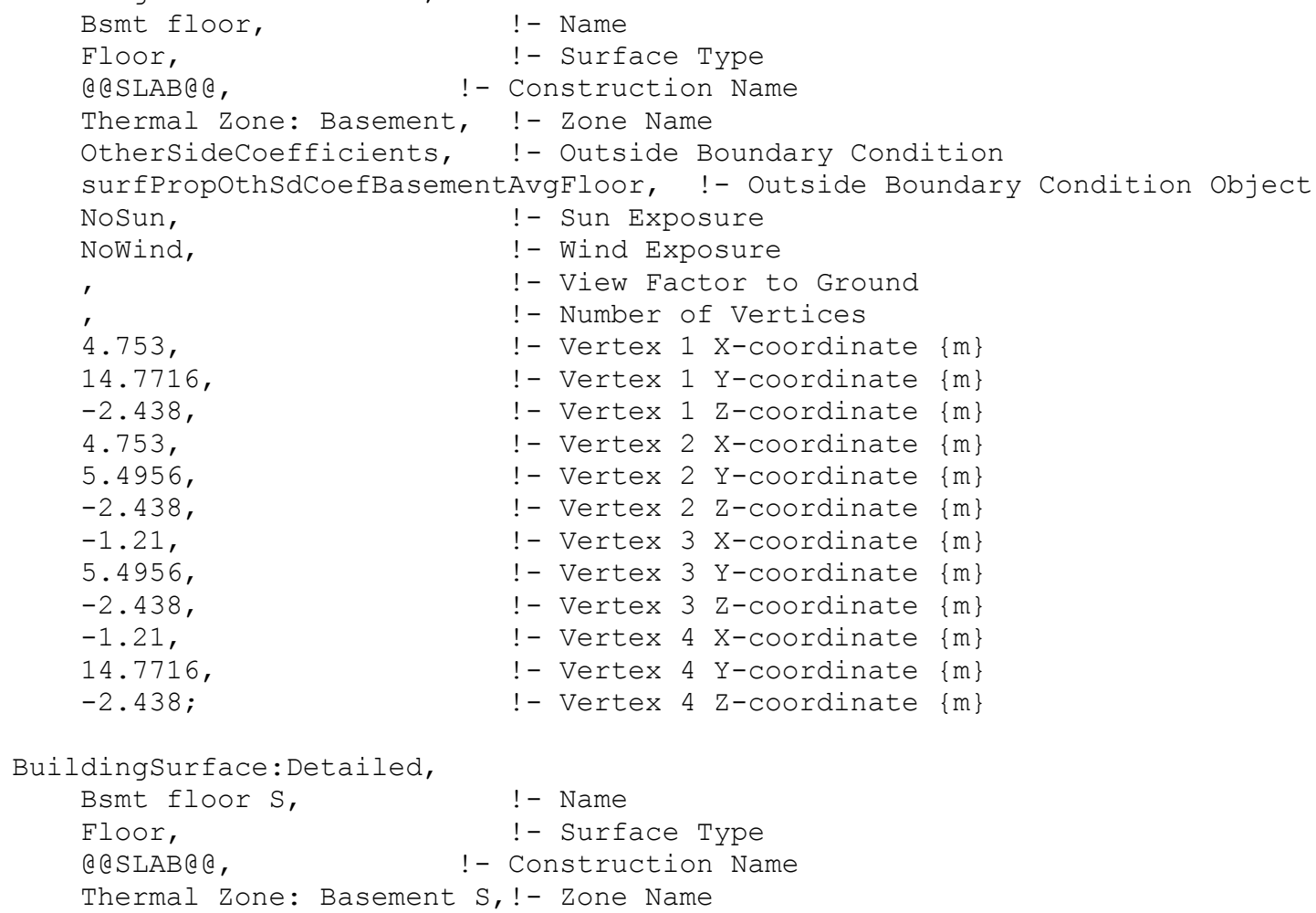

BuildingSurface: Detailed, 


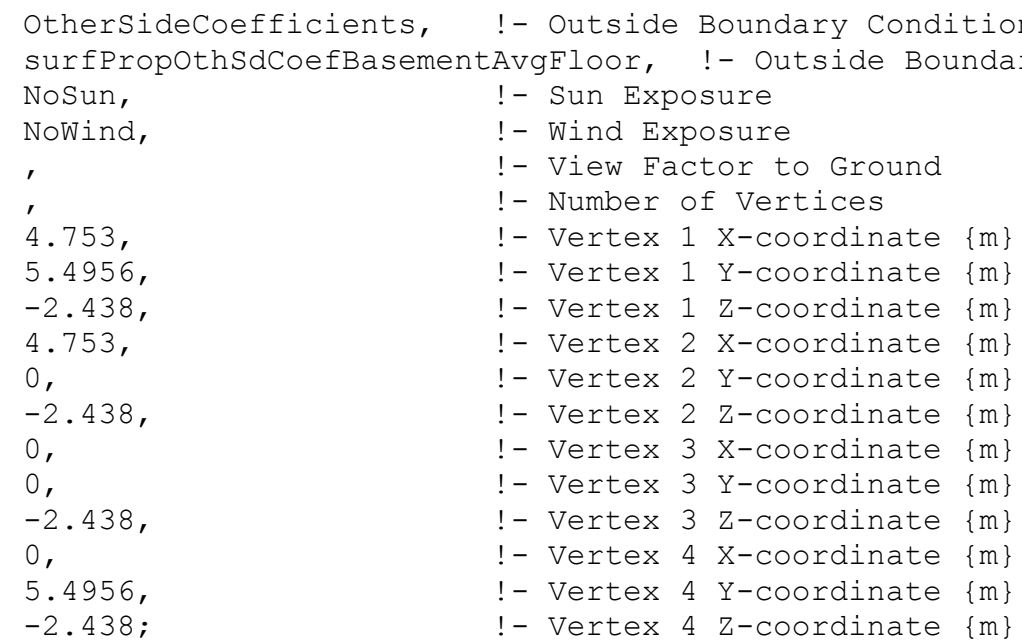

BuildingSurface: Detailed, Bsmt west bg wall 1, Wall,

! - Name

@@BGWALLA@, !- Construction Name

Thermal Zone: Basement, !- Zone Name

OtherSideCoefficients, !- Outside Boundary Condition

surfPropothSdCoefBasementAvgWall, !- Outside Boundary Condition Object NoSun, !- Sun Exposure

NoWind, ! - Wind Exposure

,

,

$-1.21$

14.7716,

-1.16 ,

-1.21 ,

14.7716,

-2.438 ,

-1.21 ,

5. 4956,

-2.438 ,

! - View Factor to Ground

! - Number of Vertices

!- Vertex 1 X-coordinate $\{\mathrm{m}\}$

!- Vertex 1 Y-coordinate $\{m\}$

!-Vertex 1 Z-coordinate $\{m\}$

!-Vertex 2 X-coordinate $\{\mathrm{m}\}$

!- Vertex 2 Y-coordinate $\{m\}$

!- Vertex 2 Z-coordinate $\{m\}$

!- Vertex 3 X-coordinate $\{m\}$

!- Vertex 3 Y-coordinate $\{\mathrm{m}\}$

!- Vertex 3 Z-coordinate $\{m\}$

-1.21 ,

5.4956,

!- Vertex 4 X-coordinate $\{m\}$

!- Vertex 4 Y-coordinate $\{m\}$

-1.16 ;

!- Vertex 4 Z-coordinate $\{m\}$

BuildingSurface: Detailed, Bsmt east bg wall S, Wall,

! - Name

Wall,

!- Surface Type

a@BGWALLAa, !- Construction Name

Thermal Zone: Basement $\mathrm{S}$, ! - Zone Name

OtherSideCoefficients, !- Outside Boundary Condition

surfPropothSdCoefBasementAvgWall, !- Outside Boundary Condition Object NoSun,

NoWind,

!- Sun Exposure

!- Wind Exposure

! - View Factor to Ground

! - Number of Vertices

4.753,

!- Vertex 1 X-coordinate $\{\mathrm{m}\}$

0 ,

!- Vertex 1 Y-coordinate $\{\mathrm{m}\}$

-1.16 ,

!- Vertex 1 Z-coordinate $\{\mathrm{m}\}$

4.753

!- Vertex $2 \mathrm{X}$-coordinate $\{\mathrm{m}\}$

0 ,

!- Vertex 2 Y-coordinate $\{\mathrm{m}\}$

-2.438,

4.753,

5.4956,

-2.438,

!-Vertex 2 Z-coordinate $\{m\}$

!- Vertex $3 \mathrm{X}$-coordinate $\{\mathrm{m}\}$

!- Vertex 3 Y-coordinate $\{\mathrm{m}\}$

!- Vertex 3 Z-coordinate $\{\mathrm{m}\}$ 

4.753,
!- Vertex 4 X-coordinate $\{m\}$
5.4956,
!- Vertex 4 Y-coordinate $\{\mathrm{m}\}$
$-1.16$
!- Vertex 4 Z-coordinate $\{\mathrm{m}\}$

BuildingSurface: Detailed,

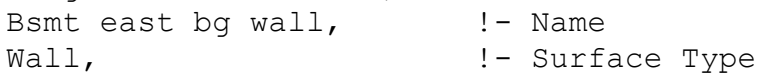

BuildingSurface: Detailed, Bsmt west ag wall 1, !- Name

BuildingSurface: Detailed,

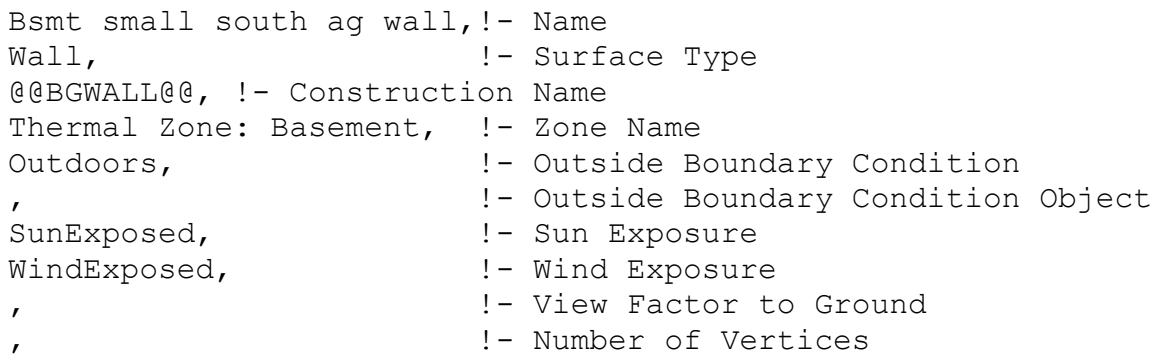




$$
\begin{aligned}
& -1.21, \\
& 5.4956, \\
& 0, \\
& -1.21, \\
& 5.4956, \\
& -1.16, \\
& 0, \\
& 5.4956, \\
& -1.16, \\
& 0, \\
& 5.4956, \\
& 0 ;
\end{aligned}
$$

BuildingSurface: Detailed, Bsmt west ag wall S, Wall,

!- Vertex $1 \mathrm{X}$-coordinate $\{\mathrm{m}\}$

!- Vertex 1 Y-coordinate $\{\mathrm{m}\}$

!- Vertex 1 Z-coordinate $\{\mathrm{m}\}$

!- Vertex $2 \mathrm{X}$-coordinate $\{\mathrm{m}\}$

!- Vertex 2 Y-coordinate $\{\mathrm{m}\}$

!- Vertex 2 Z-coordinate $\{\mathrm{m}\}$

!- Vertex $3 \mathrm{X}$-coordinate $\{\mathrm{m}\}$

!- Vertex 3 Y-coordinate $\{\mathrm{m}\}$

!- Vertex 3 Z-coordinate $\{m\}$

!- Vertex $4 \mathrm{X}$-coordinate $\{\mathrm{m}\}$

!- Vertex 4 Y-coordinate $\{\mathrm{m}\}$

!- Vertex 4 Z-coordinate $\{\mathrm{m}\}$

! - Name

a@BGWALLAa, !- Construction Name

Thermal Zone: Basement S,!- Zone Name

Outdoors,

!- Outside Boundary Condition

SunExposed,

WindExposed,

!- Outside Boundary Condition Object

!- Sun Exposure

!- Wind Exposure

! - View Factor to Ground

!- Number of Vertices

'́,

!- Vertex $1 \mathrm{X}$-coordinate $\{\mathrm{m}\}$

5.4956,

0,

!- Vertex 1 Y-coordinate $\{m\}$

!- Vertex 1 Z-coordinate $\{\mathrm{m}\}$

0 ,

!- Vertex $2 \mathrm{X}$-coordinate $\{\mathrm{m}\}$

5.4956,

-1.16 ,

0 ,

!- Vertex 2 Y-coordinate $\{\mathrm{m}\}$

!- Vertex 2 Z-coordinate $\{\mathrm{m}\}$

!- Vertex $3 \mathrm{X}$-coordinate $\{\mathrm{m}\}$

0 ,

!- Vertex 3 Y-coordinate $\{\mathrm{m}\}$

-1.16, !- Vertex 3 Z-coordinate $\{\mathrm{m}\}$

0 ,

!- Vertex $4 \mathrm{X}$-coordinate $\{\mathrm{m}\}$

0,

!- Vertex 4 Y-coordinate $\{\mathrm{m}\}$

0 ;

!- Vertex 4 Z-coordinate $\{m\}$

BuildingSurface: Detailed,
Bsmt west bg wall S,
Wall,
! - Name
! - Surface Type

@eBGWALLAQ, !- Construction Name

Thermal Zone: Basement S,!- Zone Name

OtherSideCoefficients, !- Outside Boundary Condition

surfPropothSdCoefBasementAvgWall, !- Outside Boundary Condition Object NoSun,

NoWind,

!- Sun Exposure

!- Wind Exposure

! - View Factor to Ground

!- Number of Vertices

'́,

!- Vertex $1 \mathrm{X}$-coordinate $\{\mathrm{m}\}$

5.4956,

!- Vertex 1 Y-coordinate $\{\mathrm{m}\}$

$-1.16$

0 ,

!- Vertex 1 Z-coordinate $\{\mathrm{m}\}$

!- Vertex 2 X-coordinate $\{\mathrm{m}\}$

5.4956 ,

!- Vertex 2 Y-coordinate $\{\mathrm{m}\}$

-2.438 ,

0 ,

!- Vertex 2 Z-coordinate $\{\mathrm{m}\}$

!- Vertex $3 \mathrm{X}$-coordinate $\{\mathrm{m}\}$

0 ,

-2.438,

0 ,

!- Vertex 3 Y-coordinate $\{\mathrm{m}\}$

!- Vertex 3 Z-coordinate $\{\mathrm{m}\}$

!- Vertex $4 \mathrm{X}$-coordinate $\{\mathrm{m}\}$

0 ,

!- Vertex 4 Y-coordinate $\{\mathrm{m}\}$

-1.16 ;

!- Vertex 4 Z-coordinate $\{m\}$

BuildingSurface: Detailed, Bsmt north ag wall,

! - Name 


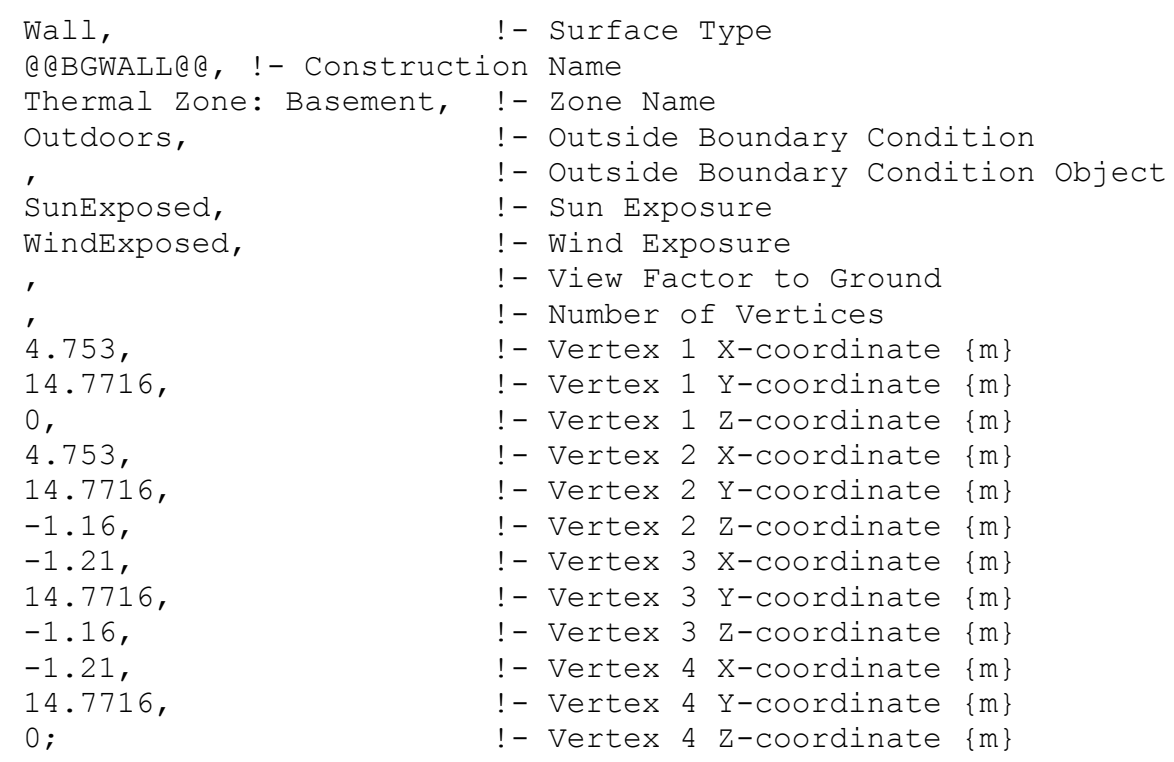

BuildingSurface: Detailed, Bedroom 2 - Baths partition, !- Name 


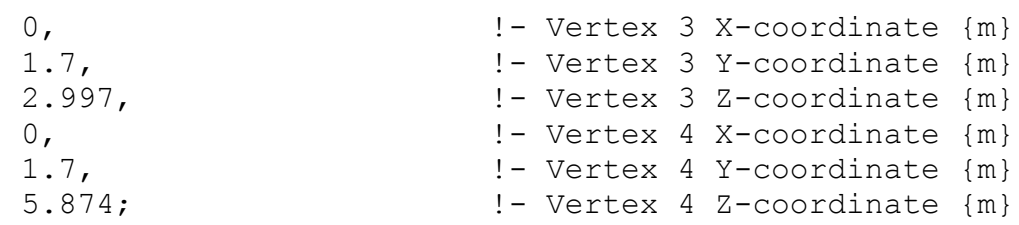

BuildingSurface: Detailed,

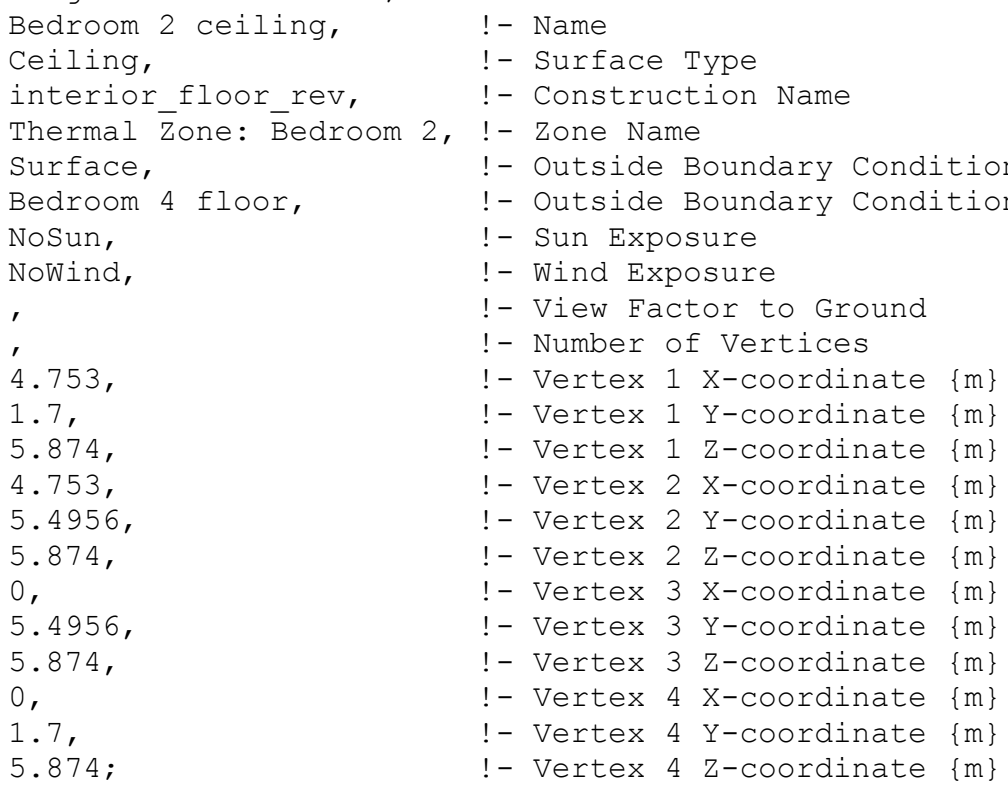

BuildingSurface: Detailed, Bedroom 2 east wall, !- Name

Wall, !- Surface Type

@eWALLAe, !- Construction Name

Thermal Zone: Bedroom 2, !- Zone Name

Outdoors,

!- Outside Boundary Condition

SunExposed,

WindExposed,

!- Outside Boundary Condition Object

! - Sun Exposure

!- Wind Exposure

,

4.753,

1.7,

5.874,

4.753,

1.7,

2.997,

4.753,

! - View Factor to Ground

! - Number of Vertices

!- Vertex $1 \mathrm{X}$-coordinate $\{\mathrm{m}\}$

!- Vertex 1 Y-coordinate $\{\mathrm{m}\}$

!- Vertex 1 Z-coordinate $\{m\}$

!- Vertex 2 X-coordinate $\{\mathrm{m}\}$

!- Vertex 2 Y-coordinate $\{\mathrm{m}\}$

!- Vertex 2 Z-coordinate $\{m\}$

!- Vertex $3 \mathrm{x}$-coordinate $\{\mathrm{m}\}$

5.4956,

!- Vertex 3 Y-coordinate $\{\mathrm{m}\}$

2.997,

4.753,

!- Vertex 3 z-coordinate $\{m\}$

!- Vertex $4 \mathrm{X}$-coordinate $\{\mathrm{m}\}$

5.4956,

!- Vertex 4 Y-coordinate $\{\mathrm{m}\}$

$5.874 ;$

!- Vertex 4 Z-coordinate $\{\mathrm{m}\}$

BuildingSurface: Detailed,

$\begin{array}{ll}\text { Bedroom } 2 \text { floor, } & \text { !- Name } \\ \text { Floor, } & \text { !- Surface Type } \\ \text { interior floor, } & \text { !- Construction Name } \\ \text { Thermal Zone: Bedroom 2, } & \text { - - Zone Name } \\ \text { Surface, } & \text { !- Outside Boundary Condition } \\ \text { Kitchen ceiling, } & !-\text { Outside Boundary Condition Object } \\ \text { NoSun, } & !-\text { Sun Exposure }\end{array}$




\begin{tabular}{|c|c|}
\hline $\begin{array}{l}\text { Nowind, } \\
, \\
\text { ', } \\
5.753, \\
\text { 2.4956, } \\
4.753, \\
1.7, \\
2.997, \\
0, \\
1.7, \\
2.997, \\
0, \\
5.4956, \\
2.997 ;\end{array}$ & $\begin{array}{l}\text { !- Wind Exposure } \\
\text { !- View Factor to Ground } \\
\text { !- Number of Vertices } \\
\text { !- Vertex } 1 \text { X-coordinate }\{m\} \\
\text { !- Vertex } 1 \text { Y-coordinate }\{m\} \\
\text { !- Vertex } 1 \text { Z-coordinate }\{m\} \\
\text { !- Vertex } 2 \text { X-coordinate }\{m\} \\
\text { !- Vertex } 2 \text { Y-coordinate }\{m\} \\
\text { !- Vertex } 2 \text { Z-coordinate }\{m\} \\
\text { !- Vertex } 3 \text { X-coordinate }\{m\} \\
\text { !- Vertex } 3 \text { Y-coordinate }\{m\} \\
\text { !- Vertex } 3 \text { Z-coordinate }\{m\} \\
\text { !- Vertex } 4 \text { X-coordinate }\{m\} \\
\text { !- Vertex } 4 \text { Y-coordinate }\{m\} \\
\text { !- Vertex } 4 \text { Z-coordinate }\{m\}\end{array}$ \\
\hline $\begin{array}{l}\text { dingSurface: Detailed, } \\
\text { Bedroom } 2 \text { south wall, } \\
\text { Wall, } \\
\text { deWALLe, !- Construction } \\
\text { Thermal Zone: Bedroom 2, } \\
\text { Outdoors, } \\
\text { ' } \\
\text { SunExposed, } \\
\text { WindExposed, } \\
\text { ' } \\
0, \\
1.7, \\
5.874, \\
0, \\
1.7, \\
2.997, \\
4.753, \\
1.7, \\
2.997, \\
4.753, \\
1.7, \\
5.874\end{array}$ & $\begin{array}{l}\text { !- Name } \\
\text { !- Surface Type } \\
\text { Name } \\
\text { !- Zone Name } \\
\text { !- Outside Boundary Condition } \\
\text { !- Outside Boundary Condition Object } \\
\text { !- Sun Exposure } \\
\text { !- Wind Exposure } \\
\text { !- View Factor to Ground } \\
\text { !- Number of Vertices } \\
\text { !- Vertex } 1 \text { X-coordinate }\{m\} \\
\text { - Vertex } 1 \text { Y-coordinate }\{m\} \\
\text { - Vertex } 1 \text { Z-coordinate }\{m\} \\
\text { - Vertex } 2 \text { X-coordinate }\{m\} \\
\text { - Vertex } 2 \text { Y-coordinate }\{m\} \\
\text { - Vertex } 2 \text { Z-coordinate }\{m\} \\
\text { - Vertex } 3 \text { X-coordinate }\{m\} \\
\text { - Vertex } 3 \text { Y-coordinate }\{m\} \\
\text { - Vertex } 3 \text { Z-coordinate }\{m\} \\
\text { - Vertex } 4 \text { X-coordinate }\{m\} \\
\text { - Vertex } 4 \text { Y-coordinate }\{m\} \\
\text { - Vertex } 4 \text { Z-coordinate }\{m\}\end{array}$ \\
\hline $\begin{array}{l}\text { dingSurface: Detailed, } \\
\text { Bedroom } 4 \text { south wall, } \\
\text { Wall, } \\
\text { dewALLe, !- Construction } \\
\text { Thermal Zone: Bedroom 4, } \\
\text { Outdoors, } \\
\text { ' } \\
\text { SunExposed, } \\
\text { WindExposed, } \\
\text { ' } \\
\text { 0, } \\
1.7, \\
8.976, \\
0, \\
1.7, \\
5.874, \\
4.753, \\
1.7, \\
5.874, \\
4.753, \\
1.7, \\
8.976 ;\end{array}$ & $\begin{array}{l}\text { !- Name } \\
\text { !- Surface Type } \\
\text { Name } \\
\text { !- Zone Name } \\
\text { !- Outside Boundary Condition } \\
\text { !- Outside Boundary Condition of } \\
\text { !- Sun Exposure } \\
\text { !- Wind Exposure } \\
\text { !- View Factor to Ground } \\
\text { !- Number of Vertices } \\
\text { !- Vertex } 1 \text { X-coordinate }\{m\} \\
\text { !- Vertex } 1 \text { Y-coordinate }\{m\} \\
\text { !- Vertex } 1 \text { Z-coordinate }\{m\} \\
\text { !- Vertex } 2 \text { X-coordinate }\{m\} \\
\text { !- Vertex } 2 \text { Y-coordinate }\{m\} \\
\text { !- Vertex } 2 \text { Z-coordinate }\{m\} \\
\text { !- Vertex } 3 \text { X-coordinate }\{m\} \\
\text { !- Vertex } 3 \text { Y-coordinate }\{m\} \\
\text { !- Vertex } 3 \text { Z-coordinate }\{m\} \\
\text { !- Vertex } 4 \text { X-coordinate }\{m\} \\
\text { !- Vertex } 4 \text { Y-coordinate }\{m\} \\
\text { !- Vertex } 4 \text { Z-coordinate }\{m\}\end{array}$ \\
\hline
\end{tabular}




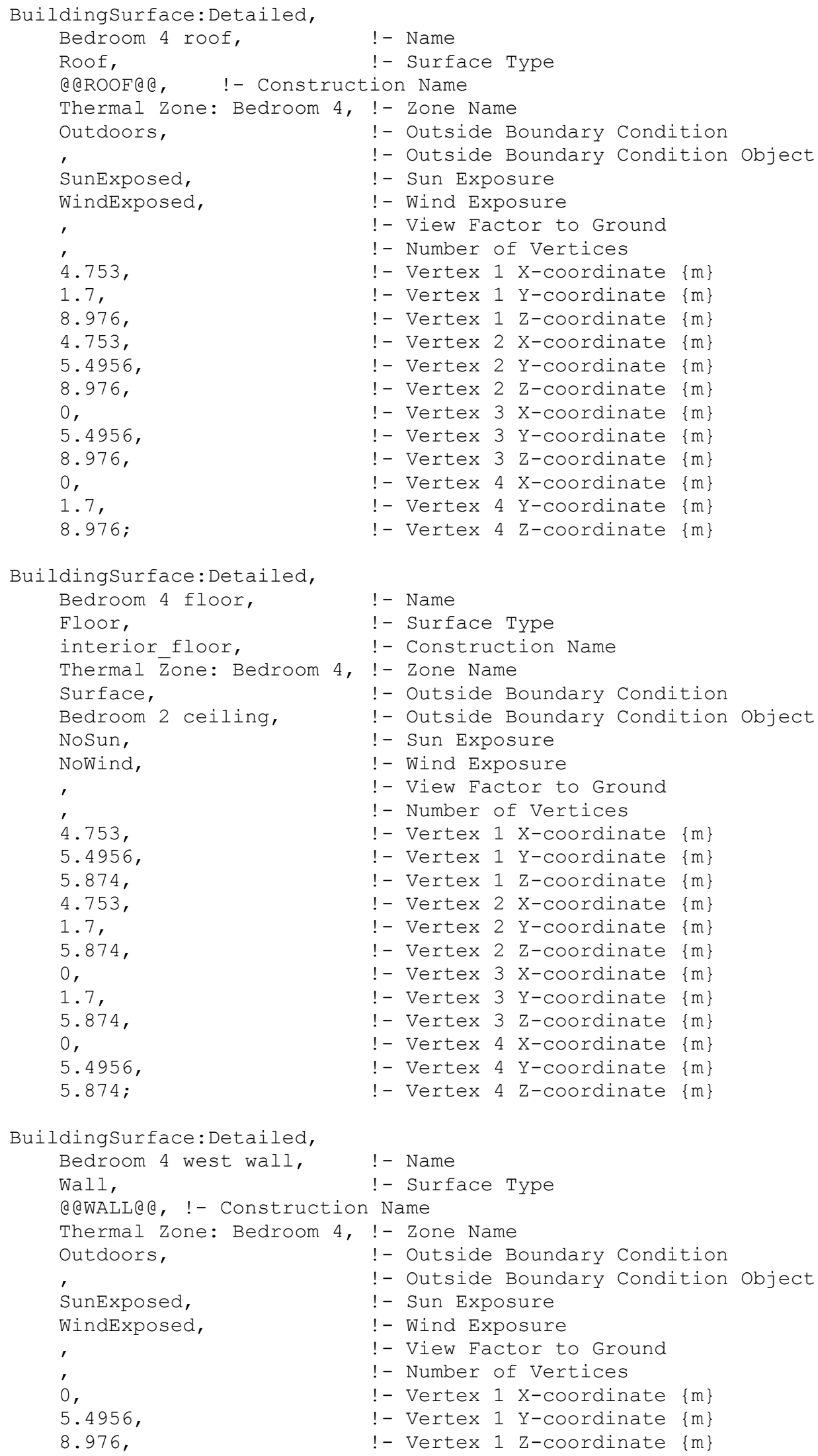



0 ,
!- Vertex $2 \mathrm{X}$-coordinate $\{\mathrm{m}\}$
5.4956,
!- Vertex 2 Y-coordinate $\{\mathrm{m}\}$
5.874,
!- Vertex 2 Z-coordinate $\{\mathrm{m}\}$
0 ,
!- Vertex $3 \mathrm{X}$-coordinate $\{\mathrm{m}\}$
1.7,
!- Vertex 3 Y-coordinate $\{\mathrm{m}\}$
5.874
!- Vertex 3 Z-coordinate $\{\mathrm{m}\}$
0,
!- Vertex $4 \mathrm{X}$-coordinate $\{\mathrm{m}\}$
1.7,
!- Vertex 4 Y-coordinate $\{\mathrm{m}\}$
8.976 ;
!- Vertex 4 Z-coordinate $\{\mathrm{m}\}$

BuildingSurface: Detailed,

Bedroom 4 - Third bath parition, !- Name

Wall, $\quad$ !- Surface Type

interior wall, !- Construction Name

Thermal Zone: Bedroom 4, !- Zone Name

Surface, !- Outside Boundary Condition

THIRD BATH - BEDROOM 4 PARTITION, !- Outside Boundary Condition Object

NoSun, $\quad !-$ Sun Exposure

NoWind, $\quad$ !- Wind Exposure

,

4.753

! - View Factor to Ground

!- Number of Vertices

!- Vertex 1 X-coordinate $\{\mathrm{m}\}$

5.4956,

!- Vertex 1 Y-coordinate $\{m\}$

8.976,

4.753,

!- Vertex 1 Z-coordinate $\{\mathrm{m}\}$

!- Vertex 2 X-coordinate $\{\mathrm{m}\}$

5.4956 ,

5.874 ,

!- Vertex 2 Y-coordinate $\{\mathrm{m}\}$

0 ,

!- Vertex 2 Z-coordinate $\{m\}$

!- Vertex $3 \mathrm{X}$-coordinate $\{\mathrm{m}\}$

5.4956 ,

5.874

!- Vertex 3 Y-coordinate $\{\mathrm{m}\}$

!- Vertex 3 Z-coordinate $\{\mathrm{m}\}$

0 ,

!- Vertex $4 \mathrm{X}$-coordinate $\{\mathrm{m}\}$

5.4956,

!- Vertex 4 Y-coordinate $\{m\}$

$8.976 ;$

!- Vertex 4 Z-coordinate $\{m\}$

BuildingSurface: Detailed, Bedroom 4 east wall,

Wall,

! - Name

@@WALL@@, !- Construction Name

Thermal Zone: Bedroom 4, !- Zone Name

outdoors,

!- Outside Boundary Condition

- Outside Boundary Condition Object

SunExposed,

WindExposed,

!- Sun Exposure

!- Wind Exposure

!- View Factor to Ground

4.753,

1.7,

8.976,

4.753,

1.7,

5.874,

4.753,

! - Number of Vertices

!- Vertex $1 \mathrm{X}$-coordinate $\{\mathrm{m}\}$

!- Vertex 1 Y-coordinate $\{\mathrm{m}\}$

!- Vertex 1 Z-coordinate $\{m\}$

!- Vertex 2 X-coordinate $\{\mathrm{m}\}$

!- Vertex 2 Y-coordinate $\{\mathrm{m}\}$

!- Vertex 2 Z-coordinate $\{\mathrm{m}\}$

!- Vertex $3 \mathrm{X}$-coordinate $\{\mathrm{m}\}$

5.4956,

!- Vertex 3 Y-coordinate $\{\mathrm{m}\}$

5.874,

4.753,

!- Vertex 3 Z-coordinate $\{\mathrm{m}\}$

!- Vertex $4 \mathrm{X}$-coordinate $\{\mathrm{m}\}$

5.4956,

!- Vertex 4 Y-coordinate $\{\mathrm{m}\}$

$8.976 ;$

!- Vertex 4 Z-coordinate $\{\mathrm{m}\}$

BuildingSurface: Detailed,

Third bath - Bedroom 3 partition, !- Name

Wall,

! - Surface Type

interior wall,

!- Construction Name

Thermal Zone: Third Bath,!- Zone Name 


Surface,
Bedroom 3 - third bath,
NoSun,
Nowind,
'
'
4.753,
7.9956,
8.976,
4.753,
7.9956,
5.874,
-1.21,
7.9956,
5.874,
-1.21,
7.9956,
$8.976 ;$

!- Outside Boundary Condition

!- Outside Boundary Condition Object

!- Sun Exposure

! - Wind Exposure

!- View Factor to Ground

! - Number of Vertices

!- Vertex $1 \mathrm{X}$-coordinate $\{\mathrm{m}\}$

!- Vertex 1 Y-coordinate $\{\mathrm{m}\}$

!- Vertex 1 Z-coordinate $\{\mathrm{m}\}$

!- Vertex 2 X-coordinate $\{\mathrm{m}\}$

!- Vertex 2 Y-coordinate $\{\mathrm{m}\}$

!- Vertex 2 Z-coordinate $\{\mathrm{m}\}$

!- Vertex $3 \mathrm{X}$-coordinate $\{m\}$

!- Vertex 3 Y-coordinate $\{\mathrm{m}\}$

!- Vertex 3 Z-coordinate $\{m\}$

!- Vertex 4 X-coordinate $\{\mathrm{m}\}$

!- Vertex 4 Y-coordinate $\{\mathrm{m}\}$

!- Vertex 4 Z-coordinate $\{\mathrm{m}\}$

BuildingSurface: Detailed, Third bath west wall, Wall,

! - Name

!- Surface Type

@@WALLAa, !- Construction Name

Thermal Zone: Third Bath, !- Zone Name

Outdoors, !- Outside Boundary Condition

SunExposed,

WindExposed,

! - Outside Boundary Condition Object

!- Sun Exposure

!- Wind Exposure

,

!- View Factor to Ground

! - Number of Vertices

$-1.21$

!- Vertex $1 \mathrm{X}$-coordinate $\{\mathrm{m}\}$

7.9956,

!- Vertex 1 Y-coordinate $\{m\}$

8.976 ,

$-1.21$

!-Vertex 1 Z-coordinate $\{m\}$

!- Vertex 2 X-coordinate $\{\mathrm{m}\}$

7.9956,

!- Vertex 2 Y-coordinate $\{\mathrm{m}\}$

!- Vertex 2 Z-coordinate $\{\mathrm{m}\}$

5.874

-1.21 ,

5.4956 ,

!- Vertex $3 \mathrm{x}$-coordinate $\{\mathrm{m}\}$

!- Vertex 3 Y-coordinate $\{\mathrm{m}\}$

5.874,

!- Vertex 3 Z-coordinate $\{\mathrm{m}\}$

-1.21 ,

5.4956

!- Vertex $4 \mathrm{X}$-coordinate $\{\mathrm{m}\}$

!- Vertex 4 Y-coordinate $\{\mathrm{m}\}$

8.976 ;

!- Vertex 4 Z-coordinate $\{m\}$

BuildingSurface: Detailed, $\begin{array}{ll}\text { third bath roof, } & !-\text { Name } \\ \text { Roof, } & !-\text { Surface Type }\end{array}$

QAROOFAQ, !- Construction Name

Thermal Zone: Third Bath,!- Zone Name

Outdoors, !- Outside Boundary Condition

'SunExposed,

WindExposed,

!- Outside Boundary Condition Object

!- Sun Exposure

!- Wind Exposure

! - View Factor to Ground

!- Number of Vertices

4.753

5.4956,

!- Vertex $1 \mathrm{X}$-coordinate $\{\mathrm{m}\}$

!- Vertex 1 Y-coordinate $\{\mathrm{m}\}$

8.976,

4.753,

7.9956,

8.976

-1.21,

7.9956,

8.976 ,

!- Vertex 1 Z-coordinate $\{\mathrm{m}\}$

!- Vertex $2 \mathrm{X}$-coordinate $\{\mathrm{m}\}$

!- Vertex 2 Y-coordinate $\{m\}$

!- Vertex 2 Z-coordinate $\{\mathrm{m}\}$

!- Vertex $3 \mathrm{x}$-coordinate $\{\mathrm{m}\}$

!- Vertex 3 Y-coordinate $\{\mathrm{m}\}$

!- Vertex 3 Z-coordinate $\{\mathrm{m}\}$ 

$-1.21$
!- Vertex 4 X-coordinate $\{m\}$
5.4956,
!- Vertex 4 Y-coordinate $\{\mathrm{m}\}$
$8.976 ;$
!- Vertex 4 Z-coordinate $\{\mathrm{m}\}$

BuildingSurface: Detailed,

THIRD BATH - BEDROOM 4 PARTITION, !- Name
Wall,
interior wall,
Thermal Zone: Third Bath,, - - Zonstruction Name
Surface,
! - Outside Boundary Condition

Bedroom 4 - Third bath parition, !- Outside Boundary Condition Object

NoSun, !- Sun Exposure

NoWind, !- Wind Exposure

,

'

0 ,

5.4956,

!- View Factor to Ground

!- Number of Vertices

8.976

!- Vertex $1 \mathrm{X}$-coordinate $\{\mathrm{m}\}$

!- Vertex 1 Y-coordinate $\{\mathrm{m}\}$

0 ,

!- Vertex 1 Z-coordinate $\{\mathrm{m}\}$

!- Vertex 2 X-coordinate $\{m\}$

5.4956 ,

!- Vertex 2 Y-coordinate $\{\mathrm{m}\}$

5.874,

4.753,

!- Vertex 2 Z-coordinate $\{\mathrm{m}\}$

!- Vertex $3 \mathrm{X}$-coordinate $\{\mathrm{m}\}$

5.4956,

!- Vertex 3 Y-coordinate $\{m\}$

5.874,

4.753,

!- Vertex 3 Z-coordinate $\{\mathrm{m}\}$

!- Vertex $4 \mathrm{X}$-coordinate $\{\mathrm{m}\}$

5.4956,

!- Vertex 4 Y-coordinate $\{m\}$

$8.976 ;$

!- Vertex 4 Z-coordinate $\{m\}$

BuildingSurface: Detailed, Third bath east wall, Wall,

! - Name

a@WALL@e, !- Construction Name

Thermal Zone: Third Bath, !- Zone Name

outdoors,

!- Outside Boundary Condition

SunExposed,

!- Outside Boundary Condition Object

WindExposed,

!- Sun Exposure

!- Wind Exposure

,

4.753,

5.4956

!- View Factor to Ground

! - Number of Vertices

!- Vertex $1 \mathrm{X}$-coordinate $\{\mathrm{m}\}$

!- Vertex 1 Y-coordinate $\{\mathrm{m}\}$

8.976,

!- Vertex 1 Z-coordinate $\{m\}$

4.753,

5.4956,

!- Vertex $2 \mathrm{X}$-coordinate $\{\mathrm{m}\}$

!- Vertex 2 Y-coordinate $\{m\}$

5.874,

! - Vertex 2 Z-coordinate $\{\mathrm{m}\}$

4.753,

!- Vertex $3 \mathrm{x}$-coordinate $\{\mathrm{m}\}$

7.9956,

!- Vertex 3 Y-coordinate $\{\mathrm{m}\}$

5.874

4.753,

!- Vertex 3 Z-coordinate $\{m\}$

!- Vertex $4 \mathrm{X}$-coordinate $\{\mathrm{m}\}$

7.9956,

!- Vertex 4 Y-coordinate $\{\mathrm{m}\}$

8.976;

!- Vertex 4 Z-coordinate $\{\mathrm{m}\}$

BuildingSurface: Detailed, Third bath floor,

Floor,

! - Name

interior floor baths,

!- Surface Type

Thermal Zone: Third Bath,!- Zone Name

Surface,

! - Construction Name

Baths ceiling 1

!- Outside Boundary Condition

NoSun,

NoWind,

!- Outside Boundary Condition Object

!- Sun Exposure

!- Wind Exposure

,

! - View Factor to Ground

!- Number of Vertices 

4.753,
!- Vertex $1 \mathrm{X}$-coordinate $\{\mathrm{m}\}$
7.9956,
!- Vertex 1 Y-coordinate $\{\mathrm{m}\}$
5.874,
!- Vertex 1 Z-coordinate $\{\mathrm{m}\}$
4.753,
! - Vertex 2 X-coordinate $\{\mathrm{m}\}$
5.4956,
!- Vertex 2 Y-coordinate $\{\mathrm{m}\}$
5.874,
!- Vertex 2 Z-coordinate $\{\mathrm{m}\}$
-1.21 ,
! - Vertex 3 X-coordinate $\{\mathrm{m}\}$
5.4956,
!- Vertex 3 Y-coordinate $\{\mathrm{m}\}$
5.874,
!- Vertex 3 Z-coordinate $\{\mathrm{m}\}$
-1.21 ,
7.9956
!- Vertex $4 \mathrm{X}$-coordinate $\{\mathrm{m}\}$
!- Vertex 4 Y-coordinate $\{\mathrm{m}\}$
$5.874 ;$
!- Vertex 4 Z-coordinate $\{m\}$

BuildingSurface: Detailed, Third bath south wall, Wall, a@WALLA@, !- Construction Name

! - Name

!- Surface Type

Thermal Zone: Third Bath, !- Zone Name

outdoors,

!- Outside Boundary Condition

!- Outside Boundary Condition Object

SunExposed,

WindExposed,

!- Sun Exposure

!- Wind Exposure

! - View Factor to Ground

-1.21,

5.4956,

! - Number of Vertices

!- Vertex $1 \mathrm{X}$-coordinate $\{\mathrm{m}\}$

8.976 ,

$-1.21$

5.4956 ,

5.874,

0 ,

!- Vertex 1 Y-coordinate $\{\mathrm{m}\}$

!- Vertex 1 Z-coordinate $\{\mathrm{m}\}$

!- Vertex $2 \mathrm{X}$-coordinate $\{\mathrm{m}\}$

!- Vertex 2 Y-coordinate $\{\mathrm{m}\}$

!- Vertex 2 Z-coordinate $\{\mathrm{m}\}$

!- Vertex $3 \mathrm{X}$-coordinate $\{\mathrm{m}\}$

5.4956,

5.874

0 ,

!- Vertex 3 Y-coordinate $\{\mathrm{m}\}$

!- Vertex 3 Z-coordinate $\{\mathrm{m}\}$

!- Vertex $4 \mathrm{X}$-coordinate $\{\mathrm{m}\}$

5.4956

8.976 ;

!- Vertex 4 Y-coordinate $\{\mathrm{m}\}$

!- Vertex 4 Z-coordinate $\{\mathrm{m}\}$

BuildingSurface: Detailed, Living floor,

Floor,

interior floor, Thermal Z̄one: Living, Surface,

Bsmt ceiling,

NoSun,

NoWind,

,

,

0,

0 ,

0 ,

0 ,

-9.276 ,

0 ,

-5.963 ,

-9.276 ,

0 ,

-5.963 ,

0 ,

0 ;

! - Name

! - Surface Type

! - Construction Name

! - Zone Name

!- Outside Boundary Condition

!- Outside Boundary Condition Object

!- Sun Exposure

!- Wind Exposure

! - View Factor to Ground

!- Number of Vertices

!- Vertex 1 X-coordinate $\{\mathrm{m}\}$

!- Vertex 1 Y-coordinate $\{\mathrm{m}\}$

!- Vertex 1 Z-coordinate $\{\mathrm{m}\}$

!- Vertex 2 X-coordinate $\{\mathrm{m}\}$

!- Vertex 2 Y-coordinate $\{\mathrm{m}\}$

!- Vertex 2 Z-coordinate $\{\mathrm{m}\}$

!- Vertex $3 \mathrm{X}$-coordinate $\{\mathrm{m}\}$

!- Vertex 3 Y-coordinate $\{m\}$

!- Vertex 3 Z-coordinate $\{\mathrm{m}\}$

!- Vertex $4 \mathrm{X}$-coordinate $\{\mathrm{m}\}$

!- Vertex 4 Y-coordinate $\{m\}$

!- Vertex 4 Z-coordinate $\{m\}$

BuildingSurface: Detailed, Living ceiling 2,

! - Name 


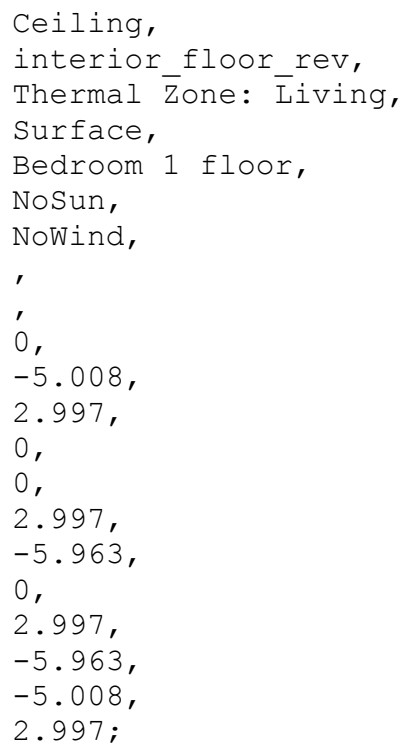

!- Surface Type

! - Construction Name

! - Zone Name

!- Outside Boundary Condition

!- Outside Boundary Condition Object

!- Sun Exposure

! - Wind Exposure

!- View Factor to Ground

!- Number of Vertices

!- Vertex $1 \mathrm{X}$-coordinate $\{\mathrm{m}\}$

!- Vertex 1 Y-coordinate $\{\mathrm{m}\}$

!- Vertex 1 Z-coordinate $\{\mathrm{m}\}$

!- Vertex $2 \mathrm{X}$-coordinate $\{\mathrm{m}\}$

!- Vertex 2 Y-coordinate $\{\mathrm{m}\}$

!- Vertex 2 Z-coordinate $\{m\}$

!- Vertex $3 \mathrm{X}$-coordinate $\{\mathrm{m}\}$

!- Vertex 3 Y-coordinate $\{\mathrm{m}\}$

!- Vertex 3 z-coordinate $\{\mathrm{m}\}$

!- Vertex $4 \mathrm{X}$-coordinate $\{\mathrm{m}\}$

!- Vertex 4 Y-coordinate $\{\mathrm{m}\}$

!- Vertex 4 Z-coordinate $\{\mathrm{m}\}$

BuildingSurface: Detailed, Living east wall,

Wall,

! - Name

@eWALLe@, !- Construction Name

Thermal Zone: Living, !- Zone Name

Outdoors,

!- Outside Boundary Condition

!- Outside Boundary Condition Object

SunExposed,

WindExposed,

!- Sun Exposure

!- Wind Exposure

,

í,

-9.276 ,

2.997,

!- View Factor to Ground

! - Number of Vertices

! - Vertex $1 \mathrm{X}$-coordinate $\{\mathrm{m}\}$

!- Vertex 1 Y-coordinate $\{m\}$

!- Vertex 1 Z-coordinate $\{\mathrm{m}\}$

0 ,

-9.276 ,

!- Vertex 2 X-coordinate $\{m\}$

!- Vertex 2 Y-coordinate $\{\mathrm{m}\}$

0 ,

!- Vertex 2 Z-coordinate $\{\mathrm{m}\}$

0 ,

!- Vertex $3 \mathrm{X}$-coordinate $\{\mathrm{m}\}$

0,

!- Vertex 3 Y-coordinate $\{\mathrm{m}\}$

0 ,

!- Vertex 3 Z-coordinate $\{m\}$

0 ,

0 ,

!- Vertex $4 \mathrm{X}$-coordinate $\{\mathrm{m}\}$

2.997;

- Vertex 4 Y-coordinate $\{m\}$

!- Vertex 4 Z-coordinate $\{m\}$

BuildingSurface: Detailed,

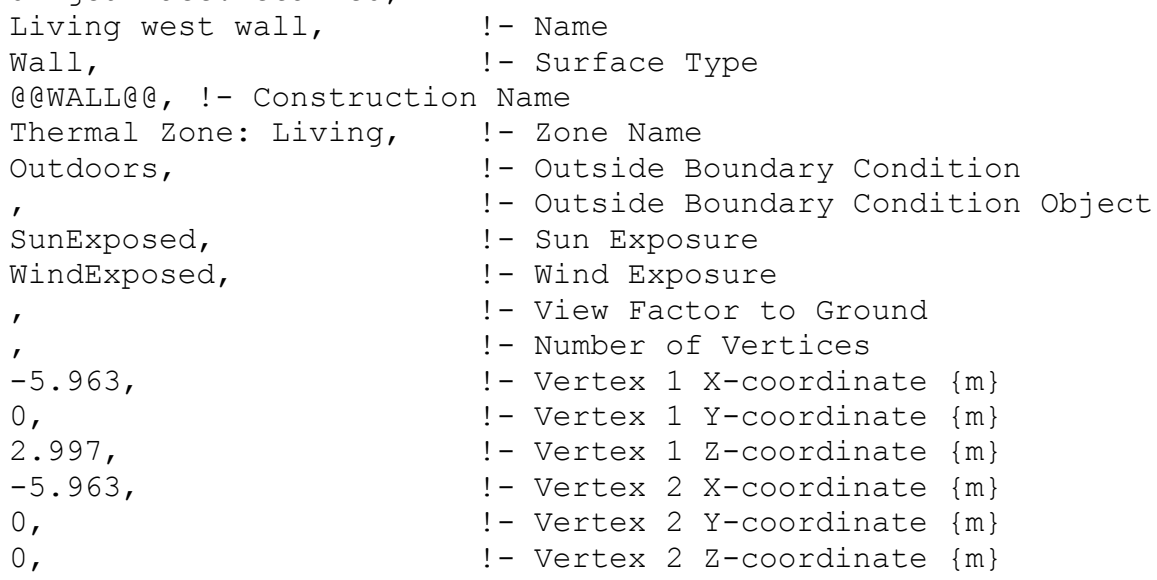




$\begin{array}{ll}-5.963, & !-\text { Vertex } 3 \text { X-coordinate }\{\mathrm{m}\} \\ -9.276, & !-\text { Vertex } 3 \text { Y-coordinate }\{\mathrm{m}\} \\ 0, & !-\text { Vertex } 3 \text { Z-coordinate }\{\mathrm{m}\} \\ -5.963, & !-\text { Vertex } 4 \text { X-coordinate }\{\mathrm{m}\} \\ -9.276, & !-\text { Vertex } 4 \text { Y-coordinate }\{\mathrm{m}\} \\ \text { 2.997; } & !-\text { Vertex } 4 \text { Z-coordinate }\{\mathrm{m}\}\end{array}$

BuildingSurface: Detailed,

$\begin{array}{ll}\text { Living south wall, } & !-\text { Name } \\ \text { Wall, } & !-\text { Surface Type }\end{array}$

@@WALL@e, !- Construction Name

Thermal Zone: Living, !- Zone Name

Outdoors,

!- Outside Boundary Condition

'́nExposed,

!- Outside Boundary Condition Object

WindExposed,

!- Sun Exposure

!- Wind Exposure

!- View Factor to Ground

,

$-5.963$

-9.276 ,

! - Number of Vertices

2.997,

!- Vertex $1 \mathrm{X}$-coordinate $\{\mathrm{m}\}$

!- Vertex 1 Y-coordinate $\{\mathrm{m}\}$

-5.963,

!- Vertex 1 Z-coordinate $\{m\}$

!- Vertex 2 X-coordinate $\{m\}$

$-9.276$

!- Vertex 2 Y-coordinate $\{\mathrm{m}\}$

0 ,

!- Vertex 2 Z-coordinate $\{\mathrm{m}\}$

-4.753,

!- Vertex $3 \mathrm{X}$-coordinate $\{\mathrm{m}\}$

-9.276 ,

0 ,

!- Vertex 3 Y-coordinate $\{\mathrm{m}\}$

!- Vertex 3 Z-coordinate $\{\mathrm{m}\}$

-4.753,

!- Vertex $4 \mathrm{X}$-coordinate $\{\mathrm{m}\}$

-9.276 ,

!- Vertex 4 Y-coordinate $\{\mathrm{m}\}$

2.997 ;

!- Vertex 4 Z-coordinate $\{\mathrm{m}\}$

BuildingSurface: Detailed,

$\begin{array}{ll}\text { Living north wall, } & !-\text { Name } \\ \text { Wall, } & !-\text { Surface Type }\end{array}$

@QWALLAQ, !- Construction Name

Thermal Zone: Living, !- Zone Name

Outdoors,

!- Outside Boundary Condition

SunExposed, WindExposed,

!- Outside Boundary Condition Object

! - Sun Exposure

! - Wind Exposure

! - View Factor to Ground

! - Number of Vertices

o,

0 ,

2.997,

!- Vertex $1 \mathrm{X}$-coordinate $\{\mathrm{m}\}$

!- Vertex 1 Y-coordinate $\{m\}$

0 ,

!- Vertex 1 Z-coordinate $\{m\}$

!- Vertex 2 X-coordinate $\{\mathrm{m}\}$

0,

!- Vertex 2 Y-coordinate $\{\mathrm{m}\}$

0 ,

-5.963 ,

!- Vertex 2 Z-coordinate $\{m\}$

!- Vertex $3 \mathrm{x}$-coordinate $\{\mathrm{m}\}$

0 ,

!- Vertex 3 Y-coordinate $\{\mathrm{m}\}$

0 ,

!- Vertex 3 Z-coordinate $\{m\}$

-5.963, !- Vertex $4 \mathrm{X}$-coordinate $\{\mathrm{m}\}$

$0, \quad !$ - Vertex 4 Y-coordinate $\{\mathrm{m}\}$

2.997; !- Vertex 4 Z-coordinate $\{\mathrm{m}\}$

BuildingSurface: Detailed, Living ceiling 1 ,

Ceiling,

! - Name

!- Surface Type

interior floor baths rev, !- Construction Name

Thermal Z̄one: L'iving, !- Zone Name

Surface,

Baths floor,

!- Outside Boundary Condition

NoSun,

!- Outside Boundary Condition Object

!- Sun Exposure 


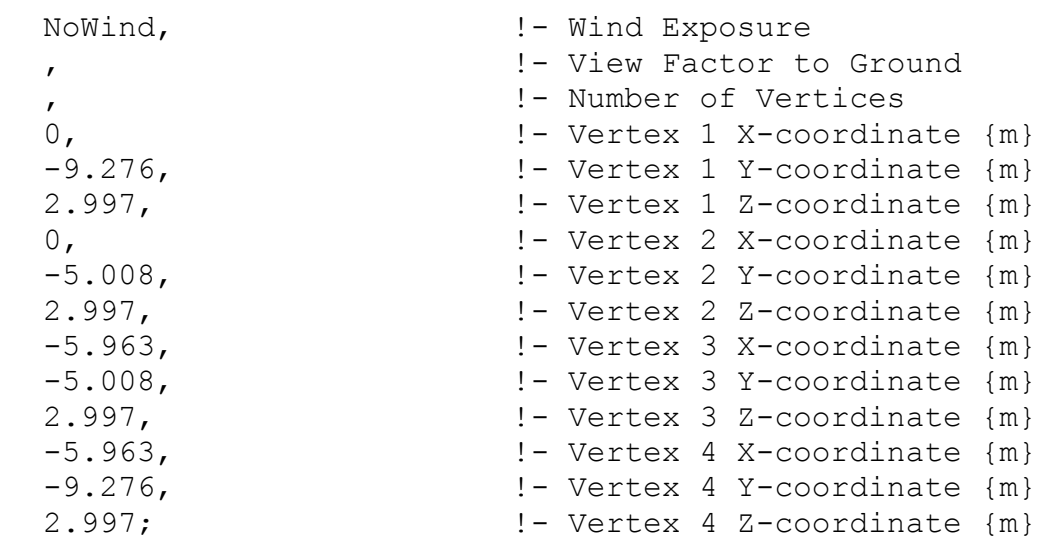

BuildingSurface: Detailed, Living - Kitchen partition, !- Name

\section{,}

-4.753 ,

$-9.276$

2.997

-4.753 ,

-9.276 ,

0 ,

0 ,

! - View Factor to Ground

!- Number of Vertices

!- Vertex $1 \mathrm{X}$-coordinate $\{\mathrm{m}\}$

!- Vertex 1 Y-coordinate $\{\mathrm{m}\}$

!- Vertex 1 Z-coordinate $\{\mathrm{m}\}$

!- Vertex $2 \mathrm{X}$-coordinate $\{\mathrm{m}\}$

!- Vertex 2 Y-coordinate $\{m\}$

!- Vertex 2 Z-coordinate $\{\mathrm{m}\}$

!- Vertex $3 \mathrm{X}$-coordinate $\{\mathrm{m}\}$

-9.276, !-Vertex 3 Y-coordinate $\{m\}$

$0, \quad !$ - Vertex 3 Z-coordinate $\{m\}$

0, !- Vertex $4 \mathrm{X}$-coordinate $\{\mathrm{m}\}$

-9.276, !- Vertex 4 Y-coordinate $\{m\}$

2.997; !- Vertex 4 Z-coordinate $\{m\}$

BuildingSurface: Detailed, Bedroom 1 - Baths partition, !- Name

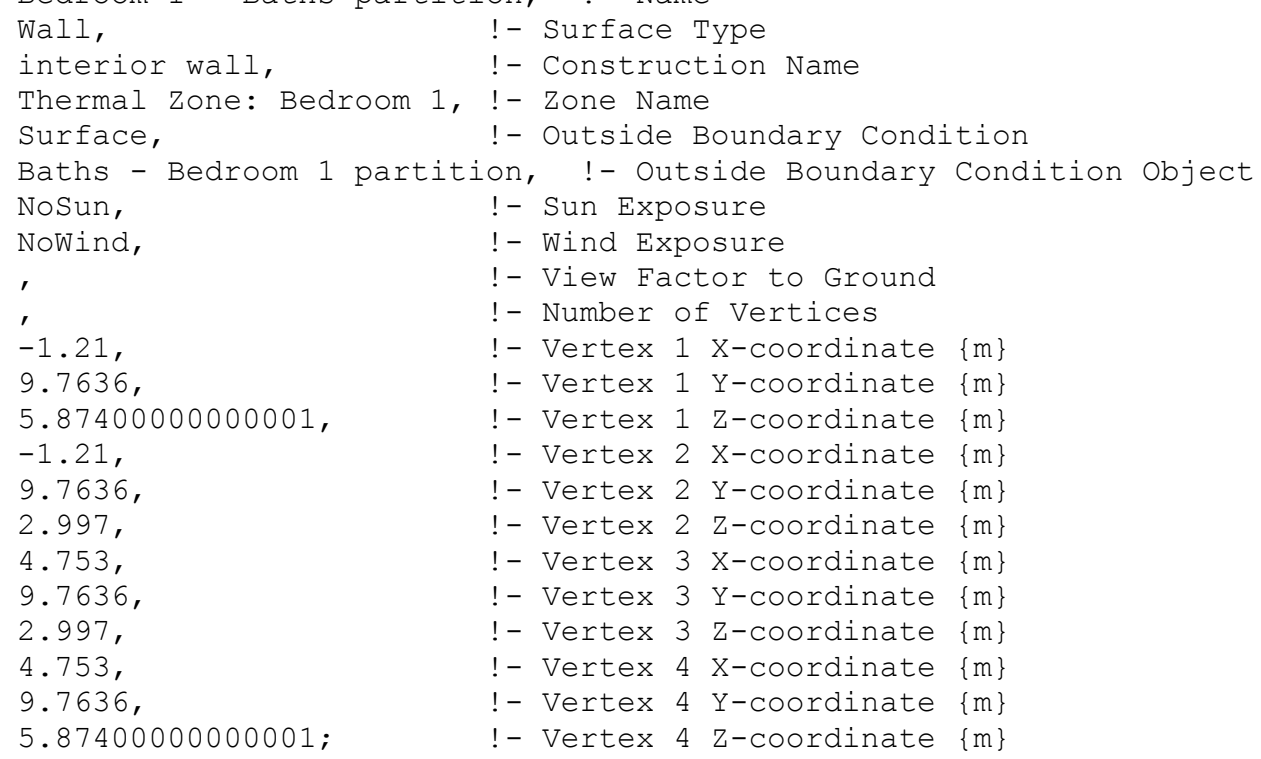




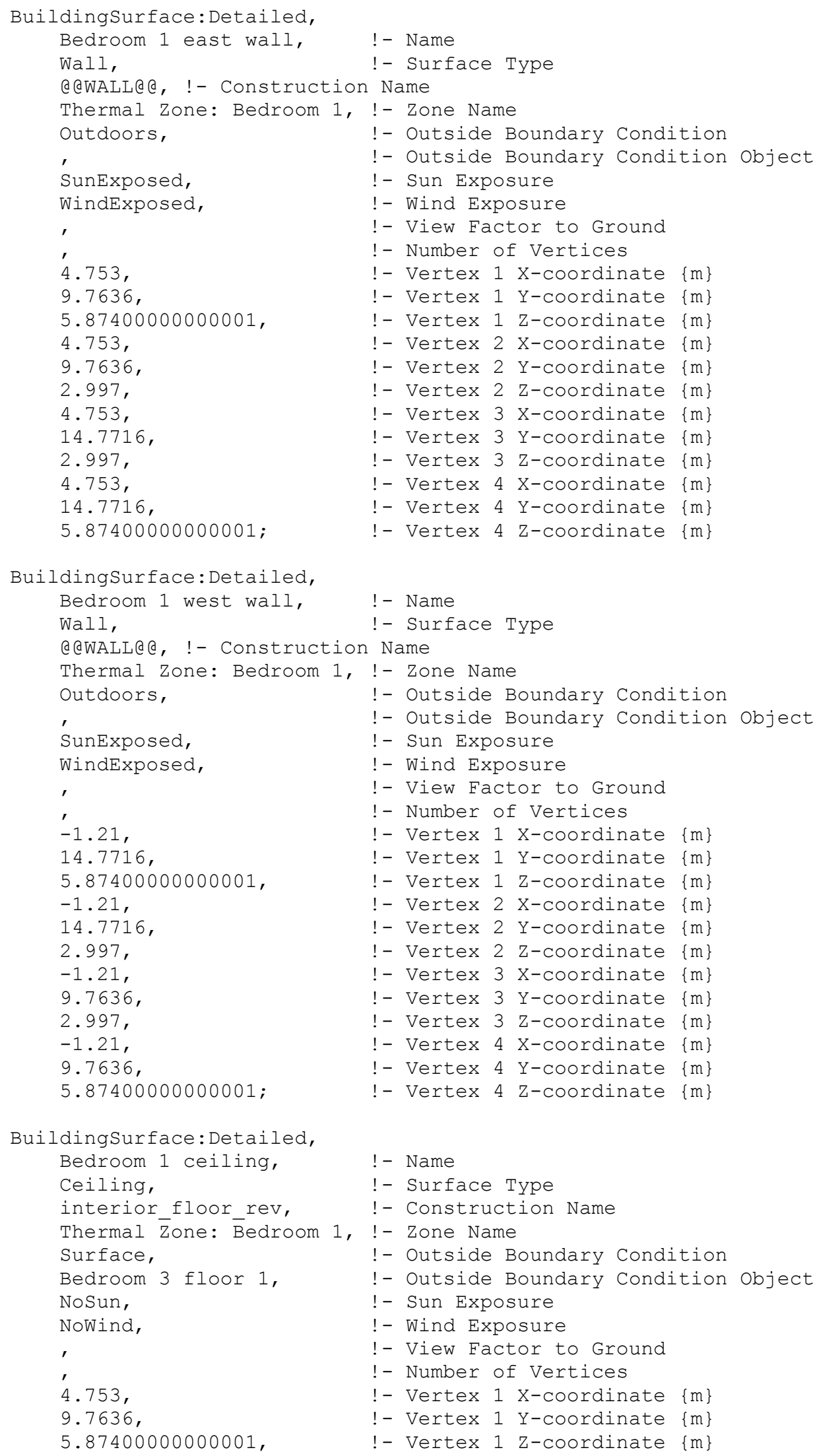


4.753,

14.7716 ,

5.87400000000001

-1.21 ,

14.7716,

5.87400000000001 ,

-1.21 ,

9.7636

5.87400000000001 ;
!- Vertex 2 X-coordinate $\{\mathrm{m}\}$

!- Vertex 2 Y-coordinate $\{\mathrm{m}\}$

!- Vertex 2 Z-coordinate $\{\mathrm{m}\}$

!- Vertex 3 X-coordinate $\{m\}$

!- Vertex 3 Y-coordinate $\{\mathrm{m}\}$

!- Vertex 3 Z-coordinate $\{\mathrm{m}\}$

!- Vertex $4 \mathrm{X}$-coordinate $\{\mathrm{m}\}$

!- Vertex 4 Y-coordinate $\{\mathrm{m}\}$

!- Vertex 4 Z-coordinate $\{\mathrm{m}\}$

BuildingSurface: Detailed, Bedroom 1 floor,

! - Name

Floor,

! - Surface Type

interior floor,

! - Construction Name

Thermal Z̄one: Bedroom 1, !- Zone Name

Surface,

!- Outside Boundary Condition

Living ceiling 2,

!- Outside Boundary Condition Object

NoSun,

! - Sun Exposure

NoWind,

!- Wind Exposure

! - View Factor to Ground

,

4.753,

!- Number of Vertices

!- Vertex 1 X-coordinate $\{\mathrm{m}\}$

14.7716,

!- Vertex 1 Y-coordinate $\{\mathrm{m}\}$

2.997,

4.753,

!- Vertex 1 Z-coordinate $\{\mathrm{m}\}$

!- Vertex 2 X-coordinate $\{\mathrm{m}\}$

9.7636,

2.997,

!- Vertex 2 Y-coordinate $\{\mathrm{m}\}$

!- Vertex 2 Z-coordinate $\{\mathrm{m}\}$

$-1.21$

9.7636

2.997,

-1.21 ,

!- Vertex $3 \mathrm{X}$-coordinate $\{\mathrm{m}\}$

!- Vertex 3 Y-coordinate $\{\mathrm{m}\}$

!- Vertex 3 Z-coordinate $\{\mathrm{m}\}$

!- Vertex $4 \mathrm{X}$-coordinate $\{\mathrm{m}\}$

14.7716 ,

2.997 ;

!- Vertex 4 Y-coordinate $\{\mathrm{m}\}$

!- Vertex 4 Z-coordinate $\{\mathrm{m}\}$

BuildingSurface: Detailed, Bedroom 1 north wall,

Wall,

! - Name

@@WALL@@, !- Construction Name

Thermal Zone: Bedroom 1, !- Zone Name

Outdoors,

!- Outside Boundary Condition

SunExposed,

WindExposed,

!- Outside Boundary Condition Object

!- Sun Exposure

!- Wind Exposure

!- View Factor to Ground

4.753,

14.7716

5.87400000000001 ,

4.753,

14.7716 ,

2.997,

-1.21 ,

14.7716,

! - Number of Vertices

!- Vertex $1 \mathrm{X}$-coordinate $\{\mathrm{m}\}$

!- Vertex 1 Y-coordinate $\{m\}$

!- Vertex 1 Z-coordinate $\{m\}$

!- Vertex 2 X-coordinate $\{\mathrm{m}\}$

!- Vertex 2 Y-coordinate $\{\mathrm{m}\}$

!- Vertex 2 Z-coordinate $\{\mathrm{m}\}$

!- Vertex $3 \mathrm{X}$-coordinate $\{\mathrm{m}\}$

!- Vertex 3 Y-coordinate $\{\mathrm{m}\}$

!- Vertex 3 Z-coordinate $\{\mathrm{m}\}$

2.997,

-1.21 ,

14.7716 ,

5.87400000000001 ;

!- Vertex $4 \mathrm{X}$-coordinate $\{\mathrm{m}\}$

!- Vertex 4 Y-coordinate $\{\mathrm{m}\}$

!- Vertex 4 Z-coordinate $\{m\}$

BuildingSurface: Detailed, Baths floor,

Floor,

interior floor baths, Thermal Z̄one: Baths,

! - Name

!- Surface Type

!- Construction Name

! - Zone Name 


Surface,
Living ceiling 1,
NoSun,
Nowind,
',
' 753,
9.7636,
2.997,
4.753,
5.4956,
2.997,
-1.21
5.4956,
2.997,
-1.21,
9.7636,
2.997

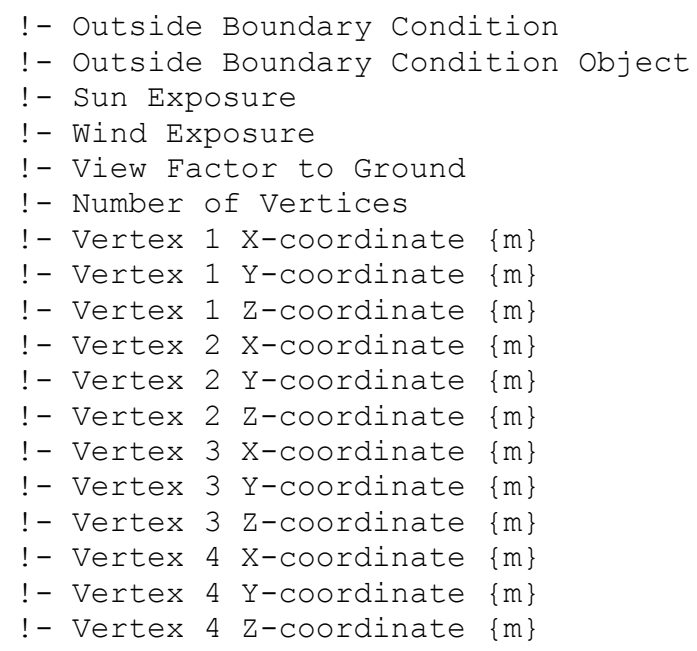

BuildingSurface: Detailed,

Baths - Bedroom 1 partition, !- Name

Wall, ! - Surface Type

interior wall, !- Construction Name

Thermal Zone: Baths, !- Zone Name

Surface, !- Outside Boundary Condition

Bedroom 1 - Baths partition, !-Outside Boundary Condition Object

NoSun, !- Sun Exposure

NoWind, $\quad$ !- Wind Exposure

, ! - View Factor to Ground

, ! - Number of Vertices

4.753, !- Vertex 1 X-coordinate $\{\mathrm{m}\}$

9.7636, !- Vertex 1 Y-coordinate $\{\mathrm{m}\}$

5.874, !- Vertex 1 Z-coordinate $\{\mathrm{m}\}$

4.753, !- Vertex 2 X-coordinate $\{\mathrm{m}\}$

9.7636, !- Vertex 2 Y-coordinate $\{\mathrm{m}\}$

2.997, !- Vertex 2 Z-coordinate $\{\mathrm{m}\}$

-1.21, !- Vertex 3 x-coordinate $\{\mathrm{m}\}$

9.7636, !- Vertex 3 Y-coordinate $\{\mathrm{m}\}$

2.997, !-Vertex 3 Z-coordinate $\{\mathrm{m}\}$

-1.21, !- Vertex $4 \mathrm{x}$-coordinate $\{\mathrm{m}\}$

9.7636, !- Vertex 4 Y-coordinate $\{\mathrm{m}\}$

5.874; !- Vertex 4 Z-coordinate $\{m\}$

BuildingSurface: Detailed, Baths - Bedroom 2 partition, !- Name

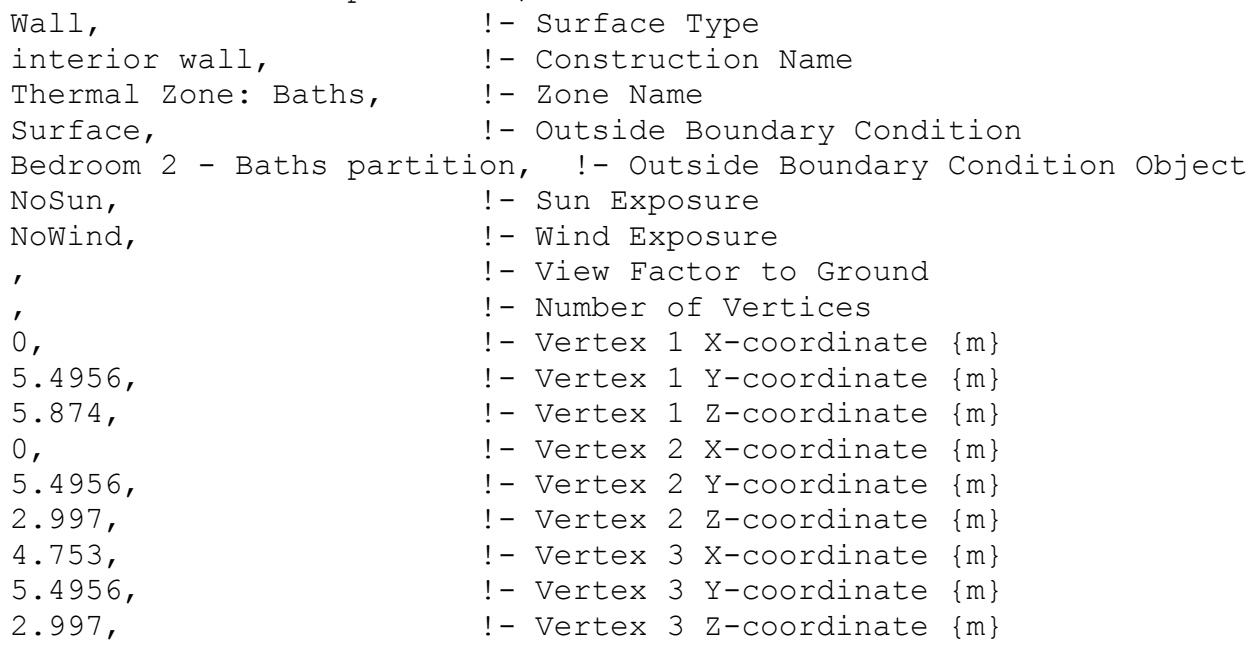



4.753,
!- Vertex $4 \mathrm{X}$-coordinate $\{\mathrm{m}\}$
5.4956,
!- Vertex 4 Y-coordinate $\{\mathrm{m}\}$
$5.874 ;$
!- Vertex 4 Z-coordinate $\{\mathrm{m}\}$

BuildingSurface: Detailed,

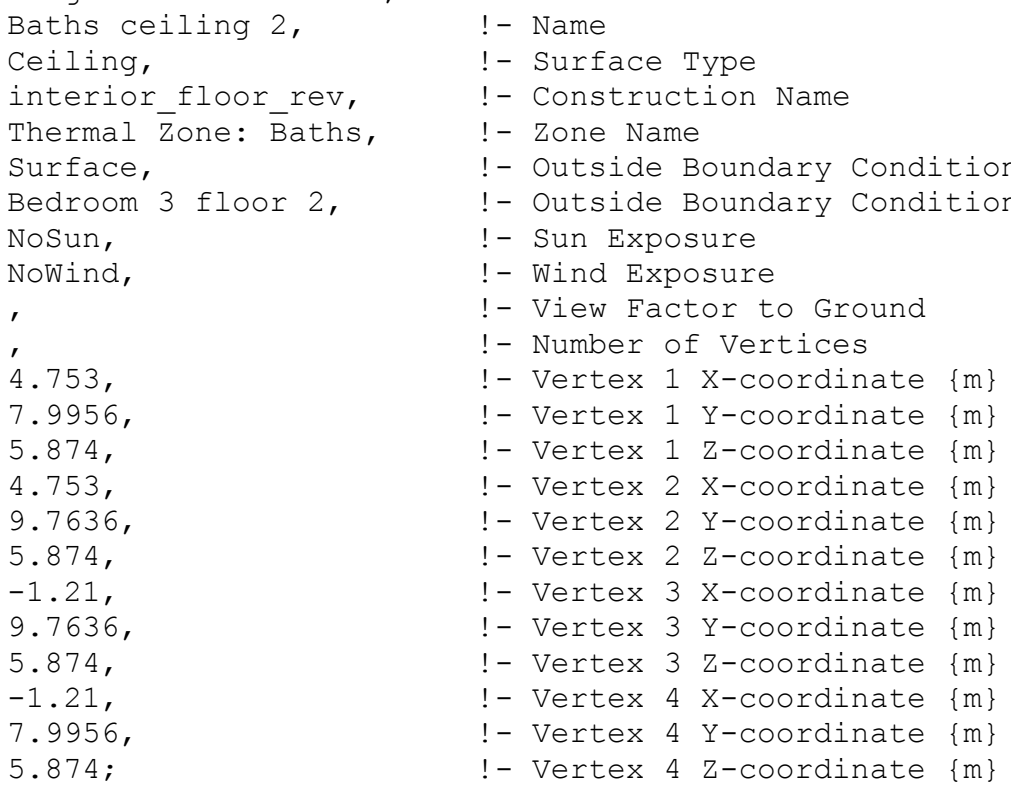

BuildingSurface: Detailed, Baths west wall.

1 - Name

Wall,

! - Surface Type

@@WALL@e, !- Construction Name

Thermal Zone: Baths,

!- Outside Boundary Condition

SunExposed,

!- Outside Boundary Condition Object

WindExposed,

!- Sun Exposure

!- Wind Exposure

! - View Factor to Ground

,

4.753,

5.4956

! - Number of Vertices

!- Vertex $1 \mathrm{X}$-coordinate $\{\mathrm{m}\}$

!- Vertex 1 Y-coordinate $\{\mathrm{m}\}$

5.874,

4.753,

5.4956

2.997,

4.753,

9.7636 ,

!- Vertex 2 X-coordinate $\{\mathrm{m}\}$

!- Vertex 2 Y-coordinate $\{\mathrm{m}\}$

!- Vertex 2 Z-coordinate $\{\mathrm{m}\}$

!- Vertex $3 \mathrm{X}$-coordinate $\{\mathrm{m}\}$

!- Vertex 3 Y-coordinate $\{\mathrm{m}\}$

2.997,

4.753,

!- Vertex 3 Z-coordinate $\{\mathrm{m}\}$

!- Vertex $4 \mathrm{X}$-coordinate $\{\mathrm{m}\}$

9.7636,

!- Vertex 4 Y-coordinate $\{\mathrm{m}\}$

$5.874 ;$

!- Vertex 4 Z-coordinate $\{m\}$

BuildingSurface: Detailed, Baths south wall,

Wall,

! - Name

a@WALLea, !- Construction Name

Thermal Zone: Baths, !- Zone Name

outdoors,

!- Outside Boundary Condition

!- Outside Boundary Condition Object

SunExposed,

WindExposed,

!- Sun Exposure

!- Wind Exposure

,

!- View Factor to Ground

! - Number of Vertices 


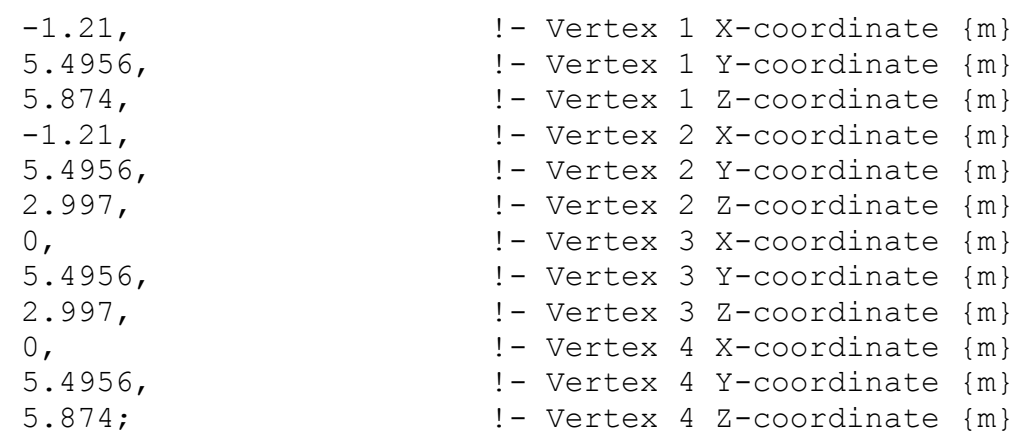

BuildingSurface: Detailed, Baths ceiling 1, !- Name Ceiling, !- Surface Type

interior floor baths rev,!- Construction Name Thermal Z̄one: Baths, !- Zone Name

Surface, !- Outside Boundary Condition

Third bath floor, !- Outside Boundary Condition object

NoSun,

NoWind,

!- Sun Exposure

!- Wind Exposure

! - View Factor to Ground

4.753,

5.4956 ,

! - Number of Vertices

!- Vertex $1 \mathrm{X}$-coordinate $\{\mathrm{m}\}$

5.874,

4.753,

7.9956,

5.874,

-1.21 ,

7.9956,

5.874,

-1.21 ,

5.4956,

!- Vertex 1 Y-coordinate $\{\mathrm{m}\}$

!- Vertex 1 Z-coordinate $\{\mathrm{m}\}$

!- Vertex $2 \mathrm{X}$-coordinate $\{\mathrm{m}\}$

!- Vertex 2 Y-coordinate $\{\mathrm{m}\}$

!- Vertex 2 Z-coordinate $\{\mathrm{m}\}$

!- Vertex $3 \mathrm{X}$-coordinate $\{\mathrm{m}\}$

!- Vertex 3 Y-coordinate $\{m\}$

!- Vertex 3 Z-coordinate $\{\mathrm{m}\}$

!- Vertex $4 \mathrm{X}$-coordinate $\{\mathrm{m}\}$

$5.874 ;$

!- Vertex 4 Y-coordinate $\{\mathrm{m}\}$

!- Vertex 4 Z-coordinate $\{\mathrm{m}\}$

BuildingSurface: Detailed,
Baths east wall,
! - Name
Wall,
!- Surface Type

@@WALL@e, !- Construction Name

Thermal Zone: Baths, !- Zone Name

Outdoors,

!- Outside Boundary Condition

'́nExposed,

WindExposed,

!- Outside Boundary Condition Object

!- Sun Exposure

!- Wind Exposure

! - View Factor to Ground

! - Number of Vertices

-1.21 ,

9.7636,

!- Vertex $1 \mathrm{X}$-coordinate $\{\mathrm{m}\}$

!- Vertex 1 Y-coordinate $\{\mathrm{m}\}$

5.874,

$-1.21$

!- Vertex 1 Z-coordinate $\{\mathrm{m}\}$

!- Vertex 2 X-coordinate $\{\mathrm{m}\}$

9.7636,

!- Vertex 2 Y-coordinate $\{\mathrm{m}\}$

2.997,

-1.21 ,

5.4956,

2.997,

$-1.21$

5.4956,

$5.874 ;$

!- Vertex 2 Z-coordinate $\{\mathrm{m}\}$

!- Vertex $3 \mathrm{X}$-coordinate $\{\mathrm{m}\}$

!- Vertex 3 Y-coordinate $\{m\}$

!- Vertex 3 Z-coordinate $\{\mathrm{m}\}$

!- Vertex $4 \mathrm{X}$-coordinate $\{\mathrm{m}\}$

!- Vertex 4 Y-coordinate $\{m\}$

!- Vertex 4 Z-coordinate $\{m\}$

BuildingSurface: Detailed, Kitchen east wall,

! - Name 


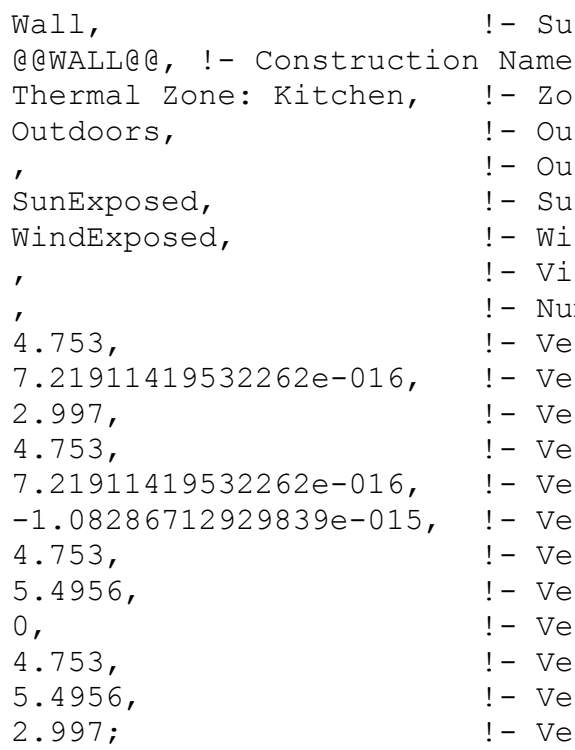

BuildingSurface: Detailed, Kitchen west wall,

Wall,

! - Name

adWALLad, !- Construction Name

Thermal Zone: Kitchen, !- Zone Name

Outdoors, !- Outside Boundary Condition

!- Outside Boundary Condition Object

SunExposed,

!- Sun Exposure

WindExposed,

! - Wind Exposure

,

'́,

!- View Factor to Ground

! - Number of Vertices

5.4956,

!- Vertex $1 \mathrm{X}$-coordinate $\{\mathrm{m}\}$

2.997,

!- Vertex 1 Y-coordinate $\{\mathrm{m}\}$

!- Vertex 1 Z-coordinate $\{\mathrm{m}\}$

0 ,

!- Vertex 2 X-coordinate $\{\mathrm{m}\}$

5.4956,

!- Vertex 2 Y-coordinate $\{\mathrm{m}\}$

!- Vertex 2 Z-coordinate $\{\mathrm{m}\}$

!- Vertex $3 \mathrm{X}$-coordinate $\{\mathrm{m}\}$

!- Vertex 3 Y-coordinate $\{\mathrm{m}\}$

!- Vertex 3 Z-coordinate $\{m\}$

!- Vertex $4 \mathrm{X}$-coordinate $\{\mathrm{m}\}$

!- Vertex 4 Y-coordinate $\{\mathrm{m}\}$

2.997;

!- Vertex 4 Z-coordinate $\{\mathrm{m}\}$

BuildingSurface: Detailed,

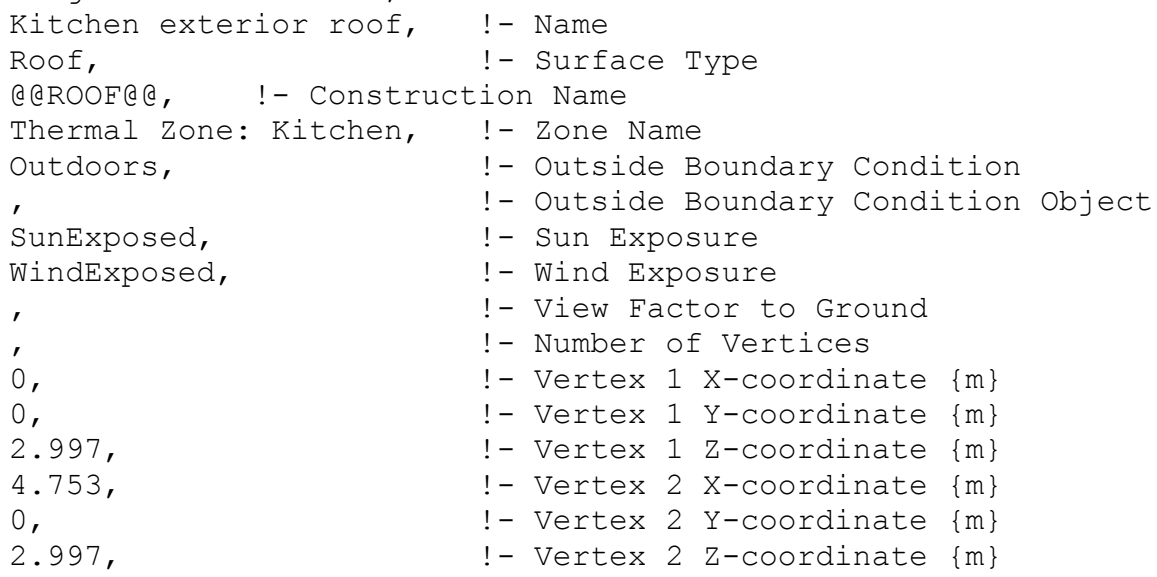



4.753,
!- Vertex $3 \mathrm{X}$-coordinate $\{\mathrm{m}\}$
1.7 ,
!- Vertex 3 Y-coordinate $\{\mathrm{m}\}$
2.997,
!- Vertex 3 Z-coordinate $\{\mathrm{m}\}$
0 ,
!- Vertex $4 \mathrm{X}$-coordinate $\{\mathrm{m}\}$
1.7,
!- Vertex 4 Y-coordinate $\{\mathrm{m}\}$
2.997
!- Vertex 4 Z-coordinate $\{m\}$

BuildingSurface: Detailed,

Kitchen ceiling,
Ceiling,
interior floor rev,
Thermal Zone: Kitchen,
Surface,
Bedroom 2 floor,
NoSun,
NoWind,
',
4.753,
1.7,
2.997,
4.753,
5.4956,
2.997,
0,
5.4956,
2.997,
0,
1.7,
$2.997 ;$

! - Name

!- Surface Type

!- Construction Name

! - Zone Name

!- Outside Boundary Condition

!- Outside Boundary Condition Object

!- Sun Exposure

!- Wind Exposure

! - View Factor to Ground

! - Number of Vertices

!- Vertex $1 \mathrm{x}$-coordinate $\{\mathrm{m}\}$

!- Vertex 1 Y-coordinate $\{\mathrm{m}\}$

!- Vertex 1 Z-coordinate $\{m\}$

!- Vertex 2 X-coordinate $\{\mathrm{m}\}$

!- Vertex 2 Y-coordinate $\{\mathrm{m}\}$

!- Vertex 2 Z-coordinate $\{\mathrm{m}\}$

!- Vertex $3 \mathrm{X}$-coordinate $\{\mathrm{m}\}$

!- Vertex 3 Y-coordinate $\{m\}$

!- Vertex 3 Z-coordinate $\{\mathrm{m}\}$

!- Vertex $4 \mathrm{X}$-coordinate $\{\mathrm{m}\}$

!- Vertex 4 Y-coordinate $\{\mathrm{m}\}$

!- Vertex 4 Z-coordinate $\{\mathrm{m}\}$

BuildingSurface: Detailed, Kitchen - Living partition, !- Name

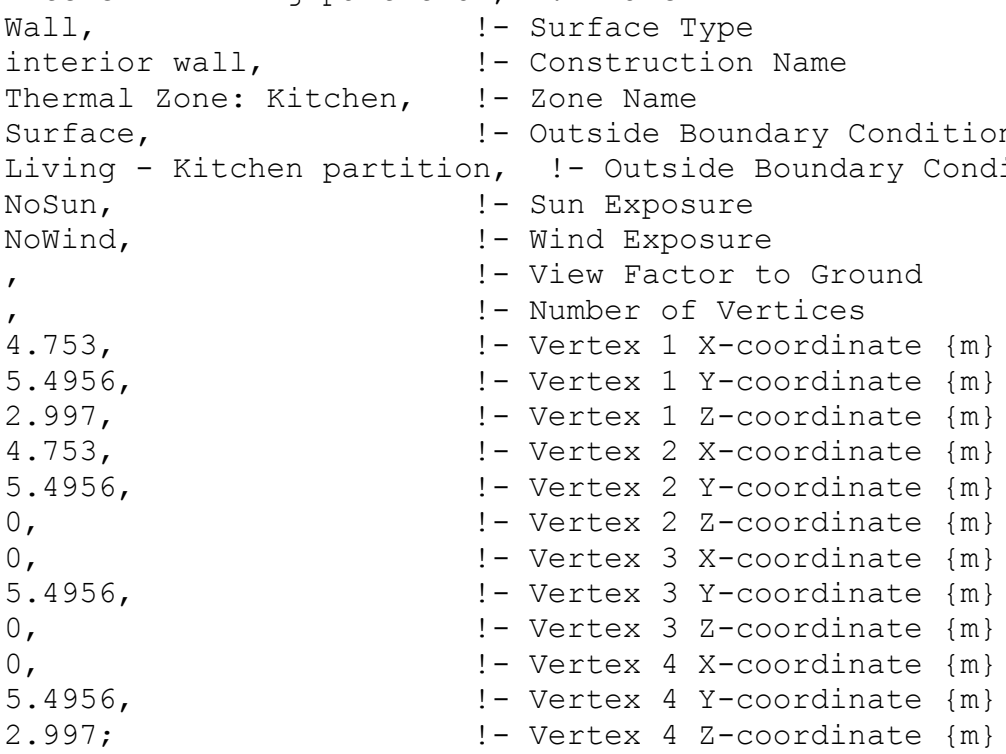

BuildingSurface: Detailed, kitchen south wall, !- Name

Wall,

!- Surface Type

@@WALLA@, !- Construction Name

Thermal Zone: Kitchen, !- Zone Name

Outdoors,

!- Outside Boundary Condition

!- Outside Boundary Condition Object

SunExposed,

!- Sun Exposure 


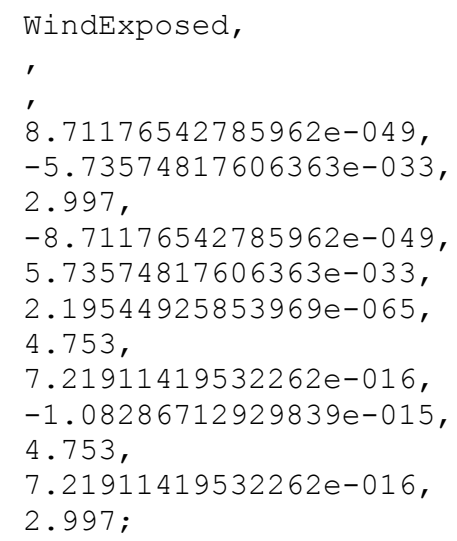

BuildingSurface: Detailed,

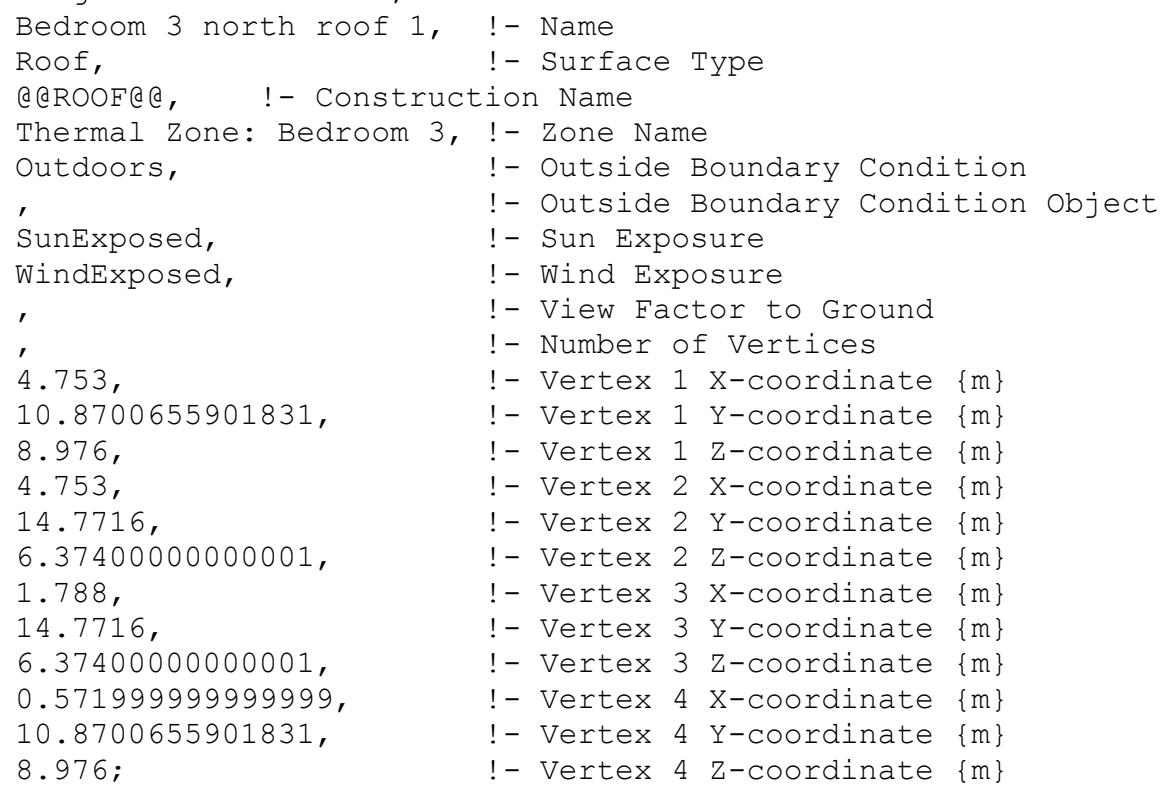




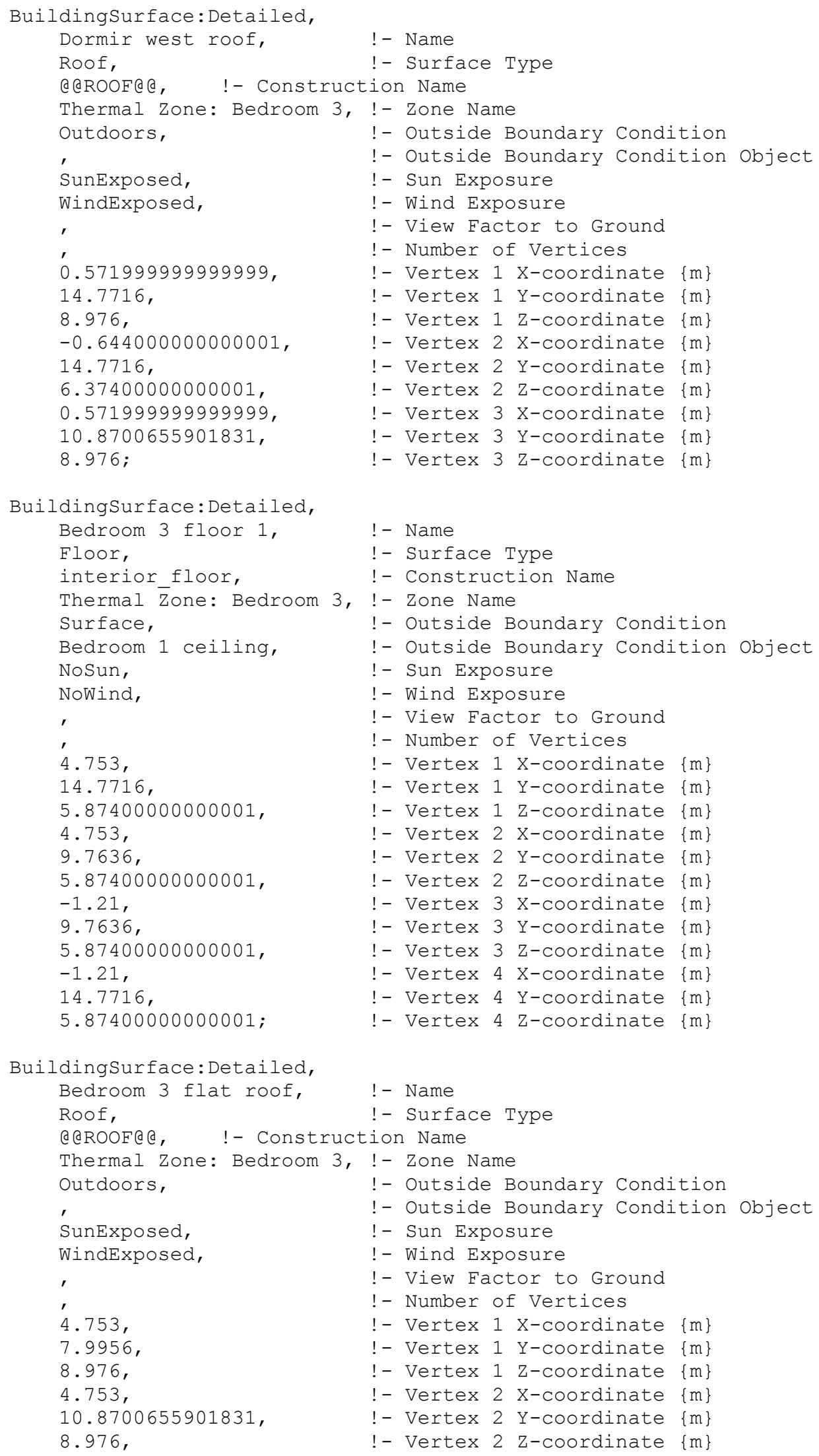


-1.21 ,

10.8700655901831 ,

8.976 ,

$-1.21$

7.9956,

8.976
!- Vertex $3 \mathrm{X}$-coordinate $\{\mathrm{m}\}$

!- Vertex 3 Y-coordinate $\{\mathrm{m}\}$

!- Vertex 3 Z-coordinate $\{\mathrm{m}\}$

!- Vertex $4 \mathrm{X}$-coordinate $\{\mathrm{m}\}$

!- Vertex 4 Y-coordinate $\{\mathrm{m}\}$

!- Vertex 4 Z-coordinate $\{m\}$

BuildingSurface: Detailed, Bedroom 3 north wall, Wall,

! - Name

QAWALLAe, !- Construction Name

Thermal Zone: Bedroom 3, !- Zone Name

Outdoors,

!- Outside Boundary Condition

'́nExposed,

!- Outside Boundary Condition Object

WindExposed,

!- Sun Exposure

!- Wind Exposure

!- View Factor to Ground

,

4.753

14.7716 ,

! - Number of Vertices

6.37400000000001 ,

!- Vertex $1 \mathrm{X}$-coordinate $\{\mathrm{m}\}$

!- Vertex 1 Y-coordinate $\{m\}$

4.753 ,

!- Vertex 1 Z-coordinate $\{\mathrm{m}\}$

!- Vertex 2 X-coordinate $\{m\}$

14.7716 ,

!- Vertex 2 Y-coordinate $\{\mathrm{m}\}$

5.87400000000001 ,

!- Vertex 2 Z-coordinate $\{\mathrm{m}\}$

-1.21 ,

14.7716,

!- Vertex $3 \mathrm{X}$-coordinate $\{\mathrm{m}\}$

!- Vertex 3 Y-coordinate $\{\mathrm{m}\}$

5.87400000000001 ,

!- Vertex 3 Z-coordinate $\{\mathrm{m}\}$

-1.21 ,

!- Vertex $4 \mathrm{X}$-coordinate $\{\mathrm{m}\}$

14.7716 ,

!- Vertex 4 Y-coordinate $\{\mathrm{m}\}$

6.37400000000001 ;

!- Vertex 4 Z-coordinate $\{m\}$

BuildingSurface: Detailed,

Dormir east roof, !- Name

Roof, !- Surface Type

aeroOFea, !- Construction Name

Thermal Zone: Bedroom 3, !- Zone Name

Outdoors, !- Outside Boundary Condition

!- Outside Boundary Condition Object

SunExposed,

WindExposed,

! - Sun Exposure

!- Wind Exposure

! - View Factor to Ground

,

0.572 ,

! - Number of Vertices

!- Vertex $1 \mathrm{X}$-coordinate $\{\mathrm{m}\}$

10.8700655901831 ,

!- Vertex 1 Y-coordinate $\{\mathrm{m}\}$

8.976

1.788,

14.7716

!- Vertex 1 Z-coordinate $\{m\}$

!- Vertex 2 X-coordinate $\{\mathrm{m}\}$

!- Vertex 2 Y-coordinate $\{\mathrm{m}\}$

6.37400000000001 ,

!- Vertex 2 Z-coordinate $\{m\}$

0.572 ,

14.7716

!- Vertex $3 \mathrm{X}$-coordinate $\{\mathrm{m}\}$

!- Vertex 3 Y-coordinate $\{\mathrm{m}\}$

8.976;

!- Vertex 3 Z-coordinate $\{m\}$

BuildingSurface: Detailed, Bedroom 3 - third bath, Wall, interior wall,

! - Name

! - Surface Type

! - Construction Name

Thermal Zone: Bedroom 3, !- Zone Name

Surface,

- Outside Boundary Condition

Third bath - Bedroom 3 partition, !- Outside Boundary Condition Object

NoSun,

NoWind,

!- Sun Exposure

!- Wind Exposure

,

!- View Factor to Ground

!- Number of Vertices 

4.753,
!- Vertex $1 \mathrm{X}$-coordinate $\{\mathrm{m}\}$
7.9956,
!- Vertex 1 Y-coordinate $\{\mathrm{m}\}$
8.97600000000001
!- Vertex 1 Z-coordinate $\{\mathrm{m}\}$
-1.21 ,
!- Vertex 2 X-coordinate $\{m\}$
7.9956,
!- Vertex 2 Y-coordinate $\{\mathrm{m}\}$
8.976 ,
!- Vertex 2 Z-coordinate $\{\mathrm{m}\}$
-1.21,
!- Vertex $3 \mathrm{X}$-coordinate $\{\mathrm{m}\}$
7.9956,
!- Vertex 3 Y-coordinate $\{\mathrm{m}\}$
5.874,
!- Vertex 3 Z-coordinate $\{\mathrm{m}\}$
4.753,
7.9956 ,
!- Vertex $4 \mathrm{X}$-coordinate $\{\mathrm{m}\}$
!- Vertex 4 Y-coordinate $\{\mathrm{m}\}$
5.87400000000001 ;
!- Vertex 4 Z-coordinate $\{m\}$

BuildingSurface: Detailed, Bedroom 3 west wall,

Wall,

! - Name

!- Surface Type

(1) - Construction Name

Thermal Zone: Bedroom 3, !- Zone Name

Outdoors,

!- Outside Boundary Condition

! - Outside Boundary Condition Object

SunExposed,

WindExposed,

!- Sun Exposure

!- Wind Exposure

! - View Factor to Ground

-1.21 ,

! - Number of Vertices

!- Vertex $1 \mathrm{X}$-coordinate $\{\mathrm{m}\}$

10.8700655901831

!- Vertex 1 Y-coordinate $\{\mathrm{m}\}$

8.976 ,

-1.21 ,

14.7716,

6.37400000000001

!- Vertex 1 Z-coordinate $\{\mathrm{m}\}$

!- Vertex $2 \mathrm{X}$-coordinate $\{\mathrm{m}\}$

!- Vertex 2 Y-coordinate $\{\mathrm{m}\}$

!- Vertex 2 Z-coordinate $\{\mathrm{m}\}$

-1.21 ,

!- Vertex $3 \mathrm{X}$-coordinate $\{\mathrm{m}\}$

14.7716,

5.87400000000001

!- Vertex 3 Y-coordinate $\{\mathrm{m}\}$

!- Vertex 3 Z-coordinate $\{\mathrm{m}\}$

!- Vertex $4 \mathrm{X}$-coordinate $\{\mathrm{m}\}$

-1.21 ,

!- Vertex 4 Y-coordinate $\{\mathrm{m}\}$

7.9956,

5.874,

$-1.21$

7.9956,

!- Vertex 4 Z-coordinate $\{m\}$

!- Vertex $5 \mathrm{X}$-coordinate $\{\mathrm{m}\}$

!- Vertex 5 Y-coordinate $\{\mathrm{m}\}$

$8.976 ;$

!- Vertex 5 Z-coordinate $\{m\}$

BuildingSurface: Detailed,

$\begin{array}{ll}\text { dormir north wall, } & !-\text { Name } \\ \text { Wall, } & !-\text { Surface Type }\end{array}$

deWALLAa, !- Construction Name

Thermal Zone: Bedroom 3, !- Zone Name

outdoors,

!- Outside Boundary Condition

SunExposed,

WindExposed,

!- Outside Boundary Condition Object

! - Sun Exposure

!- Wind Exposure

! - View Factor to Ground

!- Number of Vertices

0.571999999999999,

!- Vertex $1 \mathrm{X}$-coordinate $\{\mathrm{m}\}$

14.7716 ,

8.976

1.788,

14.7716 ,

6.37400000000001

-0.644000000000001 ,

14.7716 ,

6.37400000000001 ;

!- Vertex 1 Y-coordinate $\{\mathrm{m}\}$

!- Vertex 1 Z-coordinate $\{\mathrm{m}\}$

!- Vertex $2 \mathrm{X}$-coordinate $\{\mathrm{m}\}$

!- Vertex 2 Y-coordinate $\{\mathrm{m}\}$

!- Vertex 2 Z-coordinate $\{\mathrm{m}\}$

!- Vertex $3 \mathrm{X}$-coordinate $\{\mathrm{m}\}$

!- Vertex 3 Y-coordinate $\{\mathrm{m}\}$

!- Vertex 3 Z-coordinate $\{m\}$

BuildingSurface: Detailed, Bedroom 3 east wall,

! - Name 


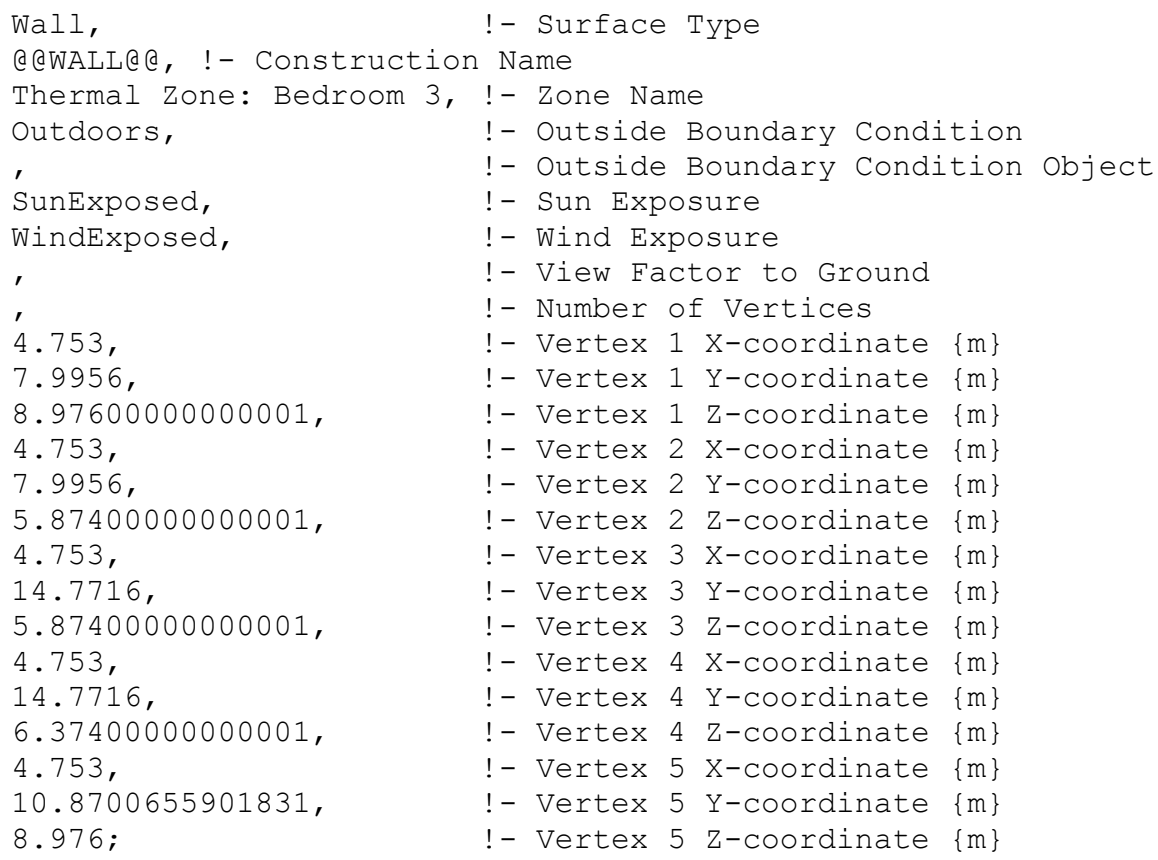

BuildingSurface: Detailed, 

4.753,
!- Vertex 2 X-coordinate $\{\mathrm{m}\}$
7.9956,
!- Vertex 2 Y-coordinate $\{\mathrm{m}\}$
5.87400000000001
!- Vertex 2 Z-coordinate $\{\mathrm{m}\}$
-1.21 ,
! - Vertex 3 X-coordinate $\{\mathrm{m}\}$
7.9956,
!- Vertex 3 Y-coordinate $\{m\}$
5.874,
!- Vertex 3 Z-coordinate $\{\mathrm{m}\}$
-1.21 ,
! - Vertex $4 \mathrm{X}$-coordinate $\{\mathrm{m}\}$
9.7636 ,
!- Vertex 4 Y-coordinate $\{\mathrm{m}\}$
5.87400000000001 ;
!- Vertex 4 Z-coordinate $\{\mathrm{m}\}$

BuildingSurface: Detailed,

Basement S - Basement partition, !- Name

Wall, !- Surface Type

interior wall, $\quad$ !- Construction Name

Thermal Zone: Basement S, !- Zone Name

Surface, $\quad$ !- Outside Boundary Condition

Basement - Basement S partition, !- Outside Boundary Condition Object

NoSun, !- Sun Exposure

NoWind, !- Wind Exposure

autocalculate, $\quad$ !- View Factor to Ground

4 ,

0 ,

!- Number of Vertices

!- Vertex 1 X-coordinate $\{\mathrm{m}\}$

5.4956, !- Vertex 1 Y-coordinate $\{\mathrm{m}\}$

-2.438, !- Vertex 1 Z-coordinate $\{\mathrm{m}\}$

4.753, !- Vertex $2 \mathrm{X}$-coordinate $\{\mathrm{m}\}$

5.4956, !- Vertex 2 Y-coordinate $\{\mathrm{m}\}$

-2.438, !- Vertex 2 Z-coordinate $\{\mathrm{m}\}$

4.753, !- Vertex $3 \mathrm{x}$-coordinate $\{\mathrm{m}\}$

5.4956, !- Vertex 3 Y-coordinate $\{m\}$

$0, \quad$ !- Vertex 3 Z-coordinate $\{\mathrm{m}\}$

0, !- Vertex $4 \mathrm{X}$-coordinate $\{\mathrm{m}\}$

5.4956, !- Vertex 4 Y-coordinate $\{m\}$

$0 ; \quad !$ - Vertex 4 Z-coordinate $\{\mathrm{m}\}$

BuildingSurface: Detailed,

Basement - Basement S partition, !- Name

Wall, !- Surface Type

interior wall, !- Construction Name

Thermal Zone: Basement, !- Zone Name

Surface, !- Outside Boundary Condition

Basement S - Basement partition, !- Outside Boundary Condition Object

NoSun, !- Sun Exposure

NoWind, $\quad$ !- Wind Exposure

autocalculate, !- View Factor to Ground

4 ,

0 ,

! - Number of Vertices

5.4956,

!- Vertex $1 \mathrm{X}$-coordinate $\{\mathrm{m}\}$

0 ,

!- Vertex 1 Y-coordinate $\{\mathrm{m}\}$

!- Vertex 1 Z-coordinate $\{m\}$

4.753,

!- Vertex 2 X-coordinate $\{\mathrm{m}\}$

5.4956 ,

- Vertex 2 Y-coordinate $\{\mathrm{m}\}$

0 ,

!- Vertex 2 Z-coordinate $\{m\}$

4.753,

!- Vertex $3 \mathrm{X}$-coordinate $\{\mathrm{m}\}$

5.4956,

! - Vertex 3 Y-coordinate $\{\mathrm{m}\}$

-2.438,

!- Vertex 3 Z-coordinate $\{\mathrm{m}\}$

0 ,

!- Vertex $4 \mathrm{X}$-coordinate $\{\mathrm{m}\}$

5.4956,

$-2.438 ;$

!- Vertex 4 Y-coordinate $\{\mathrm{m}\}$

!- Vertex 4 Z-coordinate $\{m\}$

!- $==========$ ALL OBJECTS IN CLASS: FENESTRATIONSURFACE $:$ DETAILED $==========$

FenestrationSurface: Detailed,

South bsmt door ag, !- Name 


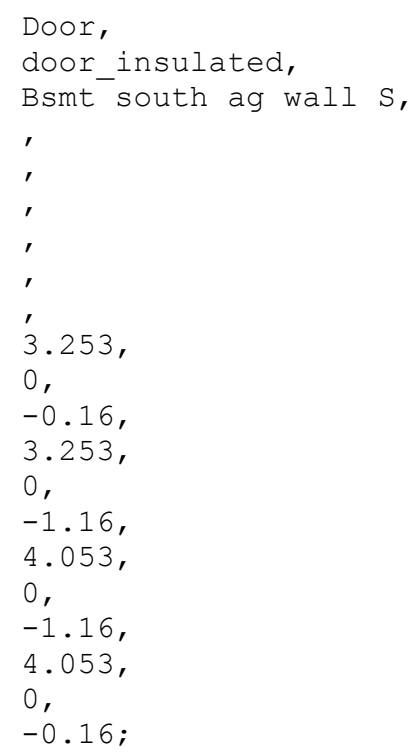

!- Surface Type

!- Construction Name

!- Building Surface Name

!- Outside Boundary Condition Object

!- View Factor to Ground

! - Shading Control Name

!- Frame and Divider Name

!- Multiplier

!- Number of Vertices

!- Vertex $1 \mathrm{X}$-coordinate $\{\mathrm{m}\}$

!- Vertex 1 Y-coordinate $\{\mathrm{m}\}$

!- Vertex 1 Z-coordinate $\{\mathrm{m}\}$

!- Vertex $2 \mathrm{X}$-coordinate $\{\mathrm{m}\}$

!- Vertex 2 Y-coordinate $\{\mathrm{m}\}$

!- Vertex 2 Z-coordinate $\{m\}$

!- Vertex $3 \mathrm{X}$-coordinate $\{\mathrm{m}\}$

!- Vertex 3 Y-coordinate $\{\mathrm{m}\}$

!- Vertex 3 z-coordinate $\{\mathrm{m}\}$

!-Vertex $4 \mathrm{X}$-coordinate $\{\mathrm{m}\}$

!- Vertex 4 Y-coordinate $\{\mathrm{m}\}$

-0.16 ;

!- Vertex 4 Z-coordinate $\{\mathrm{m}\}$

FenestrationSurface: Detailed,

$$
\text { W17, }
$$

Window,

a @GLAZ ING@ ,

Bsmt east ag wall,

,

,

,

'.753,

11.476787227817 ,

-0.199382727228982 ,

4.753,

11.476787227817 ,

-0.863382727228982 ,

4.753,

12.356787227817 ,

-0.863382727228982 ,

4.753,

12.356787227817 ,

-0.199382727228982 ;
! - Name

! - Surface Type

- Construction Name

!- Building Surface Name

! - Outside Boundary Condition Object

!- View Factor to Ground

!- Shading Control Name

! - Multiplier

! - Number of Vertices

!- Vertex $1 \mathrm{X}$-coordinate $\{\mathrm{m}\}$

!- Vertex 1 Y-coordinate $\{\mathrm{m}\}$

!- Vertex 1 Z-coordinate $\{m\}$

!-Vertex 2 X-coordinate $\{m\}$

!- Vertex 2 Y-coordinate $\{m\}$

!- Vertex 2 Z-coordinate $\{\mathrm{m}\}$

!- Vertex 3 X-coordinate $\{m\}$

!- Vertex 3 Y-coordinate $\{m\}$

!- Vertex 3 Z-coordinate $\{m\}$

!- Vertex 4 X-coordinate $\{m\}$

!- Vertex 4 Y-coordinate $\{m\}$

!- Vertex 4 Z-coordinate $\{m\}$

FenestrationSurface: Detailed,

South Bsmt door bg,

Door,

door insulated,

! - Name

Bsmt south bg wall,

!- Surface Type

!- Construction Name

!- Building Surface Name

!- Outside Boundary Condition Object

!- View Factor to Ground

! - Shading Control Name

!- Frame and Divider Name

! - Multiplier

! - Number of Vertices

3.253,

!- Vertex $1 \mathrm{X}$-coordinate $\{\mathrm{m}\}$

0 ,

!- Vertex 1 Y-coordinate $\{\mathrm{m}\}$

-1.16 ,

!- Vertex 1 Z-coordinate $\{\mathrm{m}\}$

3.253,

!- Vertex 2 X-coordinate $\{m\}$

0 ,

!- Vertex 2 Y-coordinate $\{m\}$

-2.36 ,

!- Vertex 2 Z-coordinate $\{\mathrm{m}\}$ 

4.053,
!- Vertex $3 \mathrm{x}$-coordinate $\{\mathrm{m}\}$
0 ,
-2.36 ,
!- Vertex 3 Y-coordinate $\{\mathrm{m}\}$
4.053,
!- Vertex 3 Z-coordinate $\{\mathrm{m}\}$
0 ,
!- Vertex 4 X-coordinate $\{m\}$
$-1.16$
!- Vertex 4 Y-coordinate $\{\mathrm{m}\}$
!- Vertex 4 Z-coordinate $\{\mathrm{m}\}$

FenestrationSurface: Detailed,
W20,
! - Name
Window,
!- Surface Type
@@GLAZING@e, !- Construction Name
Bsmt west ag wall 1, !- Building Surface Name
, $\quad$ ! - Outside Boundary Condit
@efRAME@e, !- Frame and Divider Name
, !- Multiplier
, !- Number of Vertices
$-1.21$
14. 4441371646333 ,
!- Vertex $1 \mathrm{X}$-coordinate $\{\mathrm{m}\}$
-0.24028175255551 ,
!- Vertex 1 Y-coordinate $\{\mathrm{m}\}$
-1.21 ,
!- Vertex 1 Z-coordinate $\{m\}$
!- Vertex 2 X-coordinate $\{m\}$
14. 4441371646333 ,
!- Vertex 2 Y-coordinate $\{\mathrm{m}\}$
-0.91628175255551 ,
!- Vertex 2 Z-coordinate $\{\mathrm{m}\}$
-1.21 ,
!- Vertex $3 \mathrm{x}$-coordinate $\{\mathrm{m}\}$
13.6361371646333
-0.91628175255551 ,
!- Vertex 3 Y-coordinate $\{\mathrm{m}\}$
!- Vertex 3 Z-coordinate $\{\mathrm{m}\}$
-1.21 ,
!- Vertex $4 \mathrm{X}$-coordinate $\{\mathrm{m}\}$
13.6361371646333,
!- Vertex 4 Y-coordinate $\{\mathrm{m}\}$
-0.24028175255551 ;
!- Vertex 4 Z-coordinate $\{m\}$

FenestrationSurface: Detailed, $\begin{array}{ll}\text { W15, } & !-\text { Name } \\ \text { Window, } & !-\text { Surface Type }\end{array}$

@@GLAZING@e, !- Construction Name

Bsmt small south ag wall,!- Building Surface Name

, $\quad$ !- Outside Boundary Condition Object

aefRAMEQ , !- Frame and Divider Name

, !- Multiplier

!- Number of Vertices

$-0.74718242986051, \quad !-$ Vertex $1 \mathrm{X}$-coordinate $\{\mathrm{m}\}$

5.4956

!- Vertex 1 Y-coordinate $\{m\}$

$-0.336847304708276, \quad !-$ Vertex 1 Z-coordinate $\{\mathrm{m}\}$

$-0.74718242986051, \quad !$ - Vertex $2 \mathrm{X}$-coordinate $\{\mathrm{m}\}$

5.4956,

!- Vertex 2 Y-coordinate $\{m\}$

-0.933847304708276 ,

-0.14718242986051 ,

!- Vertex 2 Z-coordinate $\{m\}$

!- Vertex $3 \mathrm{X}$-coordinate $\{\mathrm{m}\}$

5.4956,

!- Vertex 3 Y-coordinate $\{\mathrm{m}\}$

$-0.933847304708276, \quad !-$ Vertex 3 Z-coordinate $\{\mathrm{m}\}$

$-0.14718242986051, \quad !-$ Vertex $4 \mathrm{X}$-coordinate $\{\mathrm{m}\}$

5.4956, !- Vertex 4 Y-coordinate $\{\mathrm{m}\}$

$-0.336847304708276 ; \quad$ !- Vertex 4 Z-coordinate $\{\mathrm{m}\}$

FenestrationSurface: Detailed,

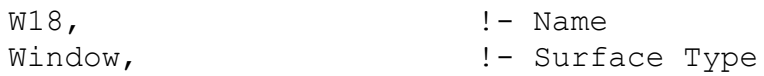

d@GLAZING@ @, !- Construction Name

Bedroom 2 east wall 1, !- Building Surface Name

! - Outside Boundary Condition Object

!- View Factor to Ground

!- Shading Control Name 


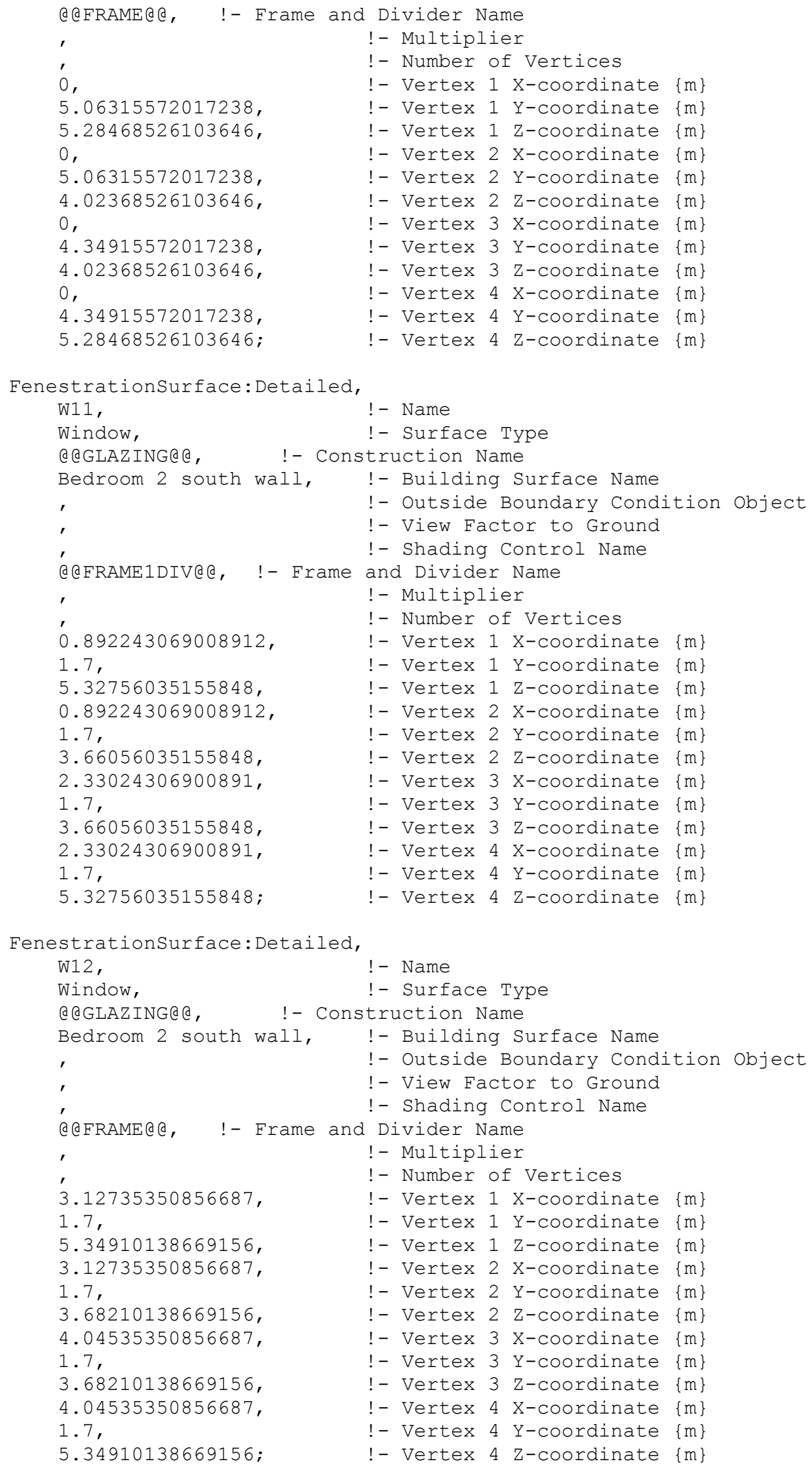




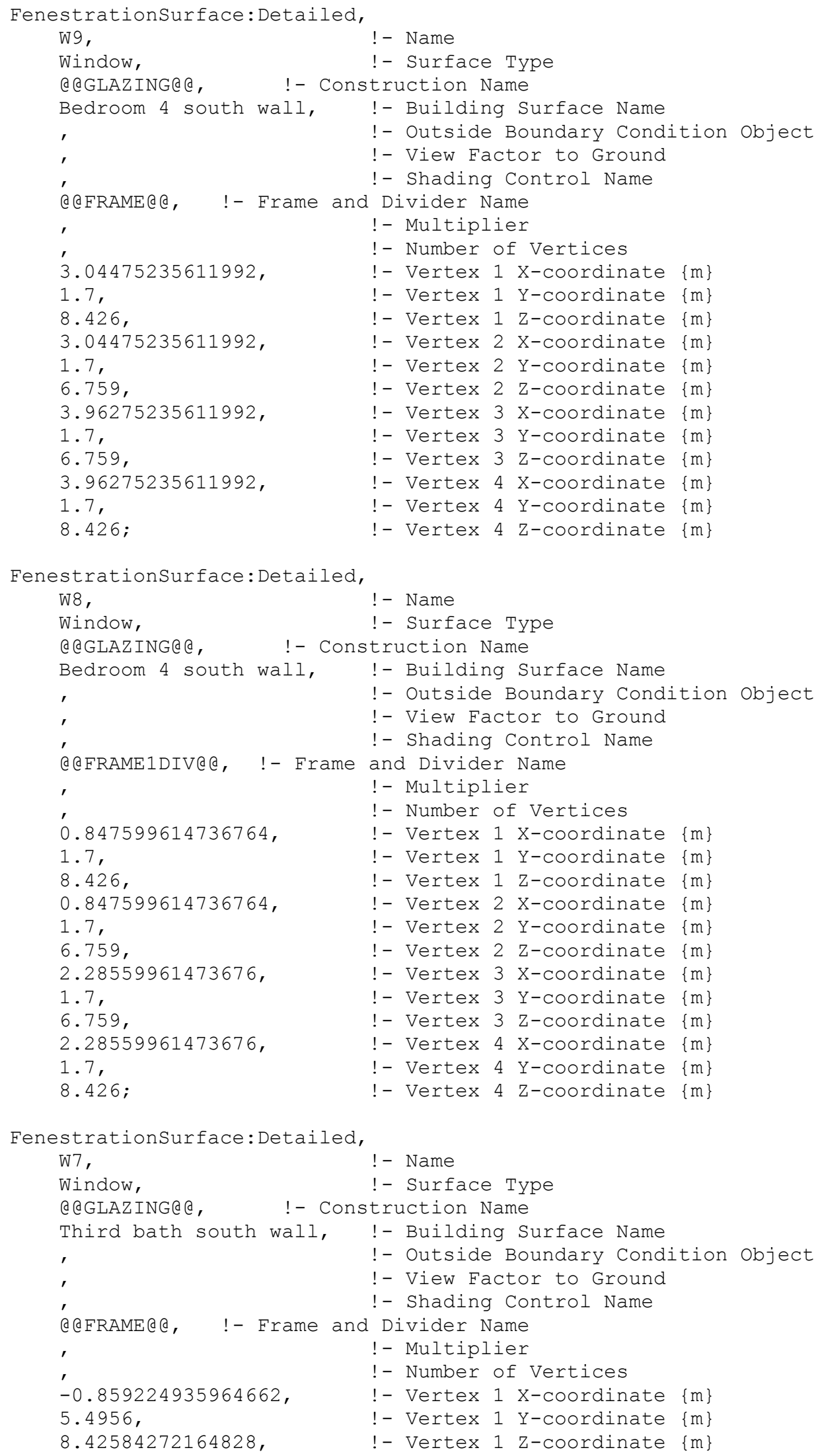




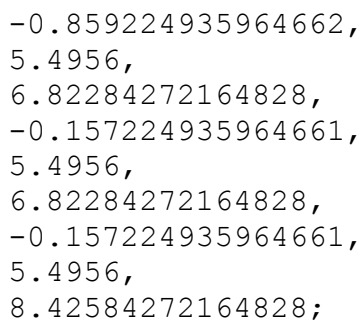

FenestrationSurface: Detailed,

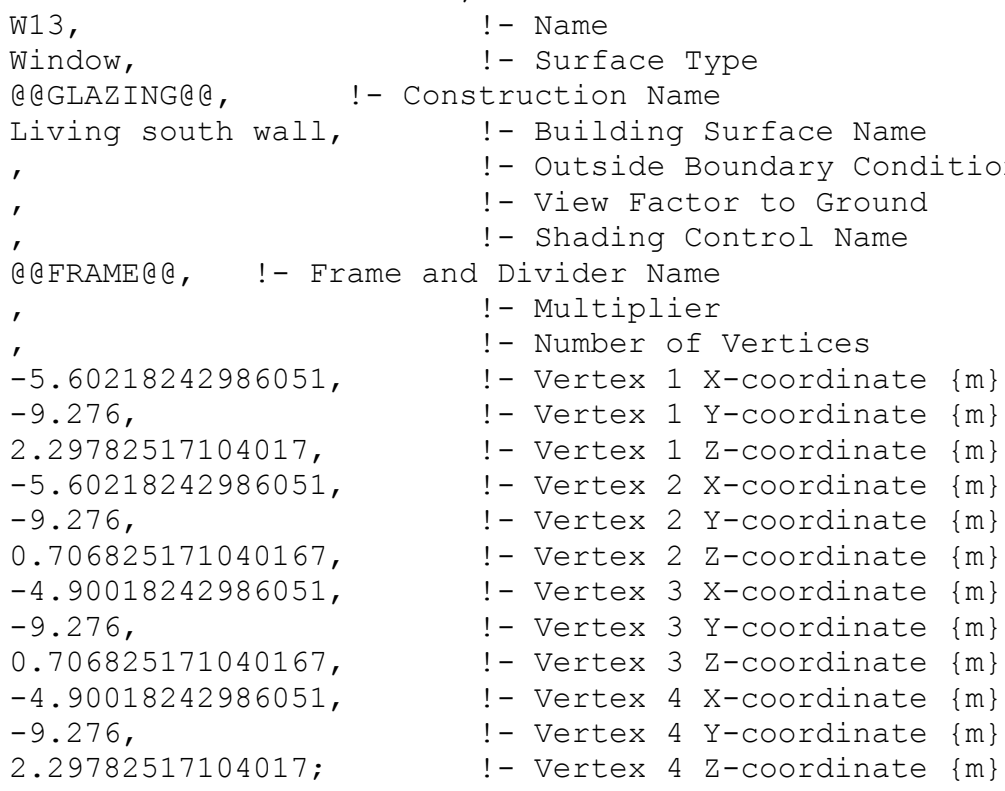

Fenestrationsurface: Detailed,

W6,

Window,

@@GLAZ ING@ @, Living north wall,

- Construction

,

@QFRAME@Q,

,

-2.97760933739877 ,

0 ,

2.032,

-2.97760933739877 ,

0 ,

0.365 ,

-4.44160933739877 ,

0 ,

0.365 ,

-4.44160933739877 ,

0 ,

2.032 ;
! - Name

! - Surface Type

!- Building Surface Name

! - Outside Boundary Condition Object

!- View Factor to Ground

! - Shading Control Name

Divider Name

! - Multiplier

! - Number of Vertices

!- Vertex 1 X-coordinate $\{m\}$

!- Vertex 1 Y-coordinate $\{\mathrm{m}\}$

!- Vertex 1 Z-coordinate $\{m\}$

!- Vertex 2 X-coordinate $\{m\}$

!- Vertex 2 Y-coordinate $\{m\}$

!- Vertex 2 Z-coordinate $\{m\}$

!- Vertex 3 X-coordinate $\{m\}$

! - Vertex 3 Y-coordinate $\{\mathrm{m}\}$

!- Vertex 3 Z-coordinate $\{m\}$

!- Vertex 4 X-coordinate $\{m\}$

!- Vertex 4 Y-coordinate $\{m\}$

!- Vertex 4 Z-coordinate $\{m\}$

FenestrationSurface: Detailed, Door 1,

Door,

door_insulated,

! - Name

Living north wall,

! - Surface Type

! - Construction Name

!- Building Surface Name 
!- Outside Boundary Condition Object

! - View Factor to Ground

! - Shading Control Name

! - Frame and Divider Name

!- Multiplier

!- Number of Vertices

$-0.583545879481815, \quad$ !- Vertex $1 \mathrm{X}$-coordinate $\{\mathrm{m}\}$

$0, \quad$ !- Vertex 1 Y-coordinate $\{\mathrm{m}\}$

2.032, !- Vertex $1 \mathrm{Z}$-coordinate $\{\mathrm{m}\}$

$-0.583545879481815, \quad !-$ Vertex $2 \mathrm{X}$-coordinate $\{\mathrm{m}\}$

$0, \quad !-$ Vertex 2 Y-coordinate $\{\mathrm{m}\}$

0, !- Vertex 2 Z-coordinate $\{\mathrm{m}\}$

$-1.49794587948182, \quad !$ - Vertex $3 \mathrm{X}$-coordinate $\{\mathrm{m}\}$

0 , !- Vertex 3 Y-coordinate $\{\mathrm{m}\}$

$0, \quad$ !- Vertex 3 Z-coordinate $\{\mathrm{m}\}$

$-1.49794587948182, \quad !$ - Vertex $4 \mathrm{X}$-coordinate $\{\mathrm{m}\}$

$0, \quad !-$ Vertex 4 Y-coordinate $\{\mathrm{m}\}$

2.032; !- Vertex $4 \mathrm{Z}$-coordinate $\{\mathrm{m}\}$

Fenestrationsurface: Detailed,

W2,

Window,

! - Name

a @ GLAZ INGQ a,

!- Surface Type

Bedroom 1 north wall, !- Building Surface Name

!- Outside Boundary Condition Object

! - View Factor to Ground

!- Shading Control Name

aefRAME@e, !- Frame and Divider Name

, !- Multiplier

, !- Number of Vertices

3.8764804021683, !- Vertex $1 \mathrm{X}$-coordinate $\{\mathrm{m}\}$

14.7716 ,

5.20127177328849,

!- Vertex 1 Y-coordinate $\{\mathrm{m}\}$

!- Vertex 1 Z-coordinate $\{m\}$

3.8764804021683, !- Vertex $2 \mathrm{X}$-coordinate $\{\mathrm{m}\}$

14.7716, !- Vertex 2 Y-coordinate $\{m\}$

4.29627177328849, !- Vertex 2 Z-coordinate $\{\mathrm{m}\}$

2.9844804021683, !- Vertex $3 \mathrm{X}$-coordinate $\{\mathrm{m}\}$

14.7716 ,

4.29627177328849 ,

!- Vertex 3 Y-coordinate $\{m\}$

2.9844804021683, !- Vertex $4 \mathrm{X}$-coordinate $\{\mathrm{m}\}$

14.7716 ,

5.20127177328849 ;

!- Vertex 4 Y-coordinate $\{\mathrm{m}\}$

!- Vertex 4 Z-coordinate $\{m\}$

FenestrationSurface: Detailed,

W3-5,

Window,

Q@GLAZING@ @,

Bedroom 1 north wall

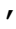

,

a

a@FRAME2DIV@e, !- Frame

2.10149060922561

14.7716 ,

5.20127177328849 ,

2.10149060922561 ,

14.7716,

3.64827177328849 ,

-0.117509390774393 ,

14.7716 ,

3.64827177328849 ,
! - Name

!- Surface Type

- Construction Name

!- Building Surface Name

!- Outside Boundary Condition Object

! - View Factor to Ground

!- Shading Control Name

and Divider Name

! - Multiplier

!- Number of Vertices

!- Vertex $1 \mathrm{X}$-coordinate $\{\mathrm{m}\}$

!- Vertex 1 Y-coordinate $\{m\}$

!- Vertex 1 Z-coordinate $\{\mathrm{m}\}$

!- Vertex $2 \mathrm{X}$-coordinate $\{\mathrm{m}\}$

!- Vertex 2 Y-coordinate $\{m\}$

!- Vertex 2 Z-coordinate $\{\mathrm{m}\}$

!- Vertex $3 \mathrm{X}$-coordinate $\{\mathrm{m}\}$

!- Vertex 3 Y-coordinate $\{\mathrm{m}\}$

!- Vertex 3 Z-coordinate $\{m\}$ 
$\begin{array}{ll}-0.117509390774393, & ! \text { - Vertex } 4 \text { X-coordinate }\{\mathrm{m}\} \\ 14.7716, & ! \text { - Vertex } 4 \text { Y-coordinate }\{\mathrm{m}\} \\ 5.20127177328849 ; & \text { !- Vertex } 4 \text { Z-coordinate }\{\mathrm{m}\}\end{array}$

FenestrationSurface: Detailed,

W10,

! - Name

Window,

! - Surface Type

@@GLAZING@e, !- Construction Name

Baths south wall, ! ! Building Surface Name

!- Outside Boundary Condition Object

!- View Factor to Ground

!- Shading Control Name

aefRAME@e, !- Frame and Divider Name

, !- Multiplier

, !- Number of Vertices

-0.84918242986051 ,

!- Vertex $1 \mathrm{X}$-coordinate $\{\mathrm{m}\}$

5.4956,

!- Vertex 1 Y-coordinate $\{m\}$

5.31356938449725 ,

-0.84918242986051 ,

!- Vertex 1 Z-coordinate $\{m\}$

!- Vertex 2 X-coordinate $\{m\}$

5.4956 ,

!- Vertex 2 Y-coordinate $\{m\}$

3. 71056938449725 ,

-0.14718242986051 ,

!- Vertex 2 Z-coordinate $\{m\}$

!- Vertex $3 \mathrm{X}$-coordinate $\{\mathrm{m}\}$

5.4956 ,

!- Vertex 3 Y-coordinate $\{\mathrm{m}\}$

3. 71056938449725 ,

-0.14718242986051 ,

!- Vertex 3 Z-coordinate $\{m\}$

5.4956,

!- Vertex $4 \mathrm{X}$-coordinate $\{\mathrm{m}\}$

5.31356938449725 ;

!- Vertex 4 Y-coordinate $\{\mathrm{m}\}$

!- Vertex 4 Z-coordinate $\{m\}$

FenestrationSurface: Detailed, W19, !- Name

Window, !- Surface Type

dagLAZINGea, !- Construction Name

Kitchen west wall, !- Building Surface Name

, !- Outside Boundary Condition object

, !- View Factor to Ground

!- Shading Control Name

@eFRAME@e, !- Frame and Divider Name

, !- Multiplier

, !- Number of Vertices

4. 99654201782453

1. 46297958938494

!- Vertex $1 \mathrm{X}$-coordinate $\{\mathrm{m}\}$

!- Vertex 1 Y-coordinate $\{\mathrm{m}\}$

!- Vertex 1 Z-coordinate $\{m\}$

0 , !- Vertex $2 \mathrm{X}$-coordinate $\{\mathrm{m}\}$

4.99654201782453, !- Vertex 2 Y-coordinate $\{\mathrm{m}\}$

$0.684979589384941, \quad$ !- Vertex 2 Z-coordinate $\{\mathrm{m}\}$

$0, \quad !$ - Vertex $3 \mathrm{X}$-coordinate $\{\mathrm{m}\}$

4.59954201782453, !- Vertex 3 Y-coordinate $\{\mathrm{m}\}$

$0.684979589384941, \quad$ !- Vertex 3 Z-coordinate $\{\mathrm{m}\}$

0 , !- Vertex $4 \mathrm{X}$-coordinate $\{\mathrm{m}\}$

4.59954201782453, !- Vertex 4 Y-coordinate $\{\mathrm{m}\}$

1.46297958938494; !- Vertex 4 Z-coordinate $\{m\}$

FenestrationSurface: Detailed,

D2,

Window,

! - Name

kitchen south wall, !- Building Surface Name

, $\quad$ ! - Outside Boundary Condition object

, !- Shading Control Name

Q@FRAME@e, !- Frame and Divider Name

, !- Multiplier

, !- Number of Vertices 


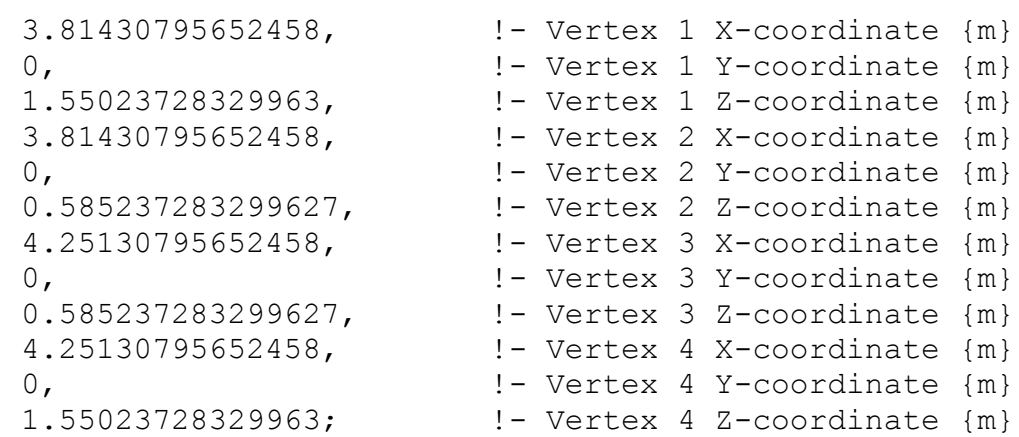

FenestrationSurface: Detailed,

W14,

Window,

a@GLAZ ING@ , kitchen south wall,

Q@ ERAME2DIVA@, !- Frame

0.70083828813791 ,

0 ,

2.3920261977145,

0.70083828813791 ,

0 ,

0.801026197714496 ,

2.69783828813791,

0 ,

0.801026197714496 ,

2.69783828813791,

0 ,

2.3920261977145;
! - Name

!- Surface Type

- Construction Name

!- Building Surface Name

!- Outside Boundary Condition Object

!- View Factor to Ground

! - Shading Control Name

!- Multiplier

! - Number of Vertices

!- Vertex $1 \mathrm{X}$-coordinate $\{\mathrm{m}\}$

!- Vertex 1 Y-coordinate $\{m\}$

!- Vertex 1 Z-coordinate $\{\mathrm{m}\}$

!- Vertex 2 X-coordinate $\{\mathrm{m}\}$

!- Vertex 2 Y-coordinate $\{\mathrm{m}\}$

!- Vertex 2 Z-coordinate $\{\mathrm{m}\}$

!- Vertex $3 \mathrm{X}$-coordinate $\{\mathrm{m}\}$

!- Vertex 3 Y-coordinate $\{m\}$

!- Vertex 3 Z-coordinate $\{m\}$

!- Vertex $4 \mathrm{X}$-coordinate $\{\mathrm{m}\}$

!- Vertex 4 Y-coordinate $\{\mathrm{m}\}$

!- Vertex 4 Z-coordinate $\{\mathrm{m}\}$

FenestrationSurface: Detailed,

\section{W1,}

Window,

@eGLAZ ING@ a,

dormir north wall,

\section{,}

a@

0.9135 ,

14.7716,

8.03500000000001 ,

0.9135 ,

14.7716,

6.77400000000001 ,

0.2305 ,

14.7716,

6.77400000000001 ,

0.2305 ,

14.7716,

8.03500000000001 ;
! - Name

! - Surface Type

! - Construction Name

!- Building Surface Name

!- Outside Boundary Condition Object

!- View Factor to Ground

! - Shading Control Name

Divider Name

! - Multiplier

! - Number of Vertices

!-Vertex $1 \mathrm{X}$-coordinate $\{\mathrm{m}\}$

!- Vertex 1 Y-coordinate $\{m\}$

!- Vertex 1 Z-coordinate $\{m\}$

!- Vertex 2 X-coordinate $\{m\}$

!-Vertex 2 Y-coordinate $\{\mathrm{m}\}$

!- Vertex 2 Z-coordinate $\{m\}$

!- Vertex 3 X-coordinate $\{\mathrm{m}\}$

!- Vertex 3 Y-coordinate $\{\mathrm{m}\}$

!- Vertex 3 Z-coordinate $\{\mathrm{m}\}$

!- Vertex 4 X-coordinate $\{m\}$

!- Vertex 4 Y-coordinate $\{m\}$

!- Vertex 4 Z-coordinate $\{m\}$

FenestrationSurface: Detailed, W16,

! - Name 


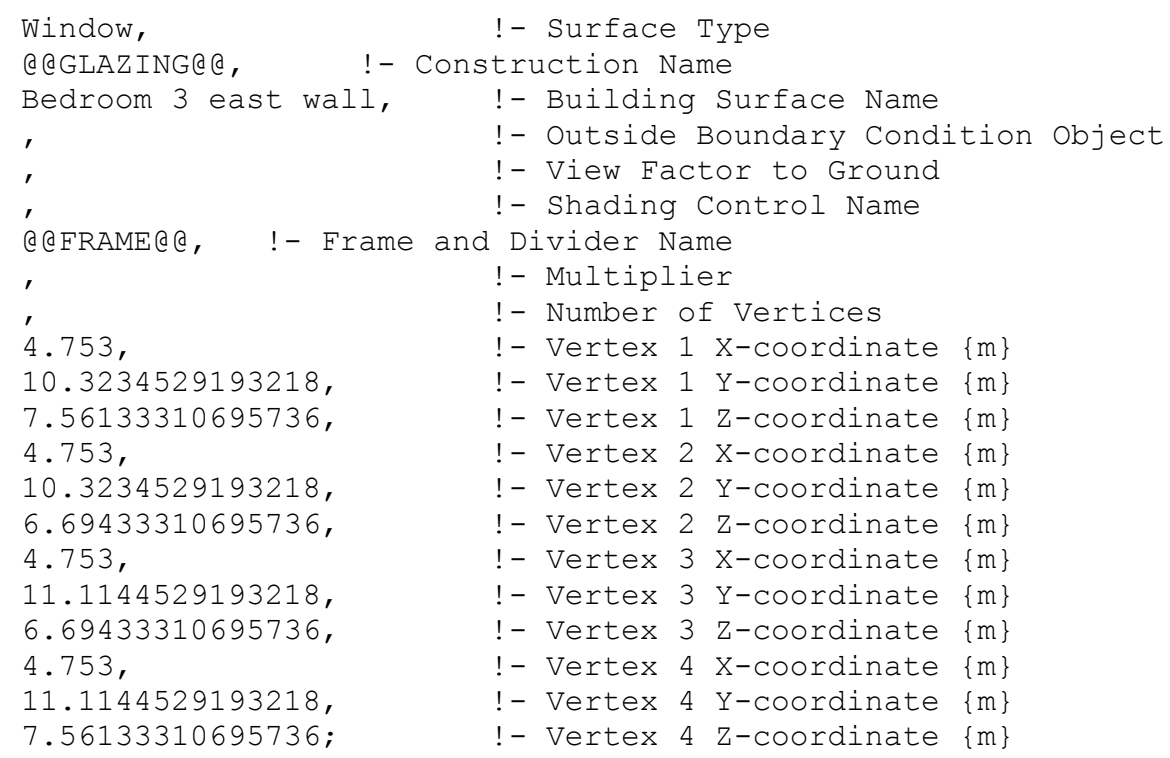

FenestrationSurface: Detailed, Basement S - Basement opening, !- Name

FenestrationSurface: Detailed,

Basement - Basement S opening, !- Name

GlassDoor, !- Surface Type

opening, $\quad$ - Construction Name

Basement - Basement S partition, !- Building Surface Name

Basement - Basement S opening, !- Outside Boundary Condition Object

autocalculate, !- View Factor to Ground

i,

4 ,

0.03,

5.4956 ,

0 ,

4.723,

5.4956 ,

0 ,

! - Shading Control Name

! - Frame and Divider Name

!- Multiplier

! - Number of Vertices

!- Vertex $1 \mathrm{X}$-coordinate $\{\mathrm{m}\}$

!- Vertex 1 Y-coordinate $\{\mathrm{m}\}$

!- Vertex 1 Z-coordinate $\{m\}$

!- Vertex 2 X-coordinate $\{m\}$

!- Vertex 2 Y-coordinate $\{\mathrm{m}\}$

!- Vertex 2 Z-coordinate $\{\mathrm{m}\}$ 

4.723,
!- Vertex $3 \mathrm{x}$-coordinate $\{\mathrm{m}\}$
5.4956,
!- Vertex 3 Y-coordinate $\{\mathrm{m}\}$
-2.438,
!- Vertex 3 Z-coordinate $\{\mathrm{m}\}$
0.03,
!- Vertex 4 X-coordinate $\{m\}$
5.4956,
!- Vertex 4 Y-coordinate $\{m\}$
$-2.438 ;$
!- Vertex 4 Z-coordinate $\{m\}$

Fenestrationsurface: Detailed,

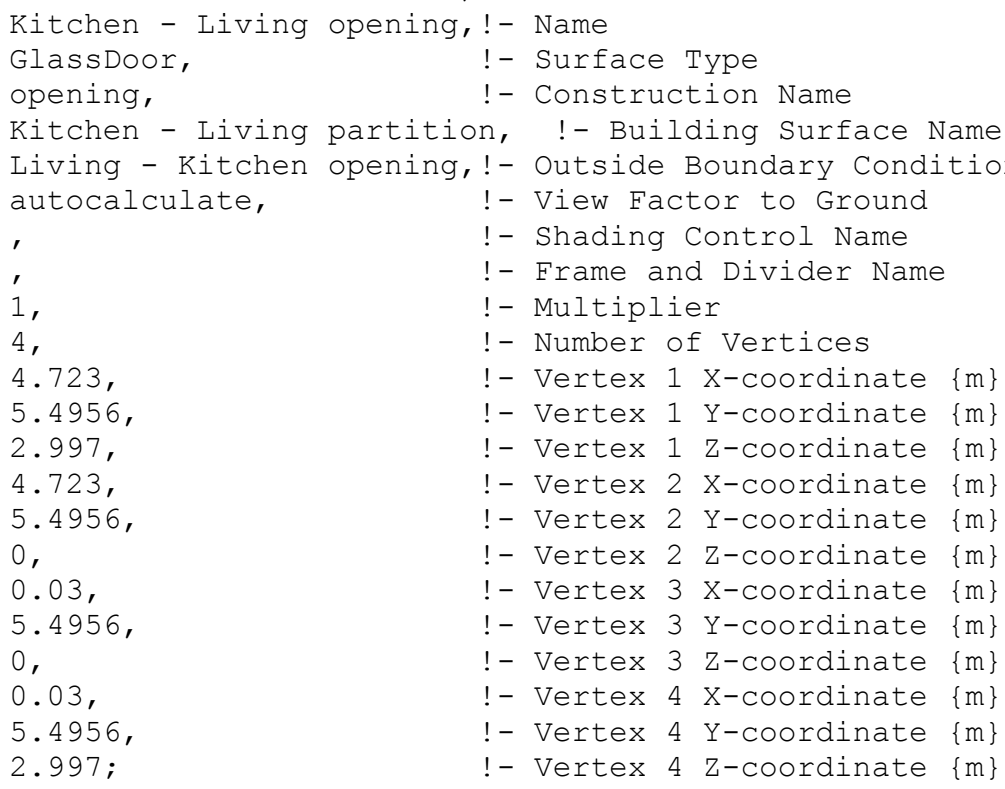

Fenestrationsurface: Detailed, Living - Kitchen opening,!- Name

FenestrationSurface: Detailed,

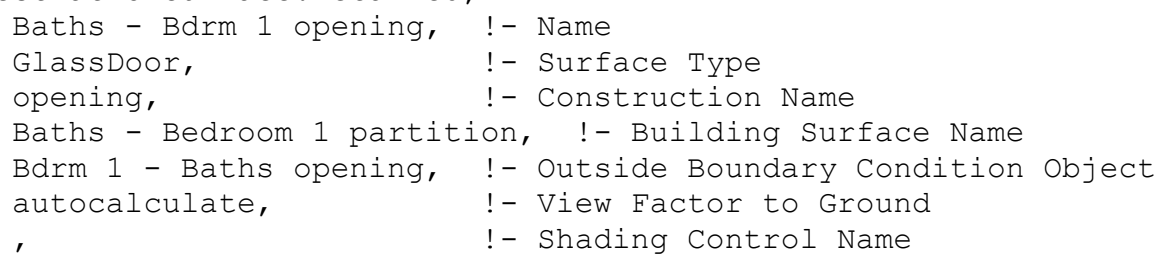




$$
\begin{aligned}
& \prime, \\
& 1, \\
& 4, \\
& 4.753, \\
& 9.7636, \\
& 5.874, \\
& 4.753, \\
& 9.7636, \\
& 2.997, \\
& 4, \\
& 9.7636, \\
& 2.997, \\
& 4, \\
& 9.7636, \\
& 5.874 ;
\end{aligned}
$$

! - Frame and Divider Name

! - Multiplier

! - Number of Vertices

! - Vertex 1 X-coordinate $\{m\}$

!- Vertex 1 Y-coordinate $\{m\}$

!- Vertex 1 Z-coordinate $\{m\}$

!- Vertex 2 X-coordinate $\{m\}$

!- Vertex 2 Y-coordinate $\{m\}$

!- Vertex 2 Z-coordinate $\{m\}$

!- Vertex 3 X-coordinate $\{m\}$

!- Vertex 3 Y-coordinate $\{m\}$

!- Vertex 3 Z-coordinate $\{m\}$

!- Vertex 4 X-coordinate $\{m\}$

!- Vertex 4 Y-coordinate $\{m\}$

!- Vertex 4 Z-coordinate $\{m\}$

FenestrationSurface: Detailed, Bdrm 1 - Baths opening, GlassDoor, opening, ! - Name !- Surface Type Bedroom 1 - Baths partition, !- Building Surface Name Baths - Bdrm 1 opening, !- Outside Boundary Condition Object autocalculate,

! - View Factor to Ground ,

1

4,

4,

9.7636 , 5.87400000000001 ,

! - Shading Control Name

! - Frame and Divider Name

! - Multiplier

! - Number of Vertices

!-Vertex $1 \mathrm{X}$-coordinate $\{\mathrm{m}\}$

!- Vertex 1 Y-coordinate $\{\mathrm{m}\}$

!- Vertex 1 Z-coordinate $\{m\}$ 4 ,

9.7636

!- Vertex $2 \mathrm{x}$-coordinate $\{\mathrm{m}\}$

!- Vertex 2 Y-coordinate $\{\mathrm{m}\}$

2.997,

4.753,

9.7636 ,

2. 997 ,

4.753,

9.7636

5. 87400000000001 ;

!- Vertex 2 Z-coordinate $\{m\}$

!- Vertex 3 X-coordinate $\{\mathrm{m}\}$

!- Vertex 3 Y-coordinate $\{m\}$

!- Vertex 3 Z-coordinate $\{m\}$

!- Vertex 4 X-coordinate $\{m\}$

!- Vertex 4 Y-coordinate $\{m\}$

!- Vertex 4 Z-coordinate $\{m\}$

FenestrationSurface: Detailed, Baths - Bdrm 2 opening, !- Name 
FenestrationSurface: Detailed, Bdrm 2 - Baths opening, opening, ! - Name Bedroom 2 - Baths partition, !- Building Surface Name Baths - Bdrm 2 opening, !- Outside Boundary Condition object autocalculate,

!- View Factor to Ground

! - Shading Control Name

,

4.753,

5.4956,

5.874,

4.753,

5.4956

!- Frame and Divider Name

! - Multiplier

!- Number of Vertices

!- Vertex $1 \mathrm{X}$-coordinate $\{\mathrm{m}\}$

!- Vertex 1 Y-coordinate $\{\mathrm{m}\}$

!- Vertex 1 Z-coordinate $\{\mathrm{m}\}$

!- Vertex $2 \mathrm{X}$-coordinate $\{\mathrm{m}\}$

!- Vertex 2 Y-coordinate $\{\mathrm{m}\}$

2.997,

4 ,

!- Vertex 2 Z-coordinate $\{\mathrm{m}\}$

!- Vertex $3 \mathrm{X}$-coordinate $\{\mathrm{m}\}$

5.4956 ,

!- Vertex 3 Y-coordinate $\{\mathrm{m}\}$

2.997,

!- Vertex 3 Z-coordinate $\{\mathrm{m}\}$

4 ,

!- Vertex $4 \mathrm{X}$-coordinate $\{\mathrm{m}\}$

5.4956

!- Vertex 4 Y-coordinate $\{m\}$

$5.874 ;$

!- Vertex 4 Z-coordinate $\{m\}$

FenestrationSurface: Detailed, Third Bath - Bdrm 3 opening, !- Name
GlassDoor,
! - Surface Type
opening,
!- Construction Name

Third bath - Bedroom 3 partition, !- Building Surface Name

Bdrm 3 - Third Bath opening, !- Outside Boundary Condition Object autocalculate,

!- View Factor to Ground

1,

- Shading Control Name

!- Frame and Divider Name

! - Multiplier

! - Number of Vertices

4.753,

7.9956,

!- Vertex $1 \mathrm{X}$-coordinate $\{\mathrm{m}\}$

8.976,

!- Vertex 1 Y-coordinate $\{\mathrm{m}\}$

!- Vertex 1 Z-coordinate $\{\mathrm{m}\}$

4.753,

7.9956,

!- Vertex 2 X-coordinate $\{m\}$

!- Vertex 2 Y-coordinate $\{\mathrm{m}\}$

5.874,

!- Vertex 2 Z-coordinate $\{\mathrm{m}\}$

4,

!- Vertex $3 \mathrm{X}$-coordinate $\{\mathrm{m}\}$

7.9956

!- Vertex 3 Y-coordinate $\{\mathrm{m}\}$

5.874 ,

!- Vertex 3 Z-coordinate $\{m\}$

4,

!- Vertex $4 \mathrm{X}$-coordinate $\{\mathrm{m}\}$

7.9956,

!- Vertex 4 Y-coordinate $\{\mathrm{m}\}$

8.976

!- Vertex 4 Z-coordinate $\{m\}$

FenestrationSurface: Detailed,

Bdrm 3 - Third Bath opening, !- Name

GlassDoor, !- Surface Type

opening, !- Construction Name

Bedroom 3 - third bath, !- Building Surface Name

Third Bath - Bdrm 3 opening, !- Outside Boundary Condition Object autocalculate,

! - View Factor to Ground

',

4,

4.753,

7.9956,

8.97600000000001 ,

!- Shading Control Name

! - Frame and Divider Name

! - Multiplier

! - Number of Vertices

!- Vertex $1 \mathrm{X}$-coordinate $\{\mathrm{m}\}$

!- Vertex 1 Y-coordinate $\{\mathrm{m}\}$

!- Vertex 1 Z-coordinate $\{m\}$ 

4 ,
7.9956,
!- Vertex $2 \mathrm{X}$-coordinate $\{\mathrm{m}\}$
8.976,
!- Vertex 2 Y-coordinate $\{\mathrm{m}\}$
4,
!- Vertex 2 Z-coordinate $\{m\}$
7.9956,
!- Vertex $3 \mathrm{X}$-coordinate $\{\mathrm{m}\}$
5.874,
!- Vertex 3 Y-coordinate $\{\mathrm{m}\}$
4.753
!- Vertex 3 Z-coordinate $\{\mathrm{m}\}$
7.9956,
!- Vertex $4 \mathrm{X}$-coordinate $\{\mathrm{m}\}$
5.87400000000001 ;
!- Vertex 4 Y-coordinate $\{\mathrm{m}\}$
!- Vertex 4 Z-coordinate $\{\mathrm{m}\}$

FenestrationSurface: Detailed,

Third Bath - Bdrm 4 opening, !- Name

GlassDoor, !- Surface Type

opening, $\quad$ - - Construction Name

THIRD BATH - BEDROOM 4 PARTITION, !- Building Surface Name

Bdrm 4 - Third Bath opening, !- Outside Boundary Condition object

autocalculate, !- View Factor to Ground

, !- Shading Control Name

, !- Frame and Divider Name

1, $\quad$ !- Multiplier

4, !- Number of Vertices

4, !- Vertex $1 \mathrm{X}$-coordinate $\{\mathrm{m}\}$

5.4956, !- Vertex 1 Y-coordinate $\{\mathrm{m}\}$

8.976, !- Vertex 1 Z-coordinate $\{m\}$

4, !- Vertex $2 \mathrm{X}$-coordinate $\{\mathrm{m}\}$

5.4956, !- Vertex 2 Y-coordinate $\{\mathrm{m}\}$

5.874, !- Vertex 2 Z-coordinate $\{\mathrm{m}\}$

4.753, !- Vertex $3 \mathrm{x}$-coordinate $\{\mathrm{m}\}$

5.4956, !- Vertex 3 Y-coordinate $\{\mathrm{m}\}$

5.874, !- Vertex 3 Z-coordinate $\{m\}$

4.753, !- Vertex $4 \mathrm{X}$-coordinate $\{\mathrm{m}\}$

5.4956, !- Vertex 4 Y-coordinate $\{m\}$

8.976; !- Vertex 4 Z-coordinate $\{\mathrm{m}\}$

FenestrationSurface: Detailed,

Bdrm 4 - Third Bath opening, !- Name

GlassDoor, ! - Surface Type

opening, !- Construction Name

Bedroom 4 - Third bath parition, !- Building Surface Name

Third Bath - Bdrm 4 opening, !- Outside Boundary Condition Object

autocalculate, !- View Factor to Ground

! - Shading Control Name

1

4,

4.753,

!- Frame and Divider Name

!- Multiplier

! - Number of Vertices

5.4956,

!- Vertex $1 \mathrm{X}$-coordinate $\{\mathrm{m}\}$

!- Vertex 1 Y-coordinate $\{\mathrm{m}\}$

8.976,

4.753,

!- Vertex 1 Z-coordinate $\{m\}$

!- Vertex 2 X-coordinate $\{\mathrm{m}\}$

5.4956,

!- Vertex 2 Y-coordinate $\{\mathrm{m}\}$

5.874,

!- Vertex 2 Z-coordinate $\{\mathrm{m}\}$

4 ,

!- Vertex $3 \mathrm{X}$-coordinate $\{\mathrm{m}\}$

5.4956

!- Vertex 3 Y-coordinate $\{m\}$

5.874,

!- Vertex 3 Z-coordinate $\{\mathrm{m}\}$

4,

!- Vertex $4 \mathrm{X}$-coordinate $\{\mathrm{m}\}$

5.4956,

!- Vertex 4 Y-coordinate $\{\mathrm{m}\}$

$8.976 ;$

!- Vertex 4 Z-coordinate $\{\mathrm{m}\}$

FenestrationSurface: Detailed, Baths - Third Bath stairs, !- Name

GlassDoor,

opening,

Baths ceiling 1,

!- Surface Type

! - Construction Name

!- Building Surface Name 


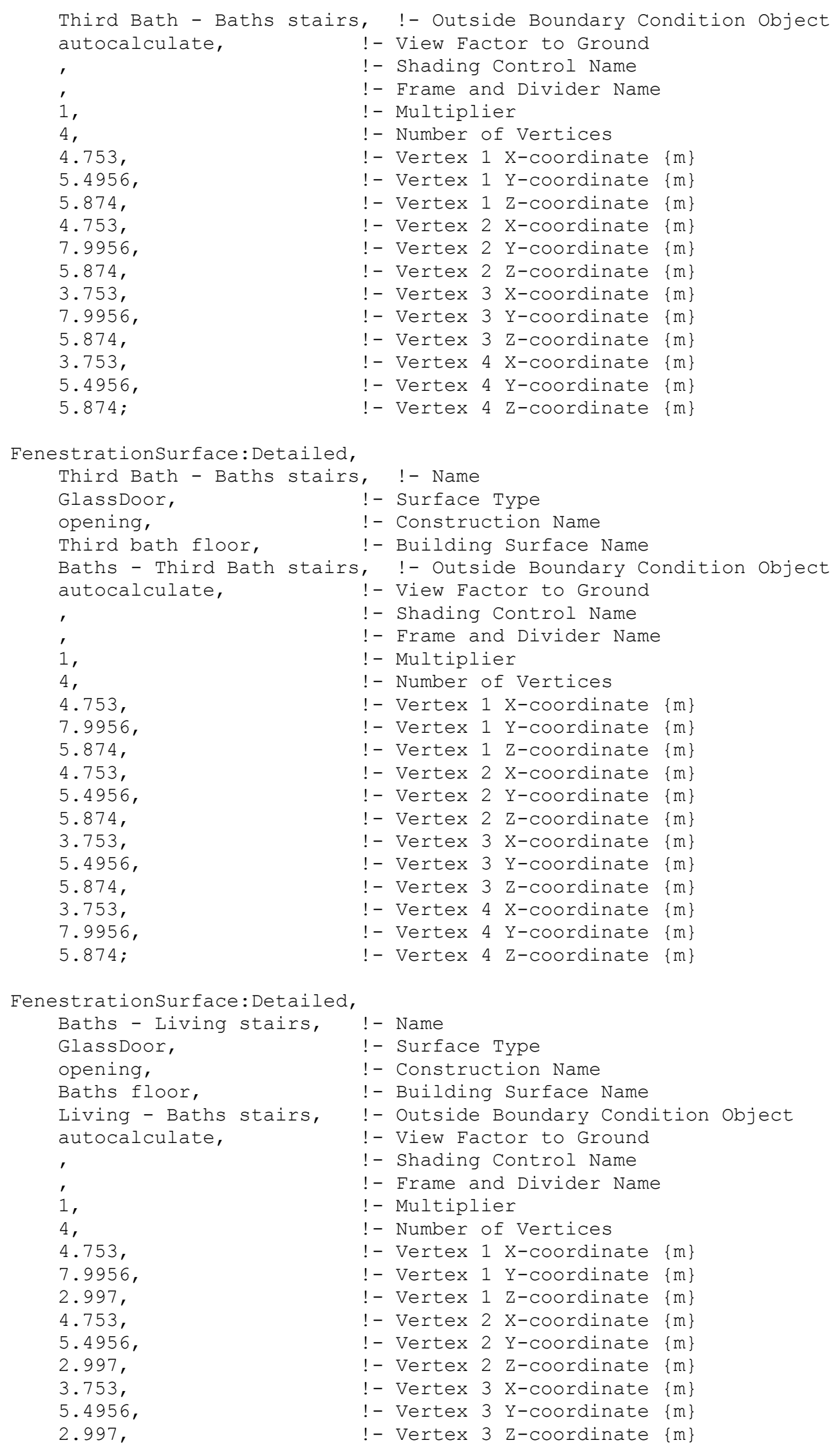



3.753,
!- Vertex 4 X-coordinate $\{m\}$
7.9956,
!- Vertex 4 Y-coordinate $\{m\}$
2.997;
!- Vertex 4 Z-coordinate $\{\mathrm{m}\}$

FenestrationSurface: Detailed,

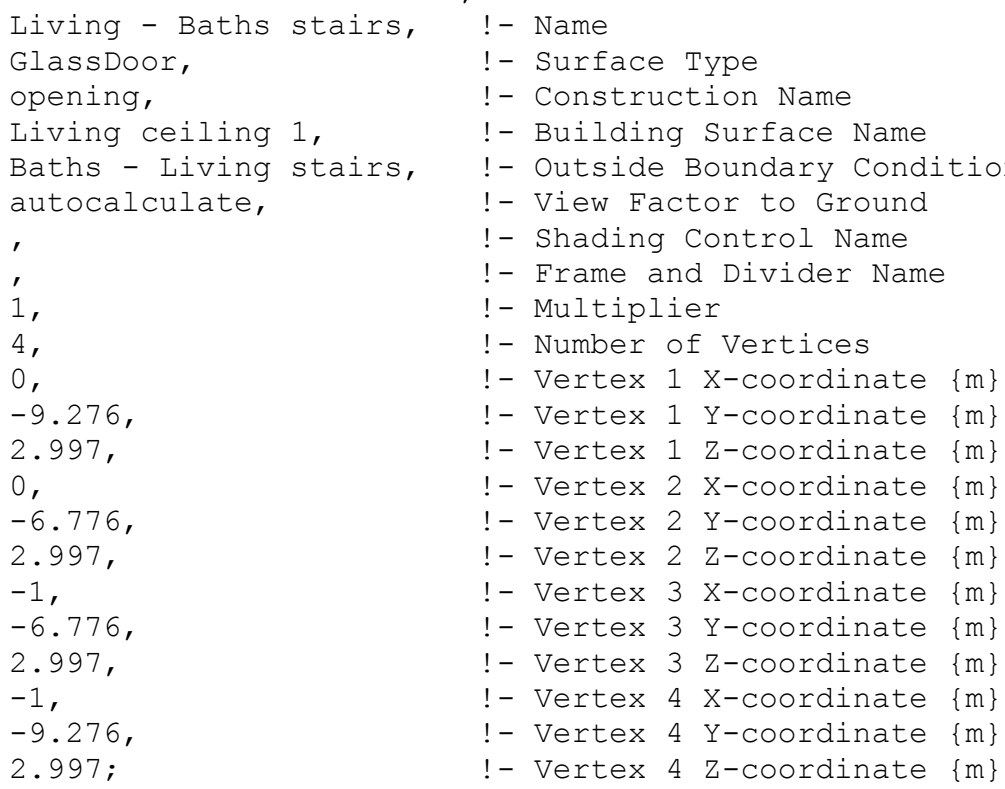

FenestrationSurface: Detailed, Living - Basement stairs, !- Name

FenestrationSurface: Detailed,

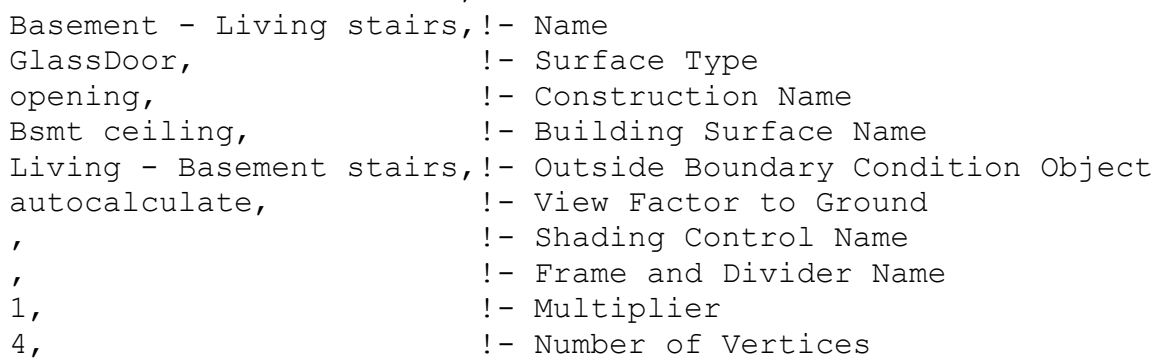




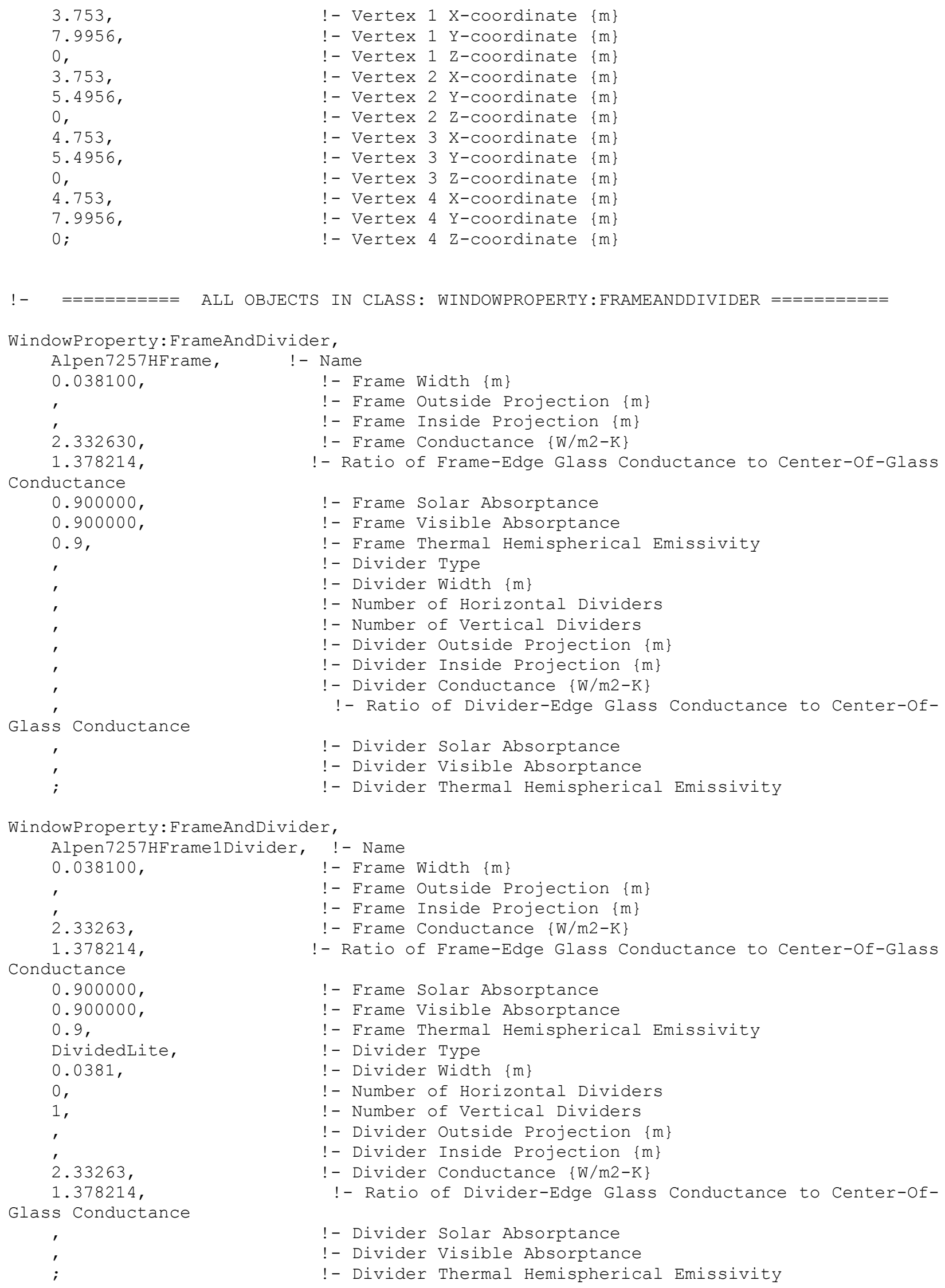

WindowProperty: FrameAndDivider, 
WindowProperty: FrameAndDivider,

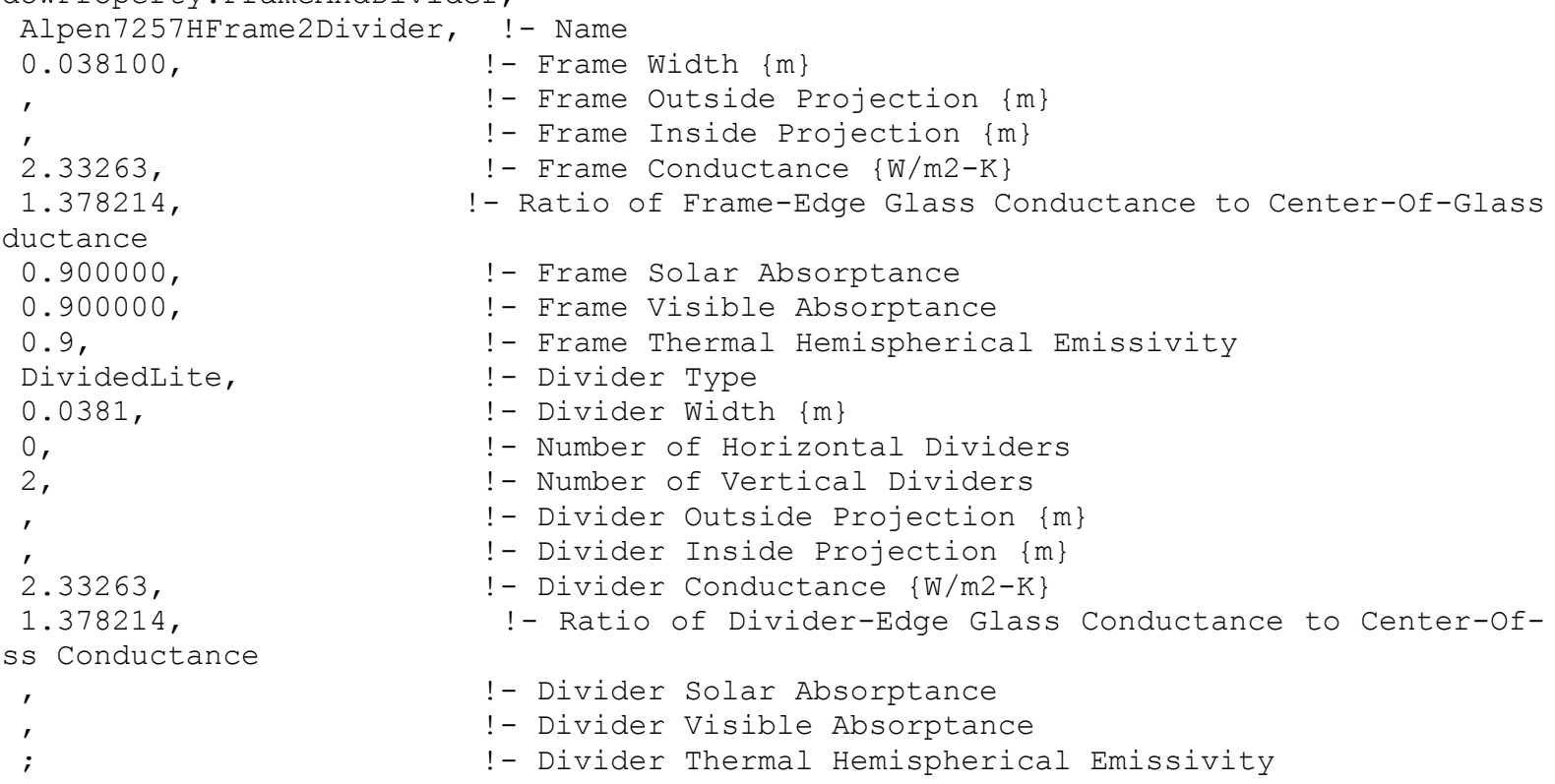

WindowProperty: FrameAndDivider, Alpen9259HFrame, $0.040640, \quad !-$ Era 0.040640 , !- Frame Width $\{\mathrm{m}\}$

!- Frame Outside Projection $\{\mathrm{m}\}$

2. 332630 1.507447 ,

!- Frame Inside Projection $\{\mathrm{m}\}$

!- Frame Conductance $\{\mathrm{W} / \mathrm{m} 2-\mathrm{K}\}$

Conductance

0.900000, !- Erame Solar Absorptance

0.900000, !- Frame Visible Absorptance

0.9, !- Frame Thermal Hemispherical Emissivity

!- Divider Type

!- Divider Width $\{m\}$

!- Number of Horizontal Dividers

!- Number of Vertical Dividers

!- Divider Outside Projection $\{\mathrm{m}\}$

!- Divider Inside Projection $\{\mathrm{m}\}$

!- Divider Conductance $\{\mathrm{W} / \mathrm{m} 2-\mathrm{K}\}$

!- Ratio of Divider-Edge Glass Conductance to Center-of-

Glass Conductance

!- Divider Solar Absorptance

!- Divider Visible Absorptance

!- Divider Thermal Hemispherical Emissivity

WindowProperty: FrameAndDivider, Alpen9259HFrame1Divider, !- Name 0.04064 ,

!- Frame Width $\{m\}$

! - Frame Outside Projection $\{m\}$

,

!- Frame Inside Projection $\{\mathrm{m}\}$

2.33263, 1.507447,

!- Frame Conductance $\{\mathrm{W} / \mathrm{m} 2-\mathrm{K}\}$

Conductance
0.900000
0.900000 ,
0.9 ,
DividedLite,
0.04064 ,
0 ,
- Frame Solar Absorptance
! - Frame Visible Absorptance
!- Frame Thermal Hemispherical Emissivity
!- Divider Type
!- Divider Width $\{\mathrm{m}\}$
!- Number of Horizontal Dividers 


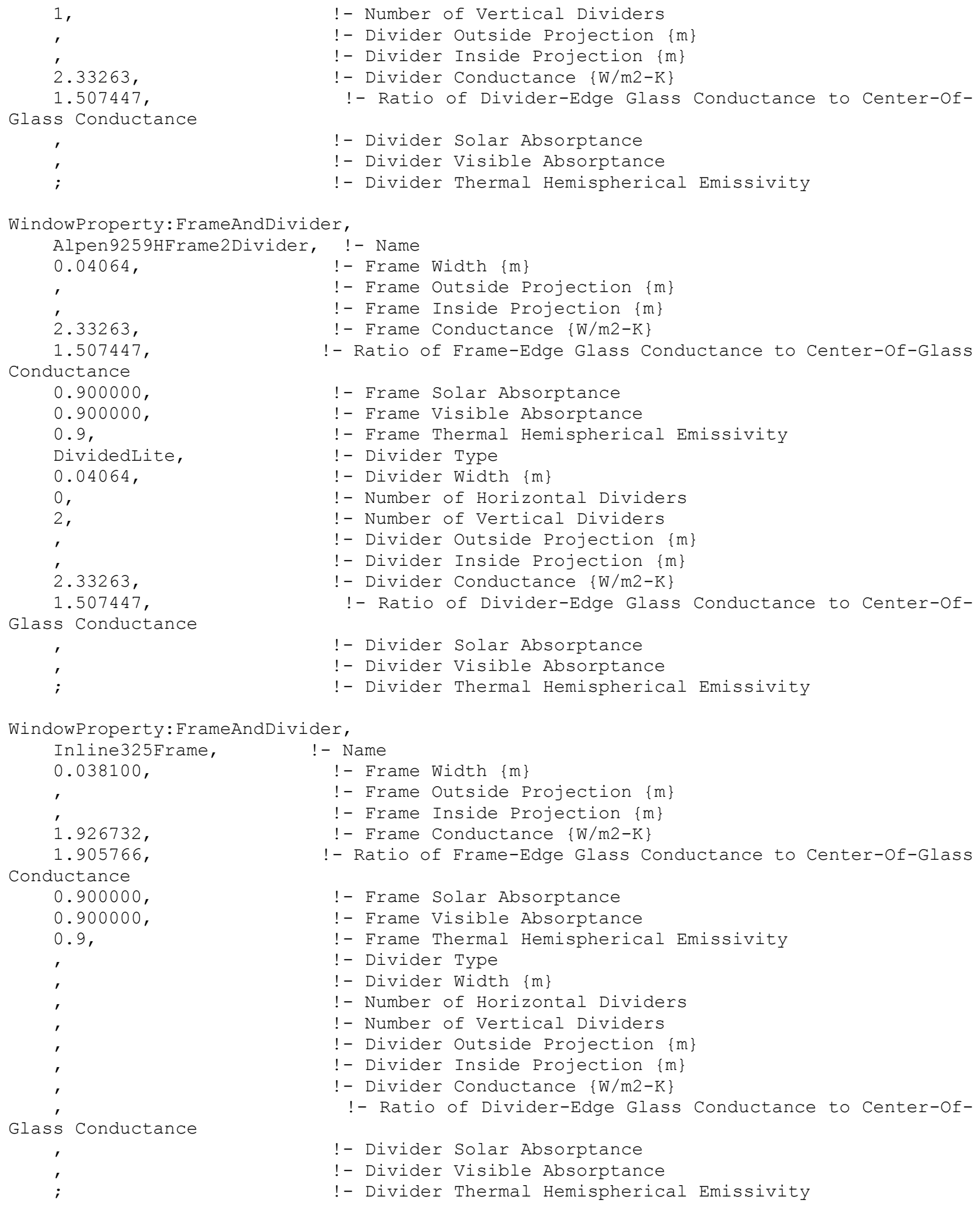

WindowProperty: FrameAndDivider, Alpen9259HFrame2Divider, !- Name

WindowProperty: FrameAndDivider, Inline325Frame, !- Name 0.038100 ,

!- Frame Width $\{\mathrm{m}\}$

,

'. 926732 ,

1.905766 ,

!- Frame Outside Projection $\{m\}$

! - Frame Inside Projection $\{\mathrm{m}\}$

!- Frame Conductance $\{\mathrm{W} / \mathrm{m} 2-\mathrm{K}\}$

Conductance

0.900000

0.900000

!- Ratio of Frame-Edge Glass Conductance to Center-Of-Glass

0.9 ,

!- Frame Solar Absorptance

! - Frame Visible Absorptance

!- Frame Thermal Hemispherical Emissivity

!- Divider Type

!- Divider Width $\{\mathrm{m}\}$

!- Number of Horizontal Dividers

!- Number of Vertical Dividers

!- Divider Outside Projection $\{\mathrm{m}\}$

!- Divider Inside Projection $\{\mathrm{m}\}$

!- Divider Conductance $\{\mathrm{W} / \mathrm{m} 2-\mathrm{K}\}$

!- Ratio of Divider-Edge Glass Conductance to Center-of-

Glass Conductance

!- Divider Solar Absorptance

!- Divider Visible Absorptance

!- Divider Thermal Hemispherical Emissivity

WindowProperty: FrameAndDivider,

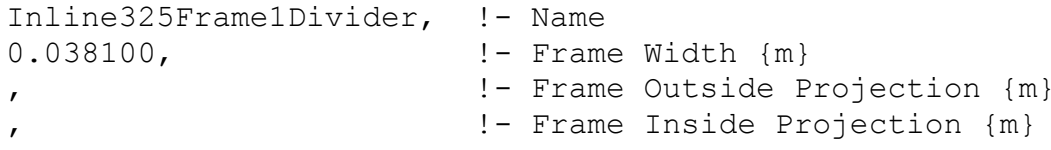




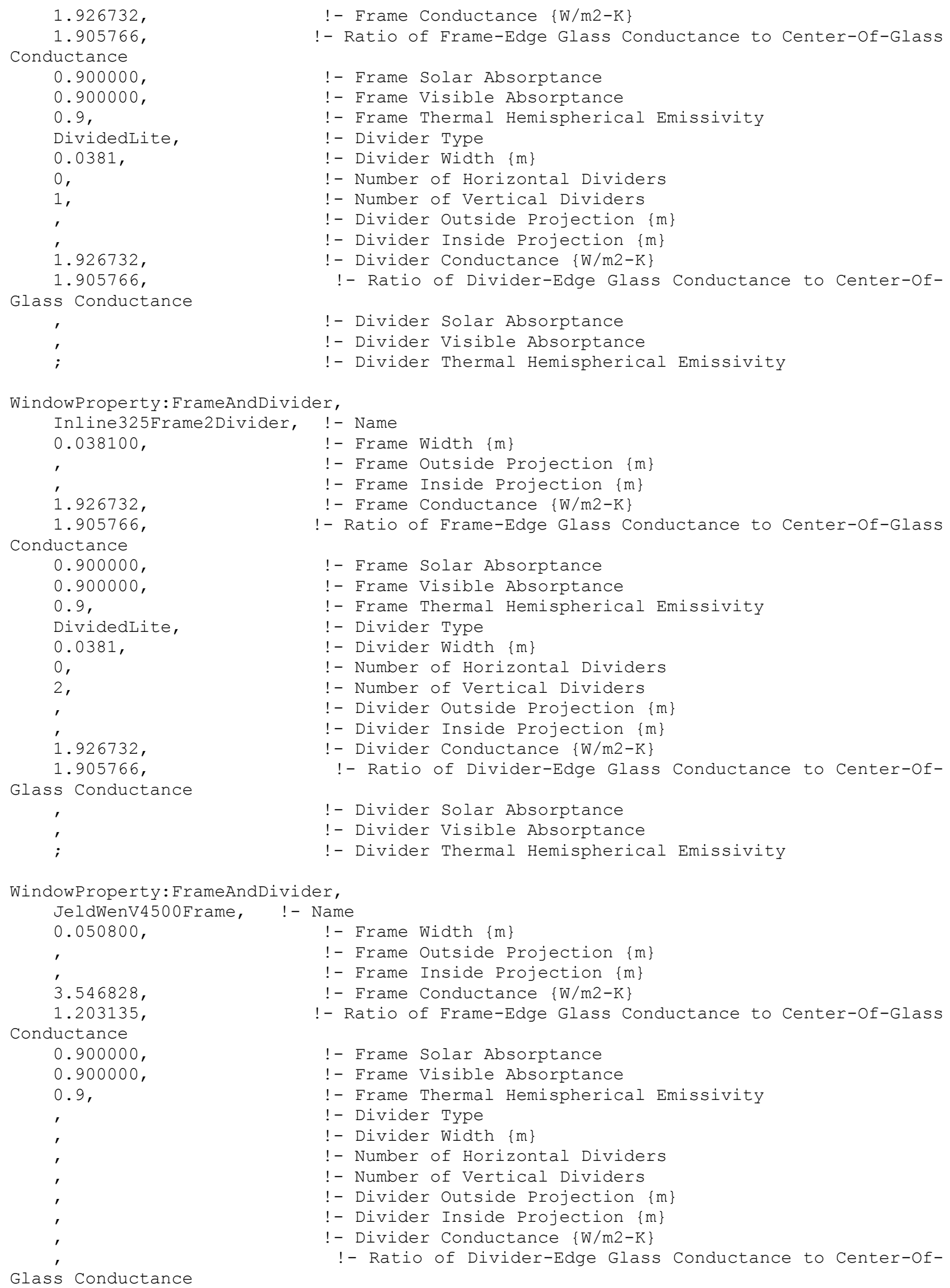

Glass Conductance 
!- Divider Solar Absorptance

!- Divider Visible Absorptance

!- Divider Thermal Hemispherical Emissivity

WindowProperty: FrameAndDivider, JeldWenV4500Frame1Divider, ! - Name 0.0508 ,

3. 546828 ,

1.203135,

Conductance

0.900000 ,

0.900000

0.9 ,

DividedLite,

0.0508 ,

0 ,

1,

,

3.546828,

1.203135,

Glass Conductance
!- Frame Width $\{\mathrm{m}\}$

!- Frame Outside Projection $\{\mathrm{m}\}$

! - Frame Inside Projection $\{m\}$

!- Frame Conductance $\{\mathrm{W} / \mathrm{m} 2-\mathrm{K}\}$

!- Ratio of Frame-Edge Glass Conductance to Center-Of-Glass

! - Frame Solar Absorptance

!- Frame Visible Absorptance

!- Frame Thermal Hemispherical Emissivity

!- Divider Type

!- Divider Width $\{\mathrm{m}\}$

!- Number of Horizontal Dividers

!- Number of Vertical Dividers

!- Divider Outside Projection $\{\mathrm{m}\}$

!- Divider Inside Projection $\{\mathrm{m}\}$

!- Divider Conductance $\{\mathrm{W} / \mathrm{m} 2-\mathrm{K}\}$

!- Ratio of Divider-Edge Glass Conductance to Center-of-

!- Divider Solar Absorptance

!- Divider Visible Absorptance

!- Divider Thermal Hemispherical Emissivity

WindowProperty: FrameAndDivider, JeldWenV4500Frame2Divider, !- Name

0.0508 ,

\section{,}

3. 546828,

1.203135,

Conductance

0.900000

0.900000

0.9 ,

DividedLite,

0.0508 ,

0 ,

2,

,

3.546828 ,

1.203135,

Glass Conductance
!- Frame Width $\{\mathrm{m}\}$

!- Frame Outside Projection $\{\mathrm{m}\}$

!- Frame Inside Projection $\{\mathrm{m}\}$

!- Frame Conductance $\{\mathrm{W} / \mathrm{m} 2-\mathrm{K}\}$

!- Ratio of Frame-Edge Glass Conductance to Center-Of-Glass

! - Frame Solar Absorptance

!- Frame Visible Absorptance

!- Frame Thermal Hemispherical Emissivity

!- Divider Type

!- Divider Width $\{\mathrm{m}\}$

!- Number of Horizontal Dividers

!- Number of Vertical Dividers

!- Divider Outside Projection $\{\mathrm{m}\}$

!- Divider Inside Projection $\{\mathrm{m}\}$

!- Divider Conductance $\{\mathrm{W} / \mathrm{m} 2-\mathrm{K}\}$

!- Ratio of Divider-Edge Glass Conductance to Center-of-

!- Divider Solar Absorptance

!- Divider Visible Absorptance

!- Divider Thermal Hemispherical Emissivity

WindowProperty: FrameAndDivider, OptiwinAlphaWinframe, !- Name

0.020320 ,

0.909425,

1.500983,

Conductance

0.900000

0.900000

0.9 ,
!- Frame Width $\{\mathrm{m}\}$

!- Frame Outside Projection $\{m\}$

!- Frame Inside Projection $\{\mathrm{m}\}$

!- Frame Conductance $\{\mathrm{W} / \mathrm{m} 2-\mathrm{K}\}$

!- Ratio of Frame-Edge Glass Conductance to Center-Of-Glass

!- Frame Solar Absorptance

! - Frame Visible Absorptance

!- Frame Thermal Hemispherical Emissivity 


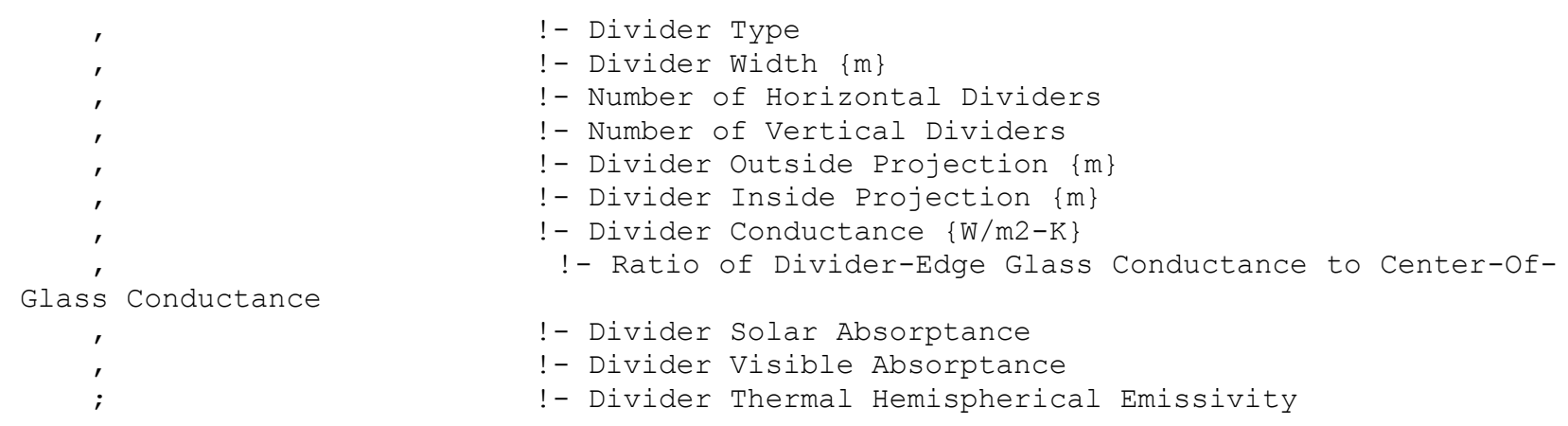

WindowProperty: FrameAndDivider, OptiwinAlphaWinframelDivider, !- Name 0.02032, !- Frame Width $\{\mathrm{m}\}$

WindowProperty: FrameAndDivider, OptiwinAlphaWinframe2Divider, !- Name 0.02032 ,

,

0.909425, 1.500983 , Conductance

0.900000 , 0.900000 0.9 , DividedLite, 0.02032 ,
!- Frame Width $\{\mathrm{m}\}$

!- Frame Outside Projection $\{\mathrm{m}\}$

!- Frame Inside Projection $\{\mathrm{m}\}$

!- Frame Conductance $\{\mathrm{W} / \mathrm{m} 2-\mathrm{K}\}$

!- Ratio of Frame-Edge Glass Conductance to Center-Of-Glass

!- Frame Solar Absorptance

! - Frame Visible Absorptance

!- Frame Thermal Hemispherical Emissivity

!- Divider Type

!- Divider Width $\{\mathrm{m}\}$

!- Number of Horizontal Dividers

!- Number of Vertical Dividers

!- Divider Outside Projection $\{\mathrm{m}\}$

!- Divider Inside Projection $\{\mathrm{m}\}$

!- Divider Conductance $\{\mathrm{W} / \mathrm{m} 2-\mathrm{K}\}$

!- Ratio of Divider-Edge Glass Conductance to Center-of-

!- Divider Solar Absorptance

!- Divider Visible Absorptance

!- Divider Thermal Hemispherical Emissivity 
! ZONES \& GEOMETRY \& Shading

! Copied from OS file

Shading:Building:Detailed, Dormir West overhang, ,

,

0.572000000000001 ,

15.2716 ,

10.136 ,

-0.644000000000001 ,

15.2716 ,

7.53400000000001 ,

-0.644000000000001 ,

14.7716 ,

7.53400000000001

0.572000000000001 ,

14.7716 ,

10.136 ;

!- Name
!- Transmittance Schedule Name
!- Number of Vertices
!- Vertex 1 X-coordinate $\{\mathrm{m}\}$
!- Vertex 1 Y-coordinate $\{\mathrm{m}\}$
!- Vertex 1 Z-coordinate $\{\mathrm{m}\}$
!- Vertex 2 X-coordinate $\{\mathrm{m}\}$
!- Vertex 2 Y-coordinate $\{\mathrm{m}\}$
!- Vertex 2 Z-coordinate $\{\mathrm{m}\}$
!- Vertex 3 X-coordinate $\{\mathrm{m}\}$
!- Vertex 3 Y-coordinate $\{\mathrm{m}\}$
!- Vertex 3 Z-coordinate $\{\mathrm{m}\}$
!- Vertex 4 X-coordinate $\{\mathrm{m}\}$
!- Vertex 4 Y-coordinate $\{\mathrm{m}\}$
!- Vertex 4 Z-coordinate $\{\mathrm{m}\}$

Shading:Building: Detailed, Dormir East Overhang,

,

0.571999999999998,

14.7716 ,

10.136 ,

1.788,

14.7716 ,

7.53400000000001 ,

1.788,

15.2716 ,

7.53400000000001

0.571999999999998 ,

15.2716,

10.136 ;

! - Name

! - Transmittance Schedule Name

! - Number of Vertices

!- Vertex $1 \mathrm{X}$-coordinate $\{\mathrm{m}\}$

!- Vertex 1 Y-coordinate $\{\mathrm{m}\}$

!- Vertex 1 Z-coordinate $\{m\}$

!- Vertex $2 \mathrm{X}$-coordinate $\{\mathrm{m}\}$

!- Vertex 2 Y-coordinate $\{m\}$

!- Vertex 2 Z-coordinate $\{\mathrm{m}\}$

!- Vertex $3 \mathrm{X}$-coordinate $\{\mathrm{m}\}$

!- Vertex 3 Y-coordinate $\{\mathrm{m}\}$

!- Vertex 3 z-coordinate $\{m\}$

!- Vertex $4 \mathrm{X}$-coordinate $\{\mathrm{m}\}$

!- Vertex 4 Y-coordinate $\{\mathrm{m}\}$

!- Vertex 4 Z-coordinate $\{m\}$

Shading:Building: Detailed, North upper overhang,

! - Name

!- Transmittance Schedule Name

,

4.753,

15.5256 ,

7.03400000000001 ,

4.753,

14.7716,

7.03400000000001 ,

-1.21 ,

14.7716 ,

7.03400000000001,

-1.21 ,

15.5256 ,

7.03400000000001 ;

!- Number of Vertices

!- Vertex 1 X-coordinate $\{\mathrm{m}\}$

!- Vertex 1 Y-coordinate $\{m\}$

!- Vertex 1 Z-coordinate $\{m\}$

!- Vertex 2 X-coordinate $\{m\}$

!- Vertex 2 Y-coordinate $\{m\}$

!- Vertex 2 Z-coordinate $\{\mathrm{m}\}$

!- Vertex $3 \mathrm{X}$-coordinate $\{\mathrm{m}\}$

!- Vertex 3 Y-coordinate $\{m\}$

!- Vertex 3 Z-coordinate $\{\mathrm{m}\}$

!- Vertex $4 \mathrm{X}$-coordinate $\{\mathrm{m}\}$

!- Vertex 4 Y-coordinate $\{\mathrm{m}\}$

!- Vertex 4 Z-coordinate $\{m\}$

Shading:Building: Detailed, Sloped east overhang,

! - Name

,

! - Transmittance Schedule Name

4.753,

10.8700655901831 ,

10.136 ,

4.753,

14.7716

7.53400000000001 ,

! - Number of Vertices

!- Vertex $1 \mathrm{X}$-coordinate $\{\mathrm{m}\}$

!- Vertex 1 Y-coordinate $\{m\}$

!- Vertex 1 Z-coordinate $\{m\}$

!- Vertex 2 X-coordinate $\{m\}$

!- Vertex 2 Y-coordinate $\{\mathrm{m}\}$

!- Vertex 2 Z-coordinate $\{\mathrm{m}\}$ 
5.053,

14.7716 ,

7.53400000000001 ,

5.053 ,

10.8700655901831 ,

10.136 ;

Shading:Building: Detailed, Small south overhang,

,

0 ,

5.1956,

10.136 ,

0 ,

5.4956 ,

10.136 ,

-1.51,

5.4956 ,

10.136 ,

-1.51 ,

5.1956,

10.136 ;

Shading:Building: Detailed, West overhang 3,

'́,

1.7 ,

10.136 ,

0 ,

5.1956 ,

10.136 ,

-0.3 ,

5.1956,

10.136 ,

-0.3 ,

1.7,

10.136 ;

Shading:Building: Detailed, Larger south overhang,

,

4.752,

1. 4,

10.136 ,

4.752 ,

1.7 ,

10.136 ,

-0.3 ,

1.7 ,

10.136 ,

-0.3 ,

1.4 ,

10.136 ;
!- Vertex 3 X-coordinate $\{m\}$

!- Vertex 3 Y-coordinate $\{m\}$

!-Vertex 3 Z-coordinate $\{m\}$

!-Vertex 4 X-coordinate $\{\mathrm{m}\}$

!- Vertex 4 Y-coordinate $\{m\}$

!- Vertex 4 z-coordinate $\{m\}$

! - Name

! - Transmittance Schedule Name

! - Number of Vertices

!- Vertex 1 X-coordinate $\{m\}$

!- Vertex 1 Y-coordinate $\{m\}$

!-Vertex 1 Z-coordinate $\{\mathrm{m}\}$

!- Vertex 2 X-coordinate $\{m\}$

!-Vertex 2 Y-coordinate $\{\mathrm{m}\}$

!-Vertex 2 Z-coordinate $\{\mathrm{m}\}$

!- Vertex 3 X-coordinate $\{m\}$

!- Vertex 3 Y-coordinate $\{m\}$

!- Vertex 3 Z-coordinate $\{m\}$

!- Vertex 4 X-coordinate $\{m\}$

!- Vertex 4 Y-coordinate $\{\mathrm{m}\}$

!- Vertex 4 Z-coordinate $\{m\}$

! - Name

! - Transmittance Schedule Name

! - Number of Vertices

!- Vertex 1 X-coordinate $\{m\}$

!- Vertex 1 Y-coordinate $\{\mathrm{m}\}$

! - Vertex 1 Z-coordinate $\{\mathrm{m}\}$

!- Vertex 2 X-coordinate $\{m\}$

!-Vertex 2 Y-coordinate $\{\mathrm{m}\}$

!- Vertex 2 Z-coordinate $\{m\}$

!- Vertex 3 X-coordinate $\{m\}$

!- Vertex 3 Y-coordinate $\{m\}$

!- Vertex 3 Z-coordinate $\{m\}$

!- Vertex 4 X-coordinate $\{m\}$

!- Vertex 4 Y-coordinate $\{m\}$

!- Vertex 4 Z-coordinate $\{m\}$

! - Name

!- Transmittance Schedule Name

! - Number of Vertices

!-Vertex 1 X-coordinate $\{m\}$

!- Vertex 1 Y-coordinate $\{\mathrm{m}\}$

!- Vertex 1 Z-coordinate $\{m\}$

!- Vertex 2 X-coordinate $\{\mathrm{m}\}$

!- Vertex 2 Y-coordinate $\{\mathrm{m}\}$

!- Vertex 2 Z-coordinate $\{\mathrm{m}\}$

!- Vertex 3 X-coordinate $\{\mathrm{m}\}$

!- Vertex 3 Y-coordinate $\{m\}$

!- Vertex 3 Z-coordinate $\{m\}$

!- Vertex 4 X-coordinate $\{\mathrm{m}\}$

!- Vertex 4 Y-coordinate $\{\mathrm{m}\}$

!- Vertex 4 Z-coordinate $\{m\}$

Shading:Building: Detailed, West overhang 1 ,

I- Name

! - Transmittance Schedule Name

! - Number of Vertices

!-Vertex 1 X-coordinate $\{\mathrm{m}\}$ 


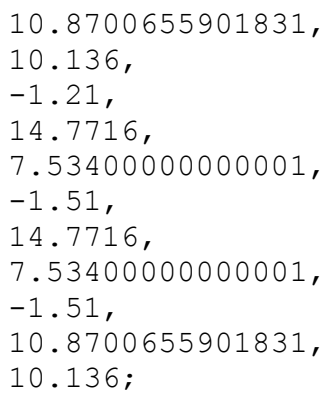

Shading:Building:Detailed, West overhang 2,

,

$-1.21$

5.4956,

10.136 ,

-1.21 ,

10.8700655901831 ,

10.136,

-1.51 ,

10.8700655901831 ,

10.136 ,

-1.51,

5.4956 ,

10.136 ;

Shading:Building: Detailed, Larger east overhang,

5. 053 ,

10.8700655901831 ,

10.136 ,

5.053,

1.4,

10.136

4.752 ,

1.4 ,

10.136

4.753,

10.8700655901831 ,

10.136 ;

Shading:Building: Detailed, 2 storey brick bld 25,

-2.01 ,

14.7716,

7.034,

-2.01 ,

14.7716,

0 ,

-2.01 ,

3.9956,

0 ,

-2.01 ,

3.9956 ,

$7.034 ;$ $\begin{array}{llll}\text { !- Vertex } & 1 & \text { Y-coordinate } & \{\mathrm{m}\} \\ \text { !- Vertex } & 1 & \text { Z-coordinate } & \{\mathrm{m}\} \\ \text { !- Vertex } 2 & \mathrm{X} \text {-coordinate } & \{\mathrm{m}\} \\ \text { !- Vertex } 2 & \text { Y-coordinate } & \{\mathrm{m}\} \\ \text { !- Vertex } 2 & \text { Z-coordinate } & \{\mathrm{m}\} \\ \text { !- Vertex } 3 & \mathrm{X} \text {-coordinate } & \{\mathrm{m}\} \\ \text { !- Vertex } & 3 & \text { Y-coordinate } & \{\mathrm{m}\} \\ \text { !- Vertex } 3 & \mathrm{Z} \text {-coordinate } & \{\mathrm{m}\} \\ \text { !- Vertex } 4 & \mathrm{X} \text {-coordinate } & \{\mathrm{m}\} \\ \text { !- Vertex } 4 & \text { Y-coordinate } & \{\mathrm{m}\} \\ \text { !- Vertex } 4 & \mathrm{Z} \text {-coordinate } & \{\mathrm{m}\}\end{array}$

! - Name

! - Transmittance Schedule Name

!- Number of Vertices

!- Vertex 1 X-coordinate $\{\mathrm{m}\}$

!- Vertex 1 Y-coordinate $\{m\}$

!- Vertex 1 Z-coordinate $\{\mathrm{m}\}$

!- Vertex 2 X-coordinate $\{\mathrm{m}\}$

!- Vertex 2 Y-coordinate $\{\mathrm{m}\}$

!- Vertex 2 Z-coordinate $\{\mathrm{m}\}$

!- Vertex $3 \mathrm{X}$-coordinate $\{\mathrm{m}\}$

!- Vertex 3 Y-coordinate $\{\mathrm{m}\}$

!- Vertex 3 Z-coordinate $\{\mathrm{m}\}$

!- Vertex 4 X-coordinate $\{m\}$

!- Vertex 4 Y-coordinate $\{\mathrm{m}\}$

!- Vertex 4 Z-coordinate $\{m\}$

! - Name

!- Transmittance Schedule Name

! - Number of Vertices

!- Vertex $1 \mathrm{X}$-coordinate $\{\mathrm{m}\}$

!- Vertex 1 Y-coordinate $\{\mathrm{m}\}$

!- Vertex 1 Z-coordinate $\{\mathrm{m}\}$

!- Vertex 2 X-coordinate $\{\mathrm{m}\}$

!- Vertex 2 Y-coordinate $\{\mathrm{m}\}$

!- Vertex 2 Z-coordinate $\{\mathrm{m}\}$

!- Vertex $3 \mathrm{X}$-coordinate $\{\mathrm{m}\}$

!- Vertex 3 Y-coordinate $\{\mathrm{m}\}$

!- Vertex 3 Z-coordinate $\{m\}$

!- Vertex $4 \mathrm{X}$-coordinate $\{\mathrm{m}\}$

!- Vertex 4 Y-coordinate $\{\mathrm{m}\}$

!- Vertex 4 Z-coordinate $\{\mathrm{m}\}$

! - Name

! - Transmittance Schedule Name

! - Number of Vertices

!- Vertex $1 \mathrm{X}$-coordinate $\{\mathrm{m}\}$

!- Vertex 1 Y-coordinate $\{\mathrm{m}\}$

!- Vertex 1 Z-coordinate $\{\mathrm{m}\}$

!- Vertex 2 X-coordinate $\{\mathrm{m}\}$

!- Vertex 2 Y-coordinate $\{\mathrm{m}\}$

!- Vertex 2 Z-coordinate $\{\mathrm{m}\}$

!- Vertex $3 \mathrm{X}$-coordinate $\{\mathrm{m}\}$

!- Vertex 3 Y-coordinate $\{\mathrm{m}\}$

!- Vertex 3 z-coordinate $\{m\}$

!- Vertex $4 \mathrm{X}$-coordinate $\{\mathrm{m}\}$

!- Vertex 4 Y-coordinate $\{\mathrm{m}\}$

!- Vertex 4 Z-coordinate $\{m\}$ 
Shading:Building: Detailed, 2 storey brick bld 29,

! - Name

! - Transmittance Schedule Name

!- Number of Vertices

5. 553,

14.7716 ,

7.034,

5.553,

14.7716 ,

1.16,

5.553,

3.9956,

1.16

5.553,

3.9956,

$7.034 ;$
!- Vertex $1 \mathrm{X}$-coordinate $\{\mathrm{m}\}$

!- Vertex 1 Y-coordinate $\{\mathrm{m}\}$

!- Vertex 1 Z-coordinate $\{m\}$

!- Vertex $2 \mathrm{X}$-coordinate $\{\mathrm{m}\}$

!- Vertex 2 Y-coordinate $\{\mathrm{m}\}$

!- Vertex 2 Z-coordinate $\{\mathrm{m}\}$

!- Vertex $3 \mathrm{X}$-coordinate $\{\mathrm{m}\}$

!- Vertex 3 Y-coordinate $\{\mathrm{m}\}$

!- Vertex 3 Z-coordinate $\{m\}$

!- Vertex $4 \mathrm{X}$-coordinate $\{\mathrm{m}\}$

!- Vertex 4 Y-coordinate $\{\mathrm{m}\}$

!- Vertex 4 Z-coordinate $\{m\}$

Shading:Building: Detailed, 1 storey stucco dwelling,!- Name

5.553 ,

3. 9956 ,

4.157,

5.553 ,

3. 9956 ,

1. 16 ,

5.553,

0 ,

1. 16 ,

5. 553,

0 ,

4.157;

Shading:Building: Detailed, 2 stry brick bld 29 2,

,

5. 553 ,

14.7716 ,

1. 16 ,

5.553,

14.7716,

0 ,

5. 553,

0 ,

0 ,

5. 553,

0 ,

1. 16 ;

Shading:Building: Detailed, Front porch overhang,

,

4.753,

17.5716,

4.157,

4.753,

14.7716,

4.157,

-1.21 ,

14.7716,
! - Transmittance Schedule Name

! - Number of Vertices

!- Vertex $1 \mathrm{X}$-coordinate $\{\mathrm{m}\}$

!- Vertex 1 Y-coordinate $\{\mathrm{m}\}$

!- Vertex 1 Z-coordinate $\{\mathrm{m}\}$

!- Vertex 2 X-coordinate $\{\mathrm{m}\}$

!- Vertex 2 Y-coordinate $\{\mathrm{m}\}$

!- Vertex 2 Z-coordinate $\{\mathrm{m}\}$

!- Vertex 3 X-coordinate $\{m\}$

!- Vertex 3 Y-coordinate $\{m\}$

!- Vertex 3 Z-coordinate $\{m\}$

!- Vertex 4 X-coordinate $\{m\}$

!- Vertex 4 Y-coordinate $\{m\}$

!-Vertex 4 Z-coordinate $\{\mathrm{m}\}$

! - Name

! - Transmittance Schedule Name

! - Number of Vertices

!-Vertex $1 \mathrm{X}$-coordinate $\{\mathrm{m}\}$

!- Vertex 1 Y-coordinate $\{m\}$

!- Vertex 1 Z-coordinate $\{\mathrm{m}\}$

!- Vertex 2 X-coordinate $\{\mathrm{m}\}$

!- Vertex 2 Y-coordinate $\{\mathrm{m}\}$

!- Vertex 2 Z-coordinate $\{\mathrm{m}\}$

!- Vertex 3 X-coordinate $\{\mathrm{m}\}$

!- Vertex 3 Y-coordinate $\{\mathrm{m}\}$

!- Vertex 3 Z-coordinate $\{m\}$

!-Vertex 4 X-coordinate $\{\mathrm{m}\}$

!- Vertex 4 Y-coordinate $\{m\}$

!-Vertex 4 Z-coordinate $\{m\}$

! - Name

! - Transmittance Schedule Name

! - Number of Vertices

!- Vertex 1 X-coordinate $\{m\}$

!- Vertex 1 Y-coordinate $\{\mathrm{m}\}$

!- Vertex 1 Z-coordinate $\{m\}$

!- Vertex 2 X-coordinate $\{\mathrm{m}\}$

!-Vertex 2 Y-coordinate $\{\mathrm{m}\}$

!- Vertex 2 Z-coordinate $\{\mathrm{m}\}$

!- Vertex 3 X-coordinate $\{m\}$

!- Vertex 3 Y-coordinate $\{m\}$ 

4.157,
!- Vertex 3 Z-coordinate $\{m\}$
-1.21 ,
!- Vertex $4 \mathrm{X}$-coordinate $\{\mathrm{m}\}$
17.5716 ,
!- Vertex 4 Y-coordinate $\{\mathrm{m}\}$
4.157;
!- Vertex 4 Z-coordinate $\{\mathrm{m}\}$

$!-$

$===========$ ALL OBJECTS IN CLASS: SURFACEPROPERTY $:$ OTHERSIDECOEFFICIENTS $===========$

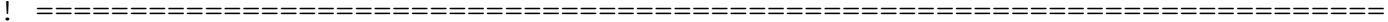

! The following was created by the Basement preprocessor program.

! Weather File Location=592803 592803592803 TMY2

!

SurfaceProperty: OtherSideCoefficients,

surfPropothSdCoefBasementAvgWall, !- Name

0.0, !- Combined Convective/Radiative Film Coefficient $\{\mathrm{W} / \mathrm{m} 2-\mathrm{K}\}$

1.0, !- Constant Temperature $\{\mathrm{C}\}$

1.0, !- Constant Temperature Coefficient

0.0, !- External Dry-Bulb Temperature Coefficient

0.0, !- Ground Temperature Coefficient

$0.0, \quad$ ! - Wind Speed Coefficient

0.0, !- Zone Air Temperature Coefficient

scheduleoscBasementWallSurfaceTemp, !-Constant Temperature Schedule Name

No, !- Sinusoidal Variation of Constant Temperature Coefficient

24; !- Period of Sinusoidal Variation $\{$ hr $\}$

SurfaceProperty: OtherSideCoefficients, surfPropothSdCoefBasementAvgFloor, !- Name
0.0 ,
1.0,
!- Combined Convective/Radiative Film Coefficient $\{\mathrm{W} / \mathrm{m} 2-\mathrm{K}\}$
1.0,
!- Constant Temperature $\{\mathrm{C}\}$
!- Constant Temperature Coefficient
0.0 ,
!- External Dry-Bulb Temperature Coefficient
0.0,
!- Ground Temperature Coefficient
0.0,
!- Wind Speed Coefficient
0.0 ,
!- Zone Air Temperature Coefficient
scheduleosCBasementFloorTemp, !-Constant Temperature Schedule Name
No, !- Sinusoidal Variation of Constant Temperature Coefficient
24; !- Period of Sinusoidal Variation $\{$ hr $\}$

SurfaceProperty: OtherSideCoefficients, surfPropothSdCoefBasementUpperWall, !- Name

0.0, !- Combined Convective/Radiative Film Coefficient $\{\mathrm{W} / \mathrm{m} 2-\mathrm{K}\}$

1.0 ,

!- Constant Temperature $\{\mathrm{C}\}$

1.0,

!- Constant Temperature Coefficient

0.0,

!- External Dry-Bulb Temperature Coefficient

0.0,

!- Ground Temperature Coefficient

0.0,

!- Wind Speed Coefficient

0.0 ,

!- Zone Air Temperature Coefficient

scheduleosCBasementUpperWallTemp, !- Constant Temperature Schedule Name

No, !- Sinusoidal Variation of Constant Temperature Coefficient

24; !- Period of Sinusoidal Variation $\{$ hr $\}$

SurfaceProperty: OtherSideCoefficients, surfPropothSdCoefBasementLowerWall, !- Name
0.0,
1.0,
!- Combined Convective/Radiative Film Coefficient $\{\mathrm{W} / \mathrm{m} 2-\mathrm{K}\}$
1.0,
! - Constant Temperature $\{\mathrm{C}\}$
!- Constant Temperature Coefficient
0.0,
!- External Dry-Bulb Temperature Coefficient
!- Ground Temperature Coefficient
0.0,
!- Wind Speed Coefficient
0.0
!- Zone Air Temperature Coefficient
scheduleosCBasementLowerWallTemp, !-Constant Temperature Schedule Name
No, !- Sinusoidal Variation of Constant Temperature Coefficient
$24 ;$
!- Period of Sinusoidal Variation $\{$ hr $\}$ 
People,

Master Bedroom humans sleep, !- Name

Thermal Zone: Bedroom 1, !- Zone or ZoneList Name

Occupant Sleep Schedule, !- Number of People Schedule Name

People, !- Number of People Calculation Method

2,

!- Number of People

,

!- People per Zone Floor Area \{person/m2\}

!- Zone Floor Area per Person \{m2/person\}

0.30,

! - Fraction Radiant

0.40,

! - Sensible Heat Fraction

Occupant Sleep Activity Schedule; !- Activity Level Schedule Name

People,

Bedroom 3 humans sleep, !- Name

Thermal Zone: Bedroom 3, !- Zone or ZoneList Name

Occupant Sleep Schedule, !- Number of People Schedule Name

People, !- Number of People Calculation Method

1,

!- Number of People

,

!- People per Zone Floor Area \{person/m2

0.30,

!- Zone Floor Area per Person \{m2/person

0.4 ,

! - Fraction Radiant

Occupant Sleep Activity Schedule; !- Activity Level Schedule Name

People,

Bedroom 4 humans sleep, !- Name

Thermal Zone: Bedroom 4, !- Zone or ZoneList Name

Occupant Sleep Schedule, !- Number of People Schedule Name

People, !- Number of People Calculation Method

$1, \quad !-$ Number of People

, ! - People per Zone Floor Area \{person/m2\}

, !- Zone Floor Area per Person \{m2/person\}

$0.30, \quad$ !- Eraction Radiant

0.4, !- Sensible Heat Fraction

Occupant Sleep Activity Schedule; !- Activity Level Schedule Name

People,

Bedroom 2 humans sleep, !- Name

Thermal Zone: Bedroom 2, !- Zone or ZoneList Name

Occupant Sleep Schedule, !- Number of People Schedule Name

People, !- Number of People Calculation Method

1, !- Number of People

, !- People per Zone Floor Area \{person/m2

, !- Zone Floor Area per Person $\{\mathrm{m} 2 /$ person

$0.30, \quad$ !- Fraction Radiant

0.4, !- Sensible Heat Fraction

Occupant Sleep Activity Schedule; !- Activity Level Schedule Name

People,

All house humans awake, !- Name

All Living Space Zones, !- Zone or ZoneList Name

Occupant Day Schedule, !- Number of People Schedule Name

Area/Person, ! - Number of People Calculation Method

, !- Number of People

,

58.4,

!- People per Zone Floor Area \{person/m2

0.3,

!- Zone Floor Area per Person \{m2/person\}

0.4 ,

! - Fraction Radiant

Occupant Day Activity Schedule; !- Activity Level Schedule Name 
! 응 values for heat fractions for lighting taken from http://apps1.eere.energy.gov/buildings/publications/pdfs/ssl/thermal_led_feb07_2.pdf ! Basement 20 8W LEDS

Lights,

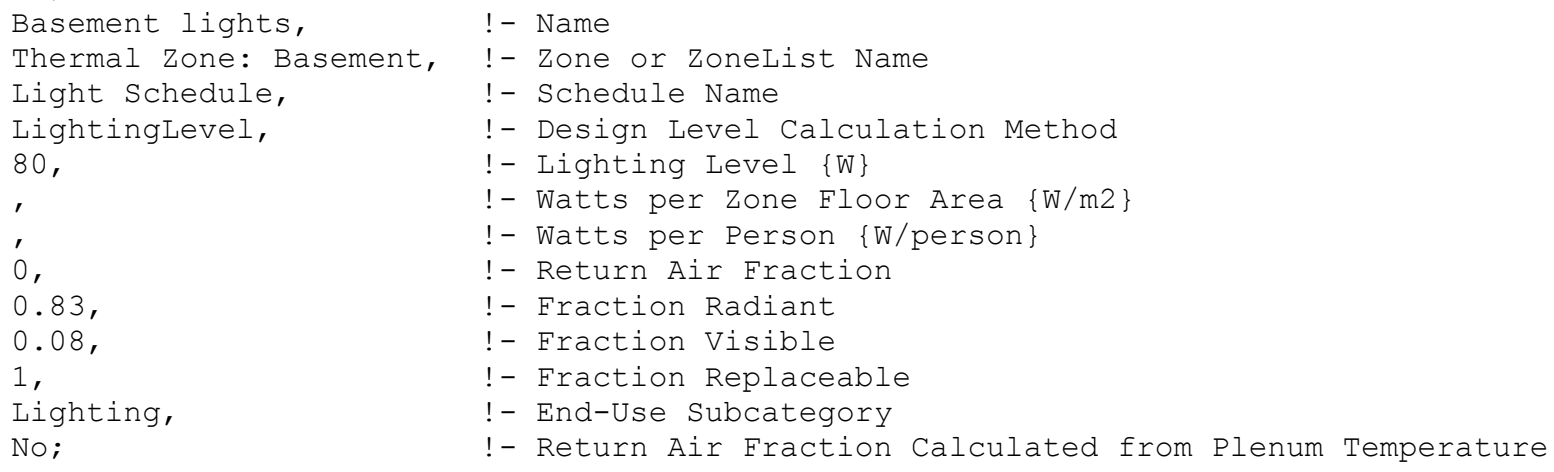




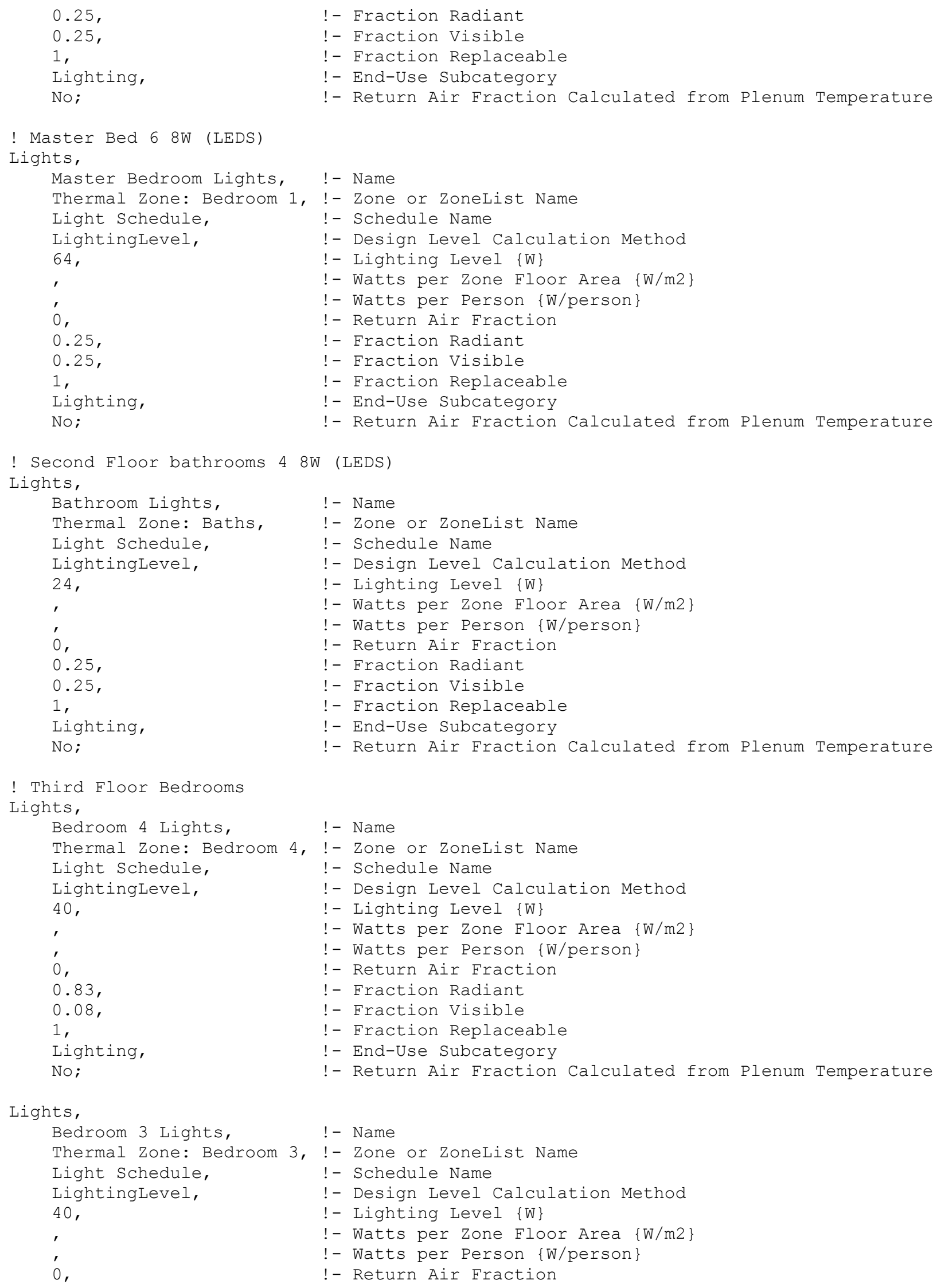




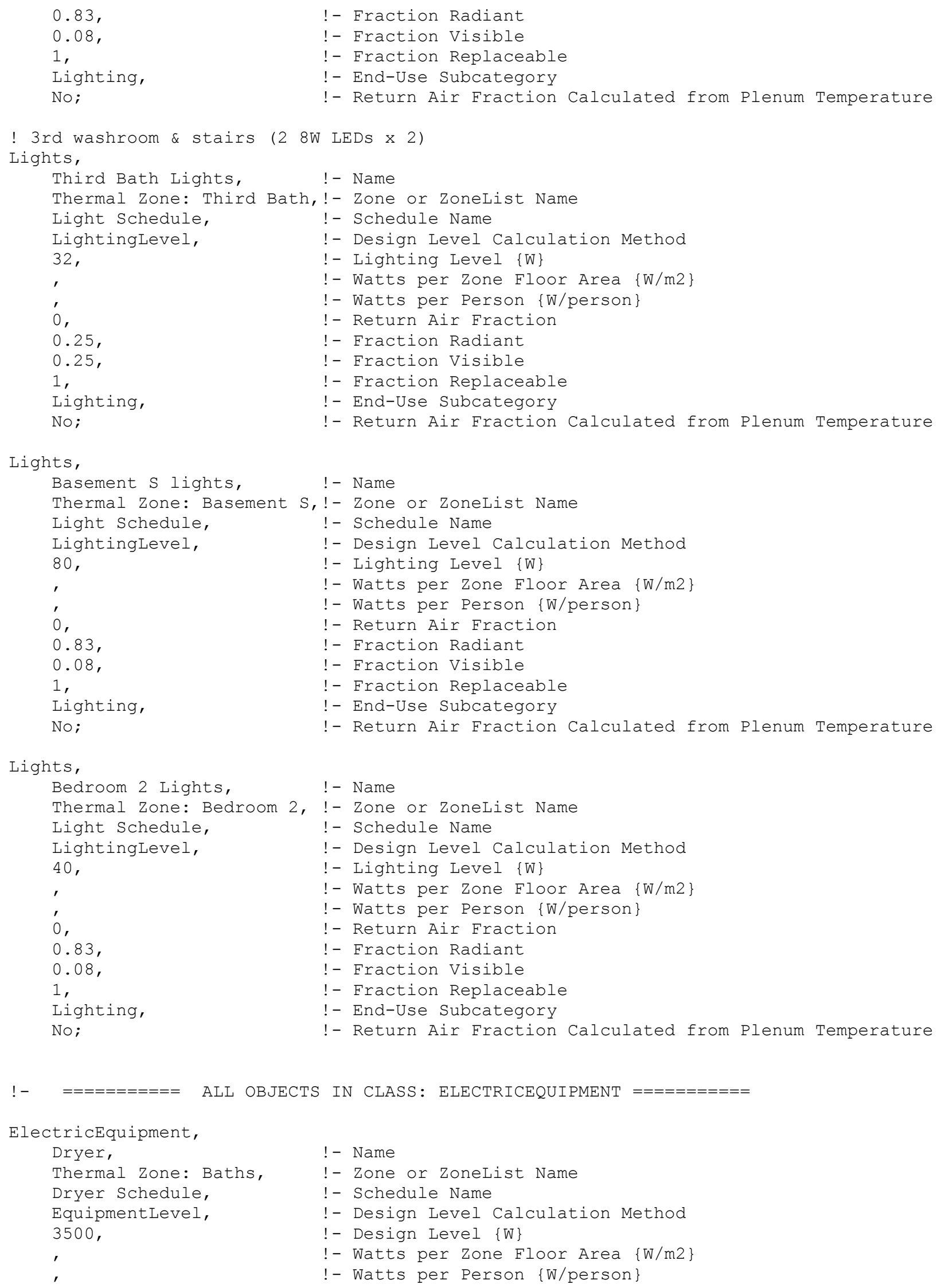




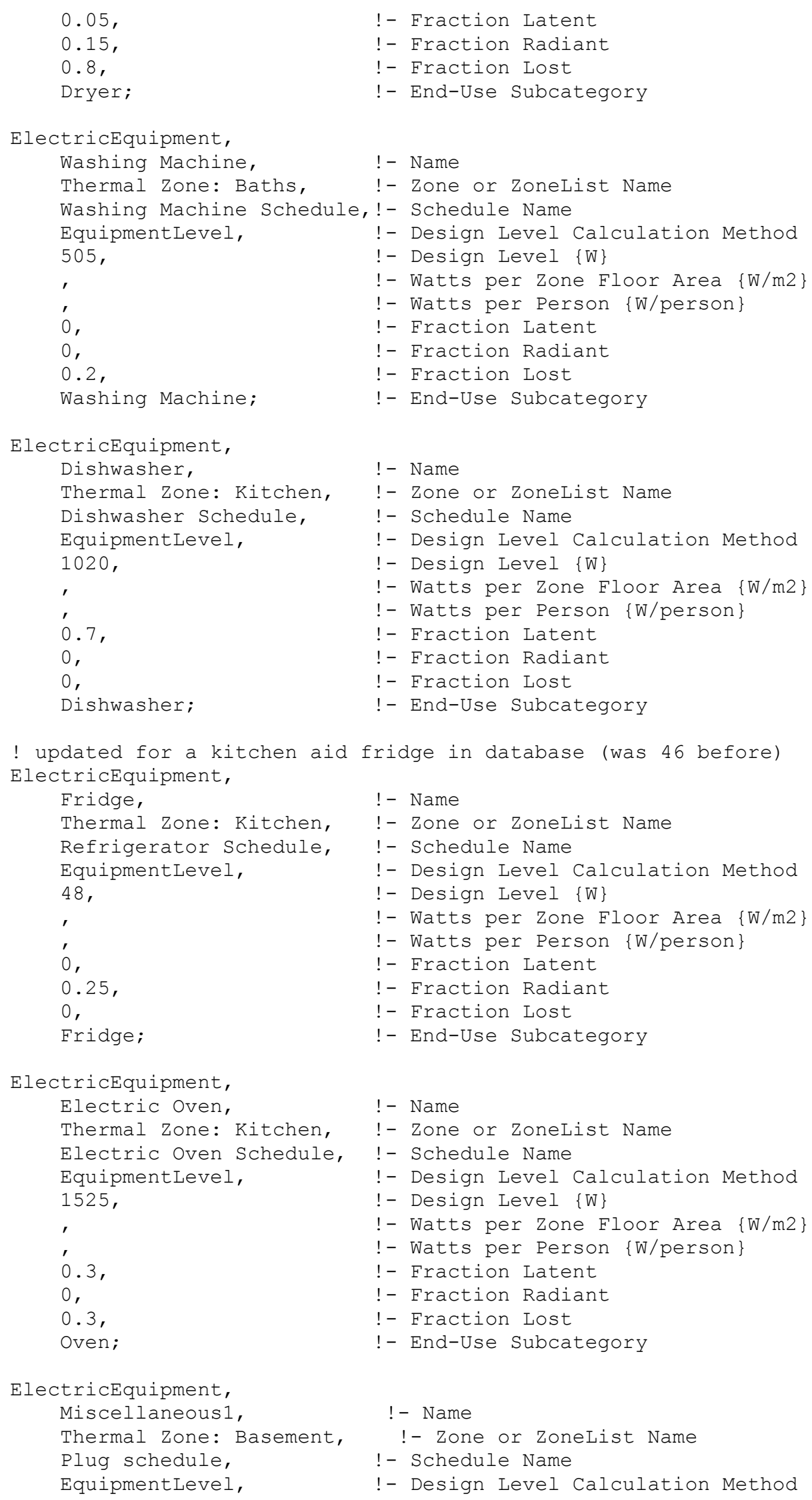




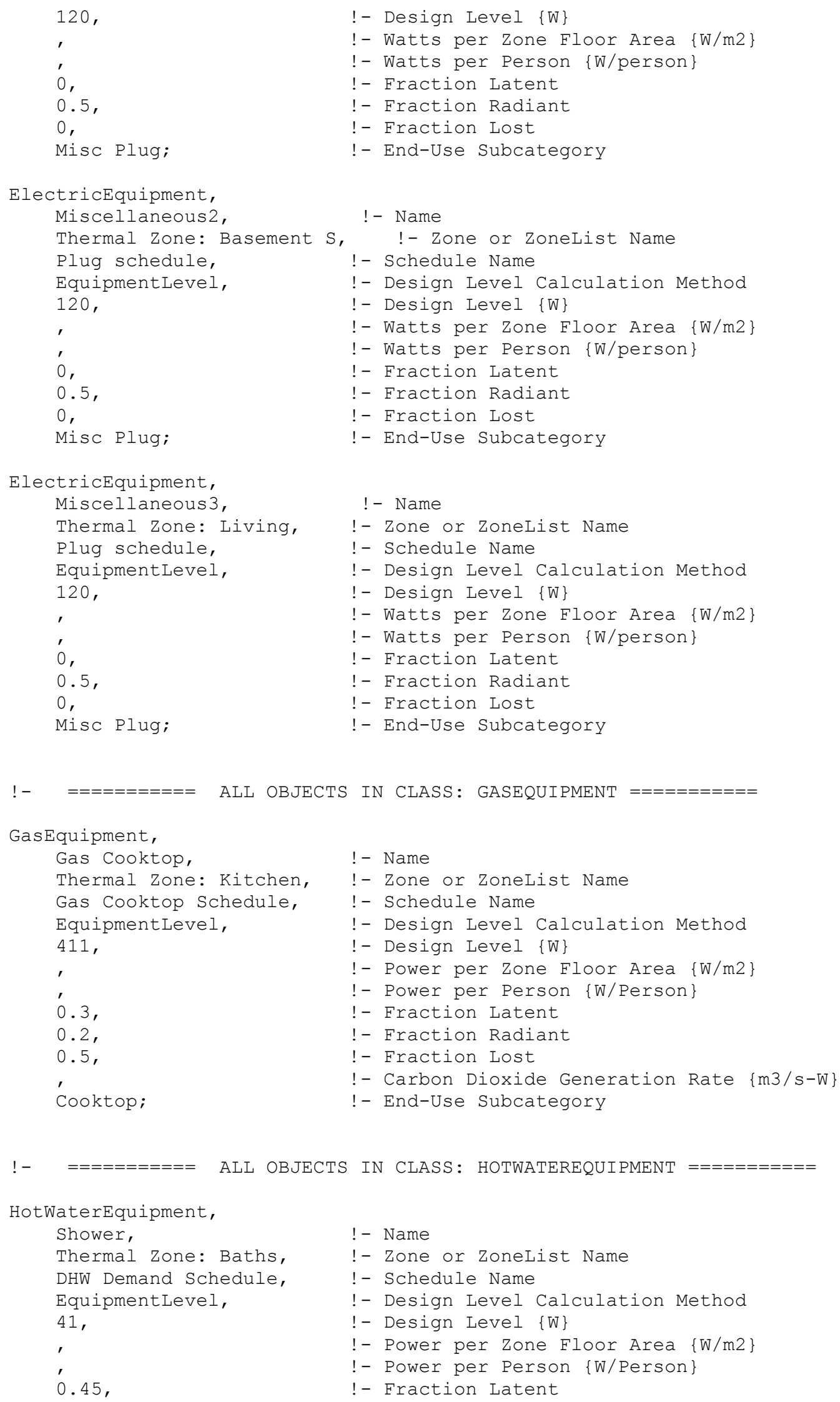



0,
0.1 ,
! - Fraction Radiant
Shower;
!- Fraction Lost
!- End-Use Subcategory

HotWaterEquipment,

Kitchen Sink,

! - Name

Thermal Zone: Kitchen,

DHW Demand Schedule,

!- Zone or Zonelist Name

EquipmentLevel,

! - Schedule Name

20,

!- Design Level Calculation Method

,

0.5 ,

!- Design Level $\{W\}$

!- Power per Zone Floor Area $\{\mathrm{W} / \mathrm{m} 2\}$

!- Power per Person $\{W /$ Person $\}$

0 ,

! - Fraction Latent

! - Fraction Radiant

0 ,

! - Fraction Lost

Kitchen Sink;

!- End-Use Subcategory

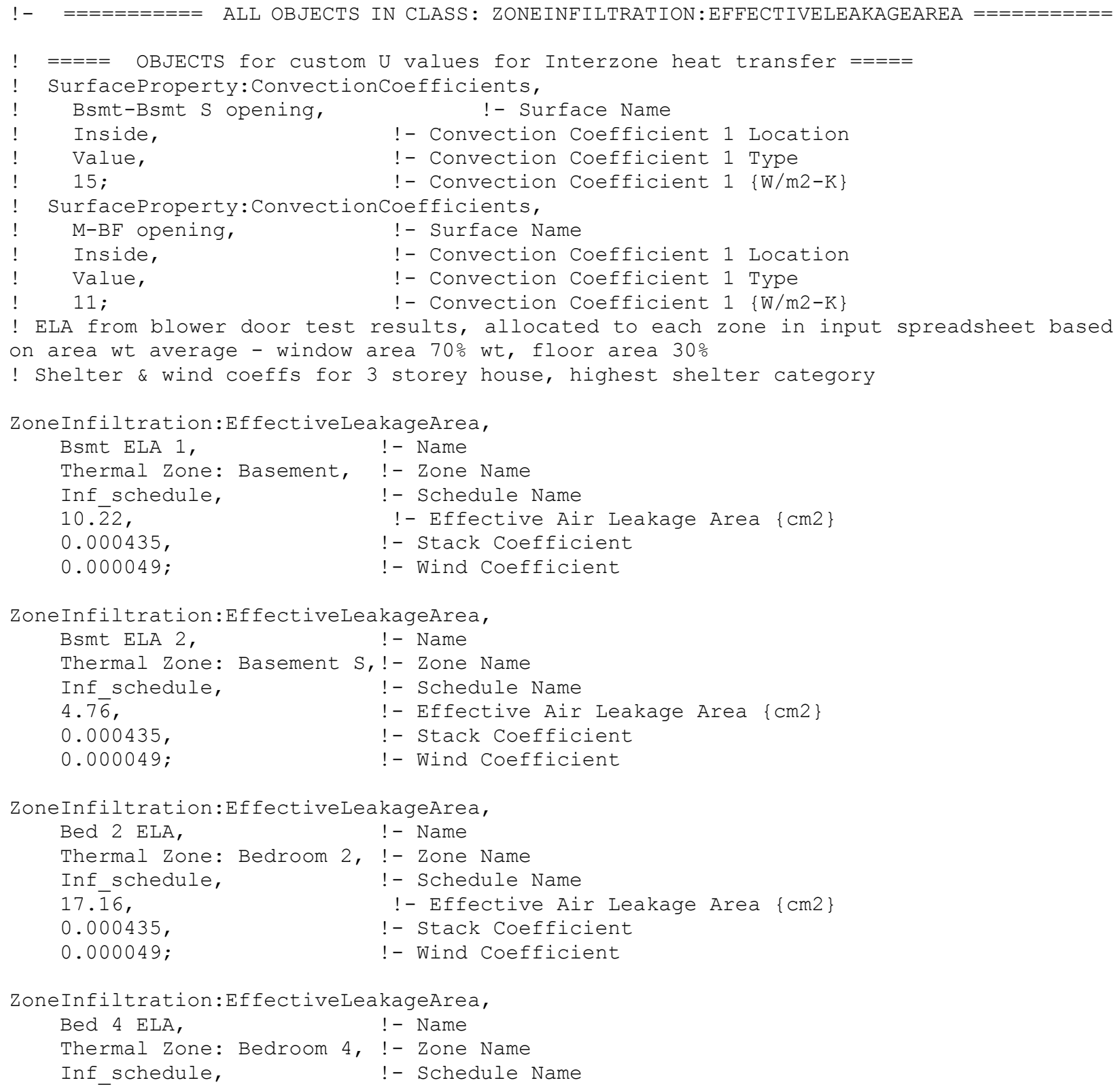



16.41,
!- Effective Air Leakage Area $\{\mathrm{cm} 2\}$
0.000435
!- Stack Coefficient
0.000049
!- Wind Coefficient

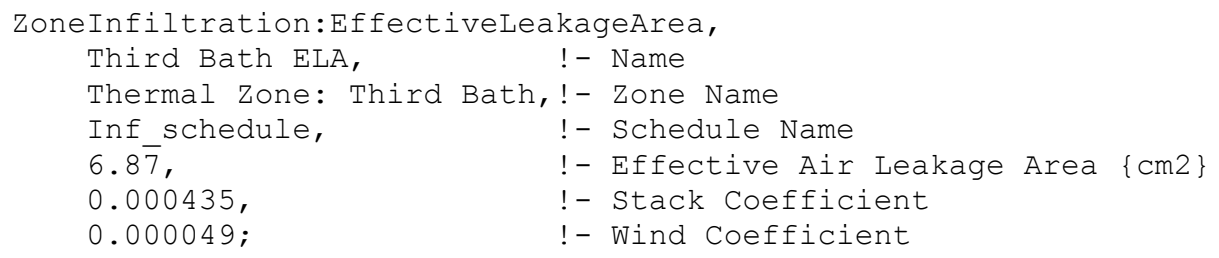




\begin{tabular}{|c|c|}
\hline 1.5, & !- Air Changes per Hour $\{1 / \mathrm{hr}\}$ \\
\hline Natural, & $\begin{array}{l}\text { !- Ventilation Type } \\
\text { !- Fan Pressure Rise }\{\mathrm{Pa}\}\end{array}$ \\
\hline , & ! - Fan Total Efficiency \\
\hline 1, & !- Constant Term Coefficient \\
\hline 0 , & !- Temperature Term Coefficient \\
\hline 0 , & !- Velocity Term Coefficient \\
\hline 0 & !- Velocity Squared Term Coefficient \\
\hline 20, & !- Minimum Indoor Temperature $\{\mathrm{C}\}$ \\
\hline & !- Minimum Indoor Temperature Schedule Name \\
\hline 100， & !- Maximum Indoor Temperature $\{\mathrm{C}\}$ \\
\hline & !- Maximum Indoor Temperature Schedule Name \\
\hline-100 & !- Delta Temperature $\{$ deltaC $\}$ \\
\hline & !- Delta Temperature Schedule Name \\
\hline-100 & !- Minimum Outdoor Temperature $\{C\}$ \\
\hline & !- Minimum Outdoor Temperature Schedule Name \\
\hline 100， & !- Maximum Outdoor Temperature $\{\mathrm{C}\}$ \\
\hline & !- Maximum Outdoor Temperature Schedule Name \\
\hline $40 ；$ & !- Maximum Wind Speed $\{\mathrm{m} / \mathrm{s}\}$ \\
\hline
\end{tabular}

ZoneVentilation: DesignFlowRate,

Natural Ventilation Kitchen, !- Name

Thermal Zone: Kitchen, !- Zone or Zonelist Name

Natural Ventilation Schedule, !- Schedule Name

AirChanges/Hour, !- Design Flow Rate Calculation Method

, !- Design Flow Rate $\{\mathrm{m} 3 / \mathrm{s}\}$

, ! - Flow Rate per Zone Floor Area $\{\mathrm{m} 3 / \mathrm{s}-\mathrm{m} 2\}$

, !- Flow Rate per Person $\{\mathrm{m} 3 / \mathrm{s}-$ person $\}$

1.5, !- Air Changes per Hour $\{1 / \mathrm{hr}\}$

Natural, !- Ventilation Type

, !- Fan Pressure Rise $\{\mathrm{Pa}\}$

, !- Fan Total Efficiency

1, !- Constant Term Coefficient

0, !- Temperature Term Coefficient

0, !- Velocity Term Coefficient

0, !- Velocity Squared Term Coefficient

20, !- Minimum Indoor Temperature $\{\mathrm{C}\}$

, !- Minimum Indoor Temperature Schedule Name

100, !- Maximum Indoor Temperature $\{\mathrm{C}\}$

, 100

!- Maximum Indoor Temperature Schedule Name

-100, !- Delta Temperature \{deltaC

, !- Delta Temperature Schedule Name

-100, !- Minimum Outdoor Temperature $\{\mathrm{C}\}$

, !- Minimum Outdoor Temperature Schedule Name

100, !- Maximum Outdoor Temperature $\{\mathrm{C}\}$

, !- Maximum Outdoor Temperature Schedule Name

40; !- Maximum Wind Speed $\{\mathrm{m} / \mathrm{s}\}$

ZoneVentilation: DesignFlowRate,

Natural Ventilation Bdrm 1, !- Name

Thermal Zone: Bedroom 1, !- Zone or ZoneList Name

Natural Ventilation Schedule, !- Schedule Name

Airchanges/Hour, ! - Design Flow Rate Calculation Method

,

,

,

1.5,

Natural, !- Ventilation Type

!- Design Flow Rate $\{\mathrm{m} 3 / \mathrm{s}\}$

!- Flow Rate per Zone Floor Area \{m3/s-m2

!- Flow Rate per Person $\{\mathrm{m} 3 / \mathrm{s}$-person $\}$

,

! - Fan Pressure Rise \{Pa\}

! - Fan Total Efficiency

1,

! - Constant Term Coefficient

0 ,

!- Temperature Term Coefficient

!- Velocity Term Coefficient 


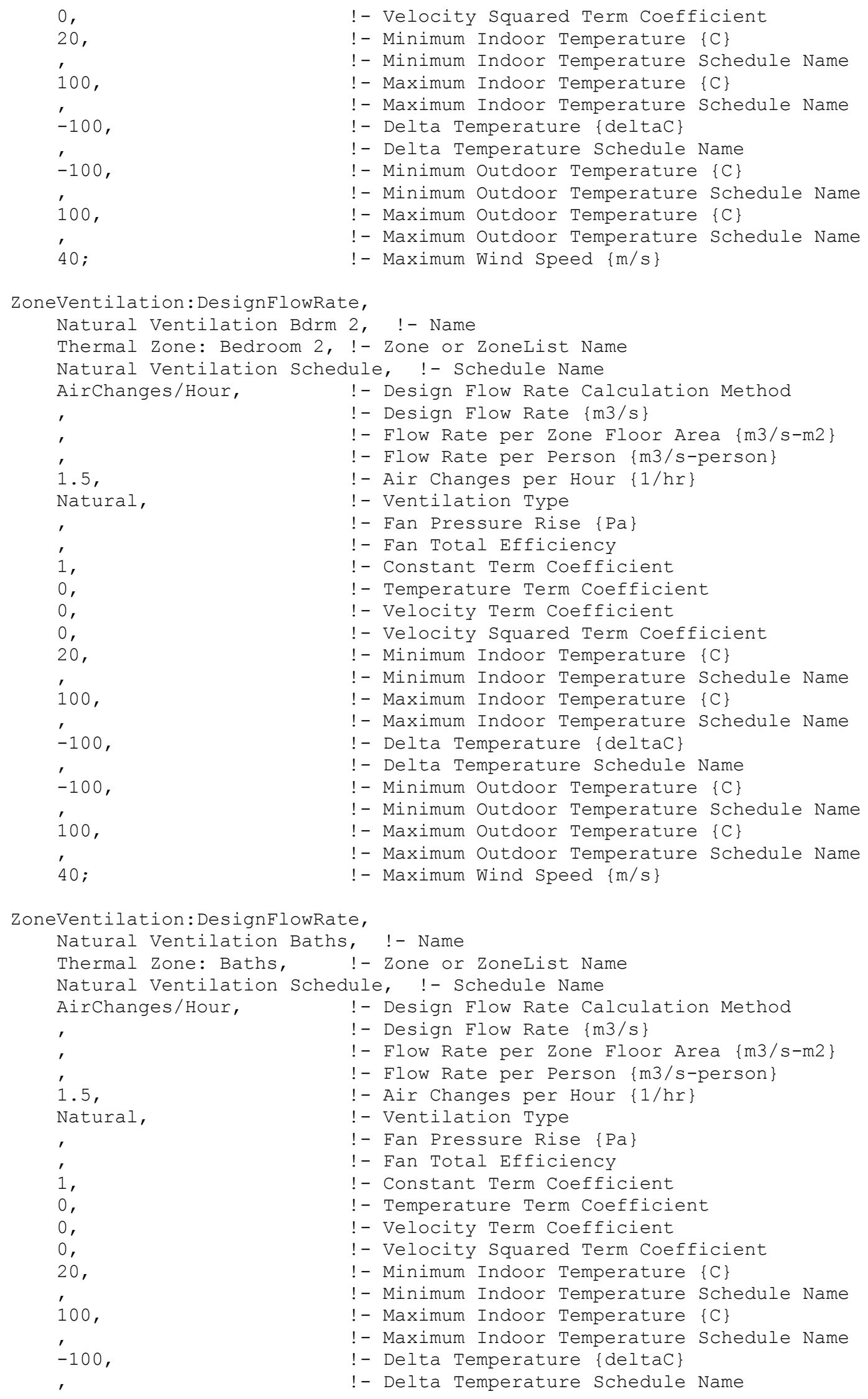




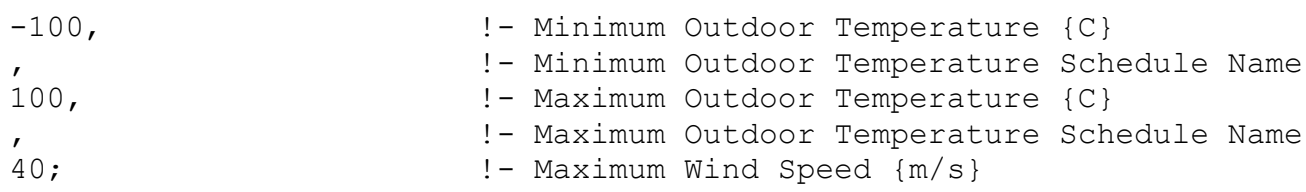

ZoneVentilation:DesignFlowRate, Natural Ventilation Bdrm 3, !- Name Thermal Zone: Bedroom 3, !- Zone or ZoneList Name Natural Ventilation Schedule, !- Schedule Name AirChanges/Hour, !- Design Flow Rate Calculation Method , !- Design Flow Rate $\{\mathrm{m} 3 / \mathrm{s}\}$

ZoneVentilation: DesignFlowRate, Natural Ventilation Bdrm 4, !- Name Thermal Zone: Bedroom 4, !- Zone or ZoneList Name Natural Ventilation Schedule, !- Schedule Name

\begin{tabular}{|c|c|}
\hline AirChanges/Hour, & $\begin{array}{l}\text { !- Design Flow Rate Calculation Method } \\
\text { !- Design Flow Rate }\{\mathrm{m} 3 / \mathrm{s}\}\end{array}$ \\
\hline , & !- Flow Rate per Zone Floor Area $\{\mathrm{m} 3 / \mathrm{s}-\mathrm{m} 2\}$ \\
\hline & !- Flow Rate per Person \{m3/s-person $\}$ \\
\hline 1.5, & !- Air Changes per Hour $\{1 / \mathrm{hr}\}$ \\
\hline Natural, & !- Ventilation Type \\
\hline , & !- Fan Pressure Rise $\{\mathrm{Pa}\}$ \\
\hline ， & !- Fan Total Efficiency \\
\hline 1 , & !- Constant Term Coefficient \\
\hline 0 , & !- Temperature Term Coefficient \\
\hline 0 , & !- Velocity Term Coefficient \\
\hline 0 , & !- Velocity Squared Term Coefficient \\
\hline 20， & !- Minimum Indoor Temperature $\{\mathrm{C}\}$ \\
\hline & !- Minimum Indoor Temperature Schedule Name \\
\hline 100, & !- Maximum Indoor Temperature $\{\mathrm{C}\}$ \\
\hline & !- Maximum Indoor Temperature Schedule Name \\
\hline-100 & !- Delta Temperature $\{$ deltaC $\}$ \\
\hline & !- Delta Temperature Schedule Name \\
\hline-100 & !- Minimum Outdoor Temperature $\{\mathrm{C}\}$ \\
\hline & !- Minimum Outdoor Temperature Schedule Name \\
\hline 100 & !- Maximum Outdoor Temperature $\{\mathrm{C}\}$ \\
\hline & !- Maximum Outdoor Temperature Schedule Name \\
\hline & !- Maximum Wind Speed $\{\mathrm{m} / \mathrm{s}\}$ \\
\hline
\end{tabular}

ZoneVentilation: DesignFlowRate, 
Natural Ventilation Third Bath, !- Name

Thermal Zone: Third Bath,!- Zone or ZoneList Name

Natural Ventilation Schedule, !- Schedule Name

AirChanges/Hour, !- Design Flow Rate Calculation Method

,

,

1.5 ,

Natural,

!- Design Flow Rate $\{\mathrm{m} 3 / \mathrm{s}\}$

!- Flow Rate per Zone Floor Area \{m3/s-m2\}

!- Flow Rate per Person \{m3/s-person $\}$

!- Ventilation Type

'

0

0,

0 ,

20 ,

100

,

$-100$

-100 ,

100

'

- Air Changes per Hour $\{1 / \mathrm{hr}\}$

!- Fan Pressure Rise $\{\mathrm{Pa}\}$

! - Fan Total Efficiency

!- Constant Term Coefficient

!- Temperature Term Coefficient

!- Velocity Term Coefficient

!- Velocity Squared Term Coefficient

!- Minimum Indoor Temperature $\{\mathrm{C}\}$

!- Minimum Indoor Temperature Schedule Name

!- Maximum Indoor Temperature $\{\mathrm{C}\}$

!- Maximum Indoor Temperature Schedule Name

!- Delta Temperature \{deltaC\}

!- Delta Temperature Schedule Name

!- Minimum Outdoor Temperature $\{\mathrm{C}\}$

!- Minimum Outdoor Temperature Schedule Name

!- Maximum Outdoor Temperature $\{\mathrm{C}\}$

!- Maximum Outdoor Temperature Schedule Name

40

!- Maximum Wind Speed $\{\mathrm{m} / \mathrm{s}\}$

!- $==========$ ALL OBJECTS IN CLASS : ZONEMIXING $===========$

ZoneMixing,

Third Bath to Bdrm 3, !- Name

Thermal Zone: Bedroom 3, !- Zone Name

$\mathrm{ON}$,

Flow/Zone,

! - Schedule Name

1 ,

!- Design Flow Rate Calculation Method

!- Design Flow Rate $\{\mathrm{m} 3 / \mathrm{s}\}$

!- Flow Rate per Zone Floor Area \{m3/s-m2

!- Flow Rate per Person \{m3/s-person $\}$

!- Air Changes per Hour $\{1 / \mathrm{hr}\}$

Thermal Zone: Third Bath, !- Source Zone Name

0 ; !- Delta Temperature \{deltaC

ZoneMixing,

Third Bath to Bdrm 4, !- Name

Thermal Zone: Bedroom 4, !- Zone Name

ON,

Flow/Zone, $\quad$ !- Design Flow Rate Calculation Method

1,

!- Design Flow Rate $\{\mathrm{m} 3 / \mathrm{s}\}$

!- Flow Rate per Zone Floor Area $\{\mathrm{m} 3 / \mathrm{s}-\mathrm{m} 2\}$

!- Flow Rate per Person $\{\mathrm{m} 3 / \mathrm{s}$-person $\}$

,

Thermal Zone: Third Bath, !- Source Zone Name

0 ;

!- Delta Temperature $\{$ deltac

ZoneMixing,

Third Bath to Baths,

! - Name

Thermal Zone: Baths,

!- Zone Name

! - Schedule Name

Flow/Zone,

!- Design Flow Rate Calculation Method

1 ,

!- Design Flow Rate $\{\mathrm{m} 3 / \mathrm{s}\}$

!- Flow Rate per Zone Floor Area $\{\mathrm{m} 3 / \mathrm{s}-\mathrm{m} 2\}$

!- Flow Rate per Person \{m3/s-person $\}$

!- Air Changes per Hour $\{1 / \mathrm{hr}\}$ 
Thermal Zone: Third Bath, !- Source Zone Name

$0 ; \quad$ !- Delta Temperature \{deltaC

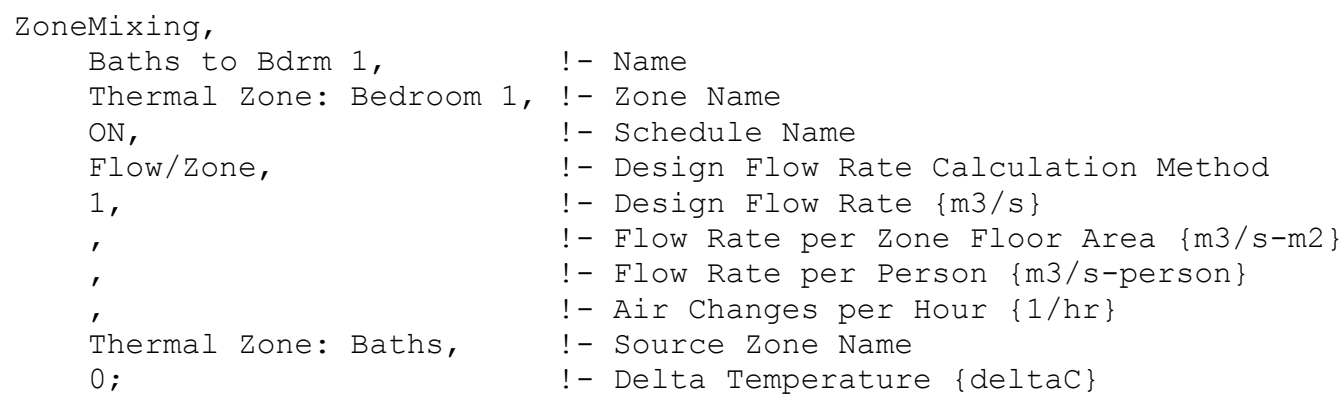




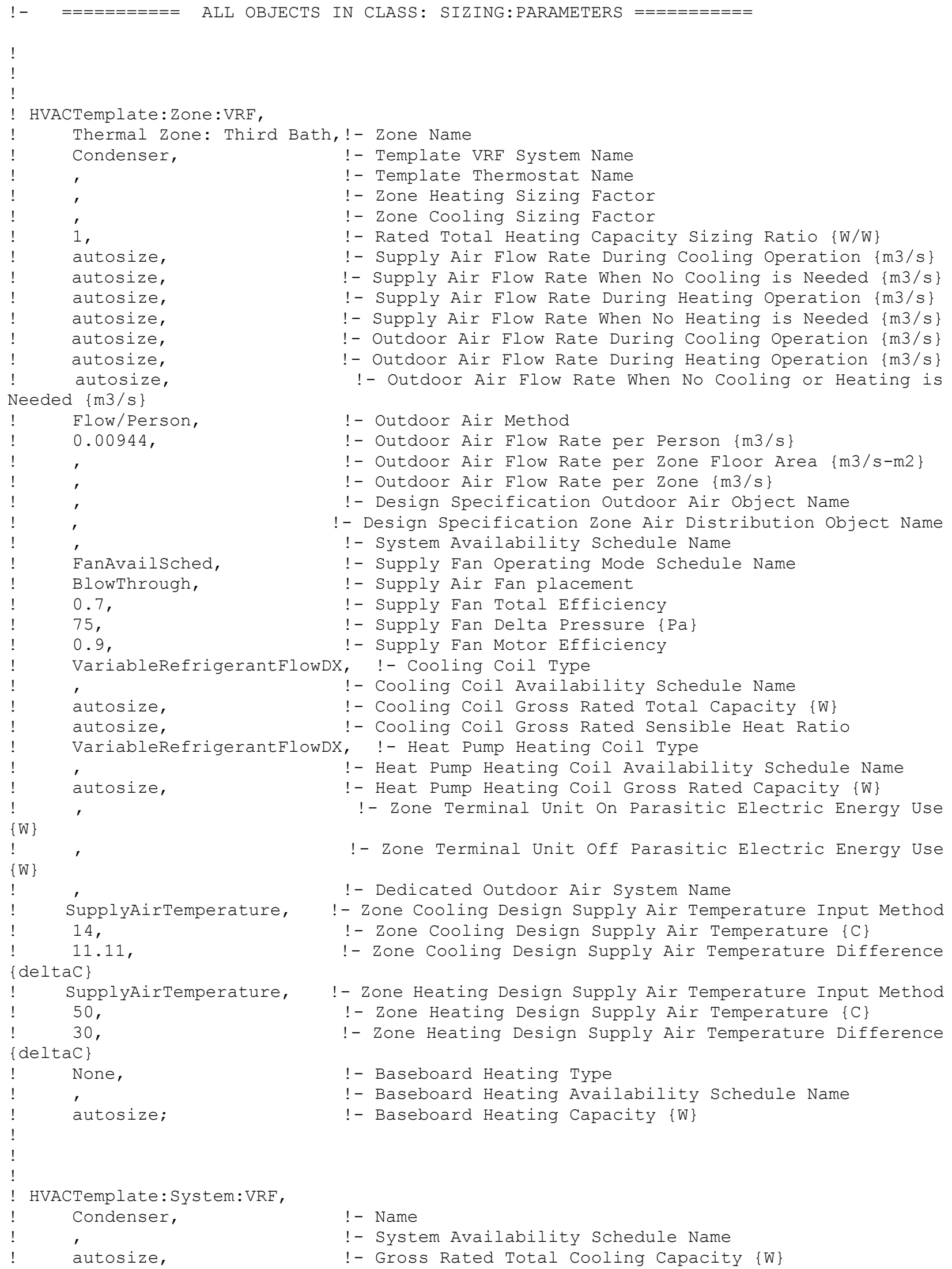




\begin{tabular}{|c|c|}
\hline$!$ & 33 \\
\hline$!$ & -6, \\
\hline$!$ & 43 \\
\hline$!$ & autosize, \\
\hline$!$ & 1, \\
\hline$!$ & 3.4, \\
\hline ! & -20 \\
\hline$!$ & 16 \\
\hline$!$ & 0.15 \\
\hline$!$ & Thermal Zone: Third E \\
\hline$!$ & MasterThermostatPrior \\
\hline$!$ & , \\
\hline$!$ & No, \\
\hline$!$ & 30 \\
\hline & I in Cooling Mode $\{\mathrm{m}\}$ \\
\hline$!$ & 10 \\
\hline$!$ & 30 \\
\hline & $r$ in Heating Mode $\{m\}$ \\
\hline$!$ & 33 \\
\hline$!$ & 2, \\
\hline$!$ & 0.5 \\
\hline & \\
\hline$!$ & 5, \\
\hline & $r\{\mathrm{C}\}$ \\
\hline$!$ & Resistive, \\
\hline$!$ & Timed, \\
\hline$!$ & 0.058333 \\
\hline$!$ & autosize, \\
\hline$!$ & 5, \\
\hline & tion $\{C\}$ \\
\hline$!$ & Aircooled, \\
\hline$!$ & autosize, \\
\hline$!$ & 0.9, \\
\hline$!$ & autosize, \\
\hline$!$ & , \\
\hline$!$ & , \\
\hline$!$ & 2, \\
\hline$!$ & , \\
\hline$!$ & Electricity, \\
\hline$!$ & -15 \\
\hline$!$ & $45 ;$ \\
\hline & g:Parameters, \\
\hline & \\
\hline
\end{tabular}

!- Gross Rated Cooling COP $\{\mathrm{W} / \mathrm{W}\}$

!- Minimum Outdoor Temperature in Cooling Mode $\{\mathrm{C}\}$

!- Maximum Outdoor Temperature in Cooling Mode $\{\mathrm{C}\}$

!- Gross Rated Heating Capacity $\{W\}$

! - Rated Heating Capacity Sizing Ratio $\{W / W\}$

!- Gross Rated Heating COP $\{\mathrm{W} / \mathrm{W}\}$

!- Minimum Outdoor Temperature in Heating Mode $\{\mathrm{C}\}$

!- Maximum Outdoor Temperature in Heating Mode $\{\mathrm{C}\}$

!- Minimum Heat Pump Part-Load Ratio \{dimensionless\}

Thermal Zone: Third Bath, !- Zone Name for Master Thermostat Location

MasterThermostatPriority,!- Master Thermostat Priority Control Type

!- Thermostat Priority Schedule Name

!- Heat Pump Waste Heat Recovery

!- Equivalent Piping Length used for Piping Correction

!- Vertical Height used for Piping Correction Factor $\{\mathrm{m}\}$

!- Equivalent Piping Length used for Piping Correction

!- Crankcase Heater Power per Compressor $\{W\}$

!- Number of Compressors \{dimensionless\}

!- Ratio of Compressor Size to Total Compressor Capacity

!- Maximum Outdoor Dry-bulb Temperature for Crankcase

!- Defrost Strategy

!- Defrost Control

!- Defrost Time Period Fraction \{dimensionless\}

!- Resistive Defrost Heater Capacity $\{W\}$

!- Maximum Outdoor Dry-bulb Temperature for Defrost

! - Condenser Type

!- Water Condenser Volume Flow Rate $\{\mathrm{m} 3 / \mathrm{s}\}$

!- Evaporative Condenser Effectiveness \{dimensionless\}

!- Evaporative Condenser Air Flow Rate $\{\mathrm{m} 3 / \mathrm{s}\}$

!- Evaporative Condenser Pump Rated Power Consumption $\{W\}$

! - Basin Heater Capacity $\{W / K\}$

!- Basin Heater Setpoint Temperature $\{\mathrm{C}\}$

!- Basin Heater Operating Schedule Name

! - Fuel Type

!- Minimum Outdoor Temperature in Heat Recovery Mode $\{\mathrm{C}\}$

!- Maximum Outdoor Temperature in Heat Recovery Mode $\{\mathrm{C}\}$

!- Heating Sizing Factor

!- Cooling Sizing Factor

!- $===========$ ALL OBJECTS IN CLASS: SIZING $:$ ZONE $==========$

Sizing:Zone,

Thermal Zone: Basement, !- Zone or ZoneList Name

SupplyAirTemperature, !- Zone Cooling Design Supply Air Temperature Input Method 14,

$\{$ del'tac

!- Zone Cooling Design Supply Air Temperature \{C\}

!- Zone Cooling Design Supply Air Temperature Difference

SupplyAirTemperature, !- Zone Heating Design Supply Air Temperature Input Method 50 ,

'

!- Zone Heating Design Supply Air Temperature \{C\}

!- Zone Heating Design Supply Air Temperature Difference

$\{$ deltac

0.009 ,

$\{$ kgWater/kgDryAir\}

0.009 ,

$\{$ kgWater/kgDryAir\}

$$
\begin{aligned}
& \text { !- Zone Cooling Design Supply Air Humidity Ratio } \\
& \text { !- Zone Heating Design Supply Air Humidity Ratio }
\end{aligned}
$$

!- Design Specification Outdoor Air Object Name 

0.0,
!- Zone Heating Sizing Factor
0.0 ,
!- Zone Cooling Sizing Factor
DesignDay,
!- Cooling Design Air Flow Method
0 ,
!- Cooling Design Air Flow Rate $\{\mathrm{m} 3 / \mathrm{s}\}$
,
!- Cooling Minimum Air Flow per Zone Floor Area \{m3/s-m2\}
,
!- Cooling Minimum Air Flow $\{\mathrm{m} 3 / \mathrm{s}\}$
DesignDay,
!- Cooling Minimum Air Flow Fraction
0 ;
!- Heating Design Air Flow Method
!- Heating Design Air Flow Rate $\{\mathrm{m} 3 / \mathrm{s}\}$

Sizing:Zone, Thermal Zone: Basement S,!- Zone or ZoneList Name SupplyAirTemperature, 14,

,

!- Zone Cooling Design Supply Air Temperature Input Method !- Zone Cooling Design Supply Air Temperature \{C\}

!- Zone Cooling Design Supply Air Temperature Difference

$\{$ deltac $\}$

SupplyAirTemperature, !- Zone Heating Design Supply Air Temperature Input Method 50 ,

\{del'tac

0.009 ,

$\{$ kgWater/kgDryAir\} 0.009 ,

$\{$ kgWater/kgDryAir\}

0.0 ,

0.0 ,

DesignDay,

0 ,

- Zone Heating Design Supply Air Temperature $\{\mathrm{C}\}$

!- Zone Heating Design Supply Air Temperature Difference

!- Zone Cooling Design Supply Air Humidity Ratio

!- Zone Heating Design Supply Air Humidity Ratio

!- Design Specification Outdoor Air Object Name

!- Zone Heating Sizing Factor

!- Zone Cooling Sizing Factor

!- Cooling Design Air Flow Method

!- Cooling Design Air Flow Rate $\{\mathrm{m} 3 / \mathrm{s}\}$

!- Cooling Minimum Air Flow per Zone Floor Area $\{\mathrm{m} 3 / \mathrm{s}-\mathrm{m} 2\}$

!- Cooling Minimum Air Flow $\{\mathrm{m} 3 / \mathrm{s}\}$

!- Cooling Minimum Air Flow Fraction

!- Heating Design Air Flow Method

DesignDay,

0 ;

!- Heating Design Air Flow Rate $\{\mathrm{m} 3 / \mathrm{s}\}$

Sizing:Zone,

Thermal Zone: Bedroom 2, !- Zone or Zonelist Name

SupplyAirTemperature,

14,

!- Zone Cooling Design Supply Air Temperature Input Method

!- Zone Cooling Design Supply Air Temperature \{C\}

!- Zone Cooling Design Supply Air Temperature Difference

$\{$ deltac

SupplyAirTemperature, !- Zone Heating Design Supply Air Temperature Input Method 50 ,

$\{$ del'tac

0.009 ,

$\{$ kgWater/kgDryAir\}

0.009 ,

$\{\mathrm{kgWater/kgDryAir \}}$

0.0 ,

0.0 ,

DesignDay,

0 ,

!- Zone Heating Design Supply Air Temperature $\{\mathrm{C}\}$

!- Zone Heating Design Supply Air Temperature Difference

,

,

DesignDay,

0 ;

$$
\begin{aligned}
& \text { !- Zone Cooling Design Supply Air Humidity Ratio } \\
& \text { !- Zone Heating Design Supply Air Humidity Ratio }
\end{aligned}
$$

! - Design Specification Outdoor Air Object Name

!- Zone Heating Sizing Factor

!- Zone Cooling Sizing Factor

!- Cooling Design Air Flow Method

!- Cooling Design Air Flow Rate $\{\mathrm{m} 3 / \mathrm{s}\}$

!- Cooling Minimum Air Flow per Zone Floor Area \{m3/s-m2

!- Cooling Minimum Air Flow $\{\mathrm{m} 3 / \mathrm{s}\}$

!- Cooling Minimum Air Flow Fraction

!- Heating Design Air Flow Method

!- Heating Design Air Flow Rate $\{\mathrm{m} 3 / \mathrm{s}\}$

Sizing:Zone,

Thermal Zone: Bedroom 4, !- Zone or ZoneList Name

SupplyAirTemperature,

!- Zone Cooling Design Supply Air Temperature Input Method 


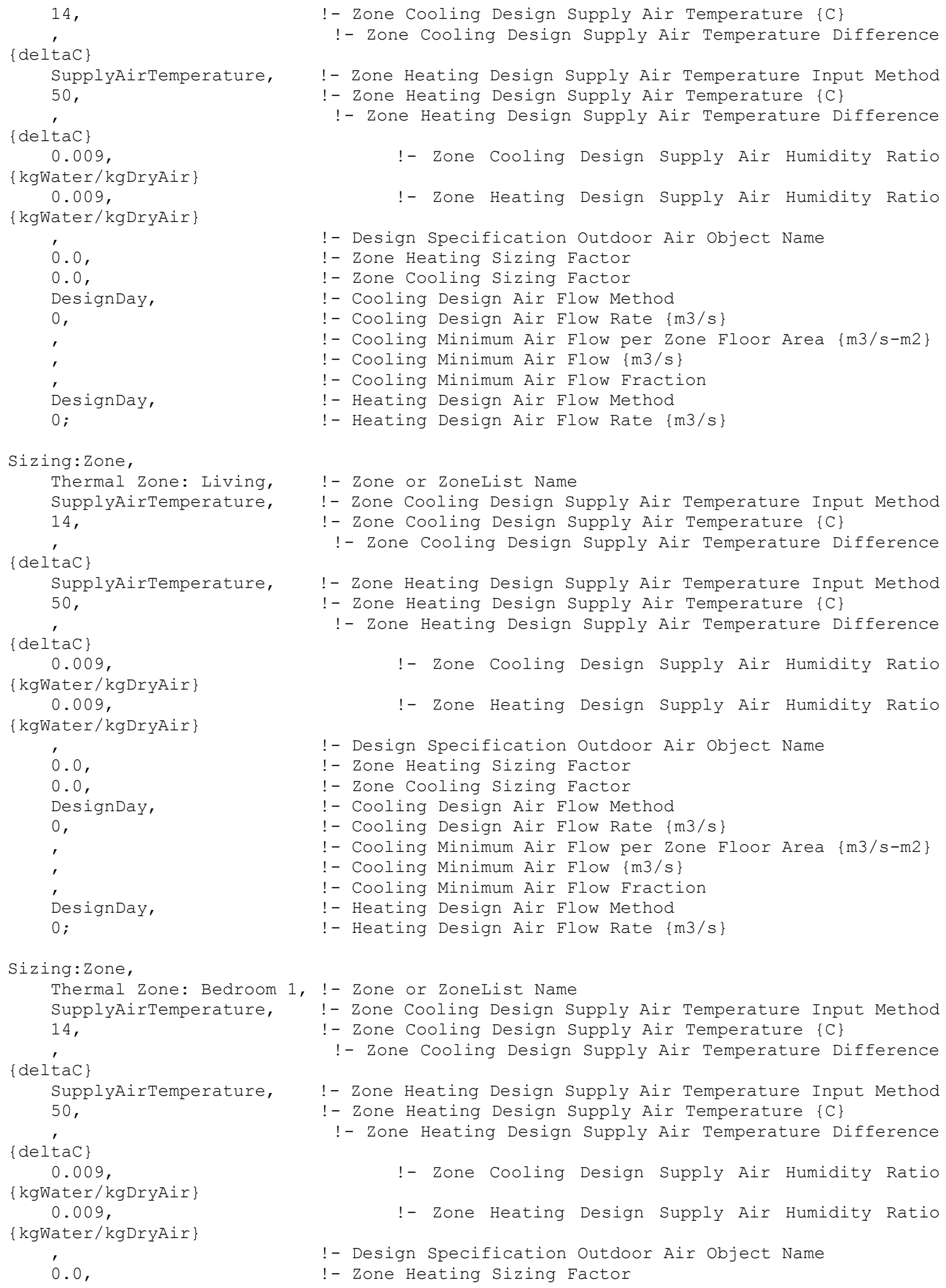




\author{
0.0 , \\ DesignDay, \\ 0 , \\ , \\ , \\ DesignDay, \\ 0 ;
}

Sizing:Zone,

Thermal Zone: Baths, SupplyAirTemperature, 14,

$\{$ del'tac

SupplyAirTemperature, 50 ,

$\{$ deltac

0.009 ,

\{kgWater/kgDryAir\}

0.009 ,

\{kgWater/kgDryAir\}

'

0.0,

0.0 ,

DesignDay,

0 ,

,

,

DesignDay,

0 ;

Sizing:Zone,

Thermal Zone: Kitchen, SupplyAirTemperature, 14,

$\{$ del'tac

SupplyAirTemperature, 50 ,

$\{$ deltac

0.009 ,

$\{$ kgWater/kgDryAir\} 0.009 ,

\{kgWater/kgDryAir\}

0.0 ,

0.0 ,

DesignDay,

0 ,

,

,

DesignDay,

0 ;
!- Zone Cooling Sizing Factor

!- Cooling Design Air Flow Method

!- Cooling Design Air Flow Rate $\{\mathrm{m} 3 / \mathrm{s}\}$

!- Cooling Minimum Air Flow per Zone Floor Area $\{\mathrm{m} 3 / \mathrm{s}-\mathrm{m} 2\}$

!- Cooling Minimum Air Flow $\{\mathrm{m} 3 / \mathrm{s}\}$

!- Cooling Minimum Air Flow Fraction

!- Heating Design Air Flow Method

!- Heating Design Air Flow Rate $\{\mathrm{m} 3 / \mathrm{s}\}$

!- Zone or ZoneList Name

!- Zone Cooling Design Supply Air Temperature Input Method

!- Zone Cooling Design Supply Air Temperature $\{C\}$

!- Zone Cooling Design Supply Air Temperature Difference

!- Zone Heating Design Supply Air Temperature Input Method !- Zone Heating Design Supply Air Temperature \{C\}

!- Zone Heating Design Supply Air Temperature Difference !- Zone Cooling Design Supply Air Humidity Ratio !- Zone Heating Design Supply Air Humidity Ratio

!- Design Specification Outdoor Air Object Name

!- Zone Heating Sizing Factor

!- Zone Cooling Sizing Factor

!- Cooling Design Air Flow Method

!- Cooling Design Air Flow Rate $\{\mathrm{m} 3 / \mathrm{s}\}$

!- Cooling Minimum Air Flow per Zone Floor Area \{m3/s-m2\}

!- Cooling Minimum Air Flow $\{\mathrm{m} 3 / \mathrm{s}\}$

!- Cooling Minimum Air Flow Fraction

!- Heating Design Air Flow Method

!- Heating Design Air Flow Rate $\{\mathrm{m} 3 / \mathrm{s}\}$

!- Zone or Zonelist Name

!- Zone Cooling Design Supply Air Temperature Input Method

!- Zone Cooling Design Supply Air Temperature \{C\}

!- Zone Cooling Design Supply Air Temperature Difference

!- Zone Heating Design Supply Air Temperature Input Method !- Zone Heating Design Supply Air Temperature $\{\mathrm{C}\}$

!- Zone Heating Design Supply Air Temperature Difference !- Zone Cooling Design Supply Air Humidity Ratio

!- Zone Heating Design Supply Air Humidity Ratio

!- Design Specification Outdoor Air Object Name

!- Zone Heating Sizing Factor

!- Zone Cooling Sizing Factor

!- Cooling Design Air Flow Method

!- Cooling Design Air Flow Rate $\{\mathrm{m} 3 / \mathrm{s}\}$

!- Cooling Minimum Air Flow per Zone Floor Area $\{\mathrm{m} 3 / \mathrm{s}-\mathrm{m} 2\}$

!- Cooling Minimum Air Flow $\{\mathrm{m} 3 / \mathrm{s}\}$

!- Cooling Minimum Air Flow Fraction

!- Heating Design Air Flow Method

!- Heating Design Air Flow Rate $\{\mathrm{m} 3 / \mathrm{s}\}$

Sizing:Zone, Thermal Zone: Bedroom 3, !- Zone or ZoneList Name SupplyAirTemperature, 14,

!- Zone Cooling Design Supply Air Temperature Input Method !- Zone Cooling Design Supply Air Temperature \{C\} 


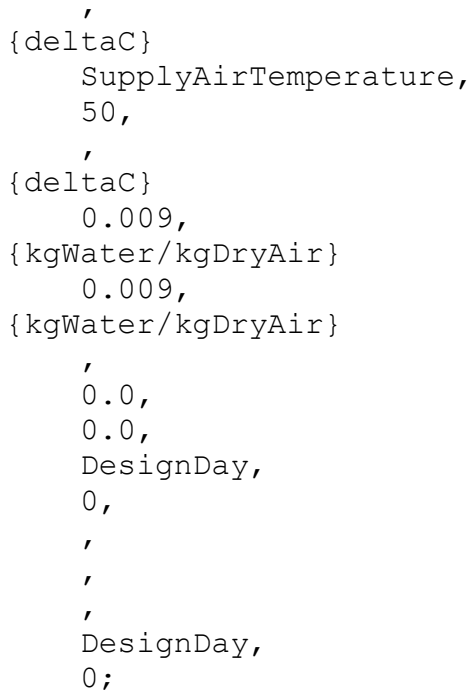




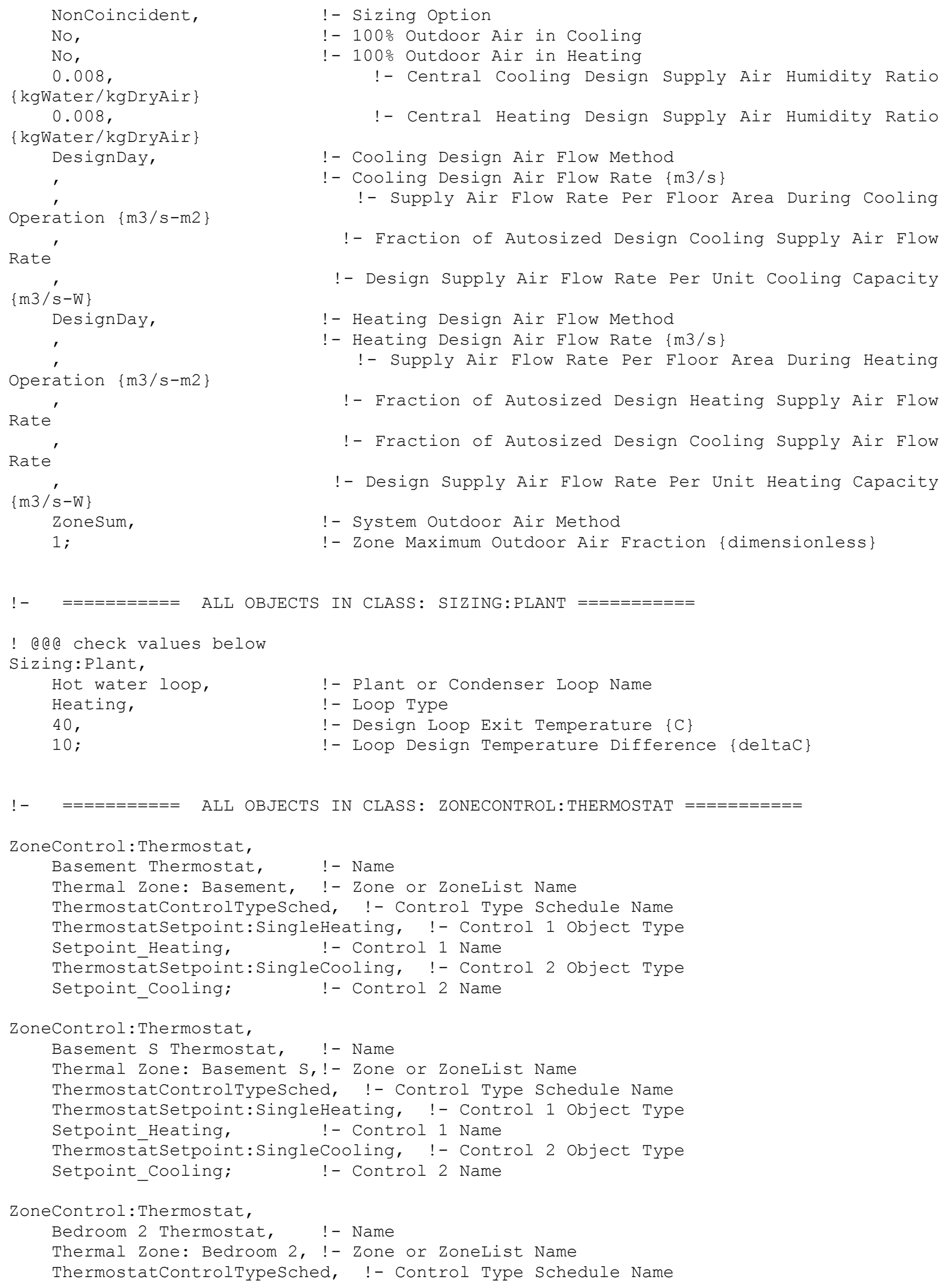


ThermostatSetpoint:SingleHeating, !- Control 1 Object Type Setpoint_Heating, !-Control 1 Name

ThermostatSetpoint:SingleCooling, !- Control 2 Object Type Setpoint_Cooling; !- Control 2 Name

ZoneControl: Thermostat,

Bedroom 4 Thermostat, !- Name

Thermal Zone: Bedroom 4, !- Zone or ZoneList Name

ThermostatControlTypeSched, !- Control Type Schedule Name

ThermostatSetpoint:SingleHeating, !- Control 1 Object Type

Setpoint_Heating, !-Control 1 Name

ThermostātSetpoint:Singlecooling, !- Control 2 object Type

Setpoint_Cooling; !- Control 2 Name

ZoneControl: Thermostat,

Third Bath Thermostat, !- Name

Thermal Zone: Third Bath,!- Zone or ZoneList Name

ThermostatControltypeSched, !- Control Type Schedule Name ThermostatSetpoint:SingleHeating, !- Control 1 object Type Setpoint Heating, !- Control 1 Name

ThermostatSetpoint:SingleCooling, !- Control 2 Object Type Setpoint_Cooling; !- Control 2 Name

Zonecontrol: Thermostat,

LivingThermostat, ! - Name

Thermal Zone: Living, !- Zone or ZoneList Name

ThermostatControlTypeSched, !- Control Type Schedule Name ThermostatSetpoint:SingleHeating, !-Control 1 object Type Setpoint Heating, !- Control 1 Name

ThermostatSetpoint:Singlecooling, !- Control 2 object Type Setpoint_Cooling; !- Control 2 Name

ZoneControl: Thermostat,

Bedroom 1Thermostat, !- Name

Thermal Zone: Bedroom 1, !- Zone or ZoneList Name

ThermostatControlTypeSched, !- Control Type Schedule Name ThermostatSetpoint:SingleHeating, !- Control 1 object Type Setpoint_Heating, !- Control 1 Name ThermostātSetpoint:SingleCooling, !- Control 2 object Type Setpoint_Cooling; !- Control 2 Name

ZoneControl: Thermostat,

Baths Thermostat, !- Name

Thermal Zone: Baths, !- Zone or ZoneList Name

ThermostatControlTypeSched, !- Control Type Schedule Name ThermostatSetpoint:SingleHeating, !- Control 1 object Type Setpoint Heating, !-Control 1 Name

ThermostātSetpoint:SingleCooling, !- Control 2 object Type Setpoint_Cooling; !- Control 2 Name

ZoneControl: Thermostat,

Kitchenthermostat, ! - Name

Thermal Zone: Kitchen, !- Zone or ZoneList Name

ThermostatControlTypeSched, !- Control Type Schedule Name ThermostatSetpoint:SingleHeating, !-Control 1 object Type Setpoint Heating, !- Control 1 Name

Thermostatsetpoint:SingleCooling, !- Control 2 Object Type Setpoint_Cooling; !-Control 2 Name

ZoneControl: Thermostat, Bedroom 3 Thermostat, !- Name Thermal Zone: Bedroom 3, !- Zone or ZoneList Name ThermostatControlTypeSched, !- Control Type Schedule Name 


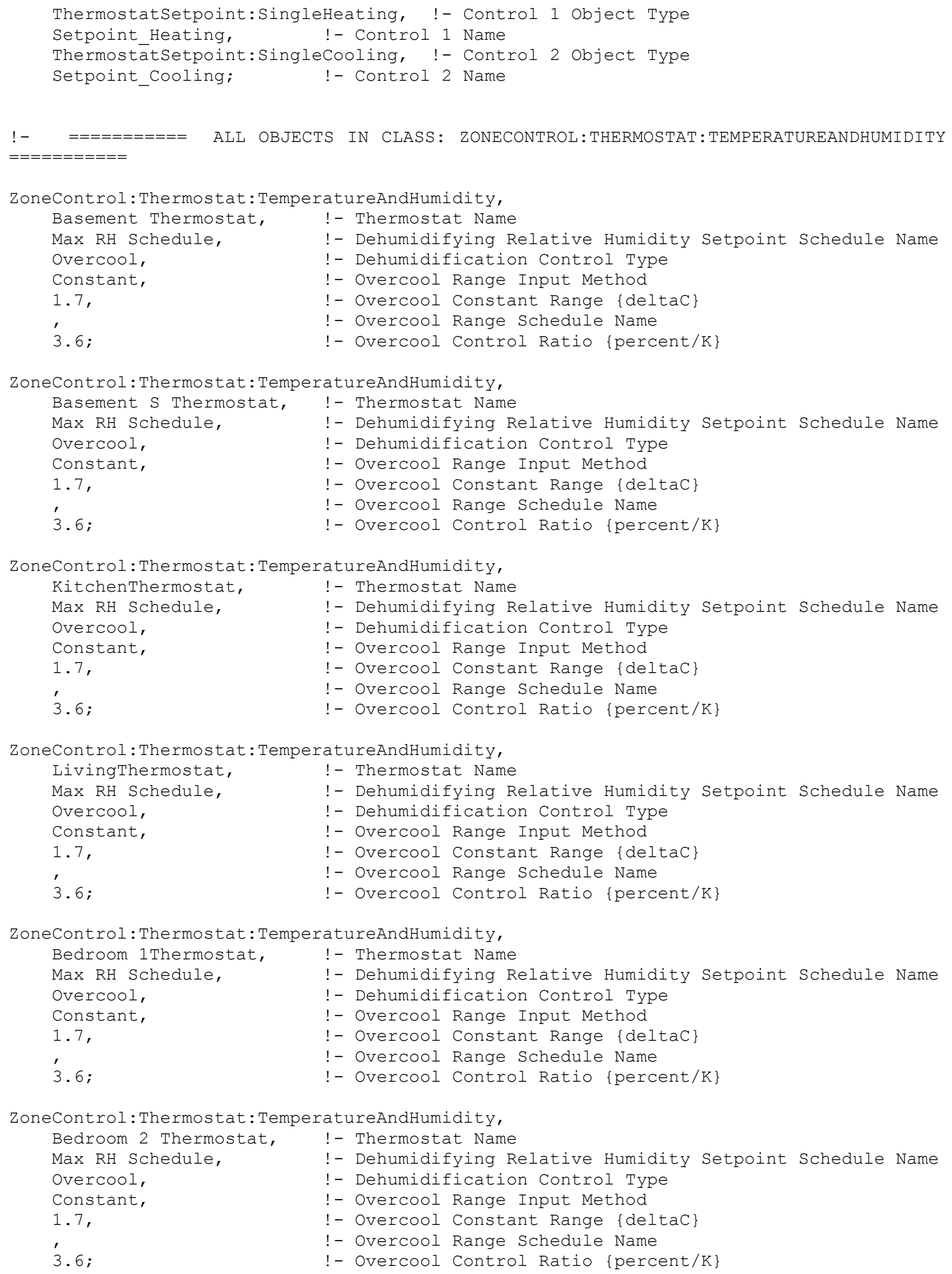




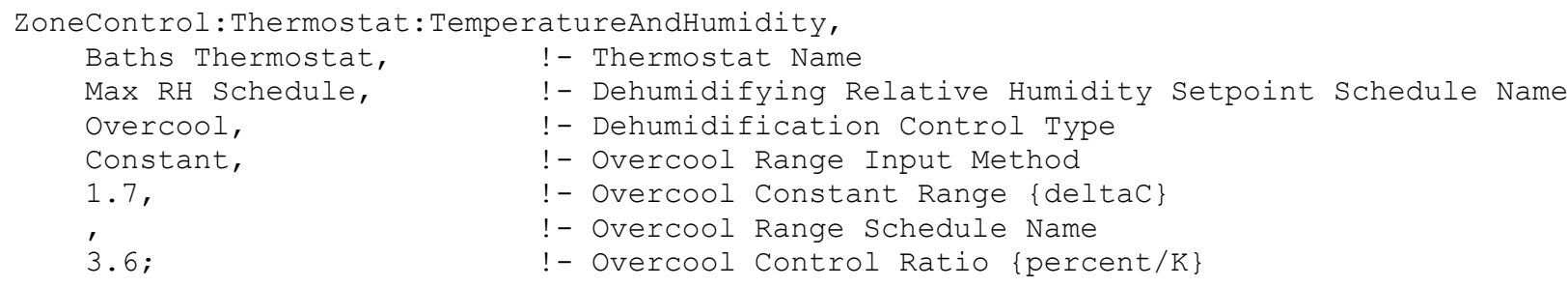




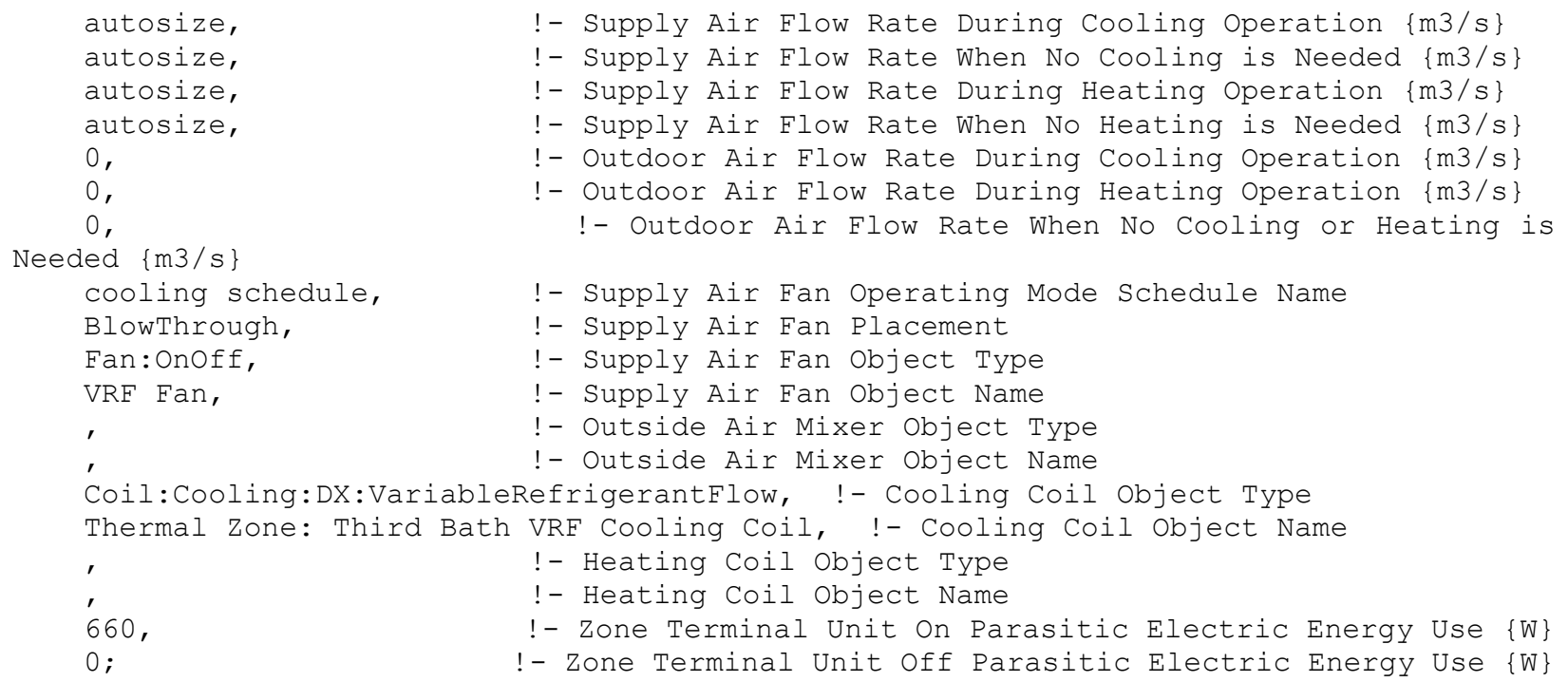

!- $\quad=========$ ALL OBJECTS IN CLASS : ZONEHVAC $:$ LOWTEMPERATURERADIANT:VARIABLEFLOW

$=+=+==+===$

ZoneHVAC: LowTemperatureRadiant:VariableFlow, Basement Radiant Floor, !- Name Mechanical Ventilation Schedule, !- Availability Schedule Name Thermal Zone: Basement, !- Zone Name Bsmt Floor, 0.012 , !- Surface Name or Radiant Surface Group Name autosize, MeanAirTemperature,

!- Hydronic Tubing Inside Diameter $\{\mathrm{m}\}$

!- Hydronic Tubing Length $\{\mathrm{m}\}$

! - Temperature Control Type HeatingDesignCapacity, Autosize,

!- Heating Design Capacity Method

!- Heating Design Capacity $\{W\}$

!- Heating Design Capacity Per Floor Area $\{\mathrm{W} / \mathrm{m} 2\}$

!- Fraction of Autosized Heating Design Capacity

autosize, !- Maximum Hot Water Flow $\{\mathrm{m} 3 / \mathrm{s}\}$

Basement Radiant Water Inlet Node, !- Heating Water Inlet Node Name Basement Radiant Water Outlet Node, !- Heating Water Outlet Node Name 2 , Heating Setpoint, ! - Heating Control Throttling Range \{deltaC CoolingDesignCapacity, !- Heating Control Temperature Schedule Name !- Cooling Design Capacity Method

!- Cooling Design Capacity $\{W\}$

!- Cooling Design Capacity Per Floor Area $\{\mathrm{W} / \mathrm{m} 2\}$

!- Fraction of Autosized Cooling Design Capacity

!- Maximum Cold Water Flow $\{\mathrm{m} 3 / \mathrm{s}\}$

! - Cooling Water Inlet Node Name

!- Cooling Water Outlet Node Name

!- Cooling Control Throttling Range \{deltaC

!- Cooling Control Temperature Schedule Name

!- Condensation Control Type

!- Condensation Control Dewpoint offset $\{\mathrm{C}\}$

!- Number of Circuits

!- Circuit Length $\{\mathrm{m}\}$

ZoneHVAC: LowTemperatureRadiant:VariableFlow, Basement S Radiant Floor, !- Name Mechanical Ventilation Schedule, !- Availability Schedule Name Thermal Zone: Basement S,!- Zone Name Bsmt Floor $\mathrm{S}$, 0.012 , autosize,

! - Surface Name or Radiant Surface Group Name

!- Hydronic Tubing Inside Diameter $\{\mathrm{m}\}$

!- Hydronic Tubing Length $\{\mathrm{m}\}$ 


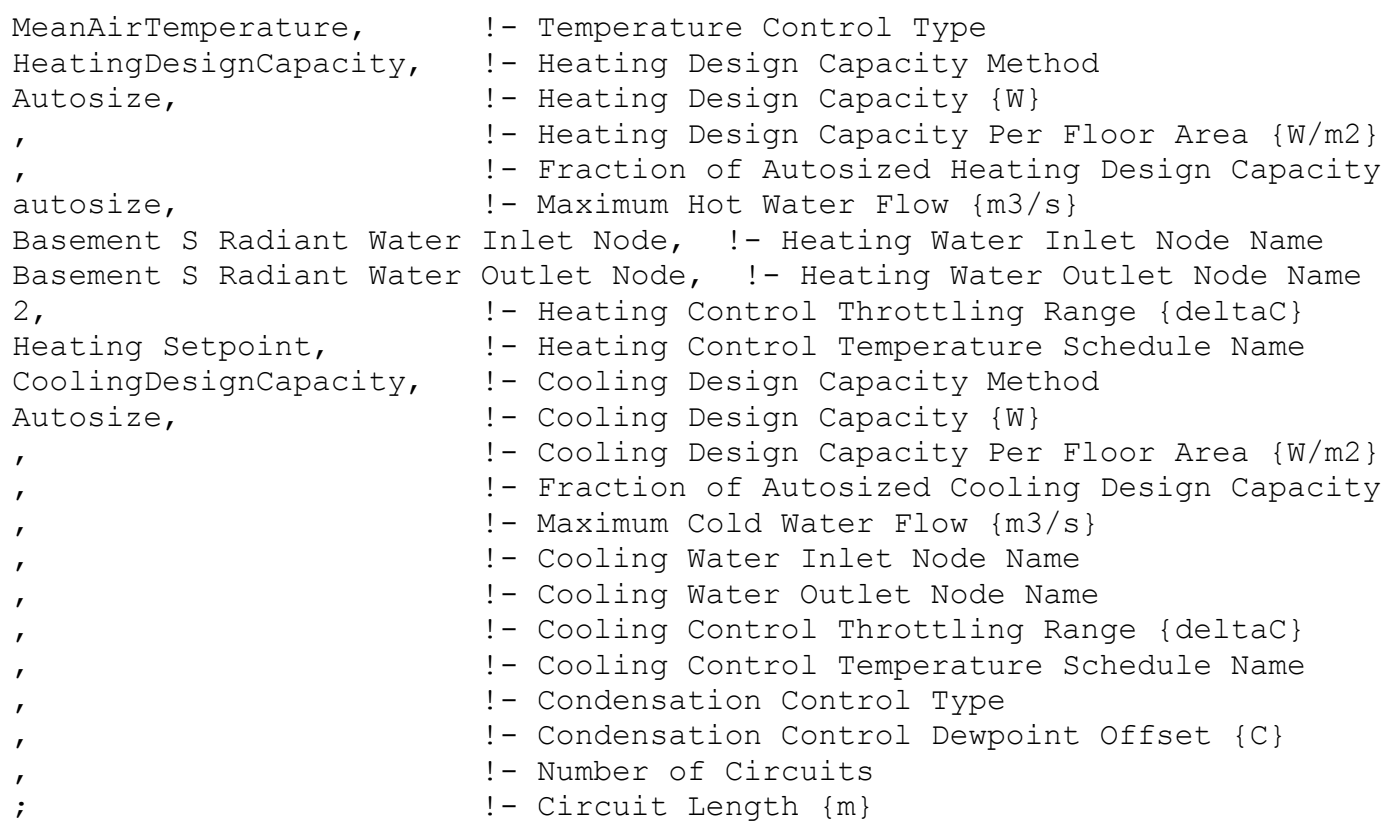

ZoneHVAC: LowTemperatureRadiant:VariableFlow, Living Radiant Floor, !- Name

ZoneHVAC: LowTemperatureRadiant:VariableFlow, Kitchen Radiant Floor, !- Name Mechanical Ventilation Schedule, !- Availability Schedule Name Thermal Zone: Kitchen, !- Zone Name 


\begin{tabular}{|c|c|}
\hline HeatingDesignCapacity, & !- Heating Design Capacity Method \\
\hline Autosize, & !- Heating Design Capacity $\{\mathrm{W}\}$ \\
\hline ' & !- Heating Design Capacity Per Floor Area $\{\mathrm{W} / \mathrm{m} 2\}$ \\
\hline & !- Fraction of Autosized Heating Design Capacity \\
\hline autosize, & !- Maximum Hot Water Flow $\{\mathrm{m} 3 / \mathrm{s}\}$ \\
\hline Kitchen Radiant Water & Inlet Node, !- Heating Water Inlet Node Name \\
\hline $\begin{array}{l}\text { Kitchen Radiant water } \\
2 \text {, }\end{array}$ & $\begin{array}{c}\text { Outlet Node, !- Heating Water Outlet Node Name } \\
\text { !- Heating Control Throttling Range }\{\text { deltaC }\end{array}$ \\
\hline Heating Setpoint, & !- Heating Control Temperature Schedule Name \\
\hline CoolingDesignCapacity, & !- Cooling Design Capacity Method \\
\hline Autosize, & !- Cooling Design Capacity $\{W\}$ \\
\hline & !- Cooling Design Capacity Per Floor Area $\{\mathrm{W} / \mathrm{m} 2\}$ \\
\hline & !- Fraction of Autosized Cooling Design Capacity \\
\hline & !- Maximum Cold Water Flow $\{\mathrm{m} 3 / \mathrm{s}\}$ \\
\hline ' & !- Cooling Water Inlet Node Name \\
\hline ' & !- Cooling Water Outlet Node Name \\
\hline r & !- Cooling Control Throttling Range $\{$ deltaC $\}$ \\
\hline & !- Cooling Control Temperature Schedule Name \\
\hline ， & !- Condensation Control Type \\
\hline . & !- Condensation Control Dewpoint Offset $\{C\}$ \\
\hline & !- Number of Circuits \\
\hline & it Length $\{\mathrm{m}\}$ \\
\hline
\end{tabular}

ZoneHVAC: LowTemperatureRadiant:VariableFlow,

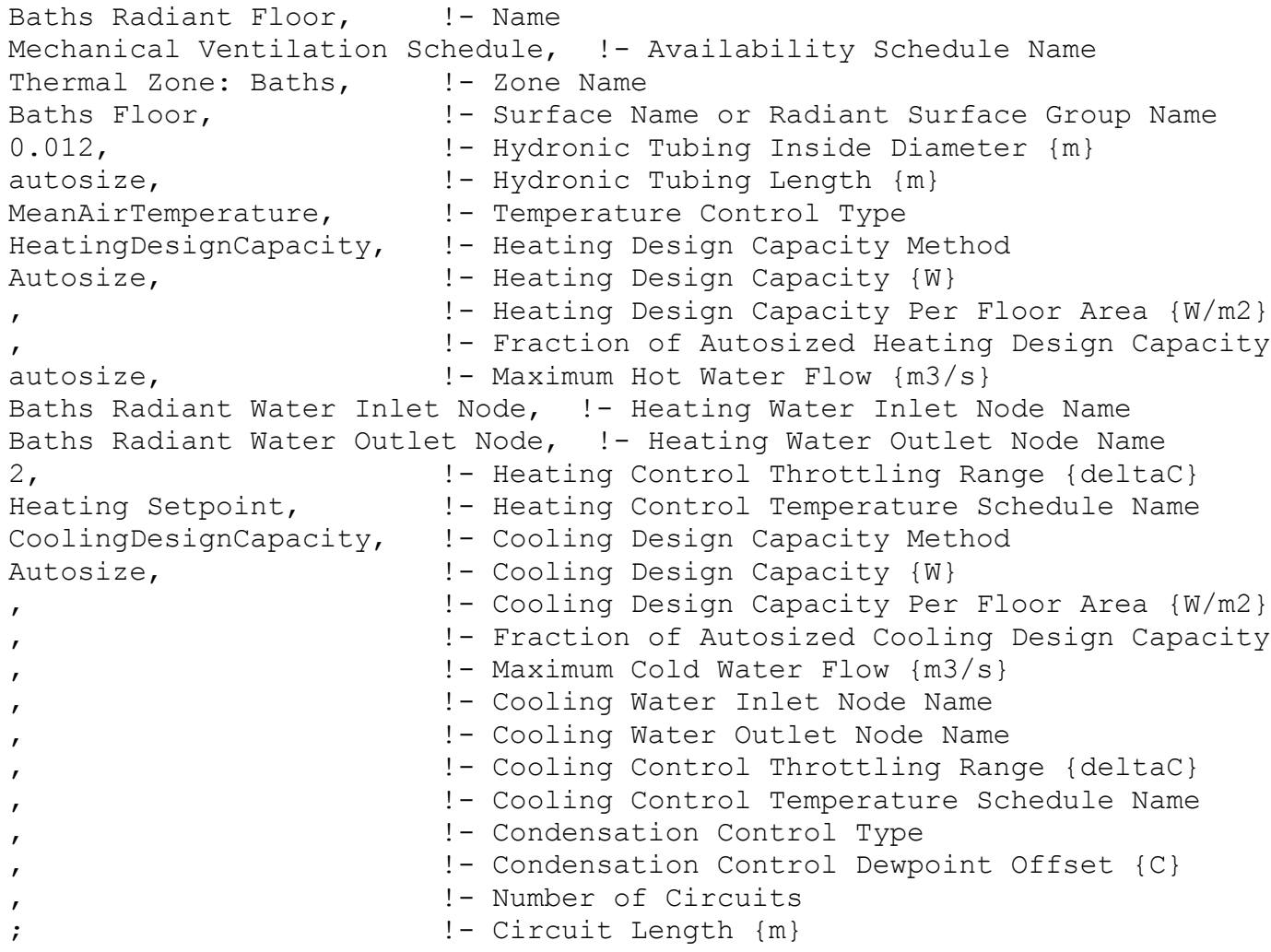

ZoneHVAC: LowTemperatureRadiant:VariableFlow,

Third Bath Radiant Floor, !- Name

Mechanical Ventilation Schedule, !- Availability Schedule Name

Thermal Zone: Third Bath,!- Zone Name

Third Bath Floor, !- Surface Name or Radiant Surface Group Name

0.012, !- Hydronic Tubing Inside Diameter $\{\mathrm{m}\}$

autosize,

MeanAirTemperature,

!- Hydronic Tubing Length $\{\mathrm{m}\}$

HeatingDesignCapacity, !- Heating Design Capacity Method 


\begin{tabular}{|c|c|}
\hline Autosize, & !- Heating Design Capacity $\{W\}$ \\
\hline , & !- Heating Design Capacity Per Floor Area $\{\mathrm{W} / \mathrm{m} 2\}$ \\
\hline & !- Fraction of Autosized Heating Design Capacity \\
\hline autosize, & !- Maximum Hot Water Flow $\{\mathrm{m} 3 / \mathrm{s}\}$ \\
\hline Third Bath Radiant Water & Inlet Node, !- Heating Water Inlet Node Name \\
\hline Third Bath Radiant Water & $\begin{array}{l}\text { Outlet Node, !- Heating Water Outlet Node Name } \\
\text { !- Heating Control Throttling Range }\{\text { deltaC }\end{array}$ \\
\hline Heating Setpoint, & !- Heating Control Temperature Schedule Name \\
\hline CoolingDesignCapacity, & !- Cooling Design Capacity Method \\
\hline Autosize, & !- Cooling Design Capacity $\{W\}$ \\
\hline & !- Cooling Design Capacity Per Floor Area $\{\mathrm{W} / \mathrm{m} 2\}$ \\
\hline & !- Fraction of Autosized Cooling Design Capacity \\
\hline & !- Maximum Cold Water Flow $\{\mathrm{m} 3 / \mathrm{s}\}$ \\
\hline & !- Cooling Water Inlet Node Name \\
\hline & !- Cooling Water Outlet Node Name \\
\hline & !- Cooling Control Throttling Range $\{$ deltaC $\}$ \\
\hline & !- Cooling Control Temperature Schedule Name \\
\hline & !- Condensation Control Type \\
\hline & !- Condensation Control Dewpoint Offset $\{C\}$ \\
\hline & !- Number of Circuits \\
\hline & !- Circuit Length $\{\mathrm{m}\}$ \\
\hline
\end{tabular}

ZoneHVAC: LowTemperatureRadiant:VariableFlow, Bedroom 1 Radiant Floor, !- Name Mechanical Ventilation Schedule, !- Availability Schedule Name Thermal Zone: Bedroom 1, !- Zone Name Bedroom 1 Floor, !- Surface Name or Radiant Surface Group Name 0.012 , autosize, MeanAirTemperature, !- Hydronic Tubing Inside Diameter $\{\mathrm{m}\}$ MeanAirtemperature, !- Hydronic Tubing Length $\{\mathrm{m}\}$

!- Temperature Control Type Autosize,

!- Heating Design Capacity Method

!- Heating Design Capacity $\{W\}$

!- Heating Design Capacity Per Floor Area $\{\mathrm{W} / \mathrm{m} 2\}$

,

!- Fraction of Autosized Heating Design Capacity

autosize,

!- Maximum Hot Water Flow $\{\mathrm{m} 3 / \mathrm{s}\}$

Bedroom 1 Radiant Water Inlet Node, !- Heating Water Inlet Node Name Bedroom 1 Radiant Water Outlet Node, !- Heating Water Outlet Node Name 2, Heating Setpoint, !- Heating Control Throttling Range \{deltaC CoolingDesignCapacity, !- Heating Control Temperature Schedule Name Autosize,

!- Cooling Design Capacity Method

!- Cooling Design Capacity $\{W\}$

!- Cooling Design Capacity Per Floor Area $\{\mathrm{W} / \mathrm{m} 2\}$

!- Fraction of Autosized Cooling Design Capacity

!- Maximum Cold Water Flow $\{\mathrm{m} 3 / \mathrm{s}\}$

!- Cooling Water Inlet Node Name

!- Cooling Water Outlet Node Name

!- Cooling Control Throttling Range \{deltaC\}

!- Cooling Control Temperature Schedule Name

!- Condensation Control Type

!- Condensation Control Dewpoint offset $\{\mathrm{C}\}$

!- Number of Circuits

!- Circuit Length $\{\mathrm{m}\}$

ZoneHVAC: LowTemperatureRadiant:VariableFlow, Bedroom 2 Radiant Floor, !- Name Mechanical Ventilation Schedule, !- Availability Schedule Name Thermal Zone: Bedroom 2, !- Zone Name Bedroom 2 Floor, 0.012 , autosize, MeanAirTemperature, HeatingDesignCapacity, Autosize,

!- Surface Name or Radiant Surface Group Name

!- Hydronic Tubing Inside Diameter $\{m\}$

!- Hydronic Tubing Length $\{\mathrm{m}\}$

! - Temperature Control Type

!- Heating Design Capacity Method

!- Heating Design Capacity $\{W\}$ 
autosize,

!- Heating Design Capacity Per Floor Area $\{\mathrm{W} / \mathrm{m} 2\}$

!- Fraction of Autosized Heating Design Capacity

! - Maximum Hot Water Flow $\{\mathrm{m} 3 / \mathrm{s}\}$

Bedroom 2 Radiant Water Inlet Node, !- Heating Water Inlet Node Name

Bedroom 2 Radiant Water Outlet Node, !- Heating Water Outlet Node Name

2,

!- Heating Control Throttling Range \{deltaC

Heating Setpoint,

!- Heating Control Temperature Schedule Name

CoolingDesignCapacity,

!- Cooling Design Capacity Method

Autosize,

!- Cooling Design Capacity $\{W\}$

!- Cooling Design Capacity Per Floor Area $\{\mathrm{W} / \mathrm{m} 2\}$

!- Fraction of Autosized Cooling Design Capacity

!- Maximum Cold Water Flow $\{\mathrm{m} 3 / \mathrm{s}\}$

! - Cooling Water Inlet Node Name

! - Cooling Water Outlet Node Name

!- Cooling Control Throttling Range \{deltac\}

!- Cooling Control Temperature Schedule Name

!- Condensation Control Type

!- Condensation Control Dewpoint offset $\{\mathrm{C}\}$

! - Number of Circuits

!- Circuit Length $\{\mathrm{m}\}$

! a there are three floors for bed 3 may need to add more

ZoneHVAC: LowTemperatureRadiant:VariableFlow, Bedroom 3 Radiant Floor, !- Name

Mechanical Ventilation Schedule, !- Availability Schedule Name

Thermal Zone: Bedroom 3, !- Zone Name

Bedroom 3 Floor 1, !- Surface Name or Radiant Surface Group Name

0.012 ,

!- Hydronic Tubing Inside Diameter $\{\mathrm{m}\}$

autosize,

MeanAirTemperature,

!- Hydronic Tubing Length $\{\mathrm{m}\}$

- Temperature Control Type

HeatingDesignCapacity, !- Heating Design Capacity Method

Autosize,

!- Heating Design Capacity $\{W\}$

!- Heating Design Capacity Per Floor Area $\{\mathrm{W} / \mathrm{m} 2\}$

,

!- Fraction of Autosized Heating Design Capacity

autosize,

! - Maximum Hot Water Flow $\{\mathrm{m} 3 / \mathrm{s}\}$

Bedroom 3 Radiant Water Inlet Node, !- Heating Water Inlet Node Name

Bedroom 3 Radiant Water Outlet Node, !- Heating Water Outlet Node Name

2,

Heating Setpoint,

!- Heating Control Throttling Range \{deltaC

CoolingDesignCapacity,

!- Heating Control Temperature Schedule Name

Autosize,

!- Cooling Design Capacity Method

!- Cooling Design Capacity $\{W\}$

!- Cooling Design Capacity Per Floor Area $\{\mathrm{W} / \mathrm{m} 2\}$

!- Fraction of Autosized Cooling Design Capacity

!- Maximum Cold Water Flow $\{\mathrm{m} 3 / \mathrm{s}\}$

! - Cooling Water Inlet Node Name

!- Cooling Water Outlet Node Name

!- Cooling Control Throttling Range \{deltaC

!- Cooling Control Temperature Schedule Name

!- Condensation Control Type

!- Condensation Control Dewpoint offset $\{\mathrm{C}\}$

!- Number of Circuits

!- Circuit Length $\{\mathrm{m}\}$

ZoneHVAC:LowTemperatureRadiant:VariableFlow,

Bedroom 4 Radiant Floor, !- Name

Mechanical Ventilation Schedule, !- Availability Schedule Name

Thermal Zone: Bedroom 4, !- Zone Name

Bedroom 4 Floor,

!- Surface Name or Radiant Surface Group Name

0.012 ,

autosize,

!- Hydronic Tubing Inside Diameter $\{m\}$

MeanAirTemperature,

!- Hydronic Tubing Length $\{\mathrm{m}\}$

HeatingDesignCapacity,

!- Heating Design Capacity Method

Autosize,

!- Heating Design Capacity $\{W\}$ 


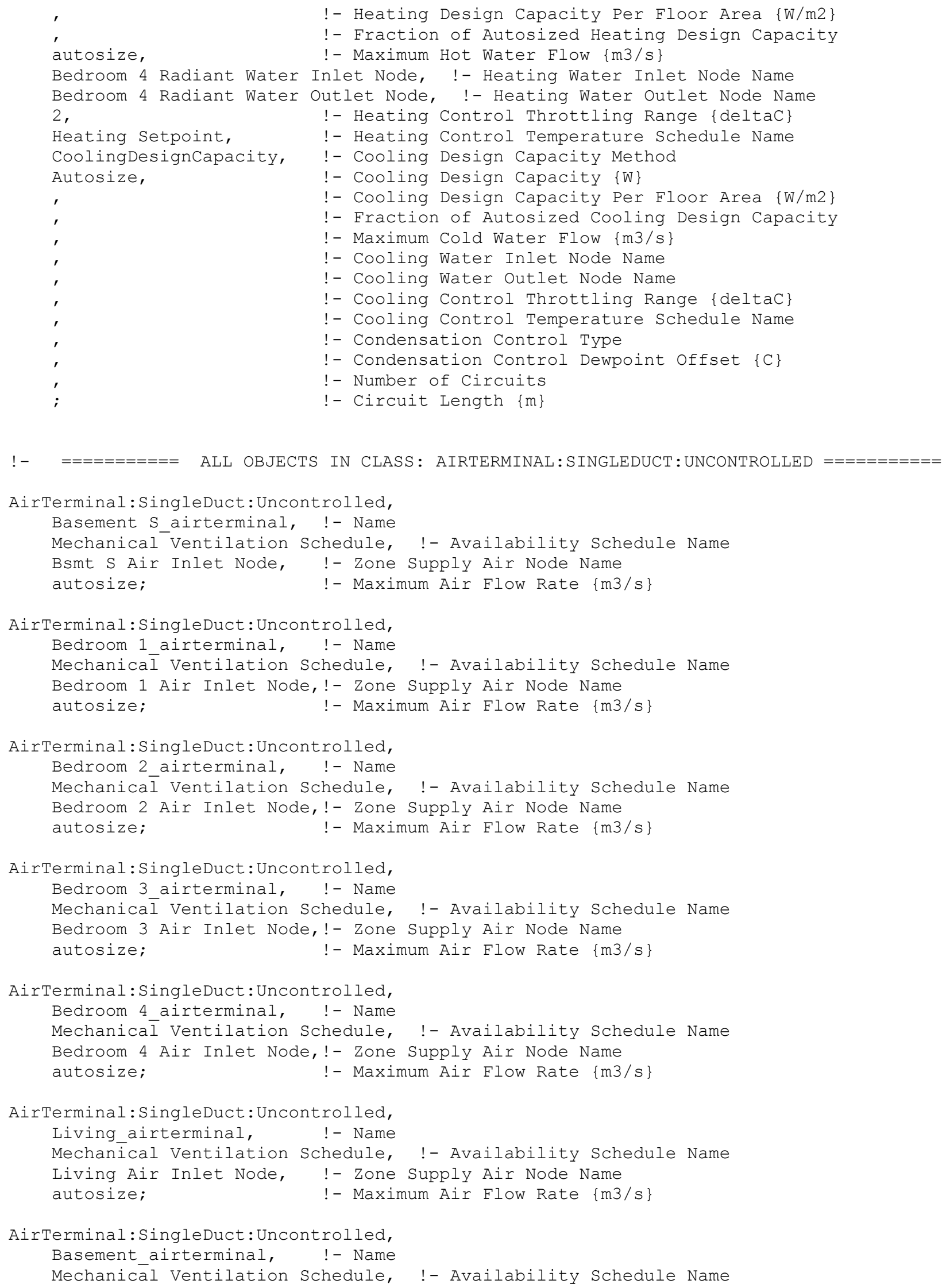


Basement Bsmt Air Inlet Node, !- Zone Supply Air Node Name

autosize; !- Maximum Air Flow Rate $\{\mathrm{m} 3 / \mathrm{s}\}$

AirTerminal: SingleDuct: Uncontrolled, Kitchen_airterminal, !- Name Mechanical Ventilation Schedule, !- Availability Schedule Name Kitchen Air Inlet Node, !- Zone Supply Air Node Name autosize; !- Maximum Air Flow Rate $\{\mathrm{m} 3 / \mathrm{s}\}$

AirTerminal:SingleDuct: Uncontrolled, Baths airterminal, !- Name Mechānical Ventilation Schedule, !- Availability Schedule Name Baths Air Inlet Node, !- Zone Supply Air Node Name autosize; !- Maximum Air Flow Rate $\{\mathrm{m} 3 / \mathrm{s}\}$

AirTerminal:SingleDuct: Uncontrolled, Third Bath airterminal, !- Name Mechanical Ventilation Schedule, !- Availability Schedule Name Third Bath Air Inlet Ventilation Node, !- Zone Supply Air Node Name autosize; !- Maximum Air Flow Rate $\{\mathrm{m} 3 / \mathrm{s}\}$

!- $==========$ ALL OBJECTS IN CLASS : ZONEHVAC $:$ EQUIPMENTLIST $=========$

! Zone HVAC Equipment

ZoneHVAC: EquipmentList, Basement HVAC Equipment, !- Name

ZoneHVAC:LowTemperatureRadiant:VariableFlow, !- Zone Equipment 1 Object Type Basement Radiant Floor, !- Zone Equipment 1 Name

2, !- Zone Equipment 1 Cooling Sequence

2, !- Zone Equipment 1 Heating or No-Load Sequence

AirTerminal:SingleDuct:Uncontrolled, !- Zone Equipment 2 object Type

Basement airterminal, !- Zone Equipment 2 Name

1, - !- Zone Equipment 2 Cooling Sequence

1; !- Zone Equipment 2 Heating or No-Load Sequence

ZoneHVAC:EquipmentList, Basement S HVAC Equipment, !- Name

ZoneHVAC:LowTemperatureRadiant:VariableFlow, !- Zone Equipment 1 Object Type Basement S Radiant Floor,!- Zone Equipment 1 Name

2, !- Zone Equipment 1 Cooling Sequence

2, !- Zone Equipment 1 Heating or No-Load Sequence

AirTerminal:SingleDuct:Uncontrolled, !- Zone Equipment 2 object Type

Basement S airterminal, !- Zone Equipment 2 Name

1, ! - Zone Equipment 2 Cooling Sequence

1; !- Zone Equipment 2 Heating or No-Load Sequence

ZoneHVAC: EquipmentList,

Living HVAC Equipment, !- Name

ZoneHVAC:LowTemperatureRadiant:VariableFlow, !- Zone Equipment 1 Object Type

Living Radiant Floor, !- Zone Equipment 1 Name

2, !- Zone Equipment 1 Cooling Sequence

2, !- Zone Equipment 1 Heating or No-Load Sequence

AirTerminal:SingleDuct:Uncontrolled, !- Zone Equipment 2 object Type

Living_airterminal, !- Zone Equipment 2 Name

1 ,

1; !- Zone Equipment 2 Heating or No-Load Sequence

ZoneHVAC: EquipmentList,

Kitchen HVAC Equipment, !- Name

ZoneHVAC:LowTemperatureRadiant:VariableFlow, !- Zone Equipment 1 Object Type

Kitchen Radiant Floor, !- Zone Equipment 1 Name

2, !- Zone Equipment 1 Cooling Sequence 
2, !- Zone Equipment 1 Heating or No-Load Sequence

AirTerminal:SingleDuct:Uncontrolled, !- Zone Equipment 2 object Type

Kitchen_airterminal, !- Zone Equipment 2 Name

1, !- Zone Equipment 2 Cooling Sequence

1; !- Zone Equipment 2 Heating or No-Load Sequence

ZoneHVAC: EquipmentList, Baths HVAC Equipment, !- Name

ZoneHVAC:LowTemperatureRadiant:VariableFlow, !- Zone Equipment 1 Object Type

Baths Radiant Floor, !- Zone Equipment 1 Name

2, !- Zone Equipment 1 Cooling Sequence

2, !- Zone Equipment 1 Heating or No-Load Sequence

AirTerminal:SingleDuct:Uncontrolled, !- Zone Equipment 2 object Type

Baths_airterminal, !- Zone Equipment 2 Name

1, - !- Zone Equipment 2 Cooling Sequence

1; !- Zone Equipment 2 Heating or No-Load Sequence

ZoneHVAC:EquipmentList,

Bedroom 1 HVAC Equipment, !- Name

ZoneHVAC:LowTemperatureRadiant:VariableFlow, !- Zone Equipment 1 Object Type

Bedroom 1 Radiant Floor, !- Zone Equipment 1 Name

2, !- Zone Equipment 1 Cooling Sequence

2, !- Zone Equipment 1 Heating or No-Load Sequence

AirTerminal:SingleDuct:Uncontrolled, !- Zone Equipment 2 object Type

Bedroom 1_airterminal, !-Zone Equipment 2 Name

1, - !- Zone Equipment 2 Cooling Sequence

1; !- Zone Equipment 2 Heating or No-Load Sequence

ZoneHVAC:EquipmentList,

Bedroom 2 HVAC Equipment, !- Name

ZoneHVAC:LowTemperatureRadiant:VariableFlow, !- Zone Equipment 1 object Type

Bedroom 2 Radiant Floor, !- Zone Equipment 1 Name

2, !- Zone Equipment 1 Cooling Sequence

2, !- Zone Equipment 1 Heating or No-Load Sequence

AirTerminal:SingleDuct:Uncontrolled, !- Zone Equipment 2 object Type

Bedroom 2_airterminal, !- Zone Equipment 2 Name

1, - !- Zone Equipment 2 Cooling Sequence

1; !- Zone Equipment 2 Heating or No-Load Sequence

ZoneHVAC: EquipmentList,

Bedroom 3 HVAC Equipment, !- Name

ZoneHVAC:LowTemperatureRadiant:VariableFlow, !- Zone Equipment 1 object Type

Bedroom 3 Radiant Floor, !- Zone Equipment 1 Name

2, !- Zone Equipment 1 Cooling Sequence

2, !- Zone Equipment 1 Heating or No-Load Sequence

AirTerminal:SingleDuct:Uncontrolled, !- Zone Equipment 2 object Type

Bedroom 3_airterminal, !- Zone Equipment 2 Name

1, $\quad$ !- Zone Equipment 2 Cooling Sequence

1; !- Zone Equipment 2 Heating or No-Load Sequence

ZoneHVAC: EquipmentList,

Bedroom 4 HVAC Equipment, !- Name

ZoneHVAC:LowTemperatureRadiant:VariableFlow, !- Zone Equipment 1 Object Type

Bedroom 4 Radiant Floor, !- Zone Equipment 1 Name

2, !- Zone Equipment 1 Cooling Sequence

2, !- Zone Equipment 1 Heating or No-Load Sequence

AirTerminal:SingleDuct:Uncontrolled, !- Zone Equipment 2 object Type

Bedroom 4_airterminal, !- Zone Equipment 2 Name

1, - !- Zone Equipment 2 Cooling Sequence

1; !- Zone Equipment 2 Heating or No-Load Sequence

ZoneHVAC:EquipmentList,

Third Bath HVAC Equipment, !- Name 
ZoneHVAC:TerminalUnit:VariableRefrigerantFlow, !- Zone Equipment 1 Object Type Thermal Zone: Third Bath VRF Terminal Unit, !- Zone Equipment 1 Name

3, !- Zone Equipment 1 Cooling Sequence

3, !- Zone Equipment 1 Heating or No-Load Sequence

ZoneHVAC:LowTemperatureRadiant:VariableFlow, !- Zone Equipment 2 object Type

Third Bath Radiant Floor,!- Zone Equipment 2 Name

2, !- Zone Equipment 2 Cooling Sequence

2, !- Zone Equipment 2 Heating or No-Load Sequence

AirTerminal:SingleDuct:Uncontrolled, !- Zone Equipment 3 object Type

Third Bath_airterminal, !- Zone Equipment 3 Name

1 ,

!- Zone Equipment 3 Cooling Sequence

$1 ;$

!- Zone Equipment 3 Heating or No-Load Sequence

!- $==========$ ALL OBJECTS IN CLASS : ZONEHVAC $:$ EQUIPMENTCONNECTIONS $==========$

! Zone HVAC Equipment Connections

$-1$

ZoneHVAC: EquipmentConnections,

Thermal Zone: Basement, !- Zone Name

Basement HVAC Equipment, !- Zone Conditioning Equipment List Name

Basement Bsmt Air Inlet Node, !- Zone Air Inlet Node or Nodelist Name

, !- Zone Air Exhaust Node or NodeList Name

Basement Bsmt Air Node, !- Zone Air Node Name

Basement Bsmt Return Air Node; !- Zone Return Air Node Name

ZoneHVAC: EquipmentConnections,

Thermal Zone: Basement S, !- Zone Name

Basement S HVAC Equipment, !- Zone Conditioning Equipment List Name

Bsmt S Air Inlet Node, !-Zone Air Inlet Node or NodeList Name

! - Zone Air Exhaust Node or NodeList Name

Bsmt S Air Node, !- Zone Air Node Name

Bsmt S Return Air Node; !- Zone Return Air Node Name

ZoneHVAC:EquipmentConnections,

Thermal Zone: Living, !- Zone Name

Living HVAC Equipment, !- Zone Conditioning Equipment List Name

Living Air Inlet Node, !- Zone Air Inlet Node or NodeList Name

, ! - Zone Air Exhaust Node or NodeList Name

Living Air Node, !- Zone Air Node Name

Living Return Air Node; !- Zone Return Air Node Name

ZoneHVAC:EquipmentConnections,

Thermal Zone: Kitchen, !- Zone Name

Kitchen HVAC Equipment, !- Zone Conditioning Equipment List Name

Kitchen Air Inlet Node, !- Zone Air Inlet Node or NodeList Name

!- Zone Air Exhaust Node or NodeList Name

Kitchen Air Node, !- Zone Air Node Name

Kitchen Return Air Node; !- Zone Return Air Node Name

ZoneHVAC:EquipmentConnections,

Thermal Zone: Baths, !- Zone Name

Baths HVAC Equipment, !- Zone Conditioning Equipment List Name

Baths Air Inlet Node, !- Zone Air Inlet Node or Nodelist Name

!- Zone Air Exhaust Node or NodeList Name

Baths Air Node,

!- Zone Air Node Name

Baths Return Air Node; !- Zone Return Air Node Name

ZoneHVAC:EquipmentConnections,

Thermal Zone: Bedroom 1, !- Zone Name

Bedroom 1 HVAC Equipment, !- Zone Conditioning Equipment List Name

Bedroom 1 Air Inlet Node,!- Zone Air Inlet Node or NodeList Name

!- Zone Air Exhaust Node or NodeList Name 


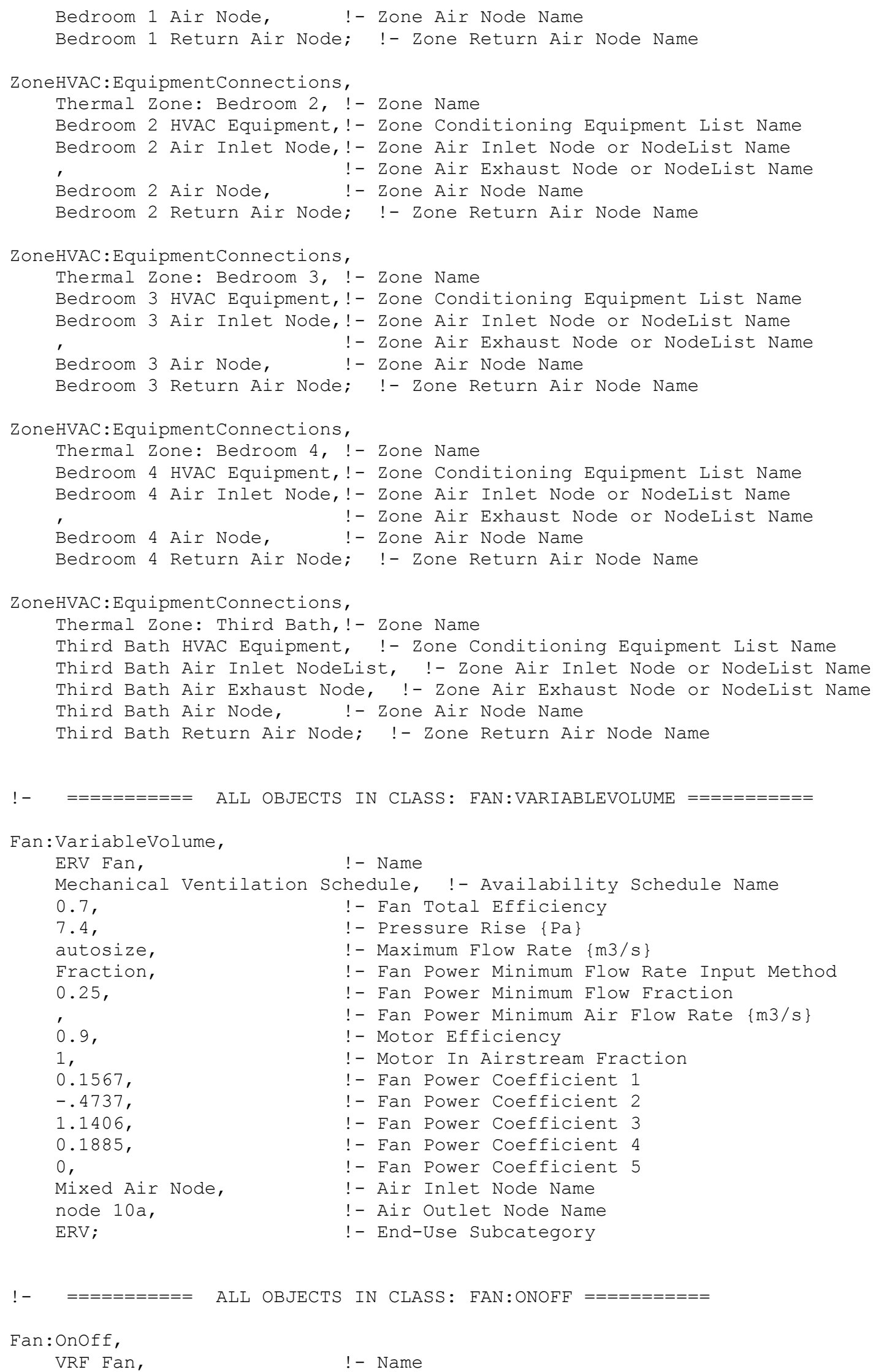


AirConditioner:VariableRefrigerantFlow,

Condenser VRF Heat Pump, !- Heat Pump Name

Cooling Schedule,

!- Availability Schedule Name

autosize,

!- Gross Rated Total Cooling Capacity $\{W\}$

5 ,

!- Gross Rated Cooling COP $\{\mathrm{W} / \mathrm{W}\}$

-20 ,

!- Minimum Outdoor Temperature in Cooling Mode $\{\mathrm{C}\}$

43 ,

!- Maximum Outdoor Temperature in Cooling Mode $\{\mathrm{C}\}$

Condenser VRFCoolCapFT, !- Cooling Capacity Ratio Modifier Function of Low Temperature Curve Name

Condenser VRFCoolCapFTBoundary, !- Cooling Capacity Ratio Boundary Curve Name

Condenser VRFCoolCapfTHi,!- Cooling Capacity Ratio Modifier Function of High Temperature Curve Name

Condenser VRFCoolEIRFT, !- Cooling Energy Input Ratio Modifier Function of Low Temperature Curve Name

Condenser VRFCoolEIRFTBoundary, !- Cooling Energy Input Ratio Boundary Curve Name Condenser VRFCoolEIRFTHi,!- Cooling Energy Input Ratio Modifier Function of High Temperature Curve Name

Condenser CoolingEIRLowPLR, !- Cooling Energy Input Ratio Modifier Function of Low Part-Load Ratio Curve Name

Condenser CoolingEIRHiPLR, !- Cooling Energy Input Ratio Modifier Function of High Part-Load Ratio Curve Name Name

Condenser CoolingCombRatio, !- Cooling Combination Ratio Correction Factor Curve

Condenser VRFCPLFFPLR,

!- Cooling Part-Load Fraction Correlation Curve Name

,

!- Gross Rated Heating Capacity $\{W\}$

!- Rated Heating Capacity Sizing Ratio $\{W / W\}$

!- Gross Rated Heating COP $\{W / W\}$

!- Minimum Outdoor Temperature in Heating Mode $\{\mathrm{C}\}$

!- Maximum Outdoor Temperature in Heating Mode $\{\mathrm{C}\}$ !- Heating Capacity Ratio Modifier Function of Low

Temperature Curve Name

!- Heating Capacity Ratio Boundary Curve Name !- Heating Capacity Ratio Modifier Function of High

Temperature Curve Name !- Heating Energy Input Ratio Modifier Function of Low

Temperature Curve Name

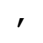

,

Temperature Curve Name

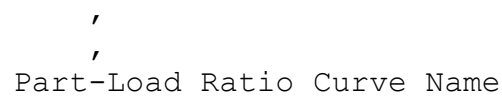

Part-Load Ratio Curve Name , Part-Load Ratio Curve Name

,

0.15 ,

Thermal Zone: Third Bath

MasterThermostatPriority,!- Master Thermostat Priority Control Type

,

CondenserTU List,

No, 30 ,

Factor in Cooling Mode $\{\mathrm{m}\}$

10 , Cooling Mode Curve Name
!- Heating Energy Input Ratio Boundary Curve Name

!- Heating Energy Input Ratio Modifier Function of High

!- Heating Performance Curve Outdoor Temperature Type

!- Heating Energy Input Ratio Modifier Function of Low

!- Heating Energy Input Ratio Modifier Function of High

!- Heating Combination Ratio Correction Factor Curve Name

! - Heating Part-Load Fraction Correlation Curve Name

!- Minimum Heat Pump Part-Load Ratio \{dimensionless\}

!- Thermostat Priority Schedule Name

!- Zone Terminal Unit List Name

! - Heat Pump Waste Heat Recovery !- Equivalent Piping Length used for Piping Correction !- Vertical Height used for Piping Correction Factor $\{\mathrm{m}\}$
Crrectionfactor, !- Piping Correction Factor for Length in 


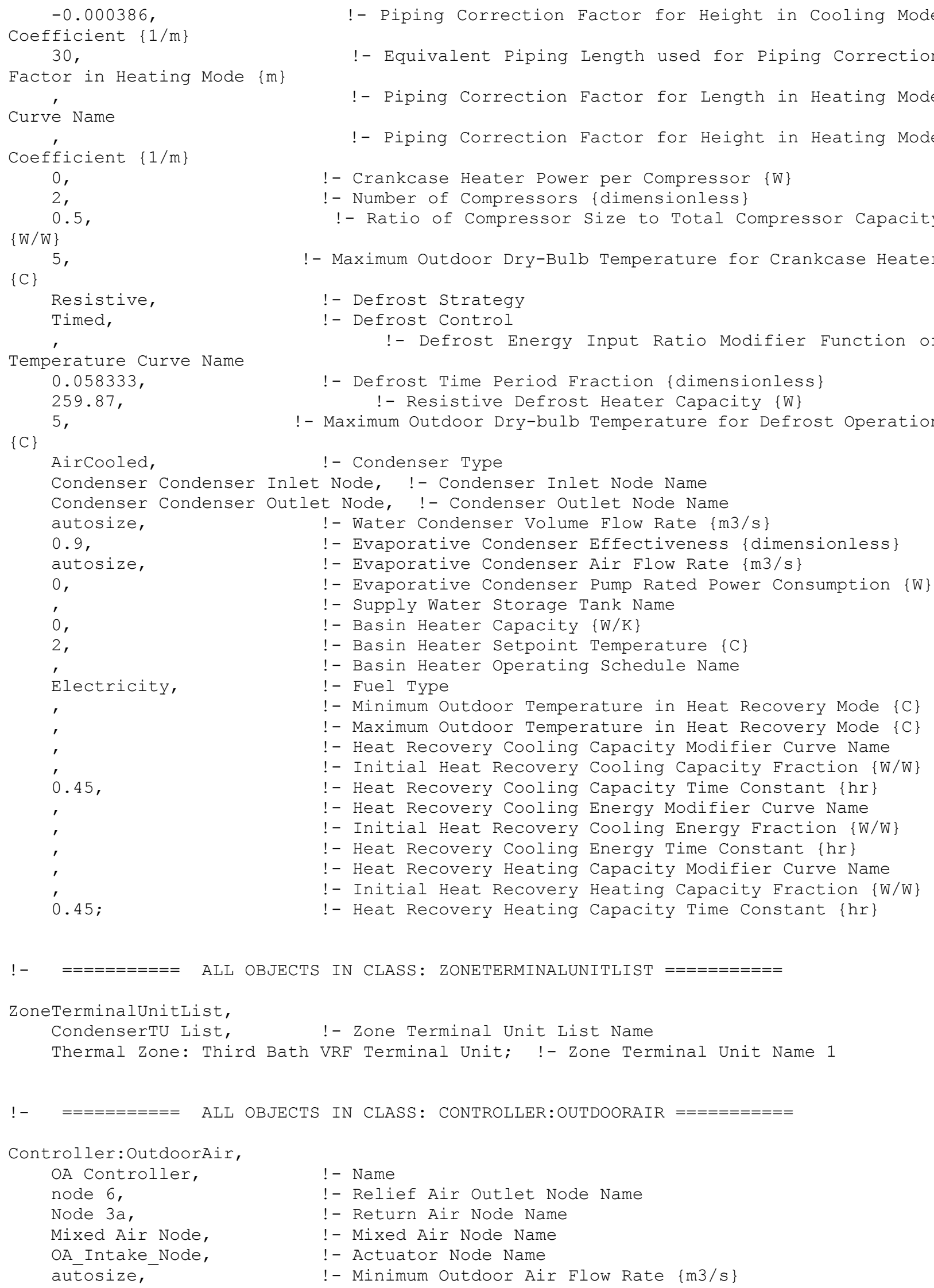




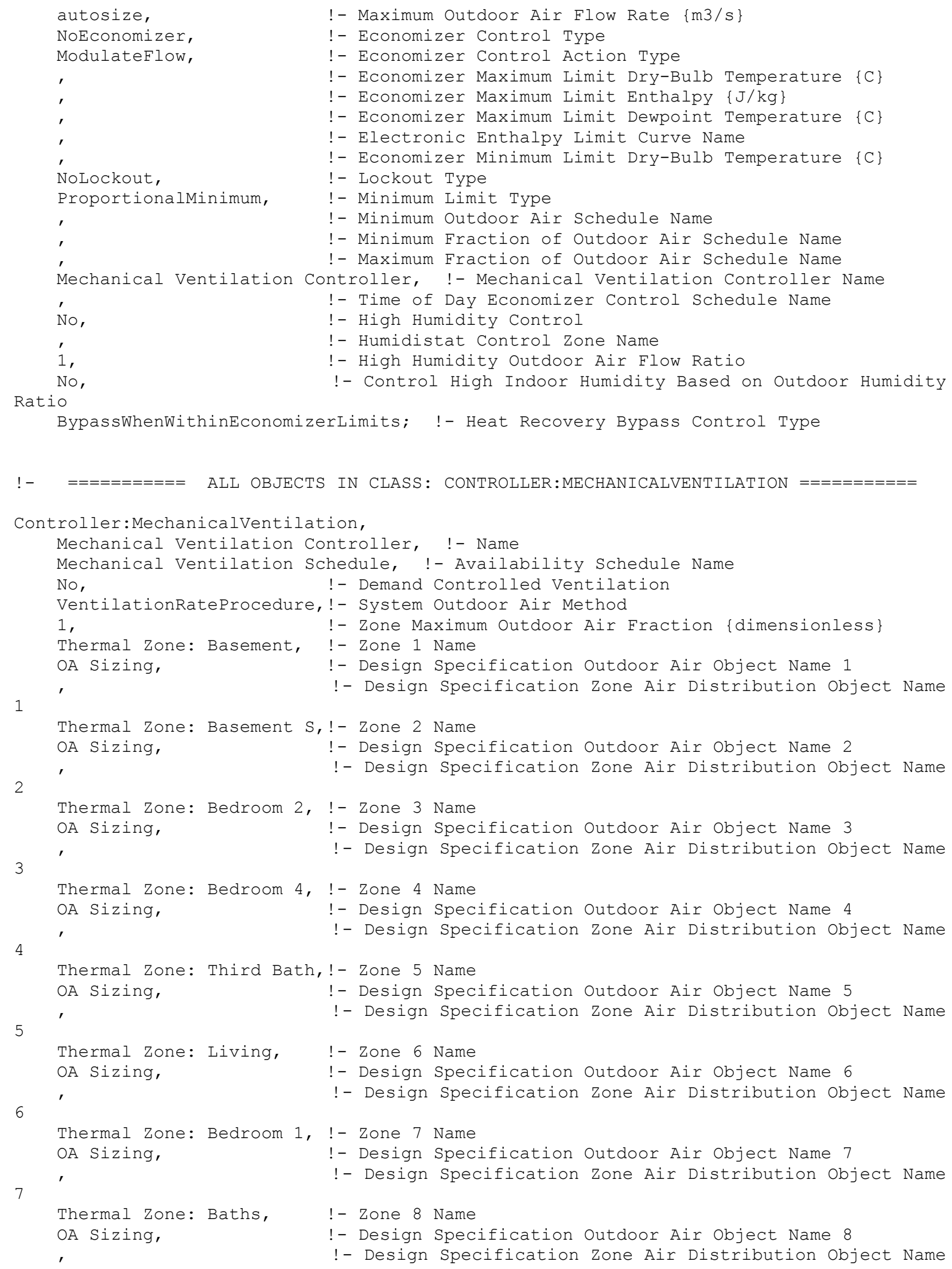




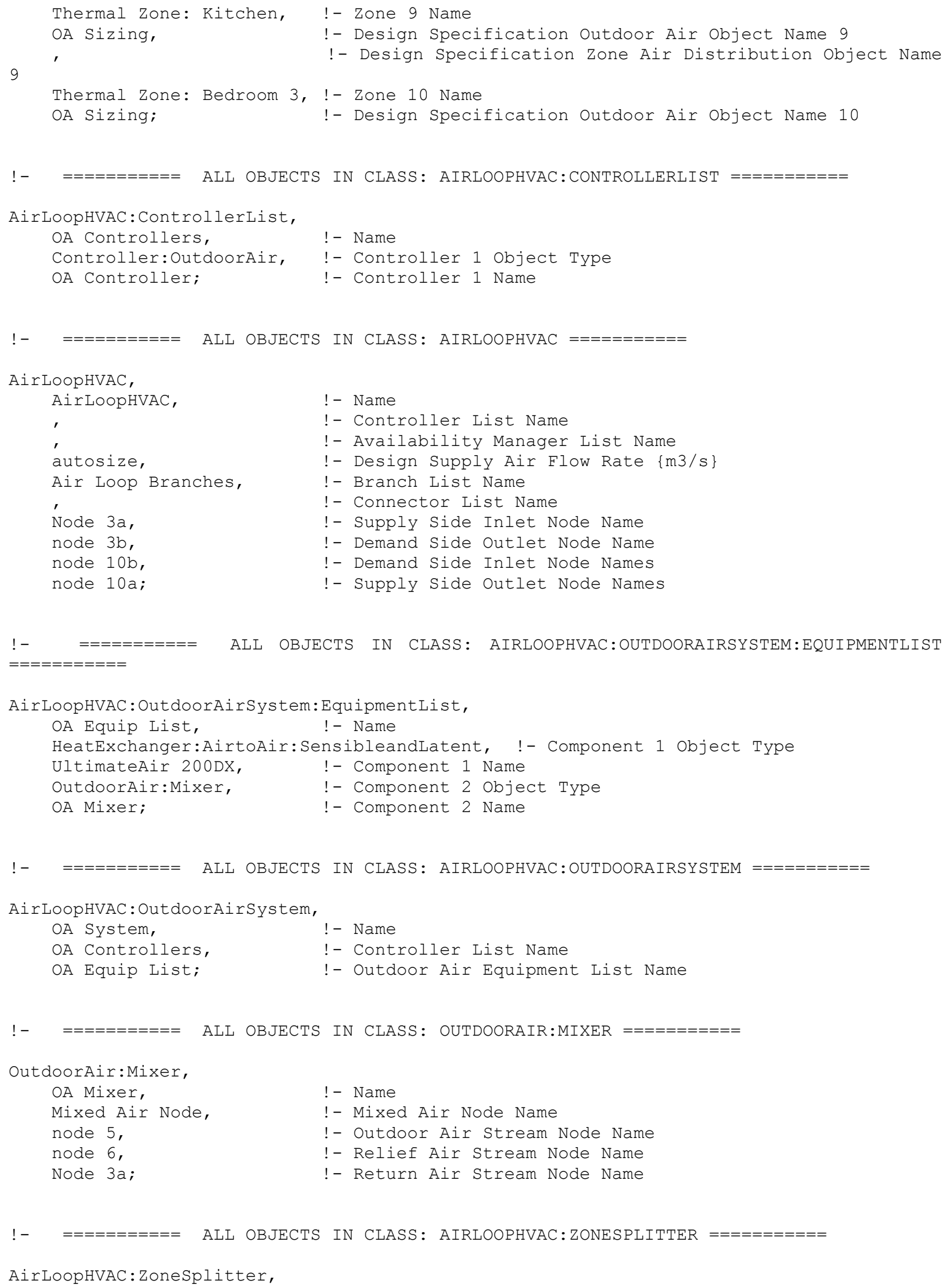




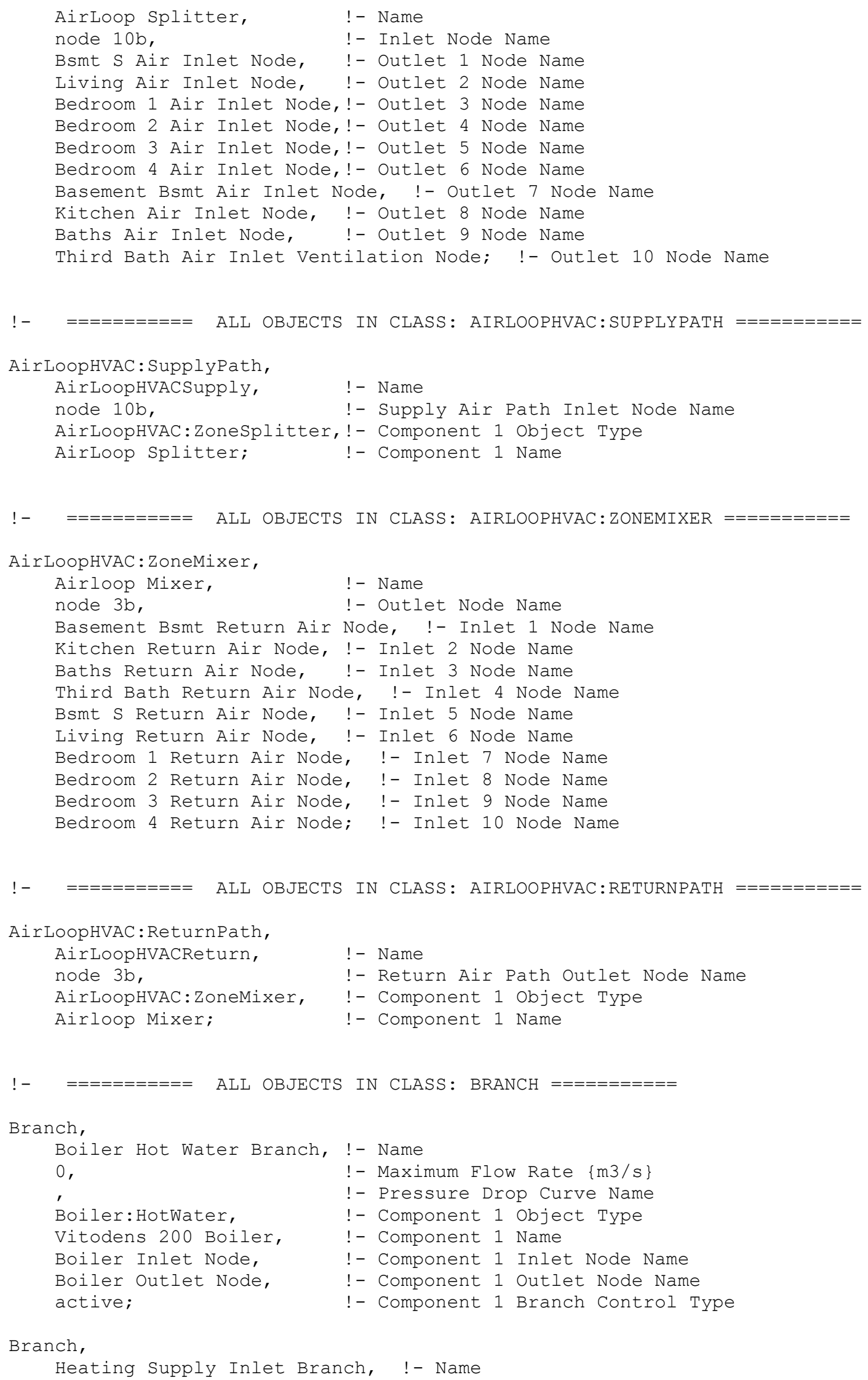



0, $\quad$ !- Maximum Flow Rate $\{\mathrm{m} 3 / \mathrm{s}\}$
,
!- Pressure Drop Curve Name
Pump:Variablespeed,
!- Component 1 Object Type
HW Circ Pump,
!- Component 1 Name
HW Supply Inlet Node,
!- Component 1 Inlet Node Name
HW Pump Outlet Node,
!- Component 1 Outlet Node Name
ACTIVE;
!- Component 1 Branch Control Type

Branch,

Heating Supply Bypass Branch, !- Name

0 , !- Maximum Flow Rate $\{\mathrm{m} 3 / \mathrm{s}\}$

, !- Pressure Drop Curve Name

Pipe:Adiabatic, !- Component 1 Object Type

Heating Supply Side Bypass, !-Component 1 Name

Heating Supply Bypass Inlet Node, !- Component 1 Inlet Node Name

Heating Supply Bypass Outlet Node, !- Component 1 Outlet Node Name

bypass; !- Component 1 Branch Control Type

Branch,

Heating Supply Outlet Branch, !- Name

0 , !- Maximum Flow Rate $\{\mathrm{m} 3 / \mathrm{s}\}$

, !- Pressure Drop Curve Name

Pipe:Adiabatic, !- Component 1 object Type

Heating Supply Outlet, !- Component 1 Name

Heating Supply Exit Pipe Inlet Node, !-Component 1 Inlet Node Name

HW Supply Outlet Node, !-Component 1 Outlet Node Name

PASSIVE; !- Component 1 Branch Control Type

Branch,

Heating Demand Inlet Branch, !- Name

$0, \quad$ !- Maximum Flow Rate $\{\mathrm{m} 3 / \mathrm{s}\}$

, !- Pressure Drop Curve Name

Pipe:Adiabatic, !- Component 1 object Type

Heating Demand Inlet Pipe, !- Component 1 Name

HW Demand Inlet Node, !- Component 1 Inlet Node Name

HW Demand Entrance Pipe Outlet Node, !-Component 1 Outlet Node Name

PASSIVE; !- Component 1 Branch Control Type

Branch,

Heating Demand Outlet Branch, !- Name

$0, \quad$ !- Maximum Flow Rate $\{\mathrm{m} 3 / \mathrm{s}\}$

, !- Pressure Drop Curve Name

Pipe:Adiabatic, !- Component 1 object Type

Heating Demand Outlet Pipe, !-Component 1 Name

HW Demand Exit Pipe Inlet Node, !-Component 1 Inlet Node Name

HW Demand Outlet Node, !-Component 1 Outlet Node Name

PASSIVE; !- Component 1 Branch Control Type

! $=====$ Demand Side Objects $==============================$

Branch,

Basement Radiant Branch, !- Name

0 ,

!- Maximum Flow Rate $\{\mathrm{m} 3 / \mathrm{s}\}$

!- Pressure Drop Curve Name

ZoneHVAC:LowTemperatureRadiant:VariableFlow, !- Component 1 object Type

Basement Radiant Floor, !- Component 1 Name

Basement Radiant Water Inlet Node, !- Component 1 Inlet Node Name

Basement Radiant Water Outlet Node, !- Component 1 Outlet Node Name

ACTIVE; !- Component 1 Branch Control Type

Branch,

Basement S Radiant Branch, !- Name

0, $\quad$ !- Maximum Flow Rate $\{\mathrm{m} 3 / \mathrm{s}\}$

, !- Pressure Drop Curve Name 
ZoneHVAC:LowTemperatureRadiant:VariableFlow, !- Component 1 Object Type Basement S Radiant Floor,!- Component 1 Name

Basement S Radiant Water Inlet Node, !- Component 1 Inlet Node Name

Basement S Radiant Water Outlet Node, !-Component 1 Outlet Node Name

ACTIVE; !- Component 1 Branch Control Type

Branch,

Living Radiant Branch, $\quad !-$ Name
0,

! ! - Pressure Drop Curve Name

ZoneHVAC:LowTemperatureRadiant:VariableFlow, !-Component 1 object Type

Living Radiant Floor, !- Component 1 Name

Living Radiant Water Inlet Node, !- Component 1 Inlet Node Name

Living Radiant Water Outlet Node, !- Component 1 Outlet Node Name

ACTIVE; !- Component 1 Branch Control Type

Branch,

Kitchen Radiant Branch, !- Name

0 , !- Maximum Flow Rate $\{\mathrm{m} 3 / \mathrm{s}\}$

!- Pressure Drop Curve Name

ZoneHVAC:LowTemperatureRadiant:VariableFlow, !-Component 1 object Type

Kitchen Radiant Floor, !- Component 1 Name

Kitchen Radiant Water Inlet Node, !- Component 1 Inlet Node Name

Kitchen Radiant Water Outlet Node, !- Component 1 Outlet Node Name

ACTIVE; !- Component 1 Branch Control Type

Branch,

Bedroom 1 Radiant Branch, !- Name

0 , !- Maximum Flow Rate $\{\mathrm{m} 3 / \mathrm{s}\}$

, !- Pressure Drop Curve Name

ZoneHVAC:LowTemperatureRadiant:VariableFlow, !- Component 1 Object Type Bedroom 1 Radiant Floor, !- Component 1 Name

Bedroom 1 Radiant Water Inlet Node, !-Component 1 Inlet Node Name

Bedroom 1 Radiant Water Outlet Node, !-Component 1 Outlet Node Name

ACTIVE; !- Component 1 Branch Control Type

Branch,

Bedroom 2 Radiant Branch, !- Name

0, $\quad$ !- Maximum Flow Rate $\{\mathrm{m} 3 / \mathrm{s}\}$

, !- Pressure Drop Curve Name

ZoneHVAC:LowTemperatureRadiant:VariableFlow, !-Component 1 Object Type

Bedroom 2 Radiant Floor, !- Component 1 Name

Bedroom 2 Radiant Water Inlet Node, !- Component 1 Inlet Node Name

Bedroom 2 Radiant Water Outlet Node, !-Component 1 Outlet Node Name

ACTIVE; !- Component 1 Branch Control Type

Branch,

Bedroom 3 Radiant Branch, !- Name

0 , !- Maximum Flow Rate $\{\mathrm{m} 3 / \mathrm{s}\}$

, !- Pressure Drop Curve Name

ZoneHVAC:LowTemperatureRadiant:VariableFlow, !- Component 1 object Type

Bedroom 3 Radiant Floor, !- Component 1 Name

Bedroom 3 Radiant Water Inlet Node, !- Component 1 Inlet Node Name

Bedroom 3 Radiant Water Outlet Node, !-Component 1 Outlet Node Name

ACTIVE; !- Component 1 Branch Control Type

Branch,

Bedroom 4 Radiant Branch, !- Name

0, $\quad$ !- Maximum Flow Rate $\{\mathrm{m} 3 / \mathrm{s}\}$

, !- Pressure Drop Curve Name

ZoneHVAC:LowTemperatureRadiant:VariableFlow, !- Component 1 object Type Bedroom 4 Radiant Floor, !-Component 1 Name

Bedroom 4 Radiant Water Inlet Node, !-Component 1 Inlet Node Name 
Bedroom 4 Radiant Water Outlet Node, !-Component 1 Outlet Node Name

ACTIVE; !- Component 1 Branch Control Type

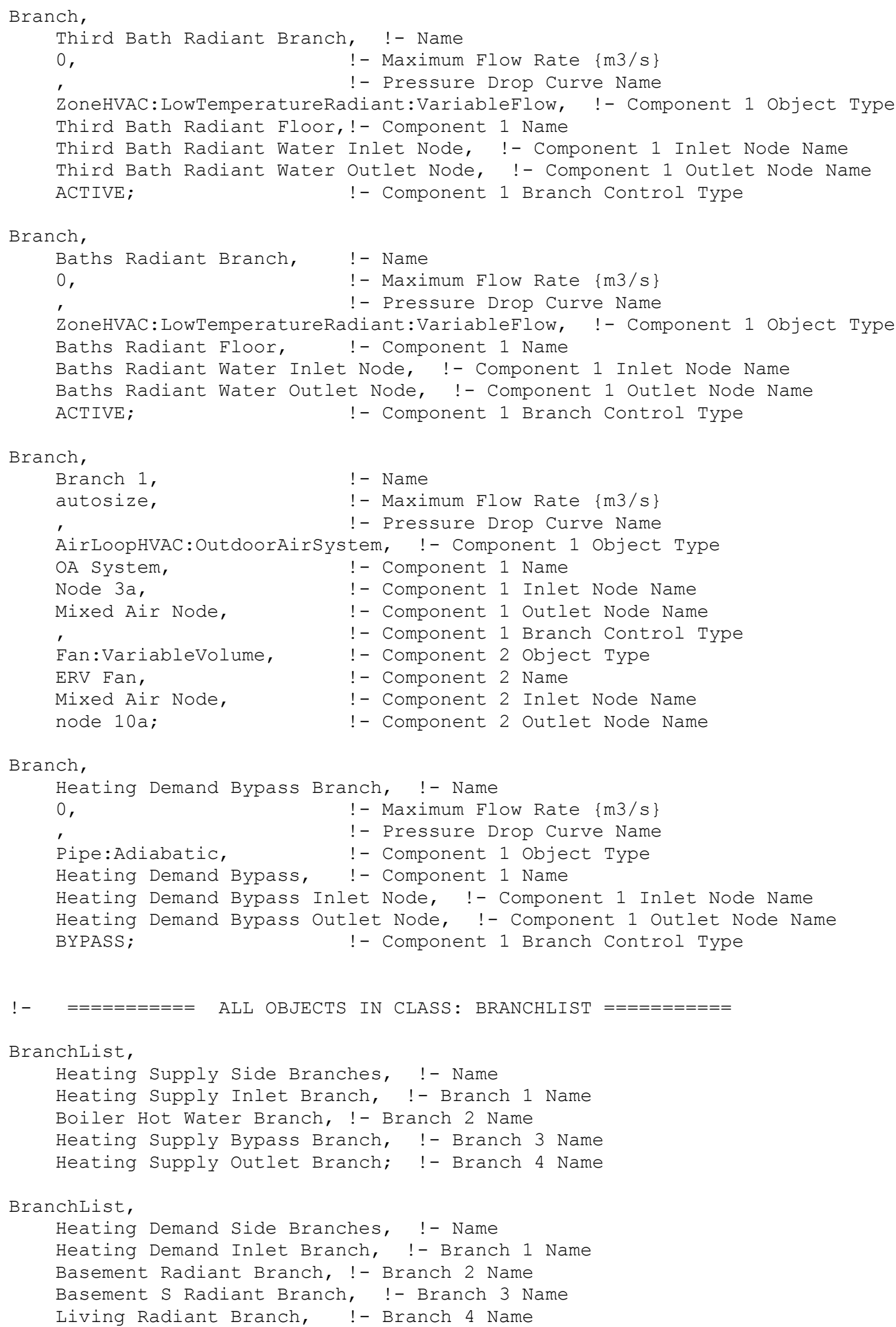


Kitchen Radiant Branch, !- Branch 5 Name

Bedroom 1 Radiant Branch,!- Branch 6 Name

Bedroom 2 Radiant Branch,!- Branch 7 Name

Bedroom 3 Radiant Branch, !- Branch 8 Name

Bedroom 4 Radiant Branch, !- Branch 9 Name

Third Bath Radiant Branch, !- Branch 10 Name

Baths Radiant Branch, !- Branch 11 Name

Heating Demand Bypass Branch, !- Branch 12 Name

Heating Demand Outlet Branch; !- Branch 13 Name

BranchList,

Air Loop Branches, !- Name

Branch 1;

!- Branch 1 Name

!- $==========$ ALL OBJECTS IN CLASS : CONNECTOR:SPLITTER $==========$

Connector:Splitter,

Heating Supply Splitter, !- Name

Heating Supply Inlet Branch, !- Inlet Branch Name

Boiler Hot Water Branch, !- Outlet Branch 1 Name

Heating Supply Bypass Branch; !- Outlet Branch 2 Name

Connector:Splitter,

Heating Demand Splitter, !- Name

Heating Demand Inlet Branch, !- Inlet Branch Name

Basement Radiant Branch, !- Outlet Branch 1 Name

Basement S Radiant Branch, !- Outlet Branch 2 Name

Living Radiant Branch, !- Outlet Branch 3 Name

Kitchen Radiant Branch, !- Outlet Branch 4 Name

Bedroom 1 Radiant Branch,!- Outlet Branch 5 Name

Bedroom 2 Radiant Branch,!- Outlet Branch 6 Name

Bedroom 3 Radiant Branch, !- Outlet Branch 7 Name

Bedroom 4 Radiant Branch,!- Outlet Branch 8 Name

Third Bath Radiant Branch, !- Outlet Branch 9 Name

Baths Radiant Branch, !- Outlet Branch 10 Name

Heating Demand Bypass Branch; !- Outlet Branch 11 Name

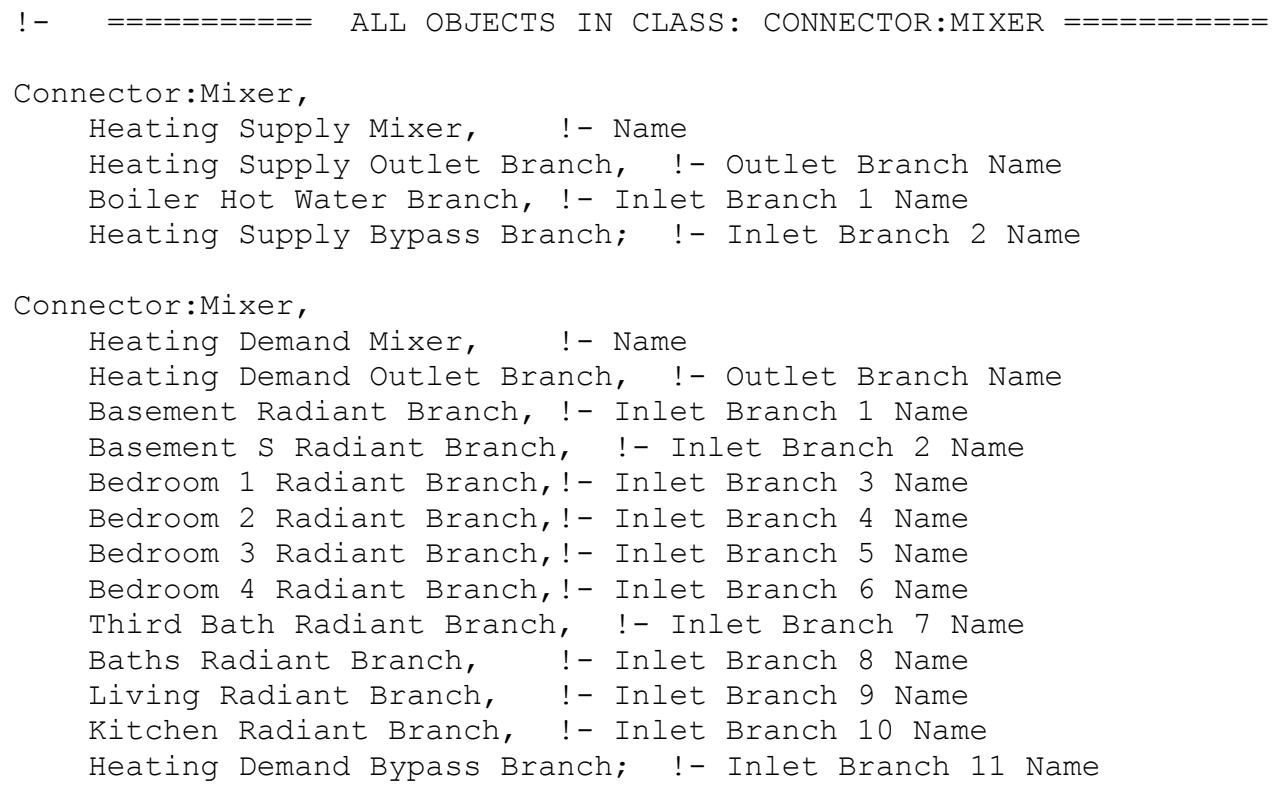




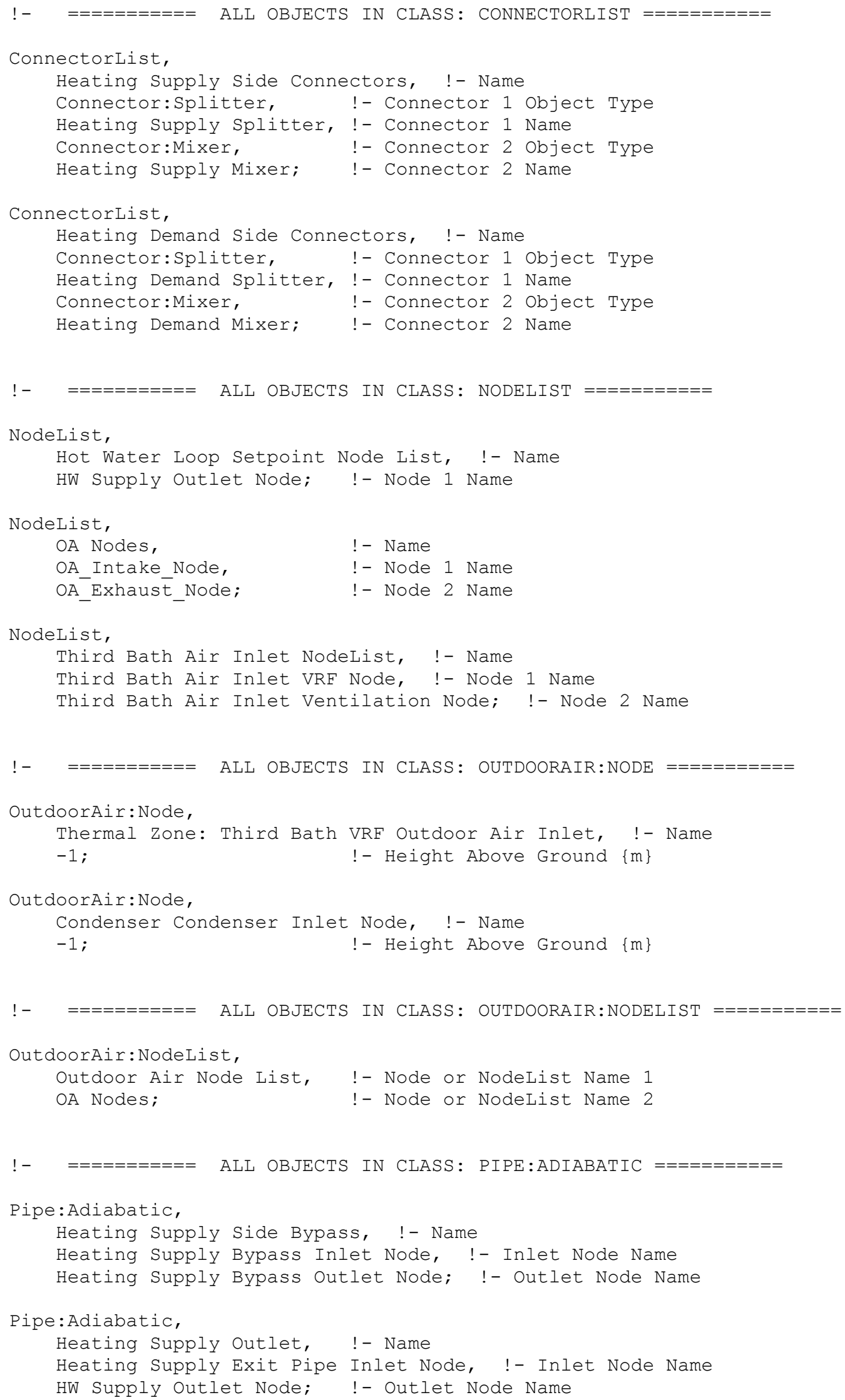




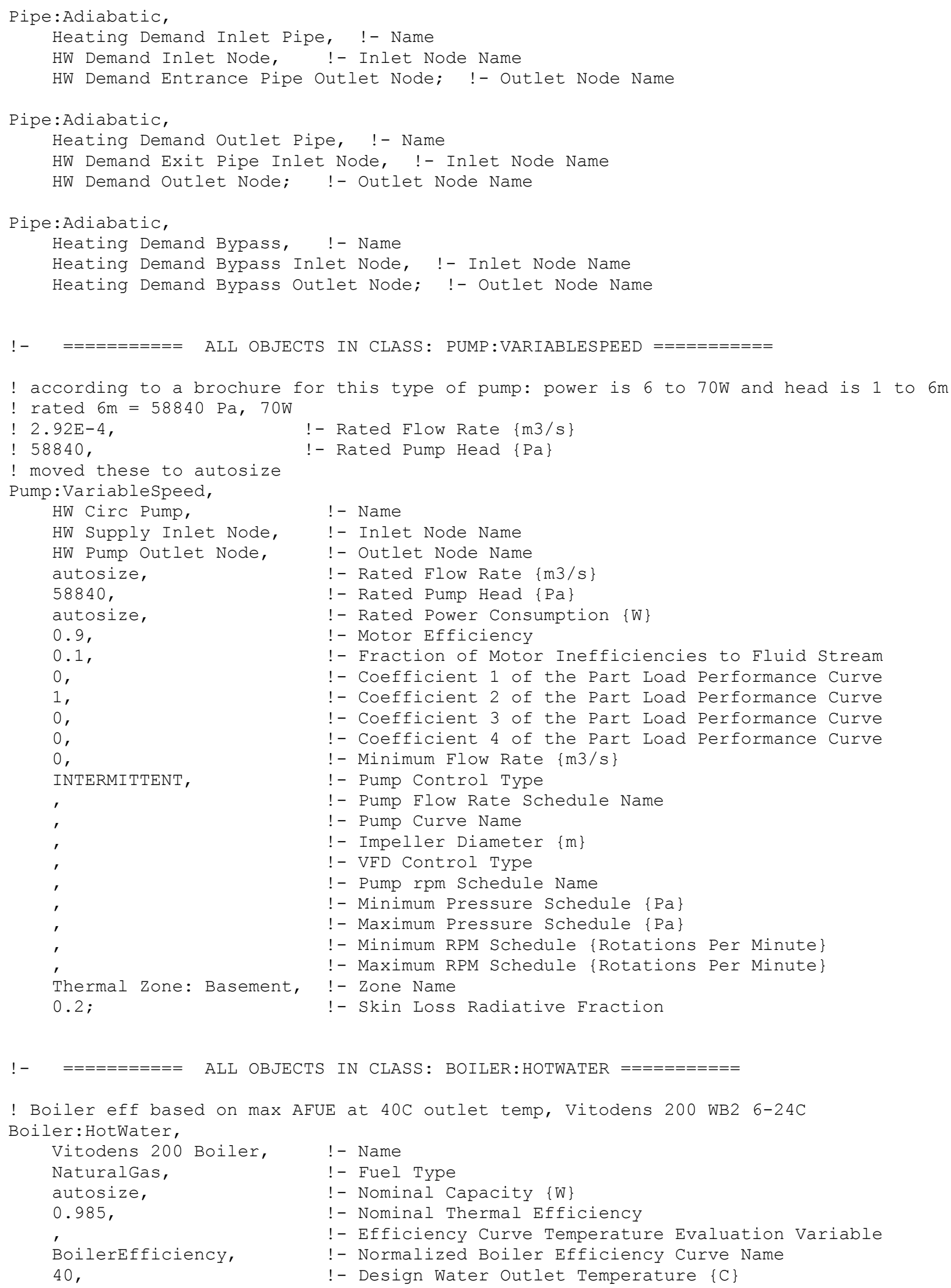




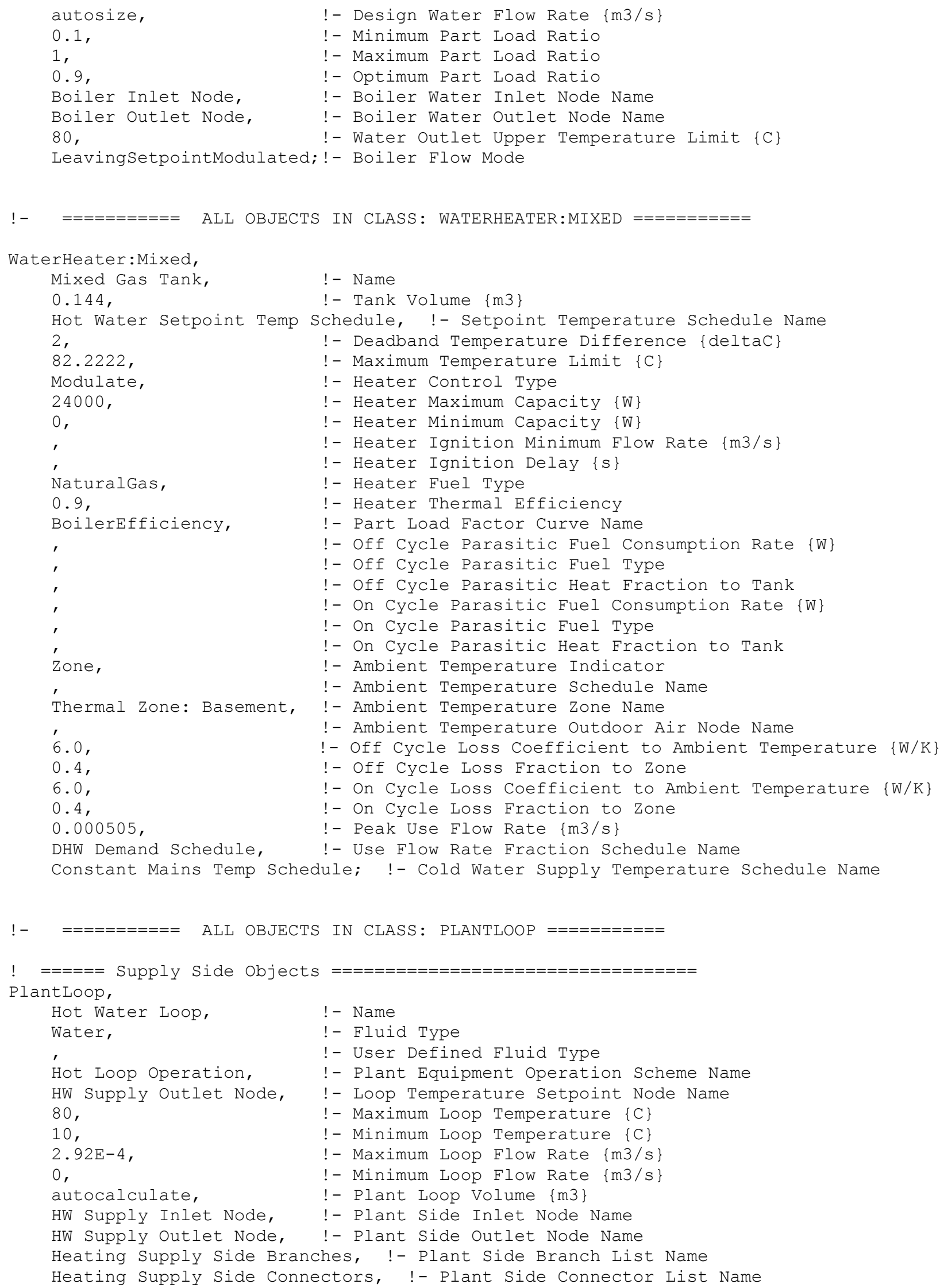




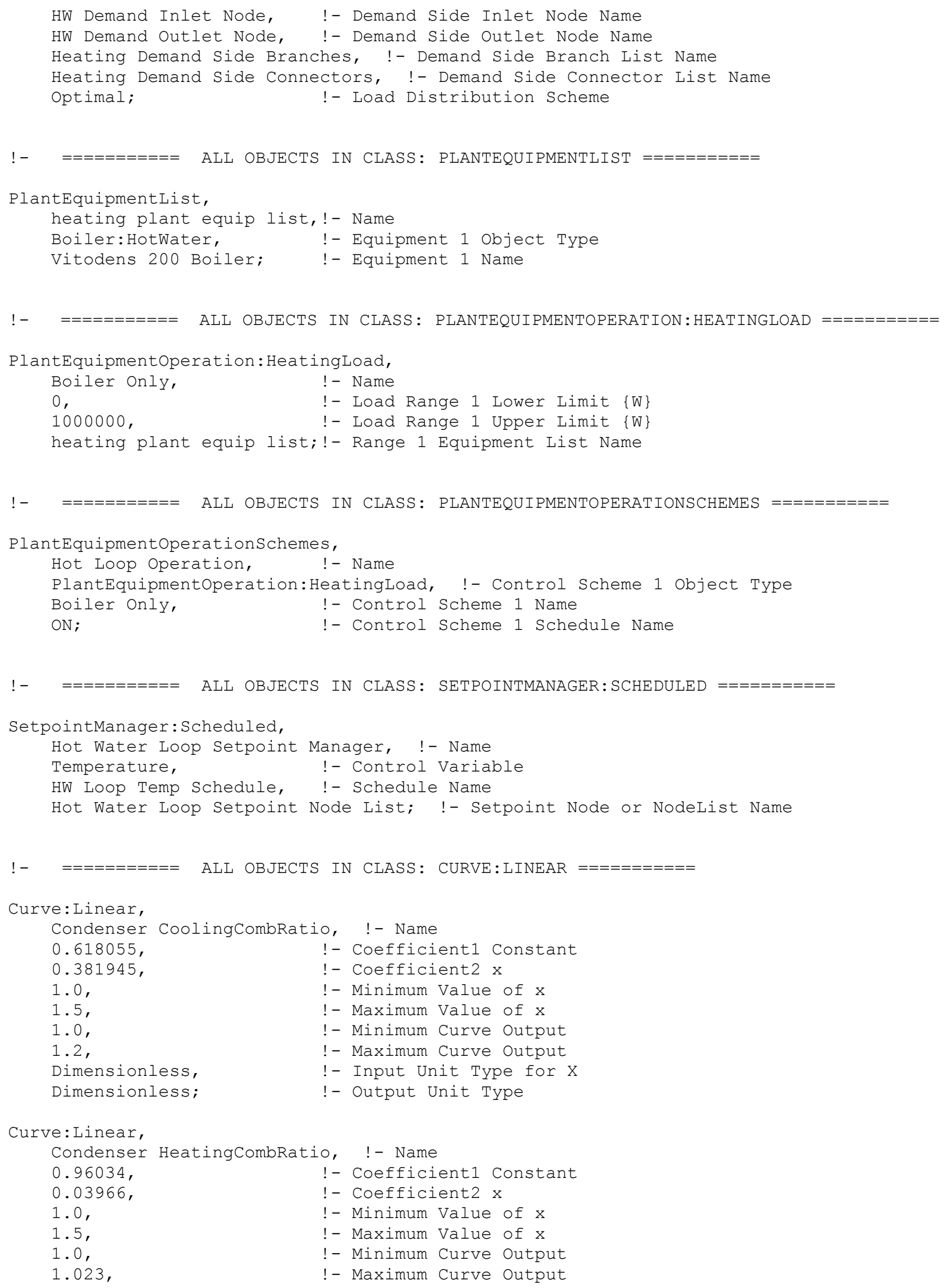




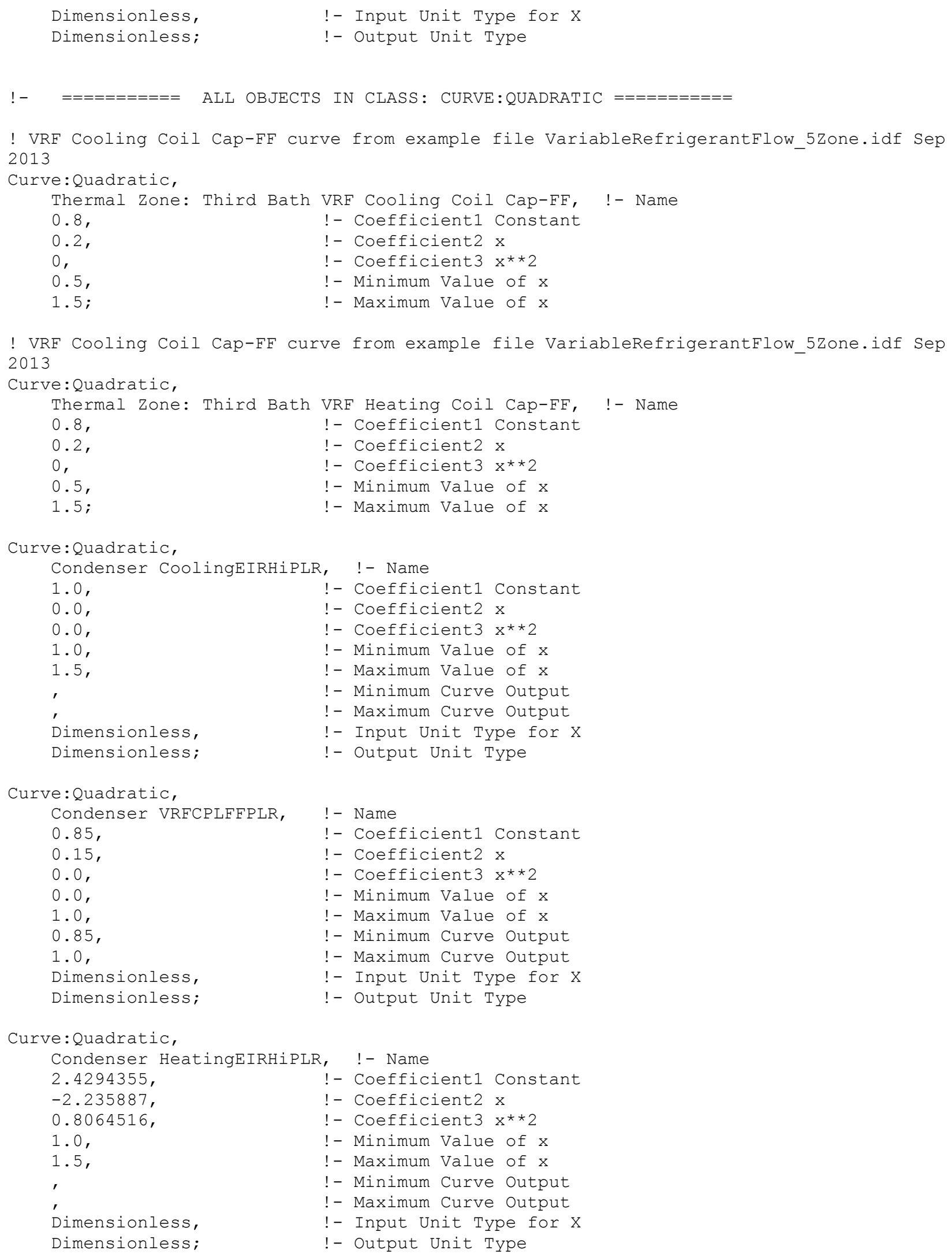




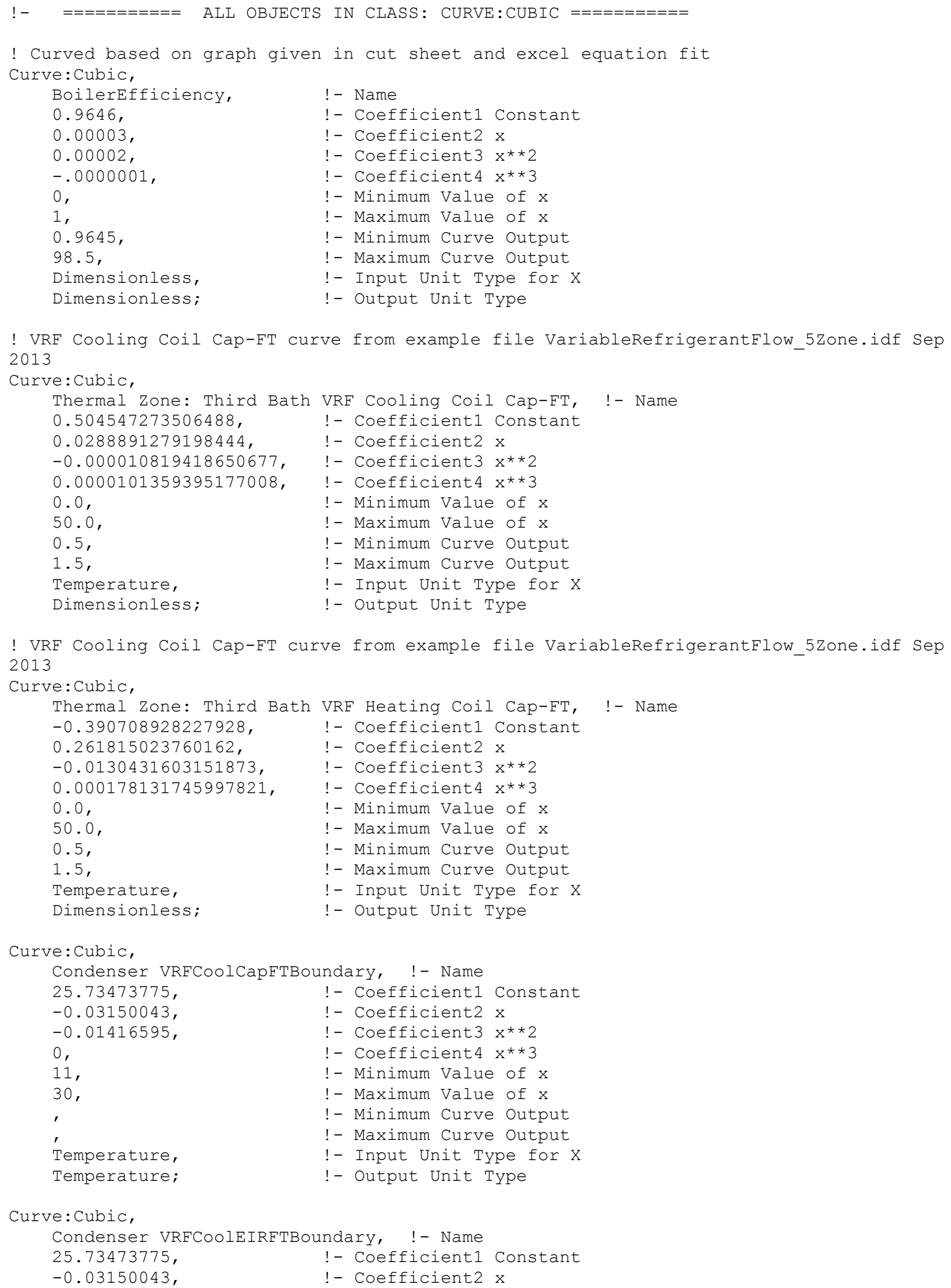




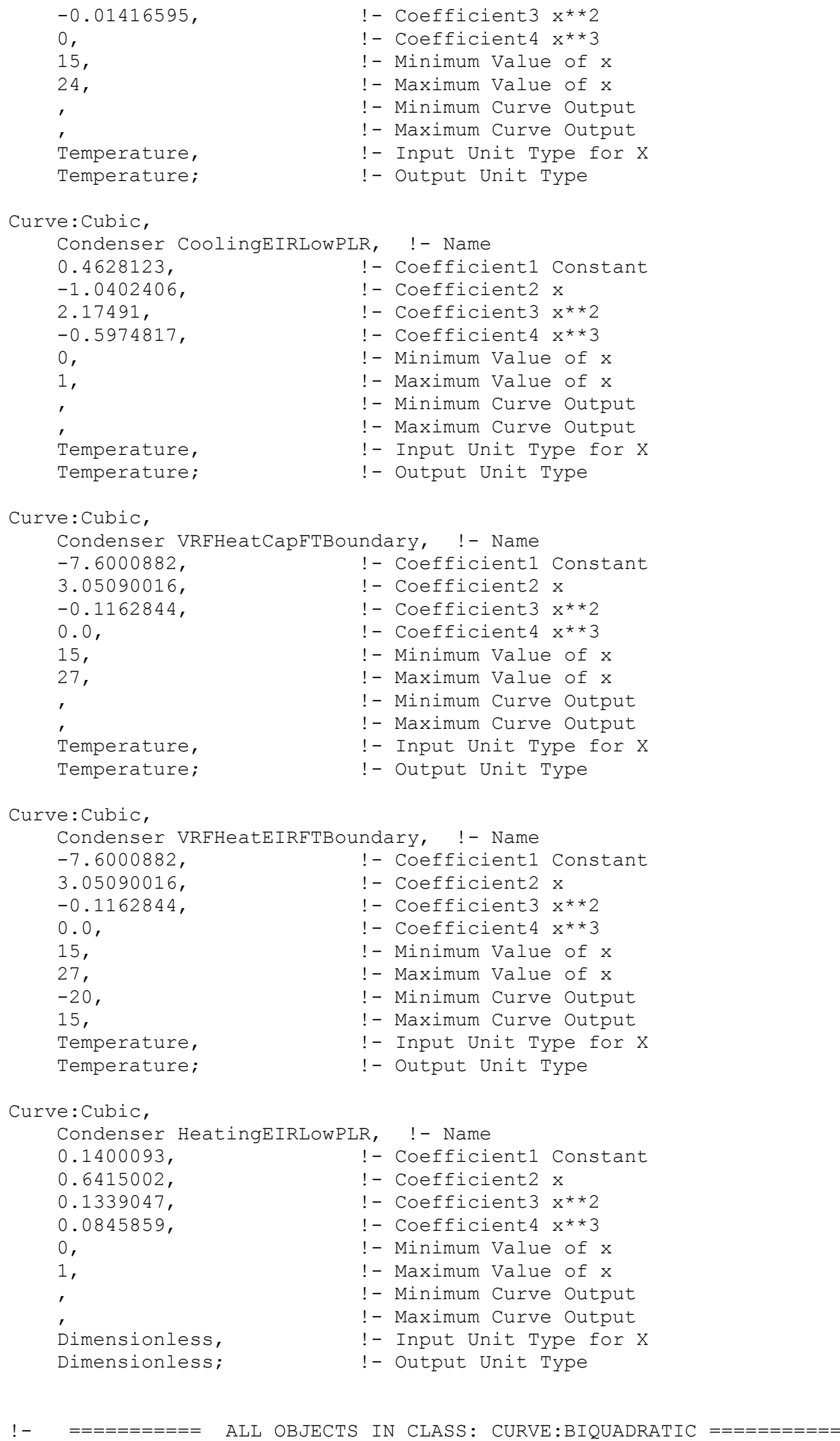




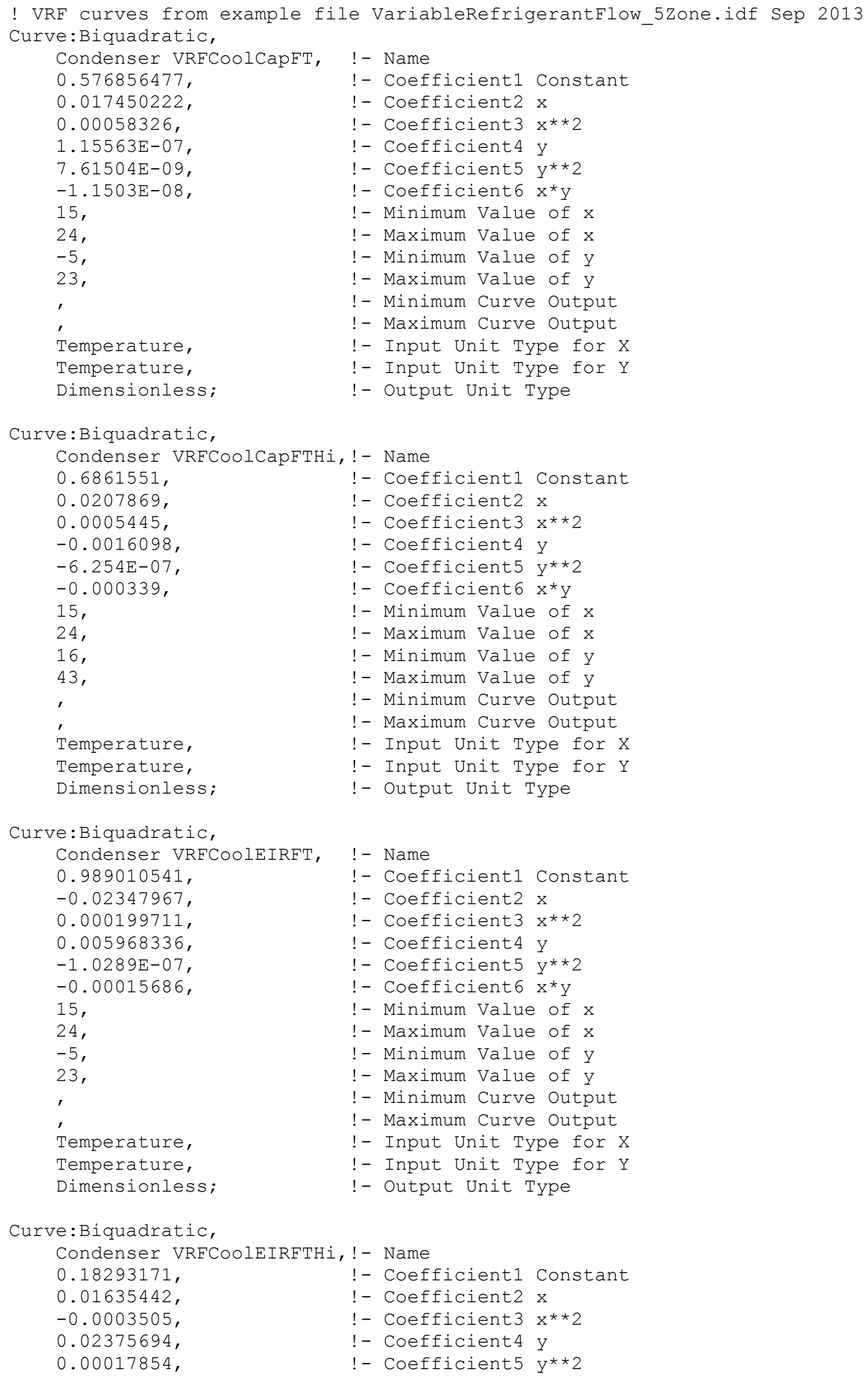




\begin{tabular}{|c|c|}
\hline & \\
\hline-0.000 & !- Coefficient $6 x^{*} y$ \\
\hline 15, & !- Minimum Value of $x$ \\
\hline 24, & !- Maximum Value of $x$ \\
\hline 16, & !- Minimum Value of y \\
\hline 43 & !- Maximum Value of y \\
\hline , & !- Minimum Curve Output \\
\hline 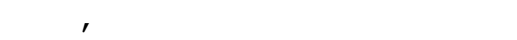 & !- Maximum Curve Output \\
\hline Temperature, & !- Input Unit Type for $\mathrm{X}$ \\
\hline Temperature, & !- Input Unit Type for $Y$ \\
\hline Dimensionless; & !- Output Unit Type \\
\hline ratic, & \\
\hline Condenser VRFHeatC & ! - Name \\
\hline 1.014599599, & !- Coefficient1 Constant \\
\hline-0.002506703 & !- Coefficient2 x \\
\hline-0.000141599 & !- Coefficient $3 x^{* * 2}$ \\
\hline 0.026931595 & !- Coefficient4 y \\
\hline $1.83538 \mathrm{E}-06$, & !- Coefficient5 $y^{\star \star 2}$ \\
\hline-0.000358147, & !- Coefficient $6 x^{*} y$ \\
\hline 15, & !- Minimum Value of $\mathrm{x}$ \\
\hline 27, & !- Maximum Value of $\mathrm{x}$ \\
\hline-20 & !- Minimum Value of $y$ \\
\hline 15, & !- Maximum Value of y \\
\hline ' & !- Minimum Curve Output \\
\hline ' & !- Maximum Curve Output \\
\hline Temperature, & !- Input Unit Type for X \\
\hline Temper & !- Input Unit Type for $Y$ \\
\hline Dimens & !- Output Unit Type \\
\hline arve:Biq & \\
\hline Cond & !- Name \\
\hline 1.161134821, & !- Coefficient1 Constant \\
\hline 0.027478868, & !- Coefficient2 $\mathrm{x}$ \\
\hline-0.00168795 & !- Coefficient $3 x * * 2$ \\
\hline 0.001783378, & !- Coefficient4 y \\
\hline $2.03208 E-06$ & !- Coefficient5 $y^{\star * 2}$ \\
\hline$-6.8969 \mathrm{E}-05$ & !- Coefficient $6 x^{*} y$ \\
\hline 15, & !- Minimum Value of $\mathrm{x}$ \\
\hline 27, & !- Maximum Value of $x$ \\
\hline-10 & !- Minimum Value of $y$ \\
\hline 15 & !- Maximum Value of y \\
\hline ' & !- Minimum Curve Output \\
\hline , & !- Maximum Curve Output \\
\hline Temp & !- Input Unit Type for $\mathrm{X}$ \\
\hline Temperatu & !- Input Unit Type for $Y$ \\
\hline Dimensionless; & !- Output Unit Type \\
\hline Iratic, & \\
\hline Condenser VRFHe & !- Name \\
\hline 0.87465501 & !- Coefficient1 Constant \\
\hline-0.01319754, & !- Coefficient2 $\mathrm{x}$ \\
\hline 0.00110307, & !- Coefficient $3 x^{* * 2}$ \\
\hline-0.0133118 & !- Coefficient4 y \\
\hline 0.00089017, & !- Coefficient5 $y^{* * 2}$ \\
\hline-0.00012766 & !- Coefficient $6 x^{*} y$ \\
\hline 15， & !- Minimum Value of $\mathrm{x}$ \\
\hline 27, & !- Maximum Value of $\mathrm{x}$ \\
\hline-20 & !- Minimum Value of y \\
\hline 12, & !- Maximum Value of y \\
\hline , & !- Minimum Curve Output \\
\hline , & !- Maximum Curve Output \\
\hline Tems & !- Input Unit Type for $\mathrm{X}$ \\
\hline Temperature, & !- Input Unit Type for $Y$ \\
\hline
\end{tabular}


Dimensionless; !- Output Unit Type

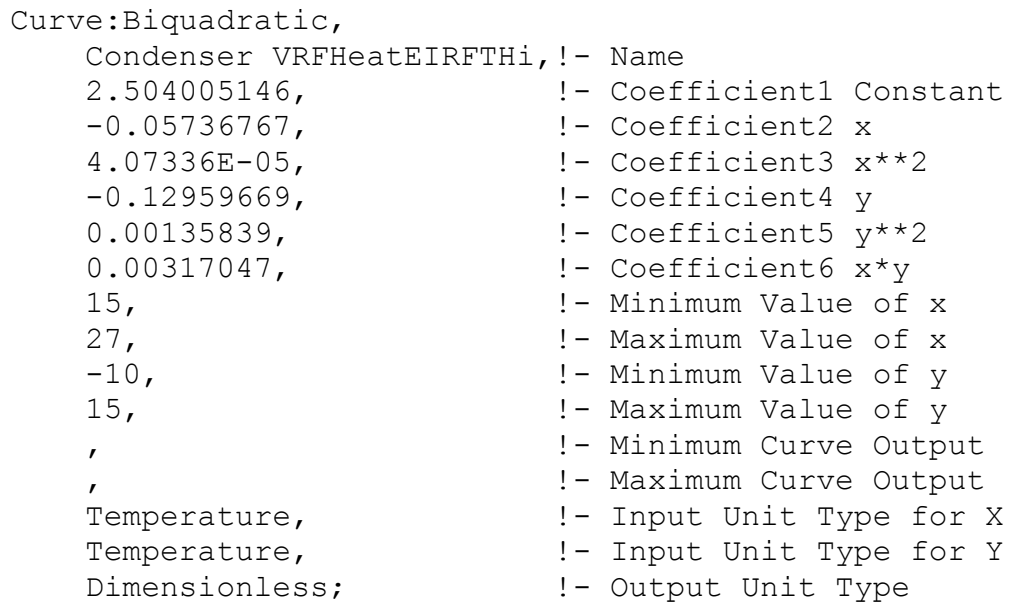

Curve:Biquadratic,

Condenser CoolingLengthCorrectionfactor, !- Name

1.0693794, !- Coefficient1 Constant

-0.0014951 ,

!- Coefficient2 $x$

2.56E-06,

-0.1151104,

!- Coefficient $3 x * * 2$

0.0511169

!- Coefficient4 y

!- Coefficient5 $\mathrm{y}^{\star * 2}$

-0.0004369 ,

!- Coefficient $6 x^{*} y$

8,

175,

!- Minimum Value of $x$

! - Maximum Value of $\mathrm{x}$

! - Minimum Value of y

0.5,

!- Maximum Value of $y$

!- Minimum Curve Output

!- Maximum Curve Output

Distance,

!- Input Unit Type for $\mathrm{X}$

Dimensionless, !- Input Unit Type for Y

Dimensionless; !- Output Unit Type

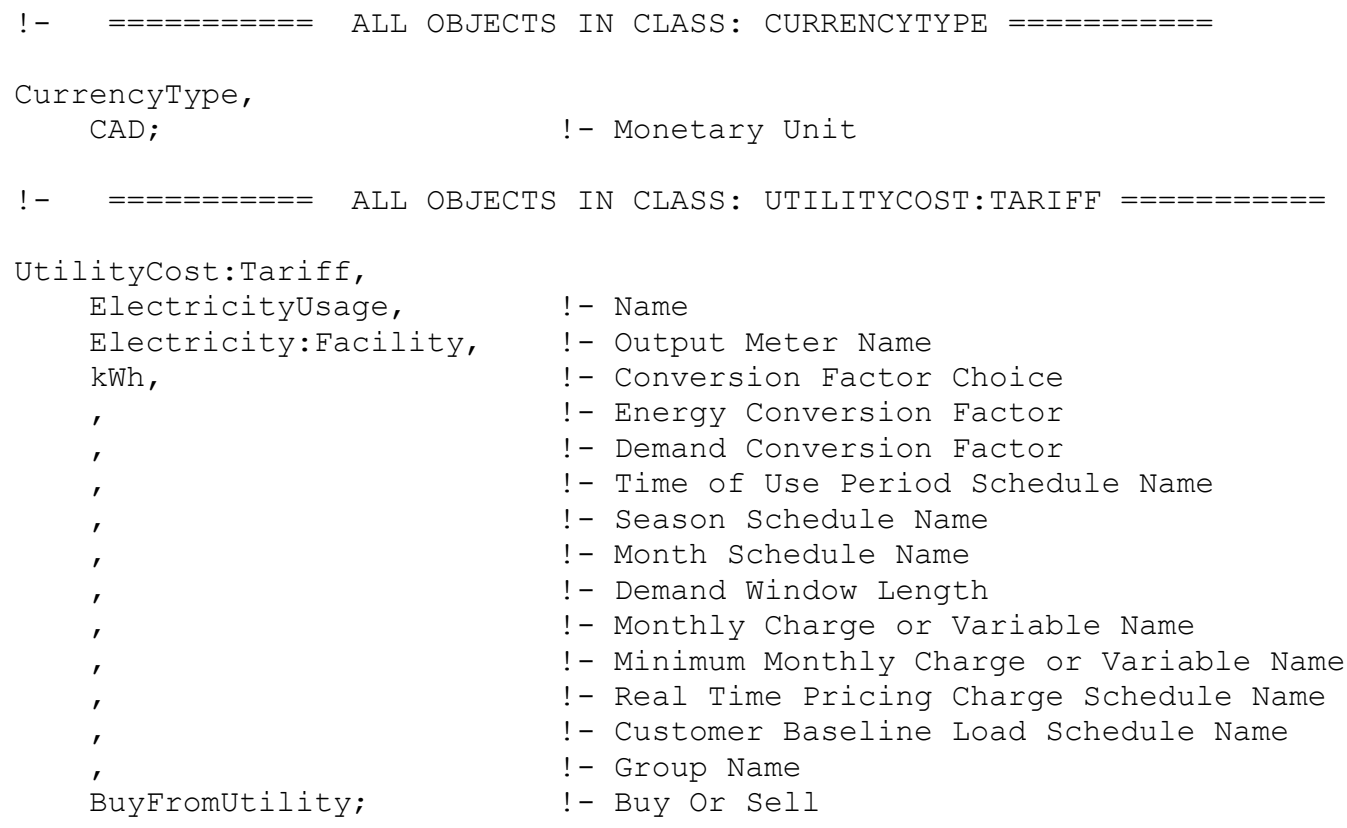




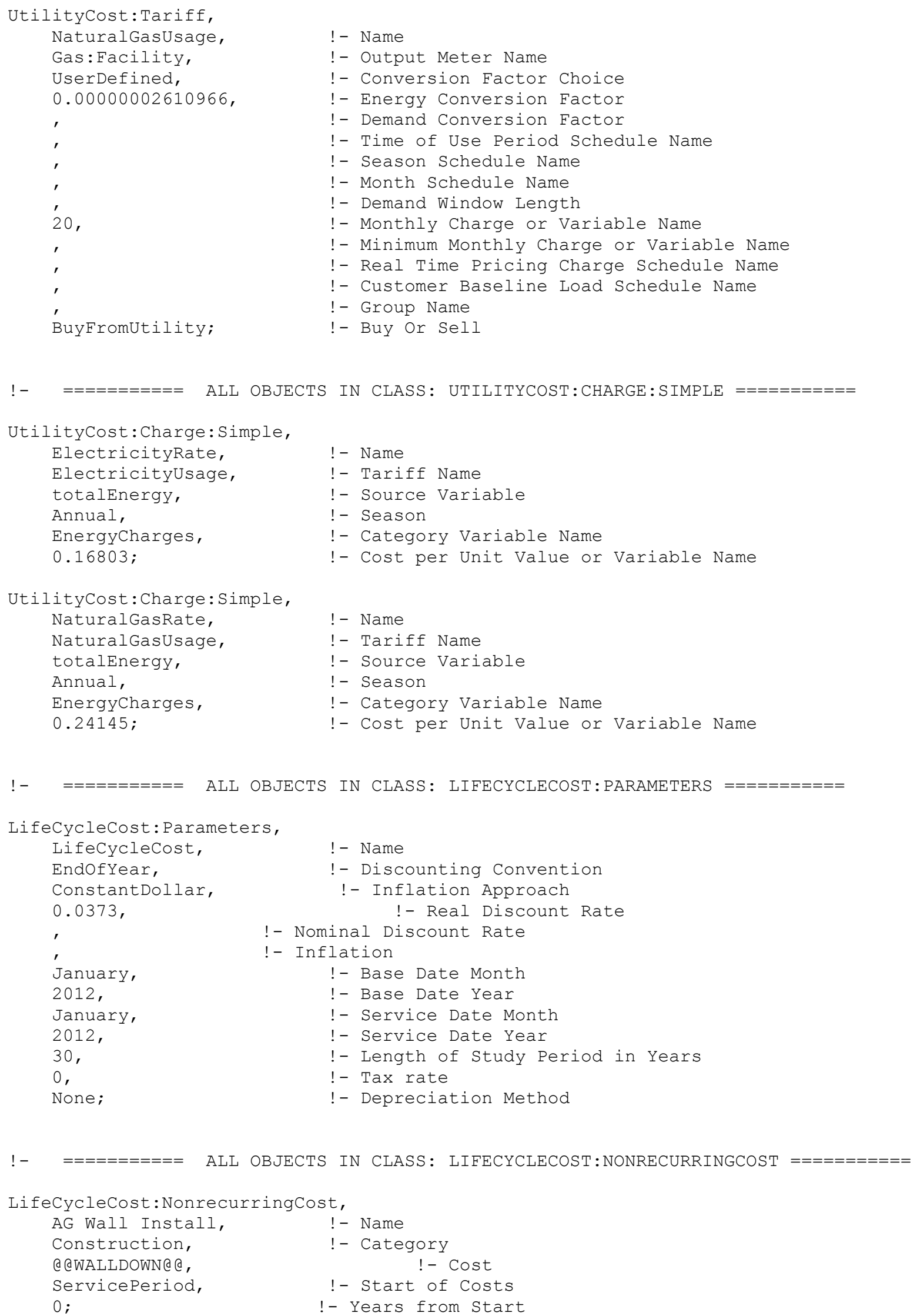




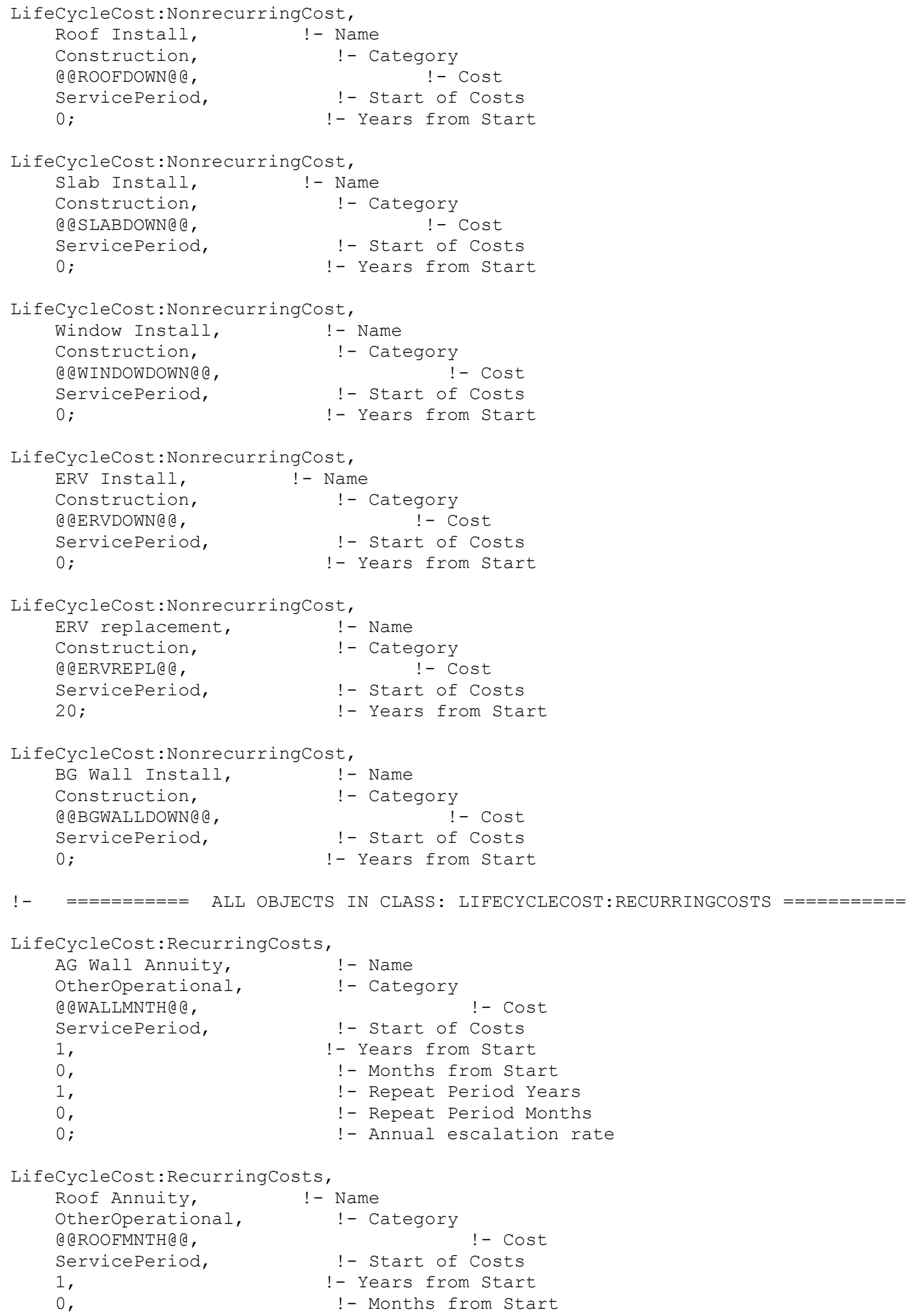




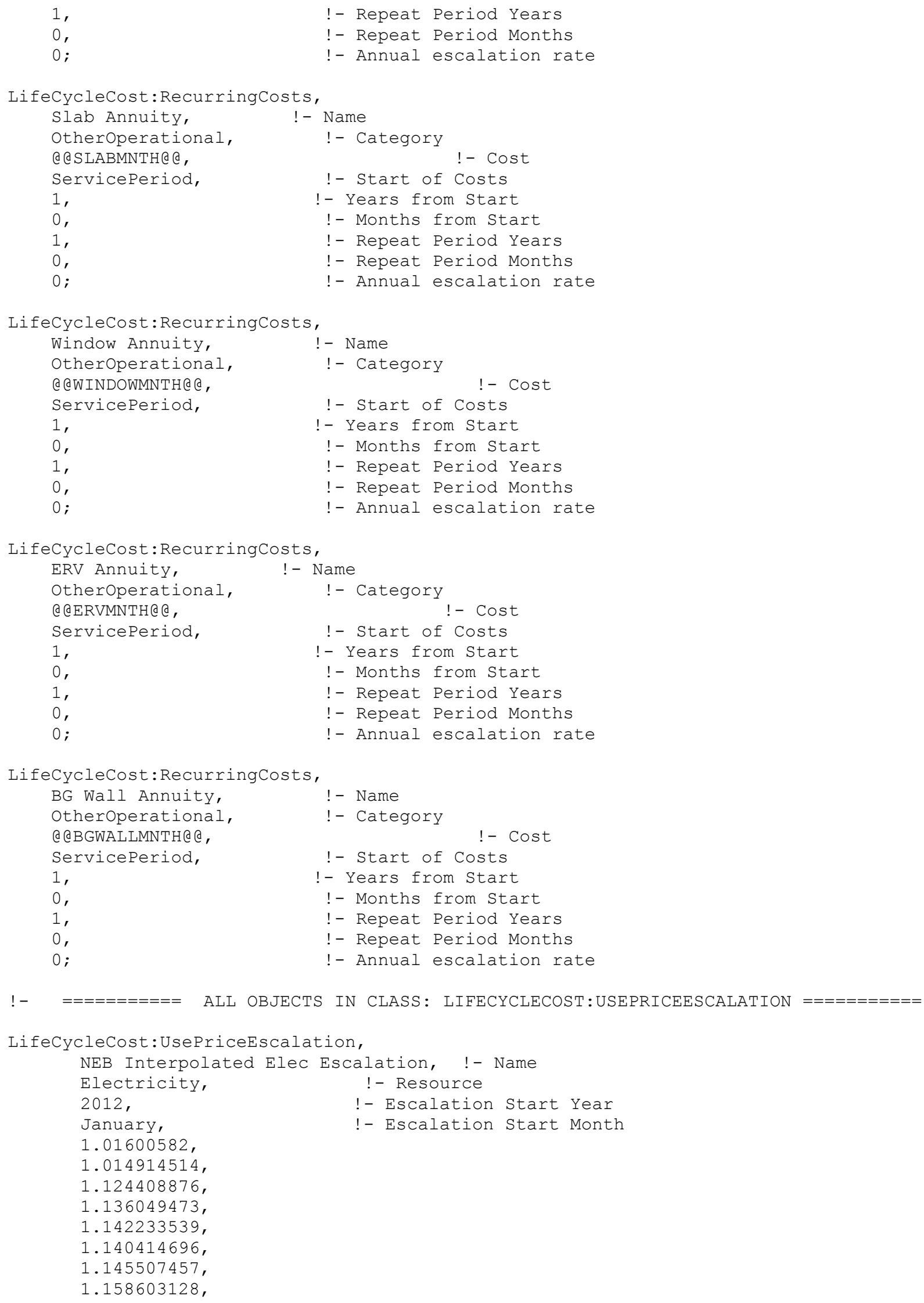




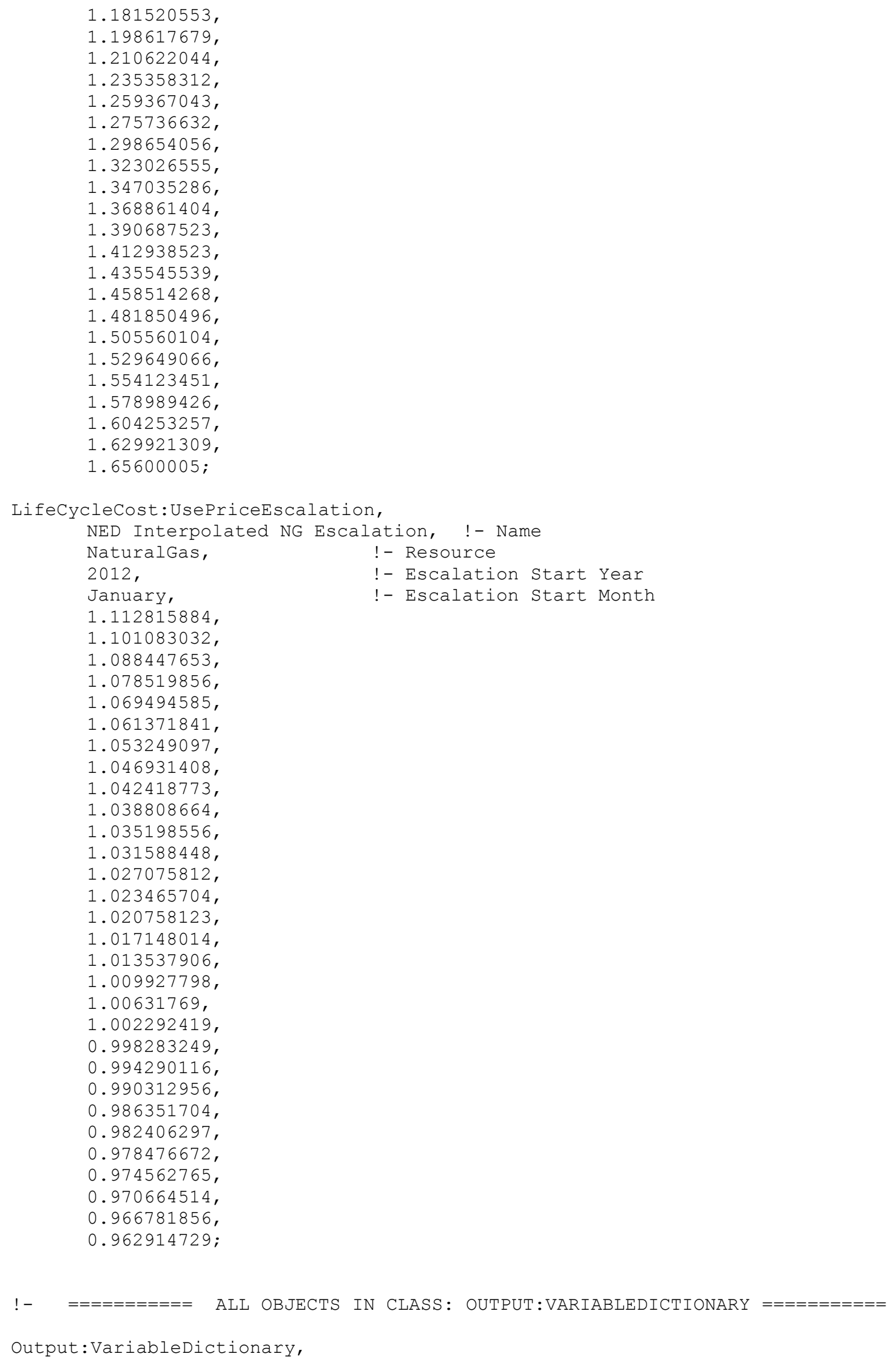




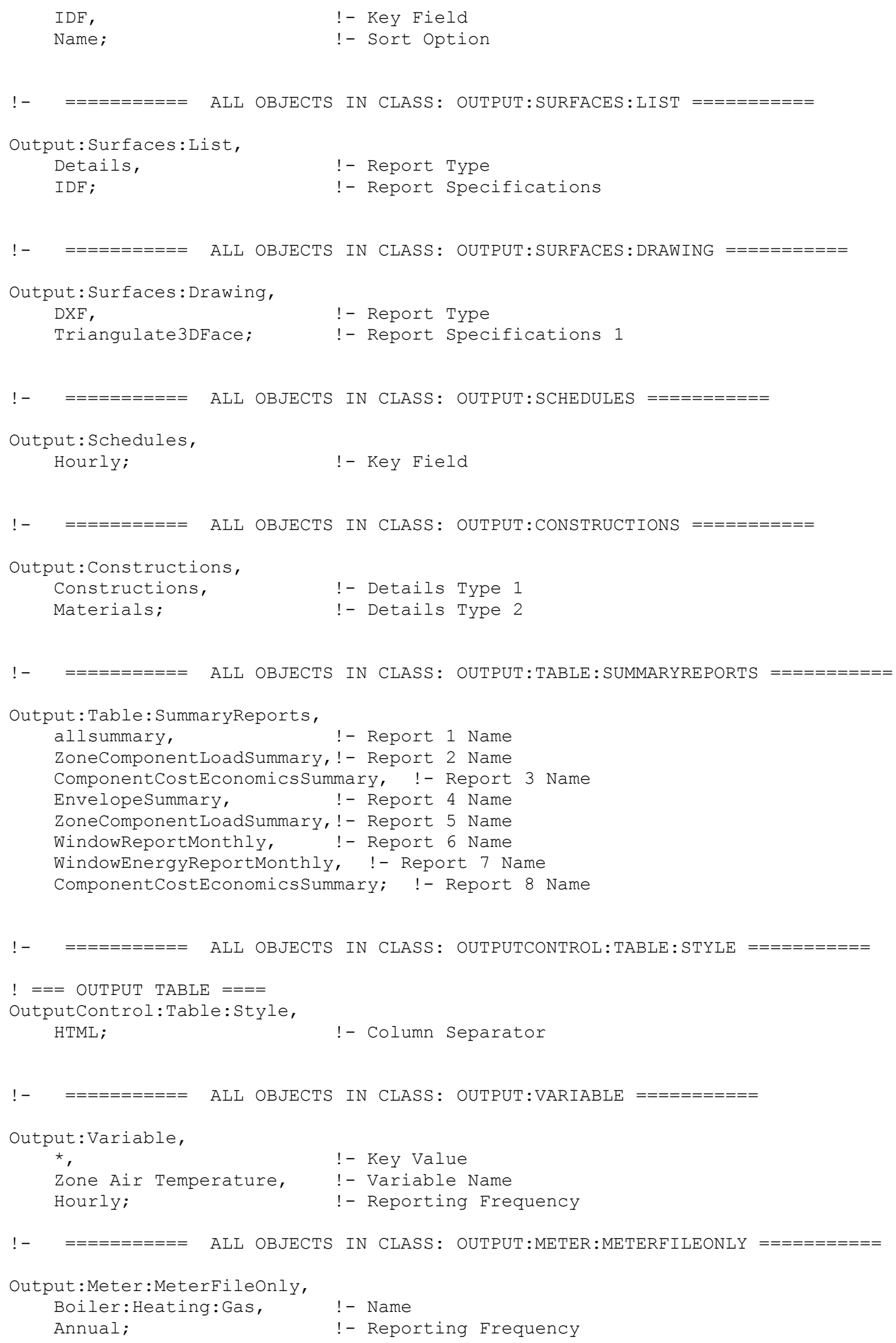




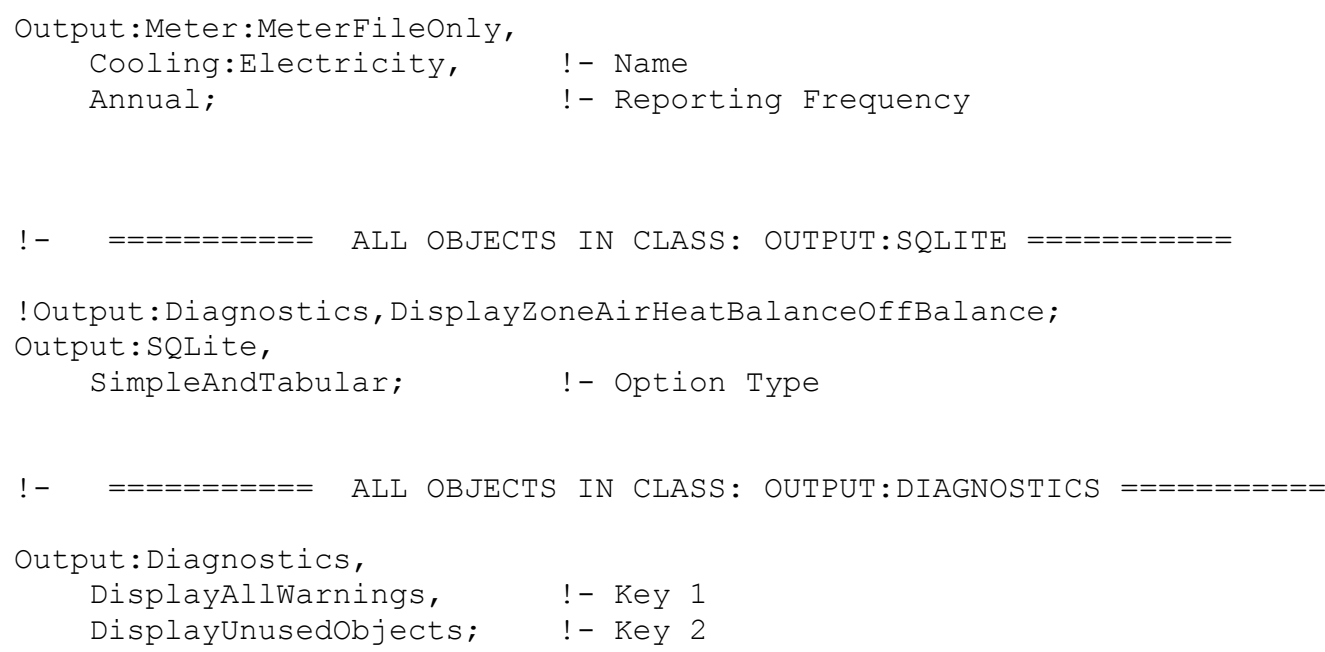




\section{Version control log and incremental results during calibration procedure}

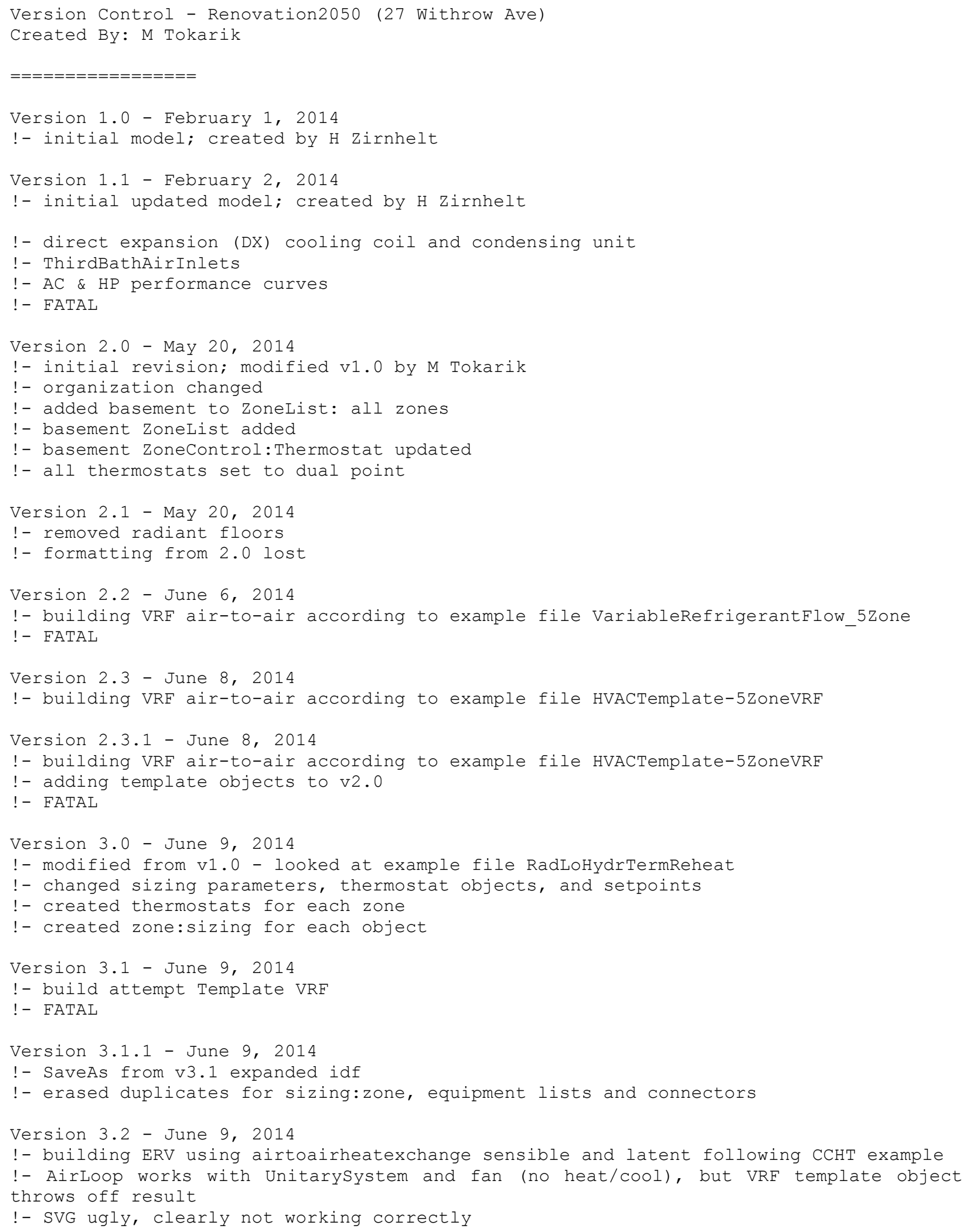


Version 3.2.1 - June 13, 2014

!- changed airloops to get ventilation and VRF working

!- SVG looks good, but ventilation system isn't real wrt supply/exhaust

Version 3.2.2 - June 17, 2014

!- changing ZoneMixing to get VRF to cool rest of house

Version 3.2.3 - June 19, 2014

!- added outputs from basement idf

!- 124 warning; 0 severe

Version 3.3 - June 19, 2014

!- changed to fullinteriorandexteriorwithreflections from fullexteriorwithreflections

Version 3.4 - June 24, 2014

!- building ariloop to match actual house

!- Broken SVG

!- submitted ticket to helpdesk to resolve issue

!- response from helpdesk, actual airflow network not possible

Version 3.5 - June 24, 2014

!- building boiler integrated DHW based on 5ZoneWaterSystems

Version 3.5.1 - Sept 2, 2014

!- building boiler integrated DHW based on 5ZoneWaterSystems from V3.2.3

!- SVG looks good

!- 8980 warning; 0 severe

Version 3.6 - Sept 5, 2014

!- building interzone heat transfer surfaces based on Hayes' method

!- added partition wall between Basement and Basement S

!- added all horizontal and vertical heat transfer surfaces as GlassDoor

!- updated flow of zone mixing

!- 8567 warning; 0 severe

!- 3 min, 27 sec full simulation

Version 3.7 - Sept 9, 2014

!- simulation to only Sizing Periods and Timestep $=6$ for run speed

! - removed unused geometry code

!- 5201 warning; 0 severe

!- systematically addressing error file

!- changed ZoneMixing to $\mathrm{m} 3 / \mathrm{s}$ from ach

!- changed AirConditioner:VariableRefrigerantFlow Min Outdoor Temp in Cooling Mode to 20C from $-6 \mathrm{C}$

!- 14 warning; 0 severe

!- Natural gas consumption order of magnitude too high - likely water systems (district heating?)

!- Unused Non-Parent objects in SVG: OutdoorAir:Node x2, HOT WATER LOOP SETPOINT MANAGER, SHWSYS1 LOOP SETPOINT MANAGER, CONDENSER VRF HEAT PUMP, OA CONTROLLER

!- Total electricity, and cooling electricity on correct order of magnitude, Natural gas consumption order of magnitude too high

!- Need to add more advanced output (ex. Output:Variable, *, Water Heater Tank Temperature, TIMESTEP;) to assess

Version 3.7.1 - Sept 16, 2014

!- WaterHeater:Mixed volume from autosize to $0.1893 \mathrm{~m} 3$ (50gal)

!- Ambient temp zone: Basement

!- PlantEquipmentoperation:HeatingLoad upper limit $=535 \mathrm{~W}$

!- Edited DHW use; moved from ElectricEquipment to WaterUse:Equipment and added showers, bath

!- Natural gas consumption on correct order of magnitude

!- 14 warning; 0 severe

!- SVG changed to reflect proper DHW 


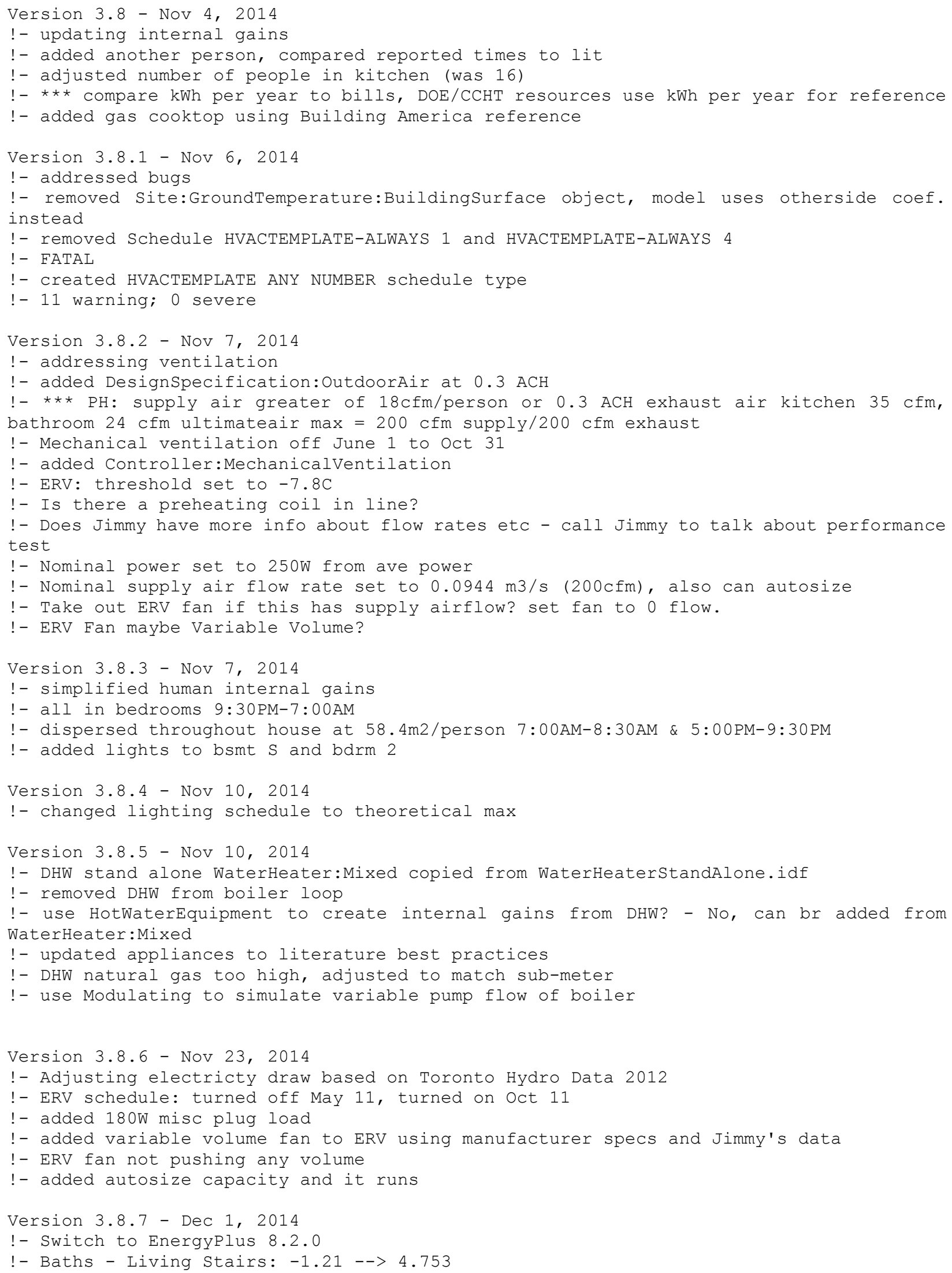


!- Ground temps turned off, using OSC, find these temps and compare to CCHT study for accuracy

!- added cooling schedule

!- manual cooling specs for MUY-GE09NA: gross rated capacity = $2638 \mathrm{~W}$ (9000BTU); 0.82

gross heating ratio; $0.1515 \mathrm{~m} 3 / \mathrm{s}$ rated air-flow (high)

!- changed boiler, vrf to autosize

!- built dashboard results viewer

!- 5 errors; 0 severe; Elapsed Time=00hr 01min $45.00 \mathrm{sec}$

Version 4.0 - Dec 2, 2014

!- Addressing known issues

!- infiltration changed from 358 to $342 \mathrm{~cm} 2$ ELA as per Nov 13, 2012 blower door test

!- NG: CV (RMSE) $\quad 56.9 \%$ NMBE $\quad-37.7 \%$

Version 4.0.1 - Dec 6, 2014

!- Updating opaque constructions

! - XPS conductivity changed from $0.034->$ to 0.028 (ie. R-5/in)

! - Spray foam changed from R5.36/in to R6.6/in (from Demilec); ie. changed Keff from 0.02911 to 0.02399

!- Deleted Spray Foam 100, 304, and 253

!- Changed Spray_Foam_And_Rafters_230 from 0.23 to 0.241 (9.5 in) and Keff from 0.0372

to 0.03275

!- NG: CV (RMSE) $44.9 \% ; \mathrm{NMBE}-26.1 \%$

!- Elec: CV (RMSE) 26.0\%; NMBE 4.3\%

Version 4.0.2 - Dec 6, 2014

!- Updating cooling conditions

!- Changed schedule to operate June 24 to Sept 13, as per 2013 cooling audit

!- Resistive capacity turned to 0 on outdoor AC

!- Cooling setpoint changed to $27.5 \mathrm{C}$

!- Cooling capacity changed to $4396 \mathrm{~W}$ (15,000 BTU)

!- COP changed to 4.0

!- NG: CV (RMSE) $\quad 37.1 \%$ NMBE $-17.3 \%$

!- Elec: CV (RMSE) 22.8\%; NMBE 21.4\%

!- Heat recovery total: 2.749 GJ; Max CFM: 297 (0.14 m3/s) too high

Version 4.0.3 - Dec 6, 2014

!- Updated ventilation rates to half the requirement b/c they were supplying to twice the rooms

!- Ventilation rate from 0.00944 to $0.00472 \mathrm{~m} 3 / \mathrm{s}$ per person

!- Heat recovery total: $2.749 \mathrm{GJ}$; Max CFM: 297 (0.14 m3/s) no change; not that bad, looking at Jimmy's data

!- NG: CV (RMSE) $31.0 \%$ NMBE $-7.9 \%$

!- Elec: CV(RMSE) 22.8\%; NMBE 21.4\%

Version 4.0.4 - Dec 6, 2014

!- Updated lighting schedule based on profile created from Toronto Hydro and monthly usage factor

!- Changed misc loads to $360 \mathrm{~W}$ varied to monthly profile

!- Elec: CV (RMSE) 6.1\%; NMBE $-0.1 \%$

!- NG: CV(RMSE) 26.5\%; NMBE $-3.4 \%$

!- NG data found for August; data still to be normalized by date, especially strange in Dec/Jan

!- Air temp data too high in summer (needs natural ventilation) and too low in winter (boiler $n$ ?)

!- Window input looks to be accurate

!- Cooling energy: 0.274 GJ

Version 4.1 - Dec 7, 2014

!- Building natural ventilation

!- Added 0.3 ACH to all zones during cooling season when indoor temp > 20C 
!- Needs to differentiate between natural and mechanical ventilation: try AvailabilityManager:HybridVentilation

!- spaces are too cool in winter - boiler capacity, design flow, leaving temp too low?

!- boiler capacity and flow changed to autosize

!- Zone radiant floor setpoint changed to "heating setpoint"

!- Changing ERV schedule to turn on 09/10 from 10/10

!- NG: CV (RMSE) 29.1\%; NMBE -17.3\%

!- Elec: CV (RMSE) 4.9\%; NMBE $-1.2 \%$

Version 4.1.1 - Dec 8, 2014

!- Tuning natural ventilation

!- changed natural ventilation to $1 \mathrm{ACH}$ (might need to be tuned up or down to match air temp)

!- Shoulder seasons still not matching, heating required, ie. windows opening when they shouldnt be, schedule wrong

!- Natural ventilation: July 1 to Sept 1; ERV off May 1 to Setp 30

!- deleted unused schedules

!- changed mechanical ventilation schedule to match electricity consumption

!- turned off evening May 10

! - turned on evening Oct 10

!- heating availability turned on/off with mechanical ventilation

!- cooling schedule available all times when heating is off but should not be on during shoulders

! - ThermostatControlTypeSched updated to match dates

!- air temp looking closer, natural ventilation requires more tuning

!- NG: CV(RMSE) 29.7\%; NMBE $-9.6 \%$

!- CV (RMSE) $4.8 \%$ NMBE $-1.1 \%$

Version 4.1.2 - Dec 8, 2014

!- Tuning natural ventilation to open only at night with higher ACH

!- schedule set to follow cooling schedule

!- windows to be open from 6PM to 9AM, natural ventilation set to $1.5 \mathrm{ACH}$

!- should all rooms have natural ventilation? interior rooms and no windows, but do they get enough heat transfer from airmixing and conduction?

!- changed solar to fullintextwithreflections

!- run time: 4 min 46 sec

!- errors: 139,973 errors; 0 severe

!- NG: CV (RMSE) $31.4 \% ; \mathrm{NMBE}-21.1 \%$

!- Elec: CV (RMSE) 4.9\%; NMBE $-0.8 \%$

Version $4.2-$ Dec 8, 2014

!- Adressing HVAC variables starting from autosize, using assumptions from Semmelhack

!- Mechanical ventilation set to $0.3 \mathrm{ACH}$

!- solar distribution set to full exterior (time cut in half)

!- CV (RMSE) $36.0 \%$ NMBE $-25.9 \%$

Version 4.2.1 - Dec 9, 2014

!- Heating setpoint changed to $20.5 \mathrm{C}$

!- Air temp looks tight, too much natural gas consumption

!- added humidistat, but doesnt seem to be affecting cooling use

!- heating in summer, changed availability schedule

!- too much natural ventilation in spring, natural venitalation to start Jun 20

!- air temp looks really good, too much natural gas

!- NG: CV(RMSE) $\quad 55.0 \% ; \mathrm{NMBE}-36.6 \%$

!- boiler eff quite high, try water setpoint? higher internal gains? ERV efficiency? Fewer losses in heating system?

Version 4.2.2 - Dec 10, 2014

!- Increasing ERV efficiency to 0.93, 0.55, 0.935, 0.595 to match test data for apparent sensible effectiveness and net moisture transfer for heating 
!- ERV efficiency set to 0 for cooling - shouldnt matter since it is off during cooling season

!- Plug load added as gain from all heat lost

!- sleeping activity changed to $90 \mathrm{~W} /$ person and awake activity to $200 \mathrm{~W} / \mathrm{person}$ !- NG: CV (RMSE) $\quad 24.8 \%$ NMBE $\quad-0.8 \%$

Version 4.2.3 - Dec 11, 2014

!- Changing VRF to respond to humidity

!- ZoneControl:Thermostat:TemperatureAndHumidity added for each zone at 55RH max

!- changed night venting to 10PM-9AM, cooling closer

!- VRF control changed to third bath

!- added output for solar, air temps (simulated and metered), heating, cooling to show zoomed in Vista

!- removed nat vent for bsmt and bmsmt $\mathrm{S}$

!- added internal gains from kitchen sink and showers

!- added variables to create elec profile

Version 5.0 - Jan 13, 2015

!- Happy birthday

!- Removed all Output:Meter except Cooling:Electricity and Heating:Gas

!- changed these variables to annual

!- removed all Output:Variable objects to resolve memory use leading to missing simresults.csv data - unsuccessful

!- emailed Dr. Zhang for help

!- changed SQL output to SimpleAndTabular

!- deleted Output:Table:Monthly

!- added UtilityCost:Tariff \& UtilityCost:Charge:Simple

!- added ComponentCost:LineItem for CCSF as example

!- added LLC calculations using example values

!- fatal error trying to process LLC using $\$ / m 3$ cost for insulation -- constructions must be $\$ / \mathrm{m} 2$

Version 5.1 - Feb 26, 2015

!- Built all glazing in WINDOW 6.3

!- Rebuilt original as-built windows -- Eco-Insulating SC75 w Inline 325 Casement

!- Removed original windows with full spectral data

!- Added Jeld-Wen, Aplen, and Optiwin

!- ComponentCost:LineItem for each window

Version 5.2 - Mar 3, 2015

!- Built ERV options

!- Aldes and Fantech

!- shows severe error because of node mix up, but not FATAL, and end utility usage remains the same

!- ComponentCost:LineItem for each unit

!- ERV LineItem has to be entered into e+ as "general" and attributed quantity

!- Seems like ERV options will have to be built in jEt if costs can be attributed in association

!- changed roof foam to 230 from $241 \mathrm{~mm}$

Version 5.3 - Mar 3, 2015

!- Added Lineltem cost for all opaque constructions on baseline

!- total base line LineItem cost: \$81329.98

Version 5.4 - Mar 3, 2015

!- Tarriff costs ok

!- discount rate changed to 3.73\%, avg 2010 GIC interest rate

!- Discount rate changed to nominal instead of real to account for inlfation

!- Inflation set to 3.69\% Canada's average inflation rate since 1950

!- Should this be lower? has been 2\% or lower in 1990

!- Added replacement cost for ERV in year 20, same price as original install

!- Changed electricity escalation to $1.2 \%$ 
! - Changed NG escalation to $0.1 \%$

!- Total base line LLC: \$135,581.83

Version 5.5 - Mar 3, 2015

!- Added all material thickness and construction parameters

!- Changed flat and sloped roof to same construction

!- Changed all external walls to same construction (bg different?)

!- Associated costs to all constructions

! - IC $=\$ 82848.75$

$!-\operatorname{LLC}=\$ 136992.42$

Version 6.0 - Mar 3, 2015

!- Changed input parameters to jEPlus language (this version is saved on thumb drive)

!- SQL retrieval messing up because of missing cooling load values in bsmt and bsmt $\mathrm{s}$

!- Redistributed lights in basement 


\section{APPENDIX C - MORTGAGE COST BREAKDOWN}

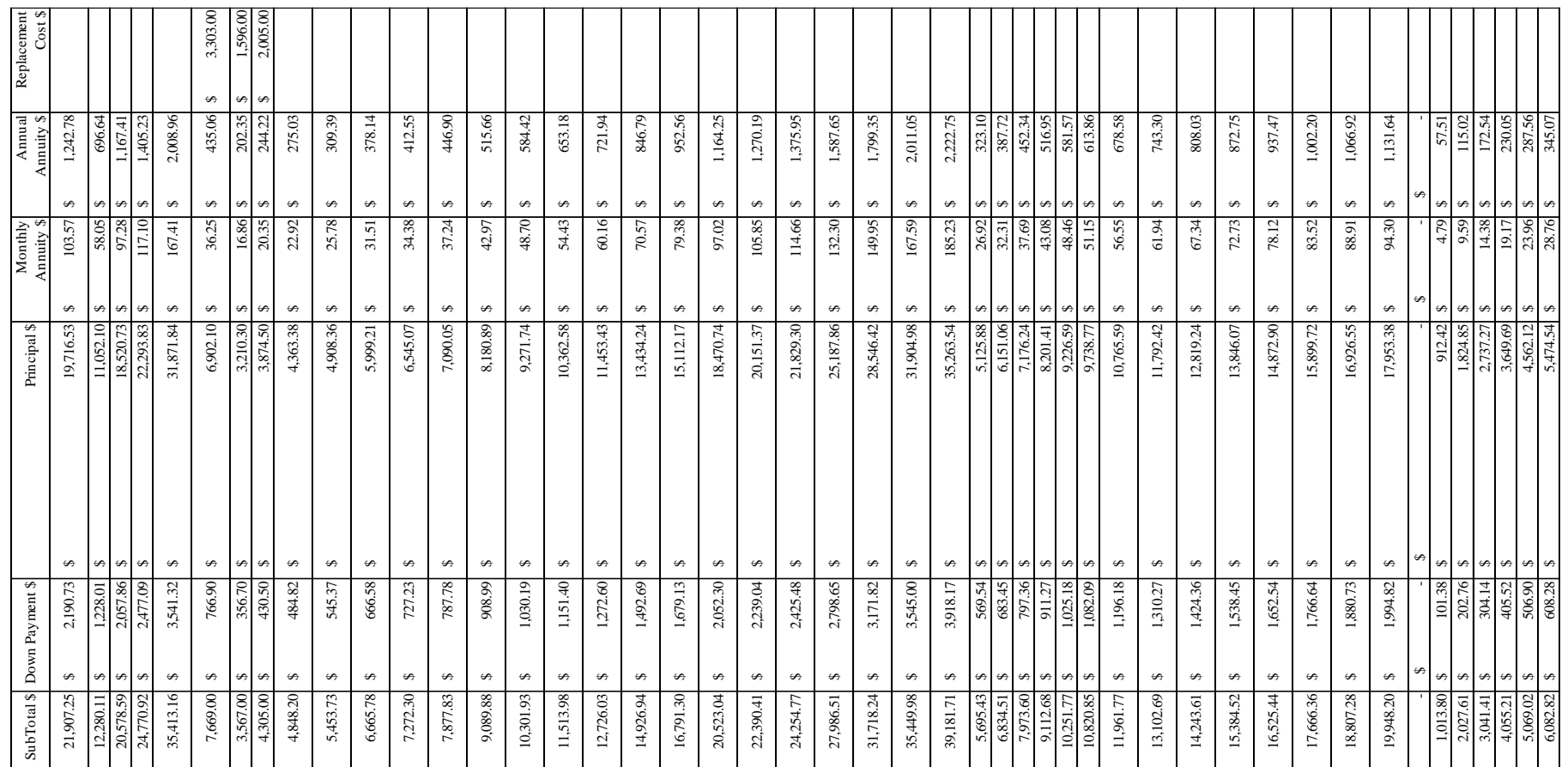

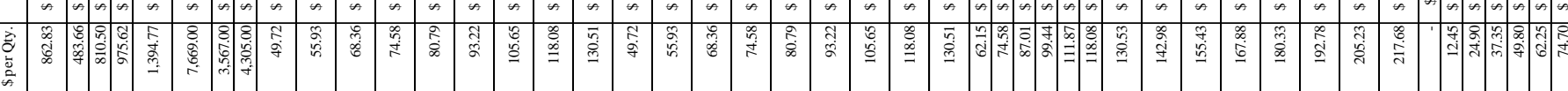

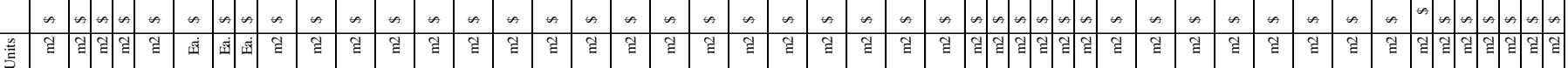

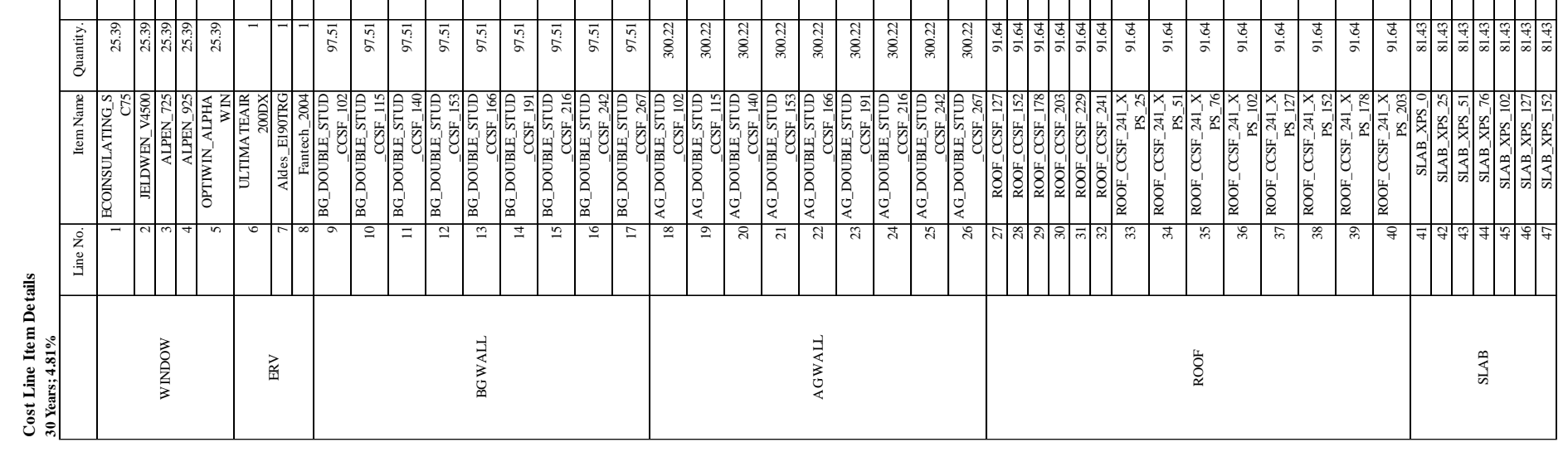




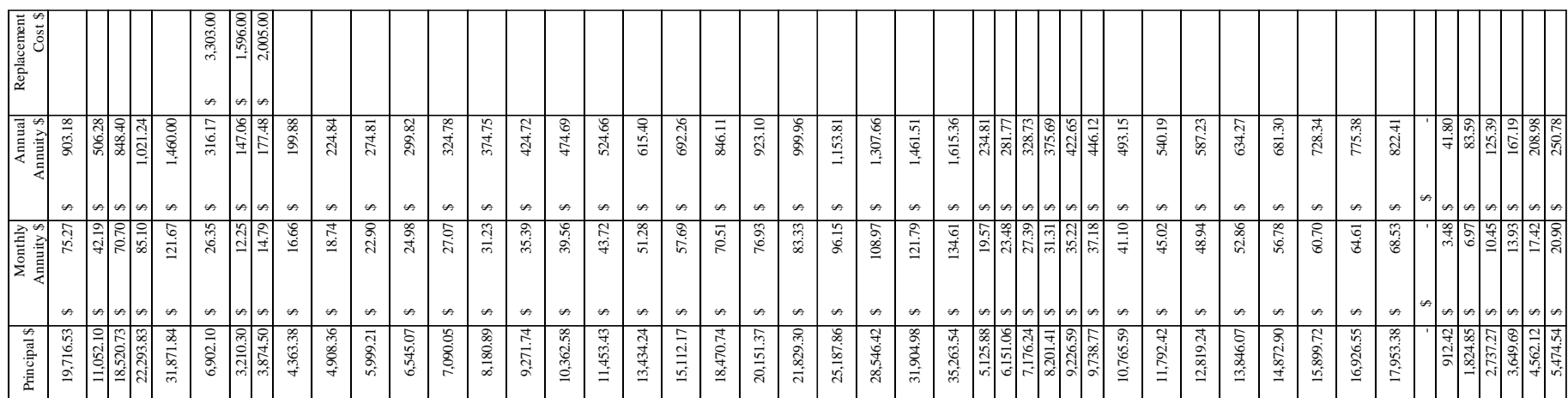

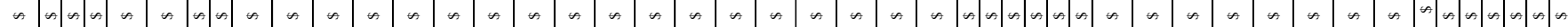

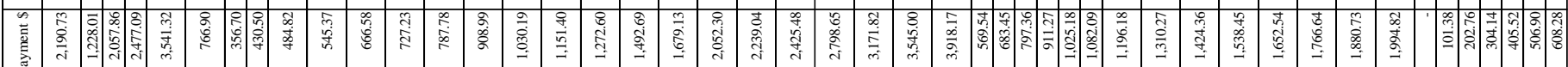

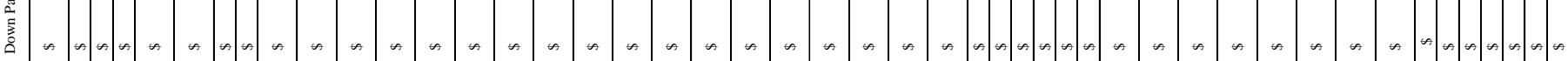

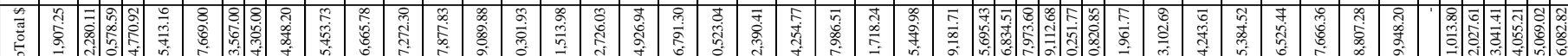

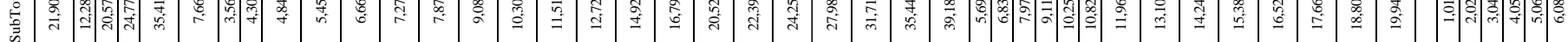

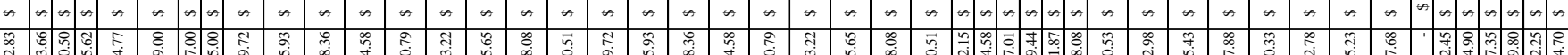

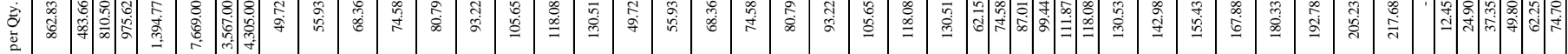

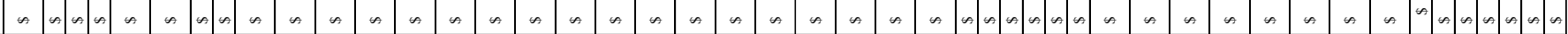

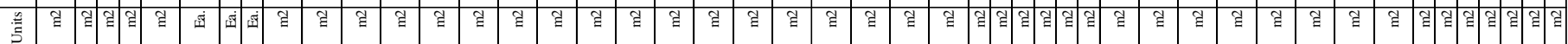

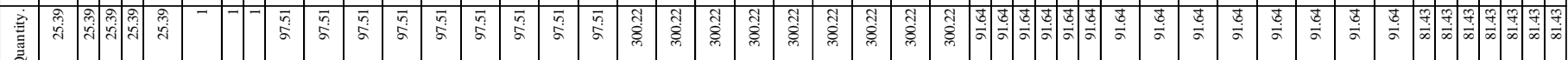

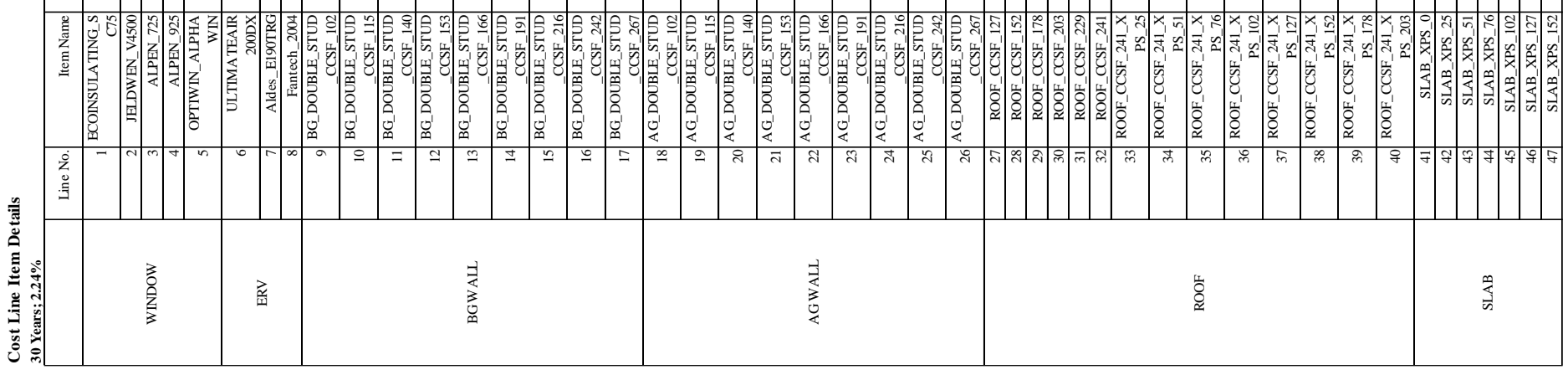




\section{APPENDIX D - OPTIMIZATION RESULTS}

Output variables for Case 1 (reference case) with total peak load performance objective

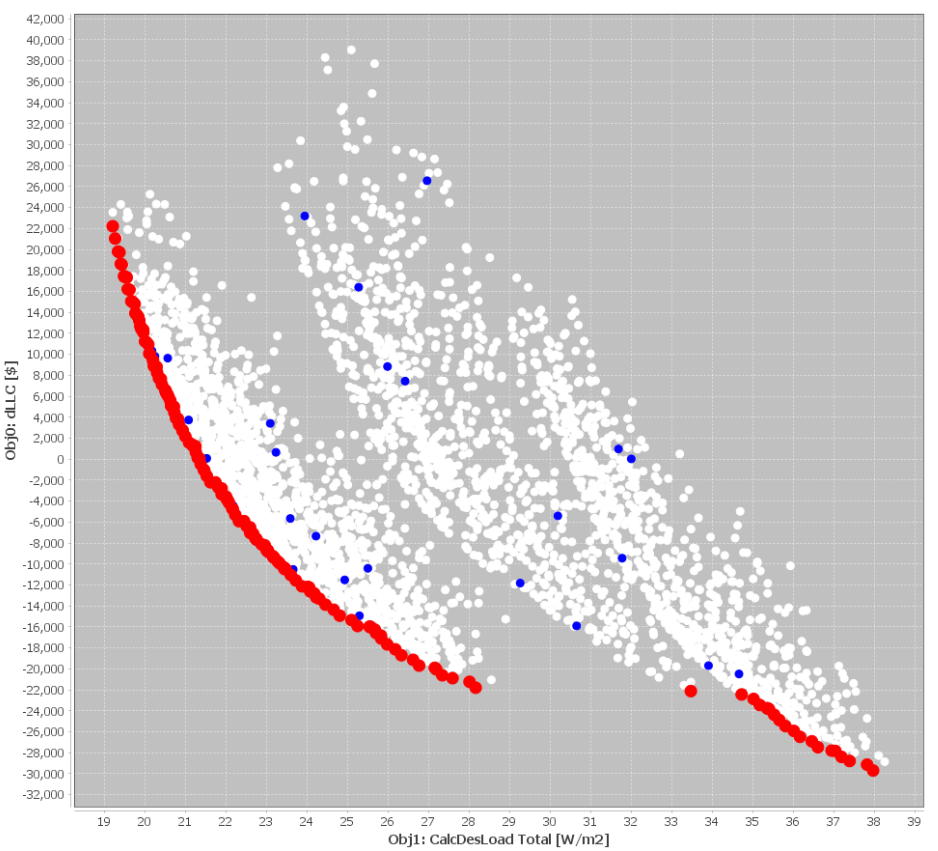

Figure 10.1: Case 1 total design load versus dLCC

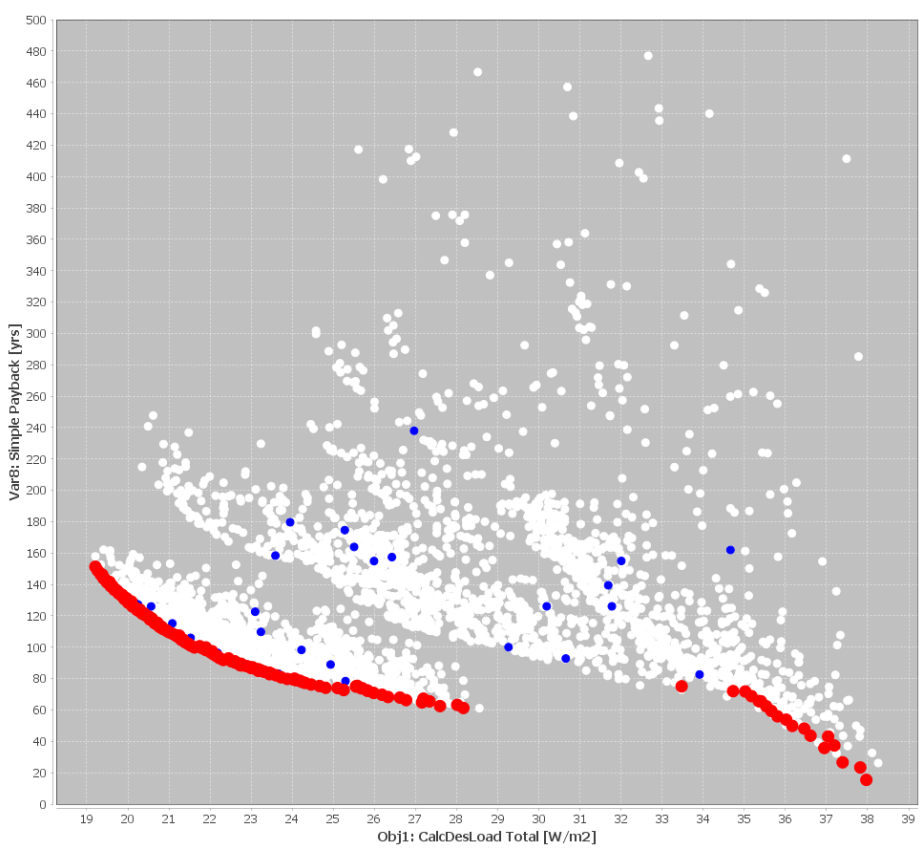

Figure 10.2: Case 1 total design load versus simple payback 


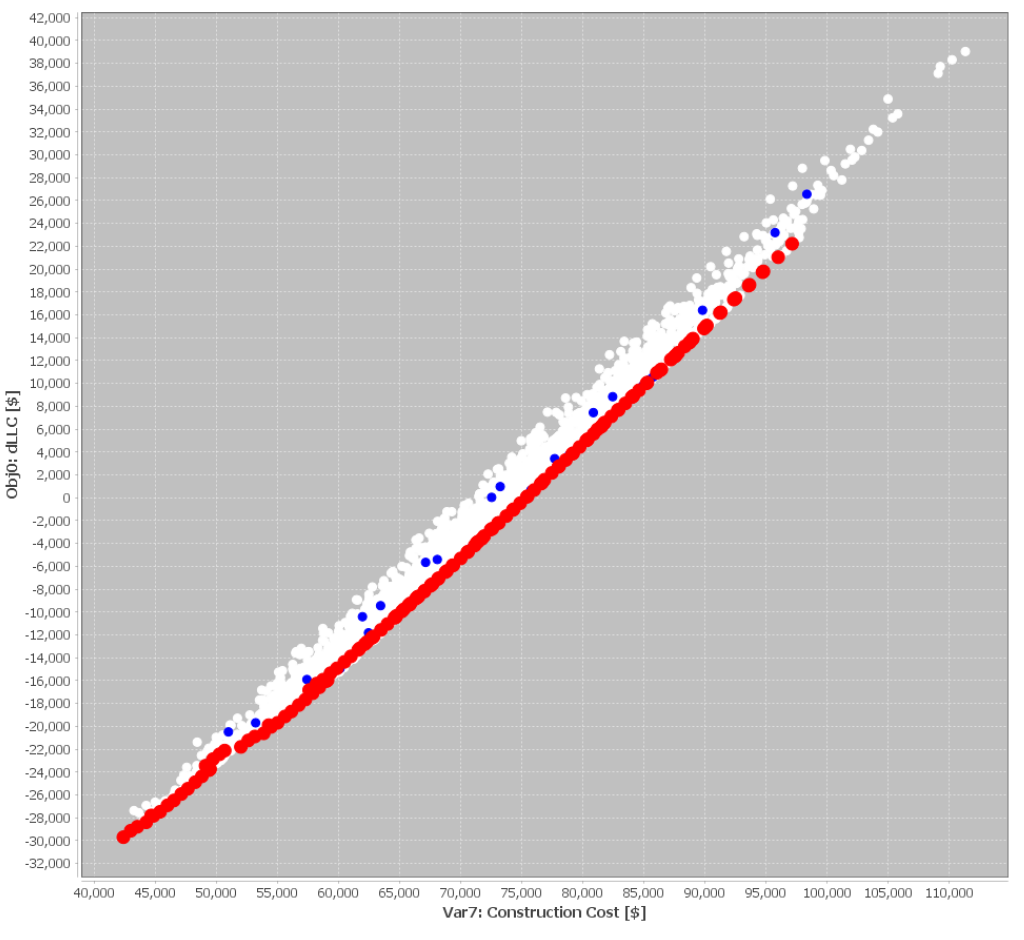

Figure 10.3: Case 1 construction cost versus dLCC

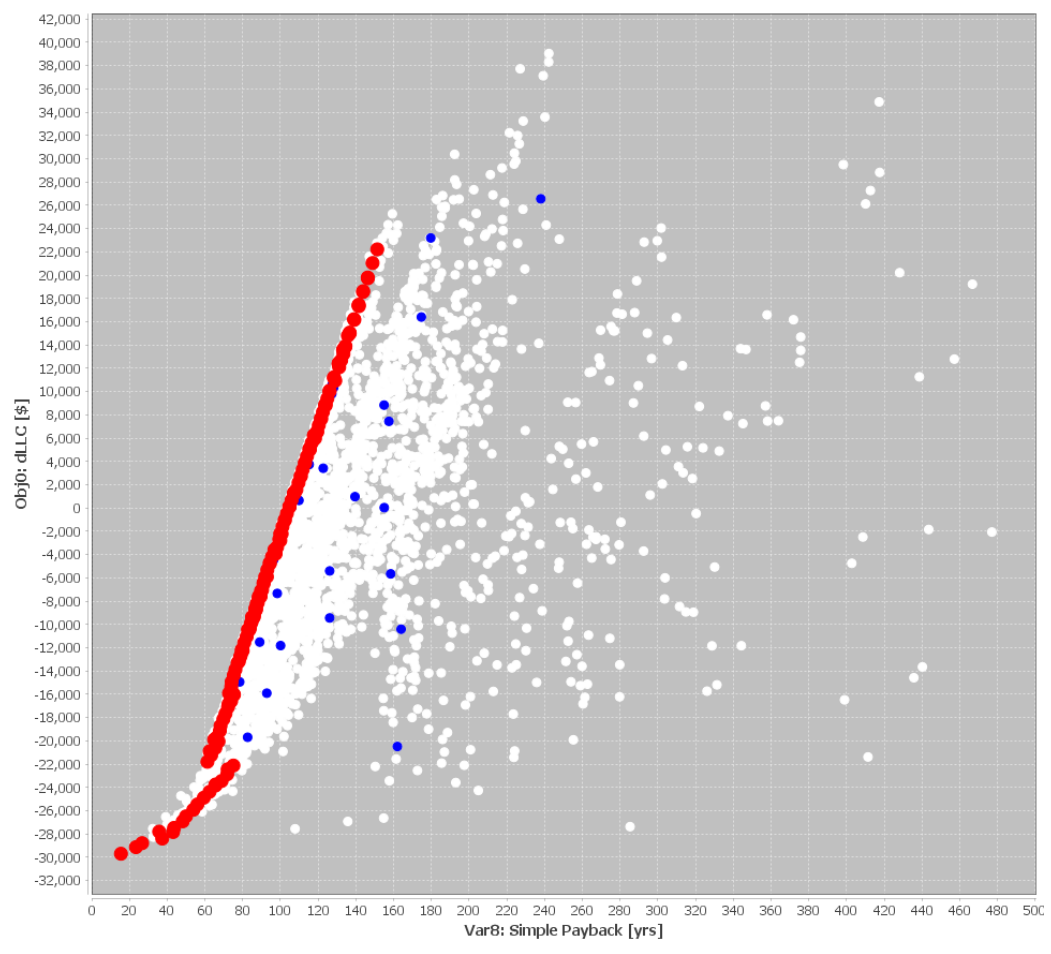

Figure 10.4: Case 1 simple payback versus dLCC 


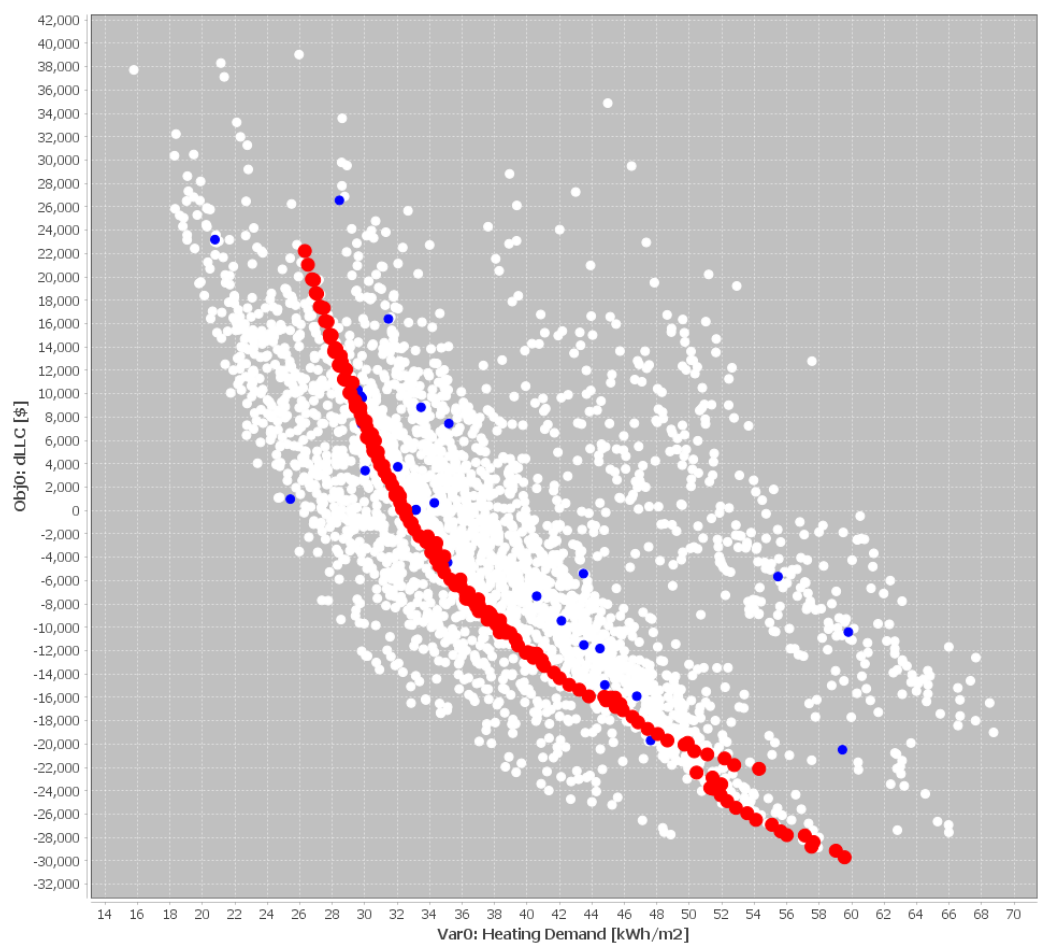

Figure 10.5: Case 1 annual heating demand versus dLCC

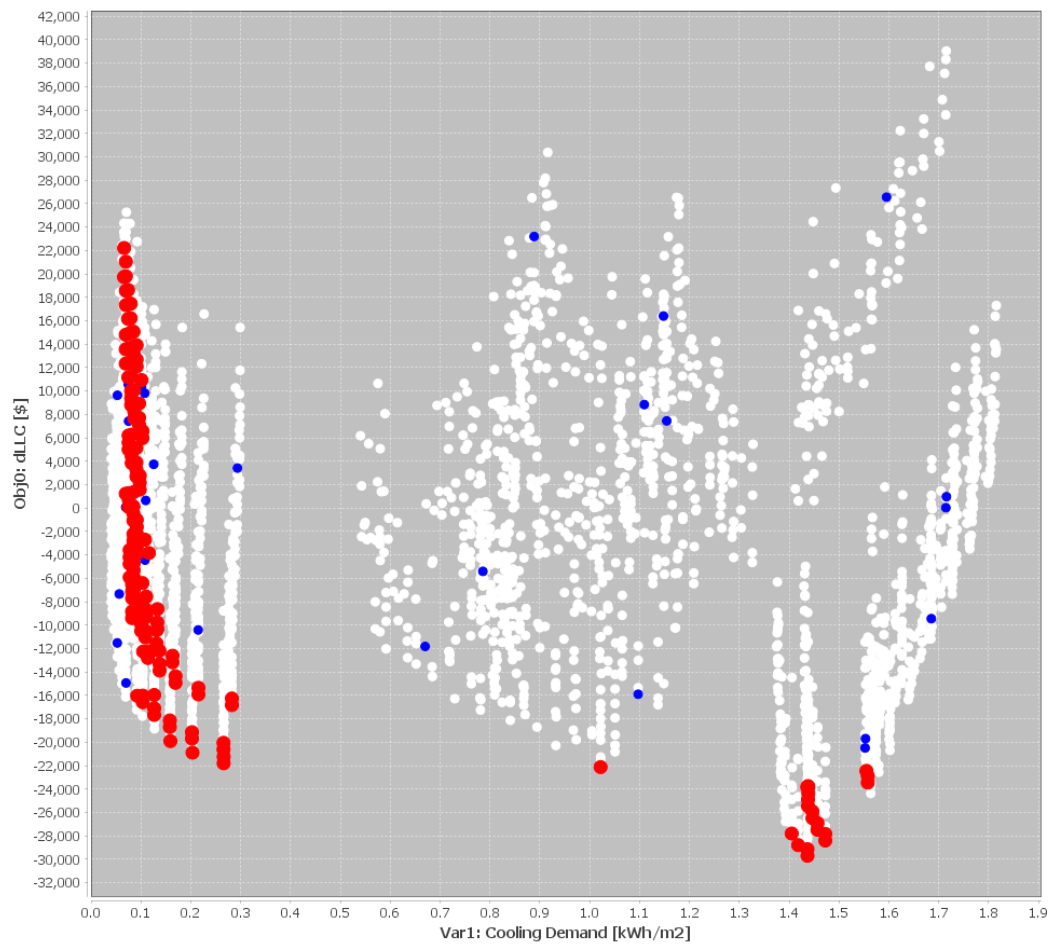

Figure 10.6: Case 1 annual cooling demand versus dLCC 


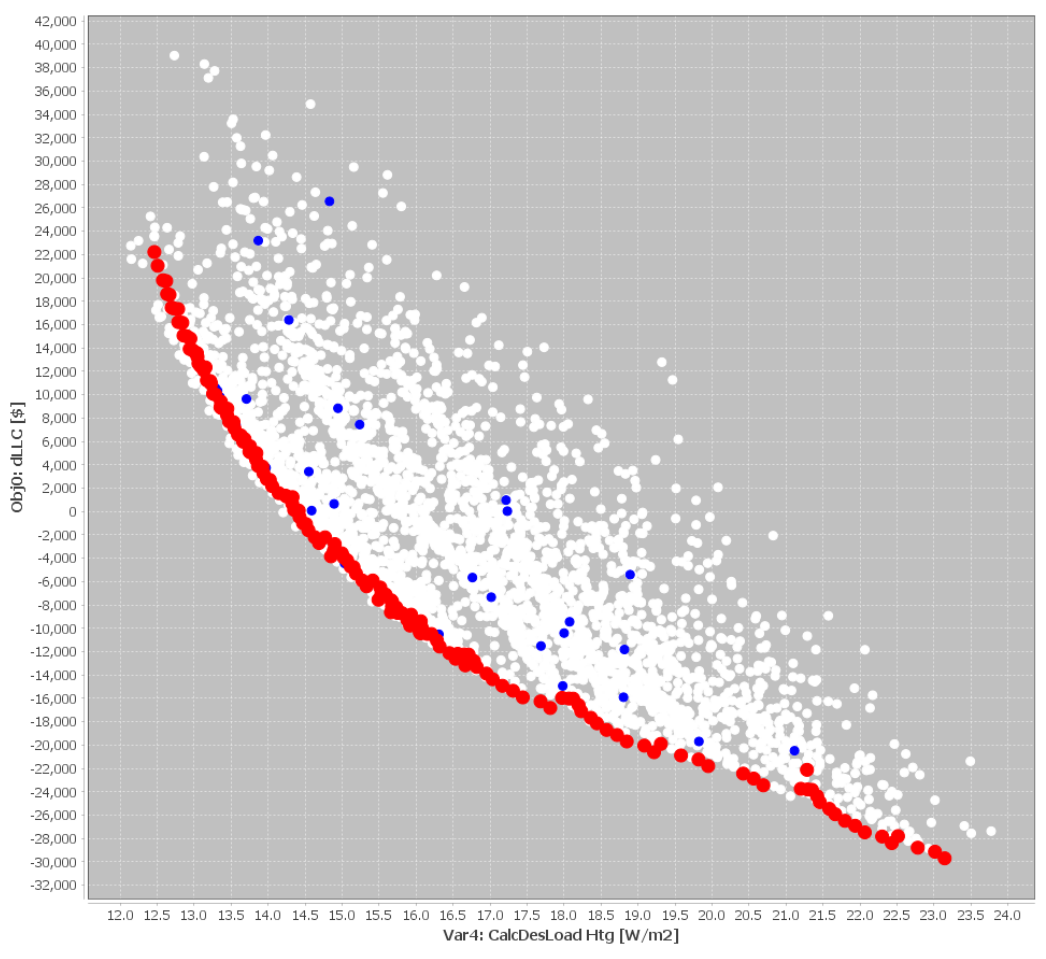

Figure 10.7: Case 1 heating design load versus dLCC

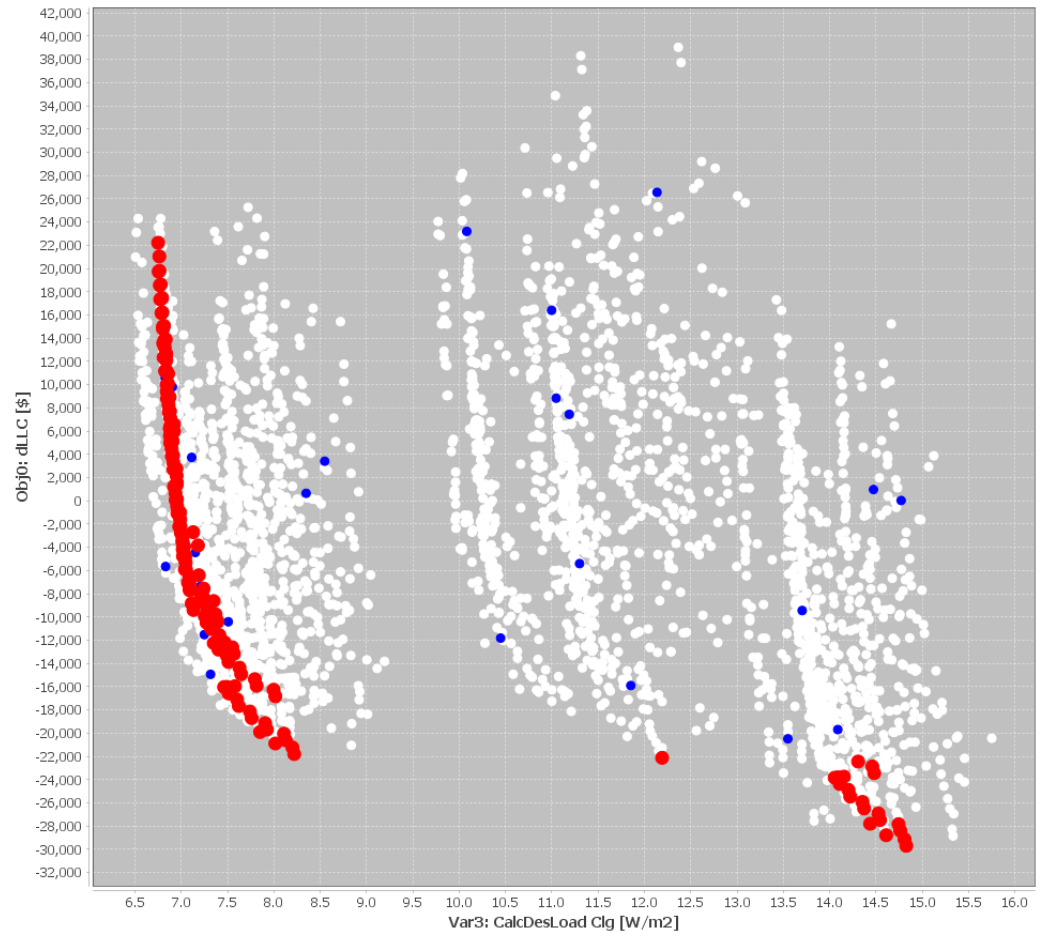

Figure 10.8: Case 1 cooling design load versus dLCC 


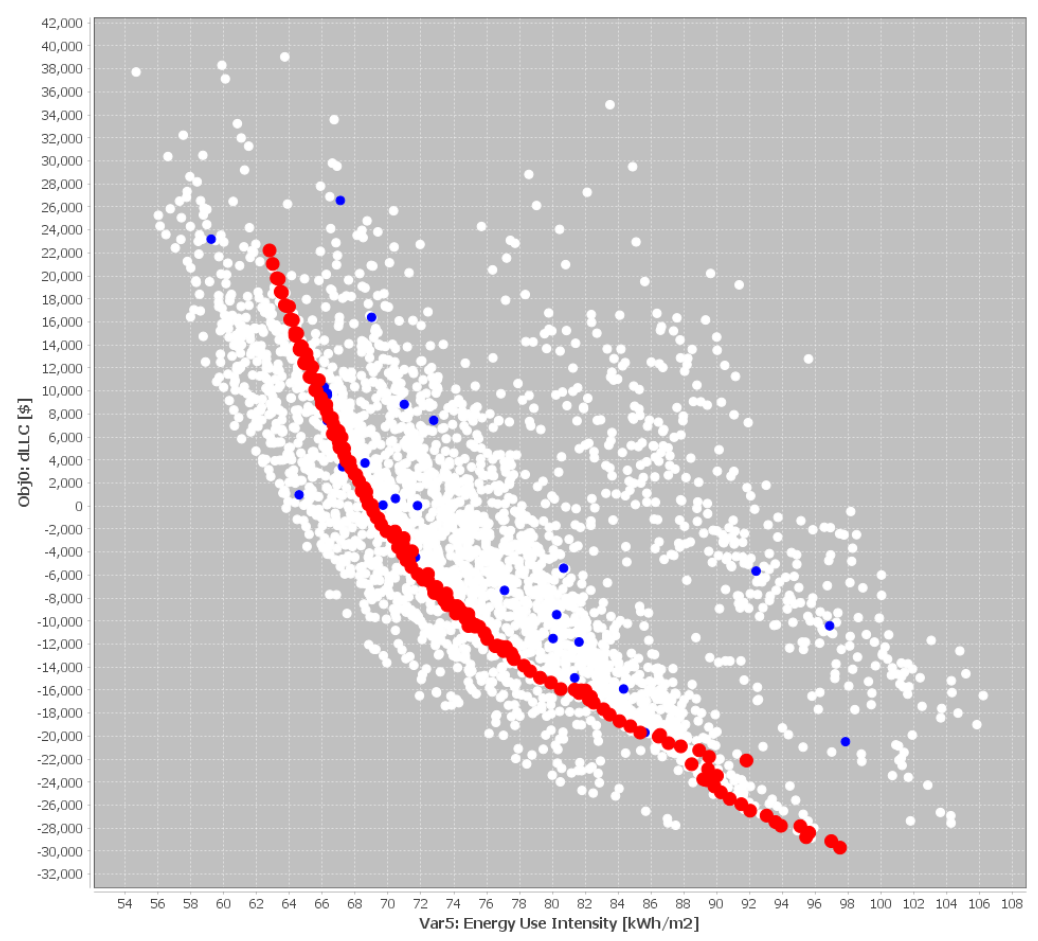

Figure 10.9: Case 1 EUI versus dLCC

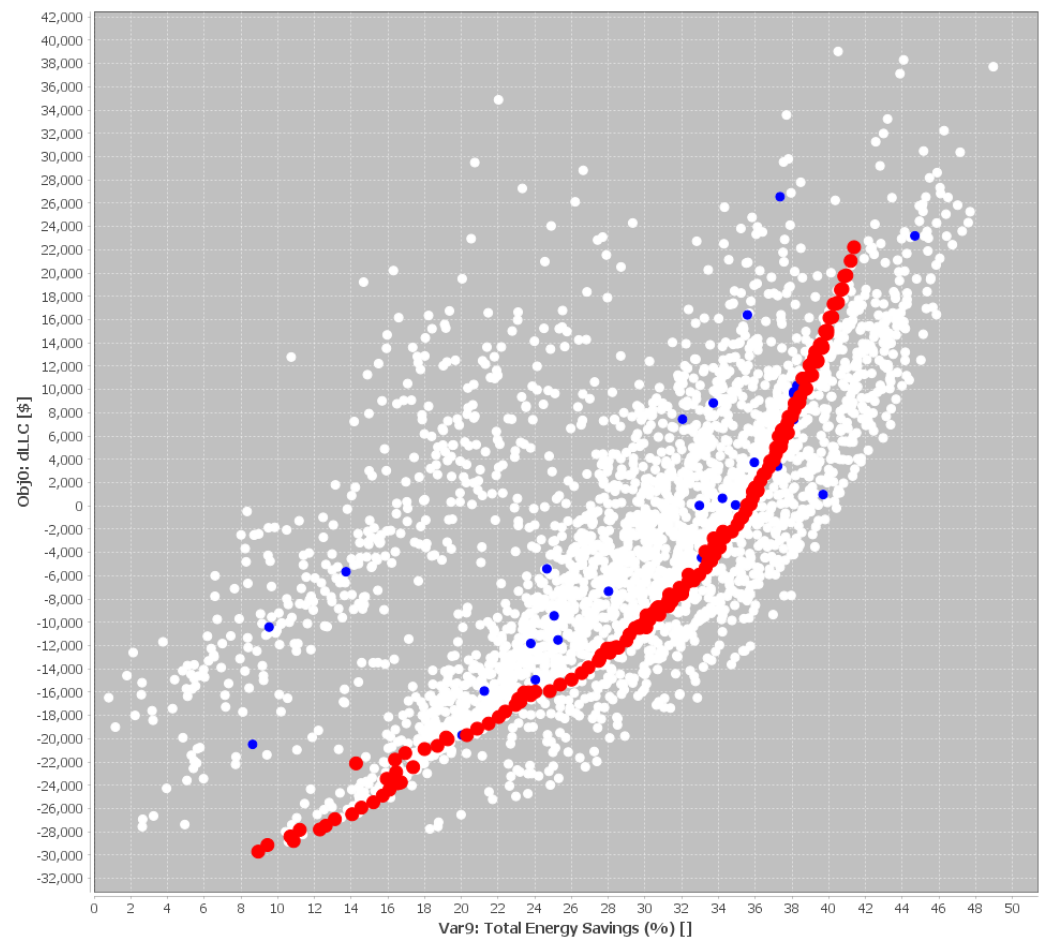

Figure 10.10: Case 1 annual energy savings versus dLCC 
Output variables for Case 2 (low discount case) with total peak load performance objective

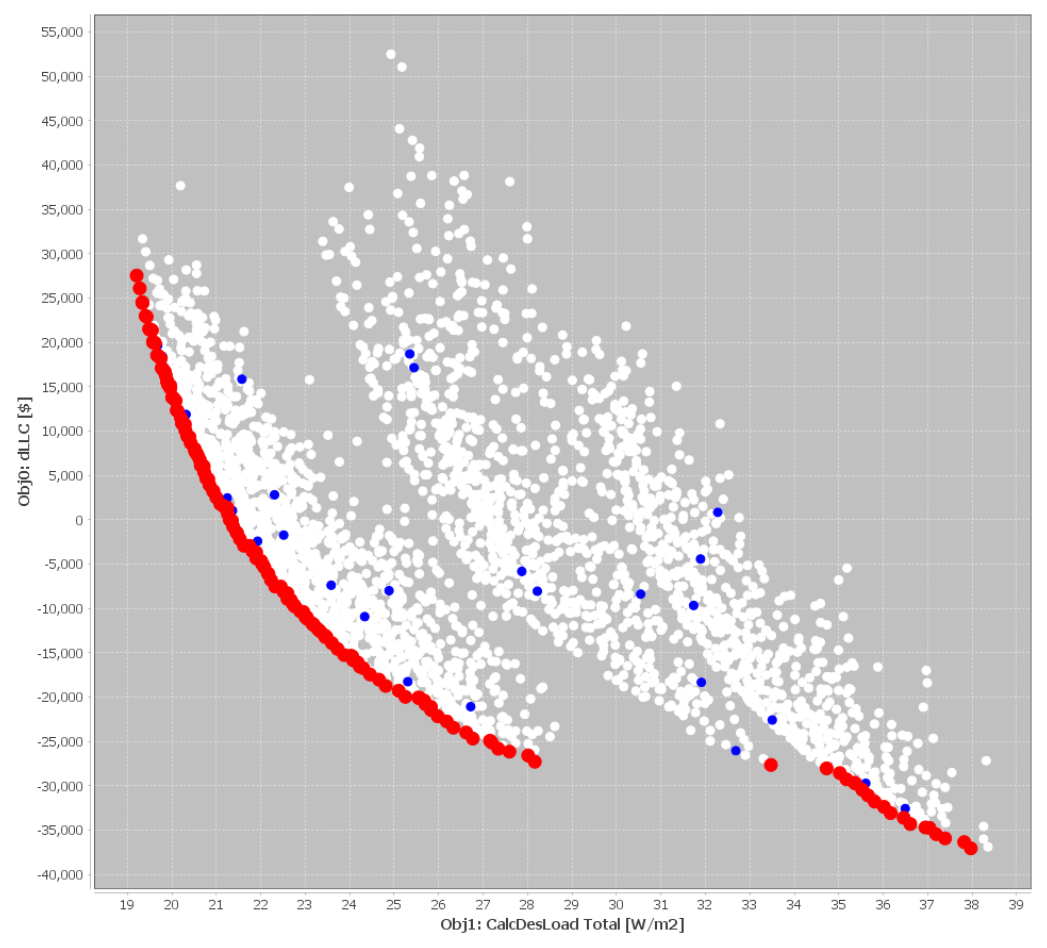

Figure 10.11: Case 2 total design load versus dLCC

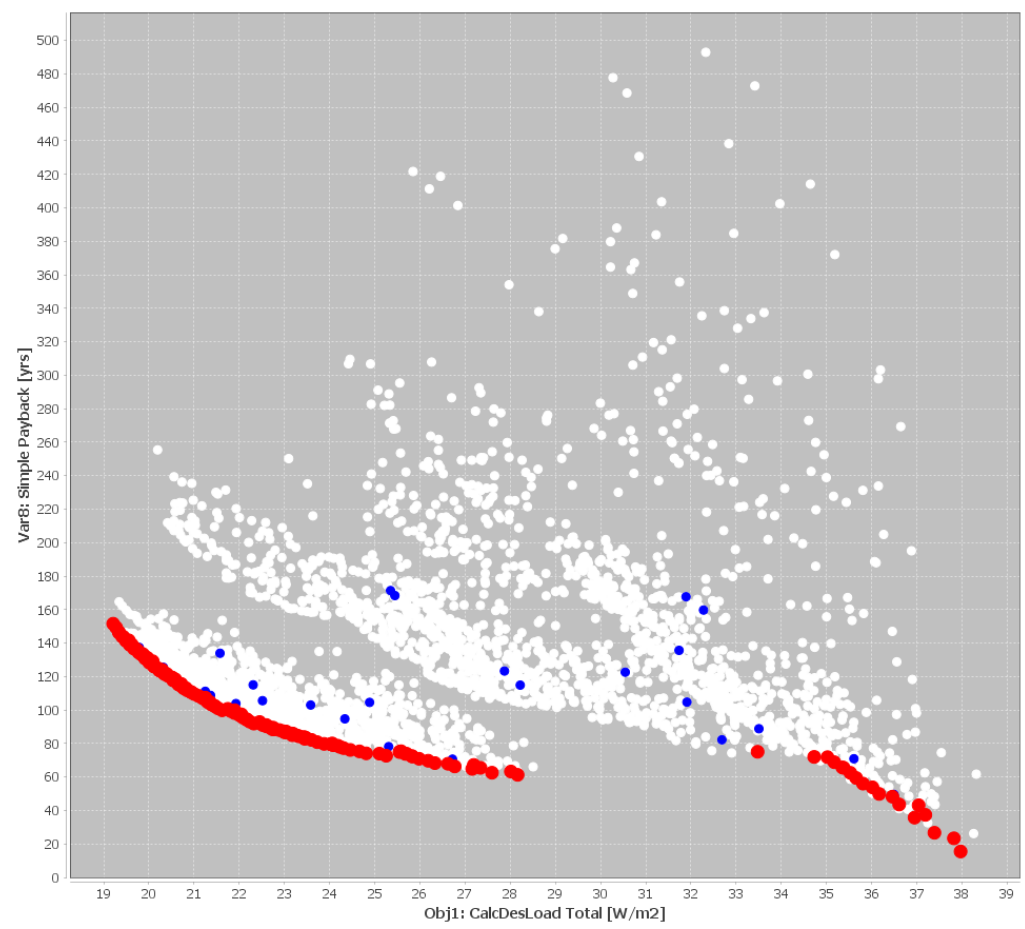

Figure 10.12: Case 2 total design load versus simple payback 


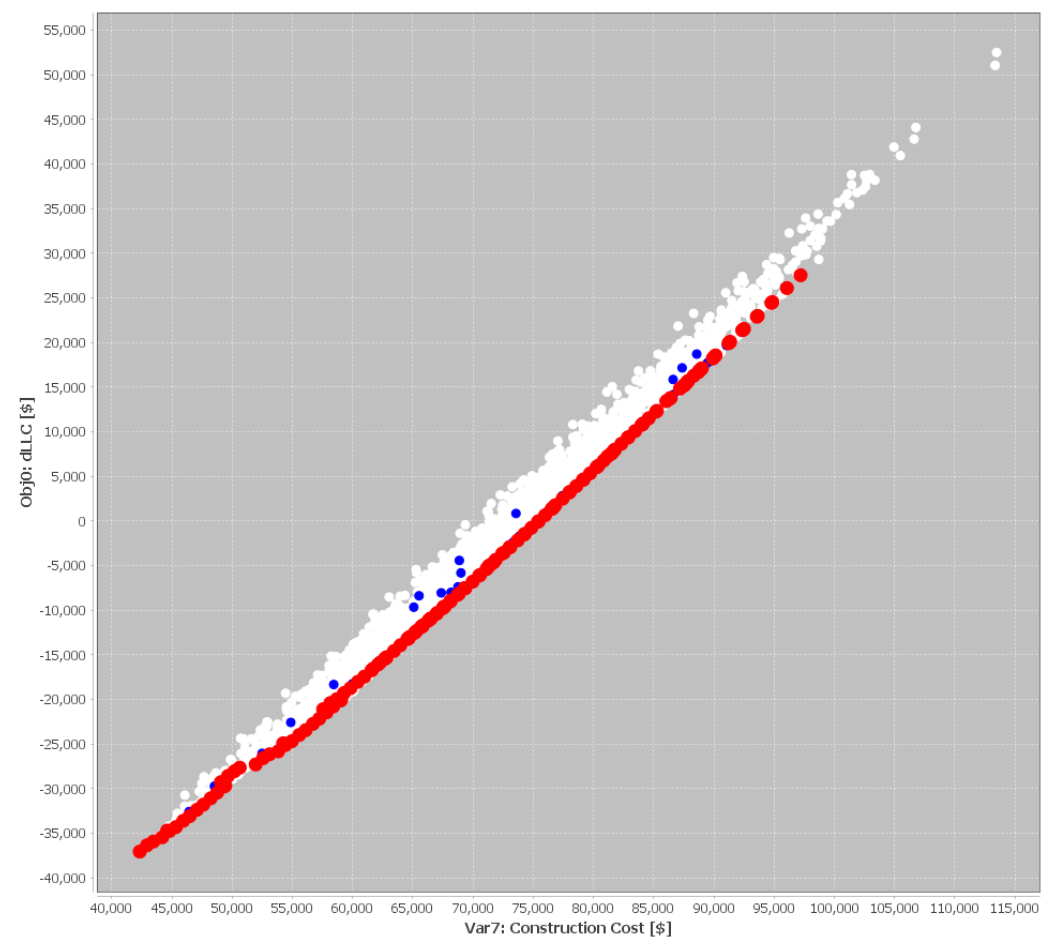

Figure 10.13: Case 2 construction cost versus dLCC

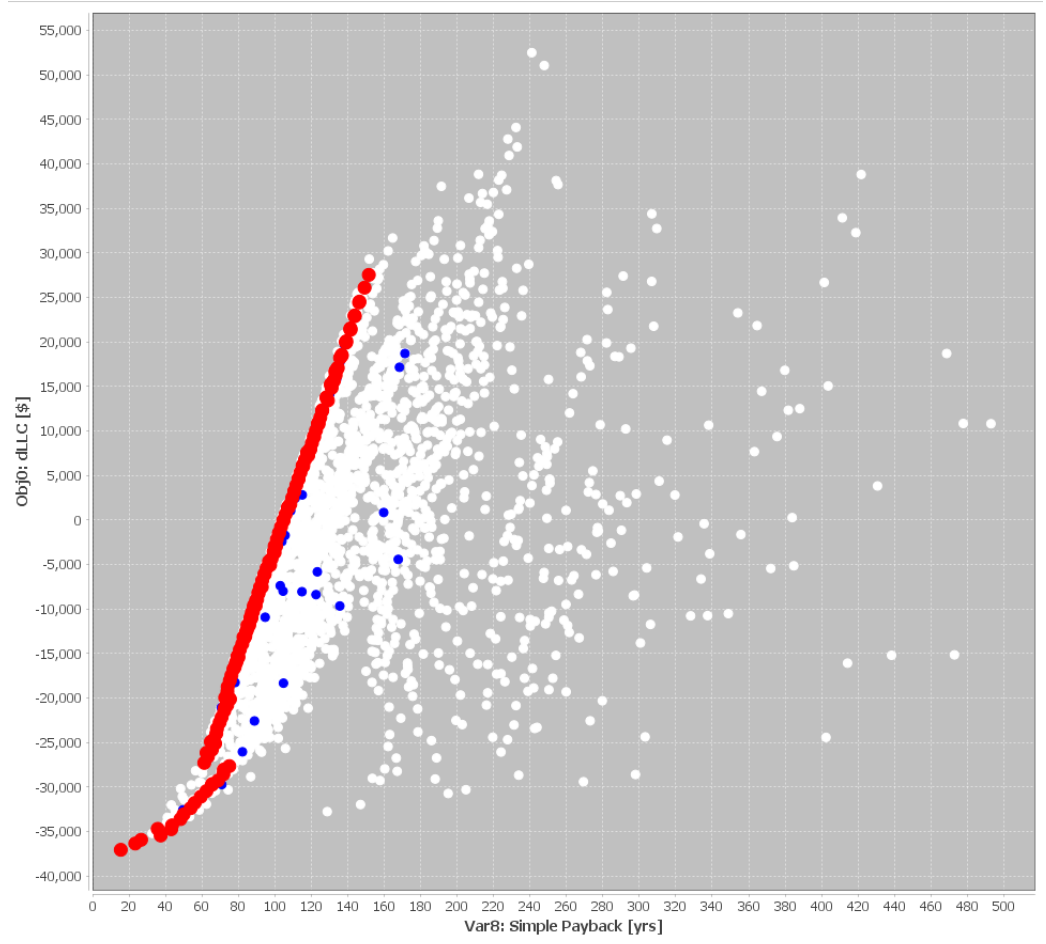

Figure 10.14: Case 2 simple payback versus dLCC 


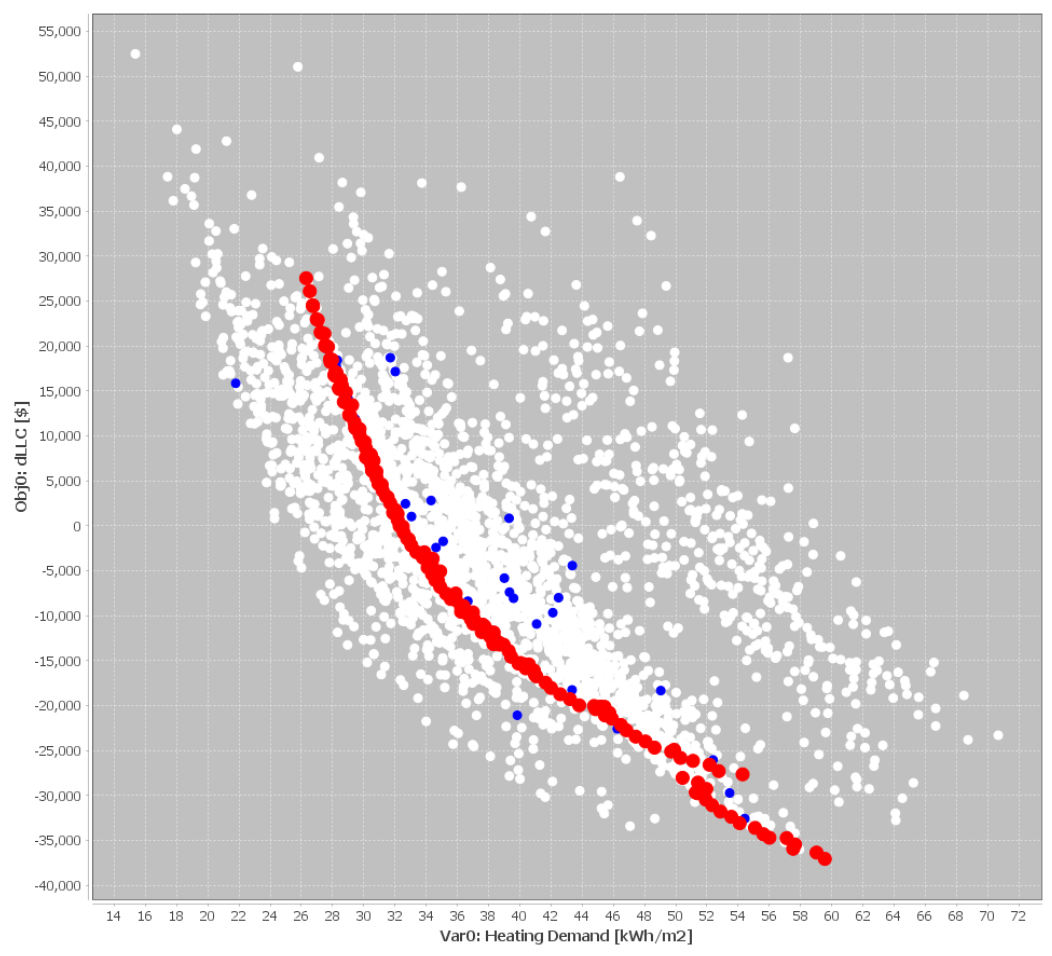

Figure 10.15: Case 2 annual heating demand versus dLCC

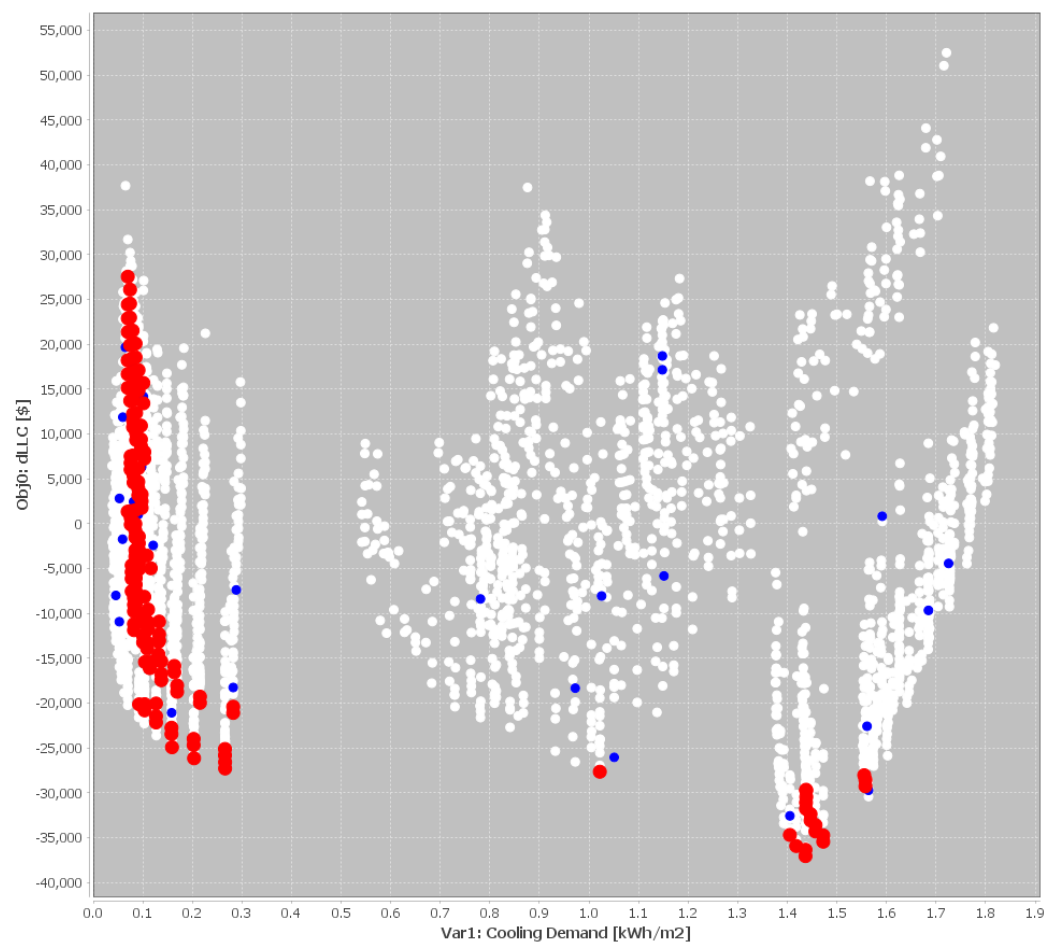

Figure 10.16: Case 2 annual cooling demand versus dLCC 


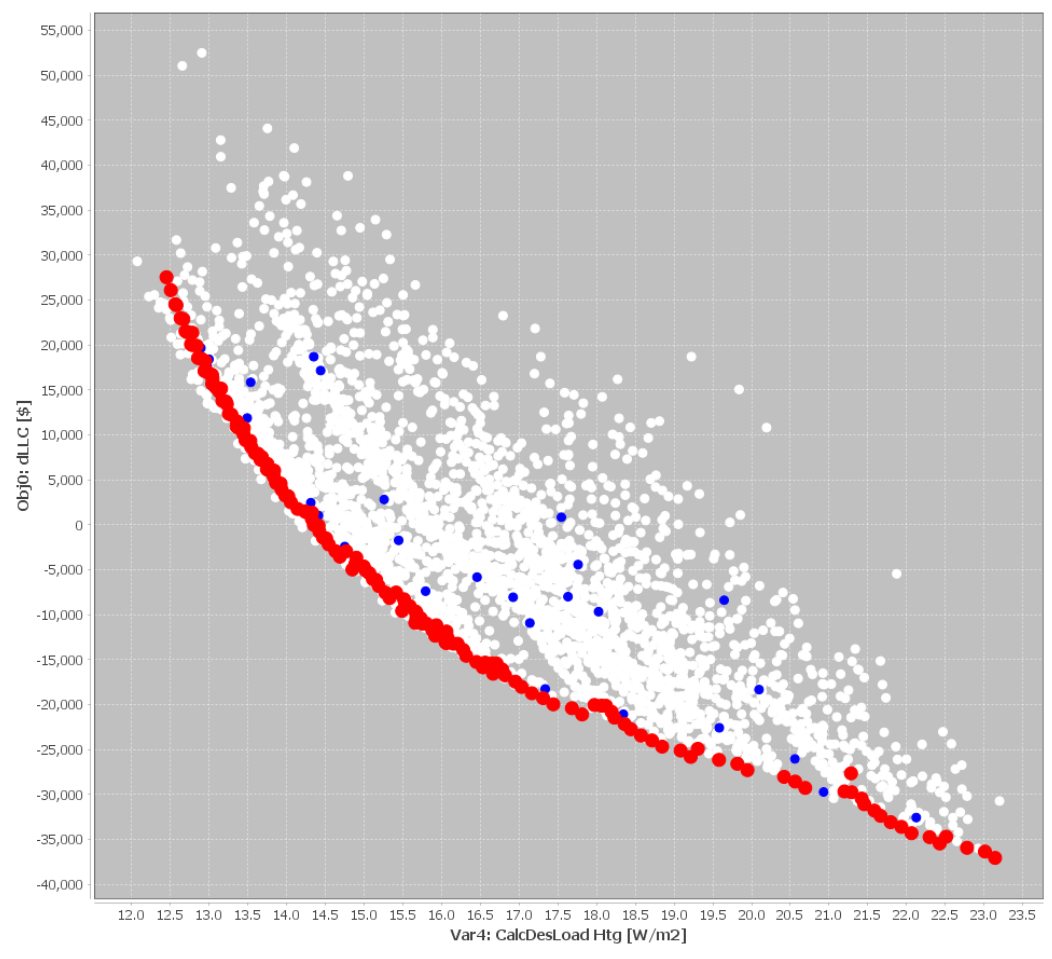

Figure 10.17: Case 2 heating design load versus dLCC

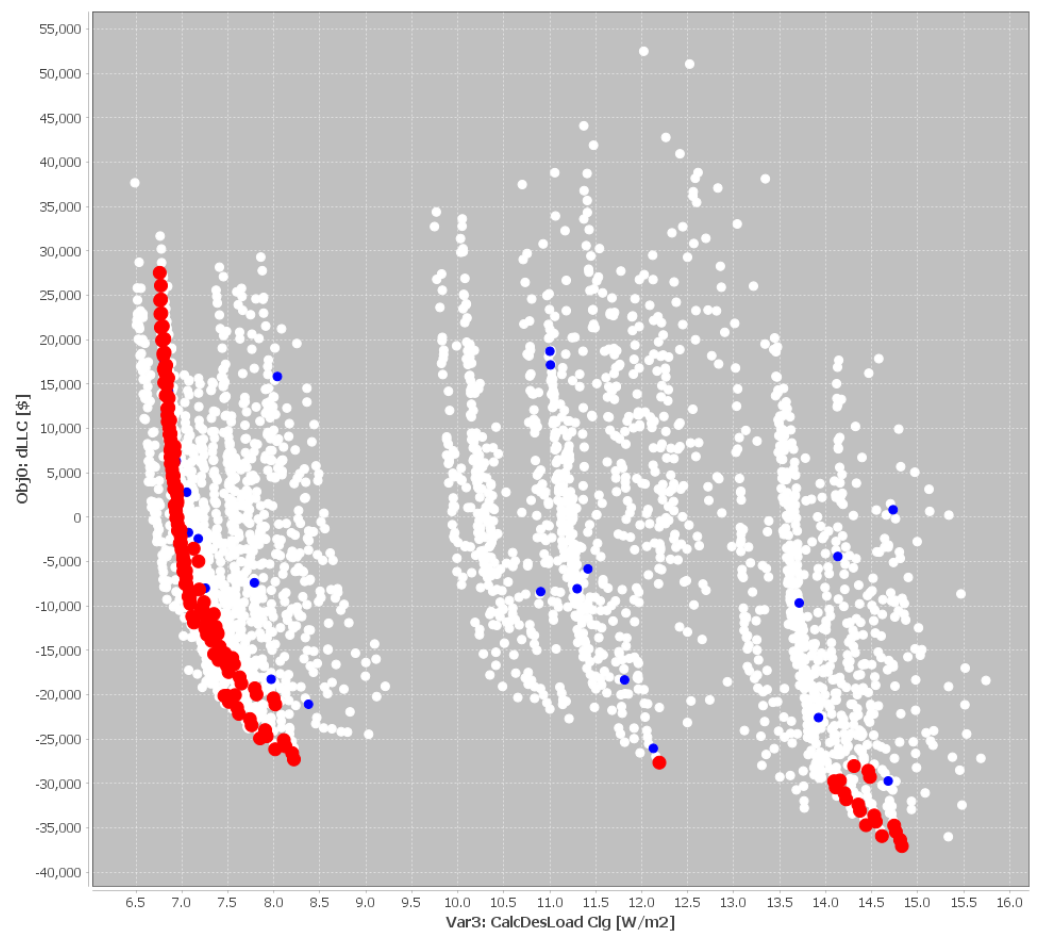

Figure 10.18: Case 2 cooling design load versus dLCC 


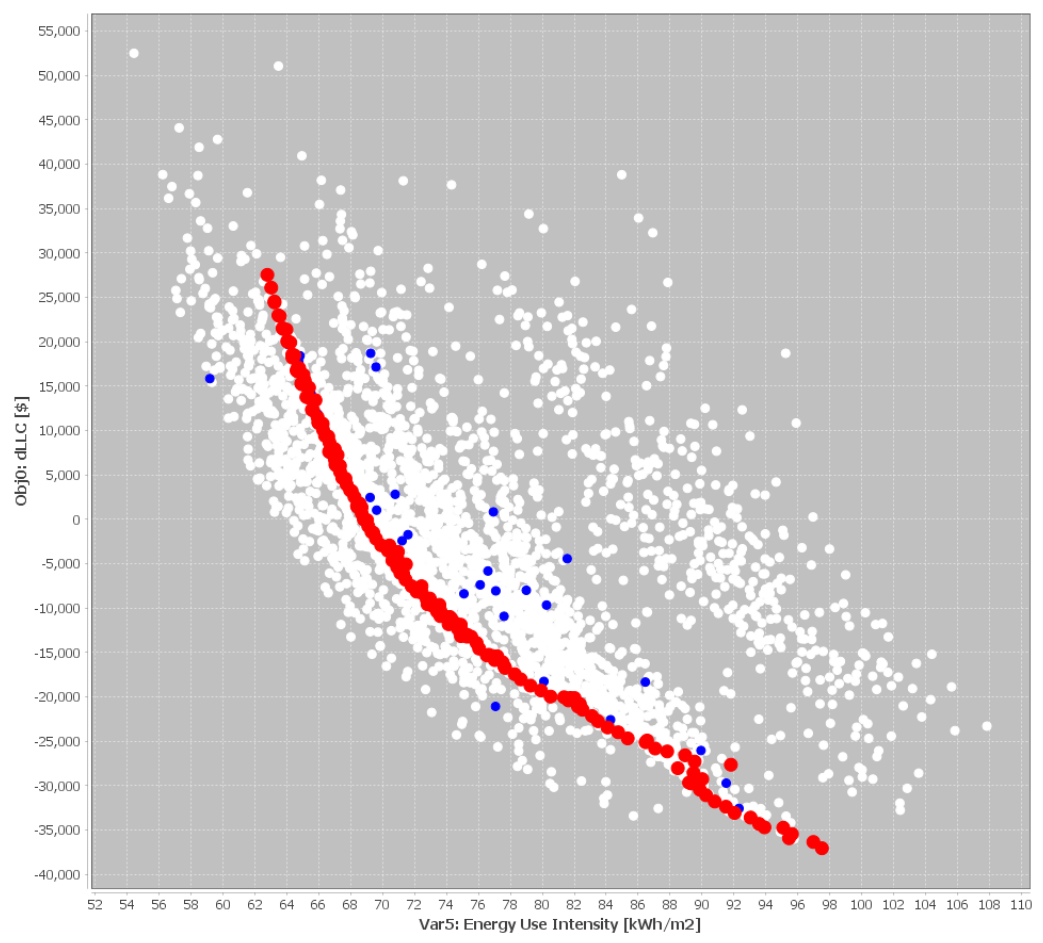

Figure 10.19: Case 2 EUI versus dLCC

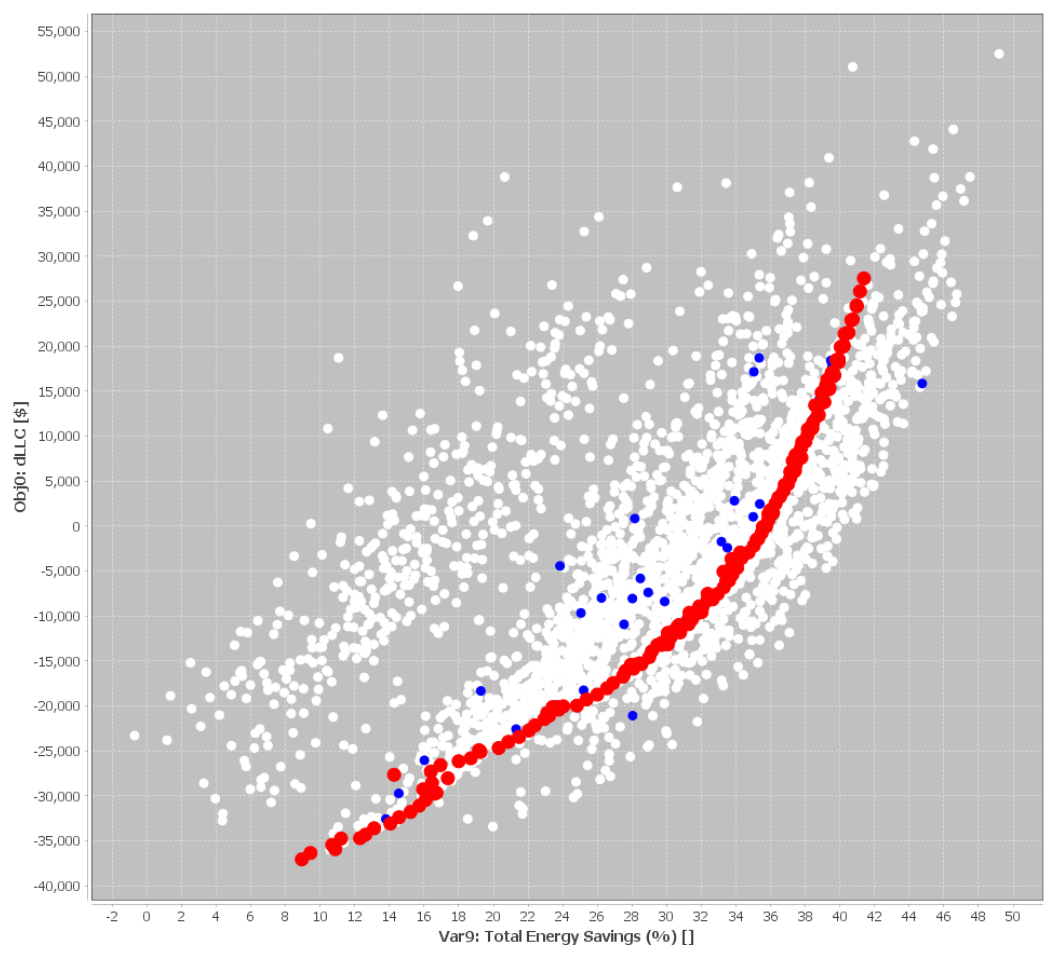

Figure 10.20: Case 2 annual energy savings versus dLCC 
Output variables for Case 3 (high escalation case) with total peak load performance objective

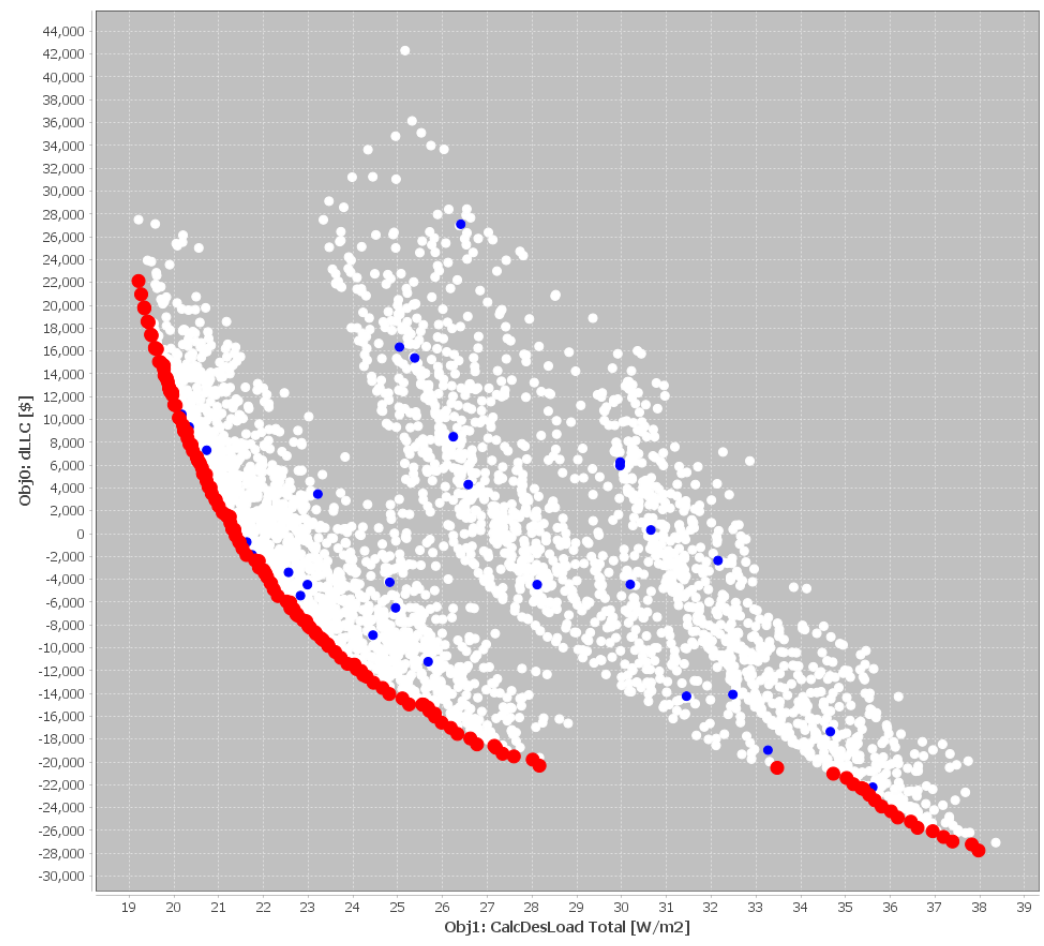

Figure 10.21: Case 3 total design load versus dLCC

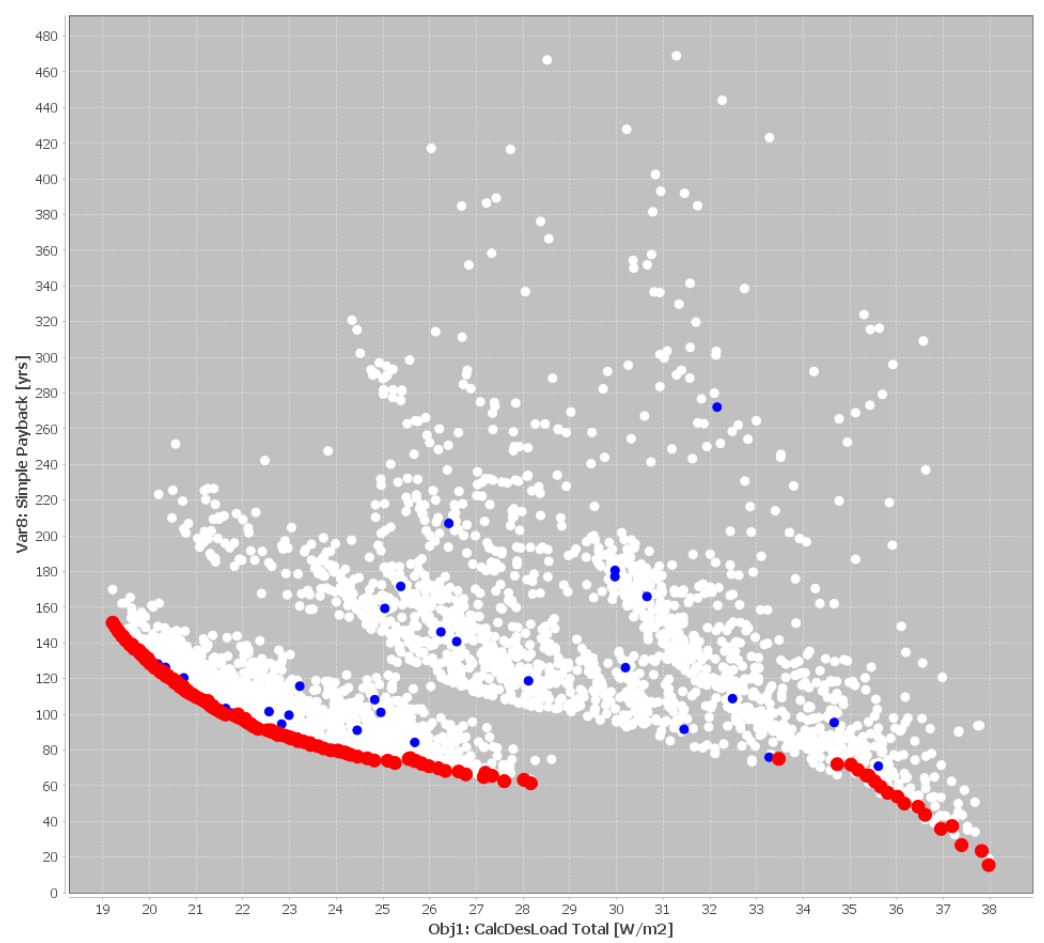

Figure 10.22: Case 3 total design load versus simple payback 


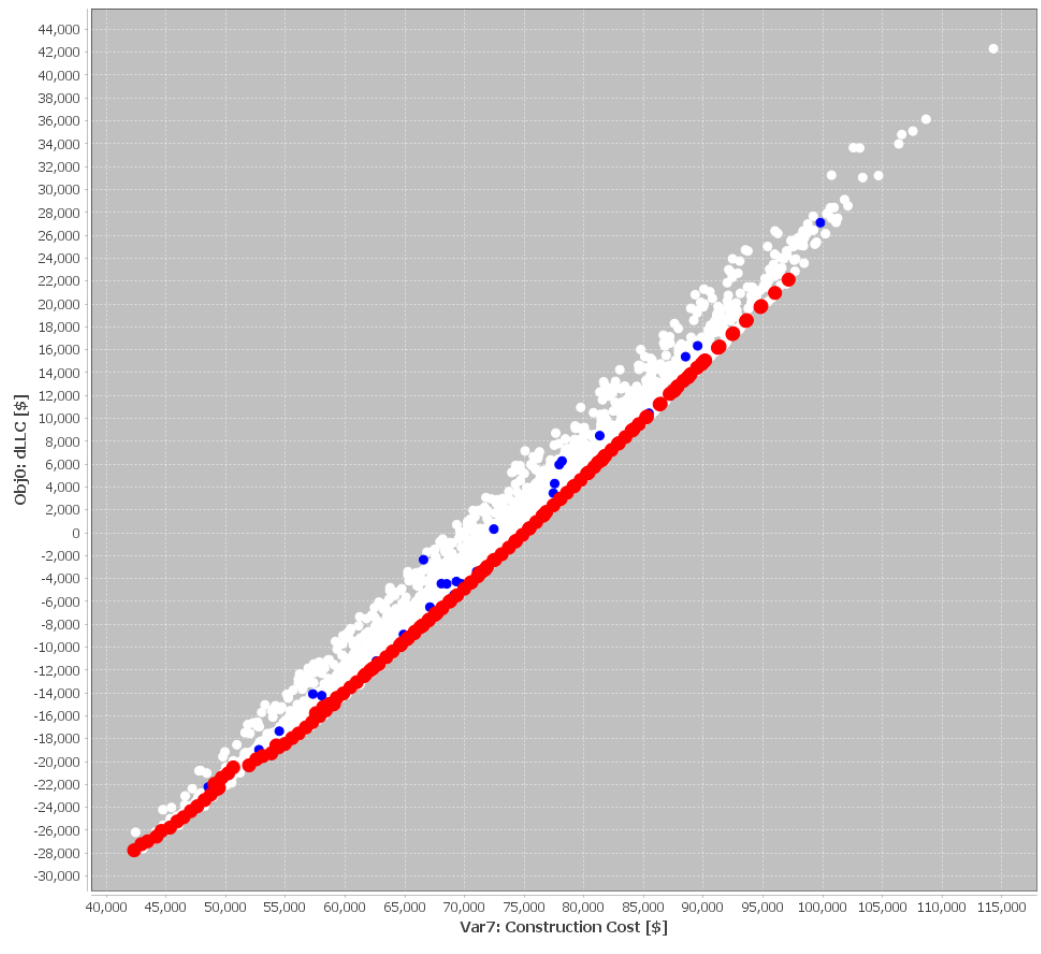

Figure 10.23: Case 3 construction cost versus dLCC

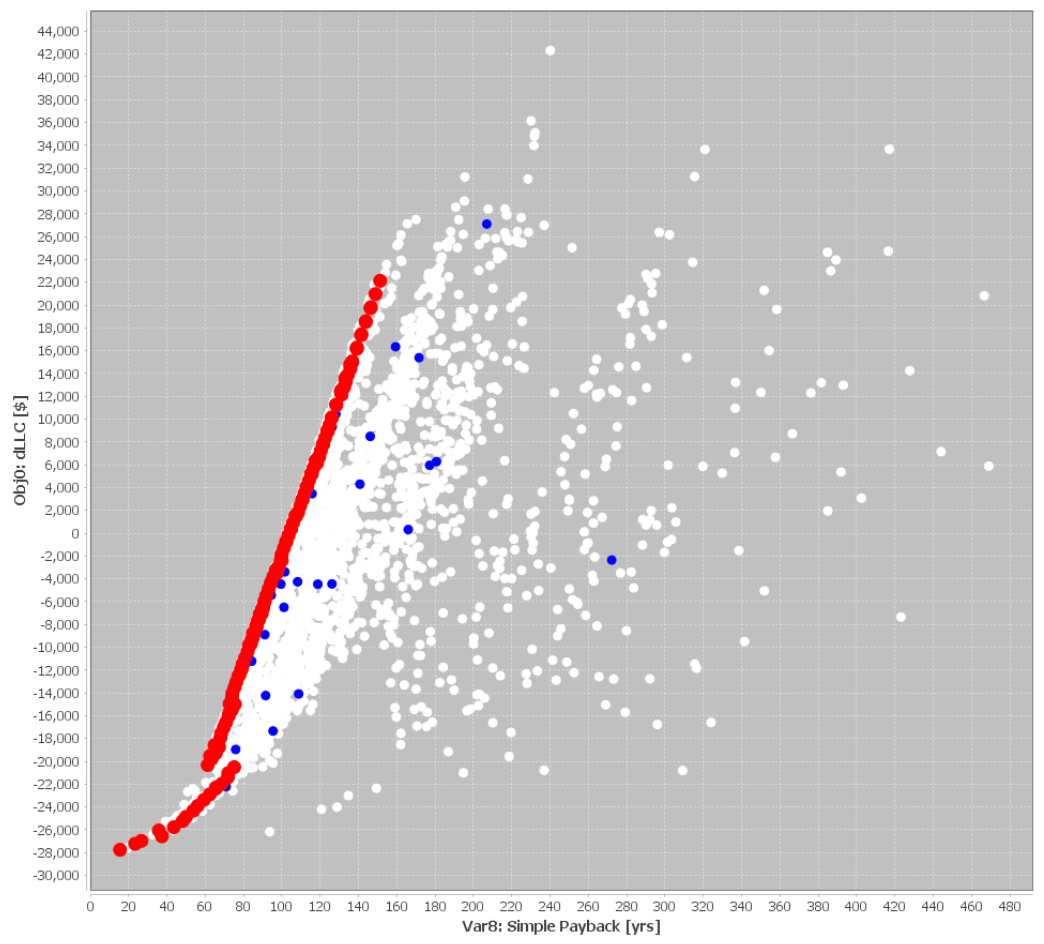

Figure 10.24: Case 3 simple payback versus dLCC 


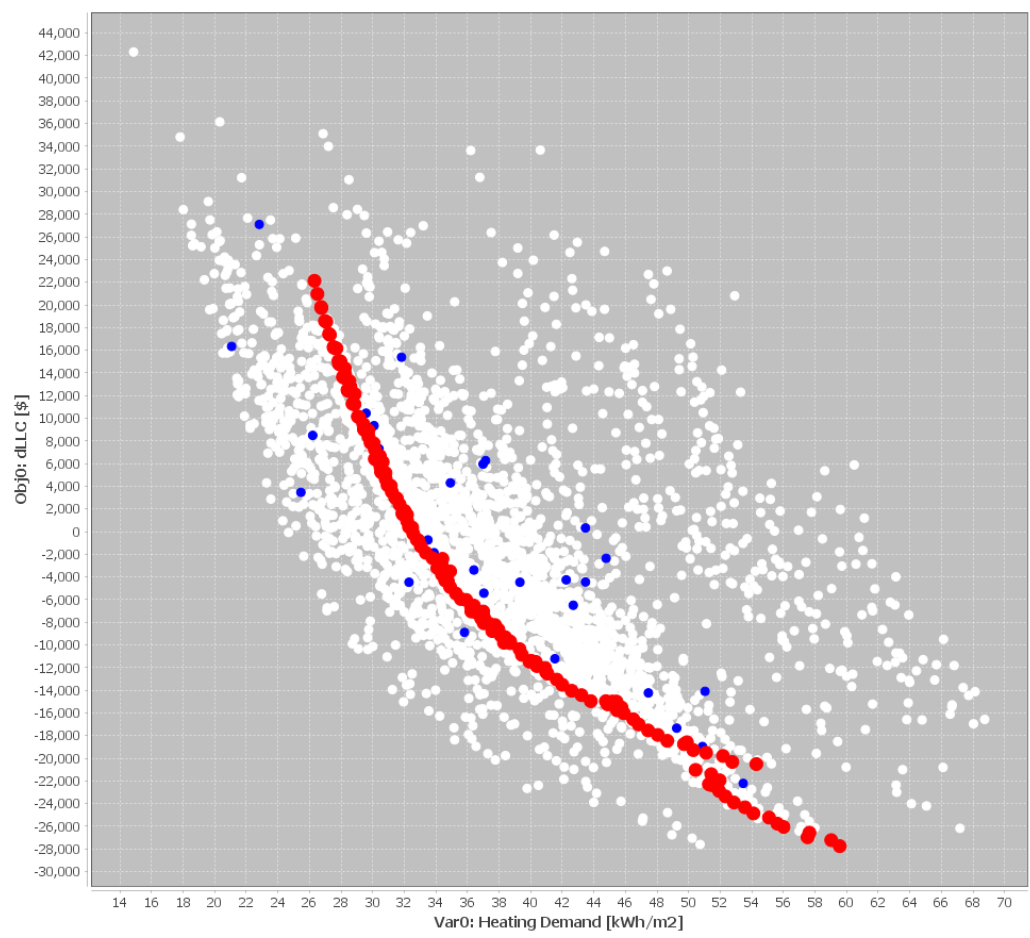

Figure 10.25: Case 3 annual heating demand versus dLCC

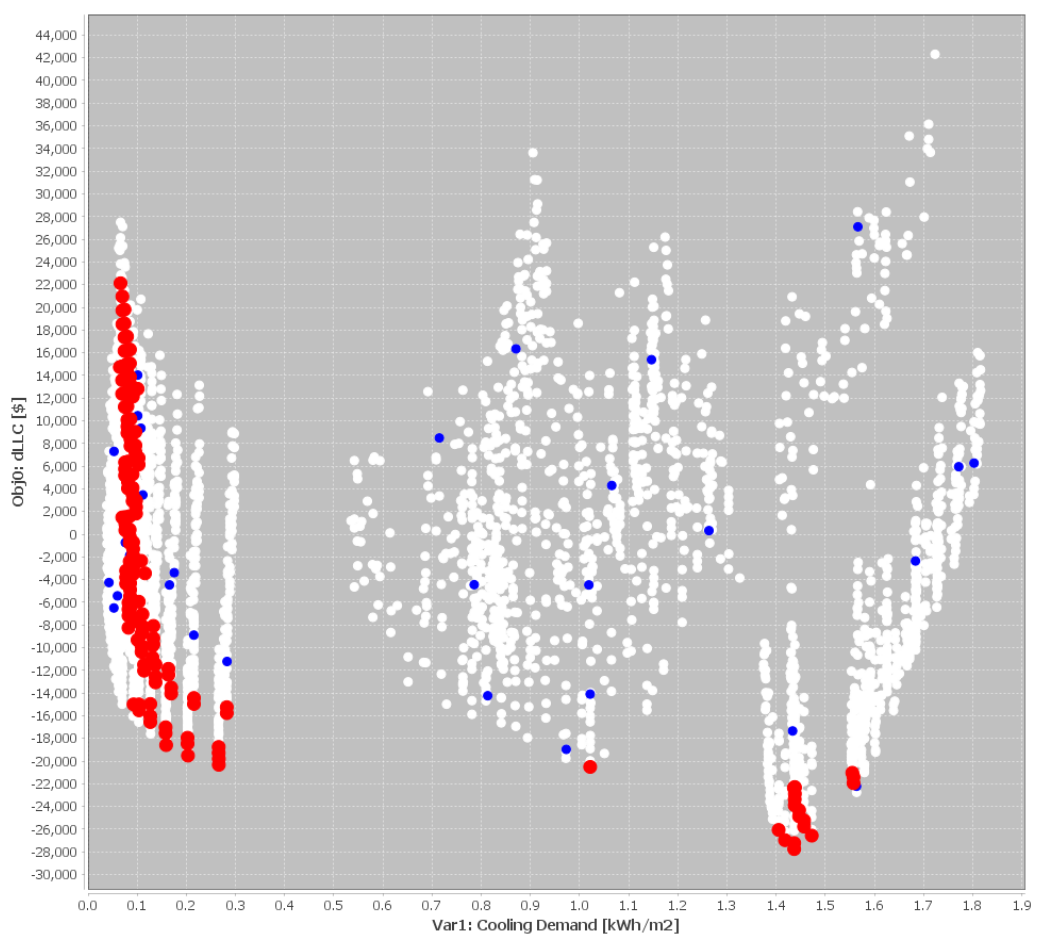

Figure 10.26: Case 3 annual cooling demand versus dLCC 


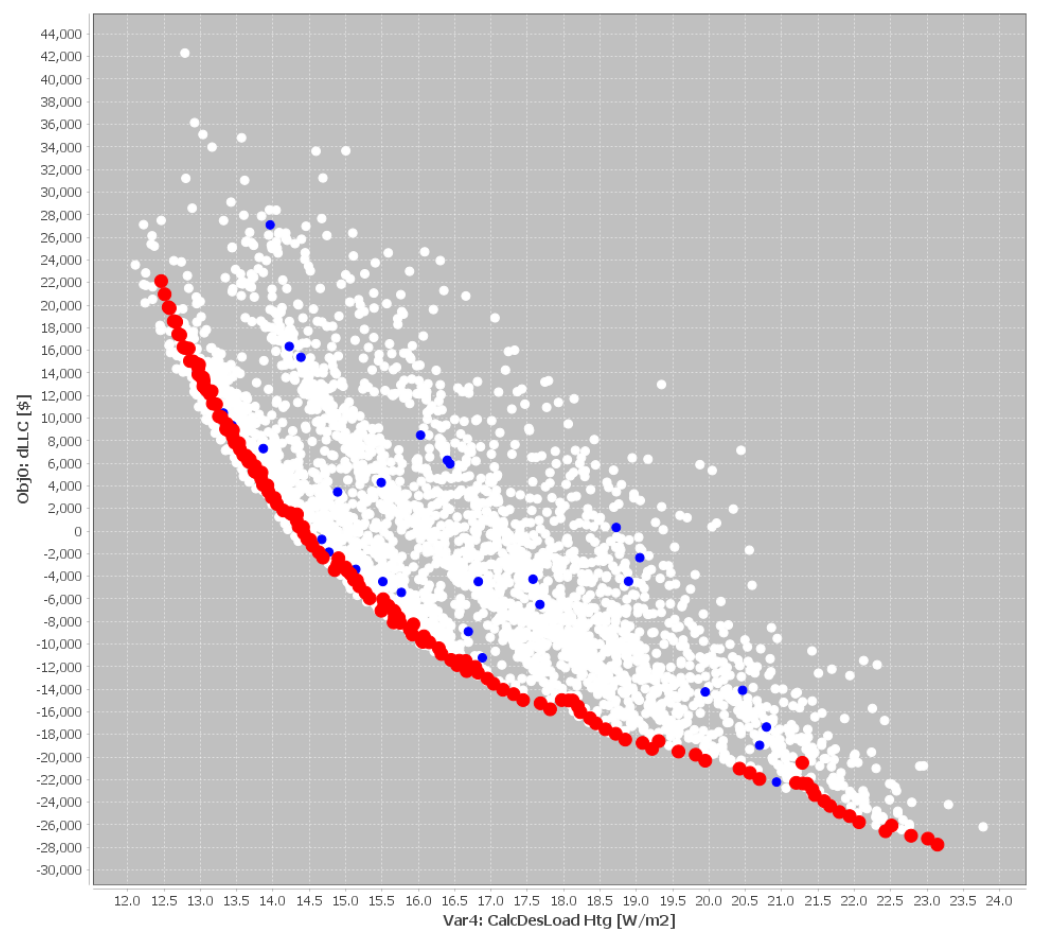

Figure 10.27: Case 3 heating design load versus dLCC

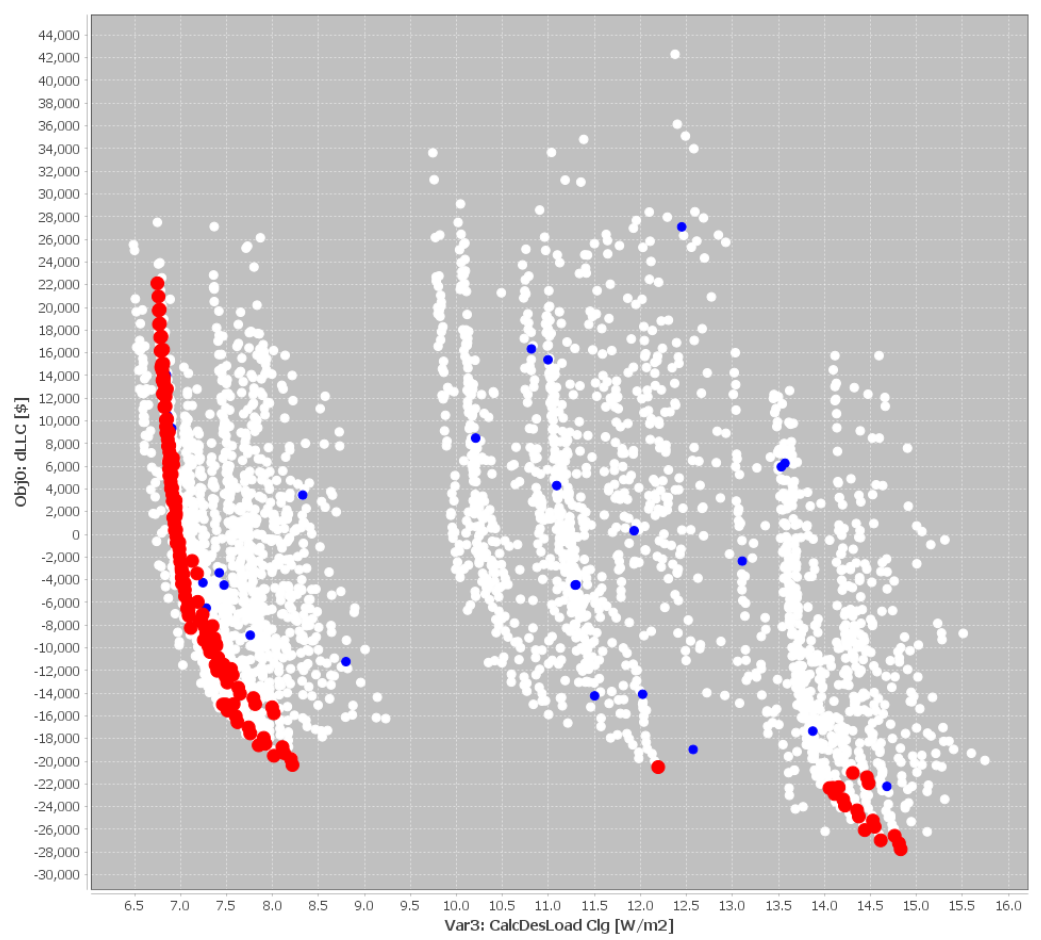

Figure 10.28: Case 3 cooling design load versus dLCC 


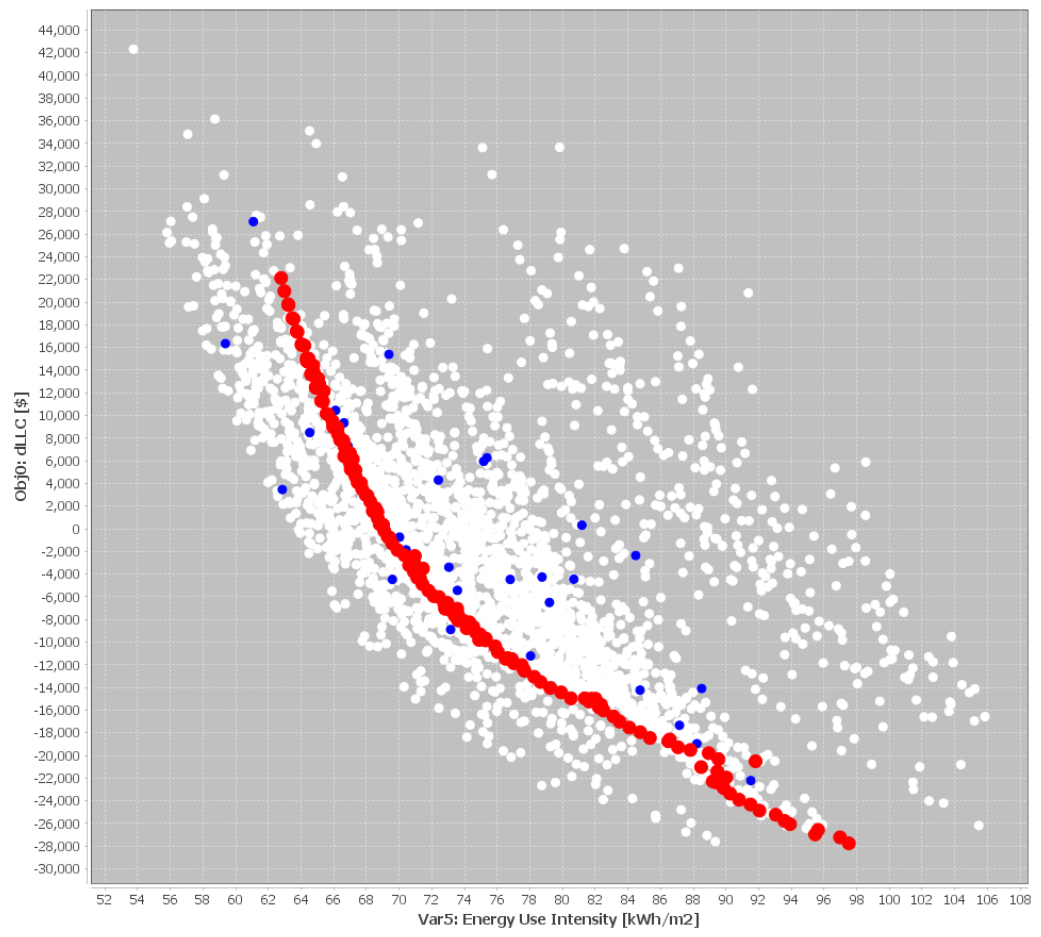

Figure 10.29: Case 3 EUI versus dLCC

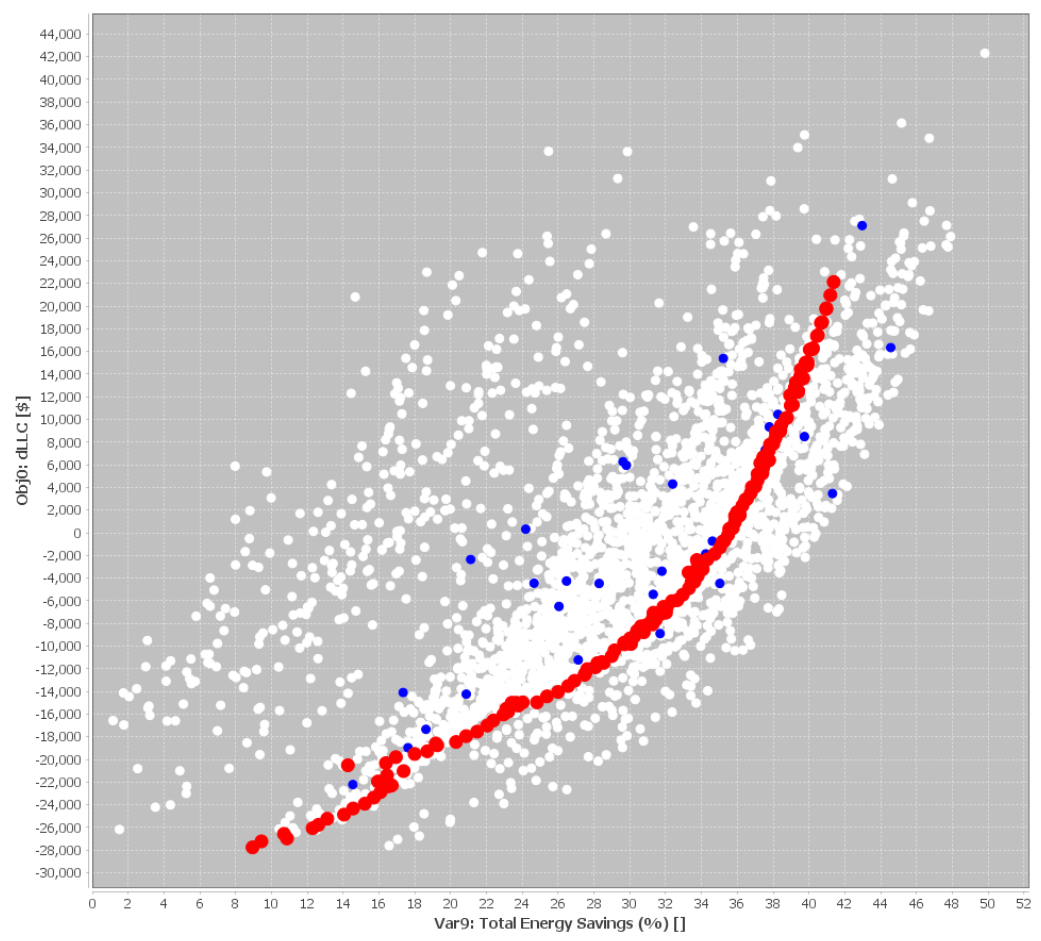

Figure 10.30: Case 3 annual energy savings versus dLCC 
Output variables for Case 4 (low mortgage case) with total peak load performance objective

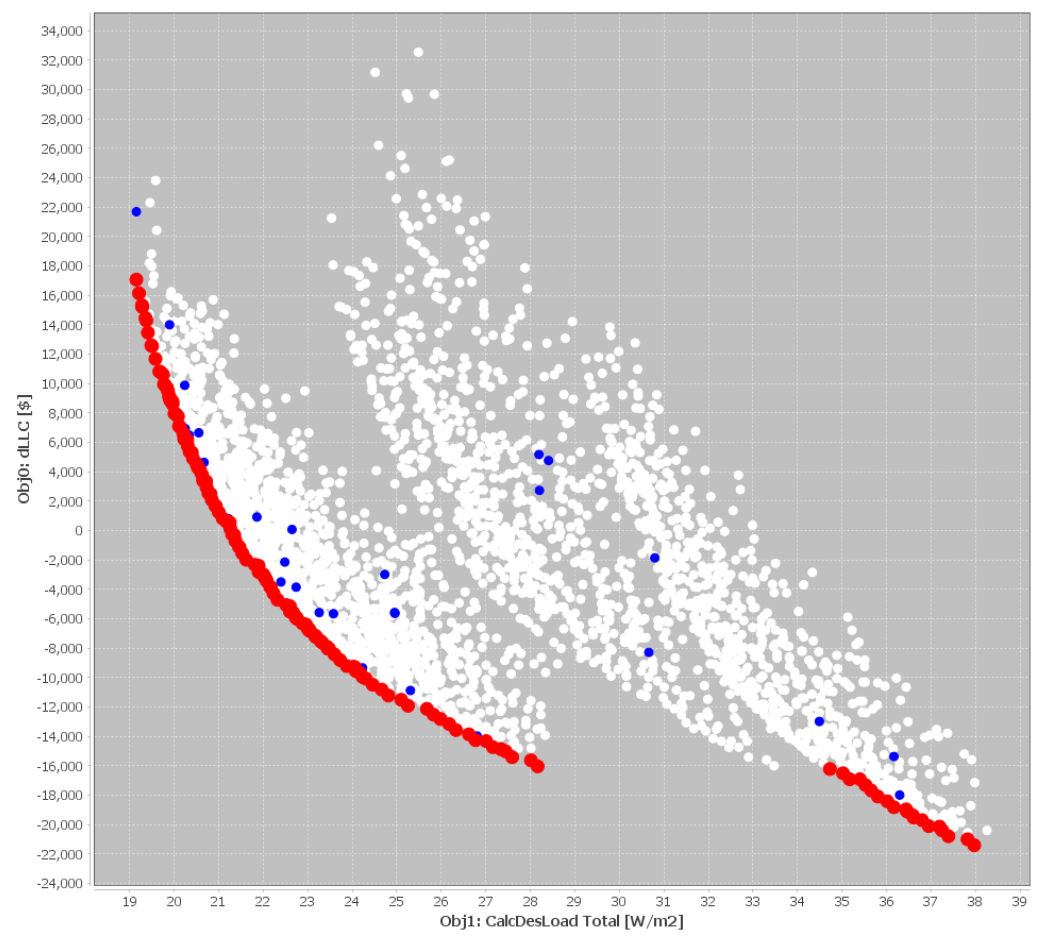

Figure 10.31: Case 4 total design load versus dLCC

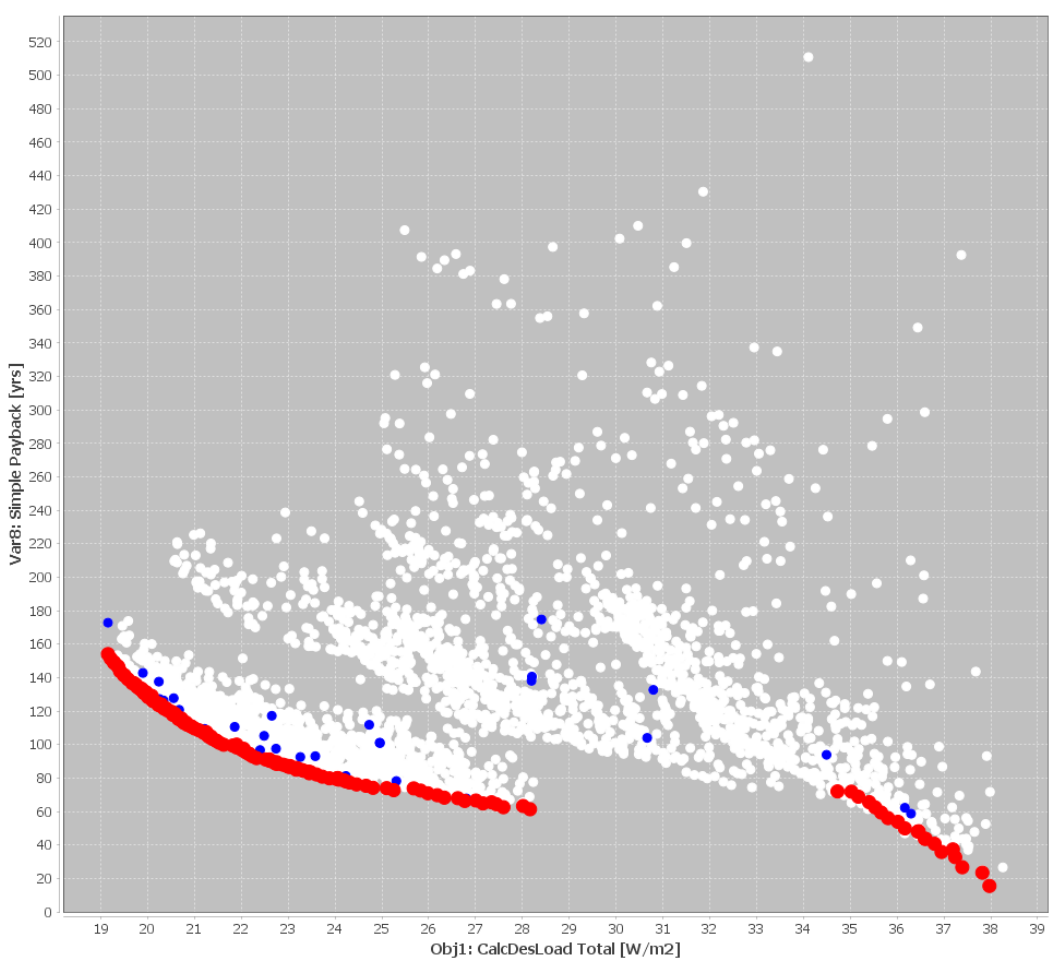

Figure 10.32: Case 4 total design load versus simple payback 


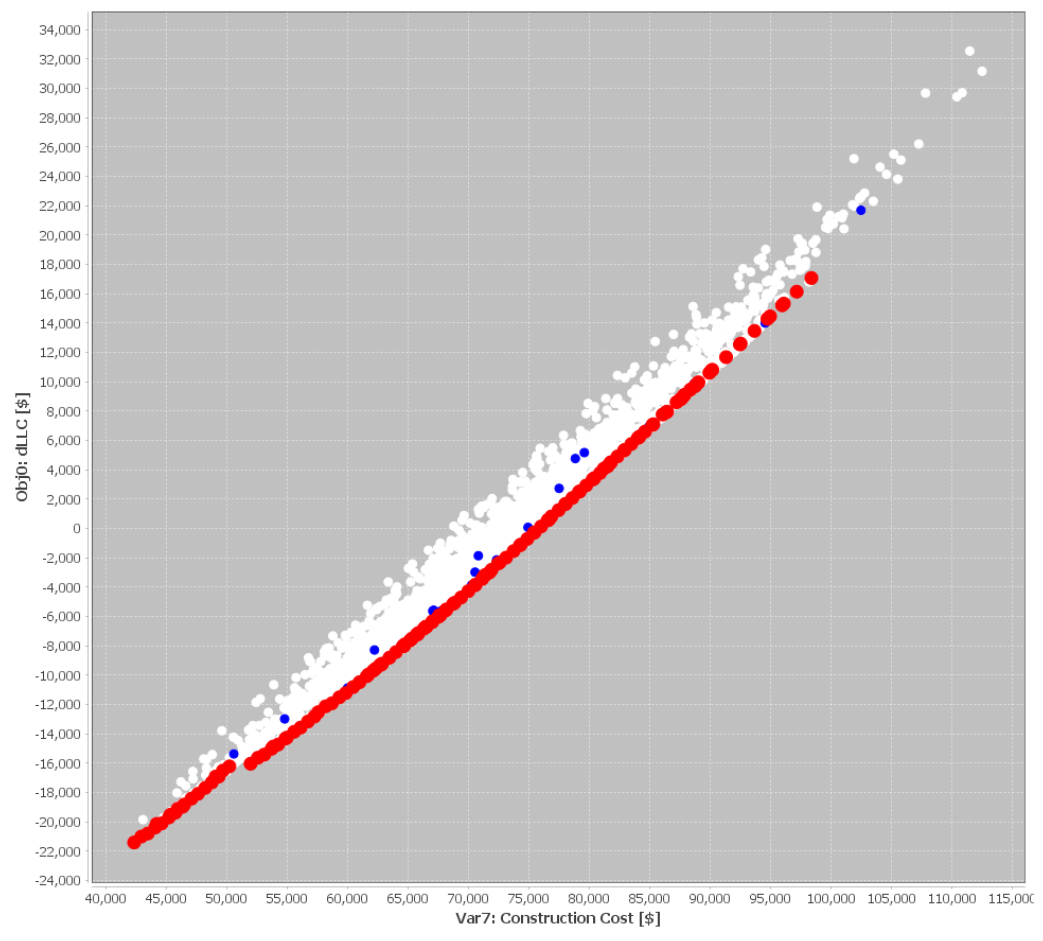

Figure 10.33: Case 4 construction cost versus dLCC

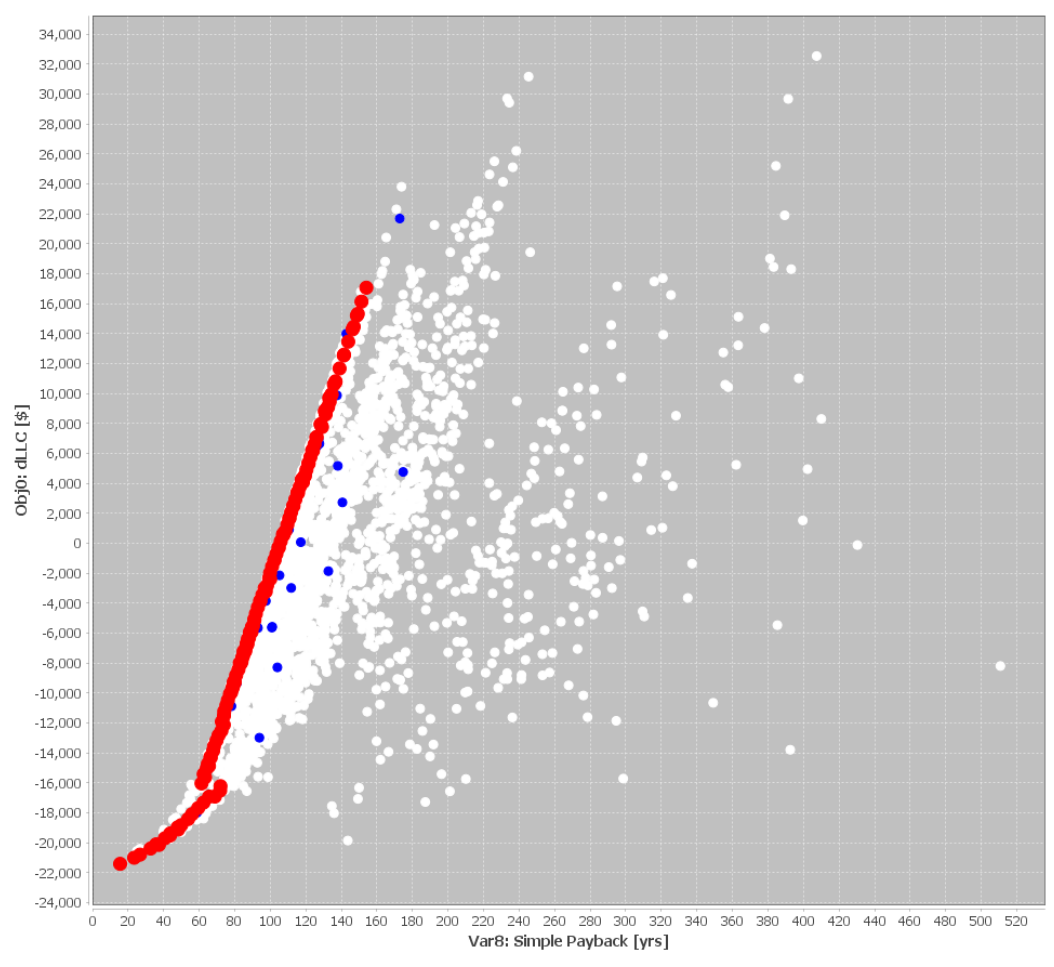

Figure 10.34: Case 4 simple payback versus dLCC 


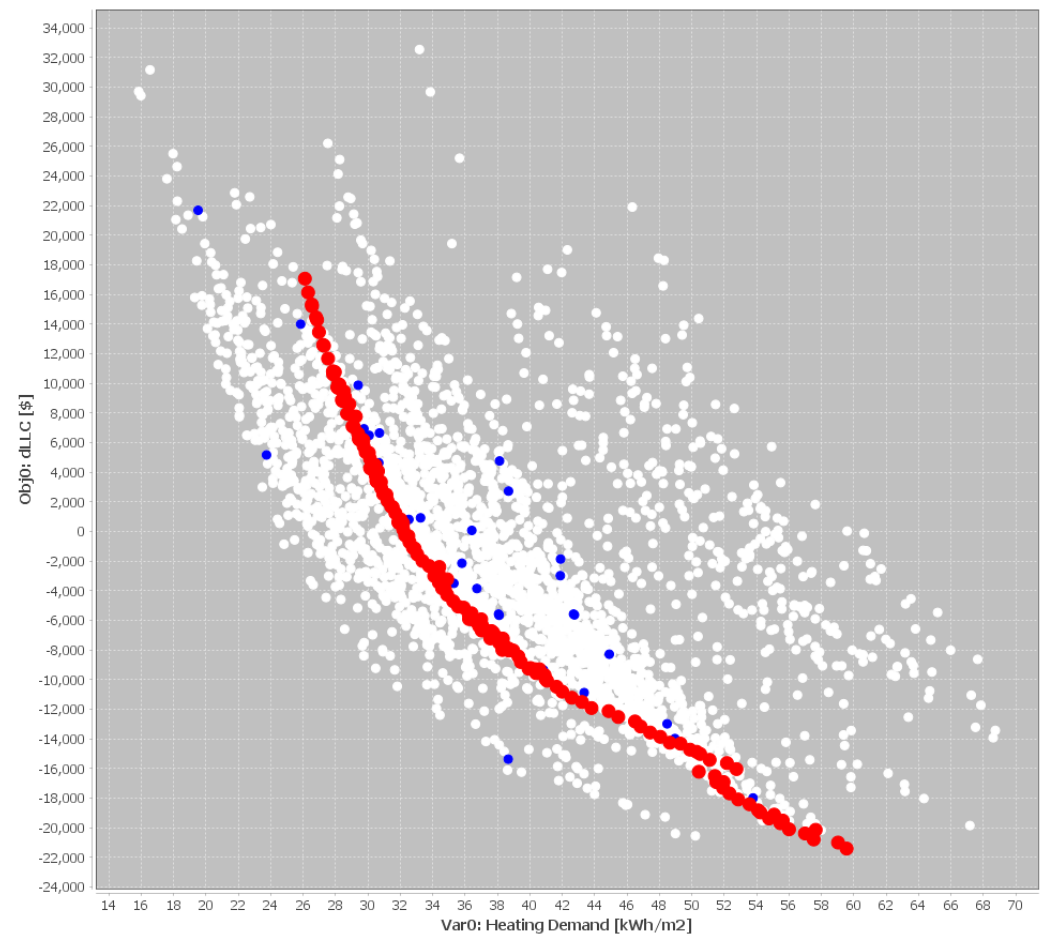

Figure 10.35: Case 4 annual heating demand versus dLCC

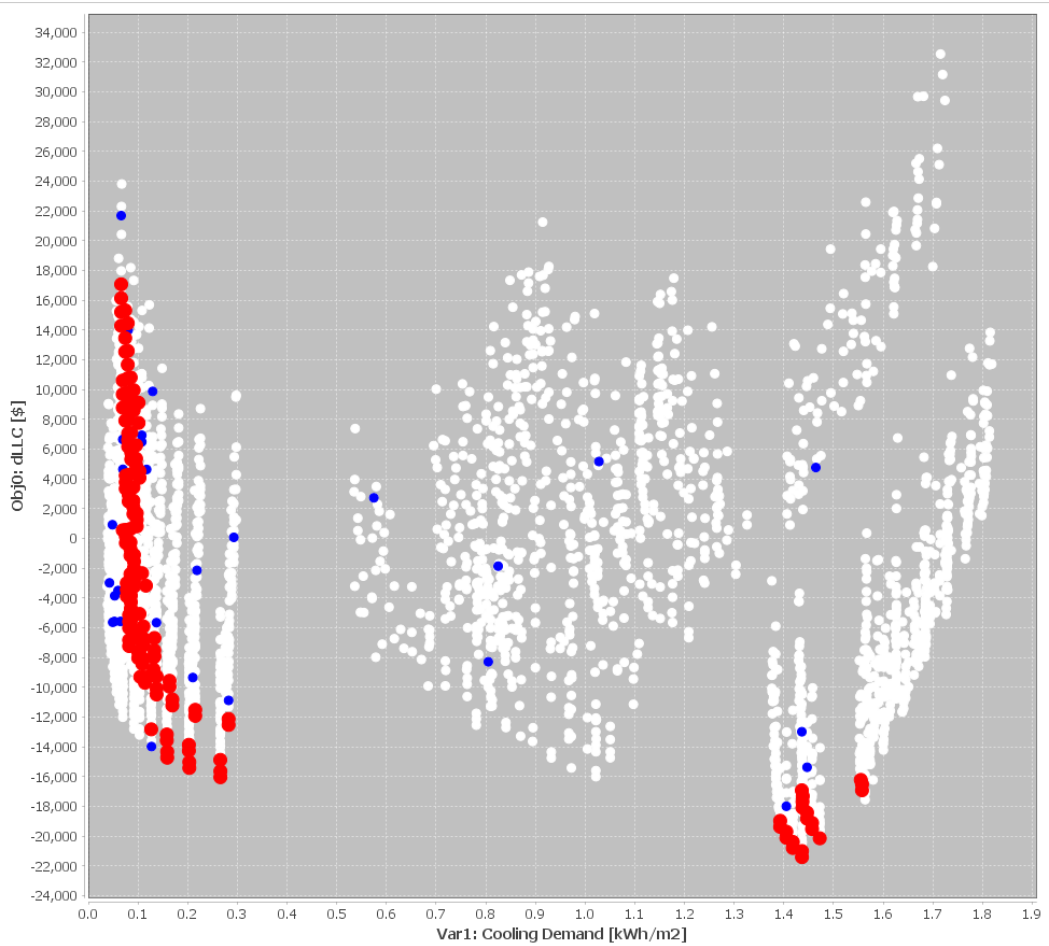

Figure 10.36: Case 4 annual cooling demand versus dLCC 


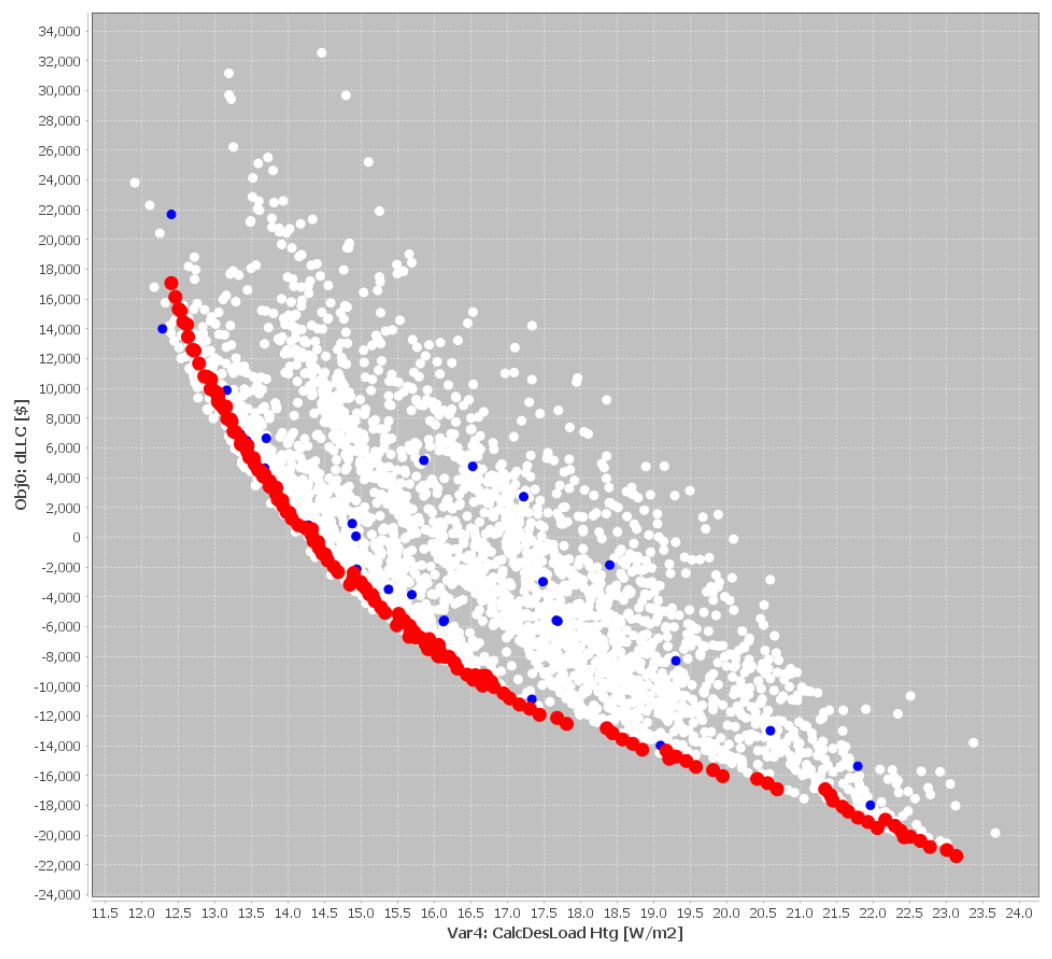

Figure 10.37: Case 4 heating design load versus dLCC

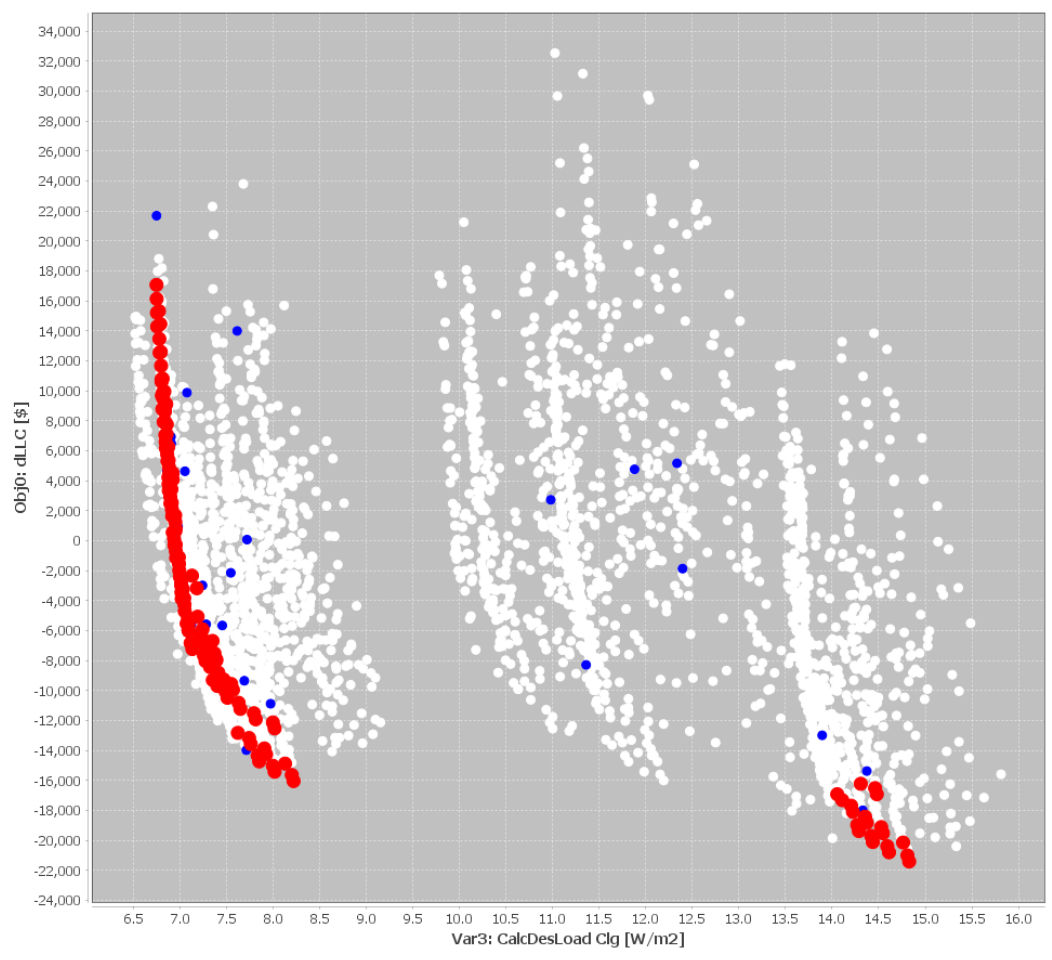

Figure 10.38: Case 4 cooling design load versus dLCC 


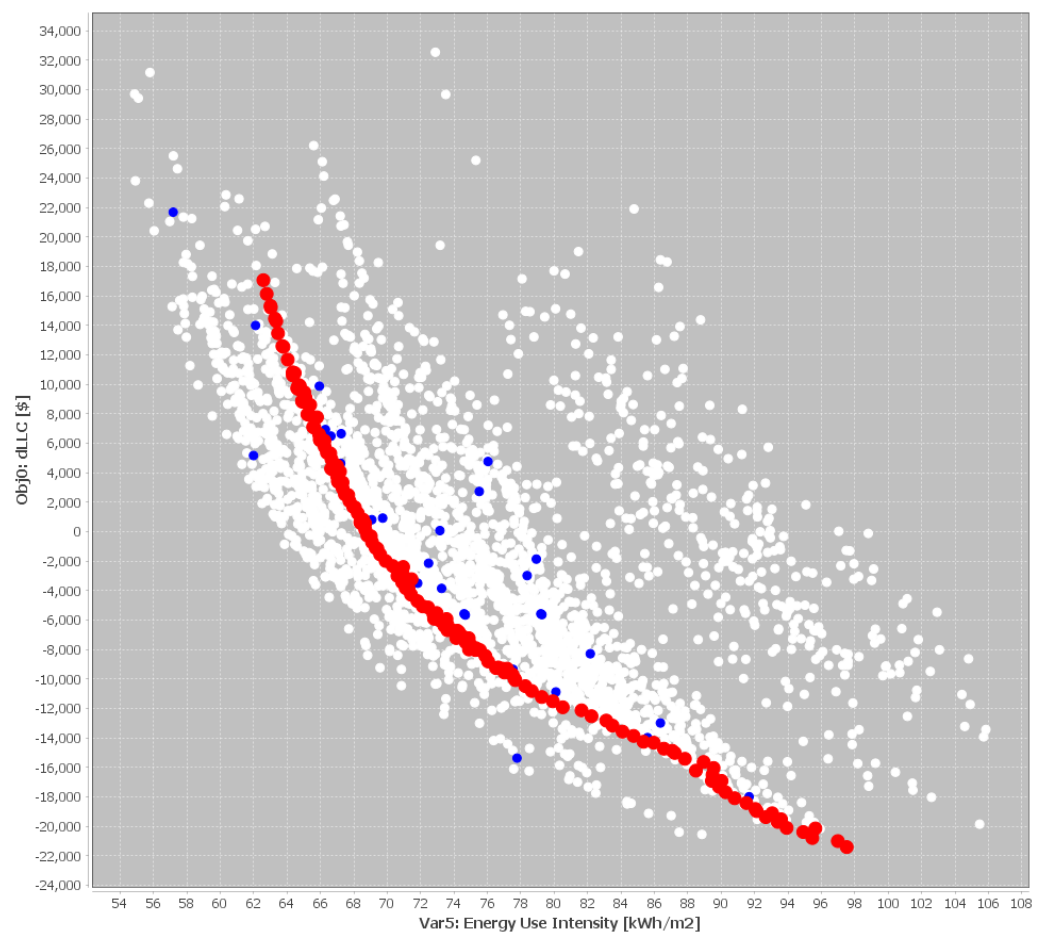

Figure 10.39: Case 4 EUI versus dLCC

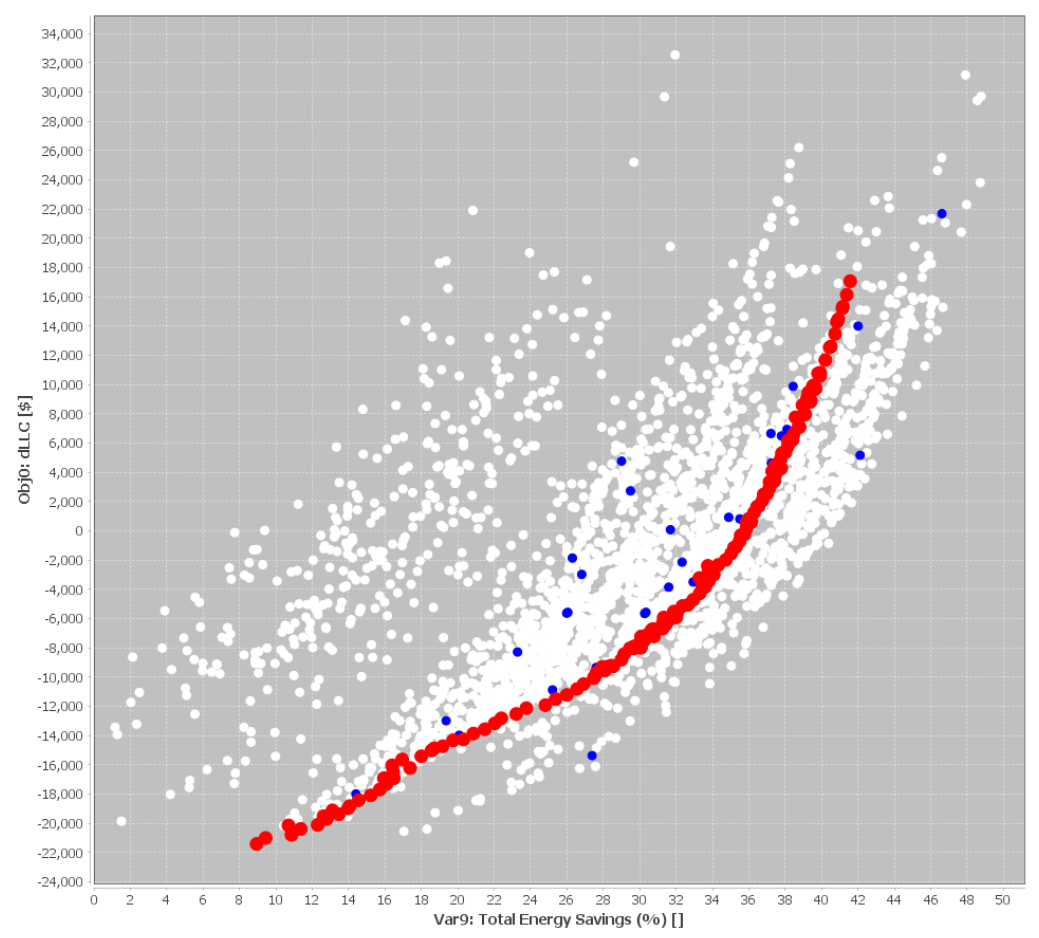

Figure 10.40: Case 4 annual energy savings versus dLCC 
Output variables for Case 5 (Passive House case) with annual energy savings objective

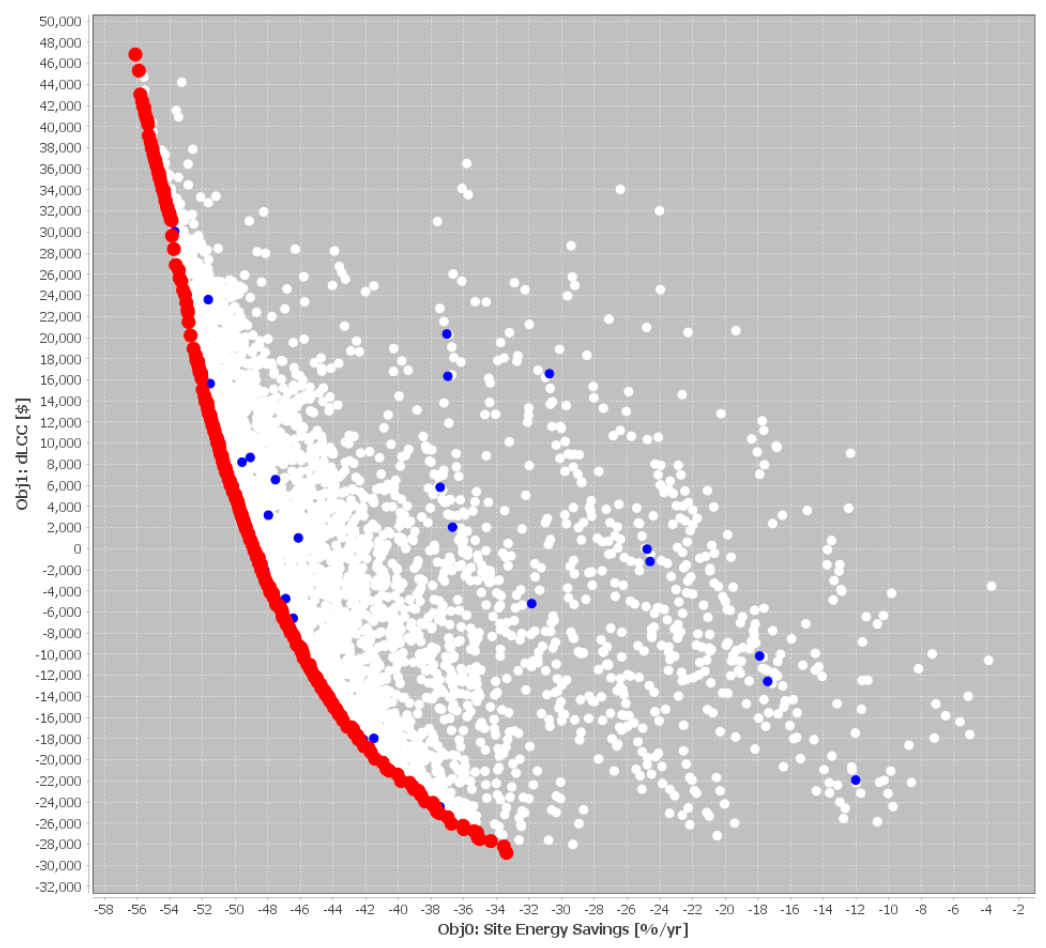

Figure 10.41: Case 5 annual energy savings versus dLCC

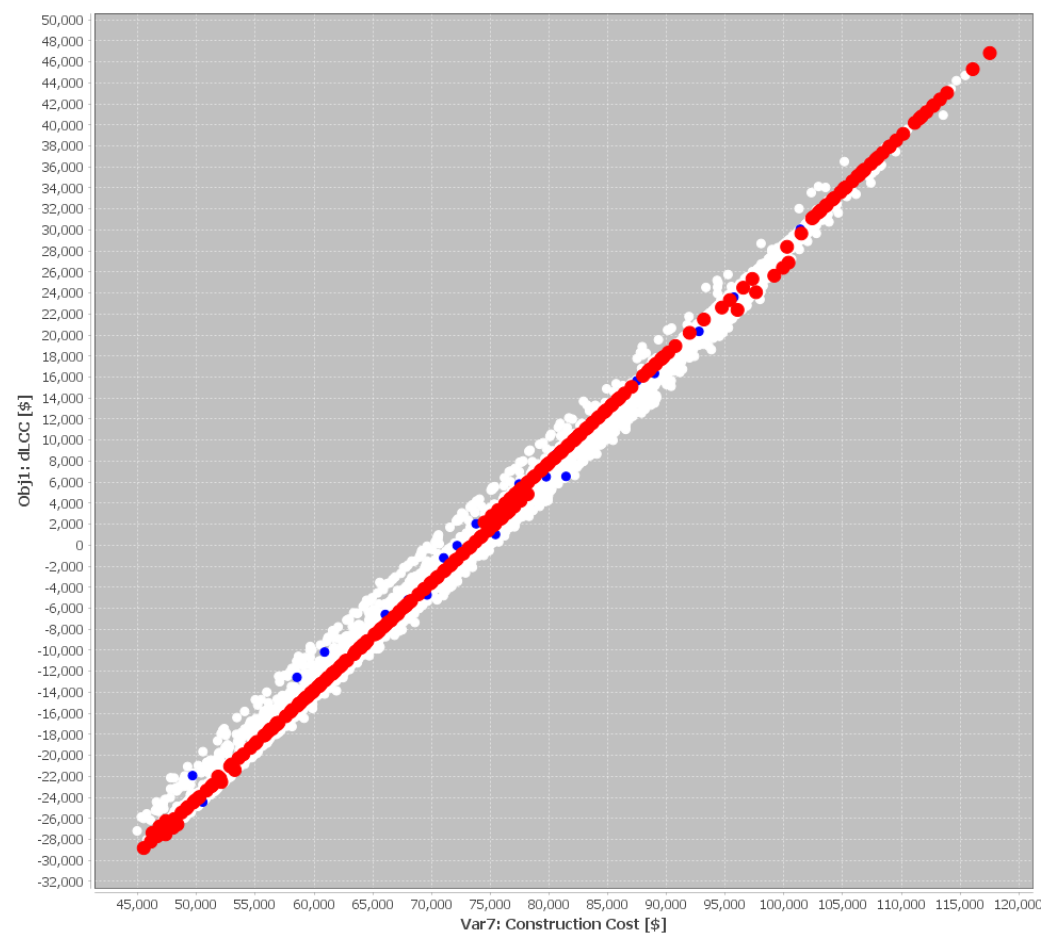

Figure 10.42: Case 5 construction cost versus dLCC 


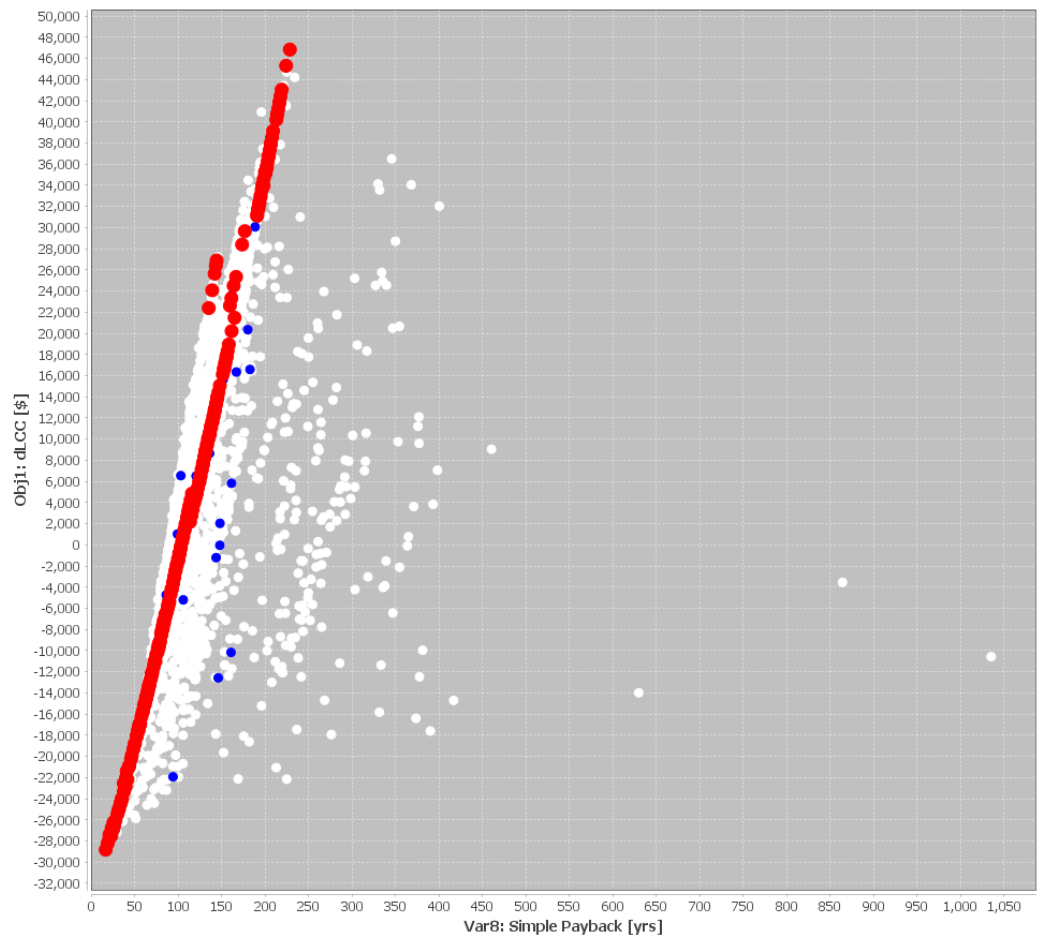

Figure 10.43: Case 5 simple payback versus dLCC

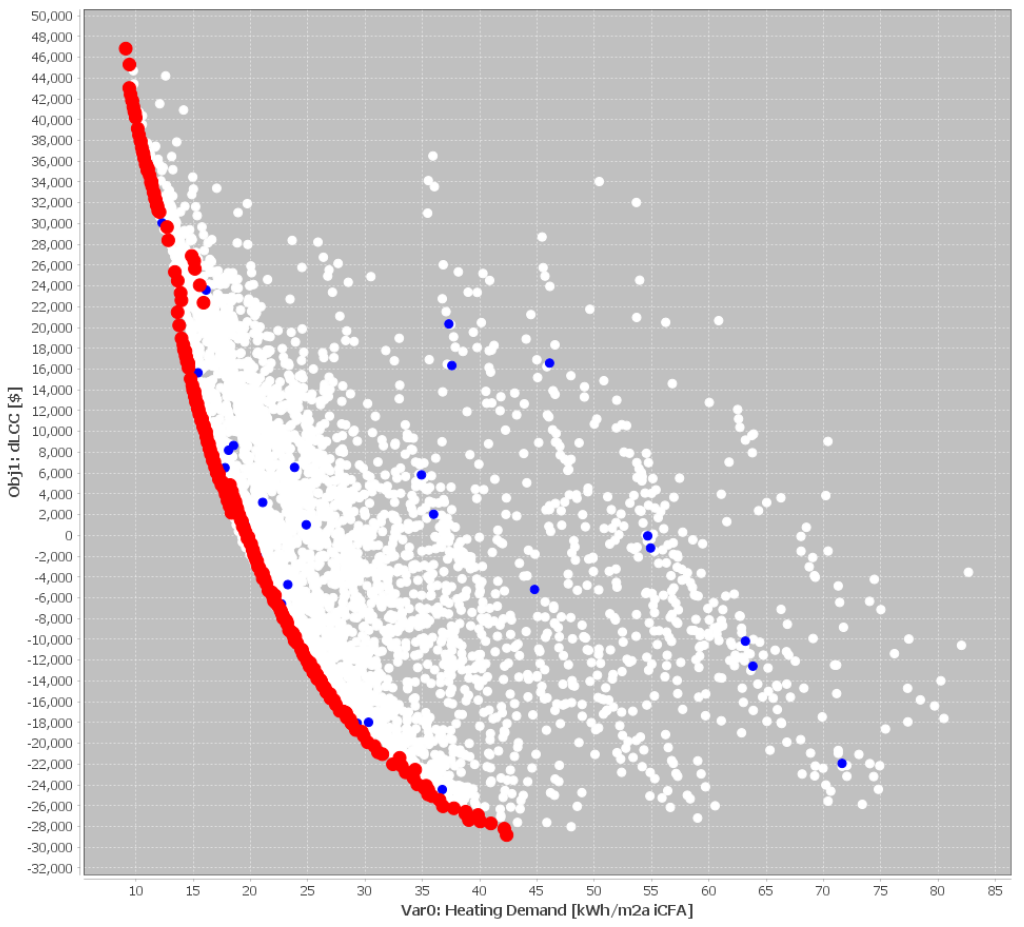

Figure 10.44: Case 5 annual heating demand versus dLCC 


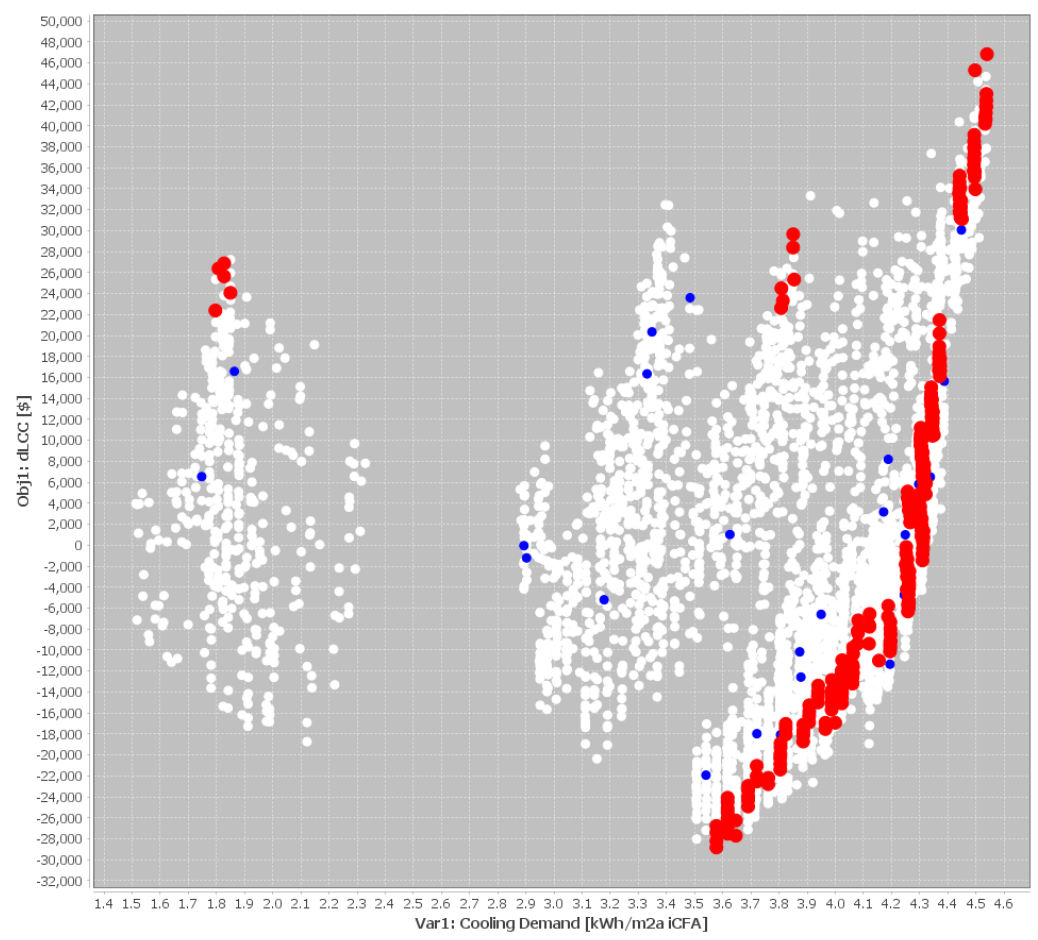

Figure 10.45: Case 5 annual cooling demand versus dLCC

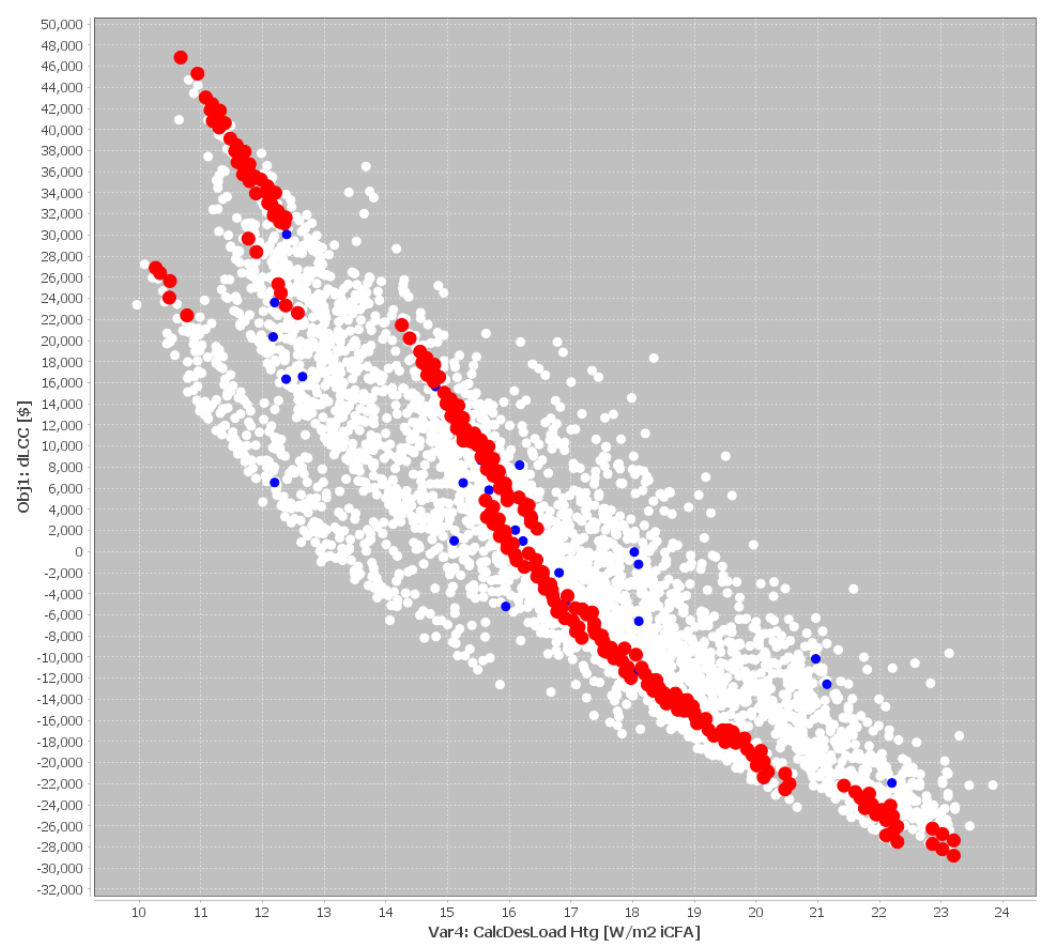

Figure 10.46: Case 5 heating design load versus dLCC 


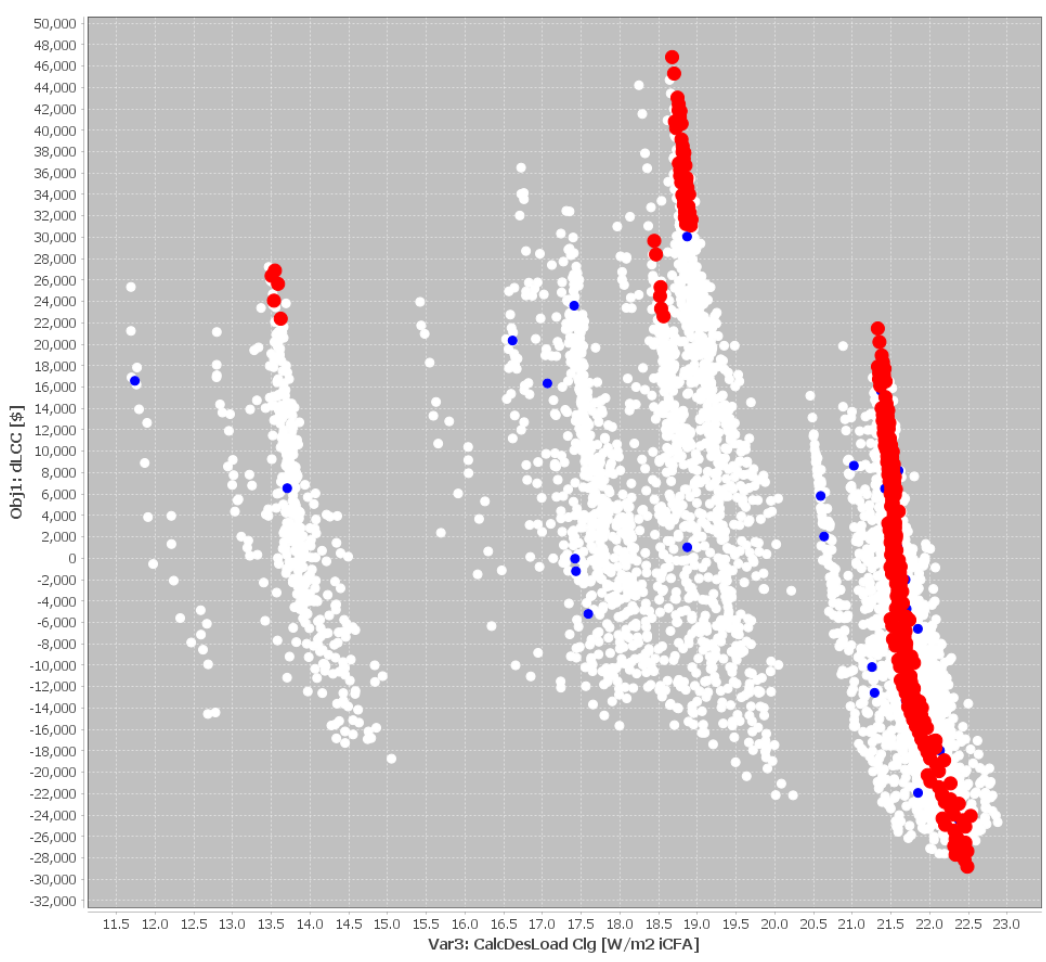

Figure 10.47: Case 5 cooling design load versus dLCC

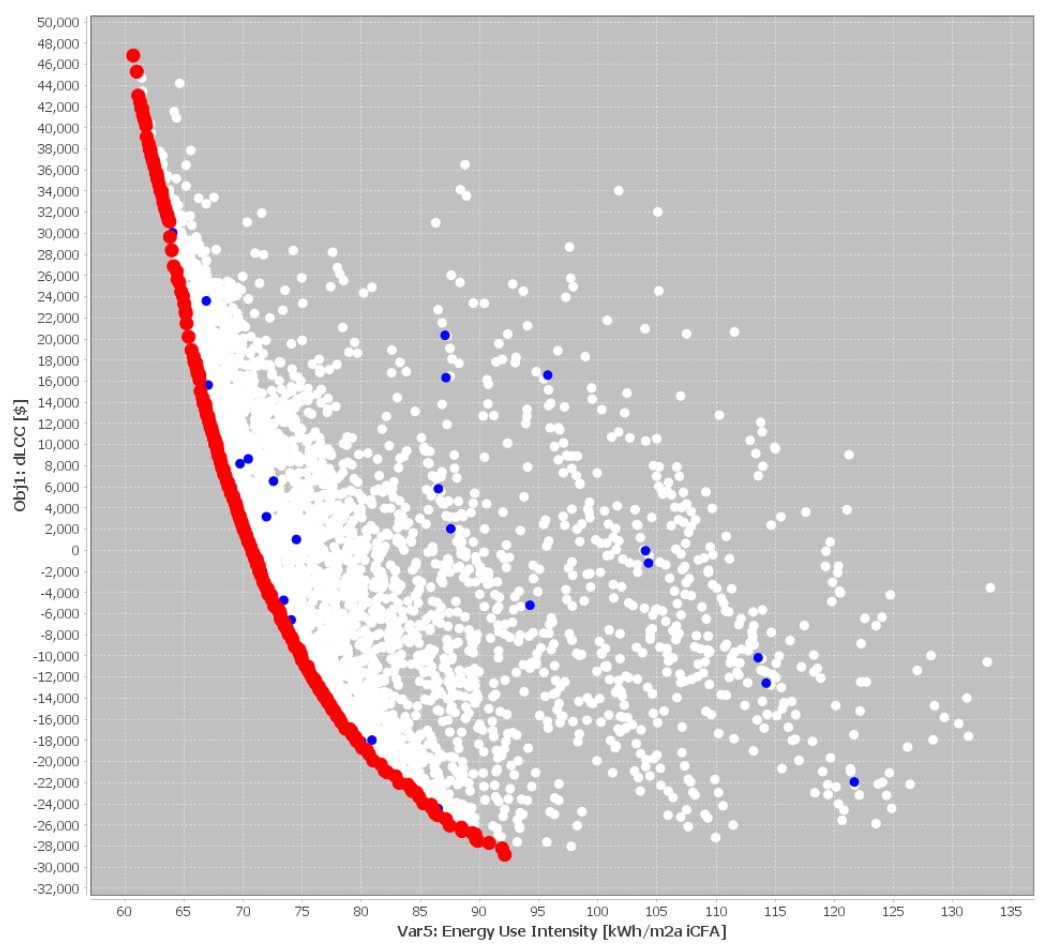

Figure 10.48: Case 5 EUI versus dLCC 


\section{REFERENCES}

Abendroth, R. (2013). A critical analysis of the Passive House standard for the climates of the United States [Master's Thesis]. Urbana, Il: University of Illinois at Urbana-Champaign.

Ahn, B. L., Jang, C. Y., Leigh, S. B., Yoo, S., \& Jeong, H. (2014). Effect of LED lighting on the cooling and heating loads in office buildings. Applied Energy, 113, 1484-1489.

Anderson, R., Christensen, C., \& Horowitz, S. (2006). Analysis of residential system strategies targeting least-cost solutions leading to net-zero energy homes. ASHRAE Transactions, 112, 330-341.

Armstrong, M. M., Swinton, M. C., Ribberink, H., Beausoleil-Morrison, I., \& Millette, J. (2009). Synthetically derived profiles for representing occupant-driven electric loads in Canadian housing. Journal of Building Performance Simulation, 2(1), 15-30.

ASHRAE. (2002). ASHRAE Guideline 14-2002: Measurement of Energy and Demand Savings. Atlanta, GA: American Society of Heating, Ventilating, and Air-Conditioning Engineers, Inc.

ASHRAE. (2005). Fundamentals. Chapter 30: Non-Residential Cooling and Heating Load Calculations. Atlanta, GA: American Society of Heating, Refrigerating and AirConditioning Engineers, Inc.

ASHRAE. (2005a). Fundamentals. Chapter 29: Residential Cooling and Heating Load Calculations. Atlanta, GA: American Society of Heating, Refrigerating and AirConditioning Engineers, Inc.

ASHRAE. (2005b). Fundamental. Chapter 39: Physical Properties of Materials. Atlanta, GA: American Society of Heating, Refrigeration and Air-Conditioning Engineers, Inc.

ASHRAE. (2010). ANSI/ASHRAE/IES Standard 90.1-2010 Energy Standard for Buildings Except Low-Rise Residential Buildings SI Edition. Atlanta, GA: American Society of Heating, Ventilating, and Air-Conditioning Engineers, Inc. 
ASHRAE. (2011). 90.1 User's Manual ANSI/ASHRAE/IES Standard 90.1-2010 Energy Standard for Buildings Except Low-Rise Residential Buildings. Atlanta, GA: American Society of Heating, Ventilating, and Air-Conditioning Engineers, Inc.

Aynur, T., Hwang, Y., \& Radermacher, R. (2009a). Simulation of a VAV air conditioning system in an existing building for the cooling mode. Energy and Buildings, 41, 922-929.

Aynur, T., Hwang, Y., \& Radermacher, R. (2009b). Simulation comparison of VAV and VRF air conditioning systems in an existing building for the cooling season. Energy and Buildings, $41,1143-1150$.

Bank of Canada. (2015). Canadian Bond Yields: 10-Year Lookup. Retrieved February 20, 2015, from Bank of Canada: http://www.bankofcanada.ca/rates/interest-rates/lookup-bond-yields/

Bank of Canada. (2015). Canadian Interest Rates and Monetary Policy Variables: 10-Year Lookup. Retrieved February 19, 2015, from Bank of Canada: http://www.bankofcanada.ca/rates/interest-rates/canadian-interest-rates/

Bank of Canada. (2015). Inflation. Retrieved February 19, 2015, from Bank of Canada: http://www.bankofcanada.ca/rates/indicators/capacity-and-inflation-pressures/inflation/

Bichiou, Y., \& Krarti, M. (2011). Optimization of envelope and HVAC systems selection for residential buildings. Energy and Buildings , 43, 3373-3382.

Blaszak, K. (2010). Towards Sustainability: Prioritizing Retrofit Options for Toronto's Singlefamily Homes [Masters Thesis]. Toronto, ON: Ryerson University.

Bucking, S., Athienitis, A., \& Zmeureanu, R. (2014). Multi-objective optimal design of a near net zero energy solar house. ASHRAE Transactions, 120(1).

Christensen, C., Horowitz, S., Givler, T., Courtney, A., \& Barker, G. (2005). BEopt: software for identifying optimal building designs on the path to net zero energy. ISES 2005 Solar World Congress, (pp. 1-6). Orlando, FL.

CMHC. (2015). Average Residential Mortgage Lending Rate - 5 year. Bank of Canada. 
CMHC. (2015). The EQuilibrium ${ }^{\mathrm{TM}}$ Sustainable Housing Demonstration Initiative. Retrieved February 4, 2015, from Canada Mortgage and Housing Corporation: http://www.cmhcschl.gc.ca/en/inpr/su/eqho/eqho_008.cfm

Coakley, D., Raftery, P., \& Molloy, P. (2012). Calibration of whole building energy simulation models: detailed case study of a naturally ventilated building using hourly measured data. Building Simulation and Optimization, 57-64.

Construction Sector Council. (2011). Green sustainable building in Canada: Implications for the commercial and residential construction workforce G2011. Ottawa, ON: The Construction Sector Council.

Cutler, D., Winkler, J., Kruis, N., Christensen, C., \& Brandemuehl, M. (2013). Improved Modeling of Residential Air Conditioners and Heat Pumps for Energy Calculations. Golden, CO: National Renewable Energy Laboratory.

DeLarm-Neri, R. (2013). Energy modeling of low-cost houses in colder climates of South Africa [Master's Thesis]. Boone, NC: Appalachian State University.

Dembo, A. (2011). Least cost analysis for Canadian new housing: identifying the most costeffective specifications to achieve improved energy efficiency standards [Master's Thesis]. Toronto, ON: Ryerson University.

Deru, M. (2003). A model for groud-coupled heat and moisture transfer from buildings. Golden, CO: NREL.

Dingwall, A. (2012). Testing the impact of using cumulative data with genetic algorithms for the analysis of building energy performance and material cost [Master's Thesis]. Atlanta, GA: Georgia Institute of Technology.

Dong, B., Kennedy, C., \& Pressnail, K. (2005). Comparing life cycle implications of building retrofit and replacement options. Canadian Journal of Civil Engineering, 32(6), 1051-1063.

Energy Simulation Solutions . (2015). JESS Online Introduction. Retrieved 3 2015, March, from http://cms.ensims.com/index.php/jess-online 
Eskin, N., \& Turkmen, H. (2008). Analysis of annual heating and cooling energy requirements for office buildings in different climates in Turkey. Energy and Buildings , 40, 763-773.

European Computer Manufacturers Association. (2013). Standard ECMA-404 The JSON Data Interchange Format. Geneva, Switzerland: ECMA International.

European Council for an Energy Efficient Economy. (2011). Cost optimal building performance requirements: Calculation methodology for reporting on national energy performance requirements on the basis of cost optimality within the framework of the EPBD. ECEEE.

Evins, R. (2013). A review of computation optimisation methods applied to sustainable building design. Renewableand Sustainable Energy Reviews, 22, 230-245.

Fanger, P. (1970). Thermal comfort: analysis and applications in environmental engineering. Yew York, NY: McGraw-Hill.

Feist, W., \& Schnieders, J. (2009). Energy efficiency - a key to sustainable housing. The European Physical Journal Special Topics, 176, 141-153.

Feist, W., Schnieders, J., Dorer, V., \& Haas, A. (2005). Re-inventing air heating: Convenient and comfortable within the frame of the Passive House concept. Energy and Buildings, 37, 11861203.

Feist, W., Schnieders, J., Dorer, V., \& Haas, A. (2005). Re-inventing air heating: Convenient and comfortable within the frame of the Passive House concept. Energy and Buildings, 37, 11861203.

Ferraraa, M., Fabriziob, E., Virgone, J., \& Filippi, M. (2014). A simulation-based optimization method for cost-optimal analysis of nearly Zero Energy Buildings. Energy and Buildings, $84,442-457$.

Fesanghary, M., Asadi, S., \& Geem, Z. (2012). Design of low-emission and energy-efficient residential buildings using a multi-objective optimization algorithm. Building and Environment , 49, 245-250.

Flynn, P. (2010). Financial Management for Engineers Fourth Edition. Edmonton, AB: Castle Rock Research Corp. 
Fuller, S., \& Petersen, S. (1996). Life-cycle costing manual for the federal energy management program NIST Handbook 1351995 Edition. Washington, DC: US Government Printing Office.

Government of Canada. (2014). Monthly Climate Summaires. Retrieved September 29, 2014, from http://climate.weather.gc.ca/prods_servs/cdn_climate_summary_e.html

Grin, A. (2008). Evaluation of High Performance Residential Housing Technology [Masters Thesis]. Waterloo, ON: University of Waterloo.

Guler, B., Fung, A., Aydinalp, M., \& Ugursal, V. (2001). Impact of energy efficiency upgrade retrofits on the residential energy consumption in Canada. International Journal of Energy Research, 25, 785-792.

Hamdy, M., Hasan, A., \& Siren, K. (2009). Combination of optimisation algorithms for a multiobjcetive building deisgn problem. Building Simulation, 173-179.

Hamdy, M., Hasan, A., \& Siren, K. (2011). Applying a multi-objective optimization approach for Design of low-emission cost-effective dwellings. Building and Environment, 46, 109-123.

Hamdy, M., Hasan, A., \& Siren, K. (2013). A multi-stage optimization method for cost-optimal and nearly-zero-energy building solutions in line with the EPBD-recast 2010. Energy and Buildings, 56, 189-203.

Hani, A., \& Koiv, T. (2012). Optimization of office building façades in a warm summer continental climate. Smart Grid and Renewable Energy, 3, 222-230.

Hasan, A., Vuolle, M., \& Siren, K. (2008). Minimisation of life cycle cost of a detached house using combined simulation and optimization. Building and Environment, 43, 2022-2034.

Hascomb. (2011). Yardsticks for Costing Cost Data for the Canadian Construction Industry Metric and Imperial. Norwell, MA: Reed Construction Data and RSMeans.

Heating, Refrigeration, and Air Conditioning Institute of Canada. (1996). Residential Heat Loss \& Heat Gain Calculaitons Student Reference Guide . Mississauga, ON: Heating, Refrigeration, and Air Conditioning Institute of Canada. 
Hendron, R., \& Engebrecht, C. (2010). Building America House Simulation Protocols. Oak Ridge, TN: US Department of Energy .

Hendron, R., \& Engebrecht, C. (2010). Building America House Simulation Protocols. National Renewable Energy Laboratory.

Home Depot. (2015). Vinyl Windows. Retrieved February 12, 2015, from http://www.homedepot.ca/catalog/vinyl-windows/170333

HVACQuick. (2015). Residential HRV \& ERV. Retrieved February 15, 2015, from http://hvacquick.com/

Ihm, P., \& Krarti, M. (2012). Design optimization of energy efficient residential buildings in Tunisia. Building and Environment, 58, 81-90.

Iqbal, I., \& Al-Homoud, M. (2007). Parametric analysis of alternative energy conservation measures in an office building in hot and humid climate. Building and Environment , 42, 2166-2177.

JEPlus. (2015). JEPlus-An EnergyPlus simulation manager for parametrics. Retrieved March 9, 2015, from http://www.jeplus.org/wiki/doku.php?id=start

jEPlus. (2015). Run Optimisation in jEPlus+EA GUI. Retrieved February 12, 2015, from http://www.jeplus.org/wiki/doku.php?id=docs:jeplus_ea:run

JEPlus. (2015, March 11). Why jEPlus $+E A$. Retrieved 2015, from http://www.jeplus.org/wiki/doku.php?id=docs:jeplus_ea:introduction

Jermyn, D. (2014). Deep energy retrofits: Toronto's urban single family housing stock [Master's Thesis]. Toronto, ON: Ryerson University.

Jokisalo, J., Kurnitski, J., Korpi, M., Kalamees, T., \& Vinha, J. (2009). Building leakage, infiltration, and energy performance analyses for Finnish detached houses. Building and Environment, 44(2), 377-387.

Kalamees, T., Korpi, M., Eskola, L., Kurnitski, J., \& Vinha, J. (2008). The distribution of the air leakage places and thermal bridges in Finnish detached houses and apartment buildings. 
Proceedings of the 8th Symposium on Building Physics in the Nordic Countries (NSB2008), (pp. 16-18). Copenhagen, Denmark.

Karaguzel, O., Zhang, R., \& Lam, L. (2014). Coupling of whole-building energy simulation and multi-dimensional numerical optimization for minimizing the life cycle costs of office buildings. Building Simulation, 7, 111-121.

Kneifel, J. (1996). NIST Technical Note 1765 - Prototype Residential Building Designs for Energy and Sustainability Assessment. National Institute of Standards and Technology Technical \& US Department of Commerce.

Kneifel, J. (2012). NIST Technical Note 1765 - Prototype Residential Building Designs for Energy and Sustainability Assessment. National Institute of Standards and Technology Technical \& US Department of Commerce.

Kruger, B. (2012). A Proposed Methodology for Determining Climate-Dependent Passive House Standards for the United States [Masters Thesis]. Boulder, CO: University of Colorado Boulder.

Lawrence Berkeley National Laboratory. (2013). THERM 6.3 / WINDOW 6.3 NFRC Simulation Manual. Berkeley, CA: University of California.

Lawrence Berkeley National Laboratory. (2013). WINDOW 6 [computer software]. Berkeley, CA. Retrieved from http://windows.lbl.gov/software/window/6/w6_download6_3_74.asp?

Leckner, M. (2008). Life Cycle Energy and Cost Analysis of a Net Zero Energy House (NZEH) Using a Solar Combisystem [Master's Thesis]. Montreal, QC: Concordia University.

Liu, G., \& Liu, M. (2011). A rapid calibration procedure and case study for simplified simulation models of commonly used HVAC systems. Building and Environment, 46, 409-420.

Lstiburek, J. (2010). BSI-030: Advanced Framing. Building Science Insights. Westford, MA: Building Science Corporation.

Marzia, E. (2015). About Us. Retrieved February 3, 2015, from Architecture 2030: http://architecture2030.org/about/about_us 
MMAH. (2009). Ontario Building Code 2006: Supplementary Standard SB-12 Energy Efficiency for Housing. Toronto, ON: Ministry of Municipal Affairs and Housing, Building and Development Branch.

MMAH. (2011). Ontario Building Code 2006: Supplementary Standard SB-12 Energy Efficiency for Housing. Toronto, ON: Ministry of Municipal Affairs and Housing, Building and Development Branch.

Naboni, E., Maccarini, A., Korolija, I., \& Zhang, Y. (2013). Comparison of conventional, parametric and evolutionary optimization approaches for the architectural design of nearly zero energy buildings. Proceedings of BS2013, (pp. 2559-2566). Chambery, France.

NAHB Research Center. (2009). Economic Database in Support of ASHRAE 90.2 (EnergyEfficient Design of Low-Rise Residential Buildings) 1481 RP. Upper Marlboro, MD: NAHB Research Center.

National Association of Home Builders. (2007). Study of Life Expectancy of Home Components. Bank of America.

National Energy Board. (2007). Appendix 2 Energy Demand. Canada's Energy Future Reference and Scenarios to 2030 Appendices. Calgary, AB: National Energy Board.

National Renewable Energy Laboratory. (2015). BEopt [computer software]. Washington, DC. Retrieved from https://beopt.nrel.gov/

Natural Resources Canada. (2005). EnerGuide for New Houses: Administrative and Technical Procedures. Ottawa, ON: Natural Resources Canada.

Natural Resources Canada. (2014). Natural Gas: A Primer. Retrieved September 29, 2014, from http://www.nrcan.gc.ca/energy/natural-gas/5641

Natural Resources Canada. (2014). Path to Net-Zero Energy Homes. Retrieved January 31, 2015, from Natural Resources Canada: http://www.nrcan.gc.ca/energy/efficiency/housing/research/5135 
Natural Resources Canada. (2014). R-2000 Net Zero Energy pilot. Retrieved January 31, 2015, from Natural Resources Canada: http://www.nrcan.gc.ca/energy/efficiency/housing/newhomes/5067

Natural Resources Canada. (2015). Natural Resources Canada. Retrieved January 31, 2015, from EnerGuide home evaluations: http://www.nrcan.gc.ca/energy/efficiency/housing/homeimprovements/5005

Natural Resources Canada's Office of Energy Efficiency. (2013). Energy efficiency trends in Canada 1990-2010. Ottawa, ON: Natural Resources Canada.

Natural Resources Canada's Office of Energy Efficiency. (2014). Energy use data handbook 1990 to 2011. Ottawa, ON: Natural Resources Canada.

NFRC. (2015). Product Directory Search. Retrieved February 15, 2015, from http://search.nfrc.org/search/searchDefault.aspx

Nguyen, A., \& Reiter, S. (2012). Optimum design of low-cost housing in developing countries using nonsmooth simulation-based optimization. 28th International PLEA Conference, Lima, Peru.

Nguyen, A., Reiter, S., \& Rigo, P. (2014). A review on simulation-based optimization methods applied to building performance analysis. Applied Energy , 113, 1043-1058.

NSERC SNEBRN. (2012). Home. Retrieved February 4, 2015, from NSERC Smart Net-Zero Energy Buildings Strategic Research Network: http://www.solarbuildings.ca/index.php/en/

O'Neill, Z., \& Eisenhower, B. (2013). Leveraging the analysis of parametric uncertainty for building energy model calibration. Building Simulation, 6(4), 365-377.

O’Neill, Z., Eisenhower, B., Fonoberov, V., \& Bailey, T. (2012). Calibration of a building energy model considering parametric uncertainty. ASHRAE Transactions, 118(2), 189-196.

O'Brien, W., Athienitis, A., \& Kesik, T. (2011). Thermal zoning and interzonal airflow in the design and simulation of solar houses: a sensitivity analysis. Journal of Building Performance Simulation, 4(3), 239-256.

OmniSense. (2015). OmniSense. Retrieved May 12, 2014, from https://www.omnisense.com/ 
Ontario Energy Board. (2015). Historical Electricity Prices. Retrieved February 21, 2015, from Ontario Energy Board: http://www.ontarioenergyboard.ca/oeb/Consumers/Electricity/Electricity\%20Prices/Histori cal\%20Electricity\%20Prices

Ontario Ministry of Energy. (2013). Achieving Balance Ontario's Long-Term Energy Plan. Toronto, ON: Ministry of Energy.

Palonen, M., Hasan, A., \& Siren, K. (2009). A genetic algorithm for optimization of building envelope and HVAC system parameters. Building Simulation, 159-166.

Pan, Y., Huang, Z., \& Wu, G. (2007). Calibrated building energy simulation and its application in a high-rise commercial building in Shanghai. Energy and Buildings, 39, 651-657.

Passive House Institute. (2007). Passive House Planning Package 2007 Requirements for QualityApproved Passive Houses. Darmstadt, Germany: Passive House Institute.

Passive House Institute. (2007). Technical Information PHI-2007/1(E) - Passive House Planning Package 2007 Requirements fo Quality-Approved Passive Houses. Passive House Institute.

Passive House Institute US. (2010). Passive Building Principles. Passive House Consultant Training . PHIUS.

PHIUS. (2015). PHIUS+ 2015: Passive Building Standard -- North America. Retrieved March 30, 2015, from http://www.phius.org/phius-2015-new-passive-building-standard-summary

Raftery, P., Keane, M., \& Costa, A. (2011b). Calibrating whole building energy models: Detailed case study using hourly measured data. Energy and Buildings, 43(12), 3666-3679.

Raftery, P., Keane, M., \& O'Donnell, J. (2011a). Calibrating whole building energy models: an evidence-based methodology. Energy and Buildings, 43(9), 2356-2364.

Rahman, M., Rasul, M., \& Khan, M. (2010). Energy conservation measures in an institutional building in sub-tropical climate in Australia. Applied Energy, 87, 2994-3004.

RDH Building Engineering Ltd. (2011). Near Net Zero - Energy Retrofits for Houses. Ottawa , ON: CMHC. 
Reddy, T. A. (2006). Literature review on calibration of building energy simulation programs: uses, problems, procedures, uncertainty, and tools. ASHRAE Transactions, 112, 226-240.

Reddy, T. A. (2006). Literature review on calibration of building energy simulation programs: uses, problems, procedures, uncertainty, and tools. ASHRAE Transactions, 226-240.

Reddy, T. A., Maor, I., \& Panjapornpon, I. (2007b). Calibrating detailed building energy simulation programs with measured data-part II: application to three case study office buildings (RP-1051). HVAC\&R Research, 13(2), 243-265.

Reddy, T. A., Maor, L., \& Panjapornpon, C. (2007a). Calibrating detailed building energy simulation programs with measured data-Part I: General methodology (RP-1051). HVAC\&R Research, 13(2), 221-241.

Richman, R. (2011). About Renovation 2050 - Goals. Retrieved March 17, 2015, from http://renovation2050.wix.com/renovation2050\#!goals/c17qt

RS Means. (2012). RS Means Building Construction Cost Data 2012. RS Means Company Inc.

Rushing, A., Kneifel, J., \& Lavappa, P. (2014). NISTIR 85-3273-29 Energy Price Indices and Discount Factors for Life-Cycle Cost Analysis 2014 Annual Supplement to NIST Handbook 135. National Institute of Standards and Technology \& US Department of Commerce.

Schnieders, J., \& Hermelink, A. (2006). CEPHEUS results: measurements and occupants' satisfaction provide evidence for Passive Houses being an option for sustainable building. Energy Policy, 34, 151-171.

Statistics Canada. (2012). Energy Statistics Handbook First Quarter 2012. Ottawa, ON: Minister of Industry.

Stecher, D., \& Klingenberg, K. (2008). Design and Performance of the Smith House, A Passive House. ASHRAE Transactions, 114(1).

Sutherland, G., Maldonado, E., Wouters, P., \& Papaglastra, M. (2013). Implementing the Energy Performance of Buildings Directive - Featuring Country Reports 2012. European Union: Energy Performance of Buildings Concerted Action. 
Swinton, M. C., Moussa, H., \& Marchand, R. G. (2001). Commissioning twin houses for assessing the performance of energy conserving technologies. Performance of Exterior Envelopes of Whole Buildings VIII: Integration of Building Envelopes, 1-10.

Swinton, M., Entchev, E., Szadkowski, F., \& Marchand, R. (2003). Benchmarking twin houses and assessment of the energy performance of two gas combo heating systems. 9th Canadian Conference on Building Science and Technology, 365-381.

TD Canada Trust. (2015). Retrieved February 15, 2015, from TD Canada Trust Mortgage Rates: http://www.tdcanadatrust.com/products-services/banking/mortgages/numbers-resl.jsp

The European Parliament and the Council of the European Union. (2010). Directive 2010/31/EU of the Euopean Parliament and of the Council on May 192010 on the energy performance of buildings (recast). Official Journal of the Europen Union.

The Gordian Group. (2015). RSMeans Online Version 5.1.1. Retrieved February 23, 2015, from http://rsmeansonline.com/SearchData

Tian, Z., \& Love, J. (2009). Energy performance optimization of radiant slab cooling using building simulation and field measurements. Energy and Buildings, 41, 320-330.

TorontoHydro. (2015). My TorontoHydro. Retrieved November 19, 2014, from https://css.torontohydro.com/Pages/Default.aspx

Tuhus-Dubrow, D., \& Krarti, M. (2010). Genetic-algorithm based approach to optimize building envelope design for residential buildings. Building and Environment , 45, 1574-1581.

US Department of Energy. (2015). EnergyPlus [computer software]. Washington, DC. Retrieved from http://apps1.eere.energy.gov/buildings/energyplus/

US Department of Energy. (2015). Guidelines for participating in the DOE zero energy ready home. Retrieved February 2, 2015, from Office of Energy Efficiency \& Renewable Energy: http://energy.gov/eere/buildings/guidelines-participating-doe-zero-energy-ready-home

US DOE. (2007). Thermal Management of White LEDs. US Department of Energy, Energy Efficiency and Renewable Energy. 
US DOE. (2013a). Getting started with EnergyPlus: basic concepts manual - essential information you need about running EnergyPlus. US DOE Energy Efficiency and Renewable Energy (EERE).

US DOE. (2013b). Tips \& tricks for using EnergyPlus: insider secrets to using EnergyPlus. US DOE Energy Efficiency and Renewable Energy (EERE).

US DOE. (2013c). Input output reference: The encyclopedic reference to EnergyPlus input. US DOE Energy Efficiency and Renewable Energy (EERE).

US DOE. (2013d). EnergyPlus EngineeringReference: TheReference toEnergyPlusCalculations. US DOE Energy Efficiency and Renewable Energy (EERE).

Verbeeck, G., \& Hens, H. (2007). Life cycle optimization of extremely low energy dwellings. Journal of Building Physics, 31(2), 143-177.

Wang, W., Zmeureanu, R., \& Rivard, R. (2005). Applying multi-objective genetic algorithmsin green building design optimization. Building and Environment , 40, 1512-1525.

Wassmer, C. (2013). Energy Model Creation and Calibration Procedures for a Residential Home using Short Term Monitored Data [Master's Thesis]. Boulder, CO: University of Colorado .

Weather Analytics. (2014). Weather Data. Retrieved September 30, 2014, from http://www.weatheranalytics.com/get-weather-data

Wetter, M. (2001). GenOpt ${ }^{\circledR}$-- A Generic Optimization Program. Building Simulation, 1-6.

Wetter, M., \& Wright, J. (2004). A comparison of deterministic and probabilistic optimization algorithms for nonsmooth simulation-based optimization. Building and Environment , 39, 989-999.

Wright, G., Klingenberg, K., \& Pettit, B. (2014). Building America Report - 1405: ClimateSpecific Passive Building Standards. Springfield, VA: U.S. Department of Energy.

Yoon, J., Lee, E., \& Claridge, D. (2003). Calibration procedure for energy performance simulation of a commercial building. Journal of solar energy engineering, 125(3), 251-257.

Zhang, Y., \& Korolija, I. (2010). Performing complex parametric simulations with jEPlus. 9th International Conference on Sustainable Energy Technologies. Shanghai, China. 
Zhang, Y. (2009). 'Parallel' EnergyPlus and the development of a parametric analysis tool. IBPSA BS2009, (pp. 27-30). Glasgow, UK.

Zhang, Y. (2012). Use jEPlus as an efficient building design optimisation tool. London, UK: CIBSE ASHRAE Technical Symposium.

Zirnhelt, H. (2013). Using calibrated simulation to quantify the energy savings from residential passive solar design in Canada [Masters Thesis]. Toronto, ON: Ryerson University. 